$$
\text { DEE/MC/28060-T.4 }
$$

\title{
LAND APPLICATION USES FOR DRY FGD BY-PRODUCTS
}

\section{Phase 1 Report}

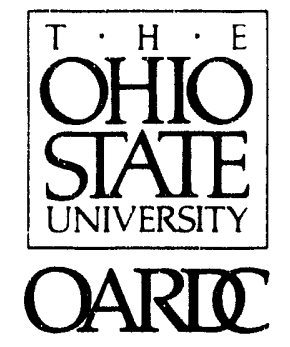

Reporting Period: December 1, 1991 to November 30, 1992

Principal Authors: OSU

J. Bigham, W. Dick, L. Forster, F. Hitzhusen,

E. McCoy, R. Stehouwer, S. Traina, W. Wolfe

USGS

R. Haefner

Report Date: April, 1993

Prepared for. Ohio Department of Development Ohio Coal Development Office Columbus, Ohio

Grant No. CDO/D-89-35

U.S. Department of Energy

Office of Fossil Energy

Morgantown Energy Technology Center

Morgantown, West Virginia

Award No. DE-FC21-91MC28060

Electric Power Research Institute

Palo Alto, California

Grant No. RP2796-02

American Electric Power Company

Columbus, Ohio

Grant No. C-8276

Ohio Edison Company

Akron, Ohio

(EPRI Collaborator)

Dravo Lime Company

Pittsburgh, Pennsylvania

Gr ant No. RF768342

Participants: Dravo Lime Company, Pittsburgh, PA; The Ohio State University, Columbus,

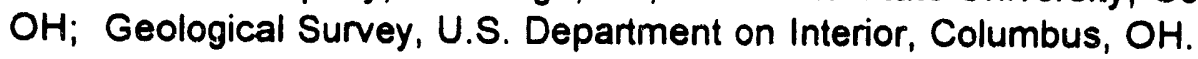




\begin{abstract}
The 1990 amendments to the Clean Air Act have spurred the development of flue gas desulfurization (FGD) processes, several of which produce a dry, solid by-product material consisting of excess sorbent, reaction products containing sulfates and sulfites, and coal fly ash. Presently FGD by-product materials are treated as solid wastes and must be landfilled. However, landfill sites are becoming more scarce and tipping fees are constantly increasing. It is, therefore, highly desirable to find beneficial reuses for these materials provided the environmental impacts are minimal and socially acceptable. Phase 1 results of a 4 and $1 / 2$ year study to demonstrate large volume beneficial uses of FGD by-products are reported. The purpose of the Phase 1 portion of the project was to characterize the chemical, physical, mineralogical and engineering properties of the FGD by-product materials obtained from various FGD technologies being developed in the state of Ohio. Phase 1 also involved the collection of baseline economic data related to the beneficial reuse of these FGD materials. A total of 58 samples were collected and analyzed. Our results indicated the chemical composition of the FGD by-product materials were dominated by $\mathrm{Ca}, \mathrm{S}, \mathrm{Al}$, and $\mathrm{Si}$ although the specific composition varies from one sample to another. Many of the elements regulated by the U.S. Environmental Protection Agency reside primarily in the fly ash. The presence of excess sorbent and reaction products causes a dilution of the concentrations of these elements in the FGD by-product materials as compared to the fly ash alone. Concentrations of the eight metals ( $\mathrm{Ag}, \mathrm{As}, \mathrm{Ba}, \mathrm{Cd}, \mathrm{Cr}, \mathrm{Hg}, \mathrm{Pb}$, and $\mathrm{Se}$ ) regulated by the Resource Conservation Recovery Act (RCRA) were below drinking water standards when measured by either the ASTM or TCLP leachate tests. Engineering tests revealed that samples made from the compacted FGD by-product materials were generally higher in strength and had greater stiffness than natural soils typically used in the construction of a highway embankment. Compacted densities were also lower than typical compacted soil densities. These data suggest that FGD by-product materials, used in construction of a highway embankment, would be lighter and require less right-of-way due to the possibility of constructing steeper slopes. Dry FGD by-products can react with with water to form ettringite, an expansive calcium sulfoaluminate hydrate mineral. This expansiion may affect how dry FGD byproduct is stockpiled and used by professional engineers and construction contractors. Based on analyses of the agricultural lime and supply demand relationships it was concluded that FGD by-product material, used as an agricultural lime substitute, would be entering a very competitive market. This substitution will be sensitive to transport distances and the FGD producer's willingness to subsidize its use in agricultural. In summary, Phase 1 results revealed that FGD by-product materials are essentially coal fly ash materials diluted with unreacted sorbent and reaction products. High volume beneficial reuses will depend on the economics of their substituting for existing materials for various types of applications (e.g. as an agricultural liming material, soil borrow for highway embankment construction, and reclamation of active and abandoned surface coal mines). Environmental constraints to the beneficial reuse of dry FGD byproduct materials, based on laboratory and leachate studies, seem to be less than for coal fly ash.
\end{abstract}




\section{ACKNOWLEDGEMENTS}

This research was conducted as part of the "Land Application Uses for Dry FGD By-Products" project which is a cooperative research project of the Ohio Agricultural Research and Development Center, The Ohio State University, The U. S. Geological Survey and the Dravo Lime Company. Funding support for this project was obtained from the Ohio Coal Development Office (C.lumbus, $\mathrm{OH}$ ) Grant No. CDO/D-89-35, the U.S. Department of Energy (Morgantown Energy Technology Center, Morgantown, WV) Award No. DE-FC21-91MC28060, Dravo Lime Company (Pittsburgh, PA) Grant No. RF768342, Electric Power Research Institute (Palo Alto, CA) Grant No. RP2796-02, Ohio Edison Company (Akron, OH), and The Ohio State University (Columbus and Wooster, $\mathrm{OH}$ ).

Appreciation is expressed to the Steering Committee (see Appendix A) for their direction and insight into the conductance of this project. Dravo Project leader, Joel Beeghly, was an important part of the team that was involved in collecting of FGD byproduct samples and in providing contacts with industry personnel and his role in helping to prepare this report is acknowledged. The cooperation of plant operators in providing us with representative FGD by-product samples for analyses and the participation of Keith Kimble of Central Fuel Company, New Philadelphia, Ohio during construction of the LIMB ash stockpile were also greatly appreciated. 
Table of Contents

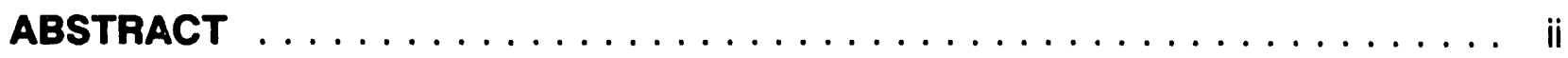

ACKNOWLEDGEMENTS $\ldots \ldots \ldots \ldots \ldots \ldots \ldots \ldots \ldots$ iii

LIST OF TABLES $\ldots \ldots \ldots \ldots \ldots \ldots \ldots \ldots \ldots \ldots \ldots \ldots$ viii

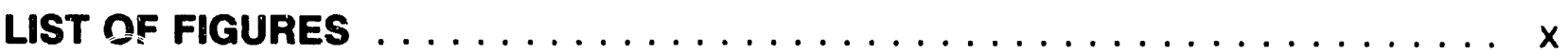

PROJECT PERSONNEL $\ldots \ldots \ldots \ldots \ldots \ldots \ldots \ldots \ldots \ldots \ldots$ xiv

EXECUTIVE SUMMARY $\ldots \ldots \ldots \ldots \ldots \ldots \ldots \ldots \ldots \ldots \ldots \ldots$ Xv

1 INTRODUCTION $\ldots \ldots \ldots \ldots \ldots \ldots \ldots \ldots \ldots \ldots \ldots \ldots \ldots \ldots$

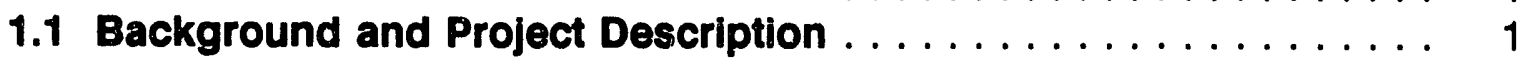

1.2 Phase 1 Objectives . . . . . . . . . . . . . . . . . 2

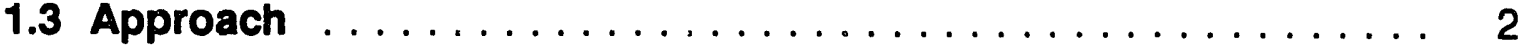

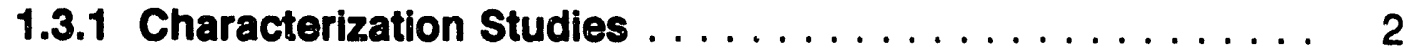

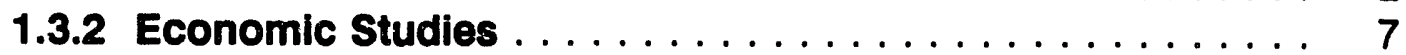

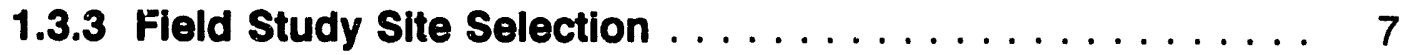

2 Reports on Phase 1 Tasks . . . . . . . . . . . . . . . . . . 8

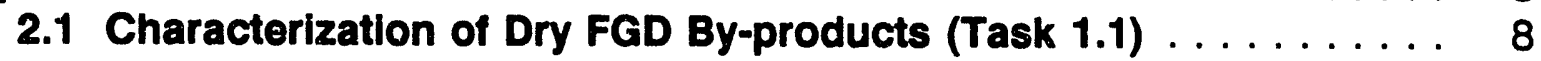

2.1.1 Sample Source Description .............. 8

2.1.1.1 Sampling Protocol and $Q A / Q C$ measures $\ldots \ldots \ldots 8$

2.1.1.2 Source Description ................. 8

2.1.2 Procedures used in Characterization Studies . . . . . . . 11

2.1.2.1 Chemical Methods and QA/QC Measures ....... 11

2.1.2.1.1 Total Chemical Analysis . . . . . . . . . 12

2.1.2.1.2 Leaching Analysis (ASTM and TCLP) . . . . . 13

2.1.2.1.3 Total Neutralizing Power (TNP), Available

Lime Index, pH, and Thermal Reactivity . . . . 14

2.1.2.1.4 Long-term Equilibrium Studies . . . . . . . . . . 14

2.1.2.2 Mineralogical Methods and QA/QC Measures . . . . 17

2.1.2.2.1 X-ray diffraction $\ldots \ldots \ldots \ldots \ldots \ldots 18$

2.1.2.2.2 Thermal analysis .............. 18

2.1.2.2.3 Calcite and Dolomite ... . . . . . . . . . 18

2.1.2.2.4 Ash content . . . . . . . . . . . . . . . . . 18

2.1.2.3 Physical Methods and QA/QC Measures ........ 19

2.1.2.3.1 Particle Size Distribution . . . . . . . . . . . . 20

2.1.2.3.2 Surface Area . . . . . . . . . . . . . . . . . 20

2.1.2.3.3 Particle Density . . . . . . . . . . . . . . 20 
2.1.2.3.4 Bulk Density and Compression Index . . . . 21

2.1.2.3.5 Water Retention . . . . . . . . . . . . . . 21

2.1.2.3.6 Hydraulic Conductivity ... . . . . . . 22

2.1.2.4 Engineering Methods and QA/QC Measures ..... 23

2.1.3 Results and Discussion of Dry FGD By-Product

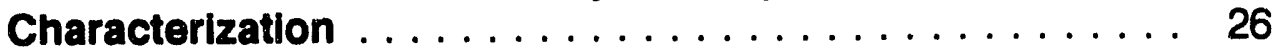

2.1.3.1 Chemical Characterization . . . . . . . . . . . 26

2.1.3.1.1 Solid Phase Chemical Composition of FGD

by-products ............... 26

2.1.3.1.2 Leaching Analysis (ASTM and TCLP) . . . . 56

2.1.3.1.3 Paste pH, Total Neutralizing Power,

Available Lime, and Thermal Reactivity . . . . 61

2.1.3.1.4 Long-term Equilibrium Studies . . . . . . . . . 65

2.1.3.2 Mineralogical Characterization . . . . . . . . . . . 72

2.1.3.2.1 X-ray diffraction . . . . . . . . . . . 72

2.1.3.2.2 Mineral "quantification" . . . . . . . . . 8 80

2.1.3.3 Physical Characterization . . . . . . . . . . . 89

2.1.3.4 Engineering Characterization .............. 103

2.1.3.4.1 Optimum Moisture Content and Density . . . . 103

2.1.3.4.2 Strength and Compressibility . . . . . . . 109

2.1.3.4.3 Permeability . . . . . . . . . . . . . 125

2.1.3.4.4 Swelling ................. 133

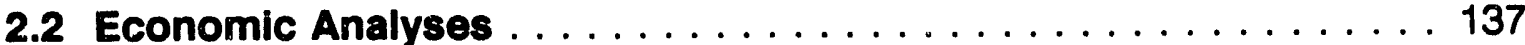

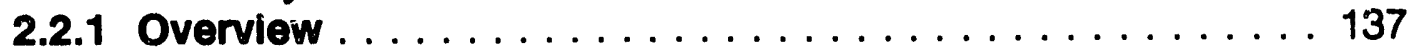

2.2.1.1 Materials Balance . . . . . . . . . . . . . . 137

2.2.1.2 Social Costs and Benefits . . . . . . . . . . . 138

2.2.2 Analysis of Agricultural Linne Demand and Supply

Relationships . . . . . . . . . . . . . . . . . . 141

2.2.2.1 Research Objective . . . . . . . . . . . . . . . 142

2.2.2.2 Data Collection ... . . . . . . . . . . . . . . . . 142

2.2.2.2.1 Industry Structure in the United States . . . . 143

2.2.2.2.2 Market Structure of Agricultural Limestone . . 143

2.2.2.2.3 Method of Estimation . . . . . . . . . . . . . . 144

2.2.2.3 Results . . . . . . . . . . . . . . . . . . . . 144

2.2.2.3.1 Demand and Supply Estima _s . . . . . . . . 144

2.2.2.4 Summary and Implications . . . . . . . . . . . 146

2.2.3 Representative Farm Prelimsinary Analysis of FGD as

Agronomic Lime Substitut $\ldots \ldots \ldots \ldots \ldots \ldots \ldots$

2.2.3.1 Farm Selection . . . . . . . . . . . . . . . 153

2.2.3.2 Agricultural Lime Use . . . . . . . . . . . . . . . . . 153

2.2.3.3 FGD By-Product Use . . . . . . . . . . . . . . 158

2.2.3.4 Implications for FGD By-Product Use . . . . . . . . 159 
2.2.4 Property Value Impacts from Landfilling and Stripmine

Reclamation ......................... 163

2.2.4.1 Model 1 . . . . . . . . . . . . . . . . . . . . . . 164

2.2.4.1.1 Demand equation estimation . . . . . . . . . . 164

2.2.4.1.2 Data . . . . . . . . . . . . . . . . . 165

2.2.4.1.3 Analysis . . . . . . . . . . . 166

2.2.4.2 Model $2 \ldots \ldots \ldots \ldots \ldots \ldots \ldots \ldots$. . . . . . . . . 167

2.2.4.3 Summary . . . . . . . . . . . . . . . . . . . . . 167

2.2.5 Financial and Economic Optimization Models of Options . 168

2.2.5.1 Transportation Problem . . . . . . . . . . . . . . 168

2.2.5.2 Example . . . . . . . . . . . . . . . . . . . 169

2.2.5.3 Model Development . . . . . . . . . . . . . . . . . . 172

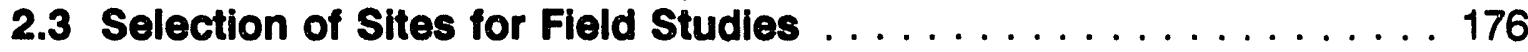

2.3.1 Active Mine Site . . . . . . . . . . . . . . . . 176

2.3.2 Abandoned Mined Site . . . . . . . . . . . . . . . 181

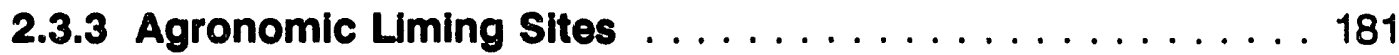

2.4 Embankment Design . . . . . . . . . . . . . . . . . . . . . 183

2.4.1 Evaluating Embankment Performance . . . . . . . . . 184

2.4.1.1 Embankment stability . . . . . . . . . . . . 184

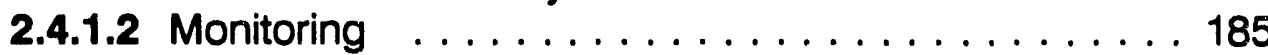

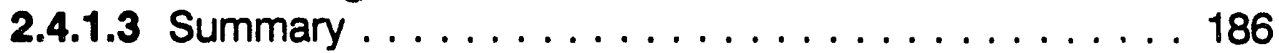

2.5 LIMB Stockplle $\ldots \ldots \ldots \ldots \ldots \ldots \ldots \ldots \ldots \ldots \ldots \ldots$

3 PROBlems ENCOUNTERED IN COMPLETING PHASE 1 TASKS . . . . . . . 189

3.1 Problems Encountered in Completing Characterization Tasks . . 189

3.2 Problems Encountered in Field Site Selection . . . . . . . . . . . 189

4 SUMMARY AND CONCLUSIONS OF PHASE 1 TASKS $\ldots \ldots \ldots \ldots \ldots \ldots 1$

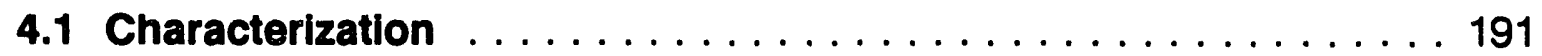

4.1.1 Chemical Properties . . . . . . . . . . . . . . . . . 191

4.1.2 Mineralogical Properties . . . . . . . . . . . . . . . . 191

4.1.3 Physical Properties . . . . . . . . . . . . . . . . . . . 192

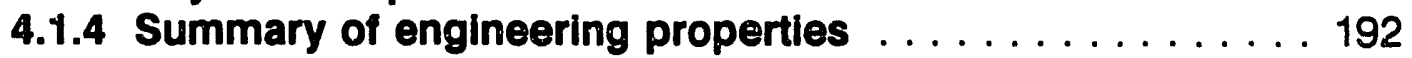

4.2 Economics . . . . . . . . . . . . . . . . . . . . . . 194

4.3 Field Site Selection . . . . . . . . . . . . . . . . . . . . . . . . . . . . 194

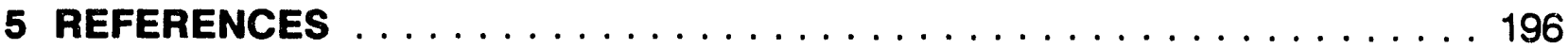

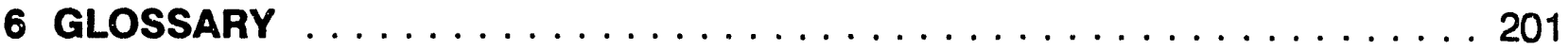

7 APPENDICES . . . . . . . . . . . . . . . . . . . . . . . . 209

7.1 Appendix A. Steering Committee. $\ldots \ldots \ldots \ldots \ldots \ldots \ldots \ldots$ A1

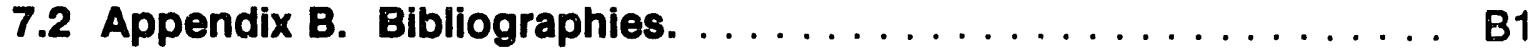


7.3 Appendix C. Plant operating parameters for dry FGD by-

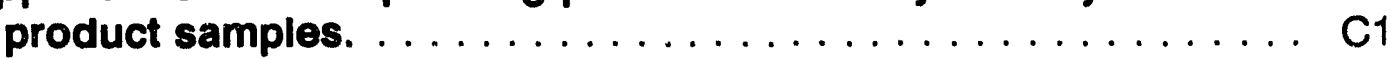

7.4 Appendix D. Chemical characterization data. . . . . . . . D1

7.5 Appendix E. Economics - ENVIROTECH paper. . . . . . . . E E1

7.6 Appendix F. Interim LIMB stockpile report. . . . . . . . . . F1 
Phase 1 Report

\section{LIST OF TABLES}

Table 1. Dry FGD by-product samples and sample description. 4

Table 2. Test protocols for laboratory determination of chemical properties of dry FGD by-products.

Table 3. Test protocols for laboratory determination of mineralogical properties of dry FGD by-products.

Table 4. Test protocols for laboratory determination of physical properties of dry FGD by-products.

Table 5. Test protocols for laboratory determination of engineering properties of dry FGD by-products.

Table 6. Laboratory test program to determine the engineering properties of dry FGD by-product.

Table 7. Elemental composition of NIST standards as measured by ICP analysis of HF-aqua-regia digests and as certified.

Table 8. Graphite furnace analysis of NIST 1633.

Table 9. Concentration of B in standard materials. 28

Table 10. Concentration of $\mathrm{Zn}$ in NiST 2691.

Table 11. Total element content in FGD by-product samples as determined by ICP, LeCO, and AA.

Table 12. Total trace element content in FGD by-product samples as determined by graphite furnace AA.

Table 13. Total boron content of FGD by-products.

Table 14. Pollutant ceiling concentrations for land application of sewage sludge

Table 15. ASTM water leachate results for 6 dry FGD by-products.

57

Table 16. TCLP acetic acid leachate results for 6 dry FGD by-products.

Table 17. Comparison of ASTM and TCLP leachates with RCRA primary drinking water limits.

Table 18. Paste $\mathrm{pH}$, calcium carbonate equivalent (CCE), available lime, and thermal reactivity of FGD by-product samples.

Table 19. Values of log SI for selected solids after 56 and 112 days of equilibration of FGD suspensions.

Table 20. FGD mineral phases detected by X-ray after 56 and 112 days of equilibration.

Table 21. Crystalline phases detected by X-ray diffraction 73

Table 22. Semiquantitative mineralogy of FGD by-products

Table 23. Mean percent finer than $0.025 \mathrm{~mm}$ and uniformity coefficients for the dry FGD materials grouped by process.

Table 24. Mean particle density and specific surface area for the dry FGD materials grouped by process.

Table 25. Mean compression index and bulk density for the dry FGD materials grouped by process.

Table 26. Mean saturated and residual water contents for the Dry FGD materials grouped by process. 
Table 27. Mean $\alpha, n$, and $r$ values from fitting the Van Genuchten equation to water retention data from the Dry FGD materials grouped by process.

Table 28. Mean $\log _{10}$ saturated hydraulic conductivity from initial testing and after 7 days for the Dry FGD materials grouped by process.

Table 29. Optimum moisture content and density for FGD samples.

Table 30. Unconfined compressive strength for FGD samples.

Table 31. One dimensional compression tests on FGD samples.

Table 32. Coefficient of permeability for FGD samples.

Table 33. Swelling test samples.

133

Table 34. Summary of swelling test results.

Table 35. Price paid by farmers for ground limestone in dollars per ton.

Table 36. Agricultural limestone sales report of crushed and broken limestone in Ohio.

Table 37. Ohio farm income.

Table 38. Price indices: I.

151

Table 39. Price indices: II.

Table 40. Lime usage and cost on representative Northwestern and Northeastern Ohio farms.

Table 41. FGD by-product usage and cost on representative Northwestern and Northeastern Ohio farms.

160

Table 42. Unit production and shipping costs (example).

Table 43. Current ash production and estimated potential FGD by-product, by source.

Table 44. Potential FGD by-product use as an agricultural lime substitute, by county (tons per year)

Table 45. Potential use of FGD by-product in surface mine reclamation

Table 46. Cost estimates used in analysis of optimum FGD by-product distribution.

Table 47. List of potential study sites for the active mine study within Ohio.

Table 48. Summary of site selection data and evaluation of four finalist candidate sites.

Table 49. Summary of properties and performance.

Table 50. Proposed field instrumentation program.

Table 51. Summary of measured properties of LIMB by-product placed in storage pile. 


\section{LIST OF FIGURES}

Fig. 1. Concentration of Al versus the weight fraction of fly ash (acid insoluble residue) in FGD by-products.

Fig. 2. Concentration of As versus the weight fraction of fly ash (acid insoluble residue) in FGD by-products.

Fig. 3. Concentration of $\mathrm{Ca}$ versus the weight fraction of fly ash (acid insoluble residue) in FGD by-products.

Fig. 4. Concentration of $S$ versus the weight fraction of fly ash (acid insoluble residue) in FGD by-products.

Fig. 5. Concentration of $B$ versus the weight fraction of fly ash (acid insoluble residue) in FGD by-products.

Fig. 6. Concentration of Cd versus the weight fraction of fly ash (acid insoluble residue) in FGD by-products.

Fig. 7. Concentration of $A s$ in the fly ash fraction (acid insoluble residue) versus the concentration of As in whole FGD by-product. Data for samples: OSU-SPD-03, BEV-DUC-02, EDG-LIM-14, TID-FLB-03 and TID-FLB-04.

Fig. 8. Concentration of $\mathrm{Cr}$ in the fly ash fraction (acid insoluble residue) versus the concentration of $\mathrm{Cr}$ in whole FGD by-product. Data for samples: OSU-SPD-03, BEV-DUC-02, EDG-LIM-14, TID-FLB-03 and TID-FLB-04.

Fig. 9. Concentration of $\mathrm{Cu}$ in the fly ash fraction (acid insoluble residue) versus the concentration of $\mathrm{Cu}$ in whole FGD by-product. Data for samples: OSU-SPD-03, BEV-DUC-02, EDG-LIM-14, TID-FLB-03 and TID-FLB-04.

Fig. 10 Concentration of $\mathrm{Ni}$ in the fly ash fraction (acid insoluble residue) versus the concentration of $\mathrm{Ni}$ in whole FGD by-product. Data for samples: OSU-SPD-03, BEV-DUC-02, EDG-LIIM-14, TID-FLB-03 and TID-FLB-04.

Concentration of $\mathrm{Pb}$ in the fly ash fraction (acid insoluble residue) versus the concentration of $\mathrm{Pb}$ in whole FGD by-product. Data for samples: OSU-SPD-03, BEV-DUC-02, EDG-LIM-14, TID-FLB-03 and TID-FLB-04.

Fig. 12. Concentration of $\mathrm{Cd}$ in the fly ash fraction (acid insoluble residue) versus the concentration of Cd in whole FGD by-product. Data for samples: OSU-SPD-03, BEV-DUC-02, EDG-LIM-14, TID-FLB-03 and TID-FLB-04.

Fig. 13. Concentration of $\mathrm{Mo}$ in the fly ash fraction (acid insoluble residue) versus the concentration of Mo in whole FGD by-product. Data for samples: OSU-SPD-03, BEV-DUC-02, EDG-LIM-14, TID-FLB-03 and TID-FLB-04. 
Fig. 14. Concentration of $S e$ in the fly ash fraction (acid insoluble residue) versus the concentration of $\mathrm{Se}$ in whole FGD by-product. Data for samples: OSU-SPD-03, BEV-DUC-02, EDG-LIM-14, TID-FLB-03 and TID-FLB-04.

Fig. 15. Concentration of $\mathrm{Ca}$ in the fly ash fraction (acid insoluble residue) versus the concentration of $\mathrm{Ca}$ in whole FGD by-product. Data for samples: OSU-SPD-03, BEV-DUC-02, EDG-LIM-14, TID-FLB-03 and TID-FLB-04.

Fig. 16. Concentration of $\mathrm{Mg}$ in the fly ash fraction (acid insoluble residue) versus the concentration of $\mathrm{Mg}$ in whole FGD by-product. Data for samples: OSU-SPD-03, BEV-DUC-02, EDG-LIM-14, TID-FLB-03 and TID-FLB-04.

Fig. 17. Concentration of $S$ in the fly ash fraction (acid insoluble residue) versus the concentration of $S$ in whole FGD by-product. Data for samples: OSU-SPD-03, BEV-DUC-02, EDG-LIM-14, TID-FLB-03 and TID-FLB-04.

Fig. 18. Effect of reaction time on the concentration of dissolved $\mathrm{Ca}$ in EDGLIM-14.

Fig. 19. Effect of reaction time on the concentration of dissolved $\mathrm{Ca}$ in TIDFLB-04.

Fig. 20. Effect of reaction time on the concentration of dissolved S in EDGLIM-14.

Fig. 21. Effect of reaction time on the concentration of dissolved B in BEVDUC-02.

Fig. 22. Effect of reaction time on the concentration of dissulved Mo in OSUSPD-03.

Fig. 23. Representative X-ray diffraction pattern for Beverly Duct Injection samples.

Fig. 24. Representative X-ray diffraction pattern for Ohio State University Spray Dryer samples.

Fig. 25. X-ray diffraction pattern from the Edgewater Coolside sample.

Fig. 26. Representative X-ray diffraction pattern for Edgewater LIMB samples. 77

Fig. 27. Representative X-ray diffraction pattern for Tidd PFBC Bed Ash samples.

Fig. 28. Representative X-ray diffraction pattern for Tidd PFBC Cyclone Ash samples.

Fig. 29. Representative thermograms for Beverly Duct Injection samples.

Fig. 30. Representative thermograms for Ohio State Spray Dryer samples.

Fig. 31. Representative thermograms for Edgewater LIMB samples.

Fig. 32. Representative thermograms for Tidd PFBC Bed Ash samples.

84

85

Fig. 33. Representative thermograms for Tidd PFBC Cyclone Ash samples.

86

Fig. 34. Representative X-ray diffraction pattern for fly ash component of FGD by-products. 
Fig. 35. The percent of particles finer than $0.025 \mathrm{~mm}$ effective diameter and the uniformity coefficient for FGD samples BEV-DUC-02, EDG-LIM-14, OSU-SPD-03, TID-FLB-03 and TID-FLB-04. Fineness results for the bed ash sample TID-FLB-04 are expressed as the percent finer than $0.25 \mathrm{~mm}$ effective diameter.

Fig. 36. The particle density and specific surface areas for FGD samples BEV-DUC-02, EDG-LIM-14, OSU-SPD-03, TID-FLB-03 and TID-FLB-04. 95

Fig. 37. The bulk density and compression index for FGD samples BEV-DUC-02, EDG-LIM-14, OSU-SPD-03, TID-FLB-03 and TID-FLB-04. 96

Fig. 38. The water retention data and fitted Van Genuchten curve for FGD sample BEV-DUC-02.

Fig. 39. The water retention data and fitted Van Genuchten curve for FGD sample EDG-LIM-14.

Fig. 40. The water retention data and fitted Van Genuchten curve for FGD sample OSU-SPD-03.

Fig. 41. The water retention data and fitted Van Genuchten curve for FGD sample TID-FLB-03.

Fig. 42. The water retention data and fitted Van Genuchten curve for FGD sample TID-FLB-04.

Fig. 43. The initial and 7 day saturated hydraulic conductivities for FGD samples BEV-DUC-02, EDG-LIM-14, OSU-SPD-03, TID-FLB-03 and TID-FLB-04.

Fig. 44. Moisture content - density relationships for the Coolside and LIMB samples.

Fig. 45. Moisture content - density relationships for the OSU and Tidd samples.

Fig. 46. Moisture content - density relationships for the EPRI High Sulfur Test Center, PEDCO, Beverly, and SNRB samples.

Fig. 47. Unconfined compression test results for compacted Tidd $3 / 4$ samples at 0,7 , and 28 days.

Fig. 48. Unconfined compression test results for compacted LIM 14 samples at 0,7 , and 28 days.

Fig. 49. Unconfined compression test results for compacted OSU 11 samples at 0,7 , and 28 days.

Fig. 50. Unconfined compression test results for compacted BEV 05 samples at 0,7 , and 28 days.

Fig. 51. Average unconfined compressive strengths: Tidd by-product.

Fig. 52. Average unconfined compressive strengths: Coolside and LIMB byproducts.

Fig. 53. Average unconfined compressive strengths: LIMB by-product.

Fig. 54. Average unconfined compressive strengths: EPRI High Sulfur Test Center, Beverly, and SNRB by-products.

Fig. 55. Average unconfined compressive strengths: OSU spray dryer byproduct and reference clay. 
Fig. 56. One dimensional compression of a compacted LIMB sample 0 days after compaction.

Fig. 57. One dimensional compression of a compacted Tidd sample 0 days after compaction.

Fig. 58. One dimensional compression of a compacted LIMB sample 425 days after compaction.

Fig. 59. One dimensional compression of a compacied LIMB sample 425 days after compaction.

Fig. 60. One dimensional compression of a compacted LIMB sample 404 days after compaction.

Fig. 61. Permeability coefficients: Tidd and PEDCO by-products.

Fig. 62. Permeability coefficients: Coolside and LIMB by-products.

Fig. 63. Permeability coefficients: LIMB by-product.

Fig. 64. Permeability coefficients: EPRI High Silfur Test Center, Beverly, and SNRB by-products.

Fig. 65. Permeability coefficients: OSU spray dryer by-product and reference clay.

Fig. 66. Swelling vs. time: Coolside by-product.

Fig. 67. Swelling vs. time: LIMB by-product.

Fig. 68. Swelling vs. time: OSU spray dryer by-product.

Fig. 69. Swelling vs. time: Tidd by-product.

Fig. 70. Concepts of economic surplus and technological externalities.

Fig. 71. Map of Ohio depicting quadrants used in liming study.

Fig. 72. Composition of an average farm in the Northeast Region of Ohio

Fig. 73. Composition of an average farm in the Northwest Region of Ohio

Fig. 74. Cost per acre of aglime vs. FGD in Northeast Ohio.

Fig. 75. Cost per acre of aglime vs. FGD in Northwest Ohio.

Fig. 76. Optimal distribution network for example problem. 


\section{PROJECT PERSONNEL}

Dravo Lime Company

Joel Beeghly

Ohio State University

\begin{tabular}{ll}
\multicolumn{1}{c}{ Agronomy } & $\begin{array}{c}\text { Agricultural } \\
\text { Economics }\end{array}$ \\
Warran Dick & Fred Hitzhusen \\
Jerry Bigham & Lynn Forster \\
Samuel Traina & Joseph Havlicek \\
Jonathan Rausch & Diane Hite \\
Ed McCoy & Najat Ennich \\
Paul Sutton & \\
Terry Logan & \\
Rattan Lal & \\
Richard Stehouwer & \\
Randy Fowler & \\
Peter Olah & \\
Ubaldo Soto &
\end{tabular}

\author{
Civil \\ Engineering \\ William Wolfe \\ Tien $\mathrm{H}$. Wu \\ Sunghwan Kim \\ Dorothy Adams
}

\section{United States Geological Survey}

Ralph Haefner

Garry Rowe

Kevin Metzker

Al Sedam

William Yost

Rodney Sheets

Anthony Robinson 


\section{EXECUTIVE SUMMARY}

Development of flue gas desulfurization (FGD) processes in the state of Ohio, as well as other coal producing states in the eastern United States, has been spurred by the 1990 amendments to the Clean Air Act. Much of the coal in the eastern United States contains sulfur at levels high enough that its combustion will cause utilities and other users to be out of compliance. The U.S. Department of Energy, the Electric Power Research Institute, the Ohio Coal Development Office, and various industries (mostly utilities) have been cooperating in the development and evaluation of a number of new sulfur dioxide removal technologies that can be retrofitted onto existing coal burning systems. Several of these technologies produce a dry, solid by-product material consisting of excess sorbent, reaction products containing sulfates and sulfites, and coal fly ash. Presently FGD by-product materials are treated as solid wastes and must be landfilled. However, landfill sites are becoming more scarce and tipping fees are constantly increasing. It is, therefore, highly desirable to find beneficial reuses for these materials provided the environmental impacts are minimal and socially acceptable.

In December of 1990, a project was begun to demonstrate high volume uses of FGD by-product materials which may substitute for other materials now being used for land reclamation (e.g. reclamation of active and abandoned acid mine lands), agriculture, and soil stabilization. This project, to be completed over a 4 and $1 / 2$ year period, is divided into three phases: Phase 1 involves FGD by-product sample collection and characterization and collection of baseline economic data; Phase 2 focuses on laboratory and greenhouse studies of mixtures of FGD by-product materials with soil or spoil and the development of economic models; and Phase 3 is to conduct field demonstrations of high volume uses of FGD by-product materials and economic and environmental analyses related to these usES.

This volume provides a report of project activities completed during Phase 1. The specific objectives of Phase 1 were to 1) characterize the chemical, physical, mineralogical and engineering properties of dry FGD by-product materials and the variability in these properties associated with by-product source and dry FGD technology, 2) conduct preliminary investigations of the economic feasibility of using dry FGD by-products as agricultural lime substitutes, as alkaline amendments for stripmine reclamation, and as soil stabilizers for embankment construction, and 3) select field sites for demonstrations of the beneficial high volume uses.

A total of 58 samples were collected and analyzed. Of these 58 samples, five samples representing four different flue gas desulfurization technologies being tested or commercially used in Ohio, were selected for more detailed analyses. The four technologies that had samples analyzed in detail included duct injection, pressurized fluidized bed combustion, spray dryer, and lime injection multistage burners. The primary components of the FGD by-product materials were excess unreacted sorbent, reaction products (primarily sulfates and sulfites) and coal fly ash.

The chemicsl composition of the FGD by-product materials were dominated by $\mathrm{Ca}$, $\mathrm{S}, \mathrm{Al}$, and $\mathrm{Si}$ although the specific composition varied from one sample to another. 
There was wide variation in concentrations of elements in the FGD by-product samples and this variation seemed to be due more to variations in the coal composition than in the type of clean coal (or FGD) technology used at a facility. Exceptions to this were sulfite and $\mathrm{Ca}(\mathrm{OH})_{2}$ which were found primarily in FGD by-product samples obtained from the low temperature spray dryer, coolside, and duct injection processes. Sulfate was the dominant sulfur form in the furnace injection and fluidized bed combustion technologies. Unhydrated $\mathrm{CaO}$ was also found in samples from furnace injection FGD technologies.

Many of the elements regulated by the U.S. Environmental Protection Agency reside primarily in the coal fly ash. The presence of excess sorbent and reaction products causes a dilution of the concentrations of these elements in the FGD byproduct materials as compared to fly ash alone. Concentrations of the eight metals (Ag, As, $\mathrm{Ba}, \mathrm{Cd}, \mathrm{Cr}, \mathrm{Hg}, \mathrm{Pb}$, and $\mathrm{Se}$ ) regulated by the Resource Conservation Recovery Act (RCRA) were below drinking water standards when measured by either the ASTM or TCLP leachate tests. Trace element contents in the FGD by-product materials could fall under the same regulatory restrictions as trace elements in fly ash from coal burning sources.

Engineering tests revealed that samples made from the compacted FGD byproduct materials were generally higher in strength and had greater stiffness than natural soils typically used in the construction of highway embankments. Compacted densities were also lower than typical compacted soil densities and good compaction could be achieved over a fairly broad range of moisture contents. These data suggest that FGD by-product materials, used in construction of a highway embankment, would be lighter and require less right-of-way due to the possibility of constructing steeper slopes. Despite considerable range in values, compacted FGD samples exhibited permeabilities typical of clays. Dry FGD by-products can react with water to form the expansive mineral, ettringite, which is a calcium sulfoaluminate hydrate. This expansion may affect how dry FGD by-product is stockpiled and used by professional engineers and construction contractors. Swelling occurred in two distinct phases: an initial hydration causing an increase in volume of 0.1 to $12 \%$ and a second episode of swelling usually beginning after 10 days or more which yield an additional volume of swelling sometimes exceeding $10 \%$. Under neutral pH regimes, precipitation of ettringite is likely to be inhibited but users of some dry FGD by-product materials for applications such as road construction, may first want to allow the materials to age and complete their swelling phase prior to use.

Based on analyses of the agricultural lime and supply demand relationships it was concluded that FGD by-product material, used as an agricultural lime substitute, would be entering a very competitive market. This substitution will be sensitive to transport distances and the FGD producer's willingness to subsidize its use in agricultural.

Field sites for three types of beneficial reuses (i.e. as an agricultural lime substitute, for reclamation of an abandoned (toxic) mine site and reclamation of an active mine site) of dry FGD by-products were selected. Criteria common to the selection of sites for these beneficial reuses included 1) the soil (spoil) must be deficient in exchangeable bases, i.e. it must have a low pH and a calcium carbonate deficiency, 2) 
the sites must be representative of a large area of the state, 3) the land must be readily accessible and available to project participants, 4) timing of the reclamation plans must fit with our research plans, 5) distance to the FGD by-product source and from Wooster should be minimized, and 6) we must know the history of land use prior to the addition of the FGD by-product material. Based on these criteria three sites in eastern Ohio (Wayne, Mahoning and Coshocton counties) were selected for conducting tests of the effectiver ess of FGD by-product material as an agricultural lime substitute, the Fleming site in Tuscarawas county was selected to study beneficial reuse of FGD by-product material for the reclamation of an abandoned mine site, and four primary and seven secondary sites were selected for use of FGD by-product materials for reclamation of an active surface coal mine.

Greenhouse and field studies are planned for Phases 2 and 3 of this project. 
Phase 1 Report

\section{INTRODUCTION}

\subsection{Background and Project Description}

The recently passed Clean Air Act has confirmed the need to develop and implement processes for sulfur dioxide $\left(\mathrm{SO}_{2}\right)$ removal from flue gasses of coal burning utility generating units. Some of these flue gas desulfurization (FGD) processes generate dry, solid by-product material consisting of calcium-based excess sorbent, reaction products containing sulfates/sulfites and fly ash (Batelle, 1989).

Recent studies indicate that as much as 7,000 to $11,000 \mathrm{MW}$ of Ohio Electric Utility generating capacity may be required to install some type of FGD system (Ohio Electric Institute, 1986). A portion of the newly installed FGD systems will be "dry" type systems, but the number of such dry systems and the tons of FGD by-product to be produced each year is yet to be determined by market forces. Presently FGD byproduct materials are treated as solid waste and must be landfilled. However, landfill sites are becoming more scarce and tipping fees are increasing. Provided the environmental ccnsequences of FGD by-product materials rel'. $\theta$ are socially acceptable, it is highly desirable to find beneficial uses for these materials.

In December of 1990 , this project was initiated to demonstrate high volume uses of dry FGD by-product materials which will substitute for other materials now being used for land reclamation (e.g. reclamation of abandoned acid mine lands), agriculture, and soil stabilization. The work for the project is being performed by Ohio State University with cooperation from the United States Geological Survey. Dravo Lime Company is the prime contractor with additional direction being provided by a steering committee made up of representatives from funding organizations, industry, state regulatory agencies and a citizens group (Appendix A).

Project objectives were developed over an 18-month period during extensive discussions with personnel from industry, regulatory agencies, and research institutions. The specific objectives of the demonstration project are as follows:

1. To characterize the material generated by dry FGD processes,

2. To demonstrate the utilization of dry FGD by-products as a soil amendment material on agricultural lands and on abandoned and active surface coal mines in Ohio,

3. To demonstrate the use of dry FGD by-product as an engineering material for soil stabilization,

4. To determine the quantities of dry FGD material that can be utilized in each of these applications,

5. To determine the environmental and economic impact of utilizing the material, and

6. To calibrate environmental, engineering, and economic models that can be used to determine the applicability and costs of utilizing these processes at other sites.

The study, to be completed in approximately $4 \frac{1}{2}$ years, is being conducted at The Ohio State University main campus (Columbus), at The Ohio Agricultural Research 
and Development Center (Wooster), at The Ohio State University branch stations, at field-scale active and abandoned coal mine sites, and at various other sites in Ohio. The project is divided into three phases. The first phase focuses on characterization of FGD by-products and collection of baseline economic data. The second phase focuses on laboratory and greenhouse studies of mixtures of FGD by-products and soil or spoil, and the development of economic models. The third phase focuses on field demonstration of various high volume uses for FGD by-products and the development of environmental, engineering and economic modeis.

\subsection{Phase 1 Objectives}

The specific objectives for Phase 1 of the project are listed below.

1. Determine the chemical, physical, mineralogical, and engineering properties of dry FGD by-products and the variability in these properties associated with byproduct source and dry FGD technology.

2. Conduct preliminary investigations of the economic feasibility of using dry FGD by-products as agricultural lime substitutes, as alkaline amendments for stripmine reclamation, and as soil stabilizers for embankment construction.

3. Select field sites for demonstrations of the use of dry FGD by-products as agricultural lime substitutes, as alkaline amendments for stripmine reclamation, and as soil stabilizers for embankment construction.

\subsection{Approach}

An extensive search and review of the scientific literature related to all aspects of characterization and land application of FGD by-products was conducted at the beginning of the project and will continue throughout the project. Bibliographies of relevant literature were constructed by the USGS Water Resources Division, and the OSU Department of Agronomy and are given in Appendix B. The USGS bibliography contains references of published works on the geology and hydrology of coal strata, geochemical considerations of coal and FGD by-products, and data-acquisition techniques. The OSU bibliography contains references of published works on chemical, mineralogical, physical, and engineering characterization, and environmental impacts of various land application uses for FGD and related by-products. There are several references which appear in both bibliographies.

\subsubsection{Characterization Studies}

The characterization studies were designed to assess the chemical, mineralogical, physical, and engineering properties of dry FGD by-products and to determine (1) how the measured properties were affected by the type of FGD process utilized, (2) how specific operating conditions within the various dry FGD processes affect the measured properties of the by-products, and (3) the variability of the measured 
properties both within specific dry FGD processes and among all dry FGD by-product samples.

Characterization studies were conducted on 58 samples collected from 13 coalfired boilers representing the following nine dry FGD tecinivologies: coolside, duct injection, atmospheric fluidized bed combustion, pressurized fluidized bed combustion, LIDS, lime injection multistage burners, rotary cascading bed bciler, spray dryer, and $\mathrm{SO}_{\mathrm{x}}-\mathrm{NO}_{\mathrm{x}}-\mathrm{R}_{\mathrm{x}}-\mathrm{Box}$. These samples are listed in Table 1, and sample sources and sampling protocol is described in section 2.1.1. Of the 58 total samples, five samples from four FGD processes in Ohio were selected for more extensive characterization. The analytical procedures used are described in section 2.1.2 and results and discussion are presented in section 2.1.3. 
Table 1. Dry FGD by-product samples and sample description.

\begin{tabular}{|c|c|c|c|c|}
\hline Sample Code & Plant & FGD Process & Sampling Point & Sampling Date \\
\hline BAB-LID-01 & $\begin{array}{l}\text { B\&W Alliance } \\
\text { Research Center }\end{array}$ & LIDS & Baghouse & July 3,1990 \\
\hline BAB-LID-02 & B\&W ARC & LIDS & Baghouse & July 20, 1990 \\
\hline BAB-LID-03 & B\&W ARC & LIDS & Dry scrubber & Jan. 4, 1991 \\
\hline BEV-DUC-02 & Muskingum River & Duct injection & ESP & Dec. 17,1990 \\
\hline BEV-DUC-03 & Muskingum River & Duct injection & ESP & Jan. 4, 1991 \\
\hline BEV-DUC-05 & Muskingum River & $\begin{array}{l}\text { Duct injection } \\
\text { (slurry recycle) }\end{array}$ & ESP & July 23, 1991 \\
\hline BEV-DUC-06 & Muskingum River & $\begin{array}{l}\text { Duct injection } \\
\text { (Cl additive) }\end{array}$ & ESP & Jan. 3, 1992 \\
\hline BEV-DUC-07 & Muskingum River & $\begin{array}{l}\text { Duct injection } \\
\text { (slurry recycle) }\end{array}$ & ESP & Feb. 10, 1992 \\
\hline BEV-DUC-08 & Muskingum River & $\begin{array}{l}\text { Duct injection } \\
\text { (slurry recycle) }\end{array}$ & ESP & Feb. 25, 1992 \\
\hline BUR-SNR-01 & Buiger & $\mathrm{SO}_{x}-\mathrm{NO}_{x}-\mathrm{R}_{\mathrm{O} x}-\mathrm{BOx}$ & Fly ash silo & June 10, 1992 \\
\hline EDG-CLS-01 & Edgewaiar & Coolside & ESP & Feb. 14,1990 \\
\hline EDG-LIM-03 & Edgewater & LIMB & ESP & June 14,1990 \\
\hline EDG-LIM-04 & Edgewater & LIMB & ESP & Oct. 23, 1990 \\
\hline EDG-LIM-05 & Edgewater & LIMB & ESP & Oct. 29,1990 \\
\hline EDG-LIM-06 & Edgewater & LIMB & ESP & Nov. 16, 1990 \\
\hline EDG-LIM-07 & Edgewater & LUMB & ESP & Nov. 20, 1990 \\
\hline EDG-LIM-08 & Edgewater & LIMB & ESP & Jan. 25, 1991 \\
\hline EDG-LJM-09 & Edgewater & LIMB & ESP & Feb. 13, 1991 \\
\hline EDG-LIM-10 & Edgewater & LIMB & ESP & Mar. 8, 1991 \\
\hline EDG-LIM-11 & Edgewater & LIMB & ESP & Apr. 16, 1991 \\
\hline EDG-LIM-12 & Edgewater & LIMB & ESP & May 24, 1991 \\
\hline EDG-LIM-13 & Edgewater & LIMB & ESP & July 10, 1991 \\
\hline EDG-LIM-14 & Edgewater & LIMB & ESP & July 15, 1991 \\
\hline GMC-FLB-01 & General Motors & Fluidized Bed & Bed ash & Jan. 13, 1992 \\
\hline GMC-FLB-02 & General Motors & Fluidized Bed & Fly ash & Jan. 13, 1992 \\
\hline GMC-FLB-03 & General Motors & Fluidized Bed & Bed +fly ash & Feb. $\quad 1992$ \\
\hline
\end{tabular}


Table 1. continued

\begin{tabular}{|c|c|c|c|c|}
\hline Sample Code & Plant & FGD Process & Sampling Point & Sampling Date \\
\hline HST-SPD-01 & $\begin{array}{l}\text { EPRI High Sulfur } \\
\text { Test Center }\end{array}$ & Spray Dryer & Baghouse & Mar. 20, 1991 \\
\hline HST-SPD-02 & EPRI HST & Spray Dryer & $\begin{array}{l}\text { Spray dryer } \\
\text { drop-out solids }\end{array}$ & Mar. 20, 1991 \\
\hline HST-SPD-03 & EPRI HST & Spray Dryer & Baghouse & Apr. 15, 1991 \\
\hline HST-SPD-04 & EPRI HST & Spray Dryer & Drop-out solids & Apr. 15, 1991 \\
\hline HST-SPD-05 & EPRI HST & Spray Dryer & $\begin{array}{l}\text { Baghouse }+ \\
\text { drop-out solids }\end{array}$ & Sep. 27, 1991 \\
\hline NSP-SPD-01 & $\begin{array}{l}\text { Northern States } \\
\text { Power }\end{array}$ & Spray Dryer & Baghouse & Mar. 7, 1991 \\
\hline NSP-SPD-02 & N. St. Power & Spray Dryer & Baghouse & Feb., 1992 \\
\hline OSU-SPD-01 & McCracken & Spray Dryer & Baghouse & Jan. 11, 1991 \\
\hline OSU-SPD-02 & McCracken & Spray Dryer & Baghouse & Feb. 22, 1991 \\
\hline OSU-SPD-03 & McCracken & Spray Dryer & Baghouse & Apr. 1, 1991 \\
\hline OSU-SPD-04 & McCracken & Spray Dryer & Bottom ash & Apr. 1, 1991 \\
\hline OSU-SPD-05 & McCracken & Spray Dryer & Baghouse & May 23, 1991 \\
\hline OSU-SPD-07 & McCracken & Spray Dryer & Economizer & May 23, 1991 \\
\hline OSU-SPD-08 & McCracken & Spray Dryer & Bottom ash & May 23, 1991 \\
\hline OSU-SPD-09 & McCracken & Spray Dryer & Bottom siftings & May 23, 1991 \\
\hline OSU-SPD-10 & McCracken & Spray Dryer & Baghouse & Jan. 29, 1992 \\
\hline OSU-SPD-11 & McCracken & Spray Dryer & Baghouse + bed & Feb.13, 1992 \\
\hline PED-RCB-01 & PEDCO & $\begin{array}{l}\text { Rotary Cascading } \\
\text { Bed Combustion }\end{array}$ & Baghouse & Sep. 24, 1991 \\
\hline QST-FLB-01 & Quaker State & Fluidized Bed & Economizer ash & Oct. 10,1990 \\
\hline QST-FLB-02 & Quaker State & Fluidized Bed & Baghouse & Oct. 10,1990 \\
\hline QST-FLB-03 & Quaker State & Fluidized Bed & Bottom ash & Oct. 24,1990 \\
\hline RPT-FLY-01 & Rockport (AEP) & Class $\mathrm{C}$ fly ash & Fly ash & Sep. 18, 1991 \\
\hline STA-FLB-01 & Staley & Fluidized Bed & Fly ash & Mar. 6, 1991 \\
\hline
\end{tabular}


Table 1. continued.

\begin{tabular}{llllr}
\hline \hline Sample Code & Plant & FGD Process & Sampling Point & Sampling Date \\
\hline TID-FLB-01 & Tidd & $\begin{array}{l}\text { Pressurized } \\
\text { Fluidized Bed }\end{array}$ & Primary cyclone & Aug. 28, 1991 \\
TID-FLB-02 & Tidd & PFBC & Boller bed & Aug. 28, 1991 \\
TID-FLB-03 & Tidd & PFBC & Primary cyclone & Sep. 16, 1991 \\
TID-FLB-04 & Tidd & PFBC & Boller bed & Sep. 16, 1991 \\
TID-FLB-05 & Tidd & PFBC & ESP & Sep. 17, 1991 \\
TID-FLB-06 & Tidd & PFBC & Primary cyclone & Mar. 6, 1992 \\
TID-FLB-07 & Tidd & PFBC & Boiler bed & Mar. 6, 1992 \\
\hline TVA-FLB-01 & TVA Shawnee & Fluidized Bed & Char overflow & Mar. 4, 1991 \\
TVA-FLB-02 & TVA Shawnee & Fluidized Bed & Fly ash & Jan.-Feb., 1991 \\
TVA-FLB-03 & TVA Shawnee & Fluidized Bed & Bed ash & Mar. 4, 1991 \\
\hline \hline
\end{tabular}


Phase 1 Report

\subsubsection{Economic Studies}

The "economics" of reusing coal-fired electric power plant dry FGD by-products as an agronomic lime substitute, as an amendment on active and abandoned stripmine spoil, and as an embankment stabilizer for highway construction will be based on two perspectives or accounting stances. The first is a financial analysis in which cost and returns are evaluated from the power piant perspective. In this case, actual costs and returns incurred by the power plant in pursuing FGD re sse options determine the "economics" of alternative options.

The second approach considers the economics of FGD disposal and reuse from a societal perspective or what is commonly referred to as benefit-cost analysis (BCA). In BCA the concern is with estimating full willingness to pay and accept measures of economic value regardless of whether or not those values are currently reflected in market prices. It recognizes that technological externalities or unpriced environment services can result in large gaps between private and social costs and benefits. Examples in the case of FGD by-product reuse include but are not limited to: monitoring, testing and remediation costs of groundwater contamination, adjacent property value impacts from reclaiming stripmines or landfilling activities, and downstream sediment impacts from reclaiming abandoned stripmines.

\subsubsection{Field Study Site Selection}

The U.S. Geological Suivey, Water Resources Division, was assigned the task of investigating the effects of applying FGD by-products to an active mine site. As part of Phase I, the initial work objectives entailed finding an active mine site (task 1.3.2). The specific objectives of the site selection were to investigate available surface coal mines and devise a site-selection strategy that included environmental and socio-political factors that govern the site. This task involved several subtasks that included a literature search and review, field surveys, and detailed mapping of the final site. This work will insure the transferability and value of the results of the research project. 
Phase 1 Report

\section{Reports on Phase 1 Tasks}

\subsection{Characterization of Dry FGD By-products (Task 1.1)}

\subsubsection{Sample Source Description}

Samples collected for the characterization studies are listed in Table 1. Of the 58 samples listed, 54 are actual FGD by-product samples. The bottom and economizer ash samples from the O.S.U. McCracken plant are not true FGD by-products in that they were collected upstream from the sorbent injection point (spray dryer). In addition a Type C fly ash sample (RPT-FLY-01) was collected from AEP's Rockport plant. Type $C$ fly ash is an alkaline ash and was included as a comparison material to the dry FGD by-product samples.

\subsubsection{Sampling Protocol and QA/QC measures}

Obtaining samples which are representative of the matrix being sampled is the first step to producing data of high quality. To assure representativeness, attempts were made to sample from a homogeneous by-product matrix produced under stable, welldefined plant operating conditions. For those samples collected from sources within Ohio, project personnel worked closely with plant personnel and monitored sampling activities. For samples collected from out-of-state sources, we relied on plant personnel to do the sampling and were unable to monitor sampling procedures. Whenever possible, records of plant operating parameters were obtained at the time of sampling. For some samples plant personnel were unable to provide us with specific operating parameters. Known operating parameters for each sample are given in Appendix C.

Samples were collected in 55 gal steel drums with plastic liner bags when possible, or in $\mathbf{5}$ gal plastic buckets with lids. All containers were filled as full as possible and tightly sealed to minimize sample contact with air and moisture.

Samples were assigned a sample number at the time of collection. The sample number is an alpha-numeric code in which the first three letters identify the plant, the second three letters identify the FGD process and the last two digits identify the sequential sample number for the particular plant. The sample number and other sample information was written on adhesive labels which were affixed to the sample container and lid. All information regarding the samples (sample number, date of collection, sampler, sample volume, plant operating parameters, and sample distribution) was entered into a sample data base.

\subsubsection{Source Description}

Dry FGD by-product samples were collected from 13 sources representing 9 dry FGD processes. These 9 processes are representative of the four dry FGD technologies described below. 
Duct Injection. Sorbent (hydrated lime) is injected into the flue gas as it enters a humidification chamber in the ductwork downstream of the boiler and air heater. Here, injection of a fine water mist lowers the gas temperature srom about $300^{\circ} \mathrm{F}$ $\left(150^{\circ} \mathrm{C}\right)$ to about 140 to $150^{\circ} \mathrm{F}\left(60\right.$ to $\left.65^{\circ} \mathrm{C}\right)$ and raises the humidity of the flue gas to a 20 to $25 F^{\circ}\left(11\right.$ to $\left.14 C^{\circ}\right)$ approach to saturation. The sorbent reacts with the $\mathrm{SO}_{2}$ in the flue gas ductwork. Dry FGD by-product is removed from the flue gas stream in a baghouse or electrostatic precipitator and contains the reaction products, fly ash, and unspent sorbent. In most configurations, recycling and reinjection of the FGD by-product with fresh hydrated lime is an option to reduce requirements for fresh sorbent.

Duct injection samples were collected from the Coolside process, a full-scale commercial demonstration at Ohio Edison's Edgewater plant; from the Duct Injection Test Facility operated on a $12 \mathrm{MW}$ slipstream from AEP's Muskingum River Power Plant; and from the $\mathrm{SO}_{x}-\mathrm{NO}_{x}-\mathrm{RO}_{\mathrm{x}}-\mathrm{BOx}$ (SNRB) test facility operating on a slipstream from Ohio Edison's Burger Plant.

Lime Injection Multistage Burners (LIMB). In the LIMB process a calcium-based sorbent is injected into the boiler where it calcines to $\mathrm{CaO}$, and reacts with $\mathrm{SO}_{2}$ and $\mathrm{O}_{2}$ in the combustion gasses to produce $\mathrm{CaSO}_{4}$. Temperatures at the point of injection approach $2,300^{\circ} \mathrm{F}\left(1260^{\circ} \mathrm{C}\right)$ and the reaction occurs between this temperature and about $1,600^{\circ} \mathrm{F}\left(870^{\circ} \mathrm{C}\right)$. Thie reacion product, and unspent sorbent are collected with the fly ash in the electrostatic precipitators. Samples were collected from the full-scale commercial LIMB demonstration at Ohio Edison's Edgewater Plant, and from the LIDS process at the Babcock and Wilcox Alliance Research Center.

Fluidized Bed Combustion (FBC). In FBC systems a calcium-based sorbent (usually limestone or dolomite) and crushed coal are introduced together into the boiler bed where they are "fluidized" or suspended by jets of air. The fluidizing process intimately mixes the coal and sorbent. Reaction of the sorbent with $\mathrm{SO}_{2}$ occurs in the boiler at temperatures generally somewhat less then $1,600^{\circ} \mathrm{F}$. Two FGD by-product streams result; the heavier, granular bed ash material, and smaller particles suspended in the flue gas which are removed with the particulate emission control system. Both by-product streams contain reaction products and unspent sorbent as well as conventional bed or fly ash.

Samples were collected from several atmospheric FBC boilers; General Motors, Quaker State, Staley, and TVA Shawnee. Several samples were collected from the full-scale commercial demonstration of Pressurized FBC at AEP's Tidd plant. In this system the boiler is pressurized and in addition to steam generation, pressurized gasses are used to power a gas turbine. Dolomite is the sorbent used in this system and boiler temperatures are high enough to calcine $\mathrm{MgCO}_{3}$ to $\mathrm{MgO}$, but are to low to calcine $\mathrm{CaCO}_{3}$. Also placed in this grouping are samples collected from a rotary cascading bed boiler (PEDCO). In this system coal and 
crushed sorbent are not fluidized by air, but are mixed by the rotating action of the boiler.

Spray Dryer. Flue gasses enter a separate scrubber vessel located downstream of the boiler and air heater where sorbent, usually a slurry of hydrated lime, is injected. The scrubber vessel allows for increased residence time of flue gas and therefore lengthens the time period for injected sorbent to react with $\mathrm{SO}_{2}$ in the flue gas. Temperature in the scrubber vessel is usually arount $300^{\circ} \mathrm{F}\left(150^{\circ} \mathrm{C}\right)$. These systems can be configursd to allow for recycling and reinjection of by-product together with fresh sorbent. Reaction products and unspent sorbent are removed together with the fly ash in the particulate emission control system. Samples of spray dryer FGD by-products were collected from the EPRI High Sulfur Test Center, Northern States Power, and the OSU McCracken Power Plant.

Five samples from four sources in Ohio representing each of the above four dry FGD systems were selected for more comprehensive characterization. These are; BEV-DUC-02, EDG-LIM-14, TID-FLB-03 (fly ash), TID-FLB-04 (bed ash), and OSUSPC-03. 


\subsubsection{Procedures used in Characterization Studies}

\subsubsection{Chemical Methods and QA/QC Measures}

The methods used for all chemical analyses described below are collected for the convenience of the reader in Table 2.

Table 2. Test protocols for laboratory determination of chemical properties of dry FGD by-products.

\begin{tabular}{|c|c|}
\hline Laboratory Procedure & Reference \\
\hline Total Chemical Analysis & Bernas, 1968 \\
\hline Total Boron & Custom Method (USGS) \\
\hline $\mathrm{pH}$ & ASTM D 1293-84' \\
\hline Eh & ASTM D 1498-76 ${ }^{1}$ \\
\hline ASTM Water Extraction & ASTM 3987-85 \\
\hline TCLP & Method $1311^{2}$ \\
\hline Total Neutralizing Potential & ASTM C $602-90^{3}$ \\
\hline Available Lime Index & ASTM C $25-90^{3}$ \\
\hline Thermal Reactivity & ASTM C $110-8-7^{3}$ \\
\hline Long-term Equilibrium Study & Custom Method \\
\hline Inorganic Carbon & Custom Method \\
\hline Equilibrium Geochemical Modelling & $\begin{array}{l}\text { Sposito and Coves, } 1988 \\
\text { Allison et al., } 1990 \\
\text { Sposito and Traina, } 1987 \\
\text { Lindsay, } 1979\end{array}$ \\
\hline Anion Analysis & Method $429^{4}$ \\
\hline Specific Conductance & Method $205^{4}$ \\
\hline
\end{tabular}

11991 Anriual Book of ASTM Standards, Vol. 11.01.

${ }^{2}$ Code of Federal Regulations, July 1991, Vol 40, Part 261, App. II, pp. 66-81.

31990 Annual Book of ASTM Standaro's, Vol. 04.01.

${ }^{4}$ Standard Methods for the Exarnination of Water and Waste Water, 1985. 


\subsection{Total Chemical Analysis}

Total chemical analysis of solids was determined according to the method of Bernas whereby $100 \mathrm{mg}$ samples were placed in Teflon decomposition vessels and wetted with an aqua-regia-HF mixture. The vessels were then placed in stainless steel digestion bombs and heated at $110^{\circ} \mathrm{C}$ for $40 \mathrm{~min}$. The digested samples were mixed with excess $\mathrm{H}_{3} \mathrm{BO}_{4}$ and diluted to $100 \mathrm{~mL}$ total volume with distilled $\mathrm{H}_{2} \mathrm{O}$. Individual samples were duplicated. Two standard reference materials (NIST coal fly ash 1633a and 2691) were analyzed after every 20th sample.

The digests were analyzed for $\mathrm{Al}, \mathrm{Ba}, \mathrm{Be}, \mathrm{Ca}, \mathrm{Fe}, \mathrm{K}, \mathrm{Li}, \mathrm{Mg}, \mathrm{Mn}, \mathrm{Mo}, \mathrm{Na}, \mathrm{P}, \mathrm{S}, \mathrm{Si}$, and $\mathrm{Sr}$ using inductively coupled plasma emission spectrometry (ICP) with a Leeman PS2000 instrument. The ICP was subjected to the following operating procedures and QA/QC measures. The sample induction system was checked and adjusted for optimum operating conditions at the beginning of each operating period. Pump tubing was inspected and replaced when necessary. Instrument peaking routines were performed to optimize the torch placement and to align the optics. The instrument was programmed to recheck and peak the optics every twenty rninutes thereafter. Standardization was performed using a four point calibration curve. Standards consisted of one blank and three solutions containing different concentrations of each element analyzed. Intermediate standard solutions served as check standards and were analyzed every ten samples. The low and high standards were also analyzed every ten samples and used to update the standardization.

Total S was also determined with a Leco Model 521 Induction Furnace equipped with a semi-automatic titrator by placing a small sample $(15-100 \mathrm{mg})$ in a crucible containing accelerator metal. The sample was heated to $3000^{\circ} \mathrm{C}$ where, in the presence of oxygen, $\mathrm{S}$ in the sample is oxidized to $\mathrm{SO}_{2}$. The $\mathrm{SO}_{2}$ produced was bubbled through a blue standardized solution $\left(\mathrm{KIO}_{3}+\mathrm{KI}+\mathrm{HCl}+\right.$ starch) which fades as $\mathrm{SO}_{2}$ is added. The color of the solution was monitored by a photoelectric cell and was back titrated to the original blue color. Percent $\mathbf{S}$ was based on the amount or titrant $\left(\mathrm{KIO}_{3}\right)$ used and was read directly from the calibrated buret. Standardization was performed by using a three point calibration curve using Leco metal rings containing known amounts of S. Two standard reference materials (NIST coal fly ash 2690 and 2691) were analyzed during each operating period.

Zn contents were determined by atomic absorption using a Varian Techtron Atomic Absorption Spectrophotometer AA6 instrument. The instrument was calibrated using a $5 \mathrm{~mA}$ lamp current, $213.9 \mathrm{~nm}$ wavelength, $0.2 \mathrm{~nm}$ spectral band pass, and an airacetylene flame. Standardization was performed using a three point calibration curve selecting standards within the optimum working range of $0.4-1.6 \mu \mathrm{g} \mathrm{mL} \mathrm{m}^{-1}$. The low, intermediate, and high standards were analyzed every six samples and used to update the standardization. Samples were analyzed in duplicate. A standard reference material (NIST coal fly ash 1633a) was analyzed during the operation period.

Total B contents were determined by a custom method (USGS-sodium peroxide sinter procedure) whereby $100 \mathrm{mg}$ samples were placed in platinum crucibles and mixed with $0.4 \mathrm{~g}$ of $\mathrm{Na}_{2} \mathrm{H}_{2} \mathrm{O}_{2}$. The crucibles were heated at $445^{\circ} \mathrm{C}$ for 30 minutes and 
allowed to sinter. The samples were then removed from the furnace and cooled rapidly. Fourteen $\mathrm{mL}$ of distilled $\mathrm{H}_{2} \mathrm{O}$ was added to the sinter cakes and stirred for 10 minutes. Six $\mathrm{mL}$ of $6 \mathrm{M} \mathrm{HCl}$ were then added to the solution and stirred until the sinter cakes were completely dissolved. The solutions were diluted to $100 \mathrm{~mL}$ total volume with distilled $\mathrm{H}_{2} \mathrm{O}$ and heated in a drying oven for one hour at $100^{\circ} \mathrm{C}$. The solutions were analyzed for B using inductively coupled plasma emission spectrometry with a Leeman PS 2000 instrument. Calibration and standardization of the instrument was performed as described previously in this section. Individual samples were duplicated. Two standard reference materials (CANMET Sy-2 and Sy-3 rock samples) were analyzed after every 10th sample.

The concentrations of $\mathrm{As}, \mathrm{Cd}, \mathrm{Co}, \mathrm{Cr}, \mathrm{Cu}, \mathrm{Ni}, \mathrm{Pb}$, and $\mathrm{Se}$ in the aqua-regia-HF digests were measured with a Perkin-Elmer 4100-ZL, graphite-furnace, atomic absorption spectrophotometer, equipped with a Zeeman background corrector and L'vov-platform atomization. Electrode-discharge lamps were used for As and $\mathrm{Se}$ analysis, and hollow cathode lamps were used for all other elements. Matrix-modifier composition and the temperature program of the graphite furnace were optimized for each element. The graphite pyrolysis tubes were inspected daily and replaced when necessary. Standardization was performed using a four point calibration curve. Standards consisted of one blank and three solutions containing different concentrations of each element analyzed. Intermediate standard solutions served as check standards and were analyzed every 8 samples, after which standard resloping was initiated. An aqua-regia-HF digest of a standard fly ash, NIST-1633a was also analyzed every 8 samples. Analytical matrix blanks were run for each element analyzed. Automatic sample dilution was initiated by the auto-sampler whenever the total absorbance from the analyte exceeded the linear response range.

\subsection{Leaching Analysis (ASTM and TCLP)}

Standard 20:1 ( $w / w$ extractant to FGD), $18 \mathrm{~h}$ leachings were performed using the ASTM water leaching method (ASTM D 3987-85) and the U.S. EPA Toxicity Characteristic Leaching Procedure (TCLP) dilute acetic acid method (Method 1311). For both procedures, $2 \mathrm{~L}$ of extractant was added to $100 \mathrm{~g}$ of FGD by-product in a Teflon bottle. For the ASTM procedure the extractant was de-ionized water. Fur the TCLP procedure extractant 2 was used $(5.7 \mathrm{~mL}$ glacial acetic acid diluted to $1 \mathrm{~L}$ with de-ionized water, $\mathrm{pH}=2.88 \pm 0.05$ ). Bottles were placed on an end-over-end rotary shaker for $18 \mathrm{~h}$ rotating at $30 \mathrm{rpm}$ at $25^{\circ} \mathrm{C}$. Leachates were filtered and analyzed for $\mathrm{pH}$, total dissolved solids, for 5 anions by ion chromatography (IC), and for 30 elements by ICP and graphite furnace atomic absorption spectrophotometry (GFAA). A total of 26 samples were analyzed using the ASTM water method, and 7 samples by the TCLP method.

Quality assurance and control measures consisted of the standard operation protocols for the analytical instruments used: pH meter, IC, ICP, and GFAA (described elsewhere in section 2.1.2.1). The ASTM extraction and analyses were performed in duplicate on 6 samples and the TCLP extraction and analyses were 
performed in duplicate on 3 samples. Results of the duplicate extractions and analyses are given in Appendix D, Table D1.

\subsection{Total Neutralizing Power (TNP), Available Lime Index, $\mathrm{pH}$, and Thermal Reactivity}

Total neutralizing power was determined using ASTM C 602-90, where samples are neated with excess standard hydrochloric acid and back-titrated with standard sodium hydroxide. Samples were analyzed in triplicate and reagent grade $\mathrm{Ca}\left(\mathrm{CO}_{3}\right)_{2}$ was used as a standard reference material.

Available lime index was determined on selected samples using ASTM C 25-90 section 33, (the rapid sugar method). Samples are slaked with water and the lime is solubilized by reaction with sugar to form calcium sucrate which is then determined by titration with standard $\mathrm{HCl}$.

Paste pH of FGD samples was determined by placing equal volumes of FGD byproduct and distilled water into a $70 \mathrm{~mL}$ cup. The mixture was stirred and allowed to equilibrate for 30 minutes. The stirring and equilibration step was then repeated. Measurements were conducted with an Orion Research Expandable Ion Analyzer EA920. The meter was calibrated at the beginning of each operation period using two commercially-prepared buffer solutions. Buffer solutions were used once and discarded. The electrode was inspected weekly for scratches, cracks, salt crystal build-up or membrane-junction deposits. The reference chamber was drained, flushed, and filled weekly with fresh Ross Filling Solution. The electrode was soaked in $0.1 \mathrm{M} \mathrm{HCl}$ for half an hour, followed by soaking in storage solution for one hour monthiy. Sample pH's of the FGD by-products were measured in duplicate.

\subsection{Long-term Equilibrium Studies}

Long-term solubility studies were initiated on five samples; BEV-DUC-02, EDG-LIM14, OSU-SPD-03, TID-FLB-03, and TID-FLB-04, and TID-FLB-MIX, a mixture of 59.5\% TID-FLB-03 and 40.5\% TID-FLB-04. Eight $\mathrm{g}$ of sample and $40 \mathrm{~g}$ of distilled water (1:5 solid/solution ratio) were placed in a $50 \mathrm{~mL}$ polypropylene centrifuge tube and capped. Sufficient replicates of each sample were prepared to allow destructive sampling for eight sampling events over a four month period. The samples were stored in an incubator at $25^{\circ} \mathrm{C}$ and were shaken and aerated weekly. The concentrations of elemental constituents released to solution were measured in duplicate tubes at each sampling event $(1,7,21,36,56,70,84$ and 112 days). Therefore, all parameters measured are represented by two data points for each of the samples at all of the eight sampling times. At each sampling time the solutions were centrifuged at $5000 \mathrm{rpm}$ for one hour, filtered (except for solutions for conductivity, $\mathrm{pH}$ and Eh) through $0.2 \mu \mathrm{m}$ polycarbonate filters and analyzed. The solid residues were quick-frozen with liquid $\mathrm{N}_{2}$ and freeze-dried for subsequent XRD analysis. 
Elemental analysis of solutions. The solutions from each sampling time were analyzed for $\mathrm{Al}, \mathrm{B}, \mathrm{Ba}, \mathrm{Be}, \mathrm{Ca}, \mathrm{Cd}, \mathrm{Co}, \mathrm{Cr}, \mathrm{Cu}, \mathrm{Fe}, \mathrm{K}, \mathrm{Li}, \mathrm{Mg}, \mathrm{Mn}, \mathrm{Mo}, \mathrm{Na}, \mathrm{Ni}, \mathrm{P}, \mathrm{S}$, $\mathrm{Si}, \mathrm{Sr}$, and $\mathrm{Zn}$ using inductively coupled plasma emission spectrometry with a Leeman PS2000 instrument. Calibration and standardization was performed as described in section 2.1.2.1.1. Solutions from days 1 to 36 , and from days 56 and 70 were analyzed at $1: 2$ and $1: 1$ sample/diluent ratios, respectively. Solutions from day 84 and 112 were not diluted prior to analysis.

The aqueous concentrations of $\mathrm{Cl}^{\circ}, \mathrm{SO}_{3}{ }^{2-}$, and $\mathrm{SO}_{4}{ }^{2-}$, were determined according to Method 429, Standard Methods for the Examination of Water and Waste Water (1985). Analyses were performed on a Dionex 2000i ion chromatograph equipped with a AS4A anion separator column and a AG4A guard column. Before each day's work, eluant flow rate and the detector were adjusted to achieve the ion peak separation outlined in the method. The system was then allowed to come to equilibrium indicated by a stable baseline. A standard containing a mixture of anions $\left(\mathrm{Cl}^{-}\right.$and $\mathrm{SO}_{4}{ }^{2-} ; \mathrm{SO}_{3}{ }^{-}$determined separately) was injected to determine anion retention times. Three different concentrations of each of the anions were injected and a calibration curve plotting peak area against concentration was constructed. The instrument was re-calibrated whenever the detector setting was changed.

Inorganic carbon. Inorganic carbon concentrations were determined by the sparge technique using a Dohrmann DC-80 Carbon Analyzer. One $\mathrm{mL}$ volumes of sample were injected into a reactor vessel where carbon due to carbonates and bicarbonates were removed by first acidifying (phosphoric acid) the sample and then bubbling a clean gas $\left(\mathrm{O}_{2}\right)$ through it to remove $\mathrm{CO}_{2}$ from solution. The $\mathrm{CO}_{2}$ evolved was measured by infrared detection. Calibration was performed at the beginning of each operating period by injecting a $10 \mathrm{mg} \mathrm{C} / \mathrm{L}$ standard three times and averaging the values. The $\mathrm{C}$ standards were prepared from reagent grade anhydrous $\mathrm{Na}_{2} \mathrm{CO}_{3}$, stored in dark glass under refrigeration, and replaced weekly. Standardization was performed using a five point calibration curve.

Solution $\mathrm{pH}$. Solution $\mathrm{pH}$ values were determined according to the method described in ASTM D1293 by electrometric measurement using the glass electrode as the sensor. Measurements were conducted with an Orion Research Expandable Ion Analyzer EA920. The meter was calibrated at the beginning of each operating period using two commercially-prepared buffer solutions. Buffer solutions were used once and discarded. The electrode was inspected weekly for scratches, cracks, salt crystal build-up, or membrane/junction deposits. The reference chamber was drained, flushed, and filled weekly with fresh Ross Filling Solution. The electrode was soaked in $0.1 \mathrm{M} \mathrm{HC1}$ for half an hour, followed by soaking in storage solution for one hour monthly. The solution $\mathrm{pH}$ was measured while degassing the head space with nitrogen gas. 
Oxidation-reduction potentials. The oxidation-reduction potentials (Eh) were determined according to the method described in ASTM D1498. The measurements were conducted on a Orion Research Expandable Ion Analyzer EA920 fitted with a platinum electrode coupled with a silver-silver chloride reference electrode. The meter was calibrated at the beginning of each operating period using a ferrous-ferric reference solution. The ferrous-ferric solution was discarded and replaced every 30 days. The electrodes were inspected weekly for scratches, cracks, or deposits. In addition, the electrodes were cleaned at the beginning of each operating period. The Eh of the ferrous-ferric reference solution was measured at least after each 12th sample. If the measured value was different from the published value for the reference solution by more than $2 \%$, the meter was recalibrated and all samples measured after the previous calibration were repeated.

Solution Conductivity. Conductivity was determined according to Method 205, Standard Methods for the Examination of Water and Waste Water (1985).

Measurements were conducted with a YSi Specific Conductance Meter (Model 32) fitted with a YSI 3403 conductivity cell. The meter was calibrated at the beginning of each operating period using a YSI calibrator solution (1000 umhos $/ \mathrm{cm})$. The calibration solution was used once and discarded. The electrode was inspected weekly for scratches, cracks, and deposits. The electrode was rinsed thoroughly between measurements and was kept immersed in distilled water when not in use.

Equilibrium Geochemical Modeling. The aqueous-phase geochemical speciation of the long-term solubility data for sample solutions collected at 56 and $112 \mathrm{~d}$, were calculated with the geochemical speciation computer programs, Soilchem (Sposito and Coves, 1988) and MinteqA2 (Allison et. al, 1990). The former model contains an extended Debye-Huckle expression which allows for accurate calculation of single ion activity coefficients, and accurate predictions of mineral solubilities in solutions with ionic strengths $\left(I_{s}\right) \leq 2 \mathrm{~mol} \mathrm{~L}^{-1}$ (Sposito and Traina, 1987). In the present study, molar solution composition data were input into the Soilchem model and the chemical species that would occur under closed conditions (no reaction with atmospheric $\mathrm{CO}_{2}$ ) and with precipitation prohibited were predicted. The predicted equilibrium solution concentration of free cations and anions and the calculated values of ionic strength (based on the Soilchem results) were recorded. The total solution composition data were then input into MinteqA2, along with the values of ionic strength calculated by the Soilchem program. The solution concentrations of free cations and anions from the Soilchem output were used as the initial "guesses" for the "free" ion concentrations in the MinteqA2 calculations. All MinteqA2 calculations were conducted with precipitation prohibited. Log Saturation Index values (log SI) were calculated by MinteqA2 with the following equation

$$
\log S|=\log | A P-\log K_{s p}
$$

where IAP is the activity product of the solution concentrations of "free" cations and 
anions present in a given solid, and $\mathrm{K}_{\mathrm{sp}}$ is the solubility product for that solid.

Given a general solid, $A_{a} B_{b}(s)$ the $K_{s p}$ for each solid is given by:

$$
\begin{gathered}
A_{a} B_{b}(s)=a A^{b+}(a q)+b B^{a-}(a q) \\
K_{s p}=\left(a A^{b+}\right)\left(b B^{a-}\right)
\end{gathered}
$$

where ( ) denotes ion activities. The ion activity product is given by:

$$
I A P=\left(a A^{b+}\right)\left(b B^{a}\right) .
$$

Equality between the $\mathrm{K}_{\mathrm{sp}}$ and the IAP indicate that a solution may be at equilibrium with a given solid, this is denoted by a log SI value equal to 0 .

Values of $\log \mathrm{SI}$ for the solids, ettringite and $\mathrm{Ca}$-molybdate $\left(\mathrm{CaMoO}_{4}\right)$, were calculated manually using the aqueous activities of the cations and anions obtained from the geochemical computer modeling. A value of 111.32 was used for the log $\mathrm{K}_{\mathrm{sp}}$ of ettringite and the $\log \mathrm{K}_{\mathrm{sp}}$ for Ca-molybdate was -7.94 (Lindsay, 1979).

\subsubsection{Mineralogical Methods and QA/QC Measures}

Mineralogical analyses were limited to FGD by-products obtained from the Beverly (BEV), Edgewater (EDG), McCracken (OSU), Pontiac (GMC) and Tidd (TID) power plants. A variety of analytical methods were employed to derive semi-quantitative measures of mineralogical composition from these materials. These methods and references are listed in Table 3.

Table 3. Test protocols for laboratory determination of mineralogical properties of dry FGD by-products.

\begin{tabular}{ll}
\hline \hline Laboratory Procedure & Reference \\
\hline X-Ray Diffraction & Custom Method \\
Thermal Analysis & ASTM STP 997' \\
Ash Content & Custom Method \\
Calcite and Dolomite Determination & Dreimanis, 1962 \\
\hline \hline
\end{tabular}

'Earnest, C.M. 1988. Compositional Analysis by Thermogravimetry, ASTM STP 997. 


\subsection{X-ray diffraction}

$X$-ray diffraction (XRD) patterns were obtained from randomly-oriented powder mounts using $\mathrm{Cu} K \alpha$ radiation and a Phillips PW 1216/90 wide-range goniometer equipped with a theta-compensating slit and a graphite monochromator. Diffraction patterns were recorded from 5 to $70^{\circ} 2 \theta$ with a step interval of $0.05^{\circ} 2 \theta$ and a counting time of $4 \mathrm{sec}$ per step. The instrument was calibrated using both low (cholesterol) and high angle (NIST SRM 640b Si powder) diffraction standards. Quartz, a ubiquitous phase in coal fly ash, was employed as an internal standard to verify the accuracy of diffractometer readings from sample materials. Crystalline phase assignments were based on published literature, searches of the JCPDS-international data base, and comparative analyses of reference mineral samples.

\subsection{Thermal analysis}

Thermal studies were conducted using a Seiko SSC5020 instrument that provided simultaneous thermogravimetric (TGA) and differential thermal analysis (DTA). Samples were heated from 105 to $1125^{\circ} \mathrm{C}$ at a rate of $20^{\circ} \mathrm{C} / \mathrm{min}$ under a continuous flow $(200 \mathrm{ml} / \mathrm{min})$ of dry $\mathrm{N}_{2}$. Calibration of the temperature signal was achieved using the melting points of In and $\mathrm{Sn}$. Calibration of the thermal balance was performed using a reference weight provided by the instrument manufacturer. Thermal events observed with heating of sample materials were assigned to phase transitions based on published literature and analyses of standard mineral samples. A reference calcite $\left(\mathrm{CaCO}_{3}\right)$ was analyzed after every 20 samples to assure instrument standardization. Weight losses induced by thermal decomposition of the standard were maintained within $\pm 5 \%$ of calculated (ideal) values.

\subsection{Calcite and Dolomite}

Calcite and dolomite could not be consistently distinguished by thermal analysis. When both phases were present in a sample, contents were determined by the gasometric method of Dreimanis (1962) using a Chittick apparatus. The amount of $\mathrm{CO}_{2}$ evolved from the sample following the addition of $20 \mathrm{~mL}$ of $6 \mathrm{M} \mathrm{HCl}$ containing ${ }^{2.6}$ $\mathrm{g}$ of $\mathrm{FeCl}_{2}$ was measured after $30 \mathrm{sec}$ (for calcite) and $30 \mathrm{~min}$ (for dolomite). After volume corrections were made for temperature and pressure, regression equations developed from the results of Dreimanis (1962) were used to calculate the percent calcite and dolomite.

\subsection{Ash content}

Ash contents were determined by mixing weighed samples (10 - 20g) of FGD byproduct with sodium acetate-acetic acid buffer ( $\mathrm{pH}$ 5.0) to form thick slurries. The slurries were then treated with $30 \% \mathrm{H}_{2} \mathrm{O}_{2}$ to convert $\mathrm{CaSO}_{3} \cdot 0.5 \mathrm{H}_{2} \mathrm{O}$ to the more soluble $\mathrm{CaSO}_{4} \cdot 2 \mathrm{H}_{2} \mathrm{O}$. Following oxidation and heating at $60^{\circ} \mathrm{C}$ to decompose excess 
$\mathrm{H}_{2} \mathrm{O}_{2}$, the samples were quantitatively transferred to cellulose dialysis bags and submerged in sodium acetate-acetic acid buffer (pH 5.0) for 4 to 6 days to remove acid-soluble materials. The samples were then dialyzed against distilled $\mathrm{H}_{2} \mathrm{O}$ to remove excess salt and to dissolve residual $\mathrm{CaSO}_{4} \cdot 2 \mathrm{H}_{2} \mathrm{O}$. Removal was judged to be complete when a negative test for dissolved $\mathrm{SO}_{4}{ }^{2-}$ was obtained with $\mathrm{BaCl}_{2}$. The samples were then quantitatively transferred to tared beakers, dried at $100^{\circ} \mathrm{C}$, and weighed to determine the residual ash contents.

\subsubsection{Physical Methods and QA/QC Measures}

Physical prcperties included measurements of particle size distributions, particle density, specific surface area, compression index, compressed bulk density, water retention characteristics and saturated hydraulic conductivity. These methods and references are listed in Table 4. All pressure gauges and electronic balances employed in the preceding methods were checked for accuracy yearly. These units were serviced and rechecked if deviations exceeded manufacturer recommended tolerances.

Table 4. Test protocols for laboratory determination of physical properties of dry FGD by-products.

\begin{tabular}{ll}
\hline \hline Procedure & Reference \\
\hline Particle Size Distribution & ASTM D 422-63 \\
Surface Area & ASTM D 4567 \\
Particle Density & Custom Method (Micromeritics) \\
Bulk Density and Compression Index & Bradford and Gupta (1986) \\
Water Retention & Klute (1986) \\
& Rawlins and Campbel (1986) \\
Hydraulic Conductivity & Klute and Dirksen (1986) \\
\hline \hline
\end{tabular}

a1990 Annual Book of ASTM Standards, Vol. 4.08 
Phase 1 Report

\subsection{Particle Size Distribution}

Particle size distributions were determined using the hydrometer and dry sieving methods of ASTM D 422-63, employing Dispersion Apparatus A. Independent particle density values were employed for all size distribution calculations. Results were expressed as the percent of particles finer than $0.025 \mathrm{~mm}$ (or for coarse samples the percent of particles finer than $0.25 \mathrm{~mm}$ ) and the Coefficient of Uniformity $\left(C_{u}\right)$ given by (Gee and Bauder, 1986):

$$
C_{u}=D_{60} / D_{10}
$$

where $D_{x}$ is the effective particle diameter separating the finer $x$ percent of the particles from the coarser. For example, $D_{10}$ corresponds to the diameter of a hypothetical sieve that would retain $90 \%$ of the particles and allow $10 \%$ of the particles to pass. Duplicate particle size determinations were conducted on each sample. All QA/QC protocols as recommended by ASTM D $422-63$ were employed during particle size measurements.

\subsection{Surface Area}

Single-point determinations of specific surface area were performed using nitrogen adsorption by the continuous flow method (ASTM D4567) with a Micromeritics Flowsorb II 300 instrument. The instrument was calibrated at the beginning of each operating period. Calibration was achieved by injecting a known volume of analytical grade nitrogen gas as described in ASTM D4567. Two standard reference materials (NIST 8570 and 8571) were analyzed at the beginning of each operating period and after every 20th sample. The quantities of both standards and samples were adjusted to yield surface areas in the range of 0.5 to $25 \mathrm{~m}^{2}$ as per instrument manufacturer specifications. Sample materials were analyzed in triplicate or until individual analyses were within $\pm 10 \%$ of the mean values following removal of any outlying data points.

\subsection{Particle Density}

Particle densities were determined using a Micromeritics 1305 Multivolume Gas Pycnometer by placing approximately $4 \mathrm{~cm}^{3}$ of weighed sample into a sample chamber of known volume. The sample chamber was pressurized to a predetermined level with helium. The gas in the chamber was then allowed to expand into a second precisely measured volume yielding a lower pressure which becomes progressively smaller for larger particle volumes. Application of mass balance equations for the gas permits computation of skeletal volumes and the determination of particle densities. The instrument was initially calibrated by placing steel balls in the sample chamber. Two checks were made to determine if the instrument needed recalibration. One checks the zero offset or additive errors of the instrument and the other checks the scale factor. These checks were made if changes occurred in the instrumentation or if 
Phase 1 Report

the temperature differed appreciably from the temperature at the time of the previous calibration. Individual samples were duplicated. Particle densities reported represent the mean of three instrument measurements for each replicate. A standard reference material (NIST 1825) was analyzed to verify precision and accuracy at the beginning of each operating period and after every $20^{\text {th }}$ sample.

\subsection{Bulk Density and Compression Index}

The compression index and compressed bulk density were determined on water saturated samples using a fixed ring consolidimeter that allowed for drainage of the sample during consolidation (Bradford and Gupta, 1986). Stresses employed were 0, $4,13,30,64,128$ and $172 \mathrm{kPa}$. Equilibration times between successive loading were $1.5 \mathrm{~h}$ as determined from a preliminary study. The compression index was calculated as the slope of the relation between bulk density and the natural log of stress (Bradford and Gupta, 1986). Compressed bulk density was the bulk density of the sample determined following equilibration at maximum stress (172 kPa or $25 \mathrm{psi}$ ).

Compression index and compressed bulk density measurements were determined on three replicates of each sample. The only non-mechanical device used in the consolidation apparatus was a linear voltage displacement transducer (LVDT, Model 0244, Trans-tek Inc., Ellington, CT). This device was calibrated daily using an adjustable height stand allowing displacement measurements at a resolution of 0.1 $\mathrm{mm}$. The LVDT was placed on the stand and 11 measurements ranging over $1 \mathrm{~cm}$ were collected. Linearity of the LVDT response as indicated by linear regression of the calibration data consistently yielded $r^{2}$ values exceeding 0.9999 .

\subsection{Water Retention}

Samples for water retention measurements were consolidated at $172 \mathrm{kPa}$ (25 psi) stress using the compression index protocol. Water retention measurements were conducted using Tempe cells for pressure ranges of 0 to $100 \mathrm{kPa}$, volumetric pressure extractors for pressure ranges of 100 to $200 \mathrm{kPa}$, and a Decagon (Pullman, WA) thermocouple psychrometer for soil water suctions exceeding $200 \mathrm{kPa}$ (Klute, 1986; Rawlins and Campbell, 1986). Duplicate water retention measurement values for a given sample were pooled and fit to the Van Genuchten equation Van Genuchten, 1980), an empirical relation commonly used to describe water retention properties of porous media. The required inputs to the equation are the saturated and residual water contents $\left(\mathrm{m} \mathrm{m}^{-3}\right)$, and the fitted variables are the $\alpha\left(\mathrm{MPa}^{-1}\right)$ and $n$ parameters.

The only non-mechanical device employed for these measurements was the thermocouple psychrometer. The calibration curve for this device was constructed daily using stock solutions of 100,500,900, 1100 and 1500 mOsmol (a measure of solution osmotic potential). Additionally, the 500 mOsmol solution was included with the samples as an internal standard. Periodically (after approximately 10 successive measurements using this device) the osmolarity of the stock solutions was checked using solutions of 100 and $500 \mathrm{mOsmol}$ in sealed ampules. If the readings from the 
100 and 500 mOsmol stock solutions varied by more than $5.0 \%$ from that of the solutions in sealed ampules, then all stock solutions were replaced.

\subsection{Hydraulic Conductivity}

Samples for saturated hydraulic conductivity measurements were consolidated at $172 \mathrm{kPa}$ (25 psi) stress using the compression index protocol. The samples were subsequently resaturated by capillarity and hydraulic conductivity measurements were determined using the falling head or constant head techniques as appropriate (Klute and Dirksen, 1986). Following hydraulic conductivity measurements, the samples were allowed to drain overnight, encased in a plastic bag, and stored for seven days. Hydraulic conductivity measurements were repeated on the seven day old samples.

Saturated hydraulic conductivity measurements were conducted using four replications for each sample. Hydraulic head measurements for this procedure were conducted using a Vernier gauge with resolution of $0.02 \mathrm{~mm}$. Outflow from the conductivity device was determined gravimetrically using an electronic balance. 


\subsubsection{Engineering Methods and QA/QC Measures}

All engineering tests made were based on the assumption that the FGD by-product could satisfactorily be analyzed as a geotechnical material having specific, measurable engineering properties. With the engineering properties properly evaluated, the substitution of FGD by-products for natural soils in many engineering applications could then be included in standard construction specifications. To implement this approach, laboratory experiments were conducted to identify the properties a highway engineer would need to know before recommending the use of an FGD by-product as a fill material in a typical highway construction project.

All tests were conducted using equipment that should be readily available in a quality commercial or state department of transportation geotechnical laboratory. American Society for Testing and Materials (ASTM) Standard procedures were employed to obtain the desired engineering properties in all cases where an appropriate standard existed. QA/QC procedures as specified in the relevant ASTM Standards were followed during testing. The purpose for this approach to the testing was twofold; first, to take advantage of the quality control procedures already established by ASTM and recognized throughout the engineering community; and second, to provide the interested highway or geotechnical engineer with the results of our test program in a form readily understood by the profession. Table 5 is a list of the ASTM Standard Procedures followed in the laboratory program. A listing of the FGD samples on which the tests were conducted is presented in Table 6.

Table 5. Test protocols for laboratory determination of engineering properties of dry FGD by-products.

\begin{tabular}{|c|c|}
\hline Laboratory Procedure & Reference \\
\hline $\begin{array}{l}\text { Optimum Moisture and Density } \\
\text { (Standard Proctor Compaction) }\end{array}$ & ASTM D 698-78 ${ }^{1}$ \\
\hline Unconfined Compression & ASTM D 2166-85' \\
\hline One-dimensional Swell & ASTM D $4546-85^{1}$ \\
\hline One-dimensional Consolidation & ASTM D $2435-80^{1}$ \\
\hline Falling Head Permeability & Lin and Evett, $1990^{2}$ \\
\hline
\end{tabular}

11990 Annual Book of ASTM Standards, Vol. 4.08

2 Soil Properties Testing, Measurement and Evaluation, 2nd edition, Cheng Lin and Jack B. Evett, Prentice-Hall Inc., 1990 
Table 6. Laboratory test program to determine the engineering properties of dry FGD by-product.

\begin{tabular}{|c|c|c|c|c|c|c|c|c|c|}
\hline \multirow[t]{2}{*}{$\begin{array}{c}\text { Semple } \\
\text { ID }\end{array}$} & \multirow[t]{2}{*}{$\begin{array}{c}\text { Optimum } \\
\text { Moisturi } \\
\text { Content } \\
\end{array}$} & \multirow[t]{2}{*}{$\begin{array}{l}\text { Optimum } \\
\text { Density }\end{array}$} & \multicolumn{3}{|c|}{$\begin{array}{l}\text { Unconfined } \\
\text { Compression } \\
\text { (days) }\end{array}$} & \multirow[t]{2}{*}{ Swelling } & \multicolumn{3}{|c|}{$\begin{array}{c}\text { Permeability } \\
\text { (days) } \\
\end{array}$} \\
\hline & & & 0 & 7 & 28 & & 0 & 7 & 28 \\
\hline CLS-01 & $\checkmark$ & $\checkmark$ & $\checkmark$ & $\checkmark$ & $\checkmark$ & $\checkmark$ & $\checkmark$ & $\checkmark$ & $\checkmark$ \\
\hline LIM-06 & $\checkmark$ & $\checkmark$ & $\checkmark$ & $\checkmark$ & $\checkmark$ & $\checkmark$ & $\checkmark$ & $\checkmark$ & $\checkmark$ \\
\hline LIM-07 & $\checkmark$ & $\checkmark$ & $\checkmark$ & $\checkmark$ & $\checkmark$ & $\checkmark$ & $\checkmark$ & $\checkmark$ & $\checkmark$ \\
\hline LIM-08 & $\checkmark$ & $\checkmark$ & $\checkmark$ & $\checkmark$ & $\checkmark$ & $\checkmark$ & $\checkmark$ & $\checkmark$ & $\checkmark$ \\
\hline LIM-09 & $\checkmark$ & $\checkmark$ & $\checkmark$ & $\checkmark$ & $\checkmark$ & & $\checkmark$ & $\checkmark$ & * \\
\hline LIM-10 & $\checkmark$ & $\checkmark$ & $\checkmark$ & $\checkmark$ & $\checkmark$ & $\checkmark$ & $\checkmark$ & $\checkmark$ & * \\
\hline LIM-11 & $\checkmark$ & $\checkmark$ & $\checkmark$ & $\checkmark$ & $\checkmark$ & & $\checkmark$ & $\checkmark$ & $\checkmark$ \\
\hline LIM-12 & $\checkmark$ & $\checkmark$ & $\checkmark$ & $\checkmark$ & $\checkmark$ & & $\checkmark$ & $\checkmark$ & $\checkmark$ \\
\hline LIM-13 & ' & $\checkmark$ & $\checkmark$ & $\checkmark$ & $\checkmark$ & & $\checkmark$ & $\checkmark$ & $\checkmark$ \\
\hline LIIM-14 & $\checkmark$ & $\checkmark$ & $\therefore$ & $\therefore$ & $\checkmark$ & $\checkmark$ & $\therefore$ & $\therefore$ & $\therefore$ \\
\hline OSU-01 & $\checkmark$ & $v^{*}$ & $\checkmark$ & $\checkmark$ & $\checkmark$ & & $\checkmark$ & $\checkmark$ & $\checkmark$ \\
\hline OS'J-02 & $\checkmark$ & $\checkmark$ & $a$ & $\checkmark$ & $\checkmark$ & & $\checkmark$ & ND & ND \\
\hline OSU-03 & $\checkmark$ & $\checkmark$ & $\checkmark$ & $\checkmark$ & $d$ & $\checkmark$ & $\checkmark$ & $\checkmark$ & $\checkmark$ \\
\hline OSU-11 & $\checkmark$ & $\checkmark$ & $\checkmark$ & $\checkmark$ & $\checkmark$ & & $\checkmark$ & $\checkmark$ & $\checkmark$ \\
\hline HST-01 & $\checkmark$ & $\checkmark$ & $\checkmark$ & $\checkmark$ & $\checkmark$ & & 8 & $\checkmark$ & $\checkmark$ \\
\hline HST-03 & $\checkmark$ & $d$ & $\checkmark$ & $\checkmark$ & $\checkmark$ & & $\checkmark$ & $\checkmark$ & $\checkmark$ \\
\hline HST-05 & $\therefore$ & $\checkmark$ & $\checkmark$ & 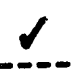 & $\therefore$ & 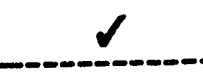 & $\therefore$ & $\therefore$ & $\therefore$ \\
\hline BEV-05 & $\checkmark$ & $\checkmark$ & $\checkmark$ & $\checkmark$ & $\checkmark$ & & $\checkmark$ & $\checkmark$ & $\checkmark$ \\
\hline BEV-06 & $\checkmark$ & $\checkmark$ & $\therefore$ & $\therefore$ & $\checkmark$ & & $\therefore$ & $\therefore$ & $\therefore$ \\
\hline $\begin{array}{l}\text { TID-1/2 } \\
60 \% / 40 \%\end{array}$ & $\checkmark$ & $\checkmark$ & ND & $\checkmark$ & ND & & $\checkmark$ & * & * \\
\hline $\begin{array}{l}\text { TID-1/2 } \\
50 \% 50 \%\end{array}$ & $\checkmark$ & $\checkmark$ & $\checkmark$ & $\checkmark$ & $\checkmark$ & & $\checkmark$ & $\checkmark$ & $\checkmark$ \\
\hline $\begin{array}{l}\text { TID-3/4 } \\
40 \% / 60 \%\end{array}$ & $\checkmark$ & $\checkmark$ & $\checkmark$ & $\checkmark$ & $\checkmark$ & $\checkmark$ & $\checkmark$ & $\checkmark$ & $\checkmark$ \\
\hline TID-05 & $\checkmark$ & $\checkmark$ & $\checkmark$ & $\checkmark$ & $\checkmark$ & & ND & ND & ND \\
\hline
\end{tabular}


Phase 1 Report

Table 6. continued

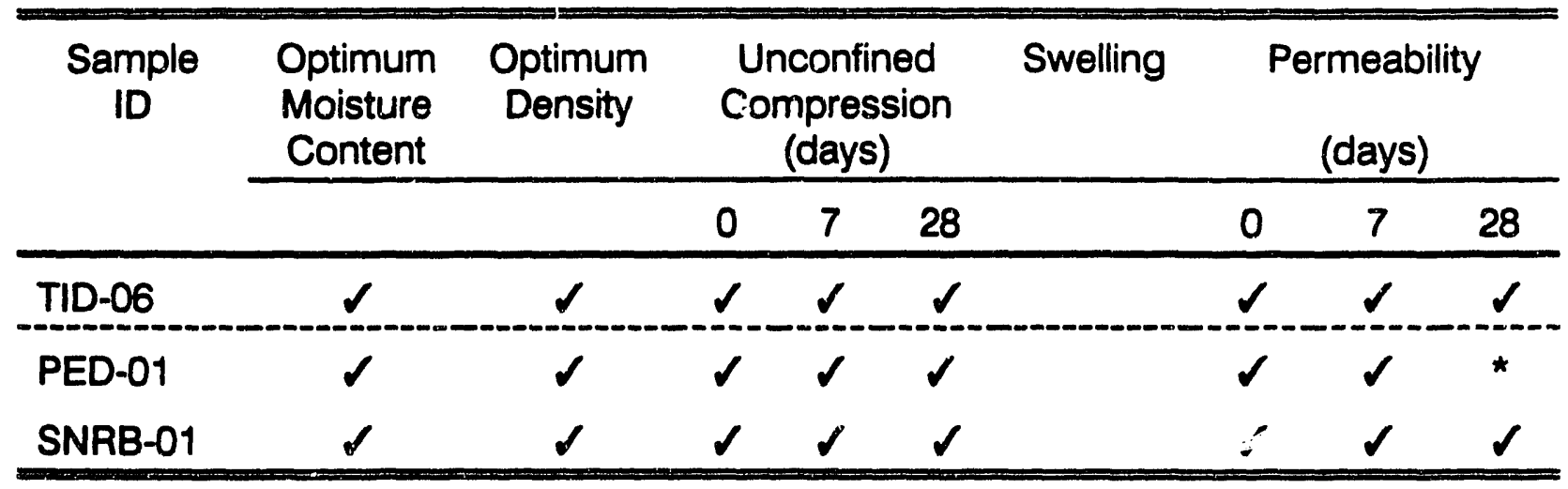

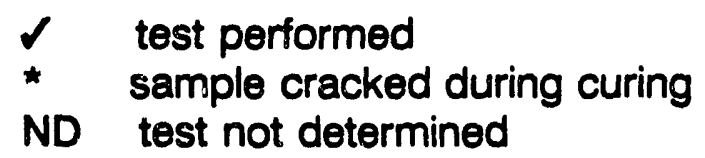

25 
Phase 1 Report

\subsubsection{Results and Discussion of Dry FGD By-Product Characterization}

\subsubsection{Chemical Characterization}

\subsection{Solid Phase Chemical Composition of FGD by-products}

Results of the total elemental analyses of standard fly ash samples are presented in Tables 7 to 10. The values reported by OSU are means from a minimum of four replicate measurements obtained by ICP or a minimum of 15 replicate measurements obtained using the GFAA. There was generally excellent agreement between the analytical values measured by OSU and the certified values reported by NIST. Boron analyses were compacted to a standard sample obtained from the Canadian Center for Mineral and Energy Technology (Table 9).

The total concentrations of $\mathrm{Al}, \mathrm{Ba}, \mathrm{Be}, \mathrm{Ca}, \mathrm{Fe}, \mathrm{K}, \mathrm{Li}, \mathrm{Mg}, \mathrm{Mn}, \mathrm{Mo}, \mathrm{P}, \mathrm{S}, \mathrm{Si}, \mathrm{Sr}, \mathrm{V}$ and $Z n$, in FGD samples were determined by ICP analyses of HF-AR digests, and are listed in Table 11. Values for total $\mathbf{S}$ measured with a Leco induction furnace are also presented in Table 11. The total concentrations of $\mathrm{As}, \mathrm{Cd}, \mathrm{Co}, \mathrm{Cr}, \mathrm{Cu}, \mathrm{Ni}, \mathrm{Pb}$, and $\mathrm{Se}$ in the FGD by-products were determined by GFAA analyses of the HF-AR digests and are given in Table 12. Total $B$ concentrations in FGD samples were determined by ICP analyses of dissolved $\mathrm{Na}_{2} \mathrm{H}_{2} \mathrm{O}_{2}$ sinter cakes and are presented in Table 13. For all elemental analyses, sample concentrations represent the means of duplicate digestions and analyses. The data in Tables 11,12, and 13 are grouped according to the type of FGD technology utilized in the coal-fire plants. The categories are Spray Dryer, Duct Inject, LIMB, Fluidized Bed Combustion, which is itself split into Bed ash and Cyclone ash, and Other.

The chemical composition of most samples is dominated by $\mathrm{Ca}, \mathrm{S}, \mathrm{Al}, \mathrm{Fe}$, and $\mathrm{Si}$. This chemistry is consistent with the FGD mineralogy as discussed in section 2.1.3.2.

The values listed as "Means" in Table 11 and 12 represent the means of the concentrations of a given element in all of the FGD samples present within a given sample category. Thus the mean concentration of $A$ in all FGD samples obtained from Spray Dryer facilities was $5.2 \pm 6.8 \%$ wt. This value is typical of many category means reported in Table 11 and 12, in that the means were comparable in size to the standard deviations of the means. This precludes any ranking of FGD technologies in terms of the relative concentrations of any given element. Calculation of means and standard deviations for each individual source, e.g. all OSU-SPD samples, did not result in any decrease in variation. The standard deviations were again comparable in size to the means (data not shown). Apparently there was sufficient variation within the composition of the inputs (coal and/or scrubbing material) and within the operating conditions of each coal-fire facility, to prohibit any calculation of average elemental concentrations for a given FGD technology or a given source of FGD byproducts. The one exception to the above general statement was the element $B$, which decreased in concentration in the FGD-products in the order Spray Dryer > LIMB > cyclone ash from Fluidized Bed Combustion > Duct Injection > fly ash from Fluidized Bed Combustion (Table 13). 


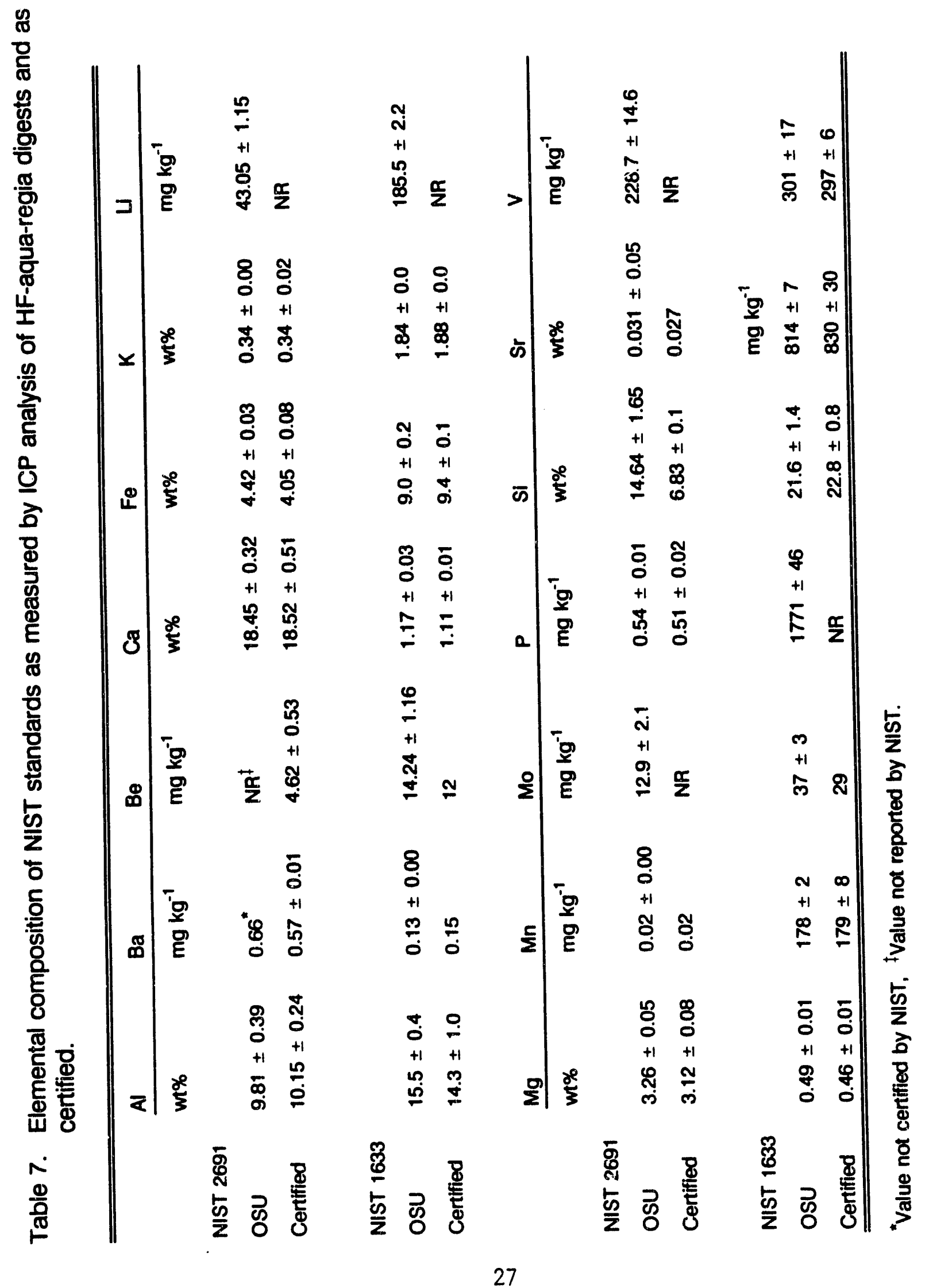


Table 8. Graphite furnace analysis of NIST 1633.

\begin{tabular}{lcccccccc}
\hline & As & Cd & Co & Cr & $\mathrm{Cu}$ & $\mathrm{Ni}$ & $\mathrm{Pb}$ & $\mathrm{Se}$ \\
\cline { 2 - 8 } & & & \multicolumn{7}{c}{$\mathrm{mg} \mathrm{kg}^{-1}$} \\
OSU & $146 \pm 31$ & $1.10 \pm 0.10$ & $32 \pm 4$ & $191 \pm 11$ & $109 \pm 6$ & $122 \pm 7$ & $73.6 \pm 2.0$ & $12.2 \pm$ \\
Certffied & $145 \pm 15$ & $1.00 \pm 0.15$ & $46^{*}$ & $196 \pm 6$ & $118 \pm 3$ & $127 \pm 4$ & $72.4 \pm 0.4$ & $10.3 \pm 0.6$ \\
\hline
\end{tabular}

Value not certified by irlST.

Table 9. Concentration of B in standard materials.

\begin{tabular}{llll}
\hline Sample & Source & Reportad Value & OSU analysis \\
\hline & & $\mathrm{mg} \mathrm{kg}^{-1}$ & $\mathrm{mg} \mathrm{kg}^{-1}$ \\
SY-2 & CANMET* & 85 & $84 \pm 7$ \\
SY-3 & CANMET & 110 & $100 \pm 5$ \\
\hline \hline
\end{tabular}

*Canadian Centre for Mineral and Energy Technology.

Table 10. Concentration of $\mathrm{Zn}$ in NIST 2691.

\begin{tabular}{|c|c|}
\hline Reported Value & OSU analysis \\
\hline $\mathrm{mg} \mathrm{Zn} \mathrm{kg-1}$ & $\mathrm{mg} \mathrm{Zn} \mathrm{kg-1}^{-1}$ \\
\hline $220 \pm 10$ & $267 \pm 30$ \\
\hline
\end{tabular}




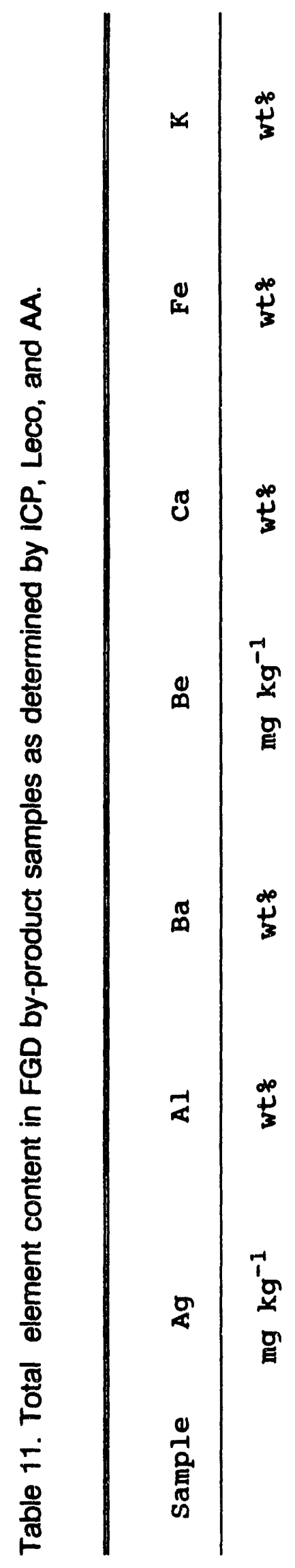

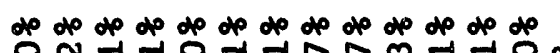
O . . . . . . . . . $\dot{0} \dot{0} \dot{0} \dot{0} \dot{0} \dot{0} \dot{0} \dot{0} \dot{0} \dot{0}$ $+1+1+1+1+1+1+1+1+1+1+1+1+1+1$

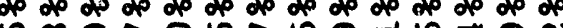

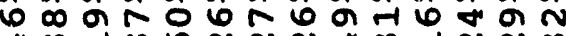
$+m-m$ Ln $N N * m-1 N N$ ㅇ $\dot{0} \dot{0} \dot{0} \dot{0} \dot{0} \dot{0} \dot{0} \dot{0} \dot{0} \dot{0}$

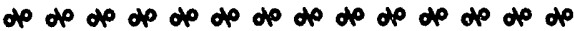

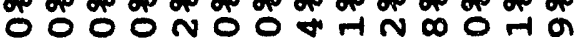
$\dot{0} \dot{0} \dot{0} \dot{0} \dot{0} \dot{0} \dot{0} \dot{0}$ $+1+1+1+1+1+1+1+1+1+1+1+1+1+1$ de de de de de de de de de de de de de de

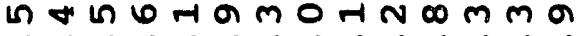
$\dot{N} \dot{N} \dot{\sim} \dot{N} \dot{H} \dot{m} \dot{m} \dot{m} \dot{m} \dot{N} \dot{m}$

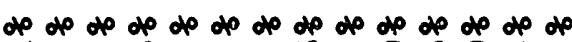

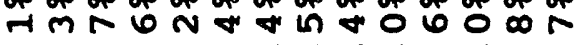
$\dot{0} \dot{0} \dot{0} \dot{0} \dot{0} \dot{0} \dot{\mathrm{r}} \dot{0} \dot{\mathrm{r}} \dot{\mathrm{r}} \dot{0} \dot{\mathrm{n}}$ $+1+1+1+1+1+1+1+1+1+1+1+1+1+1$ dp de de dp dp dp dp dp dp dp dp dp dp dp

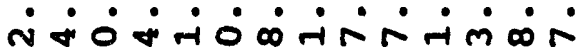
m N N N

ब NHAMOHMOMHN IN $\dot{0} \dot{0} \dot{0} \dot{0} \dot{0} \dot{0} \dot{-1} \dot{0} \dot{0} \dot{0} \dot{0}$ $+1+1+1+1+1+1+1+1+1+1+1+1+1+1$ 0 in $\mathrm{N} 6 \mathrm{~m} N \mathrm{mon}$ n

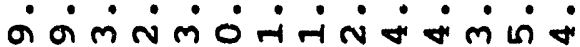

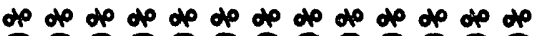

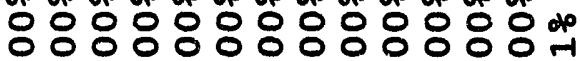
$\dot{0} \dot{0} \dot{0} \dot{0} \dot{0} \dot{0} \dot{0} \dot{0} \dot{0} \dot{0} \dot{0}$ $+1+1+1+1+1+1+1+1+1+1+1+1+1+1$ de dp de de de de de de de de de de de de

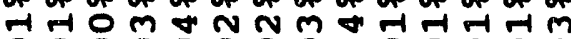
O 0000000 N 00000 $\dot{0} \dot{0} \dot{0} \dot{0} \dot{0} \dot{0} \dot{0} \dot{0} \dot{0} \dot{0} \dot{0}$

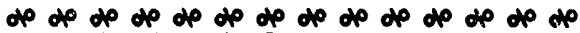
0 O 0 HO 00 in $\dot{0} \dot{0} \dot{0} \dot{0} \dot{0} \dot{0} \dot{0} \dot{0} \dot{0} \dot{0}$ $+1+1+1+1+1+1+1+1+1+1+1+1+1+$ de de dp dp de de dp dp dp de dp dp de de

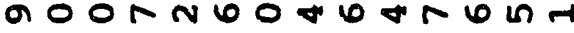
N

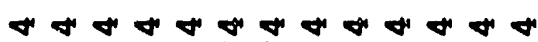

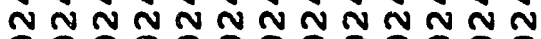
0000000000000

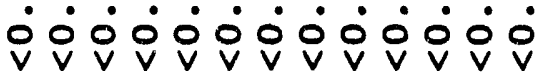

HNm

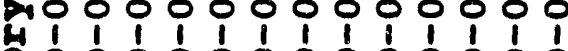

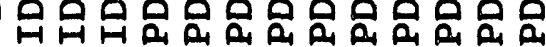
An

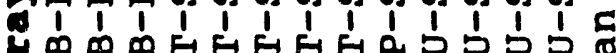
o.

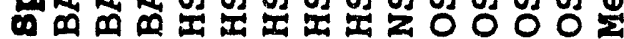

de de do do do do do do do do do do

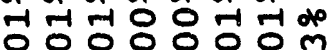
$\dot{0} \dot{0} \dot{0} \dot{0} \dot{0}$ $+1+1+1+1+1+1+1+1$ do do do do do do do do

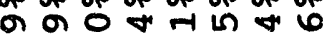
$\rightarrow m \infty \infty \infty$ ச 0 0 0 0 $\dot{0} \dot{0}$

de de de de de de de de

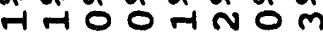
$\dot{0} \dot{0} \dot{0} \dot{0} \dot{0} \dot{0}$ $+1+1+1+1+1+1+1+1$ do do do do of do to de N In $\rightarrow \mathrm{O}$ N $\mathrm{m}$ in $\dot{*} \dot{0} \dot{0} \dot{0} \dot{0} \dot{0}$

do do do do do do do do d Ho $\rightarrow m \sim$ in $N$ $\dot{0} \dot{0} \dot{0} \dot{0} \dot{0} \dot{0}$ $+1+1+1+1+1+1+1+1$ do do do do do do do de $m \rightarrow$ in in $\infty 0$ - : ? : ?

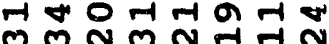

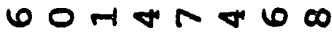
$\dot{0} \cdot \dot{0} \cdot \dot{0} \cdot$ 00000000 $+1+1+1+1+1+1+1+1$ croo an um

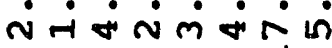

de de de de de dp do de

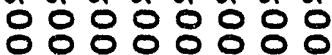
$\dot{0} \dot{0} \dot{0} \dot{0} \dot{0} \dot{0}$ $+1+1+1+1+1+1+1+1$ do de de de de de de do

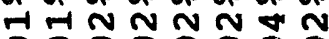
更 웅

de de de de de de de de 0 न 0 o 0 म 0 o $\dot{0} \dot{0} \dot{0} \dot{0} \dot{0} \dot{0}$ i $+1+1+1+1+1+1+1+$ de de de up de de de de $0 m \sim 0 m m \infty$ $\dot{\sim} \dot{m} \dot{0} \dot{0} \dot{0} \dot{0}$

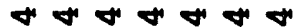
$\operatorname{Nnn} N \pi N$ O000000 - $\dot{0} \dot{0} \dot{0} \dot{0} \dot{0} 0$ - $v \vee v V \vee v V$ Unm $n N \infty$ 인 0 ロuบuบuU 4

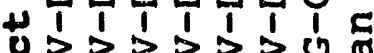

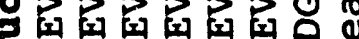

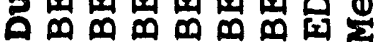




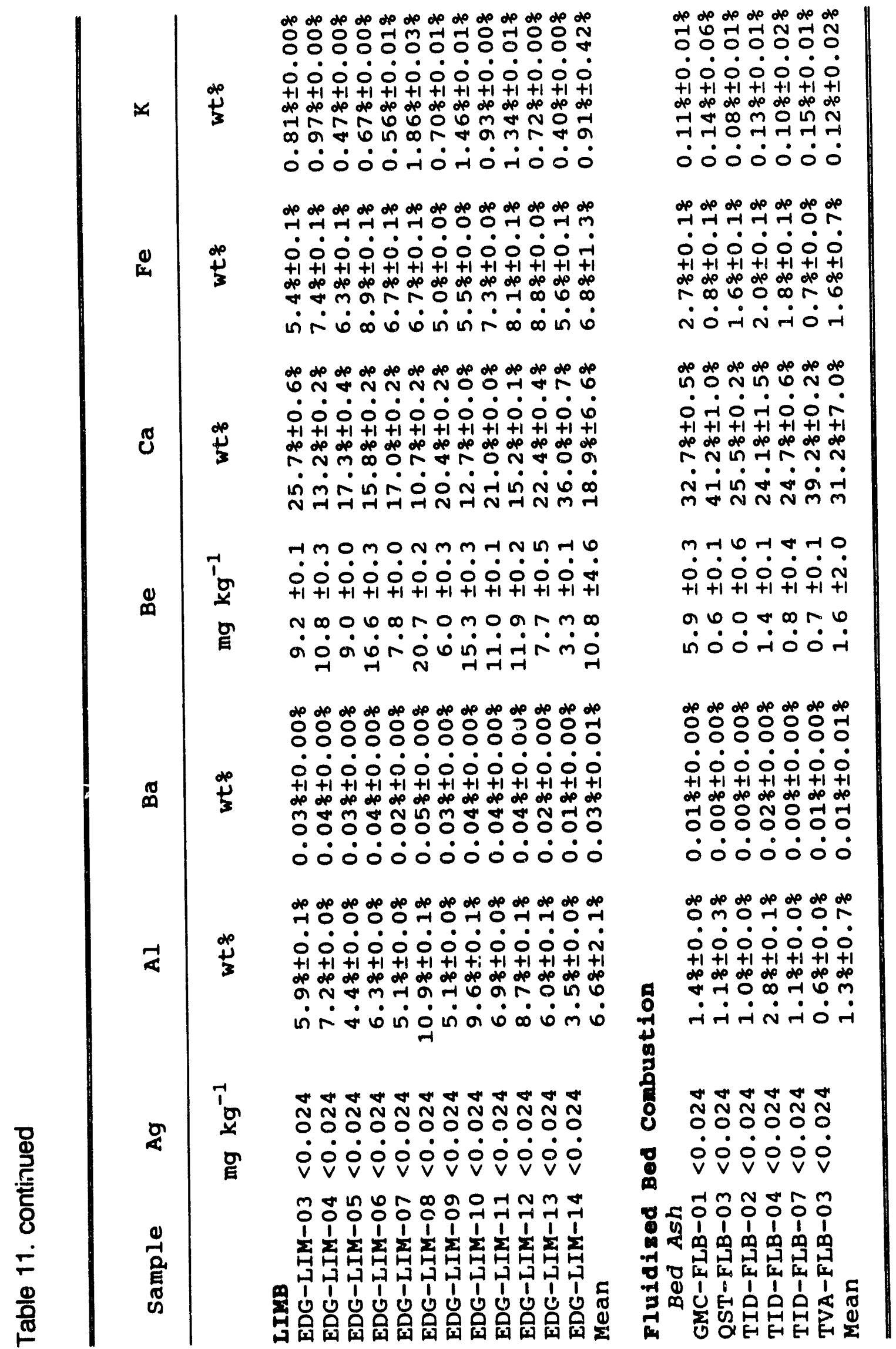




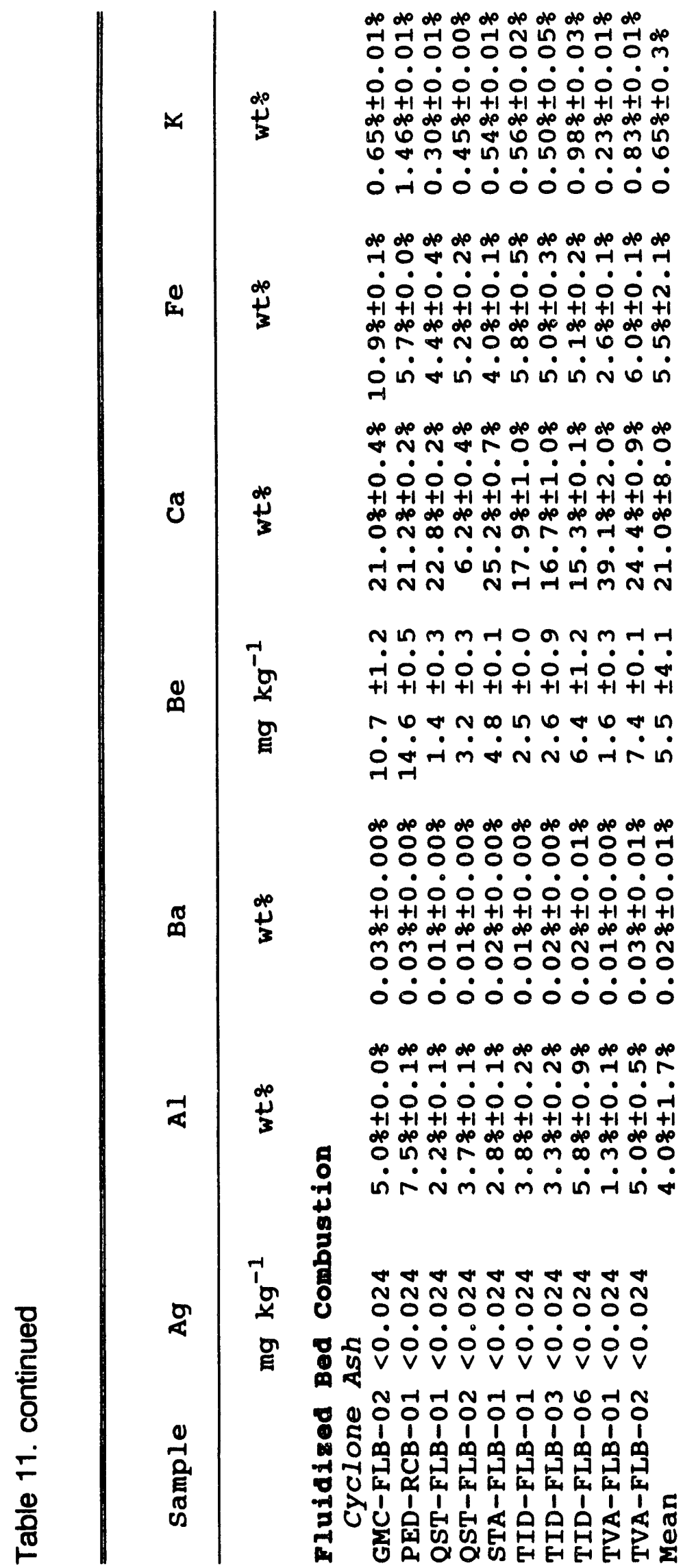

dp op op dp dp dp de de

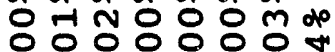

i் $\dot{0} \dot{0} \dot{0} \dot{0} \dot{0}$

$+1+1+1+1+1+1+1+1$

do dp do de do do do do

a -1 in 1 ก

H $N \infty m^{-1} N \infty$

$\dot{0} \dot{0} \dot{0} \dot{-1} \dot{0} \dot{0}$

do do do do do do do do do

$\dot{0} \dot{0} \dot{-1} \dot{0} \dot{0} \dot{0} \dot{0}$

$+1+1+1+1+1+1+1+1$

do de de de do do de do

MN $N$ N N NO

$\therefore \dot{0} \dot{0} \dot{0}-\dot{1}$

नानH

do

do de de do do do do do

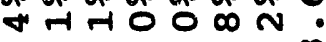

i $\dot{0} \dot{0} \dot{0} \mathrm{~m}$

$+1+1+1+1+1+1+1+1$ do do de de do do de de

onr n N N - $\dot{\text { N }} \dot{0} \dot{0} \dot{N} \mathbf{N}$ m $m$ N

ob ora a b $\dot{0} \dot{N} \dot{0} \dot{0} \dot{0}$

$+1+1+1+1+1+1+1+1$

$m+\pi+\omega N$ $\dot{0} \dot{\sigma} \dot{\sim} \dot{m} \dot{m} \dot{0}$

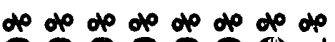
000 $\dot{0} \dot{0} \dot{0} \dot{0} \dot{0}$ $+1+1+1+1+1+1+1+1$ de de de de de de de de $N M N M m-N$ O 0000000 ○ $\dot{0} \dot{0} \dot{0} \dot{0} 0 \dot{0}$

de de de at de do do do do de $0 \mathrm{~N} N \boldsymbol{N}$ N 훙 $\dot{0} \dot{0} \dot{0} \dot{0}$ $+1+1+1+1+1+1+1+1$ de de de de de de do de $m$ m $\infty$ o $m$ o ? $m$ ! ? ? ? ? No $\dot{\sim} \dot{\sim} \dot{\sim} \dot{-1} \dot{\sim}$

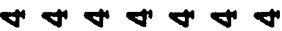

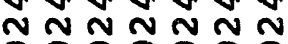
no 000000 H $\dot{0} \dot{0} \dot{0} \dot{0} \dot{0} \dot{0} \dot{0}$ H. H $m+\infty a$ on + + 1 i 1 i 1 i ฯ

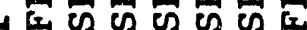
011111111 . 군? 山选期 


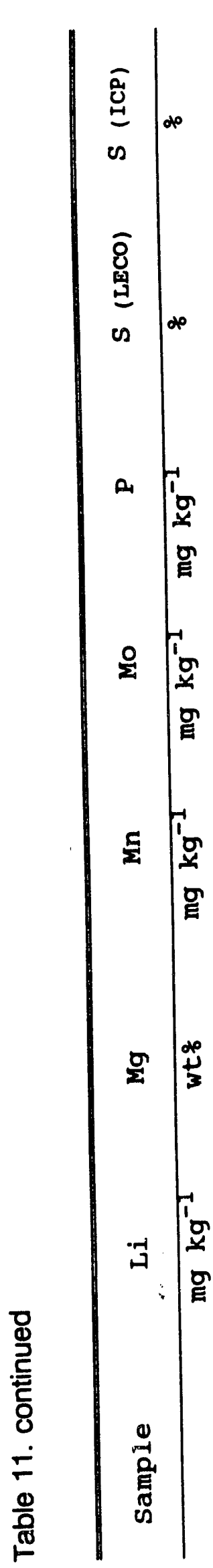

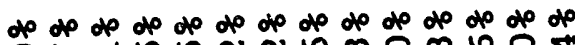

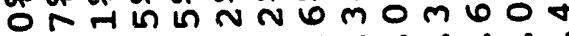
- $\dot{0} \dot{0} \dot{0} \dot{0} \dot{0} \dot{0} \dot{0} \dot{0} \dot{0}$ $0000+1+1+1+1+1+1+1+1+1+1$ do do do de de de de de de de de de de de

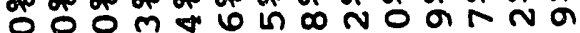
? ? ! ? :

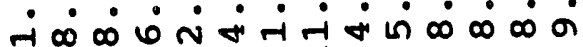
m

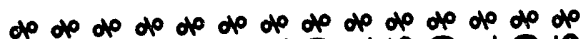
* N O HA O i $\dot{0} \dot{0} \dot{0} \dot{0} \dot{0} \dot{0} \dot{0} \dot{0} \dot{0} \dot{0} \dot{0}$ $+1+1+1+1+1+1+1+1+1+1+1+1+1+1$ $+1+1+1+1+1+1+1+1+10$ do do do de de de de de de de de de de de dp dp de de de

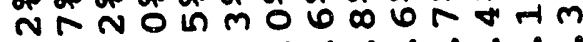

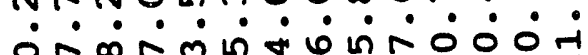

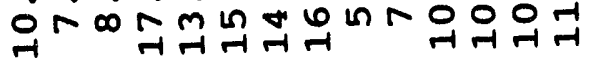

HNON

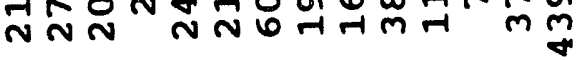

$+1+1+1+1+1+1+1+1+1+1+1+1+1+1$

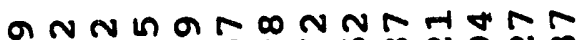
O $N+\infty$ in $N$ in $\infty N$ a $N$

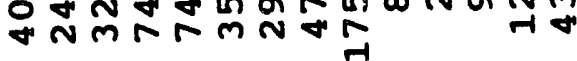

o mo o $\infty m \infty$ on $N \infty \sim m m$

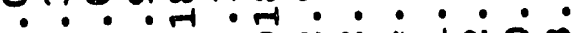
แ $+1+1+1+1 \dot{0}+1 \dot{0}+1+1+1+1+1+1+1$ NRHNVHVNNHN+mN $\dot{0} \dot{0} \dot{0} \dot{m} \dot{0} \dot{N} \dot{0} \dot{\sim} \dot{\sim}$ in $\mathrm{N}$

$$
\text { H }
$$

$+1+1+1+1+1+1+1+1+1+1+1+1+1+1$

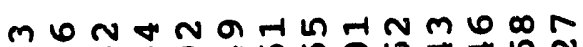
in $\begin{aligned} & n+1 \\ & \text { in }\end{aligned}$

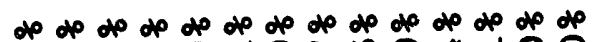
0
N

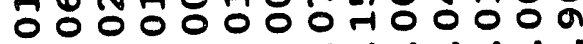
- $\dot{0} \dot{0} \dot{0} \dot{0} \dot{0} \dot{0} \dot{0} \dot{0} \dot{0}$ $+1+1+1+1+1+1+1+1+1+1+1+1+1+1$ de de de de de de de de de de de de de de

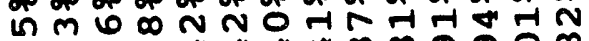

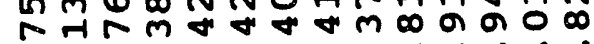

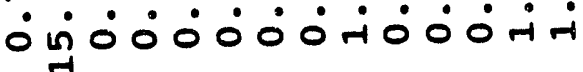

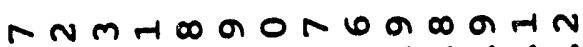

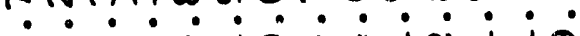
Hન૦ $+1+1+1+1+1+1+1+1+1+1+1+1+1+1$ ถ

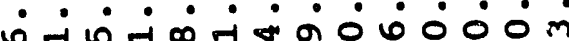

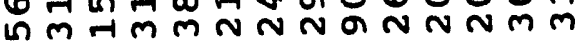

\section{4}

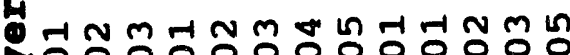

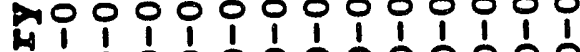
4 ó á áóááa áa

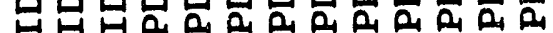
A $\rightarrow A$ US US US US US UA US

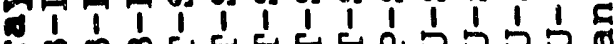

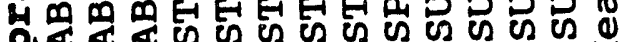
a 4 近 de of dp do dp dp dp dp a 1 N $\mathrm{N} 6 \mathrm{HN}$ i் $\dot{0} \dot{0} \dot{0} \dot{0} \dot{0}$ $+1+1+1+1+1+1+1+1$ do do do do do do do do de of de de de op do do

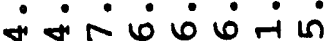

de de do do do do do do de de

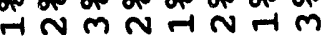
- $\dot{0} \dot{0} \dot{0} \dot{0} \dot{0}$ $+1+1+1+1+1+1+1+1$ de de de de de de de de

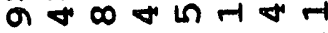
in $\dot{0} \dot{0} \dot{0} \dot{0} \dot{N}$

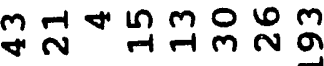
$+1+1+1+1+1+1+1+1$ - $m$ m 0 N 0 ANA

$\infty 0 \infty \pi$ a 0 \% - $\dot{0} \dot{m} \dot{0} \dot{0} \dot{0} \dot{m}$ $\dot{0}+1+1+1+1+1+1+1$ $\checkmark$ เ $\infty$ o $0 \mathrm{~m}$ - $\dot{\sim} \dot{\infty} \dot{\sim} \dot{0}$ $n \rightarrow n$

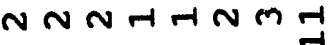
$+1+1+1+1+1+1+1+1$ o in $m \sim N \mathrm{~m}$ $* m A N m m \otimes m$ तम $\mathrm{AH}$ -

dp d d d d d d d d d d -1 0 O - $\dot{0} \dot{0} \dot{0} \dot{0} \dot{0}$ $+1+1+1+1+1+1+1+1$ op op op de de de de dp $\rightarrow+\sigma \omega a$

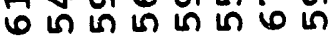
-் $\dot{0} 0 \dot{0} \dot{0} \dot{0} \dot{0}$ N $\mathrm{f}$ ( $9+\mathrm{m}$ - $\dot{0} \dot{0} \dot{0} \dot{0} \dot{0}$ $+1+1+1+1+1+1+1+1$ n 0 n - $-\dot{0} \dot{0} \dot{0} \dot{0} \dot{0}$ o in in a $r$ a 0 $\because 4$

$4 \Omega m$ in $0 \times \infty$

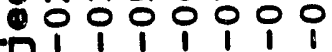

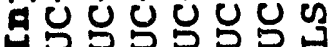
$+111111$ $4 P B P B D D$

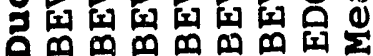




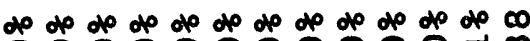
$00000000000 \mathrm{~m}$ $\dot{0} \dot{0} \dot{0} \dot{0} \dot{0} \dot{0} \dot{0} \dot{0} \dot{0} \dot{0} \dot{0}-1$ $+1+1+1+1+1+1+1+1+1+1+1+1+$ de de do de de de de ap ap de de de de

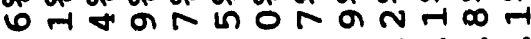

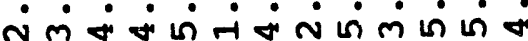

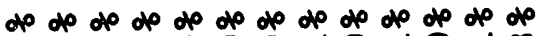
No $00000 \mathrm{H} 0 \mathrm{H} 0 \mathrm{Hm}$ $\dot{0} \dot{0} \dot{0} \dot{0} \dot{0} \dot{0} \dot{0} \dot{0} \dot{0} \dot{0} \dot{0}$ $+1+1+1+1+1+1+1+1+1+1+1+1+1$ de de dp do de de de de de de de de de $\sim \sim N O \infty N M N O 6 m$ ก

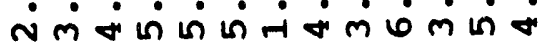

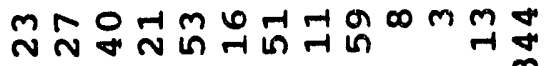

$+1+1+1+1+1+1+1+1+1+1+1+1+1$

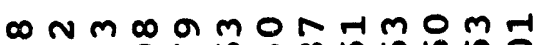
* $\infty \infty N 0$ unmm

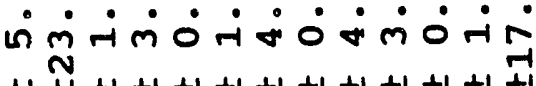
$+1+1+1+1+1+1+1+1+1+1+1+1+1$ ด Nก $\dot{a} \dot{0} \dot{A} \dot{\sim} \dot{m} \dot{N} \dot{n} \dot{n} \dot{a}$ in माก

の

$+1+1+1+1+1+1+1+1+1+1+1+1+1$

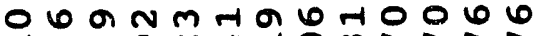
Hmman

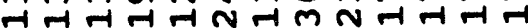

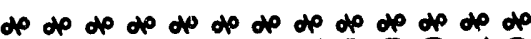

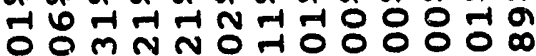
$\dot{0} \dot{0} \dot{0} \dot{0} \dot{0} \dot{0} \dot{0} \dot{0} \dot{0} \dot{0} \dot{0}$ $+1+1+1+1+1+1+1+1+1+1+1+1+$ de de of op de of de de de de de de of

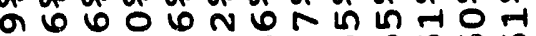
$m \infty 66$ in 60 ก - $\dot{0} \dot{0} \dot{0} \dot{0} \dot{0} \dot{0} \dot{0} \dot{0} \dot{0}$

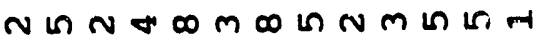

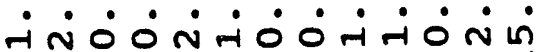
$+1+1+1+1+1+1+1+1+1+1+1+1+1$ m

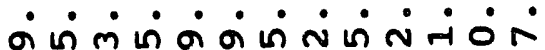
* 0 \%

m $\begin{array}{llllllllllll}0 & 0 & 0 & 0 & 0 & 0 & 0 & -1 & -1 & -1 & -1 \\ 1 & 1 & 1 & 1 & 1 & 1 & 1 & 1 & 1 & 1 & 1 & 1\end{array}$

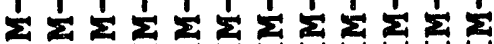

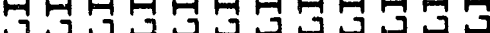
9

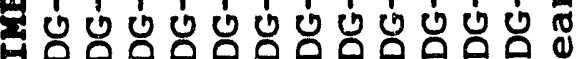

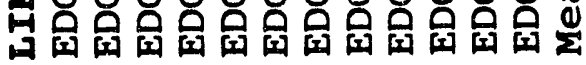

do de do do do do do do de n $\infty$ - $\infty \circ N \mathrm{~m}$ $\dot{0} \dot{0} \dot{0} \dot{0} \dot{\mathrm{m}}$ $+1+1+1+1+1+1+$ do do do do do do do $m$ in $\sim$ $m+\ln N \infty$ $\dot{\infty} \dot{\sim} \dot{\sigma} \dot{\sim} \dot{m} \dot{\sim}$

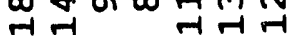

de do do do do do de de * a $00 \mathrm{c}-1 \mathrm{r}$ - $\dot{0} \dot{0} \dot{0} \cdot$ $+1+1+1+1+1+1+1$ ap do de de de de de

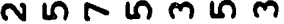
- $\dot{0} \dot{0} \dot{0} \dot{0} 0$

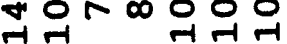

웜얼

$+1+1+1+1+1+1+1$ o in $\rightarrow$ o o $0-1$ $m M$ a $\infty$ ᄂ n $\infty$ n $m m \sim$ i $+1 \dot{0}+1+1+1+1+1$ $m \vee \ln \varphi \infty \omega$ in $\dot{0} \dot{0} \dot{0} \dot{0}$ N

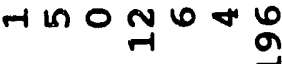
$+1+1+1+1+1+1+1$ $m$ nn $m$ n $N$ * No o 0 o 0

dp dp dp dp dp dp dp

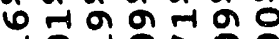
HO $\dot{0} \dot{0} \dot{0} \dot{0} \dot{0}$ $+1+1+1+1+1+1+1$ do do do do de de do in $\infty$ in $\sim 0 * \infty$ o $m \infty$ on $N$ $\dot{0} \dot{0} \dot{0} \dot{0} \dot{\sim} \dot{0}$ मी

roa $0 \mathrm{~m}$ in a - $\dot{0} \dot{0} \dot{0} \dot{0} \dot{0}$ $+1+1+1+1+1+1+1$ o 60 n $\dot{r}$ iि $\dot{-} \dot{0} \dot{0} \dot{\theta}$ न Hत

HMN - 1900000 - y

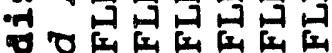
- 011 l 1 l 1 I ว

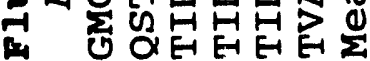




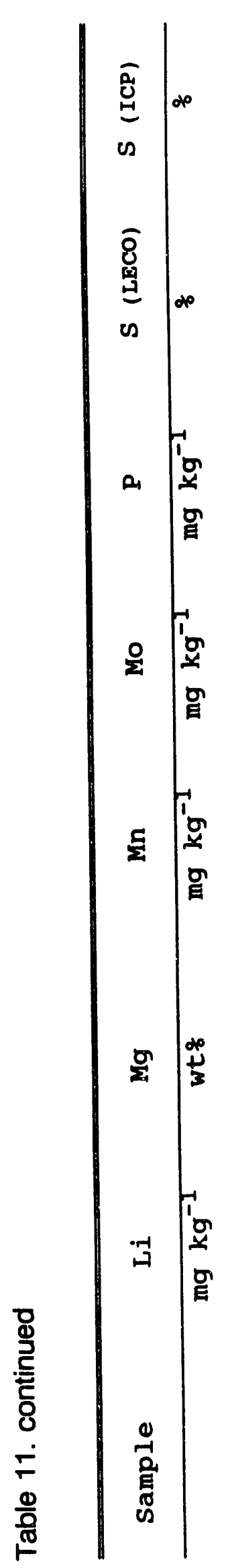

de de de de de de de de de de de de de de de

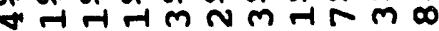
- $\dot{0} \dot{0} \dot{0} \dot{0} \dot{0}$ $0000000000000+1+1+1+1+1+1+1+1+1+1+1+10$ de de de de de de de de de de de

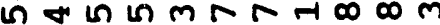

- $\dot{0} \dot{0} \dot{0} \dot{0} \dot{0} \dot{0} \dot{0}$

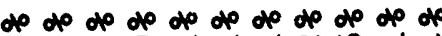
$m$ I N O $\mathrm{H}-\mathrm{H} N$ in $\mathrm{F}+$ i $\dot{0} \dot{0} \dot{0} \dot{0} \dot{0} \dot{0} \dot{0}$ $+1+1+1+1+1+1+1+1+1+1+1$ de do do do do do de de de de

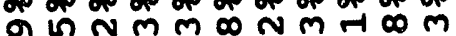
i $\dot{0} \dot{0} \dot{0} \dot{0}$ in

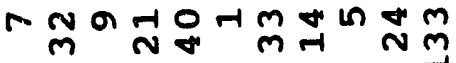

$+1+1+1+1+1+1+1+1+1+1+1$

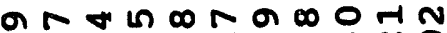

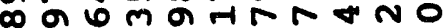
$m$ n $N m N H A m m$

$\infty \sim N \infty m m N O N N m$ - $\dot{\sim} \dot{0}$ i $+1+1+1 \dot{0}+1+1+1+1+1+1+1$ o $\infty m \vee \mu-10+\infty N$

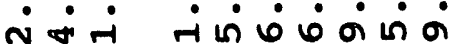
N

N

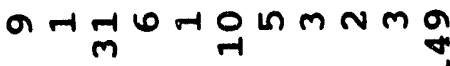
$+1+1+1+1+1+1+1+1+1+1+1$ ama $\sim \mu \infty$ L $m \infty \infty m 0 N 0$

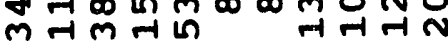

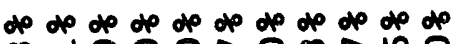
$m$ I O O O N $M$ N Hoo 00 n N 0000 웅 $\dot{0} \dot{0} \dot{0} \dot{0} \dot{0} \dot{0}$ $+1+1+1+1+1+1+1+1+1+1+1$ dp de de dp dp dp dp dp dp dp dp

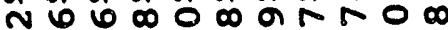
แ $\mathrm{N}$ N $\cdot \cdot \cdot \cdot \cdot \cdot \cdot \cdot \cdot \cdot \cdot$ $\frac{9}{9}$ m m 0 0 00 क $\infty m$ or $m+m m \infty n$ i $\dot{1} \dot{1} \dot{0} \dot{1} \dot{0} \dot{0} \dot{0}$ HAHOOOAHWN N $+1+1+1+1+1+1+1+1+1+1+1$ N $N$ H - $\dot{0} \dot{0} \dot{0} \dot{0} \dot{0} \dot{0} \dot{0} \dot{m}$ - $\varepsilon$ in $N N H N N M A+m$ (1)

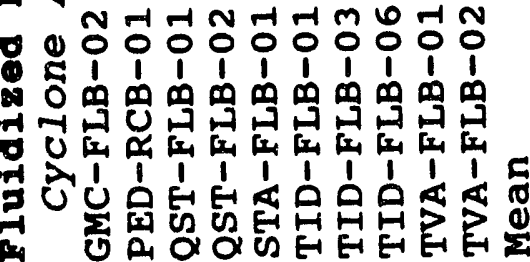

dp dp dp dp dp dp dp dp H -i $\dot{0} \dot{0} \dot{0} \dot{0}$ i i $+1+1+1+1+1+1+1+1$ do de de op op op dp d HONNM N ம் $\dot{0} \dot{0} \dot{A} \dot{A} \dot{H}$

d o p o d d d d d d d d * F 0 O 0 $\mathrm{A}$ N 0 i $\dot{0}$ i $\dot{0}$ i 0 : $+1+1+1+1+1+1+1+1$ dp dp dp dp op op op dp $\sigma$ in in $0 \mathrm{H}$ in $m \infty$ - $0 . \cdot 0$. H N 0 - $N$ N 0 น

* un 0 o $10 \mathrm{~m}$ $N m N+m$ o

$+1+1+1+1+1+1+1+1$ 0 in On $N$ in 0 o $m \sim m m m m n$

n $4000 m \infty$ n

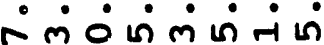
$+1+1+1+1+1+1+1+1$ क N $\dot{\sim} \dot{0} \dot{0} \dot{0} \dot{0} \dot{0} \dot{1}$

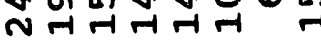

* OHNMmHN

$+1+1+1+1+1+1+1+1$ - $9 \hat{N}$ o $0 \mathrm{mH}^{-1}$ $\stackrel{\sim}{N} \mathbb{H}^{\infty}{ }^{-1}$

de de de de de de de de N $\therefore \dot{0} \dot{0} \dot{0} \dot{0}$ $+1+1+1+1+1+1+1+1$

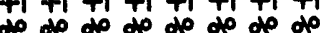
我

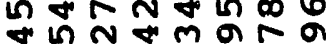
$\therefore \dot{0} \dot{0} \dot{0} \dot{0}$ HAmNGMNR -i $\dot{m} \dot{0} \dot{0} \dot{0} \dot{m}$ $+1+1+1+1+1+1+1+1$ n $\& m \sigma \& N$ $\ddot{\theta} \dot{m} \dot{\dot{m}} \dot{m} \dot{\sim} \dot{\dot{\theta}}$

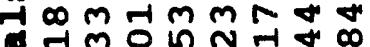

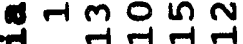

4

a $m+\infty$ a 0 in

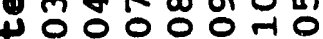
+ 1 i 1 i $1 \quad 1$ i

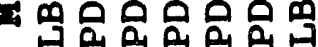
4 is cos us es es Q I 111111 c 눈?

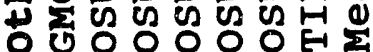




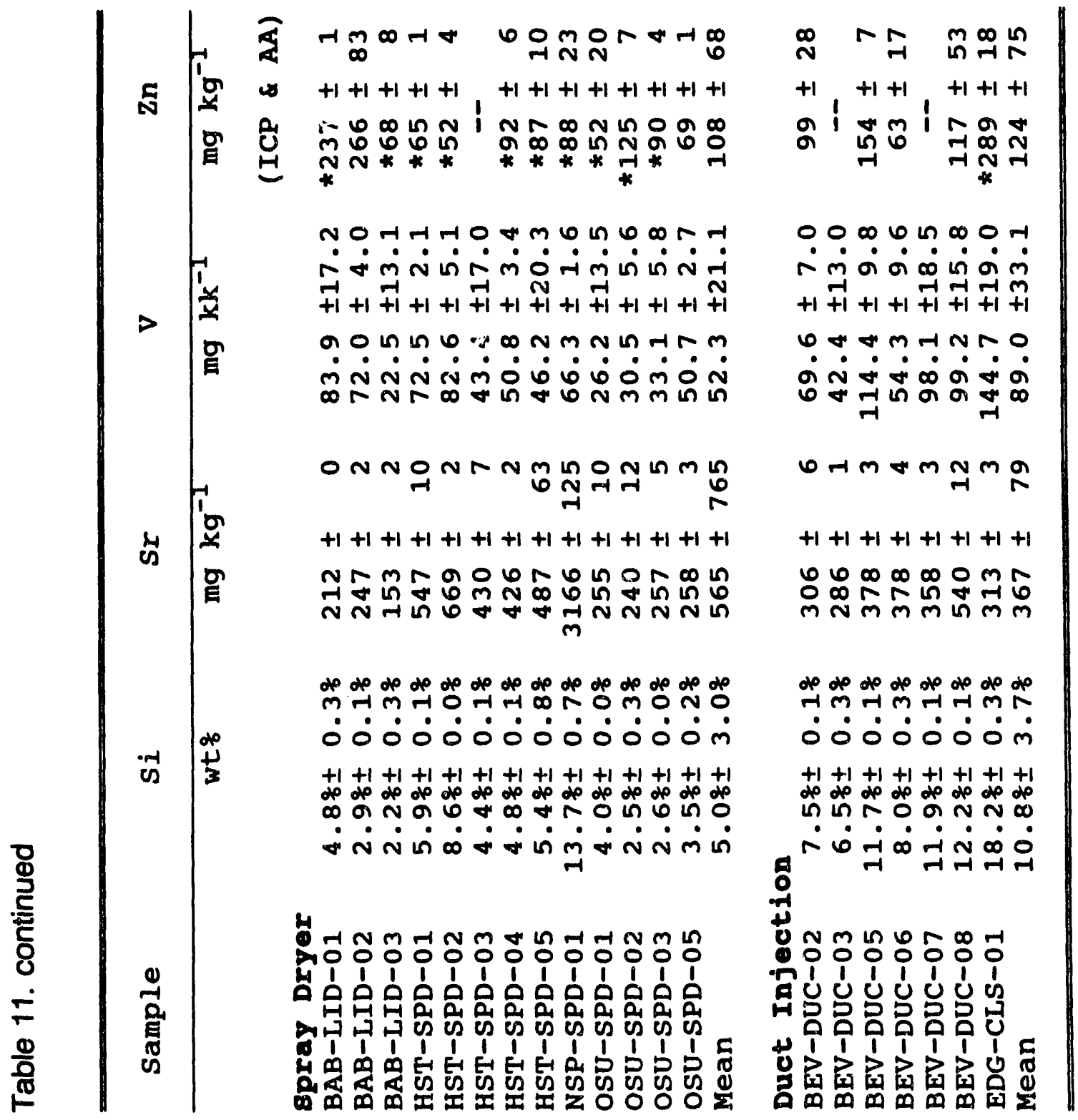




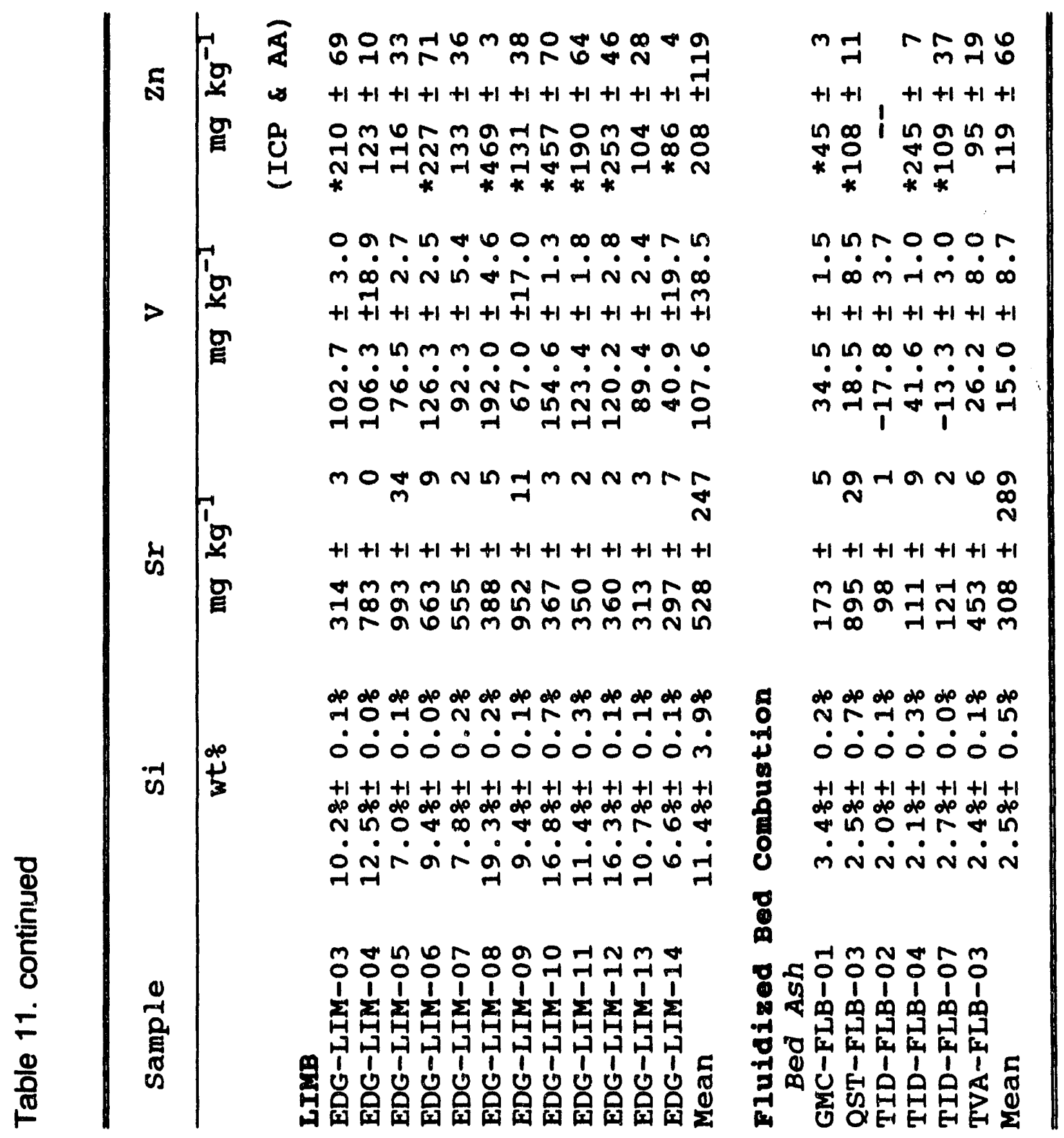




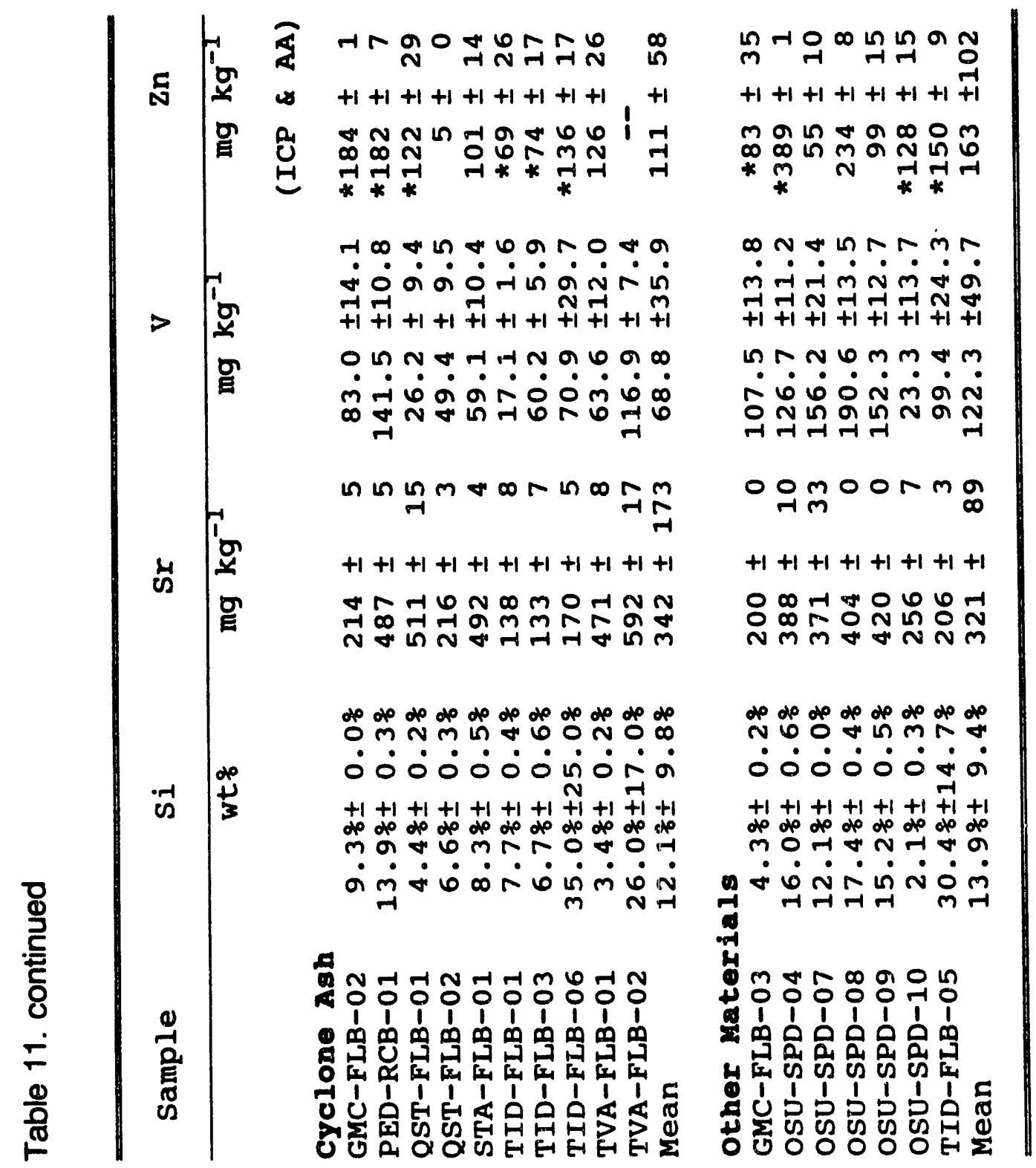




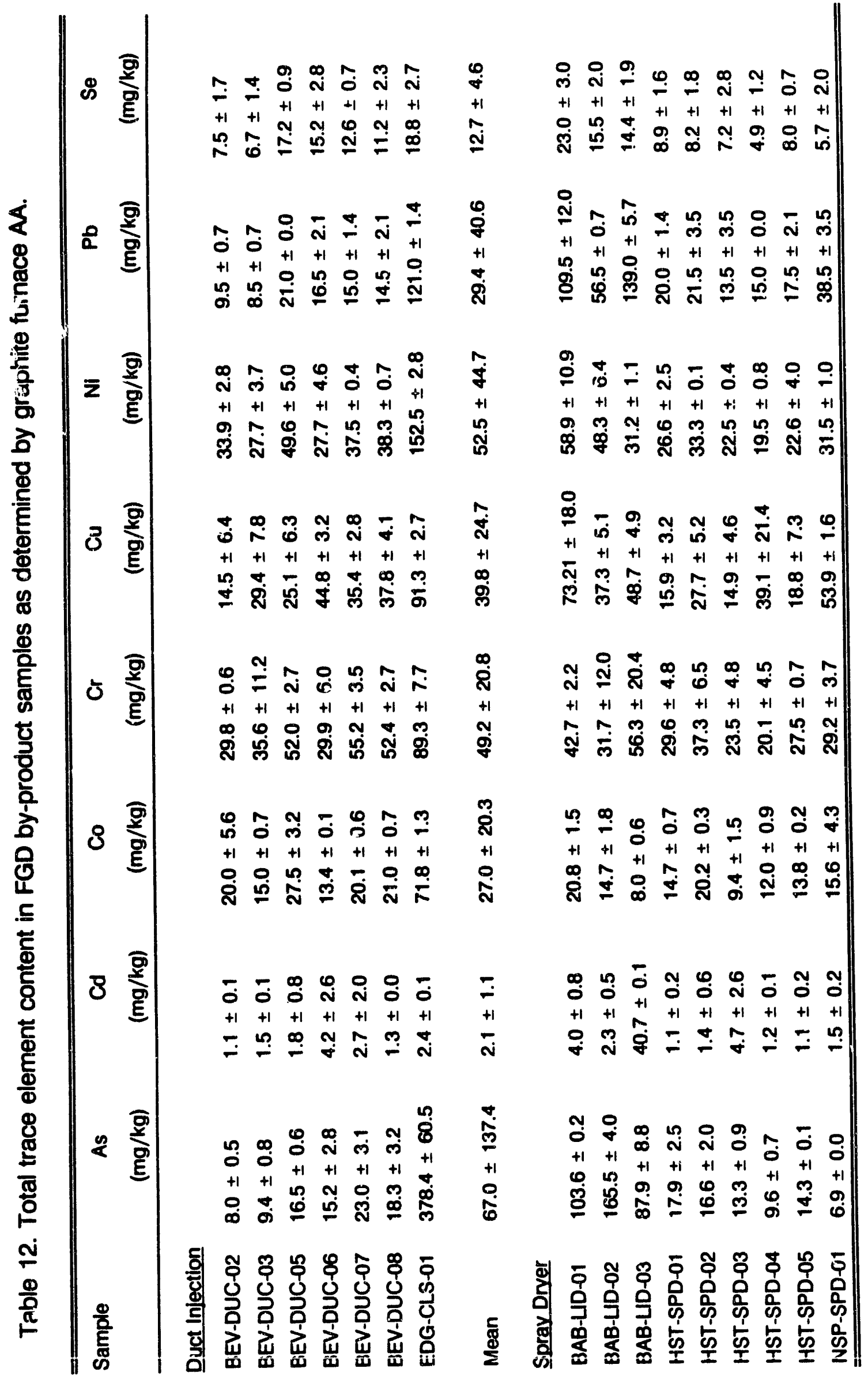




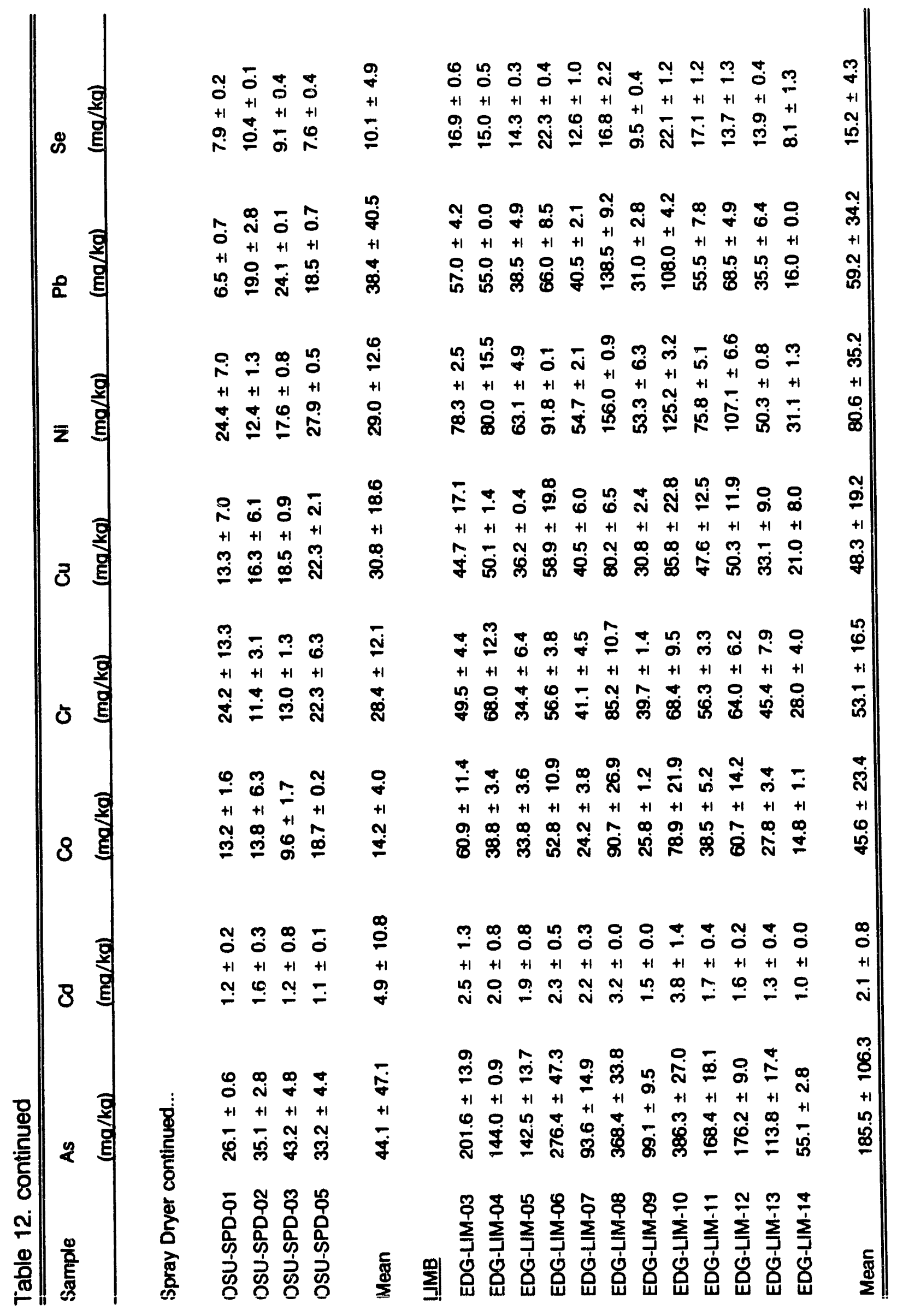




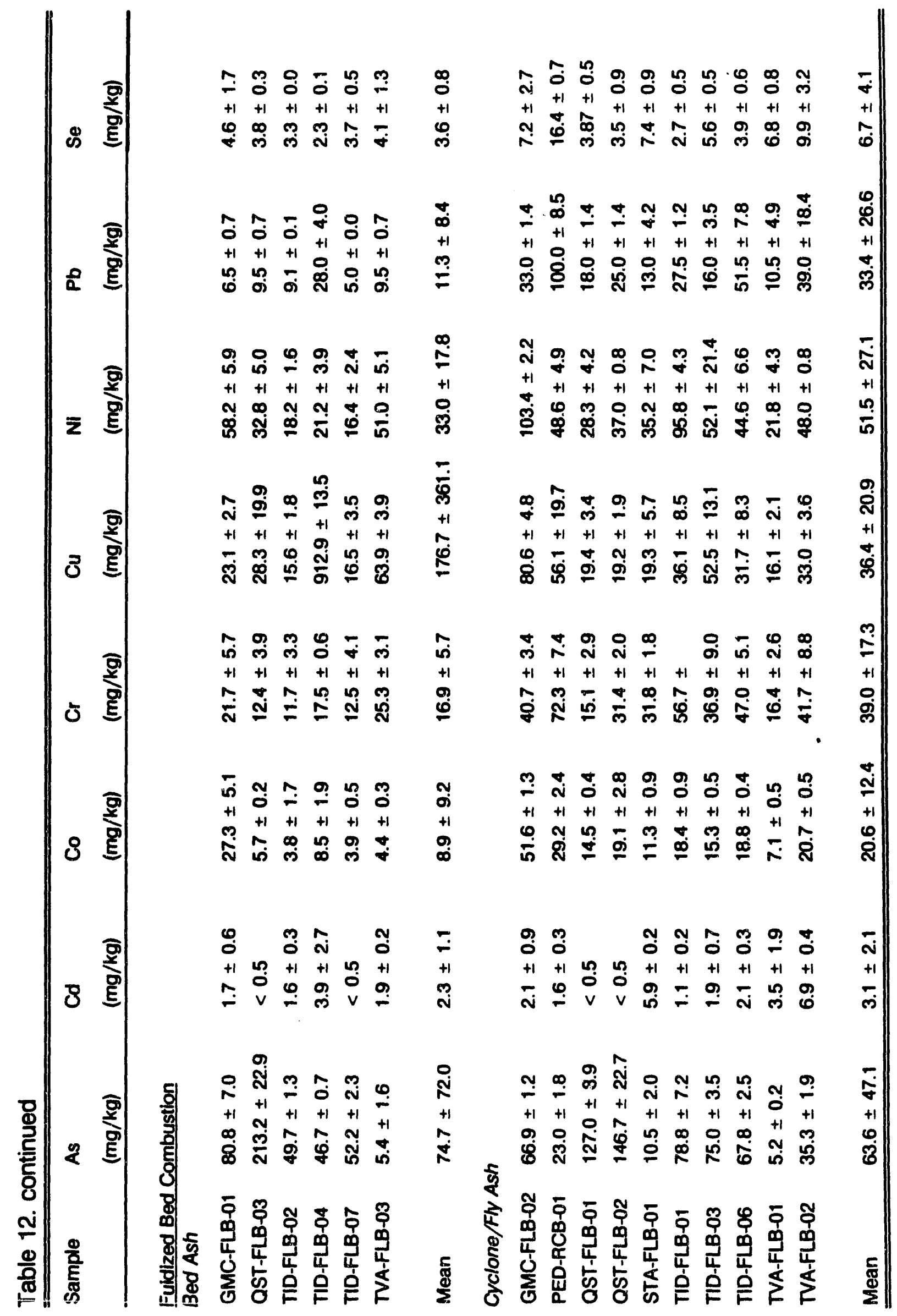




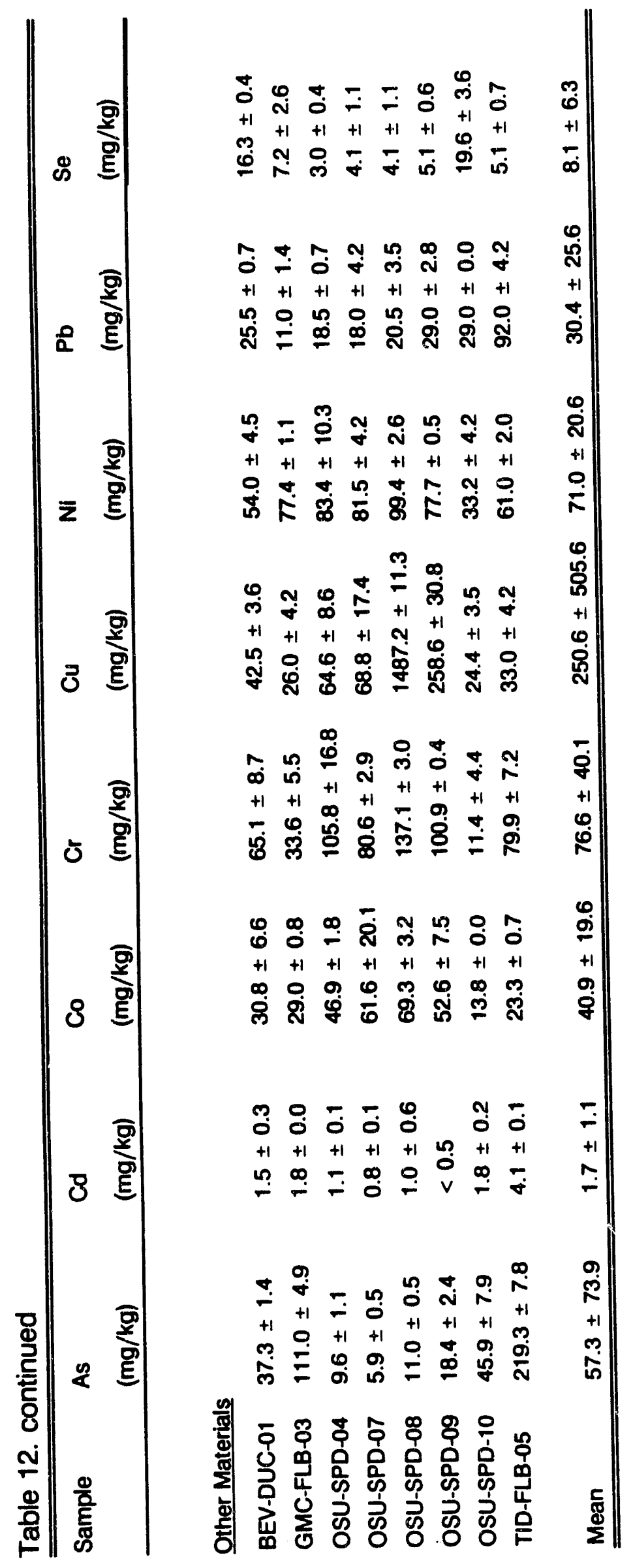


Table 13. Total boron content of FGD by-products.

\begin{tabular}{|c|c|c|c|c|c|c|}
\hline \multirow{2}{*}{$\begin{array}{l}\text { Sample } \\
\text { Duct Injection }\end{array}$} & \multicolumn{3}{|c|}{$\begin{array}{l}\text { B } \\
\mathrm{mg} \mathrm{kg}^{-1}\end{array}$} & \multirow{2}{*}{$\begin{array}{l}\text { Sample } \\
\text { LMB }\end{array}$} & \multicolumn{2}{|l|}{$\begin{array}{l}\text { B } \\
\mathrm{mg} \mathrm{kg}^{-1}\end{array}$} \\
\hline & & & & & & \\
\hline BEV-DUC-02 & 158 & \pm & 1 & EDG-LIM-03 & $297 \pm$ & 13 \\
\hline BEV-DUC-03 & 153 & \pm & 6 & EDG-LIM-04 & $389 \pm$ & 3 \\
\hline BEV-DUC-05 & 281 & \pm & 5 & EDG-LIM-05 & $320 \pm$ & 2 \\
\hline BEV-DUC-06 & 196 & \pm & 3 & EDG-LIM-06 & $524 \pm$ & 29 \\
\hline BEV-DUC-07 & 259 & \pm & 4 & EDG-LIM-07 & $399 \pm$ & 11 \\
\hline BEV-DUC-08 & 245 & \pm & 17 & EGD-LUM-08 & $364 \pm$ & 5 \\
\hline \multirow[t]{2}{*}{ EDG-CLS-01 } & 460 & \pm & 9 & EGD-LIM-09 & $334 \pm$ & 12 \\
\hline & & & & EDG-LIM-10 & $501 \pm$ & 6 \\
\hline \multirow[t]{3}{*}{ Mean } & 240 & \pm & 82 & EDG-LUM-11 & $386 \pm$ & 5 \\
\hline & & & & EDG-LIM-12 & $315 \pm$ & 8 \\
\hline & & & & EDG-LIM-13 & $442 \pm$ & 12 \\
\hline Spray Dryer & & & & EDG-LMM-14 & $233 \pm$ & 20 \\
\hline BAB-LID-01 & 948 & \pm & 12 & & & \\
\hline BAB-LID-02 & 509 & \pm & 8 & Mean & $374 \pm$ & 82 \\
\hline BAB-LID-03 & 360 & \pm & 0 & & & \\
\hline HST-SPD-01 & 418 & \pm & 7 & Eluidized Bed C & bustion & \\
\hline HST-SPD-02 & 386 & \pm & 8 & Bed Ash & & \\
\hline HST-SPD-03 & 345 & \pm & 6 & & & \\
\hline HST-SPD-04 & 303 & \pm & 19 & GMC-FLB-01 & $302 \pm$ & 57 \\
\hline HST-SPD-05 & 405 & \pm & 1 & QST-SPD-03 & $115 \pm$ & 14 \\
\hline OSU-SPD-01 & 292 & \pm & 14 & TID-FLB-02 & $100 \pm$ & 1 \\
\hline OSU-SPD-02 & 374 & \pm & 15 & TID-FLB-04 & $127 \pm$ & 9 \\
\hline OSU-SPD-03 & 315 & \pm & 8 & TID-FLB-07 & $157 \pm$ & 2 \\
\hline OSU-SPD-05 & 368 & \pm & 14 & TVA-FLB-03 & $68 \pm$ & 2 \\
\hline Mean & 418 & \pm & 177 & Mean & $145 \pm$ & 82 \\
\hline
\end{tabular}


Table 13. continued

\begin{tabular}{|c|c|c|c|c|c|}
\hline Sample & $\begin{array}{l}\text { B } \\
\mathrm{mg} \mathrm{kg}^{-1}\end{array}$ & & Sample & $\begin{array}{l}\text { B } \\
\mathrm{mg} \mathrm{kg}^{-1}\end{array}$ & \\
\hline \multirow{3}{*}{ Other Materials } & & & $\begin{array}{l}\text { Fluidized Bed Co } \\
\text { Cyclone/fly ash }\end{array}$ & bustion & \\
\hline & & & GMC-FLB-02 & $492 \pm$ & 1 \\
\hline & & & PED-RCB-01 & $375 \pm$ & 18 \\
\hline BEV-DUC-01 & $240 \pm$ & 6 & QST-FLB-01 & $147 \pm$ & 8 \\
\hline GMC-FLB-03 & $461 \pm$ & 16 & QST-FLB-02 & $204 \pm$ & 3 \\
\hline OSU-SPD-04 & $275 \pm$ & 24 & STA-FLB-01 & $525 \pm$ & 6 \\
\hline OSU-SPD-07 & $464 \pm$ & 10 & TID-FLB-01 & $169 \pm$ & 3 \\
\hline OSU-SPD-08 & $341 \pm$ & 25 & TID-FLB-03 & $171 \pm$ & 4 \\
\hline OSU-SPD-09 & $310 \pm$ & 5 & TID-FLB-06 & $208 \pm$ & 3 \\
\hline OSU-SPD-10 & $345 \pm$ & 3 & TVA-FLB-01 & $117 \pm$ & 4 \\
\hline TID-FLB-05 & $164 \pm$ & 2 & TVA-FLB-02 & $387 \pm$ & 9 \\
\hline Mean & $319 \pm$ & 96 & Mean & $280 \pm$ & 151 \\
\hline
\end{tabular}


Table 14 contains proposed ceiling concentrations for ten elements in landapplied sewage sludge. Whereas it must be recognized that the geochemical forms of metals in sewage sludge are undoubtedly dissimilar to those in FGD, the 503 regulations represent an accepted level for the application of potentially hazardous metals to soils and thus can serve in a comparative way, in assessing the suitability of land application of FGD. Additionally, it is likely that some eventual uses of FGD will include additions to sewage sludge to form lime-stabilized materials. Thus comparisons of FGD to the metal limits established in the 503 regulations is of value. By making this comparison we do not mean to imply that FGD by-products should be regulated at the same levels as sewage sludge. All of the FGD by-products analyzed in the present study met the Part 503 criteria for $\mathrm{Cd}, \mathrm{Cr}, \mathrm{Cu}, \mathrm{Pb}, \mathrm{Ni}, \mathrm{Se}$ and $\mathrm{Zn}$. One sample, EDG-LIM-08, exceeded the value for Mo, and 26 out of 56 samples ( $46 \%$ of all of the FGD by-products) exceeded the limit for As. In general, the greatest As concentrations were present in the FGD by-products from the LIMB process. The OSU laboratories did not have the facilities to determine the solid-phase concentrations of $\mathrm{Hg}$ in the samples of FGD by-product. Thus, no comparison can be made between the total $\mathrm{Hg}$ content of the FGD by-products and the regulatory limits listed in Table 14, for sewage sludge. Nevertheless, the low concentrations of dissolved $\mathrm{Hg}$ measured in the toxic characteristic leaching procedure extractions (section 2.1.3.1.2) suggest that the FGD by-products pose little threat with regards to Hg-contamination.

The acid insoluble residues result from solubilizing and washing out the reaction products and unspent sorbent in FGD samples and provide a measure of the fly ash fraction of the samples. Chemical analyses of acid residues from the Ohio FGD byproducts showed this fraction was dominated by $\mathrm{Al}, \mathrm{Fe}$, and $\mathrm{Si}$. This chemistry is consistent with the mineralogy of fly ash. Total trace element concentrations of the acid insoluble residues varied between sources and samples suggesting a dependency on coal composition and on operating conditions within a given coal-fire facility. Plots of total elemental concentrations versus the weight fraction of acid insoluble residue (Fig. 1 to 7, and Fig. D1 to D18, Appendix D) suggest a preferential partitioning of many of the elements. Elements showing partitioning primarily into the fly ash were Al, As (Fig. 1 and 2), and also $\mathrm{Ba}, \mathrm{Be}, \mathrm{Co}, \mathrm{Cr}, \mathrm{Cu}, \mathrm{Fe}, \mathrm{K}, \mathrm{Li}, \mathrm{Mn}, \mathrm{Ni}, \mathrm{P}$, $\mathrm{Pb}, \mathrm{Si}$, and $\mathrm{V}$. In contrast, $\mathrm{Ca}, \mathrm{S}$ (Fig. 3 and 4 ), and $\mathrm{Mg}$ showed an inverse relationship to the concentration of acid insoluble residue. This is to be expected since $\mathrm{Ca}$ and $\mathrm{Mg}$ are intentionally introduced as a sorbents to reduce $\mathrm{SO}_{2}$ emissions. Increases in the acid insoluble residue resulted in dilution of the $\mathrm{Ca}$ and $\mathrm{Mg}$ materials and a corresponding decrease in S content. Intermediate elemental partitioning was exhibited by B, Cd (Fig. 5 and 6), Mo, Se and Sr, indicating these elements occur in both the acid soluble and insoluble fractions. This is not surprising since these elements are known to occur in fly ash and as contaminants of limestone.

The data above suggest many of the elements regulated by EPA for solid waste materials, reside primarily in the fly-ash fraction of FGD by-products. Support for this contention can be found by comparing the elemental concentrations in the whole FGD by-products, to those present in the acid insoluble residue. Figures 7 to 11 show greater concentrations of $\mathrm{As}, \mathrm{Cr}, \mathrm{Cu}, \mathrm{Ni}$ and $\mathrm{Pb}$ in the acid insoluble residue than in 
Phase 1 Report

Table 14. Pollutant ceiling concentrations for land application of sewage sludge*.

\begin{tabular}{lr}
\hline Pollutant & Concentration \\
\hline & $\mathrm{mg} \mathrm{kg}^{-1}$ \\
Arsenic & 75 \\
Cadmium & 85 \\
Chromium & 3000 \\
Copper & 4300 \\
Lead & 840 \\
Mercury & 57 \\
Molybdenum & 75 \\
Nickel & 420 \\
Selenium & 100 \\
Zinc & 7500 \\
\hline \hline
\end{tabular}

"US Environmental Protection Agency 
the whole FGD by-products (for samples OSU-SPD-03, BEV-DUC-02, EDG-LIM-14, TID-FLB-03 and TID-FLB-04). The same trend was observed for $\mathrm{Al}, \mathrm{Ba}, \mathrm{Be}, \mathrm{Co}, \mathrm{Fe}, \mathrm{K}$, $\mathrm{Li}, \mathrm{Mn}, \mathrm{P}$, and V. Cadmium, Mo and Se (Fig. 12 to 14 ) and $\mathrm{Sr}$ were in near equivalent concentrations in the whole FGD by-products and the acid insoluble residues of the same samples. (See Fig. D19 to D29, Appendix D for elements not shown here.) In contrast, $\mathrm{Ca}, \mathrm{Mg}$ and $\mathrm{S}$ were concentrated in the whole FGD by-product (Fig. 15 to 17) as was previously noted.

From a regulatory perspective, it appears that the FGD by-products examined in the present study can be characterized as clean materials. The only exception to this is the high As content present in $46 \%$ of the samples. However, it should be noted that the data in Fig. 2 and 7 strongly suggest that the majority of the As is present in the fly ash fraction of these materials. Therefore, FGD technologies can actually be considered to dilute the As in the ash. Thus, regulation of As in FGD by-products in the same way as As is regulated in fly ash seems reasonable. 


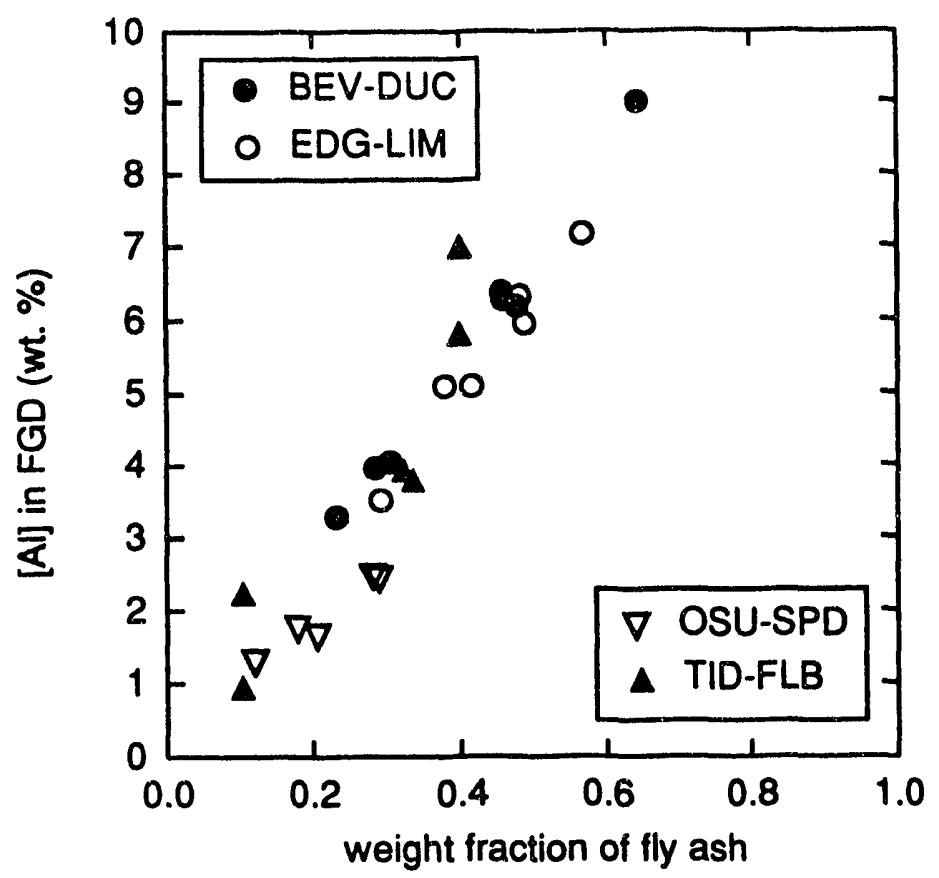

Fig. 1. Concentration of Al versus the weight fraction of fly ash (acid insoluble residue) in FGD by-products.

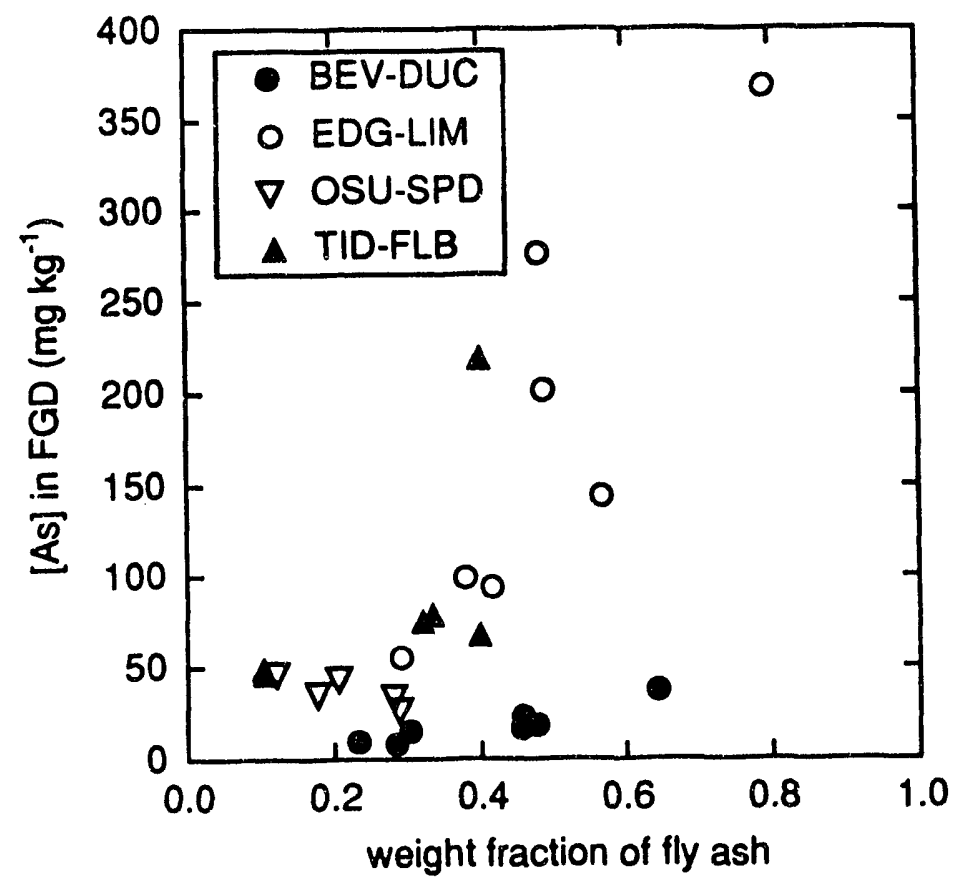

Fig. 2. Concentration of As versus the weight fraction of fly ash (acid insoluble residue) in FGD by-products. 


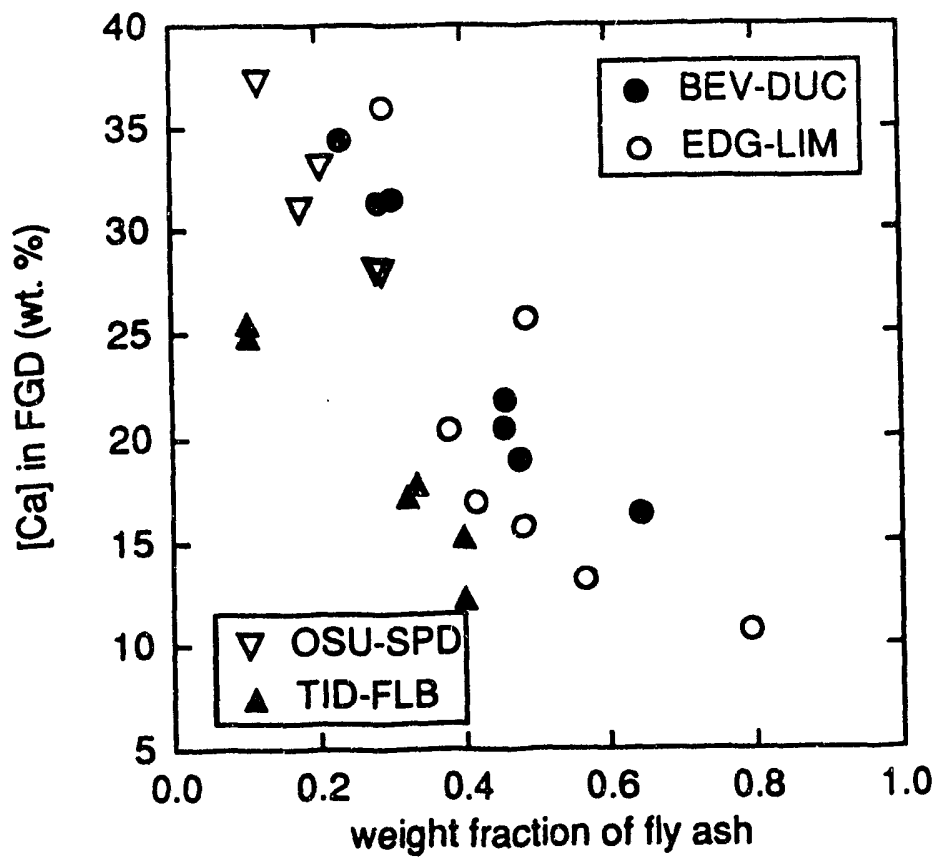

Fig. 3. Concentration of $\mathrm{Ca}$ versus the weight fraction of fly ash (acid insoluble residue) in FGD by-products.

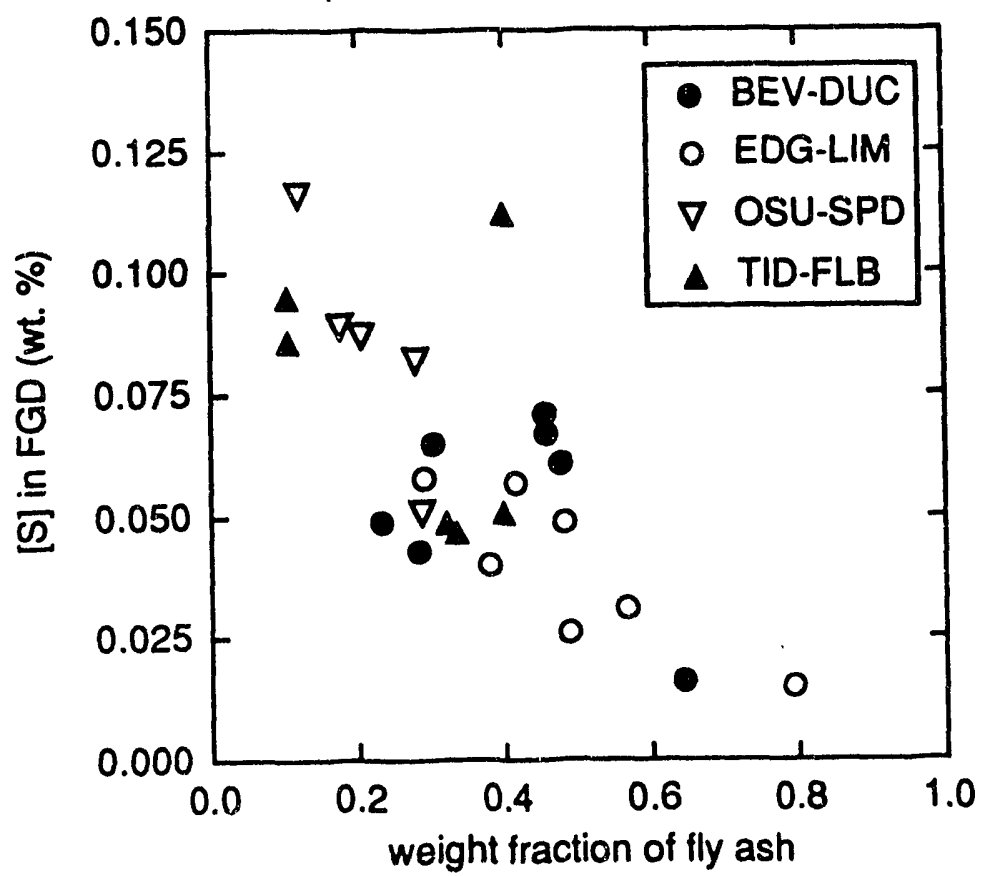

Fig. 4. Concentration of $S$ versus the weight fraction of fly ash (acid insoluble residue) in FGD by-products. 
Phase 1 Report

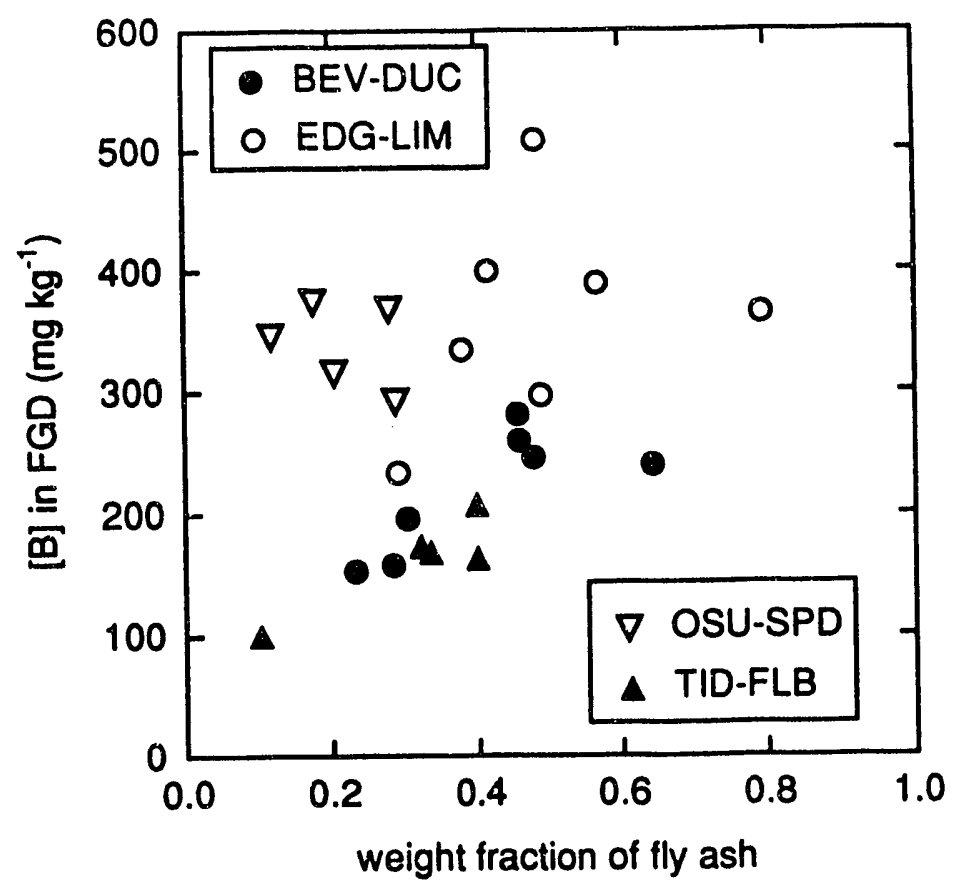

Fig. 5. Concentration of B versus the weight fraction of fly ash (acid insoluble residue) in FGD by-products.

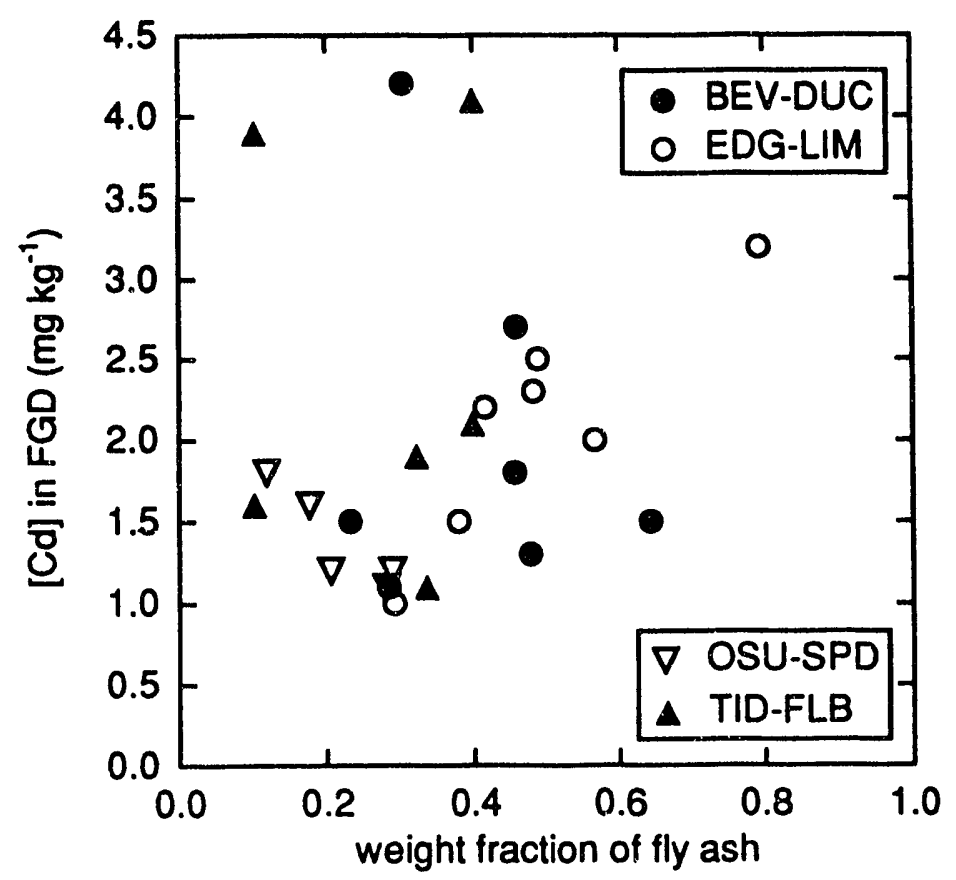

Fig. 6. Concentration of Cd versus the weight fraction of fly ash (acid insoluble residue) in FGD by-products. 


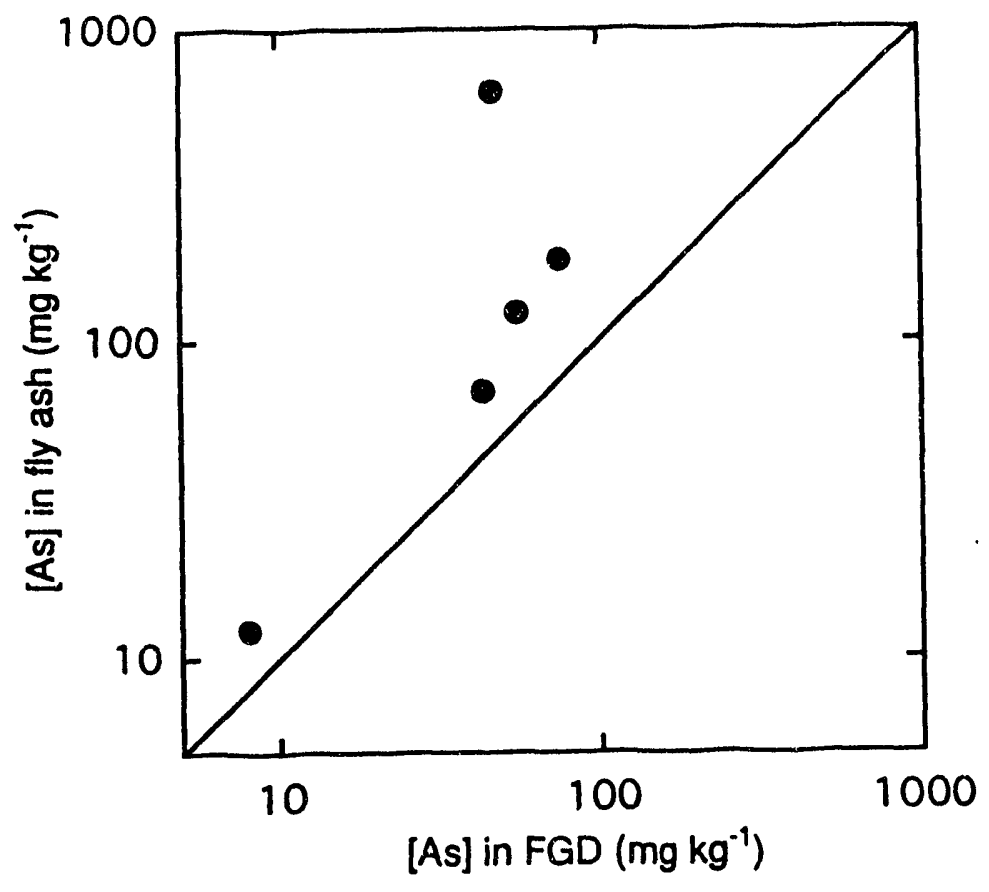

Fig. 7. Concentration of As in the fly ash fraction (acid insoluble residue) versus the concentration of As in whole FGD by-product. Data for samples:

nSI I-SPD-03. BEV-DUC-02, EDG-LIM-14, TID-FLB-03 and TID-FLB-04.

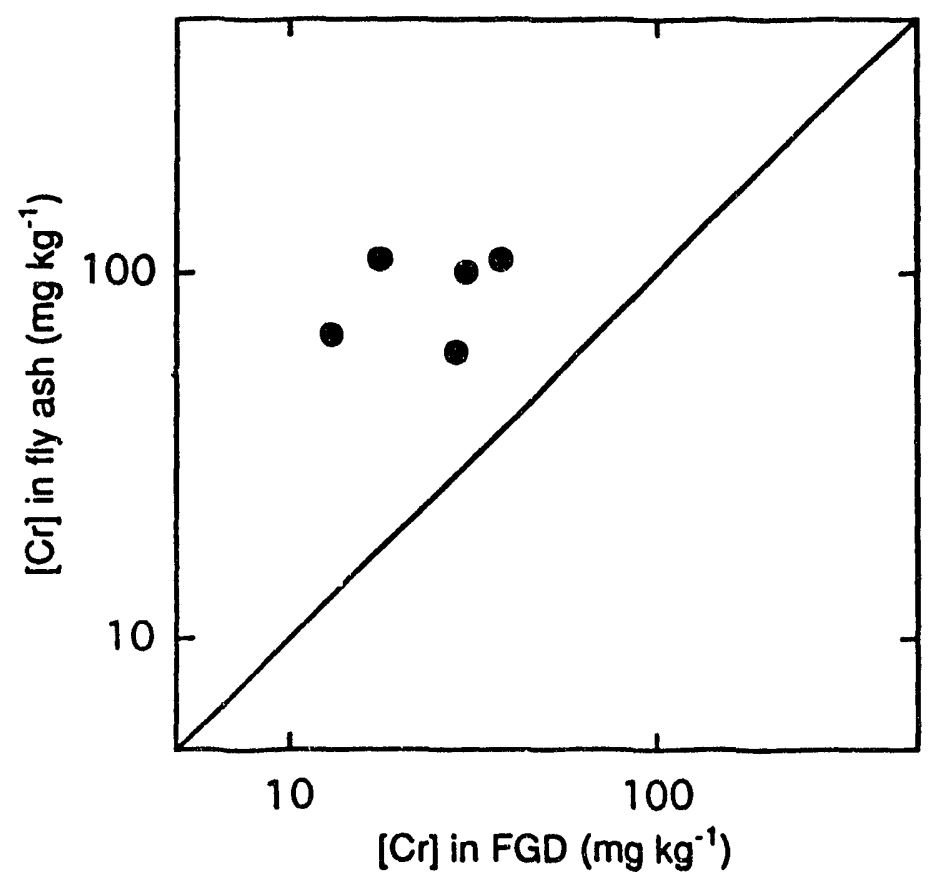

Fig. 8. Concentration of $\mathrm{Cr}$ in the fly ash fraction (acid insoluble residue) versus the concentration of $\mathrm{Cr}$ in whole FGD by-product. Data for samples: OSU-SPD-03, BEV-DUC-02, EDG-LIM-14, TID-FLB-03 and TID-FLB-04. 


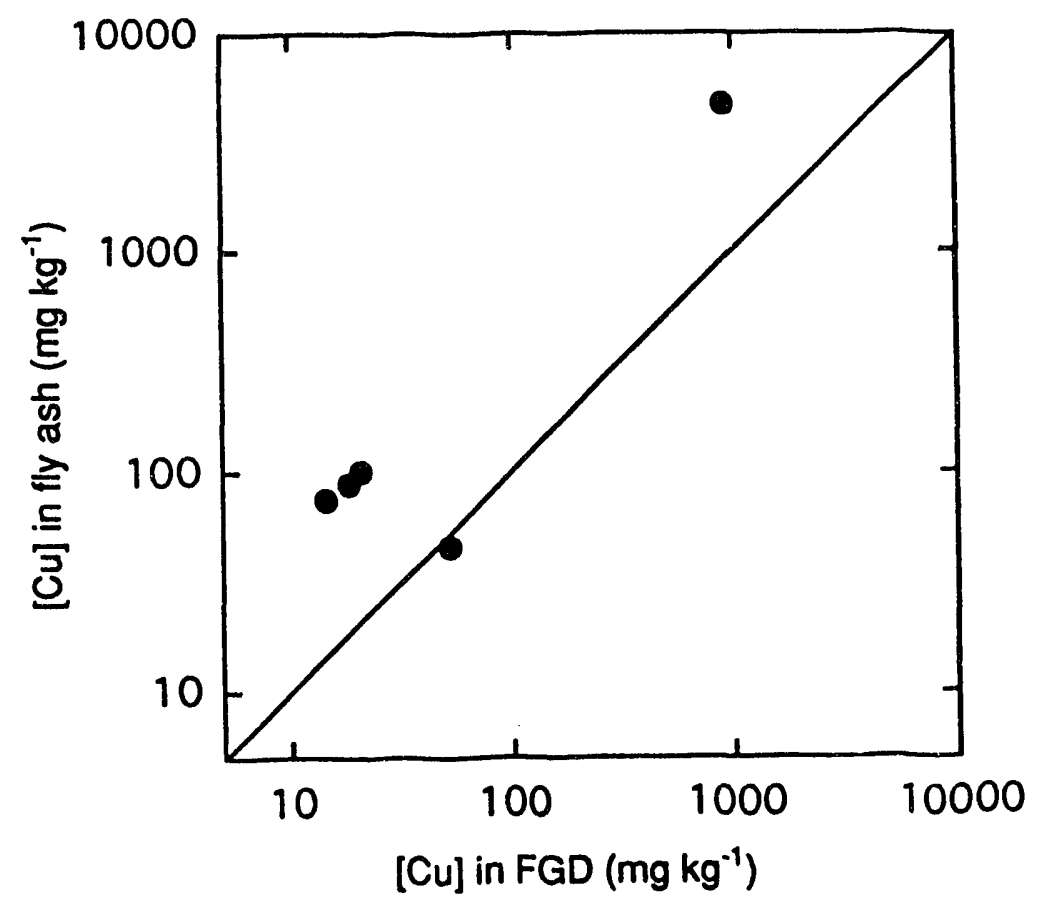

Fig. 9. Concentration of $\mathrm{Cu}$ in the fly ash fraction (acid insoluble residue) versus the concentration of $\mathrm{Cu}$ in whole FGD by-product. Data for samples:

OSU-SPD-03, BEV-DUC-02, EDG-LIM-14, TID-FLB-03 and TID-FLB-04.

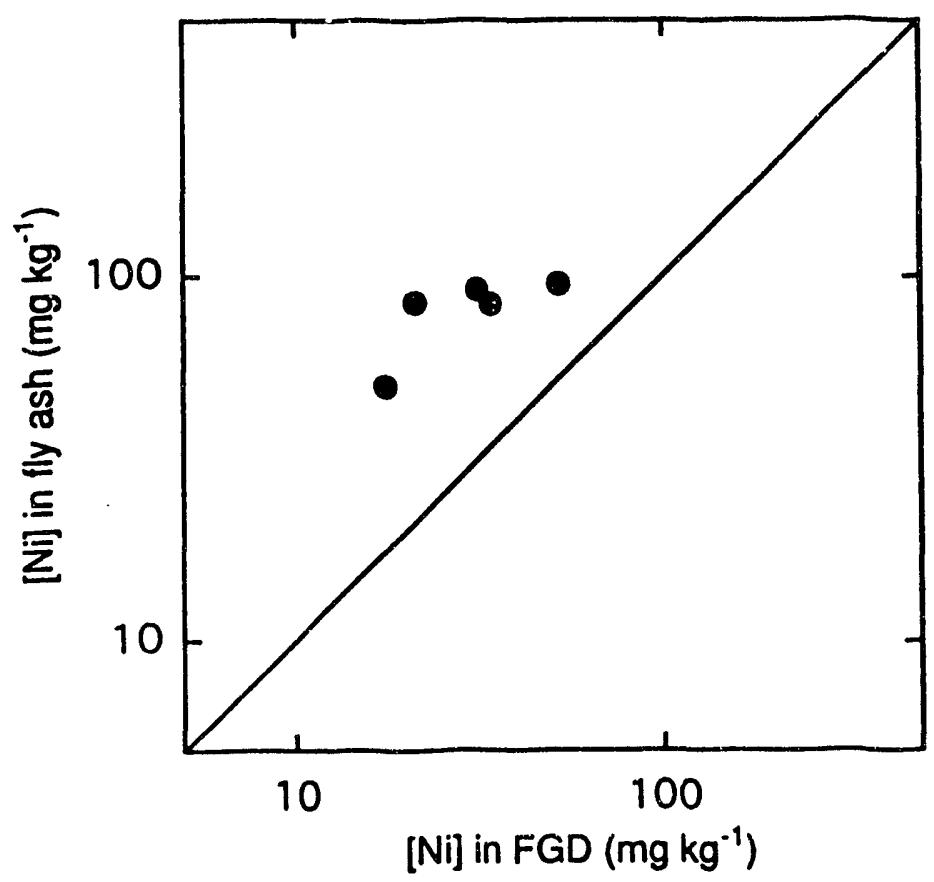

Fig. 10 Concentration of $\mathrm{Ni}$ in the fly ash fraction (acid insoluble residue) versus the concentration of $\mathrm{Ni}$ in whole FGD by-product. Data for samples:

OSU-SPD-03, BEV-DUC-02, EDG-LIM-14, TID-FLB-03 and TID-FLB-04. 
Phase 1 Report

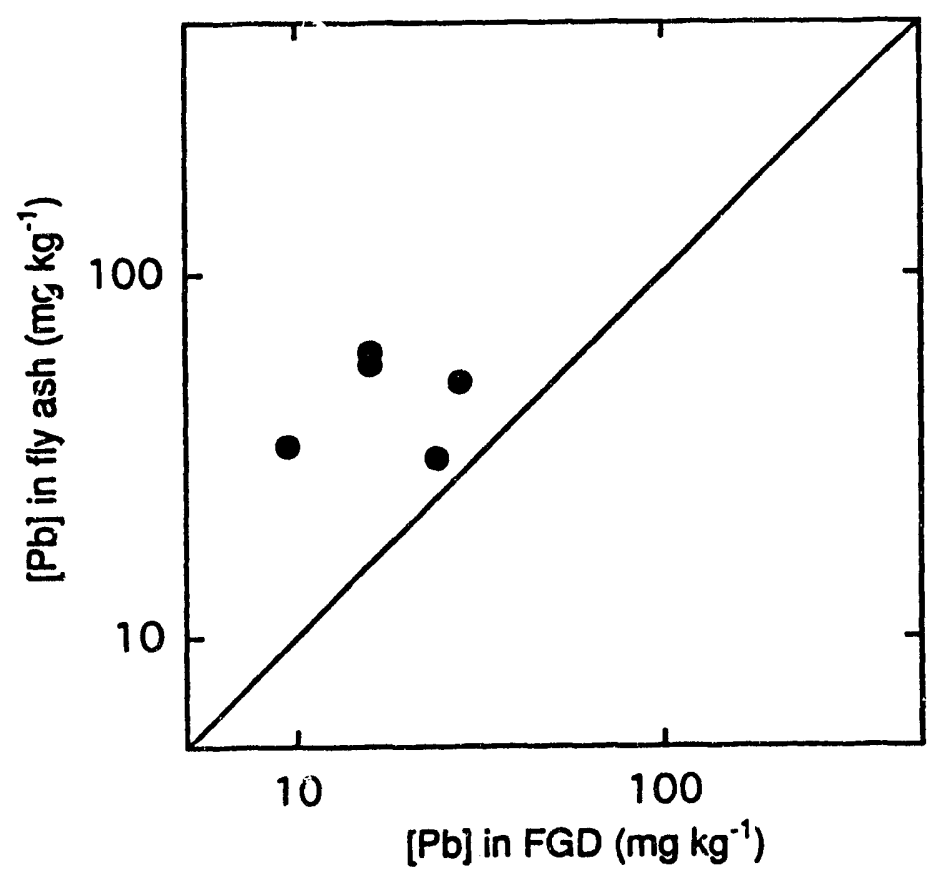

Fig. 11. Concentration of $\mathrm{Pb}$ in the fly ash fraction (acid insoluble residue) versus the concentration of $\mathrm{Pb}$ in whole FGD by-product. Data for samples: OSU-SPD-03, BEV-DUC-02, EDG-LIM-14, TID-FLB-03 and TID-FLB-04.

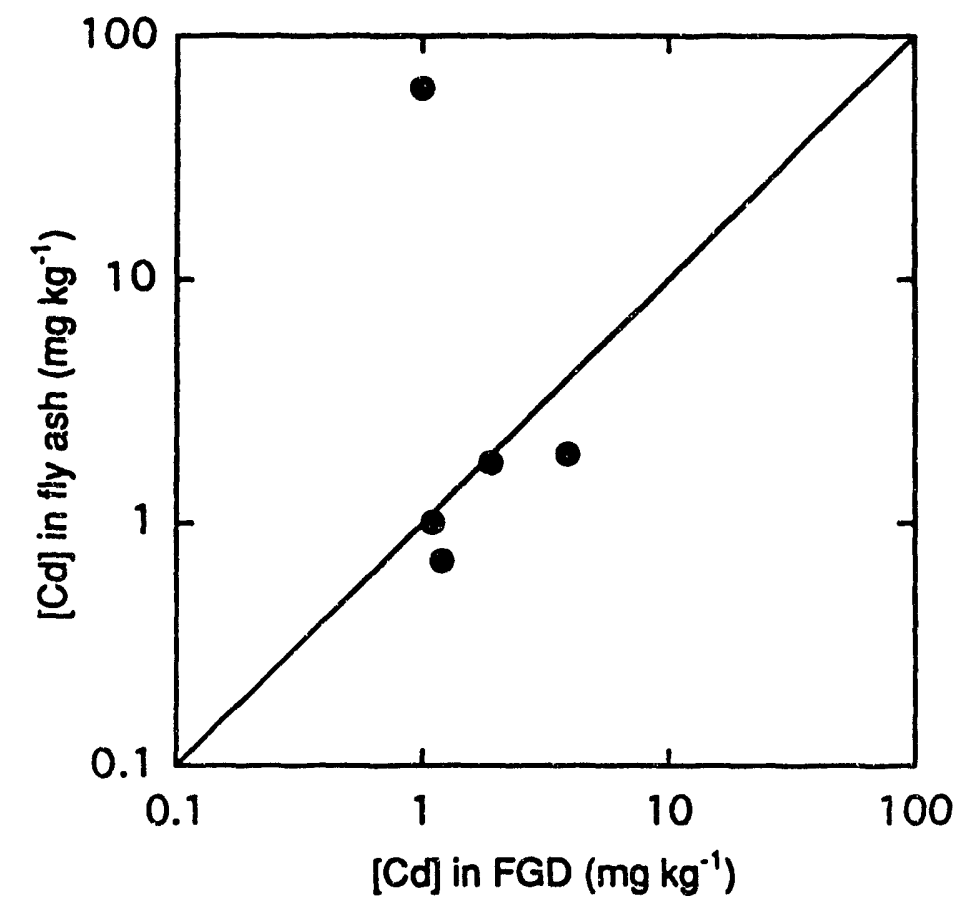

Fig. 12. Concentration of $\mathrm{Cd}$ in the fly ash fraction (acid insoluble residue) versus the concentration of $\mathrm{Cd}$ in whole FGD by-product. Data for samples: OSU-SPD-03, BEV-DUC-02, EDG-LIM-14, TID-FLB-03 and TID-FLB-04. 


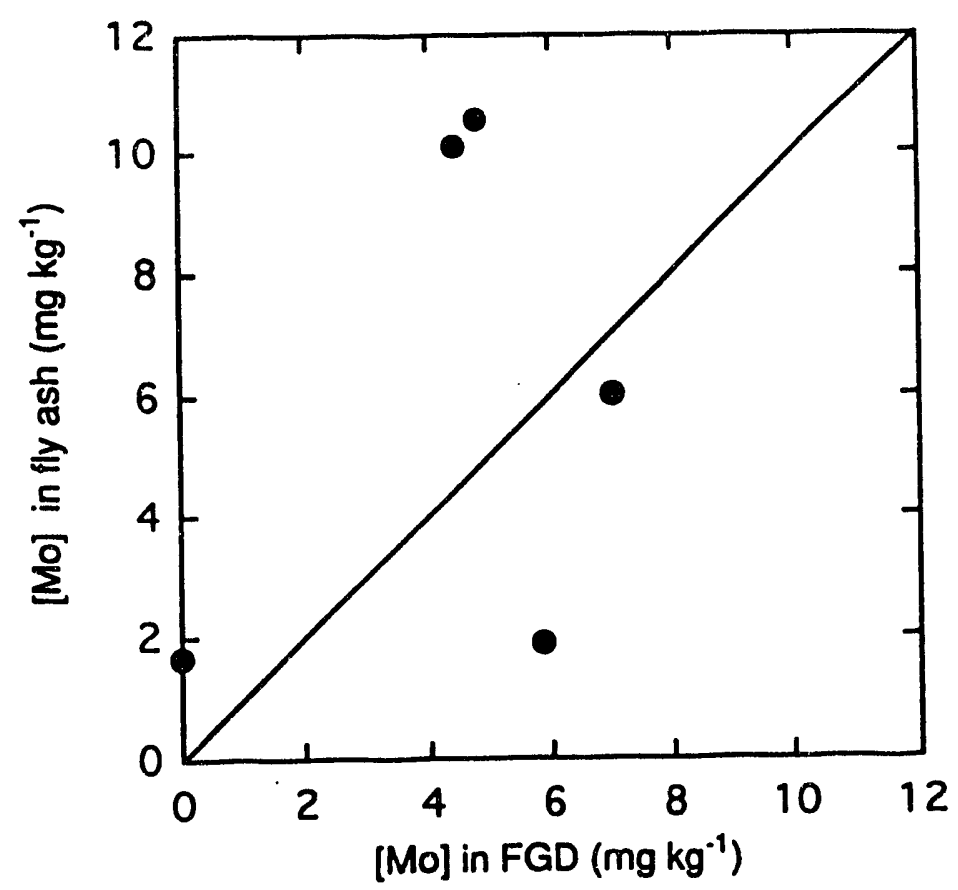

Fig. 13. Concentration of Mo in the fly ash fraction (acid insoluble residue) versus the concentration of Mo in whole FGD by-product. Data for samples: OSU-SPD-03, BEV-DUC-02, EDG-LIM-14, TID-FLB-03 and TID-FLB-04.

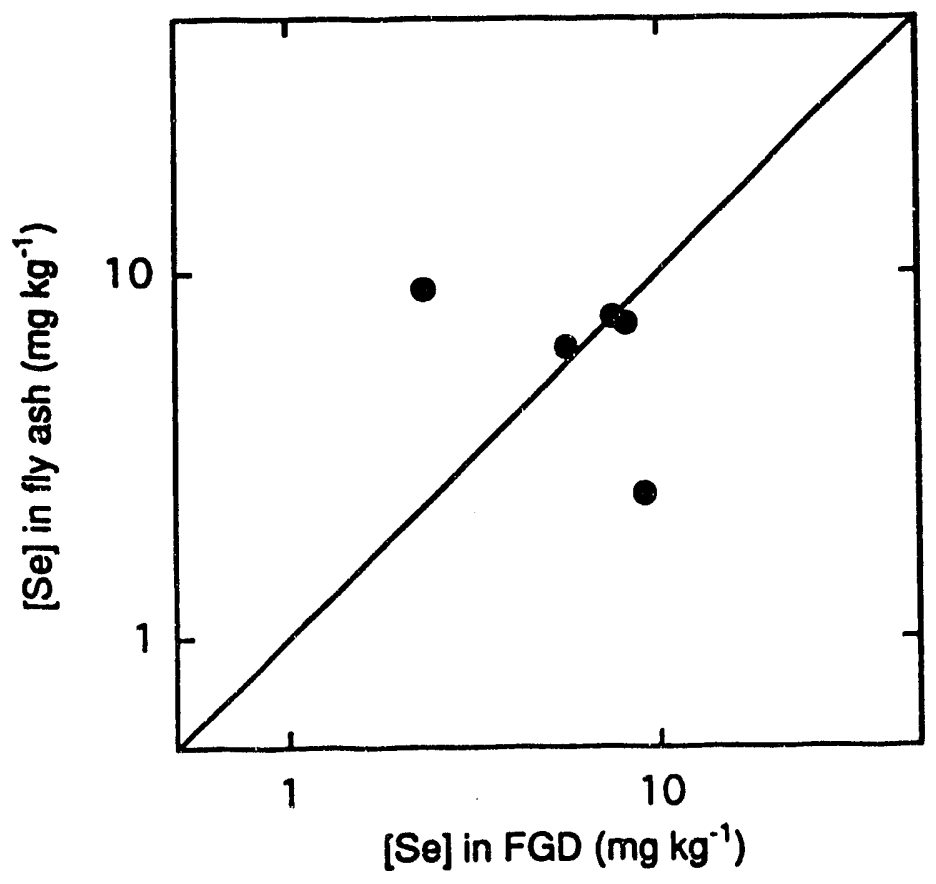

Fig. 14. Concentration of $S \theta$ in the fly ash fraction (acid insoluble residue) versus the concentration of Se in whole FGD by-product. Data for samples: OSU-SPD-03, BEV-DUC-02, EDG-LIM-14, TID-FLB-03 and TID-FLB-04. 
Phase 1 Report

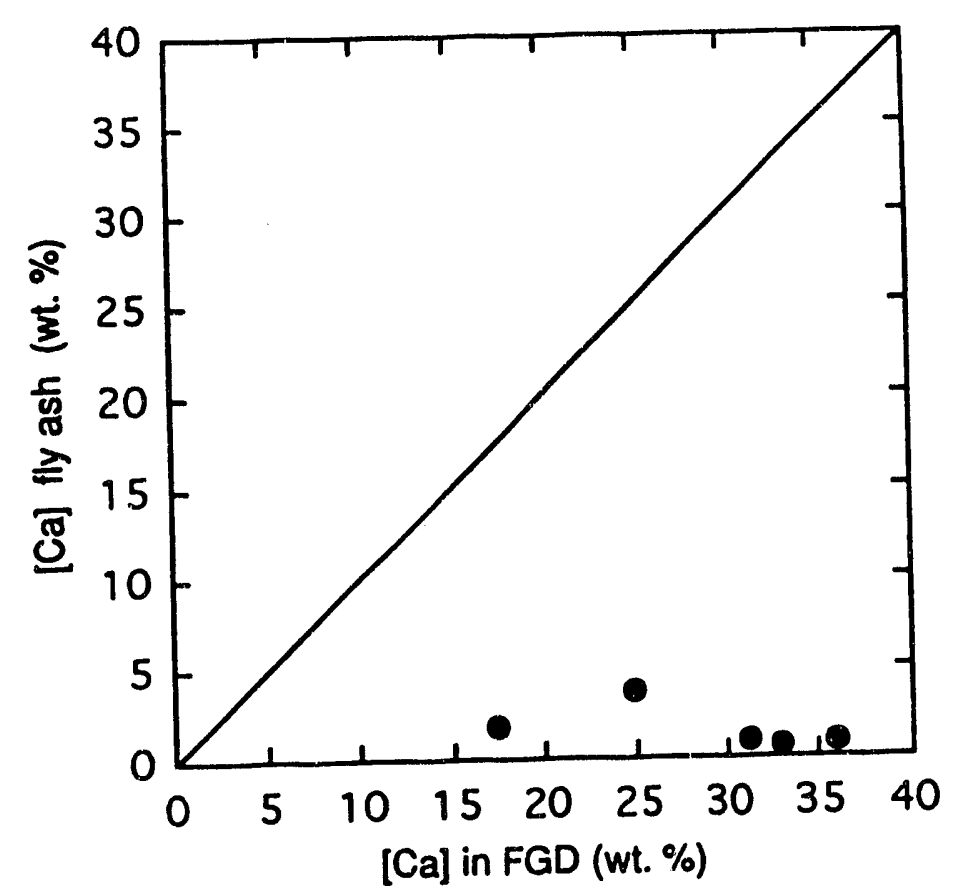

Fig. 15. Concentration of $\mathrm{Ca}$ in the fly ash fraction (acid insoluble residue) versus the concentration of $\mathrm{Ca}$ in whole FGD by-product. Data for samples: OSU-SPD-03, BEV-DUC-02, EDG-LIM-14, TID-FLB-03 and TID-FLB-04.

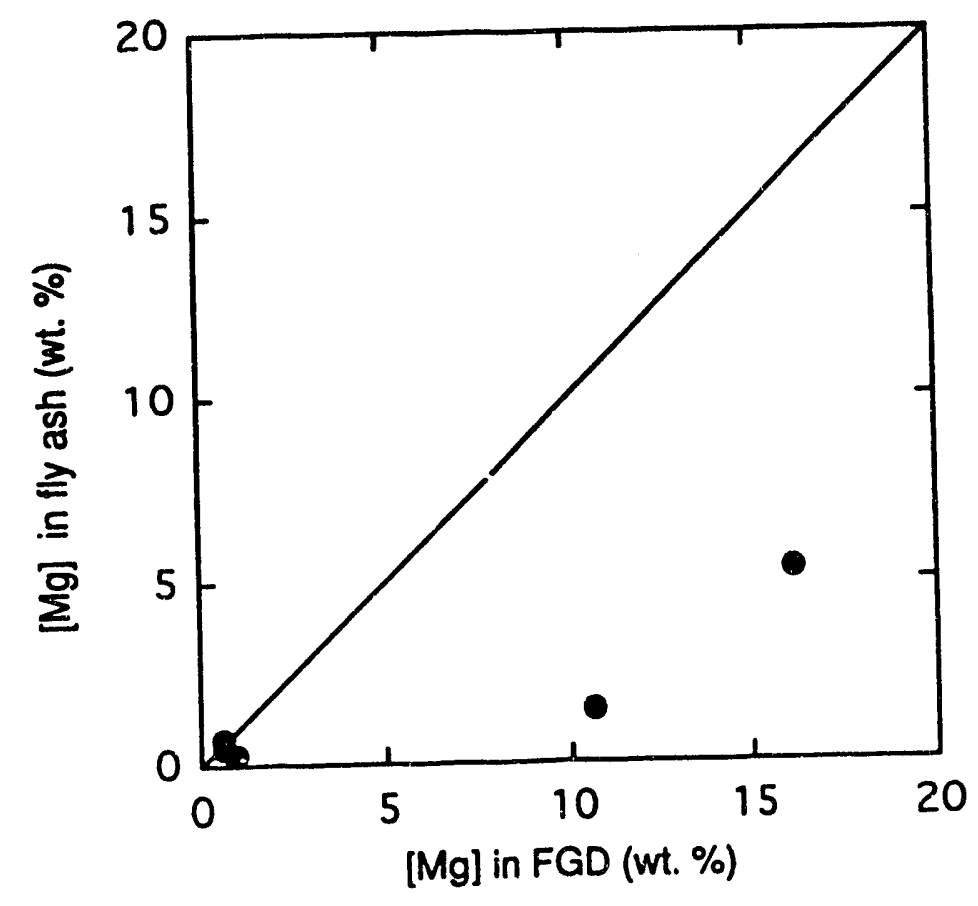

Fig. 16. Concentration of $\mathrm{Mg}$ in the fly ash fraction (acid insoluble residue) versus the concentration of $\mathrm{Mg}$ in whole FGD by-product. Data for samples: OSU-SPD-03, BEV-DUC-02, EDG-LIM-14, TID-FLB-03 and TID-FLB-04. 
Phase 1 Report

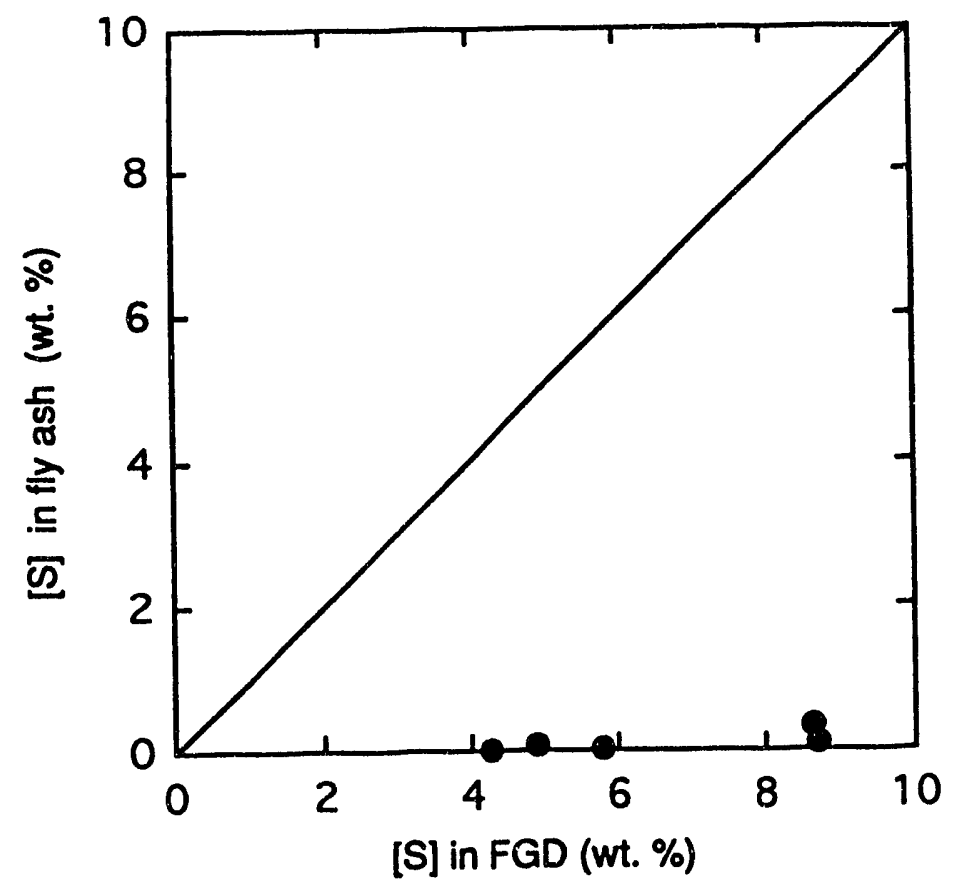

Fig. 17. Concentration of $S$ in the fly ash fraction (acid insoluble residue) versus the concentration of $S$ in whole FGD by-product. Data for samples: OSU-SPD-03, BEV-DUC-02, EDG-LIM-14, TID-FLB-03 and TID-FLB-04. 


\subsection{Leaching Analysis (ASTM and TCLP)}

Analytical results for ASTM and TCLP leachates of the five Ohio samples and GMC-FLB-03 (the samples selected for more detailed study) are given in Tables 15 and 16, respectively. Data for all ASTM analyses are provided in Appendix D, Table D2. Leachates were dominated by $\mathrm{S}$ (primarily as $\mathrm{SO}_{4}{ }_{4}^{2}$ ), $\mathrm{Ca}$, and $\mathrm{OH}^{-}$(as indicated by high $\mathrm{pH}$ ). The TCLP leachates for the TID-FLB-03 and -04 samples were also high in $\mathrm{Mg}$, reflecting the use of dolomite as a sorbent in the pressurized fluidized bed process.

The leachate $\mathrm{pH}$ (both ASTM and TCLP) for several samples was above the Resource Conservation and Recovery Act (RCRA) limit of 12 for toxic waste. These high $\mathrm{pH}$ levels result from the presence of unspent $\mathrm{CaO}$ and $\mathrm{Ca}(\mathrm{OH})_{2}$ sorbents in these samples. These leachates were obtained on fresh samples, however upon aging and exposure to moisture and atmospheric or soil $\mathrm{CO}_{2}$ the $\mathrm{CaO}$ and $\mathrm{Ca}(\mathrm{OH})_{2}$ will carbonate to form calcite $\left(\mathrm{CaCO}_{3}\right)$ and $\mathrm{pH}$ will decrease to around 8.3.

The relatively high total dissolved solids (TDS) and $\mathrm{SO}_{4}{ }^{2-}$ resulted primarily from the dissolution of $\mathrm{CaSO}_{4}$, and were higher with TCLP acid extraction than with ASTM water extraction. However, TDS and $\mathrm{SO}_{4}{ }^{2-}$ were below the levels for Class III residual wastes proposed by the Ohio EPA for ASTM water leachate ( $7500 \mathrm{mg} / \mathrm{kg}$ for each). With the exception of EDG-LIM-14, sulfite $\left(\mathrm{SO}_{3}{ }^{2}\right.$ ) was found only in leachates from duct injection and spray dryer samples (those FGD processes which occur under more reducing conditions of low temperature and high relative humidity). Also even though total sulfur in duct injection and spray dryer samples was as high or higher than in the LIMB and FBC samples, total leachate sulfur for these samples tended to be much lower than in the LIMB and FBC samples. This is because much of the $S$ in the duct injection and spray dryer samples is present as calcium sulfite $\left(\mathrm{CaSO}_{3}\right)$ which is 20 times less soluble than calcium sulfate $\left(\mathrm{CaSO}_{4}\right)$, the predominant $\mathbf{S}$ salt in LIMB and FBC samples. Thus a smaller fraction of the total sample $S$ was dissolved during leaching of duct injection and spray dryer samples compared to the LIMB and FBC samples.

Concentrations of the eight RCRA metals ( $\mathrm{Ag}, \mathrm{As}, \mathrm{Ba}, \mathrm{Cd}, \mathrm{Cr}, \mathrm{Hg}, \mathrm{Pb}$, and $\mathrm{Se}$ ) were below drinking water standards for both ASTM and TCLP leachates (Table 17). Concentrations of other trace metals in the ASTM and TCLP leachates were also generally very low for all samples. The low solubility of these metals can be accounted for by the fact that most of them are associated with the relatively insoluble mineral (fly ash) portion of the FGD matrix, rather than the more soluble fraction consisting of unspent sorbent and $\mathrm{SO}_{2}$ reaction products. (See section 2.1.3.1.1 for additional discussion.) 
Phase 1 Report

Table 15. ASTM water leachate results for 6 dry FGD by-products.

\begin{tabular}{|c|c|c|c|c|c|c|}
\hline $\begin{array}{l}\text { Constituent } \\
\left(\mathrm{mg} \mathrm{L}^{-1}\right)\end{array}$ & $\begin{array}{l}\text { BEV-DUC } \\
-02\end{array}$ & $\begin{array}{c}\text { OSU-SPD } \\
-03\end{array}$ & $\begin{array}{c}\text { EDG-LIM } \\
-14\end{array}$ & $\begin{array}{c}\text { TID-FLB } \\
-03\end{array}$ & $\begin{array}{c}\text { TID-FLB } \\
-04\end{array}$ & $\begin{array}{c}\text { GMC-FLB } \\
-03 \\
\end{array}$ \\
\hline $\mathrm{pH}$ & 12.22 & 12.26 & 12.14 & 11.42 & 11.77 & 12.01 \\
\hline $\operatorname{TDS}^{b}$ & 2910 & 3520 & 4830 & 3140 & 5150 & 4830 \\
\hline $\mathbf{A g}$ & $<0.005$ & $<0.005$ & $<0.005$ & $<0.005$ & $<0.005$ & 0.007 \\
\hline Al & $<0.05$ & $<0.05$ & $<0.05$ & $<0.05$ & $<0.05$ & $<0.05$ \\
\hline$A s^{c}$ & $<0.005$ & $<0.005$ & $<0.005$ & $<0.005$ & $<0.005$ & $<0.005$ \\
\hline$B$ & 2.33 & 5.15 & 3.93 & 0.83 & 0.21 & 1.01 \\
\hline $\mathrm{Ba}$ & 0.136 & 0.292 & 0.231 & 0.166 & 0.202 & 0.310 \\
\hline Be & $<0.002$ & $<0.002$ & $<0.002$ & $<0.002$ & $<0.002$ & $<0.002$ \\
\hline $\mathrm{Ca}$ & 1070 & 1190 & 1840 & 844 & 1140 & 1540 \\
\hline $\mathrm{Cd}^{c}$ & $<0.001$ & $<0.001$ & $<0.001$ & $<0.001$ & $<0.001$ & $<0.001$ \\
\hline Co & 0.01 & 0.01 & 0.01 & 0.02 & $<0.01$ & $<0.01$ \\
\hline $\mathrm{Cr}$ & 0.026 & $<0.011$ & $<0.011$ & $<0.011$ & $<0.011$ & $<0.011$ \\
\hline $\mathrm{Cu}$ & $<0.007$ & $<0.007$ & $<0.007$ & $<0.007$ & $<0.007$ & $<0.007$ \\
\hline $\mathrm{Fe}$ & $<0.01$ & $<0.01$ & $<0.01$ & $<0.01$ & $<0.01$ & $<0.01$ \\
\hline $\mathrm{Hg}^{d}$ & $<0.0002$ & $<0.0002$ & $<0.0002$ & $<0.0002$ & $<0.0002$ & $<0.0002$ \\
\hline K & 3.9 & 21.7 & 1.6 & 21.7 & 3.4 & 1.8 \\
\hline L & 0.15 & 0.08 & 0.05 & 0.13 & $<0.03$ & 0.04 \\
\hline $\mathrm{Mg}$ & $<0.04$ & $<0.04$ & 0.07 & 0.19 & 0.09 & 0.06 \\
\hline$M n$ & $<0.053$ & $<0.053$ & $<0.053$ & $<0.053$ & $<0.053$ & $<0.053$ \\
\hline Mo & 0.073 & 0.091 & 0.101 & 0.033 & 0.035 & 0.183 \\
\hline $\mathrm{Na}$ & 4.8 & 3.5 & 1.1 & 8.3 & 1.3 & 2.5 \\
\hline $\mathrm{Ni}$ & $<0.01$ & $<0.01$ & $<0.01$ & $<0.01$ & $<0.01$ & $<0.01$ \\
\hline $\mathbf{P}$ & $<0.092$ & $<0.092$ & $<0.092$ & $<0.092$ & $<0.092$ & $<0.092$ \\
\hline $\mathrm{Pb}$ & $<0.001$ & 0.012 & $<0.001$ & $<0.001$ & $<0.001$ & $<0.001$ \\
\hline S & 127 & 201 & 740 & 654 & 642 & 638 \\
\hline$S b$ & $<0.06$ & $<0.06$ & $<0.06$ & $<0.06$ & $<0.06$ & $<0.06$ \\
\hline$S e^{c}$ & 0.021 & $<0.005$ & $<0.005$ & $<0.005$ & $<0.005$ & $<0.005$ \\
\hline
\end{tabular}


Table 15. continued.

\begin{tabular}{lcccccc}
\hline $\begin{array}{l}\text { Constituent } \\
\left(\mathrm{mg} \mathrm{L}^{-1}\right)\end{array}$ & $\begin{array}{c}\text { BEV-DUC } \\
-02\end{array}$ & $\begin{array}{c}\text { OSU-SPD } \\
-03\end{array}$ & $\begin{array}{c}\text { EDG-LIM } \\
-14\end{array}$ & $\begin{array}{c}\text { TID-FLB } \\
-03\end{array}$ & $\begin{array}{c}\text { TID-FLB } \\
-04\end{array}$ & $\begin{array}{c}\text { GMC-FLB } \\
-03\end{array}$ \\
\hline $\mathrm{Si}$ & $<0.07$ & 0.13 & 0.12 & 1.26 & 0.34 & 0.20 \\
$\mathrm{Sr}$ & 2.56 & 2.35 & 2.58 & 0.66 & 0.61 & 1.04 \\
$\mathrm{~V}$ & $<0.006$ & $<0.006$ & $<0.006$ & $<0.006$ & $<0.006$ & $<0.006$ \\
$\mathrm{Zn}$ & $<0.006$ & 0.007 & $<0.006$ & $<0.006$ & $<0.006$ & $<0.006$ \\
$\mathrm{Cl}^{-}$ & 42.2 & 40.5 & 54.4 & 7.9 & 3.2 & 19.9 \\
$\mathrm{~F}^{-}$ & 4.0 & 2.5 & 3.4 & 2.8 & 2.3 & 2.9 \\
$\mathrm{SO}_{3}{ }^{2-}$ & 23.2 & 35.7 & 31.3 & $<1.0$ & $<1.0$ & $<1.0$ \\
$\mathrm{SO}_{4}^{2-}$ & 233 & 444 & 1870 & 1700 & 1570 & 1480 \\
\hline
\end{tabular}

all elemental analyses by ICP unless otherwise noted

b Total dissolved solids

CAnalyses by GFAA

Analyses by cold vapor generation and GFAA, conducted by Burgess and Niple, Columbus, $\mathrm{OH}$

- Analyses by ion chromatography 
Table 16. TCLP acetic acid leachate results for 6 dry FGD by-products.

\begin{tabular}{|c|c|c|c|c|c|c|}
\hline $\begin{array}{c}\text { Constituent } \\
\left(\mathrm{mg} \mathrm{L}^{\mathrm{a}}\right)\end{array}$ & $\begin{array}{c}\text { BEV-DUC } \\
-02\end{array}$ & $\begin{array}{c}\text { OSU-SPD } \\
-03\end{array}$ & $\begin{array}{c}\text { EDG-LIM } \\
-14\end{array}$ & $\begin{array}{c}\text { TID-FLB } \\
-03\end{array}$ & $\begin{array}{c}\text { TID-FLB } \\
-04 \\
\end{array}$ & $\begin{array}{c}\text { GMC-FLB } \\
-03 \\
\end{array}$ \\
\hline $\mathrm{pH}$ & 11.95 & 11.98 & 12.01 & 9.58 & 9.61 & 12.12 \\
\hline TDS $^{b}$ & 11840 & 12050 & 13790 & 12870 & 11980 & 13670 \\
\hline $\mathrm{Ag}$ & $<0.024$ & $<0.024$ & $<0.024$ & $<0.024$ & $<0.024$ & 0.024 \\
\hline Al & 0.20 & 0.20 & 0.20 & 0.12 & 0.14 & 0.22 \\
\hline$A s^{c}$ & $<0.005$ & $<0.005$ & $<0.005$ & $<0.005$ & $<0.005$ & $<0.005$ \\
\hline B & 2.165 & 4.668 & 3.455 & 0.767 & 0.543 & 9.028 \\
\hline $\mathrm{Ba}$ & 0.159 & 0.348 & 0.250 & 0.141 & 0.141 & 0.693 \\
\hline $\mathrm{Be}$ & $<0.002$ & $<0.002$ & $<0.002$ & $<0.002$ & $<0.002$ & $<0.002$ \\
\hline $\mathrm{Ca}$ & 3132 & 3224 & 3858 & 1383 & 1741 & 3694 \\
\hline$C d^{c}$ & $<0.003$ & $<0.003$ & $<0.003$ & $<0.003$ & $<0.003$ & $<0.003$ \\
\hline Co & $<0.014$ & 0.016 & 0.017 & 0.026 & 0.017 & $<0.014$ \\
\hline $\mathrm{Cr}$ & 0.028 & 0.009 & 0.007 & 0.011 & $<0.005$ & $<0.005$ \\
\hline $\mathrm{Cu}$ & $<0.013$ & $<0.013$ & $<0.013$ & $<0.013$ & $<0.013$ & $<0.013$ \\
\hline $\mathrm{Fe}$ & $<0.029$ & $<0.029$ & $<0.029$ & $<0.029$ & $<0.029$ & $<0.029$ \\
\hline $\mathrm{Hg}^{\mathrm{d}}$ & $<0.0002$ & $<0.0002$ & $<0.0002$ & $<0.0002$ & $<0.0002$ & $<0.0002$ \\
\hline K & 3.5 & 22.1 & 1.3 & 21.1 & 3.0 & 1.5 \\
\hline $\mathrm{Li}$ & 0.15 & 0.09 & 0.04 & 0.18 & 0.07 & 0.04 \\
\hline $\mathbf{M g}$ & $<0.04$ & 0.05 & 0.07 & 1351.8 & 881.5 & 0.21 \\
\hline$M n$ & $<0.001$ & $<0.001$ & $<0.001$ & $<0.001$ & $<0.001$ & $<0.001$ \\
\hline Mo & 0.059 & 0.088 & 0.103 & 0.025 & 0.031 & 0.208 \\
\hline $\mathrm{Na}$ & 4.86 & 3.64 & 1.32 & 9.82 & 1.67 & 2.62 \\
\hline $\mathrm{Ni}$ & $<0.01$ & $<0.01$ & $<0.01$ & $<0.01$ & $<0.01$ & $<0.01$ \\
\hline $\mathbf{P}$ & $<0.12$ & $<0.12$ & $<0.12$ & $<0.12$ & $<0.12$ & $<0.12$ \\
\hline $\mathrm{Pb}$ & 0.001 & 0.017 & 0.005 & $<0.001$ & $<0.001$ & 0.002 \\
\hline s & 132 & 206 & 582 & 979 & 737 & 492 \\
\hline Sb & $<0.24$ & $<0.24$ & $<0.24$ & $<0.24$ & $<0.24$ & $<0.24$ \\
\hline$S e^{c}$ & 0.004 & 0.004 & 0.005 & $<0.001$ & 0.001 & 0.005 \\
\hline
\end{tabular}


Table 16. continued.

\begin{tabular}{lcccccc}
\hline $\begin{array}{l}\text { Constituent } \\
\left(\mathrm{mg} \mathrm{L}^{-1}\right)\end{array}$ & $\begin{array}{c}\text { BEV-DUC } \\
-02\end{array}$ & $\begin{array}{c}\text { OSU-SPD } \\
-03\end{array}$ & $\begin{array}{c}\text { EDG-LIM } \\
-14\end{array}$ & $\begin{array}{c}\text { TID-FLB } \\
-03\end{array}$ & $\begin{array}{c}\text { TID-FLB } \\
-04\end{array}$ & $\begin{array}{c}\text { GMC-FLB } \\
-03\end{array}$ \\
\hline $\mathrm{Si}$ & 0.10 & 0.14 & 0.10 & 0.33 & 0.31 & 0.25 \\
$\mathrm{Sr}$ & 3.38 & 2.96 & 2.55 & 1.21 & 0.83 & 1.33 \\
$\mathrm{~V}$ & 0.022 & $<0.019$ & 0.021 & 0.022 & 0.024 & 0.056 \\
$\mathrm{Zn}$ & $<0.006$ & $<0.006$ & $<0.006$ & $<0.006$ & $<0.006$ & $<0.006$ \\
$\mathrm{Cl}^{-}$ & 43.6 & 45.5 & 67.8 & 19.6 & 28.5 & 38.0 \\
$\mathrm{SO}_{3}{ }^{2-}$ & 41.6 & 23.4 & 43.2 & $<1.0$ & $<1.0$ & $<1.0$ \\
$\mathrm{SO}_{4}^{2-6}$ & 236 & 460 & 1460 & 2800 & 2270 & 1430 \\
\hline
\end{tabular}

All elemental analyses by ICP unless otherwise noted

b Total dissolved solids

c Analyses by GFAA

A Analyses by cold vapor generation and GFAA, conducted by Burgess and Niple, Columbus, $\mathrm{OH}$

- Analyses by ion chromatography

Table 17. Comparison of ASTM and TCLP leachates with RCRA primary drinking water limits.

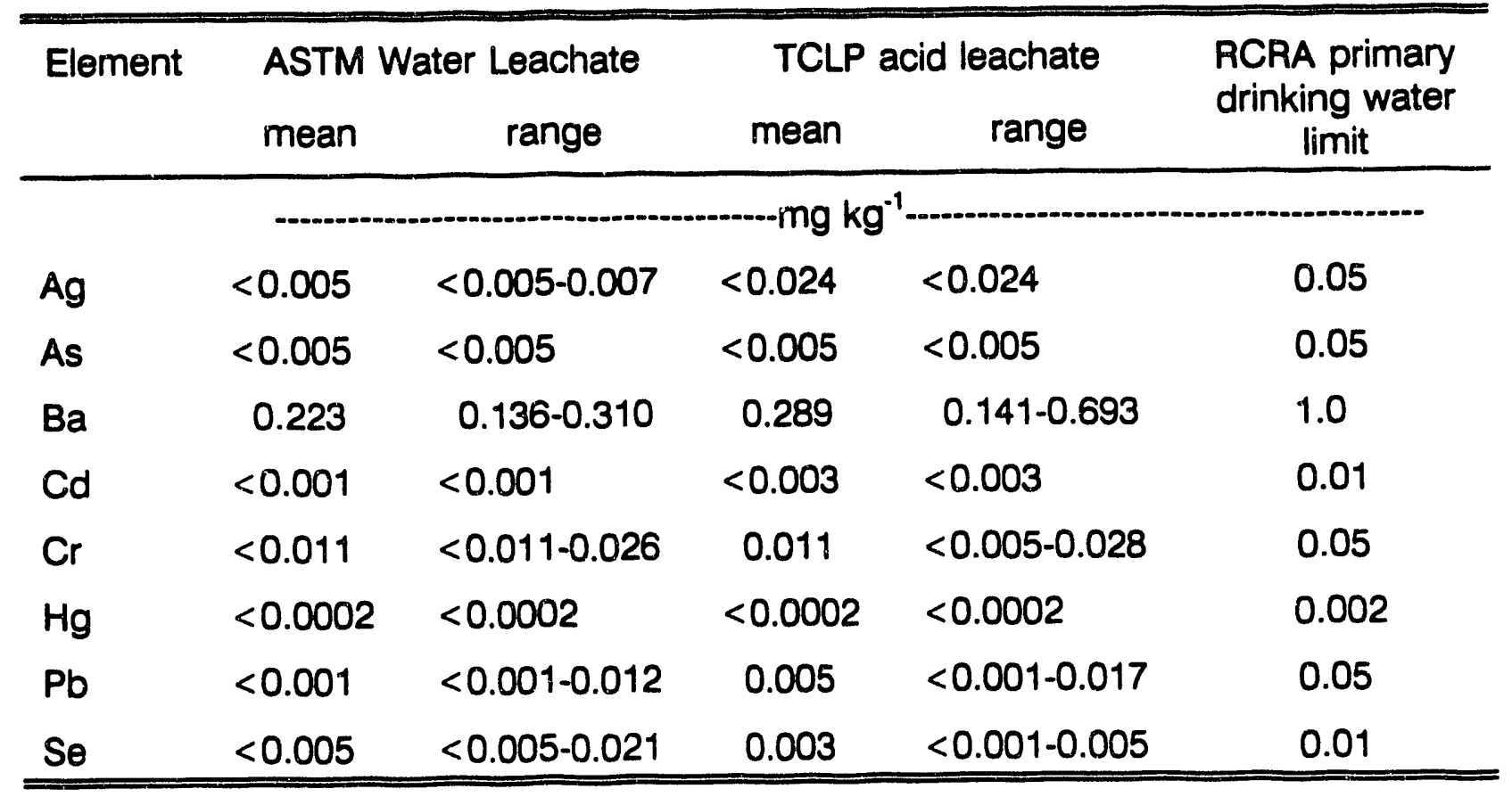


2.1.3.1.3 Paste pH, Total Neutralizing Power, Available Lime, and Thermal Reactivity

All FGD by-products, regardless of the process employed, are highly alkaline with mean $\mathrm{pH}$ values exceeding 11.7 (Table 18). Mean $\mathrm{pH}$ values for the various processes (11.7 to 12.3) and the range of observed values within each type of FGD process varied only slightly. The only exceptions were TID-FLB-01, TID-FLB-03, and TID-FLB-06 in the "Cyclone Ash'" group which yielded slightly lower pH values (9.9 to 10.5). This suggests that FGD by-product $\mathrm{pH}$ is primarily dependent on the sorbent used with the particular FGD process is of secondary importance. The lower mean pH value and wider range reported for the "other" category is a result of the inclusion of non FGD samples (i.e. bottom and economizer ashes, siftings etc.). The high pH values of most FGD samples is due to the presence of oxides and hydroxides of $\mathrm{Ca}$ and $\mathrm{Mg}$ (see section 2.1.3.4). It is expected that when these by-products are exposed to moisture and atmospheric and soil $\mathrm{CO}_{2}$ the oxides and hydroxides will be converted carbonates by carbonation reaction, thus lowering the $\mathrm{pH}$ to around 8.3.

Total neutralizing power (TNP), expressed as percent $\mathrm{CaCO}_{3}$ equivalency (CCE), ranged from 11.8 to 97.7 (Table 18), with an overall mean of $55 \%$. The great majority of the FGD by-product samples (80\%) fell in the much narrower range of 39 to $71 \%$ CCE. The spray dryer process grouping had the highest mean CCE, and the fluidized bed boiler had the lowest mean CCE (with the exception of the "other" grouping which included non-FGD samples). The high mean CCE for the spray dryer group partially results from 2 unusually high CCE values (BAB-LID-02, \& 03).

The sources of alkalinity in the samples vary according to the FGD technology and sorbents used and include $\mathrm{CaO}, \mathrm{Ca}(\mathrm{OH})_{2}, \mathrm{CaCO}_{3}, \mathrm{Ca}, \mathrm{Mg}\left(\mathrm{CO}_{3}\right)$, and $\mathrm{MgO}$ (see section 2.1.3.4). Available lime (measures both $\mathrm{CaO}$ and $\mathrm{Ca}(\mathrm{OH})_{2}$ ), and thermal reactivity (measures heat evolution from hydration of $\mathrm{CaO}$ ) results (Table 18) varied widely both within and among the sample groupings, but also give an indication of the different sources of alkalinity in the FGD by-products. Overall, it is clear that FGD byproducts contain sufficient acid neutralizing potential to warrant their use as alkaline amendments in acid soils and spoils. The generally very fine particle size of these byproducts (see section 2.1.3.3), as well as the more reactive chemical species contained in some of the by-products $(\mathrm{CaO}, \mathrm{CaOH}, \mathrm{MgO})$, suggests that the FGD byproducts will react very rapidly to neutralize soil or spoil acidity. 
Table 18. Paste pH, calcium carbonate equivalent (CCE), available lime, and thermal reactivity of FGD by-product samples.

\begin{tabular}{|c|c|c|c|c|c|}
\hline Sample & pH & CCE & & $\begin{array}{c}\text { Available } \\
\text { lime }\end{array}$ & $\begin{array}{l}\text { Thermal } \\
\text { Reactlvity }\end{array}$ \\
\hline & & $\%$ & range & $\% \mathrm{CaO}, \mathrm{Ca}(\mathrm{OH})_{2}$ & \\
\hline \multicolumn{6}{|c|}{ Duct Injection } \\
\hline BEV-DUC-02 & 12.04 & 71.6 & \pm 1.1 & 33.2 & \\
\hline BEV-DUC-03 & 12.01 & 70.7 & \pm 0.5 & 33.5 & \\
\hline BEV-DUC-05 & 12.20 & 44.7 & \pm 6.8 & 9.8 & 0.4 \\
\hline BEV-DUC-06 & 12.18 & 63.3 & \pm 1.4 & & \\
\hline BEV-DUC-07 & 12.30 & 51.8 & \pm 0.2 & & \\
\hline BEV-DUC-08 & 12.09 & 43.6 & \pm 0.4 & & \\
\hline EDG-CLS-01 & 12.47 & 27.1 & \pm 0.2 & & \\
\hline BUR-SNR-01 & & 45.8 & \pm 0.3 & 3.6 & \\
\hline Mean & 12.18 & 52.3 & & 25.5 & 0.4 \\
\hline \multicolumn{6}{|l|}{ Spray Dryer } \\
\hline BAB-LID-01 & 12.31 & 62.0 & \pm 0.1 & & \\
\hline BAB-LID-02 & 12.44 & 97.7 & \pm 3.0 & & \\
\hline BAB-LID-03 & 12.05 & 92.1 & \pm 1.0 & & \\
\hline HST-SPD-01 & 11.83 & 54.2 & \pm 1.4 & 0.8 & 0 \\
\hline HST-SPD-02 & 12.35 & 46.3 & \pm 0.9 & 1.3 & 0 \\
\hline HST-SPD-03 & 12.41 & 66.7 & \pm 1.3 & 7.0 & 0 \\
\hline HST-SPD-04 & 12.42 & 68.1 & \pm 0.6 & 7.6 & 0 \\
\hline HST-SPD-05 & 12.28 & 53.8 & \pm 2.0 & 1.7 & 0 \\
\hline NSP-SPD-01 & 12.51 & 41.6 & \pm 1.0 & 2.9 & 0.8 \\
\hline OSU-SPD-01 & 12.00 & 66.7 & \pm 0.6 & 13.6 & 0.3 \\
\hline OSU-SPD-02 & 12.25 & 64.5 & \pm 0.6 & 22.3 & 1.0 \\
\hline OSU-SPD-03 & 12.54 & 64.7 & \pm 0.6 & 24.1 & 1.1 \\
\hline OSU-SPD-05 & 12.42 & 68.9 & \pm 1.4 & & \\
\hline Mean & 12.29 & 65.2 & & 9.0 & 0.4 \\
\hline \multicolumn{6}{|l|}{ LIMB } \\
\hline EDG-LIM-03 & 12.10 & 60.6 & \pm 0.5 & 29.0 & 12.7 \\
\hline EDG-LIM-04 & 12.12 & 55.3 & \pm 0.7 & & \\
\hline
\end{tabular}


Table 18. continued

\begin{tabular}{|c|c|c|c|c|c|}
\hline Sample & pH & CCE & & $\begin{array}{c}\text { Available } \\
\text { Lime }\end{array}$ & $\begin{array}{r}\text { Thermal } \\
\text { Reactivity }\end{array}$ \\
\hline & & $\%$ & range & $\% \mathrm{CaO}, \mathrm{Ca}(\mathrm{OH})_{2}$ & \\
\hline EDG-LIM-05 & 12.37 & 66.7 & \pm 0.3 & & \\
\hline EDG-LIM-06 & 12.16 & 61.6 & \pm 0.4 & 12.3 & 4.8 \\
\hline EDG-LIM-07 & 12.10 & 74.8 & \pm 10.5 & 12.3 & \\
\hline EDG-LIM-08 & 12.27 & 19.7 & \pm 0.5 & & \\
\hline EDG-LIM-09 & 12.23 & 85.8 & \pm 0.4 & & \\
\hline EDG-LIM-10 & 12.50 & 22.1 & \pm 0.2 & & \\
\hline EDG-LIM-11 & 12.45 & 35.0 & \pm 0.4 & & \\
\hline EDG-LIM-12 & 12.39 & 27.7 & \pm 0.4 & & \\
\hline EDG-LIM-13 & 12.49 & 42.5 & \pm 0.3 & & \\
\hline EDG-LIM-14 & 12.51 & 59.4 & \pm 0.4 & & \\
\hline Mean & 12.31 & 50.9 & & 17.9 & 8.8 \\
\hline \multicolumn{6}{|c|}{ Fluidized Bed Combustion } \\
\hline \multicolumn{6}{|l|}{ Bed Ash } \\
\hline GMC-FLB-01 & 12.39 & 39.5 & \pm 1.5 & & \\
\hline QST-FLB-03 & 12.58 & 65.4 & \pm 5.9 & 38.4 & 6.0 \\
\hline TID-FLB-02 & 11.18 & 75.2 & \pm 1.7 & 2.6 & \\
\hline TID-FLB-04 & 12.20 & 60.0 & \pm 5.5 & & \\
\hline TID-FLB-07 & 12.25 & 62.8 & \pm 0.8 & & \\
\hline TVA-FLB-03 & 12.52 & 69.1 & \pm 2.1 & 28.4 & \\
\hline Mean & 12.19 & 62.0 & & 23.1 & 6.0 \\
\hline \multicolumn{6}{|c|}{ Cyclone/Fly Ash } \\
\hline GMC-FLB-02 & 12.48 & 39.2 & \pm 0.5 & & \\
\hline PED-RCB-01 & 12.30 & 53.0 & \pm 3.5 & 10.1 & 3.4 \\
\hline QST-FLB-01 & 12.60 & 11.8 & \pm 0.2 & & \\
\hline QST-FLB-02 & 12.58 & 12.5 & \pm 0.3 & & \\
\hline STA-FLB-O1 & 12.32 & 500 & +0.8 & 190 & \\
\hline
\end{tabular}


Phase 1 Report

Table 18. continued

\begin{tabular}{|c|c|c|c|c|c|}
\hline Sample & pH & CCE & & $\begin{array}{c}\text { Available } \\
\text { Lime }\end{array}$ & $\begin{array}{r}\text { Thermal } \\
\text { Reactivity }\end{array}$ \\
\hline & & $\%$ & & $\% \mathrm{CaO}, \mathrm{Ca}(\mathrm{OH})_{2}$ & \\
\hline TID-FLB-01 & 9.90 & 69.4 & \pm 1.5 & 2.3 & \\
\hline TID-FLB-03 & 10.46 & 60.3 & \pm 0.7 & & \\
\hline TID-FLB-06 & 10.09 & 56.0 & \pm 0.5 & & \\
\hline TVA-FLB-01 & 12.45 & 72.4 & \pm 2.8 & & \\
\hline TVA-FLB-02 & 12.33 & 51.3 & \pm 2.8 & 18.0 & \\
\hline Mean & 11.75 & 47.6 & & 12.4 & 3.4 \\
\hline \multicolumn{6}{|l|}{ Other } \\
\hline GMC-FLB-03 & 12.52 & 37.7 & \pm 2.1 & & \\
\hline OSU-SPD-04 & 12.20 & & & & \\
\hline OSU-SPD-07 & 7.58 & -1.0 & \pm 0.3 & & \\
\hline OSU-SPD-08 & 6.90 & 1.9 & \pm 0.7 & & \\
\hline OSU-SPD-09 & 5.16 & 1.8 & \pm 0.6 & & \\
\hline OSU-SPD-10 & & 61.1 & \pm 1.3 & 16.2 & \\
\hline TID-FLB-05 & 8.92 & 33.2 & \pm 4.2 & & \\
\hline Rockport C & & 39.0 & \pm 0.9 & 1.8 & 2.3 \\
\hline Mean & 8.88 & 24.8 & & 9.0 & 2.3 \\
\hline
\end{tabular}


Phase 1 Report

\subsection{Long-term Equilibrium Studies}

All six FGD samples chosen for the long-term equilibration study exhibited rapid equilibration with soluble salts (for complete report of data see Table D3, Appendix D). Little or no change occurred in specific conductance after $1 \mathrm{~d}$ of reaction time. Most samples showed little net change in solution $\mathrm{pH}$ over the $112 \mathrm{~d}$ reaction time. The exceptions to this were samples TID-FLB-04 and TID-FLB-MIX, both of which showed a decline in $\mathrm{pH}$ over time. The high $\mathrm{pH}$ values present in all of the samples indicates that little to no recarbonation of lime occurred during this study. The final solution $\mathrm{pH}$ values ranged from a high of 12.1, to a low of 9.9. The lower $\mathrm{pH}$ values in the TID samples was likely due partial recarbonation of the lime and the presence of dolomite. The higher $\mathrm{pH}$ values in the other samples reflect incomplete recarbonation of the lime present in most of the FGD materials. This likely resulted from the limited amount of time that the sample tubes were left open to the atmosphere. Nonetheless, the amount of gas exchange with the atmosphere was sufficient to prevent the samples from becoming anaerobic. In fact, an increase in solution Eh was observed in all samples over the total equilibration time of $112 \mathrm{~d}$. The solution Eh values after $1 \mathrm{~d}$ of equilibration, ranged from a low of $101 \mathrm{mv}$ (TID-FLB-05) to a high of $183 \mathrm{mv}$ (EDGLIM-14). By $112 \mathrm{~d}$, the lowest solution Eh value was $189 \mathrm{mv}$ (OSU-SPD-03) and the highest value was $304 \mathrm{mv}$ (TID-FLB-03).

The concentration of dissolved Ca in EDG-LIM-14, rapidly declined from 0 to 36 days, remained roughly constant through 70 days, and then decreased again to a low at $112 \mathrm{~d}$ (Fig. 18). Similar results were observed for all other samples except TID-FLB04 , which showed a rapid increase in Ca solubility followed by a plateau at 20 to 70 days, and again a subsequent decline to a low at 112 days (Fig. 19). TID-FLB-04 is a sample of the bed ash. The average particle size was much coarser than that of the other materials used in this long-term equilibration study. It is also likely that the higher temperatures in the pressurized burner resulted in greater calcining of the particle surfaces. Both of these factors would lead to different dissolution rates of the particles of FGD-by-product, and may have contributed to the different behavior of dissolved $\mathrm{Ca}$ in TID-FLB-04.

Table 19 contains values of $\log \mathrm{SI}$ for selected solids after 56 and 112 days, for each sample of FGD by-product used in this study. Values of $\log \mathrm{SI}>0$ indicate that the sample solutions were supersaturated with respect to the specified mineral, indicating that precipitation of this solid could have occurred. Values of $\log \mathrm{SI}<0$ indicate undersaturation with respect to a given solid, generally precluding its precipitation. At 56 days, all samples, except BEV-DUC-02, were near equilibrium with gypsum, and highly supersaturated with respect to ettringite (Table 19). No ettringite was detected by XRD at this sampling time (Table 20). Upon further aging to 112 days, the SI values for gypsum showed little change while those for OSU-SPD-03, BEV-DUC-02, EDG-LIM-14, and TID-FLB-04 were all near equilibrium or less supersaturated with respect to ettringite. One sample, EDG-LIM-14 did contain XRDdetectable ettringite at 112 days (Table 20). Both the XRD data and the SI values 
Phase 1 Report

indicate that Ca weathering reactions in EDG-LIM-14 resulted in the interim precipitation of gypsum as a major Ca-phase. This caused the rapid decrease and then plateau in dissolved $\mathrm{Ca}$ observed from 21 to 70 days, and likely also was responsible for the minimum in total dissolved $\mathrm{S}$ concentrations measured at the 36 day sampling time (Fig. 20). Conversion of gypsum to ettringite with longer reaction time caused the decline in dissolved $\mathrm{Ca}$ concentration, and the subsequent release of $S$ to solution (Fig. 18 to 20). The exact weathering scenarios may be somewhat different in the other FGD products, but the geochemical modeling suggests that in the absence of more significant recarbonation, the final reaction product, ettringite will form in all of the samples with the exception of TID-FLB-03 and TID-FLB-MIX. The latter two samples had significantly lower solution $\mathrm{pH}$ values and this likely inhibited ettringite formation.

Boron and Mo generally exhibited short-term increases in solution concentration followed by decreases in solubility with increasing reaction time (Fig. 21 and 22). Saturation Index calculations indicated both elements where extremely undersaturated (in excess of 2 log units) with respect to likely solid phases (data not shown). It is possible that the depletion of these ions from solution may have resulted from incorporation into an ettringite-like phase.

Whereas. -t both time points, the geochemical modeling suggests that the solutions are ...jar equilibrium with anhydrite, it is unlikely that this phase is present because all of these samples were well hydrated and anhydrite was not detected by XRD (Table 20). All samples were found to be supersaturated with calcite, which was confirmed by XRD (with the exception of BEV-DUC-02). There was good agreement between the SI values and the XRD analyses, with respect to the presence and absence of portlandite, but several minor phases predicted by the geochemical modeling (barite, celestite and strontianite) were not detected by XRD (Table 19 and 20). Since the total concentrations of $\mathrm{Ba}$ and $\mathrm{Sr}$ were low, relative to $\mathrm{Ca}$, it is possible that these phases were not present in sufficient quantity to be detected by XRD.

The results of this long-term equilibration study (XRD and SI) suggest that "closed" (incomplete recarbonation with atmospheric $\mathrm{CO}_{2}$ ), alkaline weathering conditions will lead to interim formation of gypsum and portlandite, followed by conversion of gypsum to ettringite. Such conditions may occur if FGD by-products are placed in confined settings such as road embankments :- If they are used in active surface-mine reclamation where tney could be buried as a discrete layer, at depth. 
Phase 1 Report

Table 19. Values of $\log \mathrm{SI}$ for selected solids after 56 and 112 days of equilibration of FGD suspensions.

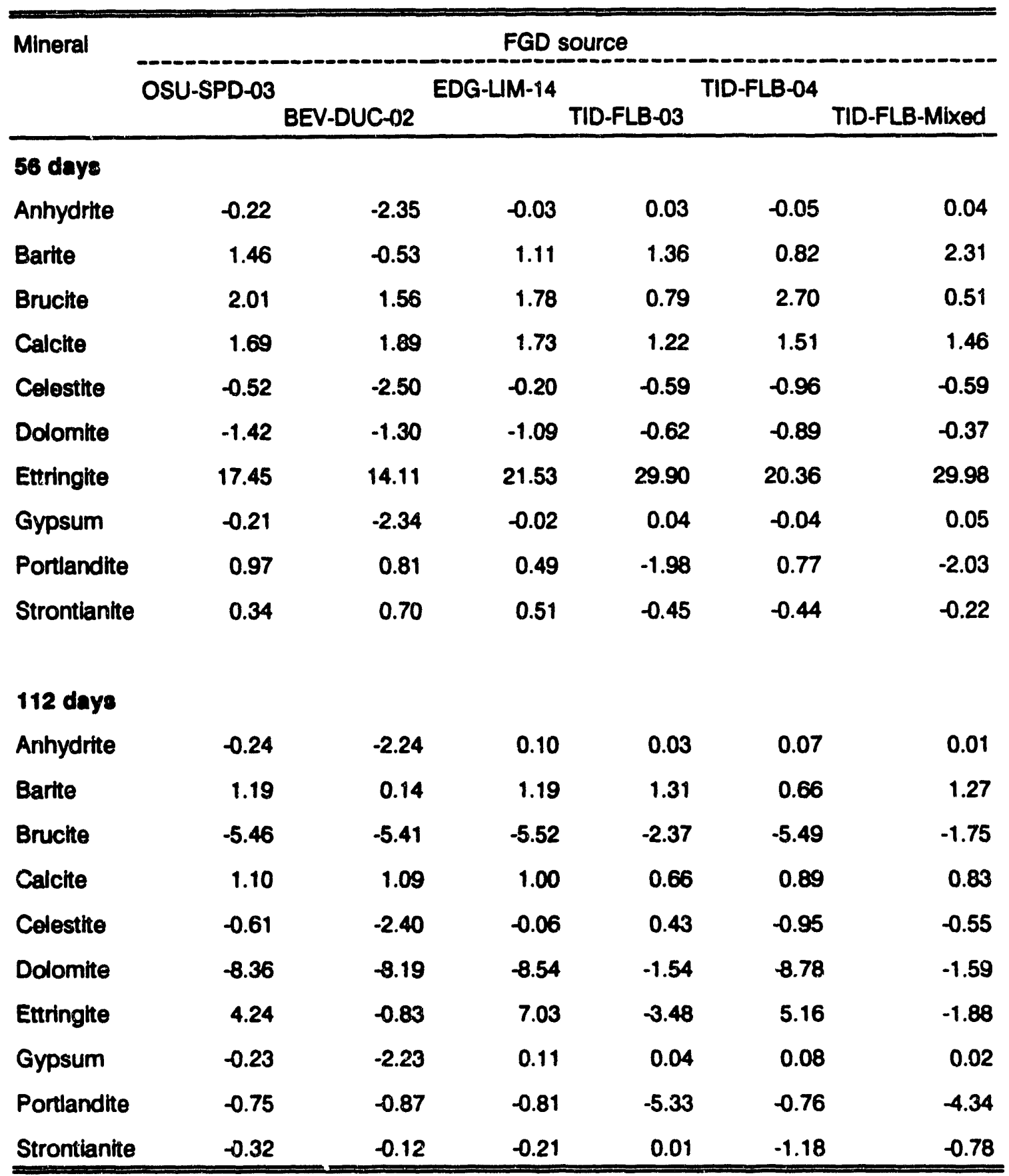


Table 20. FGD mineral phases detected by $X$-ray after 56 and 112 days of equilibration.

\begin{tabular}{|c|c|c|c|c|c|}
\hline \multirow[t]{3}{*}{ Mineral } & \multicolumn{5}{|c|}{ FGD Source } \\
\hline & \multirow[t]{2}{*}{ OSU-SPD-03 } & & EDG-LIM-14 & \multirow{2}{*}{ TID-FLB-03 } & \multirow[t]{2}{*}{ TID-FLB-04 } \\
\hline & & \multicolumn{2}{|c|}{ BEV-DUC-02 } & & \\
\hline \multicolumn{6}{|l|}{56 Days } \\
\hline Anhydrite & nd & nd & nd & nd & nd \\
\hline Barite & nd & nd & nd & nd & nd \\
\hline Brucite & nd & nd & nd & * & * \\
\hline Calcite & $\star$ & nd & * & * & * \\
\hline Celestite & nd & nd & nd & nd & nd \\
\hline Dolomite & nd & nd & nd & * & nd \\
\hline Ettringite & nd & nd & nd & nd & nd \\
\hline Gypsum & nd & nd & $\star$ & * & $\star$ \\
\hline Hemihydrite & $\star$ & * & nd & nd & nd \\
\hline Periclase & nd & nd & nd & * & * \\
\hline Portlandite & $\star$ & * & $\star$ & nd & nd \\
\hline Strontianite & nd & nd & nd & nd & nd \\
\hline \multicolumn{6}{|l|}{112 days } \\
\hline Anhydrite & nd & nd & nd & nd & nd \\
\hline Bartte & nd & nd & nd & nd & nd \\
\hline Brucite & nd & nd & nd & $\star$ & $\star$ \\
\hline Calcite & $\star$ & nd & $\star$ & $\star$ & $\star$ \\
\hline Celestite & nd & nd & nd & nd & nd \\
\hline Dolomite & nd & nd & nd & $\star$ & nd \\
\hline Ettringite & nd & nd & * & nd & nd \\
\hline Gypsum & nd & nd & nd & $\star$ & $\star$ \\
\hline Hemihydrite & $\star$ & $\star$ & nd & nd & nd \\
\hline Periclase & nd & nd & nd & $\star$ & $\star$ \\
\hline Portlandite & $\star$ & * & $\star$ & nd & nd \\
\hline Strontianite & nd & nd & nd & nd & nd \\
\hline
\end{tabular}




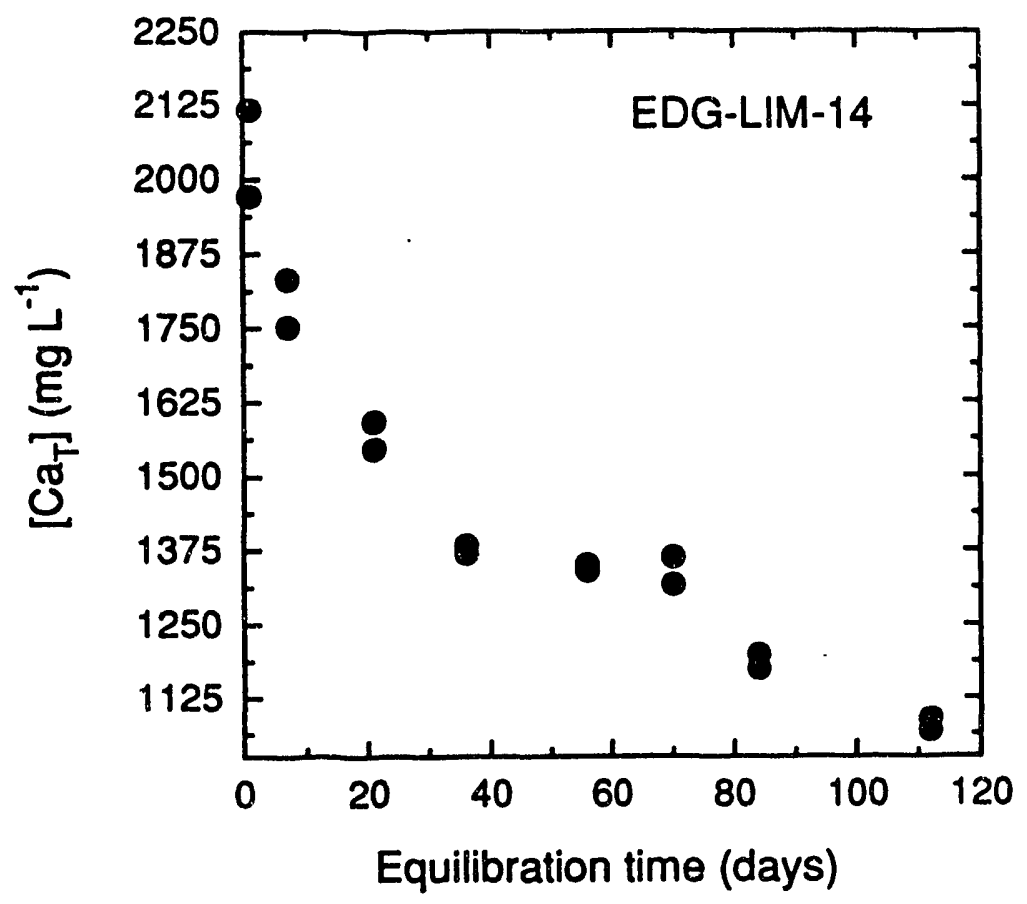

Fig. 18. Effect of reaction time on the concentration of dissolved Ca in EDG-LIM-14.

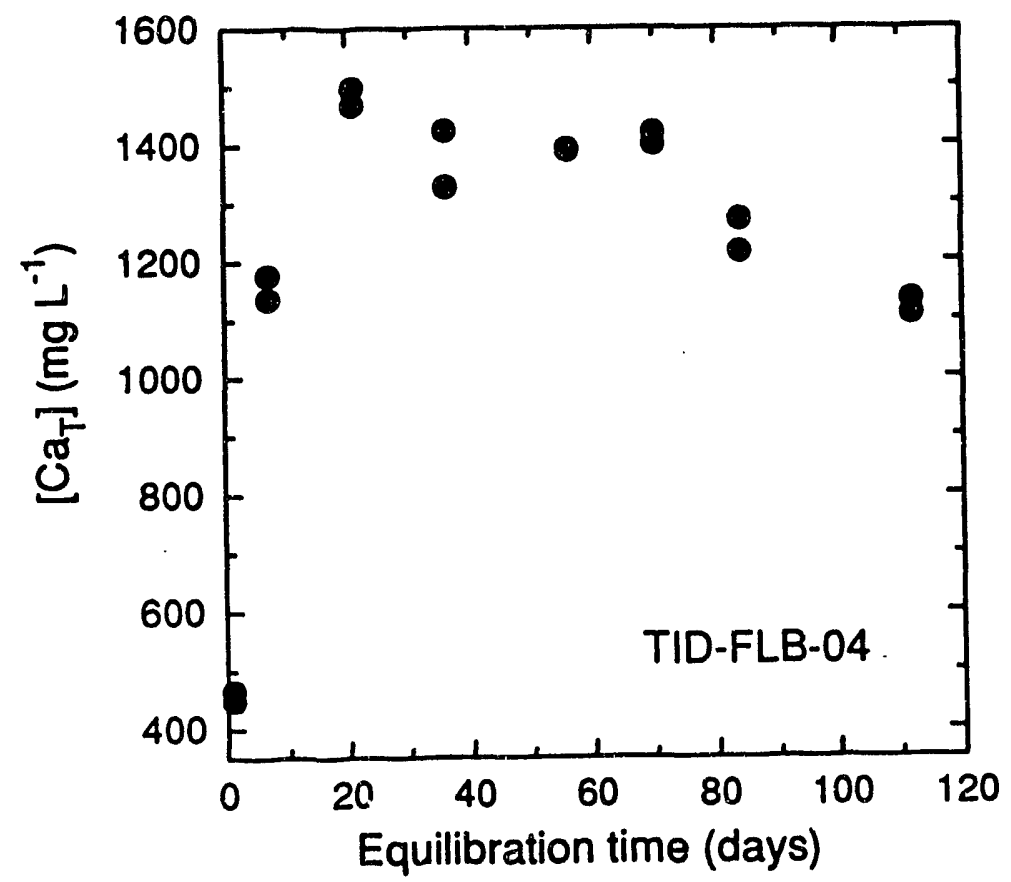

Fig. 19. Effect of reaction time on the concentration of dissolved Ca in TID-FLB-04. 


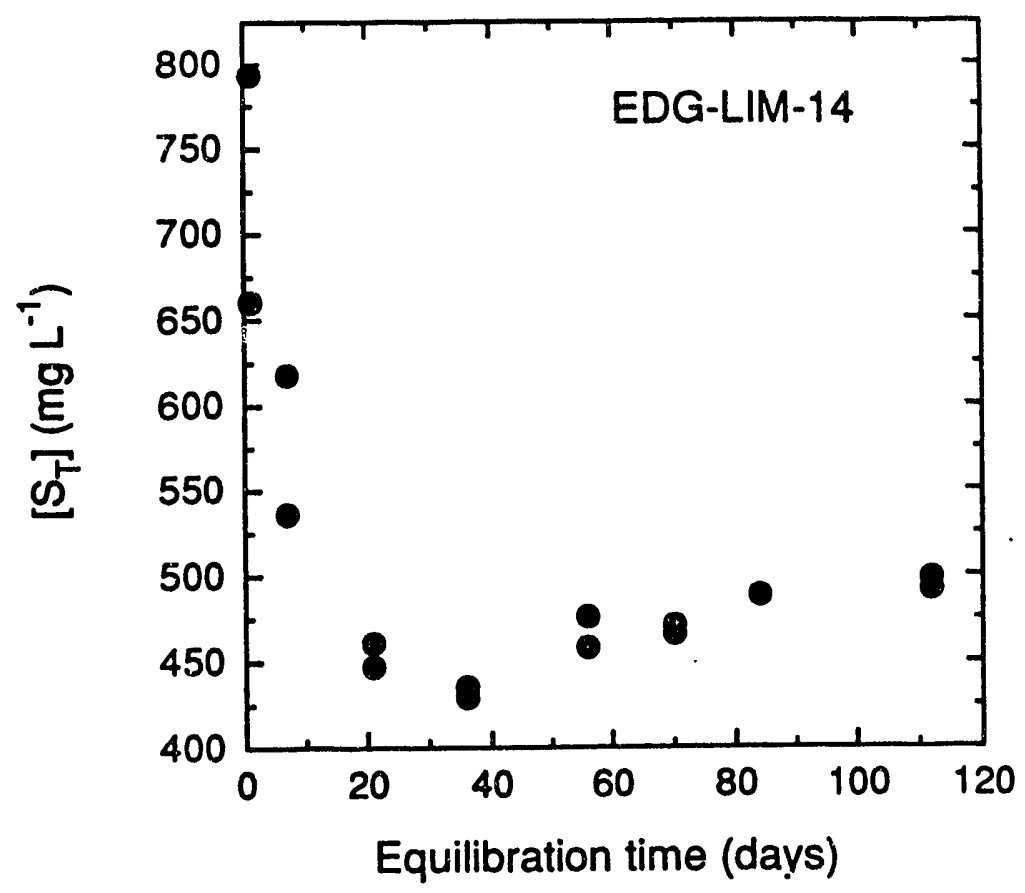

Fig. 20. Effect of reaction time on the concentration of dissolved S in EDG-LIM-14.

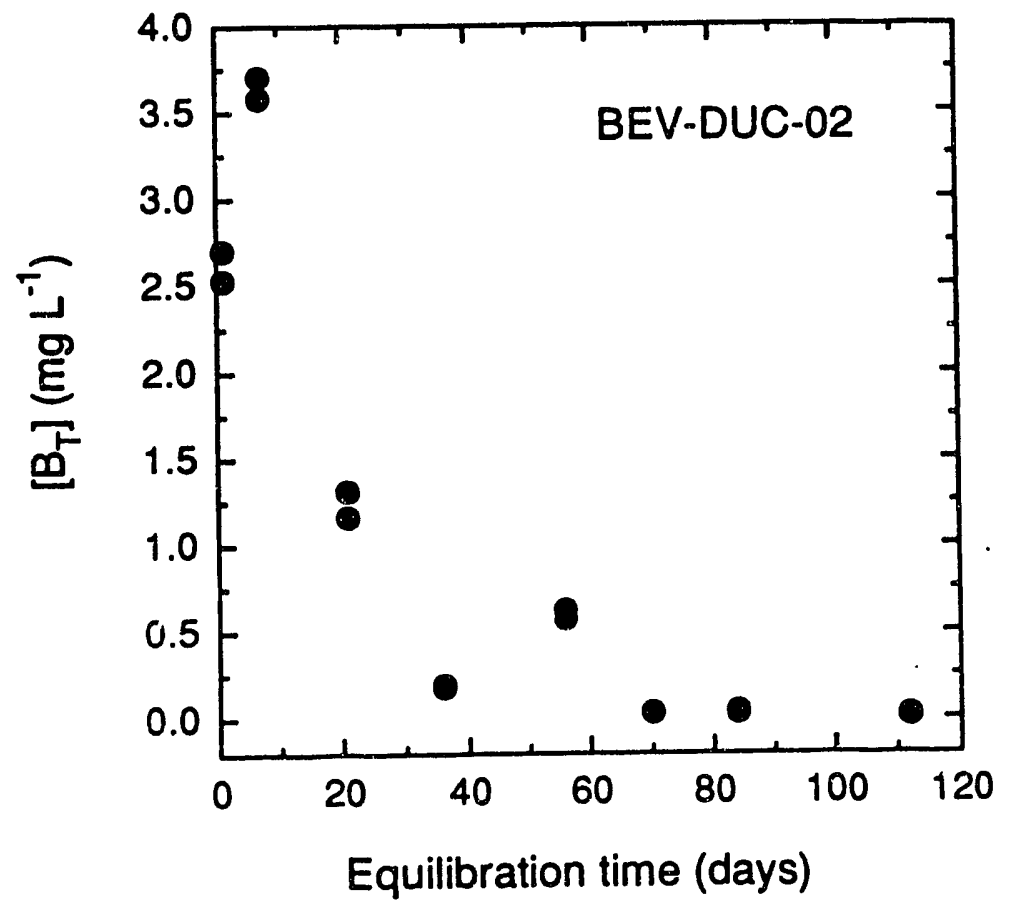

Fig. 21. Effect of reaction time on the concentration of dissolved B in BEV-DUC-02. 


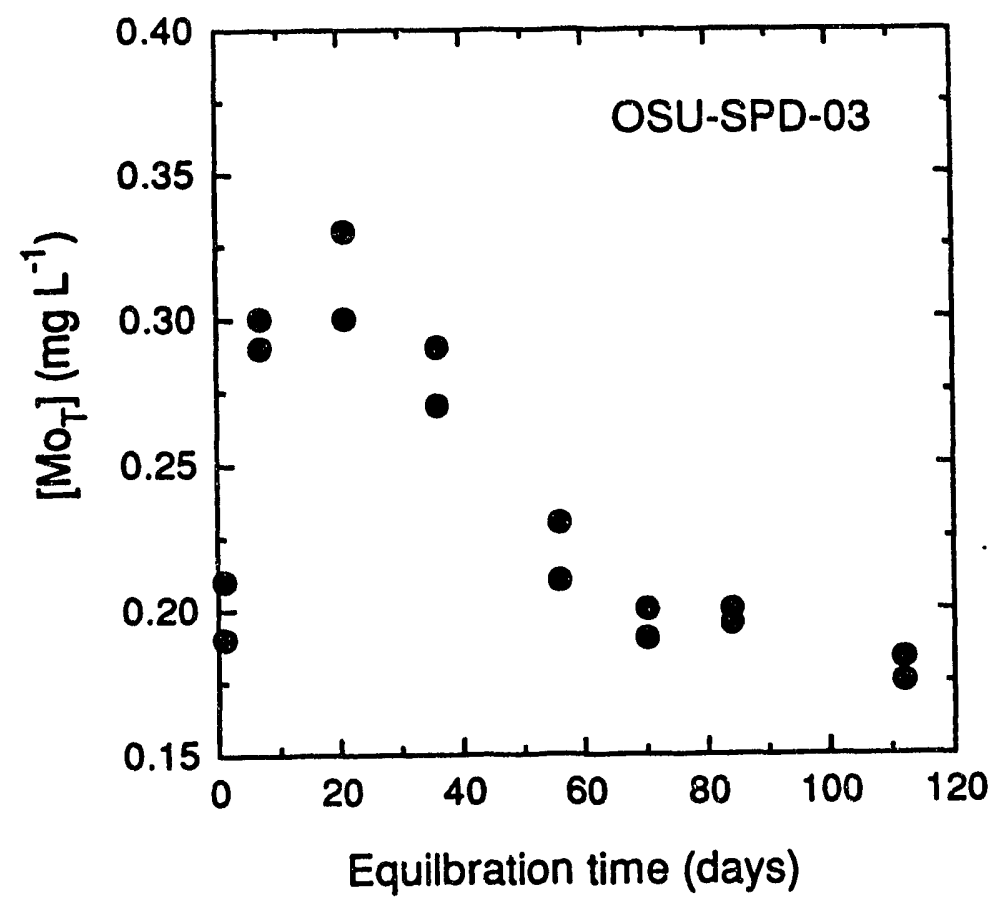

Fig. 22. Effect of reaction time on the concentration of dissolved Mo in OSU-SPD-03. 


\subsubsection{Mineralogical Characterization}

\subsection{X-ray diffraction}

Mineralogical analyses of the dry FGD by-products were initiated with the identification of crystalline phases using $X$-ray diffraction. A qualitative identification of all phases was essential in order to reliably interpret other forms of data leading to mineral quantification. Representative X-ray diffraction patterns from all six forms of by-product are presented in Figures 23 to 28 . Patterns such as these provided "fingerprints" of the crystalline phases present however proportions of various constituents in a samples could only be estimated from the relative peak intensities (Table 21). In addition, $X$-ray amorphous phases, such as the glass associated with fly ash, were not readily detected in such heterogeneous samples.

The X-ray diffraction results showed that scrubber residues from duct injection, spray dryer and coolside processes were similar and consisted primarily of $\mathrm{Ca}(\mathrm{OH})_{2}$ (portlandite) and $\mathrm{CaSO}_{3}-\mathrm{O}^{2} \mathrm{H}_{2} \mathrm{O}$ (calcium sulfite hemihydrate) (Figures 23 to 25). The former is derived from the use of excess sorbent and the latter is the primary pioduct of sorbent reaction with $\mathrm{SO}_{2}$-laden flue gas via:

$$
\mathrm{Ca}(\mathrm{OH})_{2}+\mathrm{SO}_{2} \rightarrow \mathrm{CaSO}_{3} \cdot 0.5 \mathrm{H}_{2} \mathrm{O}+0.5 \mathrm{H}_{2} \mathrm{O}
$$

Both phases are indicative of low reaction temperatures in the range of 150 to $200^{\circ} \mathrm{C}$. The coolside sample and those duct injection samples produced by re-cycle of the FGD by-product (BEV-DUC 05, 07 and 08) showed more evidence of the mineral phases typically associated with fly ash (e.g., glass, quartz, mullite, hematite and magnetite).

Most of the LIMB by-products contained significant amounts of $\mathrm{CaO}$ (lime), $\mathrm{CaSO}_{4}$ (anhydrite), and $\mathrm{CaCO}_{3}$ (calcite) (Table 21, Figure 26). In the LIMB process, the sorbent is injected directly into the upper portion of a suspension-fired boiler at temperatures ranging from 1100 to $1260^{\circ} \mathrm{C}$. At these temperatures, the sorbent calcines to form $\mathrm{CaO}$ which then reacts with $\mathrm{SO}_{2}$ and $\mathrm{O}_{2}$ in the flue gas to form $\mathrm{CaSO}_{4}$. If a dolomitic sorbent is used, $\mathrm{MgO}$ (periclase) may also be a product of the calcination process (Table 21). The presence of portlandite and gypsum $\left(\mathrm{CaSO}_{4} \cdot 2 \mathrm{H}_{2} \mathrm{O}\right)$ in some samples indicates partial re-hydration of the FGD by-product. Likewise, $\mathrm{CaCO}_{3}$ reflects re-carbonation of $\mathrm{Ca}(\mathrm{OH})_{2}$ by reaction of $\mathrm{Ca}(\mathrm{OH})_{2}$ with atmospheric $\mathrm{CO}_{2}$.

Analyses of both bed and cyclone ashes from the Tidd facility indicated that in addition to $\mathrm{CaSO}_{4}$, the bed ashes were enriched with $\mathrm{CaCO}_{3}, \mathrm{CaO}$ and $\mathrm{MgO}$. These latter two minerals were derived by calcination of dolomite $\left[\mathrm{CaMg}\left(\mathrm{CO}_{3}\right)_{2}\right]$ sorbent at temperatures ranging between 815 and $870^{\circ} \mathrm{C}$ (Table 21, Figure 27). The cyclone ashes were similar in composition but contained more unspent sorbent and $\mathrm{CaSO}_{4}$ and less MgO (Table 21, Figure 28). Comparable results were obtained for samples from the GMC plant in Pontiac, MI. 
Table 21. Crystalline phases ${ }^{1}$ detected by $X$-ray diffraction

\begin{tabular}{|c|c|c|}
\hline Sample & Major Minerals ${ }^{2}$ & Minor Minerals \\
\hline $\begin{array}{l}\text { BEV-DUC-02 } \\
\text { BEV-DUC-03 } \\
\text { BEV-DUC-05 } \\
\text { BEV-DUC-06 } \\
\text { BEV-DUC-07 } \\
\text { BEV-DUC-08 }\end{array}$ & $\begin{array}{l}P, H \\
P, H \\
P, H \\
P \\
P, H \\
P, H\end{array}$ & $\begin{array}{l}Q, F \\
C, Q \\
F, M, Q, U \\
Q, F \\
F, Q, U \\
F, Q, U\end{array}$ \\
\hline $\begin{array}{l}\text { OSU-SPD-01 } \\
\text { OSU-SPD-02 } \\
\text { OSU-SPD-03 } \\
\text { OSU-SPD-05 } \\
\text { OSU-SPD-10 }\end{array}$ & $\begin{array}{l}C, P, H \\
P, H \\
P, H \\
P, H \\
P, H\end{array}$ & $\begin{array}{l}F, M, Q, U \\
C, F, Q, U \\
C, F, Q, U \\
C, F, M, U \\
Q, U\end{array}$ \\
\hline $\begin{array}{l}\text { EDG-CLS-01 } \\
\text { EDG-LIM-03 } \\
\text { EDG-LIM-04 } \\
\text { EDG-LIM-05 } \\
\text { EDG-LIM-06 } \\
\text { EDG-LIM-07 } \\
\text { EDG-LIM-08 } \\
\text { EDG-LIM-09 } \\
\text { EDG-LIM-10 } \\
\text { EDG-LIM-11 } \\
\text { EDG-LIM-12 } \\
\text { EDG-LIM-13 } \\
\text { EDG-LIM-14 }\end{array}$ & $\begin{array}{l}Q, P, H \\
L, C, A, P \\
R, C, A \\
B, P, L, A, C, G, R \\
R, A, L, C \\
R, A, C, L \\
L, Q, A, C \\
R, L, A, C \\
A, Q, L, C \\
A, C, L \\
L, A, Q, C \\
L, A, C \\
L, A, C\end{array}$ & $\begin{array}{l}C, F, M, U \\
F, M, Q, U \\
Q, F, M, U, L \\
\cap, M, F, U \\
F, M, Q, U, P \\
P, F, M, Q, U \\
P, F, M, U \\
P, Q, F, M, U \\
P, U, F, M \\
P, Q, F, M, U \\
F, M, U \\
F, M, Q, P, U \\
P, F, M, Q, U\end{array}$ \\
\hline $\begin{array}{l}\text { TID-FLB-01 } \\
\text { TID-FLB-02 } \\
\text { TID-FLB-03 } \\
\text { TID-FLB-04 } \\
\text { TID-FLB-05 } \\
\text { TID-FLB-06 } \\
\text { TID-FLB-07 }\end{array}$ & $\begin{array}{l}D, A, R, C \\
C, A, R \\
D, A, R, C \\
R, A, C \\
D, A, Q \\
D, A, P, Q, C \\
A, R, C\end{array}$ & $\begin{array}{l}\text { Q, F } \\
\text { L, Q } \\
Q, F \\
\text { L, Q } \\
F, L, U \\
F, L \\
\text { L, Q }\end{array}$ \\
\hline $\begin{array}{l}\text { GMC-FLB-02 } \\
\text { GMC-FLB-03 }\end{array}$ & $\begin{array}{l}A, L, F, Q \\
A, L, P\end{array}$ & $\begin{array}{l}C \\
Q F C\end{array}$ \\
\hline $\begin{array}{l}A=A \\
B=B \\
D=D \\
H=H \\
L=L \\
U=A \\
P=P\end{array}$ & $\left..5 \mathrm{H}_{2} \mathrm{O}\right)$ & $\left.\int_{4}^{2} 2 \mathrm{H}_{2} \mathrm{O}\right)$ \\
\hline
\end{tabular}

2 Listed in order of estimated abundance. 


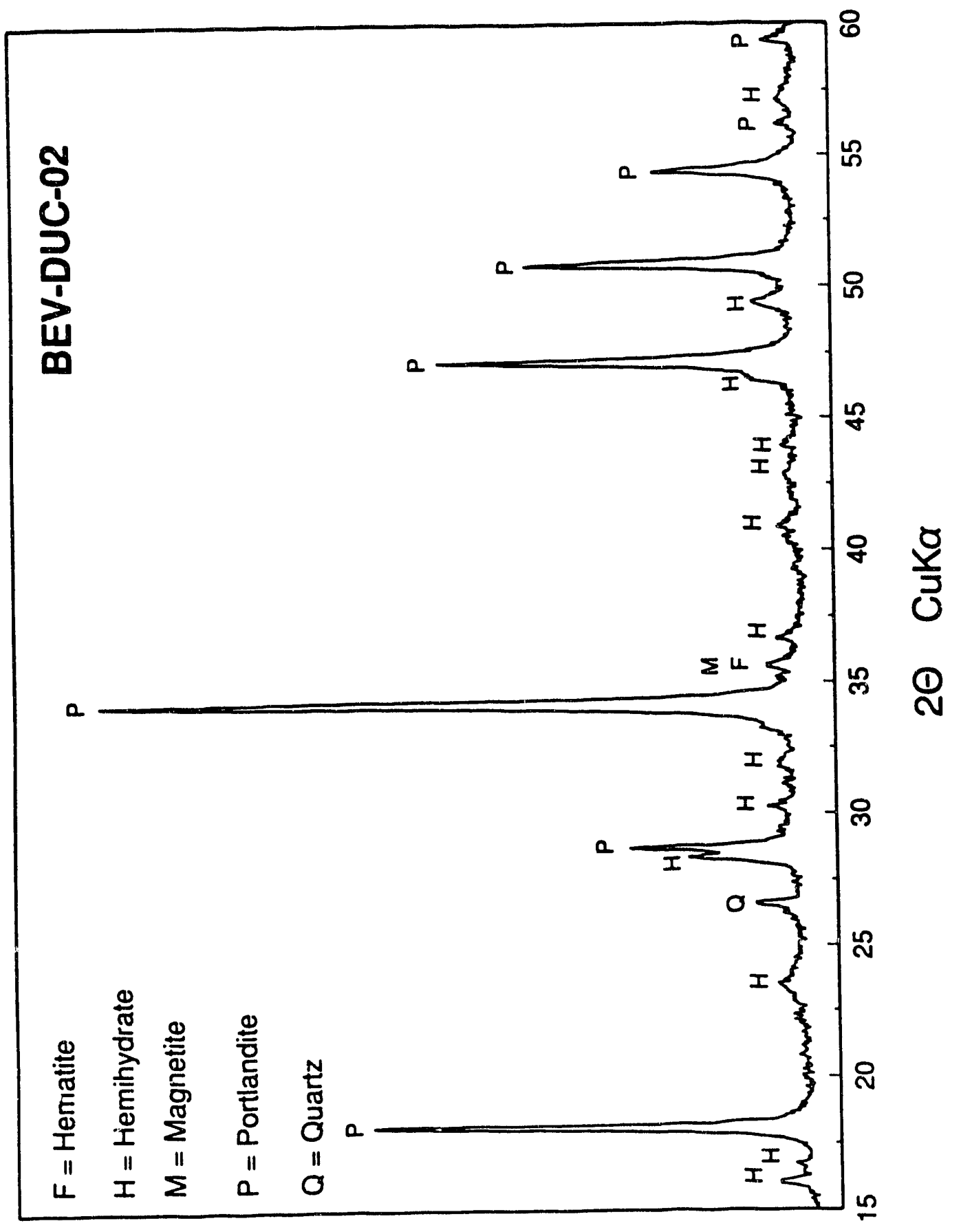

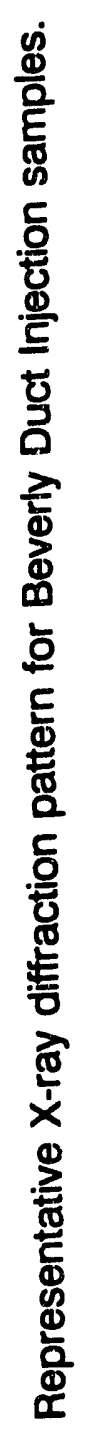

ฌู

운 


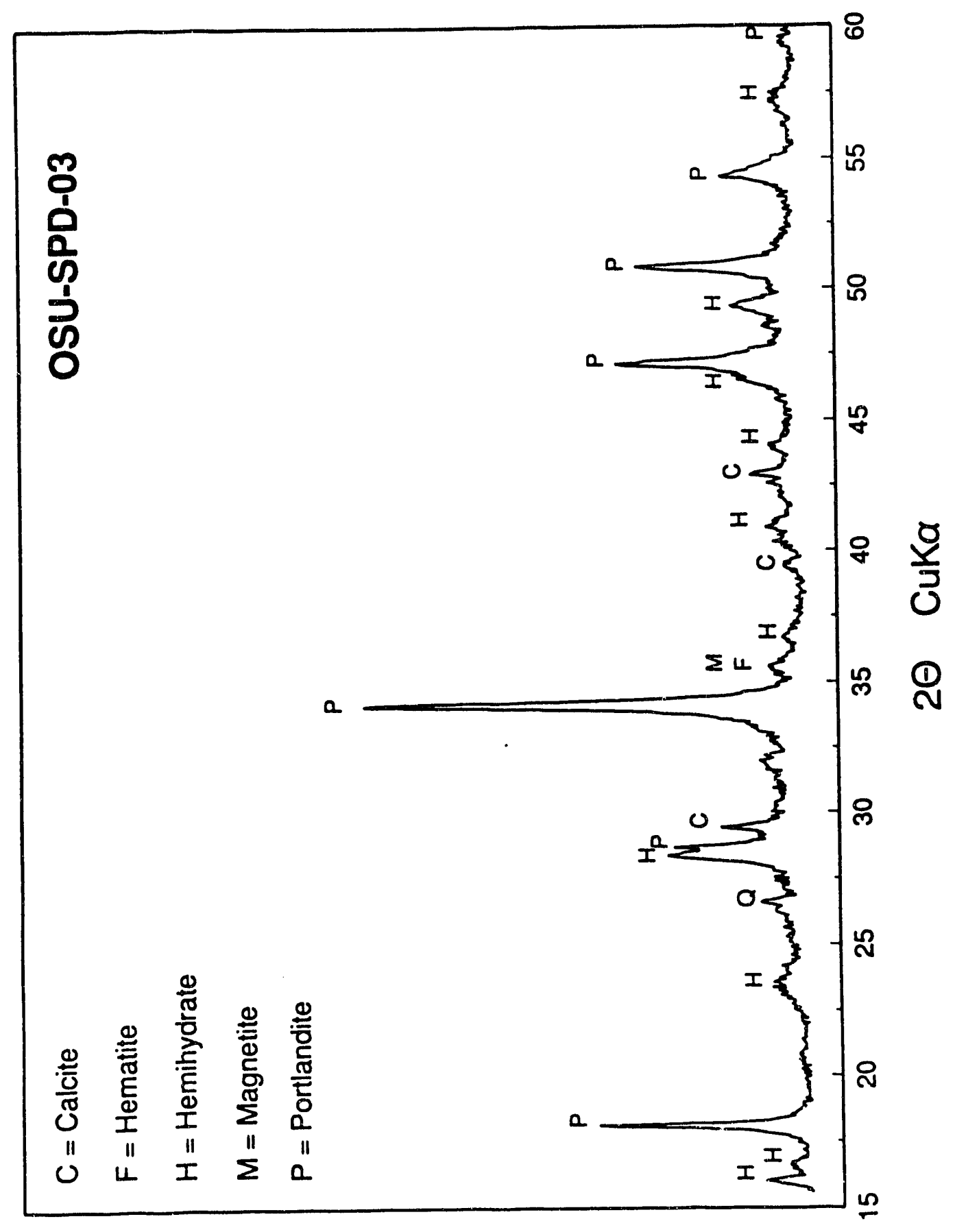

ญ்

ते

ํํㄴ 


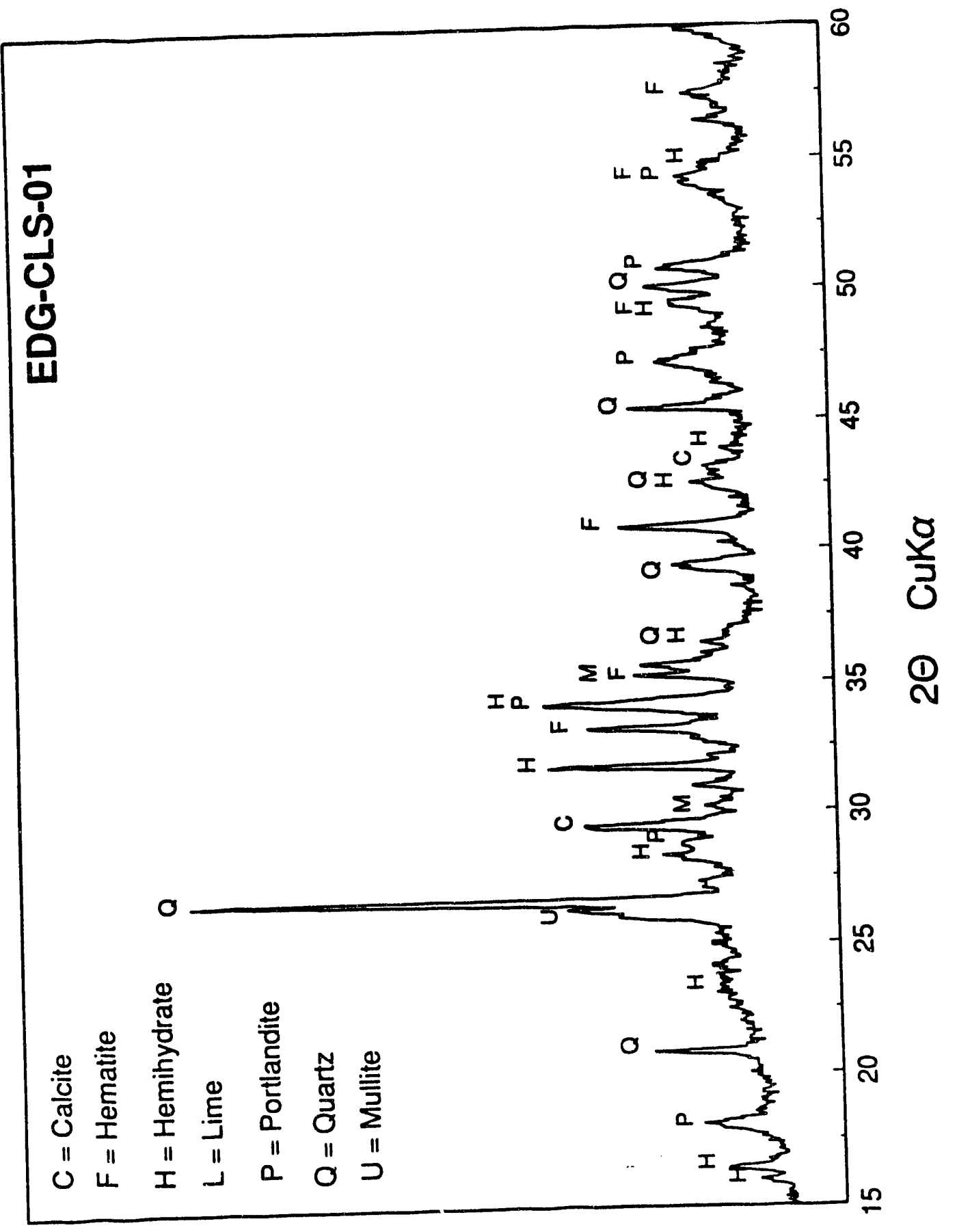

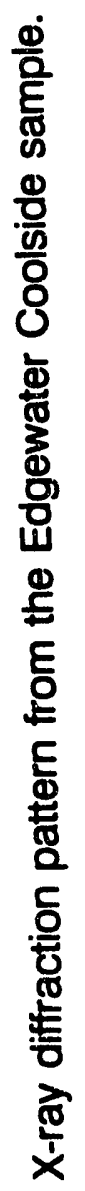

ผู่

운 


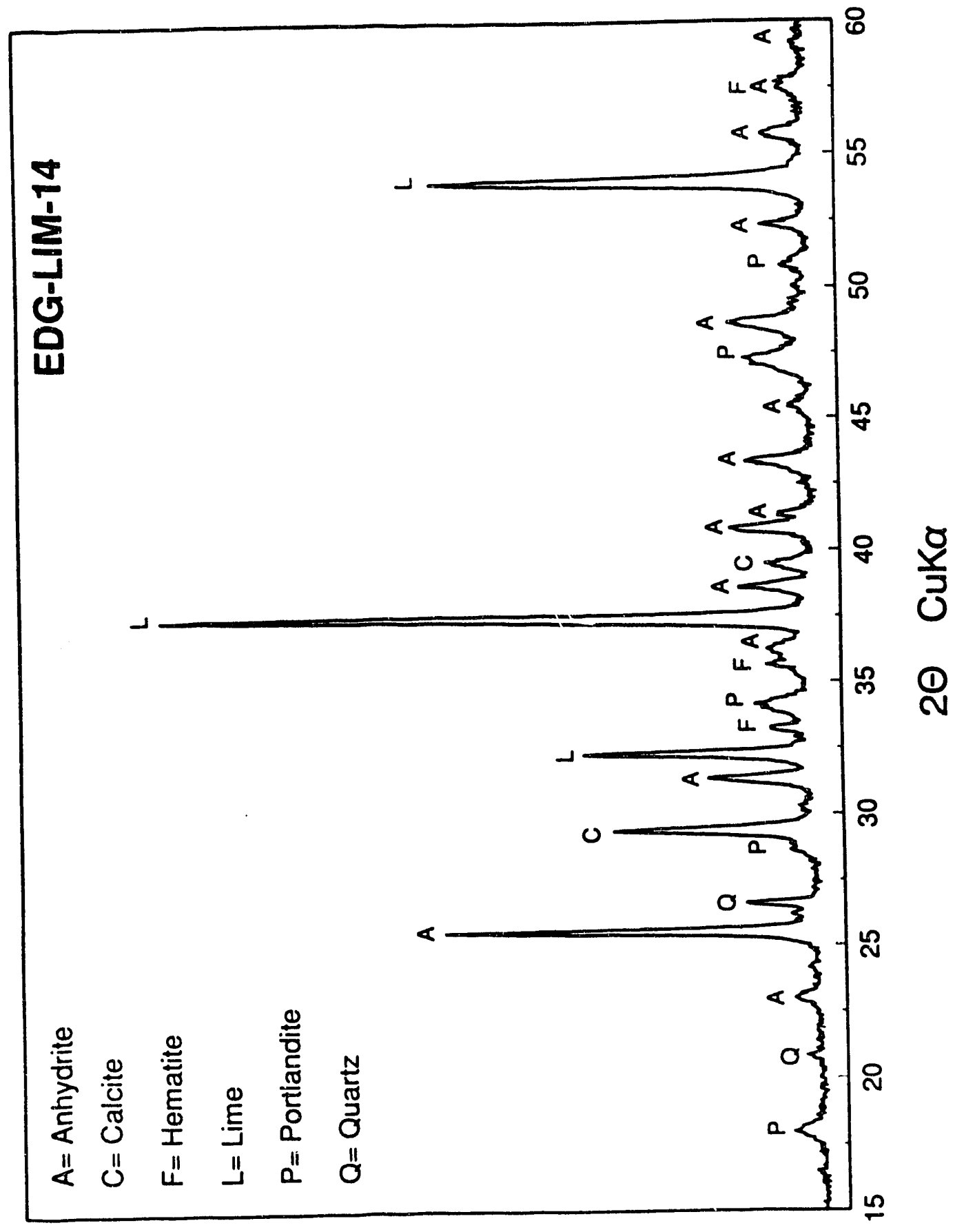

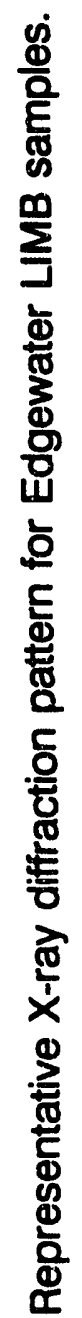

$\stackrel{\leftrightarrow}{\circ}$

운 


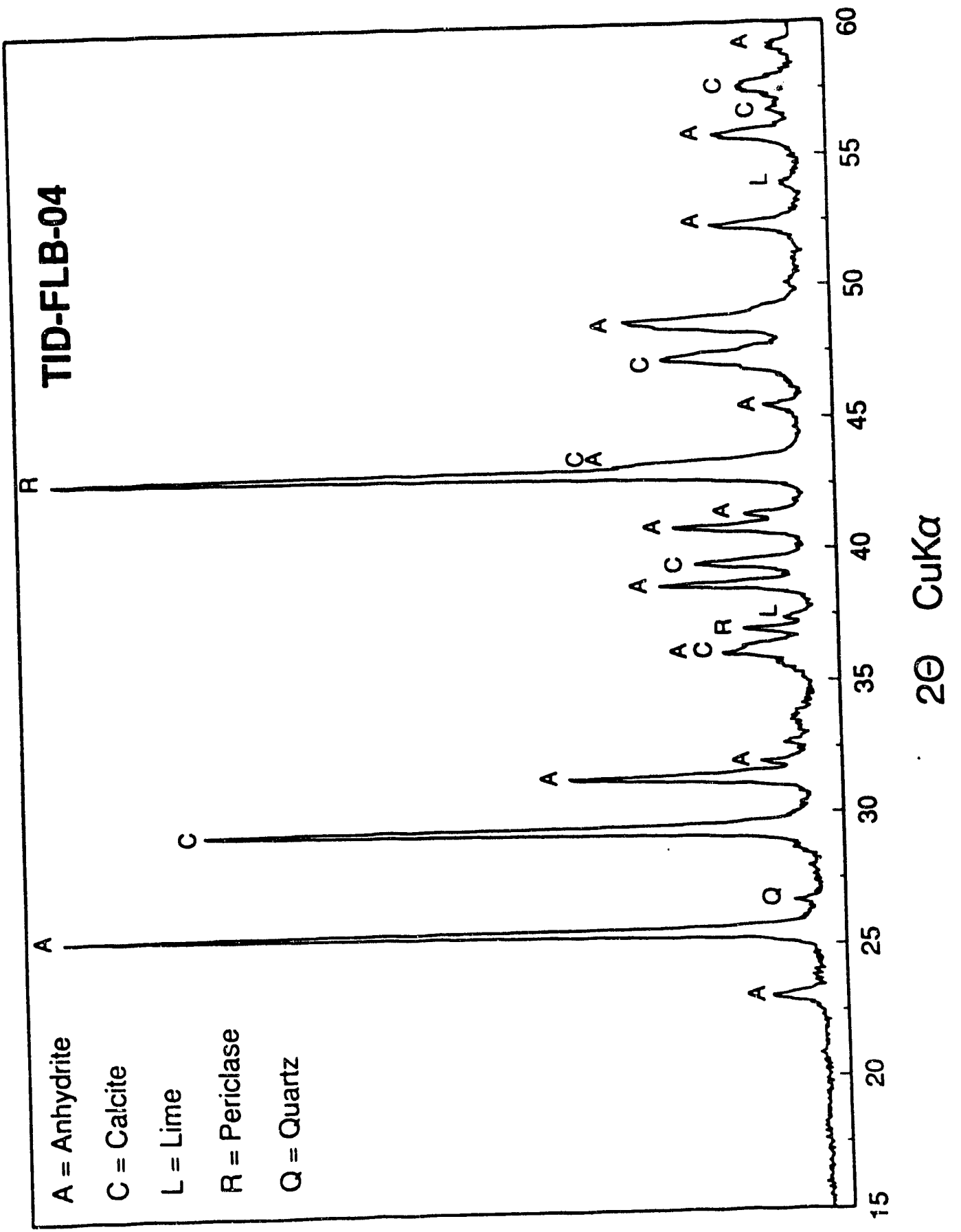

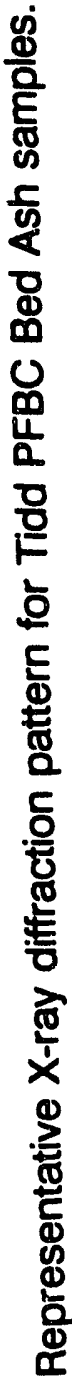

ลิ

ㅇํㄴ 


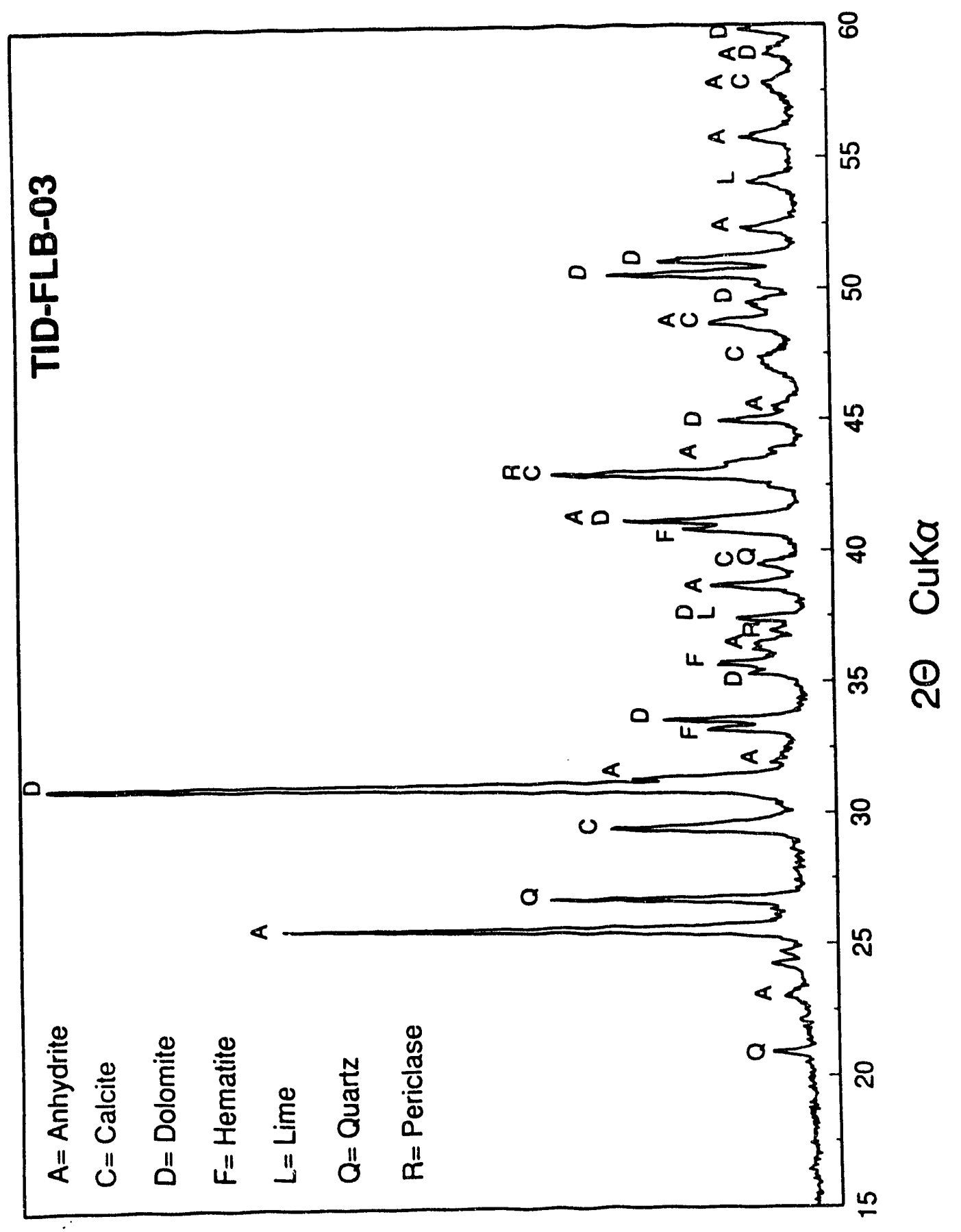

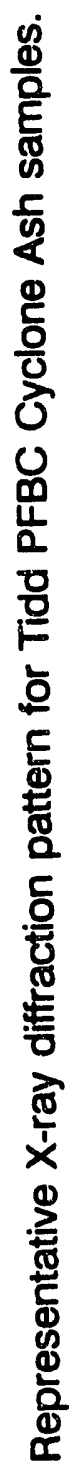

๙

욘 


\subsection{Mineral "quantification"}

Mineralogical analyses are normally semiquantitative, at best, because it is difficult to obtain reference minerals that closely match the physical, chemical and structural characteristics of the sample materials. Furthermore, in the present study no single analytical technique was adequate for "quantifying" the full range of mineral phases present in the dry FGD by-products. Therefore to obtain a measure of quantification, data from multiple procedures were used, whenever possible, to support or verify the analytical procedure of choice.

Thermal analysis was found to be an excellent tool for quantifying those compounds that were susceptible to phase transitions with heating. Standard reference materials were used to develop a basic understanding of the thermal reactivity of each phase, but the thermal characteristics of the FGD by-products were never identical to standard specimens. Variations in thermal behavior resulted from differences in particle size, crystallinity and the presence of other phases. Spiked samples, selective dissolution, $X$-ray diffraction analysis, and the technical literature were used to guide interpretations. Representative thermogravimetric and differential thermal analysis (TGA/DTA) results are reproduced in Figures 29 to 33.

A $12 \%$ stoichiometric weight loss, resulting from the dehydroxylation of $\mathrm{Ca}(\mathrm{OH})_{2}$ to form $\mathrm{CaO}$, was used to quantify the portlandite $\left(\mathrm{Ca}(\mathrm{OH})_{2}\right)$ content of relevant samples (e.g., Figure 29). In the FGD by-products studied, this thermal event occurred over the temperature range of 375 to $500^{\circ} \mathrm{C}$ and could be defined with little interference from other thermal transitions. Most FGD samples contained some portlandite, but the highest amounts occurred in the OSU spray dryer (10 to $30 \mathrm{wt} \%$ ) and the Beverly duct injection (5 to $40 \mathrm{wt} \%$ ) samples (Table 22). The effect of re-cycle in the Beverly samples was clearly evidenced by reduced quantities of $\mathrm{Ca}(\mathrm{OH})_{2}$ in the recycle samples (BEV-DUC-05, 07 \& 08) as compared to non-recycle samples (BEVDUC-02, 03 \& 06).

The contents of $\mathrm{CaSO}_{3} \mathrm{O} 0.5 \mathrm{H}_{2} \mathrm{O}$ were determined by weight loss associated with the evolution of water over a temperature range of 300 to $370^{\circ} \mathrm{C}$ (Figures 29 and 30 ). This compound was restricted to samples from the low temperature, high humidity FGD processes, namely, spray dryer (SPD), coolside (CLS), and duct injection (DUC) (Table 22). It was present at slightly elevated levels where recycle was employed.

Reference specimens of $\mathrm{CaSO}_{4}$ (anhydrite) were thermally stable over the temperature range and experimental conditions employed. Decomposition, however, was observed in most of the FGD by-products containing anhydrite. Contents of anhydrite were calculated using the stoichiometry shown in Figures 31 and 33 and weight losses observed in the range of 850 to $1050^{\circ} \mathrm{C}$ were in good agreement with totai elemental analysis of S. Because a limited number of anhydrite-bearing samples did not exhibit a weight loss in this range (Figure 33), the $\mathrm{CaSO}_{4}$ contents reported in Table 22 were calculated from total S. In general, the highest quantities of $\mathrm{CaSO}_{4}$ were associated with the PFBC bed ashes. 
The content of either $\mathrm{CaCO}_{3}$ or $\left[\mathrm{CaMg}\left(\mathrm{CO}_{3}\right)_{2}\right]$ could readily be determined by the weight loss associated with $\mathrm{CO}_{2}$ evolution. Although calcination temperatures varied from 600 to $850^{\circ} \mathrm{C}$, the analysis was straightforward when only one of the two carbonate phases was present. Optical calcite was also used as a thermal standard for instrument calibration. The recovery from multiple thermogravimetric analyses was $99.43 \pm 0.74 \%$. In materials containing both calcite and dolomite (e.g., TID-FLB-O3, Figure 32), the weight loss event resulting from dolomite decomposition was not completed prior to the onset of $\mathrm{CaCO}_{3}$ decay. In these samples, calcite and dolomite were quantified using the gasometric Chittick technique. Variable amounts of calcite were present in all samples, and dolomite occurred whenever it was employed as a sorbent (Table 22).

Both $\mathrm{CaO}$ and $\mathrm{MgO}$ are thermally inert phases and could not be measured by thermogravimetric analysis. Consequently, the $\mathrm{CaO}$ contents (Table 22) were determined by first allocating elemental $\mathrm{Ca}$ from total chemical analyses to all other $\mathrm{Ca}$ species present in the samples and then converting the remaining $\mathrm{Ca}$ to $\mathrm{CaO}$.

Periclase (MgO) commonly occurred in those samples where dolomite was used as an absorbent. When both periclase and dolomite were present, the latter was quantified by using the Chittick apparatus, and a corresponding amount of $\mathrm{Mg}$ was allocated based on a $1: 1 \mathrm{Mg}$ to $\mathrm{Ca}$ ratio. The remaining $\mathrm{Mg}$ was assigned to $\mathrm{MgO}$. The resulting values (Table 22) were in good agreement with the relative abundance of these phases as estimated from X-ray diffraction peak intensities.

Fly ash contents of the FGD by-products were highly variable, ranging from 10 to $79 w t \%$ (Table 22). Although fly ash was a significant component of most samples, it was often "hidden" in XRD patterns from whole by-product specimens. No attempt was made to quantify the fly ash mineralogy; however, $X$-ray diffraction analyses of the acid-insoluble residues showed that all were composed of glass, quartz $\left(\mathrm{SiO}_{2}\right)$, hematite $\left(\mathrm{Fe}_{2} \mathrm{O}_{3}\right)$, mullite $\left(\mathrm{Al}_{6} \mathrm{Si}_{2} \mathrm{O}_{13}\right)$ and a magnetic phase with the characteristics of partially oxidized magnetite $\left(\mathrm{Fe}_{3} \mathrm{O}_{4}\right)$. A representative $X$-ray diffracticn pattern from the fly ash component of EDG-LIM-14 is shown in Figure 34. 


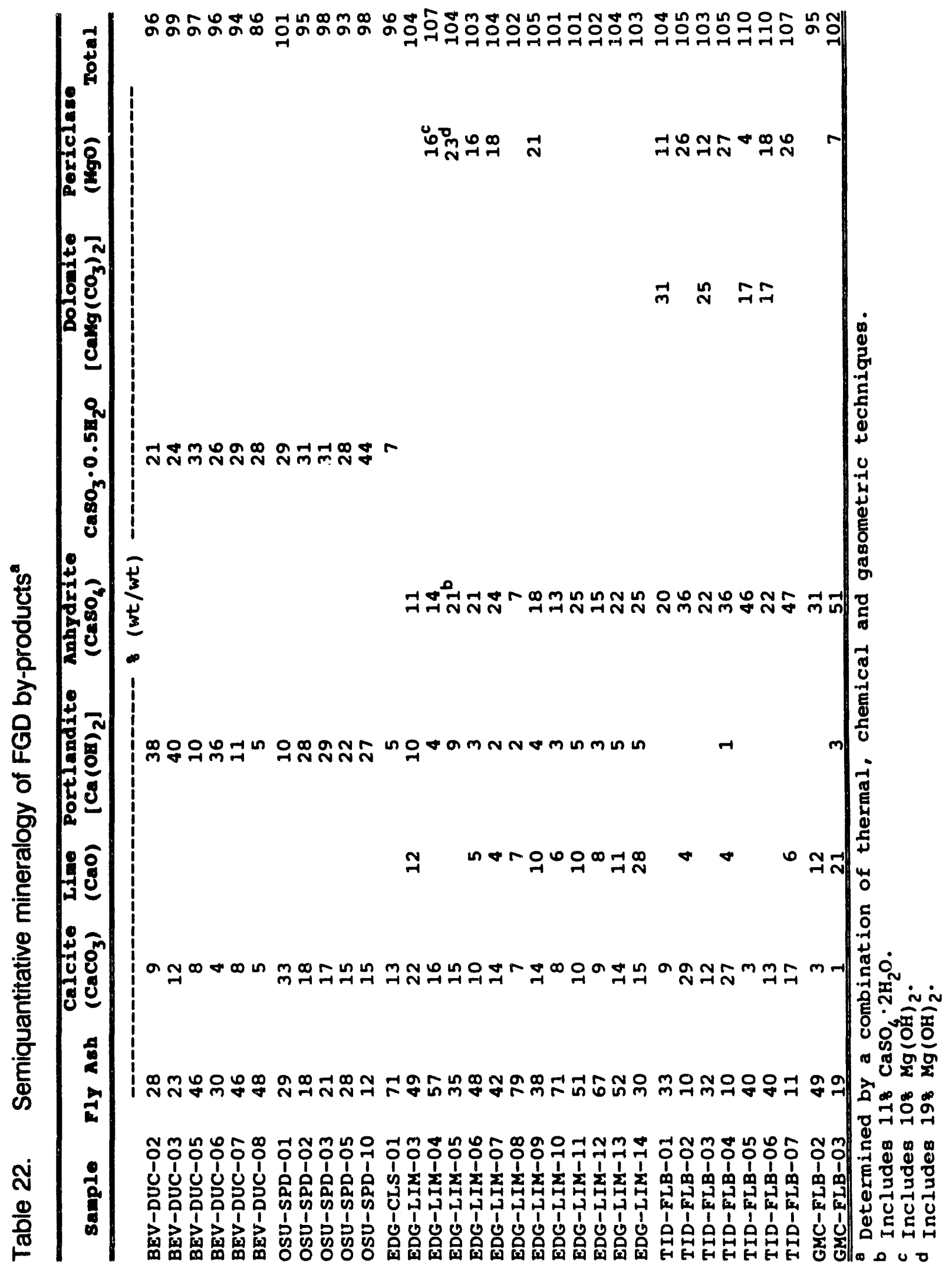




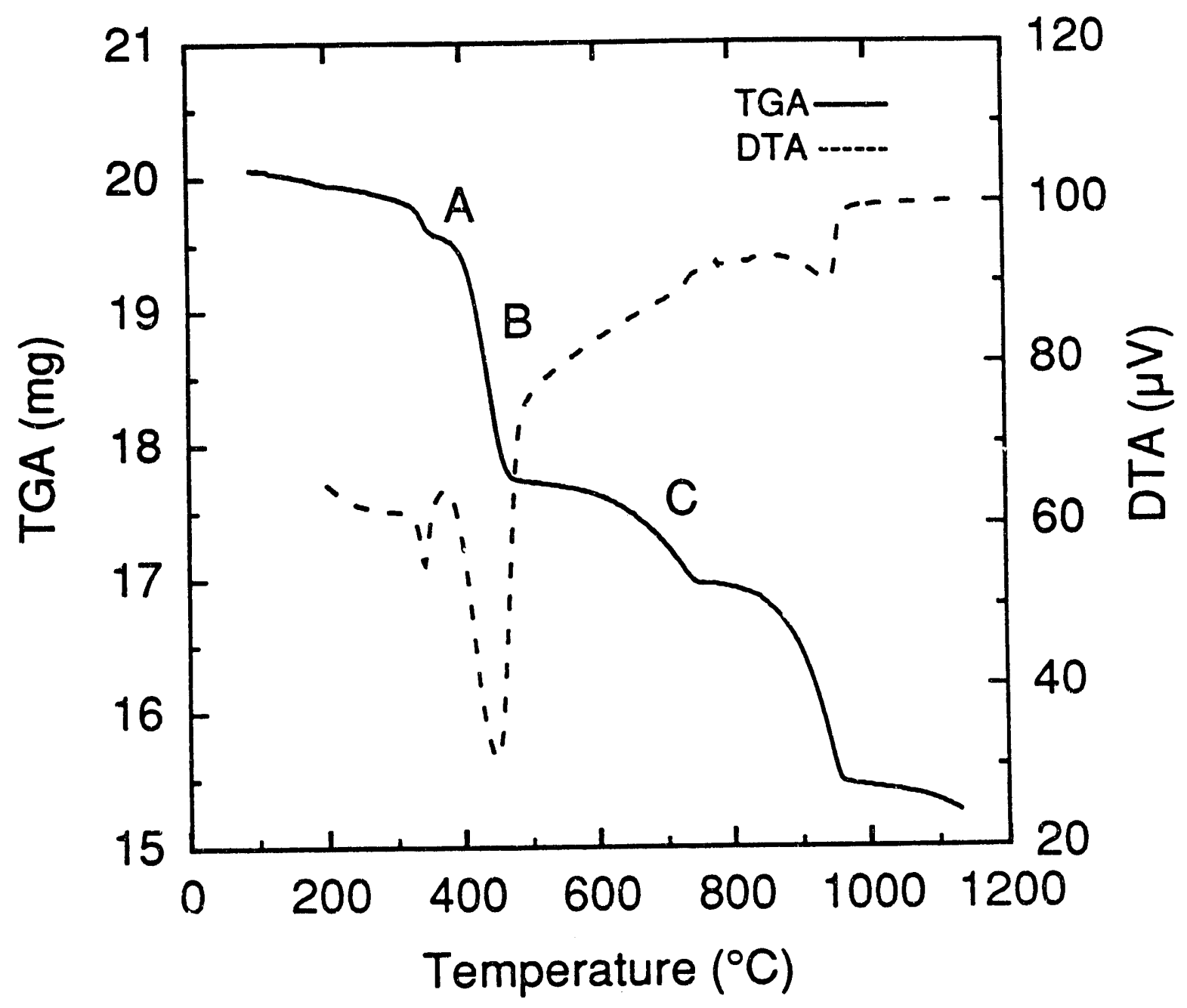

\begin{tabular}{|c|c|c|}
\hline $\begin{array}{c}\text { TGA } \\
\text { Event }\end{array}$ & Reaction & $\begin{array}{c}\text { DTA } \\
\text { Peak }\left({ }^{\circ} \mathrm{C}\right)\end{array}$ \\
\hline $\mathrm{A}$ & $\mathrm{CaSO} 3 \cdot 0.5 \mathrm{H} 2 \mathrm{O} \rightarrow \mathrm{CaSO} 3+0.5 \mathrm{H}_{2} \mathrm{O}$ & 344 \\
\hline $\mathrm{B}$ & $\mathrm{Ca}(\mathrm{OH}) 2 \rightarrow \mathrm{CaO}+\mathrm{H}_{2} \mathrm{O}$ & 448 \\
\hline $\mathrm{C}$ & $\mathrm{CaCO} 3 \rightarrow \mathrm{CaO}+\mathrm{CO}_{2}$ & 738 \\
\hline
\end{tabular}

Fig. 29. Representative thermograms for Beverly Duct Injection samples. 
Phase 1 Report

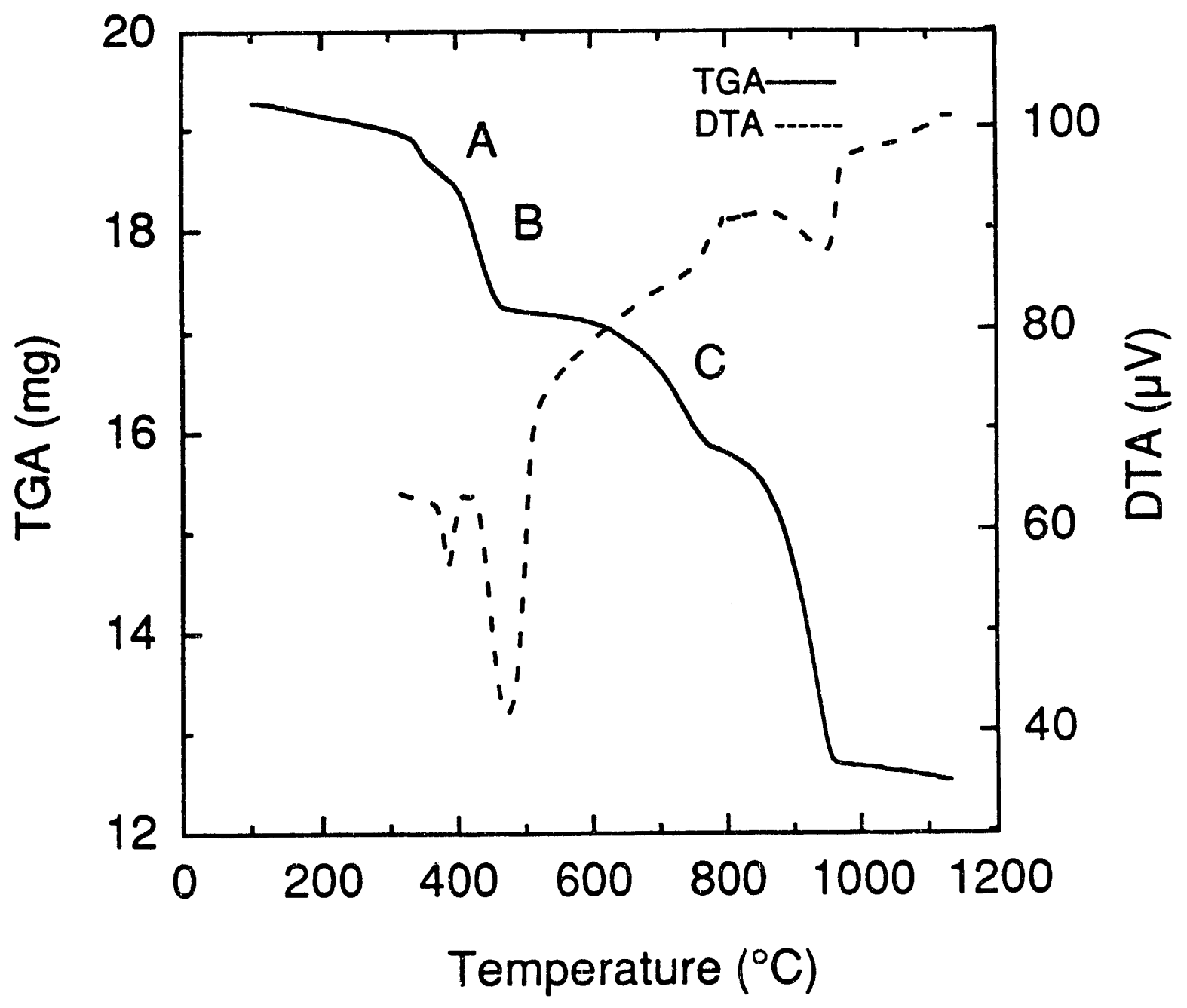

\begin{tabular}{|c|c|c|}
\hline $\begin{array}{c}\text { TGA } \\
\text { Event }\end{array}$ & Reaction & $\begin{array}{c}\text { DTA } \\
\text { Peak }\left({ }^{\circ} \text { C) }\right.\end{array}$ \\
\hline $\mathrm{A}$ & $\mathrm{CaSO}_{3} \cdot 0.5 \mathrm{H} 2 \mathrm{O} \rightarrow \mathrm{CaSO}_{3}+0.5 \mathrm{H}_{2} \mathrm{O}$ & 349 \\
\hline $\mathrm{B}$ & $\mathrm{Ca}(\mathrm{OH})_{2} \rightarrow \mathrm{CaO}+\mathrm{H}_{2} \mathrm{O}$ & 438 \\
\hline $\mathrm{C}$ & $\mathrm{CaCO} 3 \rightarrow \mathrm{CaO}+\mathrm{CO}_{2}$ & 738 \\
\hline \multicolumn{2}{|c}{} \\
\hline
\end{tabular}

Fig. 30. Representative thermoarams for Ohio State Spray Dryer samples. 
Phase 1 Report

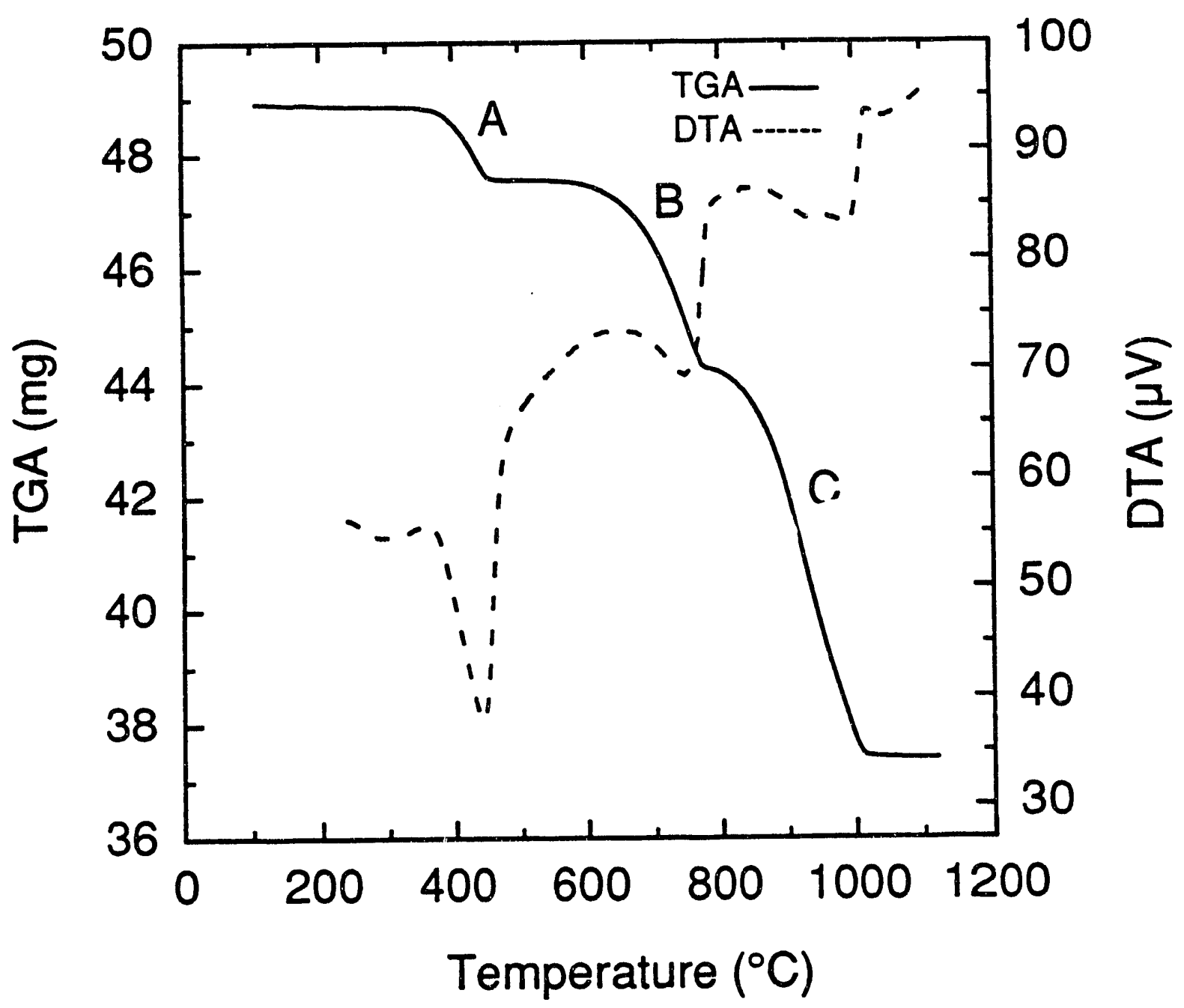

\begin{tabular}{|c|c|c|}
\hline $\begin{array}{c}\text { TGA } \\
\text { Event }\end{array}$ & Reaction & $\begin{array}{c}\text { DTA } \\
\text { Peak ( } \mathrm{C} \text { C) }\end{array}$ \\
\hline $\mathrm{A}$ & $\mathrm{Ca}(\mathrm{OH}) 2 \rightarrow \mathrm{CaO}+\mathrm{H}_{2} \mathrm{O}$ & 408 \\
\hline $\mathrm{B}$ & $\mathrm{CaCO} 3 \rightarrow \mathrm{CaO}+\mathrm{CO}_{2}$ & 708 \\
\hline $\mathrm{C}$ & $\mathrm{CaSO} 4 \rightarrow \mathrm{CaO}+\mathrm{SO}_{3}$ & 953 \\
\hline
\end{tabular}

Fig. 31. Representative thermograms for Edgewater LIMB samples. 


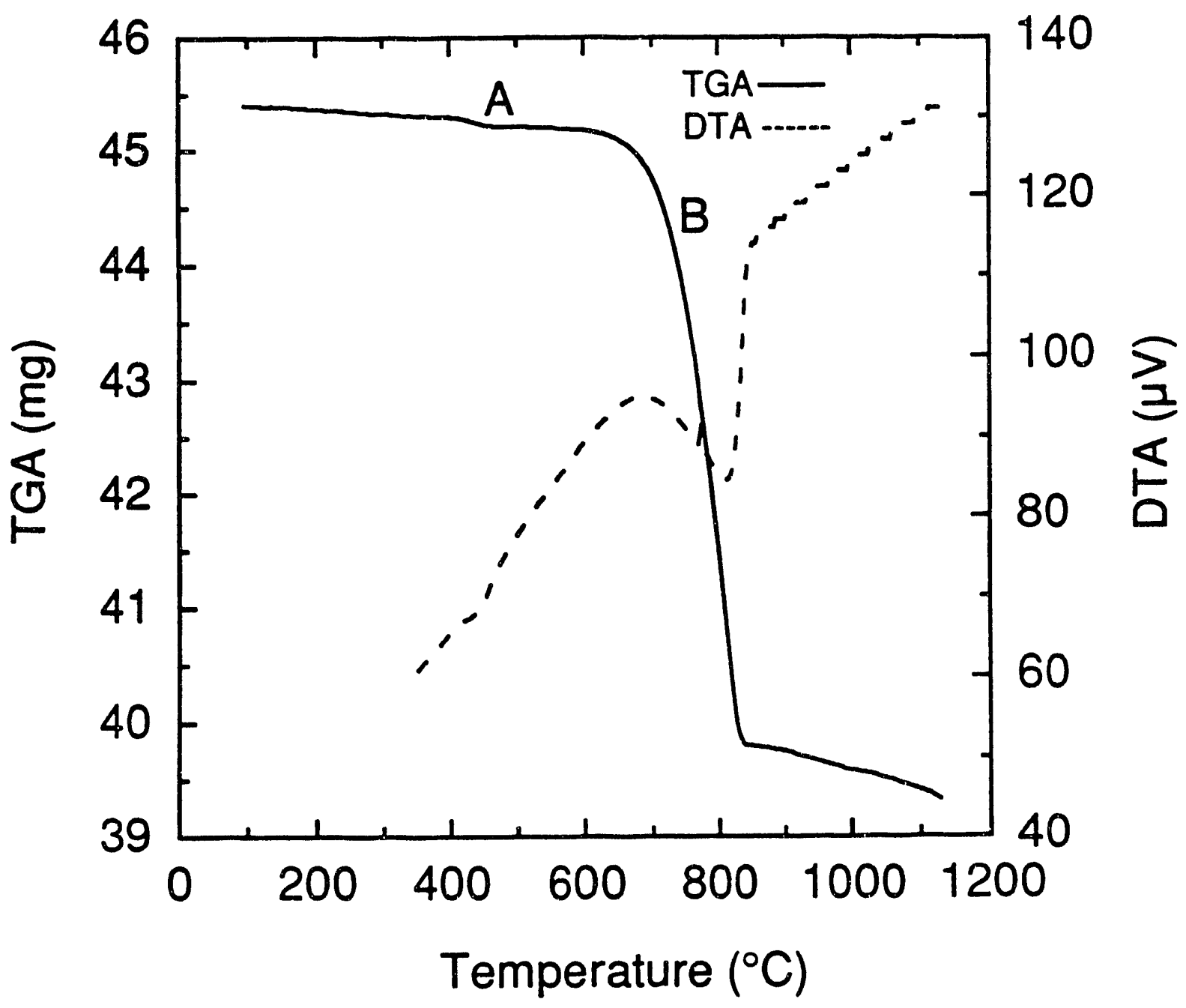

\begin{tabular}{|c|c|c|}
\hline $\begin{array}{l}\text { TGA } \\
\text { Event }\end{array}$ & Reaction & $\begin{array}{l}\text { DTA } \\
\text { Peak }\left({ }^{\circ} \mathrm{C}\right)\end{array}$ \\
\hline 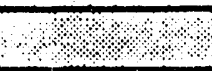 & ৩৭. & \\
\hline 1. & $\mathrm{Ca}(\mathrm{OH}) 2 \div \mathrm{CaO}+\mathrm{H} 2 \mathrm{O}$ & 443 \\
\hline 1.1.1. & (1). & 21.181 .8 \\
\hline ?. & $\mathrm{CaCO} 3 \rightarrow \mathrm{OaO}+\mathrm{CO}_{2}$ & .814 \\
\hline
\end{tabular}

Fig. 32. Representative thermograms for Tidd PFBC Bed Ash samples. 
Phase 1 Report

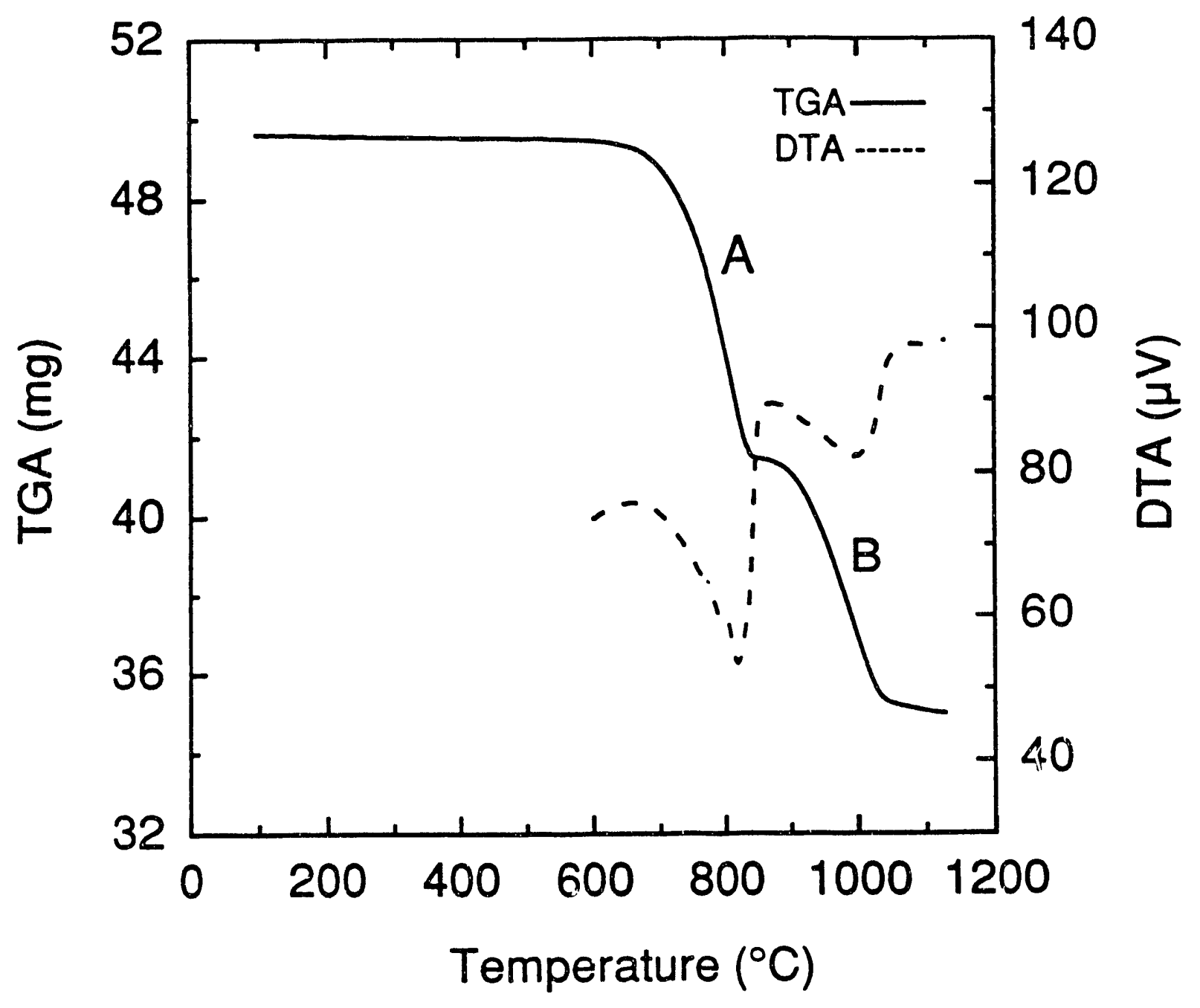

\begin{tabular}{|c|c|c|}
\hline $\begin{array}{l}\text { TGA } \\
\text { Event }\end{array}$ & Reaction & Peak $(0)$ \\
\hline ?.? & ? & \\
\hline$\because A$ & $\mathrm{MgCa}\left(\mathrm{CO}_{3}\right)_{2} \rightarrow \mathrm{MgO}+\mathrm{CaO}+2 \mathrm{CO}_{2}$ & 822 \\
\hline 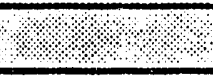 & 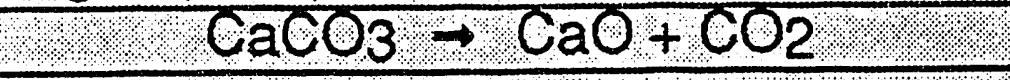 & 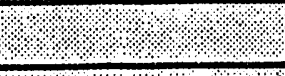 \\
\hline 18.8 .8$. & धा: & 12 \\
\hline B & $\because \because \mathrm{CaSO}_{4} \rightarrow \mathrm{CaO}+\mathrm{SO}_{3}$ & 7996 \\
\hline
\end{tabular}

Fig. 33. Representative thermograms for Tidd PFBC Cyclone Ash samples. 

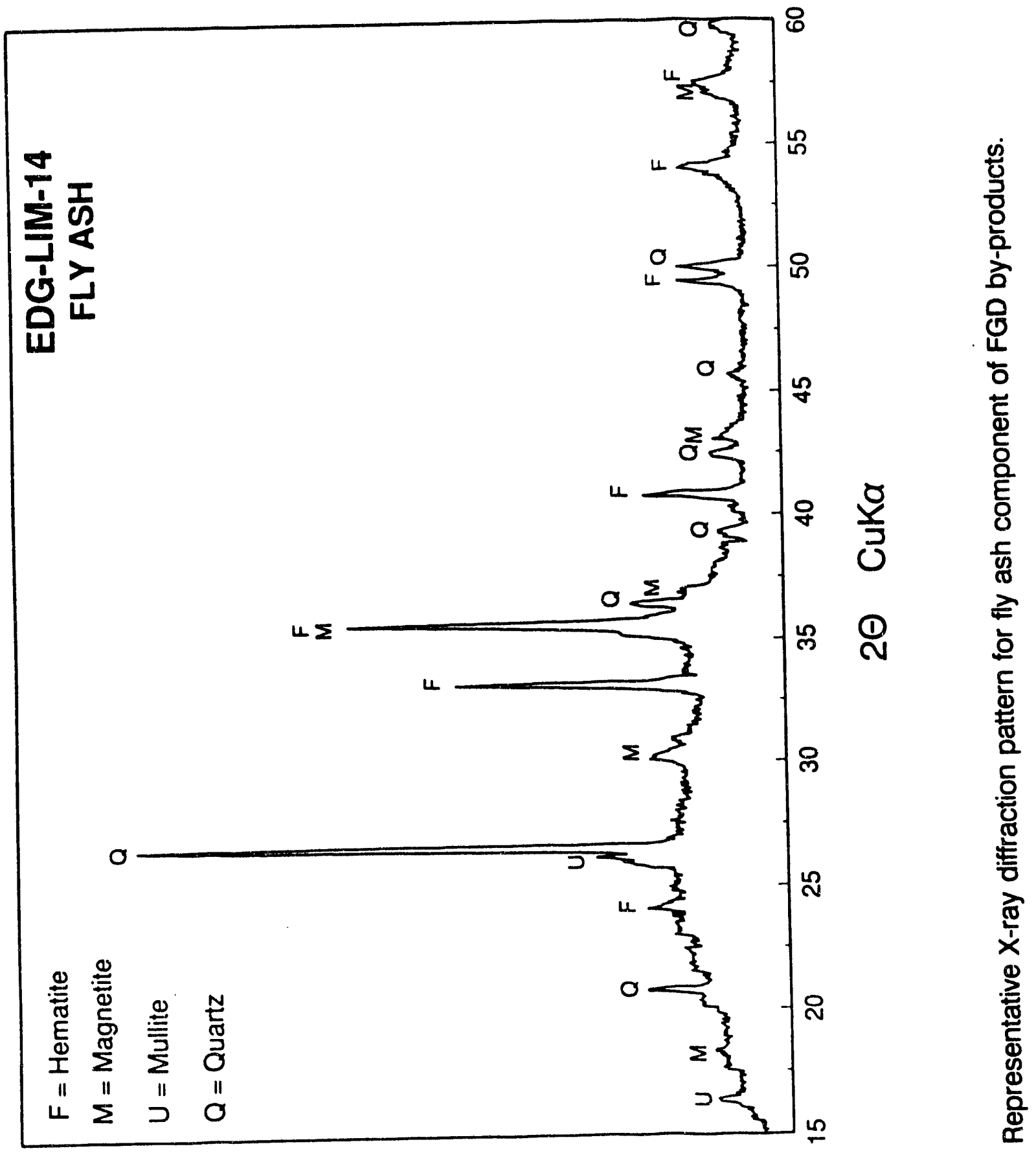

में

엄 
Phase 1 Report

\subsubsection{Physical Characterization}

Particle size analysis indicated that all fly ash materials were very fine with those from the duct injection, spray dryer and lime injection process having in excess of $80 \%$ by weight finer than $0.025 \mathrm{~mm}$ effective diameter (Table 23). The fly ash particles from the fluidized bed process were somewhat coarser as compared with the other processes. Bed ash materials were, as expected, very coarse averaging $1.4 \%$ by weight finer than $0.25 \mathrm{~mm}$ effective diameter (Table 23$)$. Uniformity coefficients $\left(\mathbf{C}_{u}\right.$, section 2.1.2.3.1) less than approximately 2 are indicative of very uniform particle size distributions. As such, FGD particles from all processes with the exception of the fluidized bed fly ash were quite uniform. The fluidized bed fly ash, on the other hand, contained a wide range of particle sizes.

Particle densities from the spray dryer, lime injection, and fluidized bed fly ash were similar ranging from 2.5 to $2.7 \mathrm{~g} \mathrm{~cm}^{-3}$, while those from the duct injection process were somewhat less and the bed ash from the fluidized bed process had somewhat greater particle densities (Table 24). Specific surface areas corresponded with particle size data with the duct injection, spray dryer and lime injection processes having larger surface areas (Table 24). The surface area of the fluidized bed fly ash was intermediate and the bed ash was low corresponding to the large size of these particles.

After compaction at 25 psi, bulk densities of the FGD materials from the duct injection, spray dryer and lime injection processes were surprisingly low, having values less than $1.0 \mathrm{~g} \mathrm{~cm}^{-3}\left(62.4 \mathrm{lbs} / \mathrm{ft}^{3}\right)$ (Table 25). The fluidized bed process produced identical bulk densities regardless of whether the source was bed or fly ash, and these were significantly higher $\left(1.3 \mathrm{~g} \mathrm{~cm}^{-3}\right)$ as compared with the other processes.

Table 26 presents experimental variables required as inputs for fitting the Van Genuchten equation (section 2.1.2.3.5) to the water retention data. Table 27 gives the values of the fitted variables $(\alpha$ and $n$ ) and the $r$ value indicating the goodness of fit. In general, the Van Genuchten equation provided an excellent description of the water retention data with mean $r$ values exceeding 0.97. Again, the bed ash showed expected deviation in its water retention properties as compared with the other materials. The bed ash had a low saturated water content, a high $\alpha$ value and a low $n$ value. The high mean $\alpha$ value (and exceedingly large S.D.) for the spray dryer process was the result of the OSU-SPD-01 sample. If this sample was eliminated, the resulting mean $\alpha$ value for this process was $3.01 \mathrm{MPa}^{-1}$, a value much closer to thie other fly ash samples.

The saturated hydraulic conductivities were lognormally distributed and therefore $a \log _{10}$ transform was applied to the results for a given sample prior to further analysis (Table 28). Initial hydraulic conductivity values roughly corresponded with the particle size results where the bed ash exhibited much higher conductivities as compared with samples from the other processes. Also, within the duct injection, spray dryer and lime injection groupings, the finer lime injection material had the lowest hydraulic conductivity. The low values for the fluidized bed fly ash did not 
correspond with this material's intermediate particle size. This, however, is explained by the high bulk density for this material as compared with the other fly ash samples. All FGD samples exhibited a decrease in hydraulic conductivity after aging for 7 days. This is explained by the cementation that occurred in these samples over time.

Five individual FGD samples were selected for a more detailed examination. These samples were BEV-DUC-02, EDG-LIM-14, OSU-SPD-03, TID-FLB-03 and TID FLB-04. The results from these samples as well as the S.D. from within sample replication are given in Figs. 35 to 43 . The results from these individual samples corresponded to those observed for the means for the respective processes. 
Table 23. Mean percent finer than $0.025 \mathrm{~mm}$ (except where noted) and uniformity coefficients for the dry FGD materials grouped by process.

\begin{tabular}{lcccc}
\hline Sample Grouping & $\begin{array}{c}\text { Percent } \\
\text { Finer }\end{array}$ & S.D. & $\begin{array}{c}\text { Uniformity } \\
\text { Coefficient }\end{array}$ & S.D. \\
\hline Duct Injection & 81.7 & 2.3 & 1.80 & 0.14 \\
Spray Dryer & 83.2 & 5.1 & 1.83 & 0.20 \\
$\begin{array}{l}\text { Lime Injection } \\
\text { Fluidized Bedd }\end{array}$ & 90.7 & 11.5 & 2.38 & 0.58 \\
$\begin{array}{c}\text { Bed Ash } \\
\text { Fluidized Bed } \\
\text { Fly Ash }\end{array}$ & $1.36^{\dagger}$ & 0.73 & 1.97 & 0.27 \\
\end{tabular}

EDG-CLS-01, BEV-DUC-02, 03, 05, 06, 07

b OSU-SPD-01, 02, 03, 05

D TID-FLB-02, 04, 07

c EDG-LIM-03 to 14

- TID-FLB-01, 03, 06

percent finer than $0.25 \mathrm{~mm}$

Table 24. Mean particle density and specific surface area for the dry FGD materials grouped by process.

\begin{tabular}{lcccc}
\hline Sample Grouping & $\begin{array}{c}\text { Particle } \\
\text { Density }\end{array}$ & S.D. & $\begin{array}{l}\text { Specific } \\
\text { Surface Area }\end{array}$ & S.D. \\
\hline & $9 \mathrm{~cm}^{-3}$ & & $\mathrm{~m}^{2} \mathrm{~g}^{-1}$ & \\
Duct Injection & 2.41 & 0.04 & 9.34 & 4.44 \\
$\begin{array}{c}\text { Spray Dryer } \\
\begin{array}{l}\text { Lime Injection } \\
\text { Fluidized Bed }\end{array}\end{array}$ & 2.51 & 0.11 & 9.49 & 3.82 \\
$\begin{array}{r}\text { Bed Ash } \\
\text { Fluidized Bed } \\
\text { Fly Ash }\end{array}$ & 2.65 & 0.21 & 7.48 & 2.33 \\
\hline
\end{tabular}

EDG-CLS-01, BEV-DUC-02, 03, 05, 06, 07, 08

b BAB-LID-01 to 03, HST-SPD-01 to 05, NSP-SPD-01, OSU-SPD-01, 02, 03,05

c EDG-IIM-03 to 14

d GMC-FLB-01, QST-FLB-03, TID-FLB-02, 04, 07, TVA-FLB-03

e GMC-FLB-02, PED-RCB-01; QST-FLB-01, 02, STA-FLB-01, TID-FLB-01, 03, 06, TVA-FLB-01, 02

$f$ excluding GMC-FLB-O1 and QST-FLB-03 
Table 25. Mean compression index and bulk density for the dry FGD materials grouped by process.

\begin{tabular}{lllcl}
\hline Sample Grouping & $\begin{array}{l}\text { Compression } \\
\text { Index }\end{array}$ & S.D. & Bulk Density & S.D. \\
\hline & & g cm $^{-3}$ & \\
Duct Injection" & 0.047 & 0.006 & 0.79 & 0.07 \\
$\begin{array}{c}\text { Spray Dryer } \\
\text { Iime Injectionc }\end{array}$ & 0.030 & 0.009 & 0.63 & 0.02 \\
$\begin{array}{c}\text { Fluidized Bed } \\
\text { Bed Ash }\end{array}$ & 0.039 & 0.010 & 0.91 & 0.08 \\
$\begin{array}{c}\text { Fluidized Bed } \\
\text { Fly Ash }\end{array}$ & 0.026 & 0.001 & 1.29 & 0.06 \\
\hline
\end{tabular}

EDG-CLS-01, BEV-DUC-02, 03, 05, 06, 07

TID-FLB-02, 04, 07

OSU-SPD-01, 02, 03, 05

- TID-FLB-01, 03, 06

C EDG-LIM-03 to 14

Table 26. Mean saturated and residual water contents for the Dry FGD materials grouped by process.

\begin{tabular}{llccc}
\hline Sample Grouping & $\begin{array}{c}\text { Saturated } \\
\text { Water Content }\end{array}$ & S.D. & $\begin{array}{c}\text { Residual } \\
\text { Water Content }\end{array}$ & S.D. \\
\hline & $\mathrm{m}^{3} \mathrm{~m}^{-3}$ & & $\mathrm{~m}^{3} \mathrm{~m}^{-3}$ & \\
Duct Injection & 0.59 & 0.17 & 0.14 & 0.07 \\
Spray Dryer & 0.79 & 0.05 & 0.20 & 0.08 \\
$\begin{array}{l}\text { Lime Injectionc } \\
\begin{array}{c}\text { Fluidized Bedd } \\
\text { Bed Ash }\end{array}\end{array}$ & 0.68 & 0.08 & 0.18 & 0.08 \\
$\begin{array}{c}\text { Fluidized Bede } \\
\text { Fly Ash }\end{array}$ & 0.40 & 0.04 & 0.04 & 0.01 \\
\hline
\end{tabular}

EDG-CLS-01, BEV-DUC-02, 03, 05, 06, 07 d TID-FLB-02, 04, 07
OSU-SPD-01, 02, 03, 05

EDG-IIM-03 to 14 
Table 27. Mean $\alpha, n$, and $r$ values from fitting the Van Genuchten equation to water retention data from the Dry FGD materials grouped by process.

\begin{tabular}{|c|c|c|c|c|c|c|}
\hline Sample Grouping & $\alpha$ & S.D. & $\mathrm{n}$ & S.D. & $\mathbf{r}$ & S.D. \\
\hline & $\mathrm{MPa}^{-1}$ & & & & & \\
\hline Duct Injection" & 2.00 & 0.64 & 2.36 & 0.26 & 0.99 & 0.01 \\
\hline Spray Dryer ${ }^{b}$ & 28.0 & 43.4 & 2.48 & 0.86 & 0.97 & 0.02 \\
\hline Lime Injection ${ }^{c}$ & 2.63 & 0.82 & 3.09 & 0.76 & 0.99 & 0.01 \\
\hline Fluidized Bedd & 85.7 & 78.3 & 1.46 & 0.09 & 0.97 & 0.01 \\
\hline $\begin{array}{c}\text { Fluidized Bede } \\
\text { Fly Ash }\end{array}$ & 2.26 & 0.79 & 2.34 & 0.71 & 0.98 & 0.02 \\
\hline
\end{tabular}

Table 28. Mean $\log _{10}$ saturated hydraulic conductivity from initial testing and after 7 days for the Dry FGD materials grouped by process.

\begin{tabular}{|c|c|c|c|c|}
\hline sample Grouping & $\begin{array}{l}\text { Initial } \\
\text { Conductivity }\end{array}$ & S.D. & $\begin{array}{l}7 \text { Day } \\
\text { Conductivity }\end{array}$ & S.D. \\
\hline & $\log _{10} \mathrm{~cm} \mathrm{~B}^{-1}$ & & $\log _{10} \mathrm{~cm} \mathrm{~s}^{-1}$ & \\
\hline Duct Injection" & -2.88 & 1.68 & -3.53 & 2.01 \\
\hline Spray Dryer ${ }^{b}$ & -2.43 & 1.17 & -3.06 & 1.22 \\
\hline Lime Injection ${ }^{c}$ & -4.15 & 0.26 & -5.43 & 0.46 \\
\hline Fluidized Bedd & -0.50 & 0.66 & -1.15 & 0.39 \\
\hline $\begin{array}{c}\text { Fluidized Bede } \\
\text { Fly Ash }\end{array}$ & -3.68 & 1.15 & -4.15 & 1.66 \\
\hline
\end{tabular}

- EDG-CLS-01, BEV-DUC-02, 03, 05, 06, 07

d TID-FLB-02, 04, 07

b OSU-SPD-01, 02, 03, 05

C TID-FLB-01, 03, 06

c EDG-LIM-03 to 14 


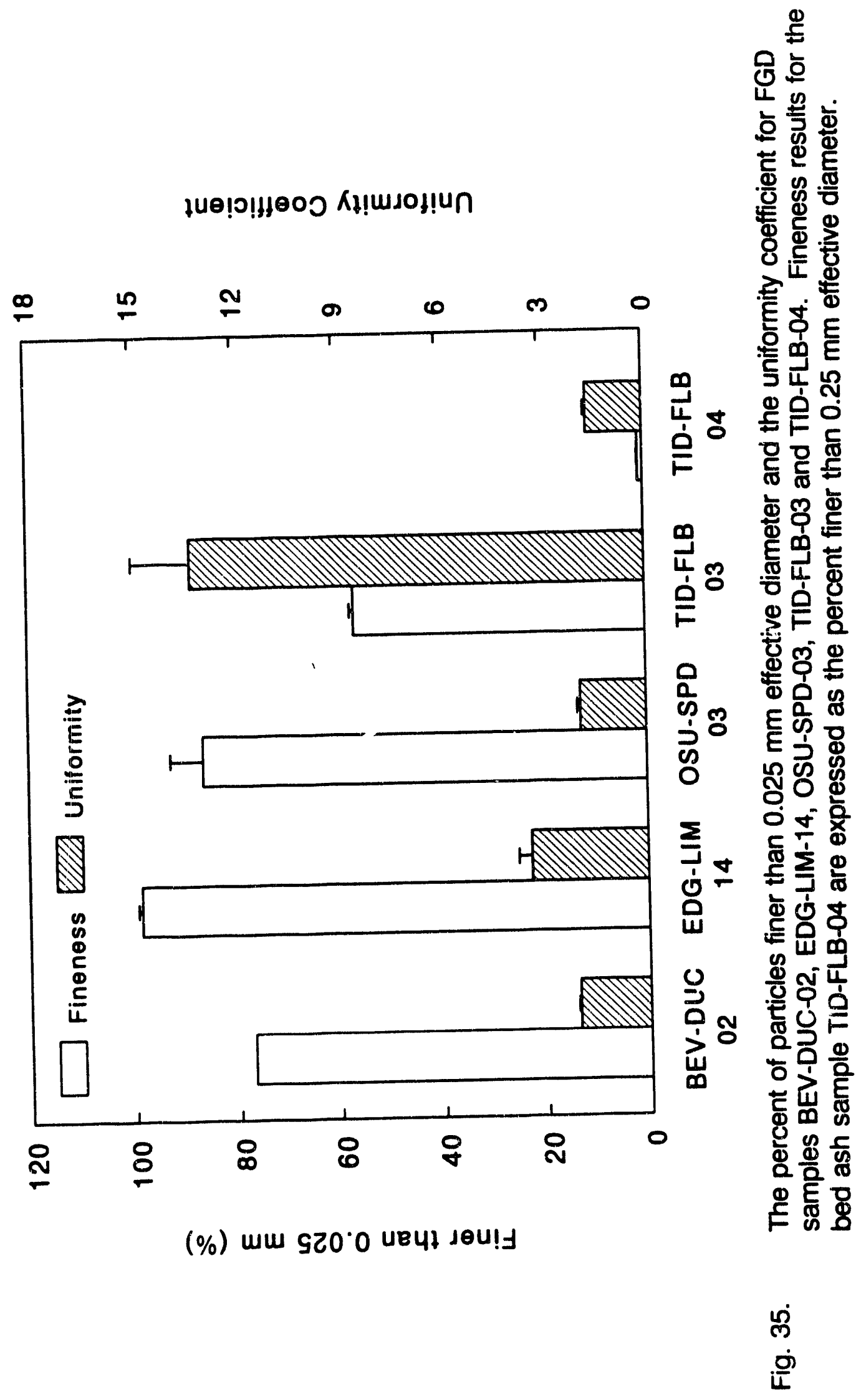




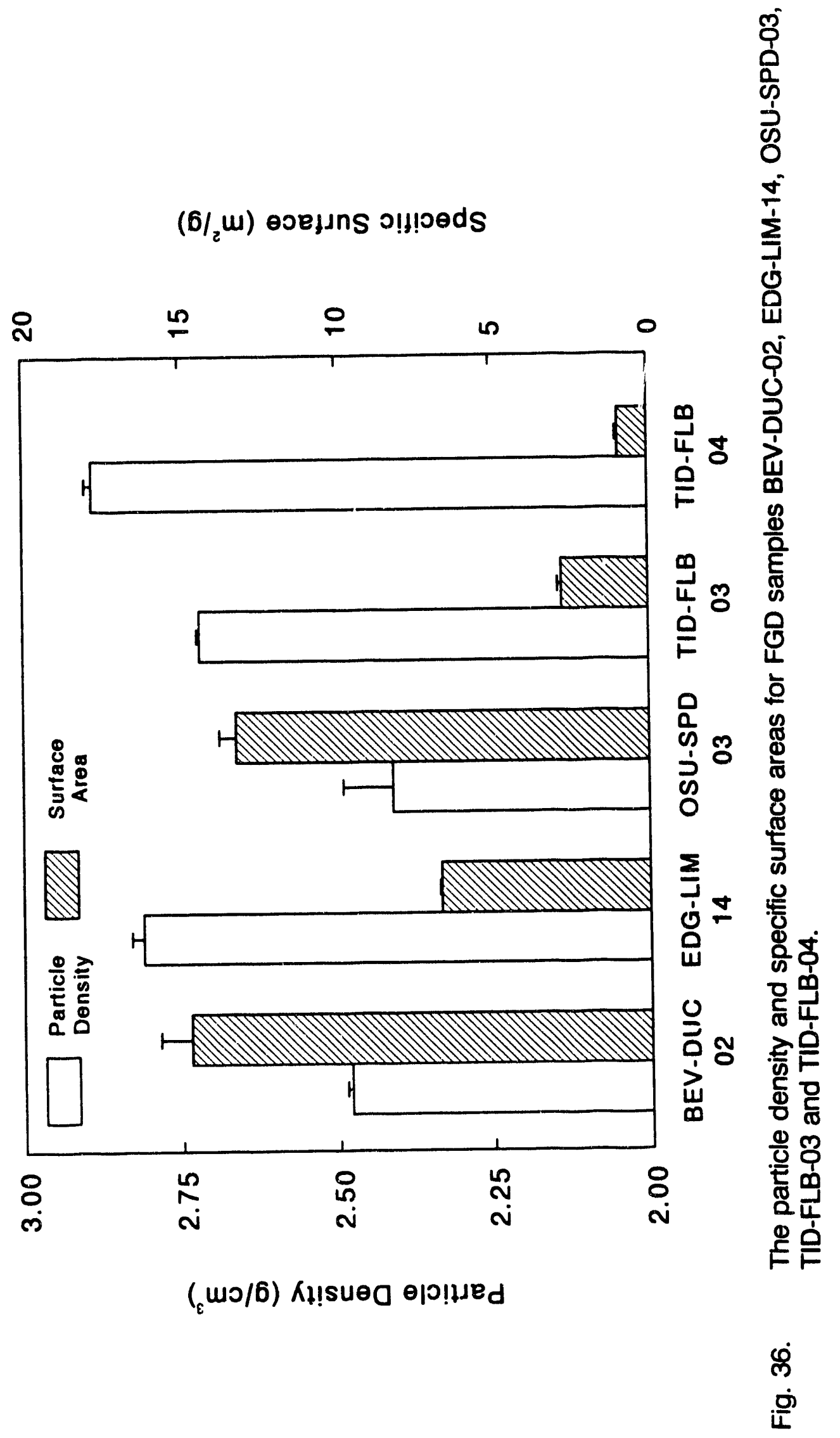




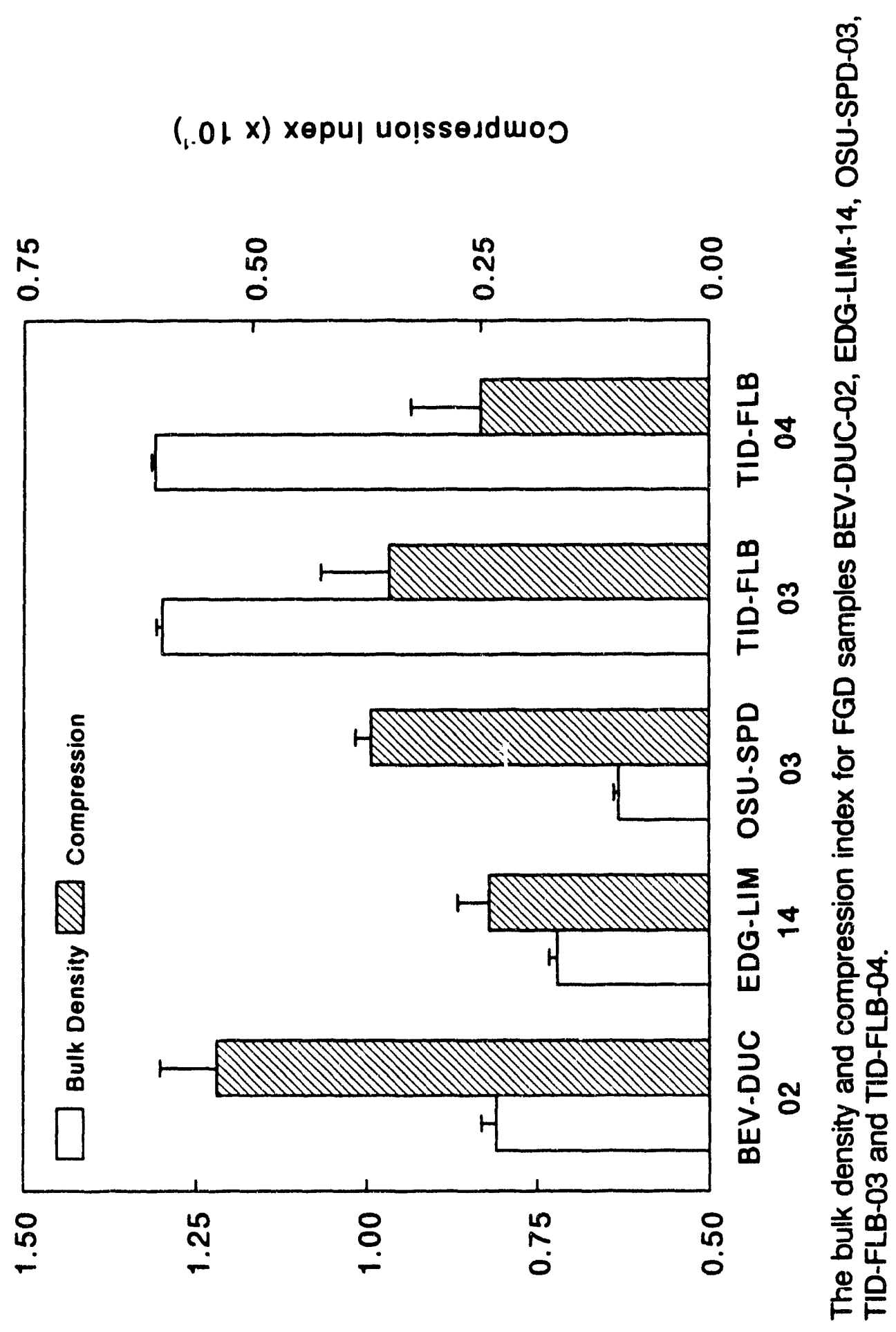

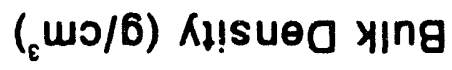



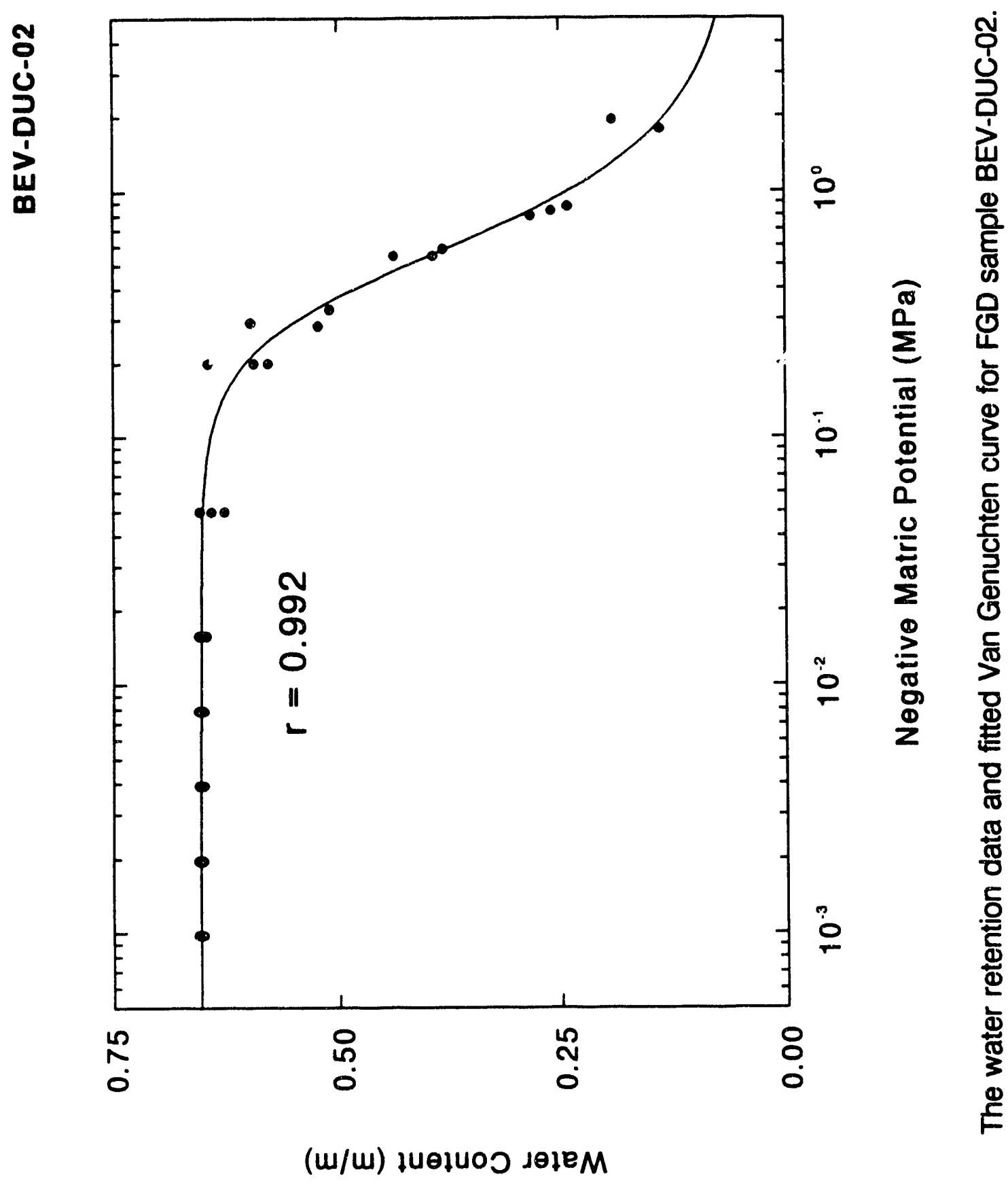

क

iํํ 


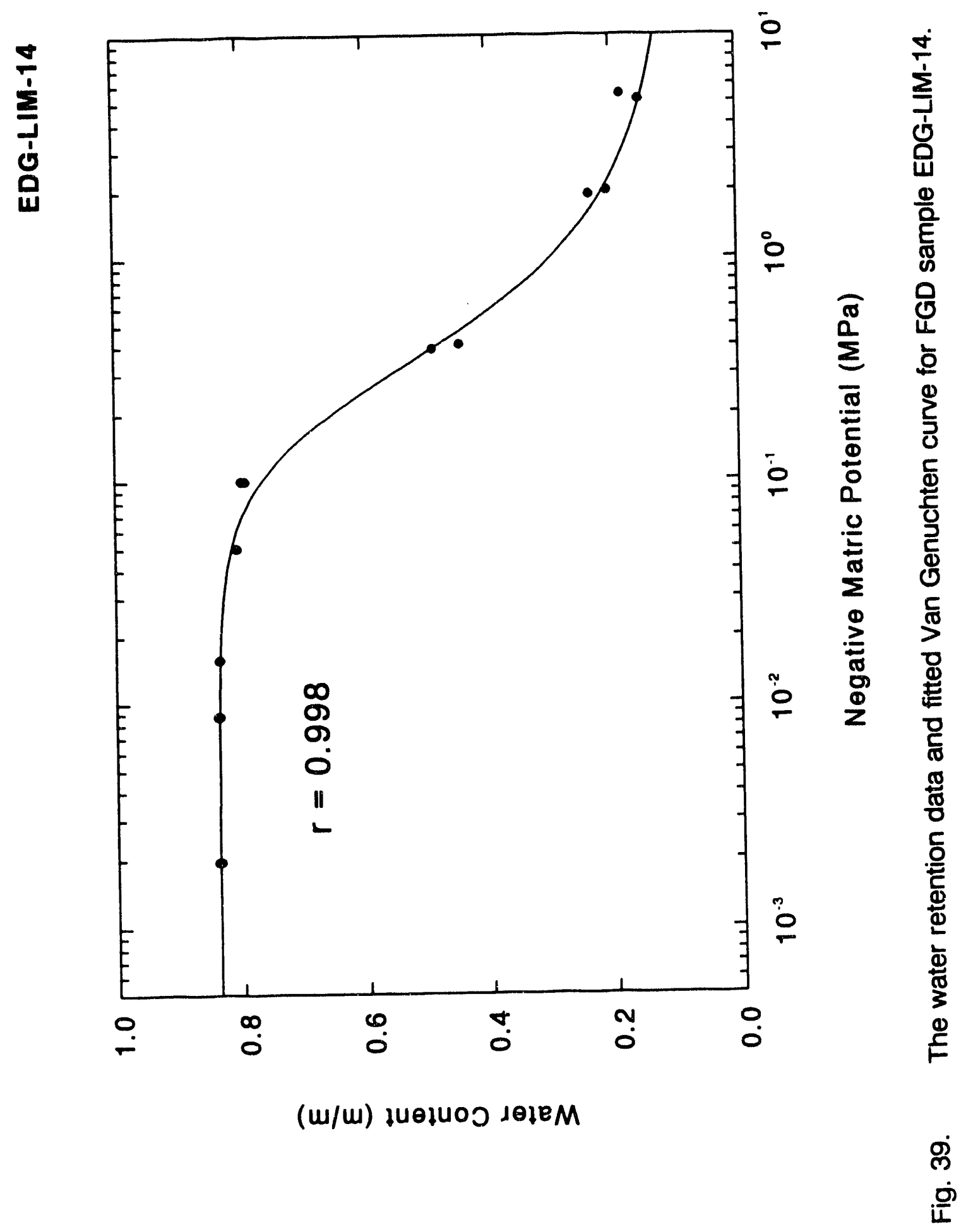




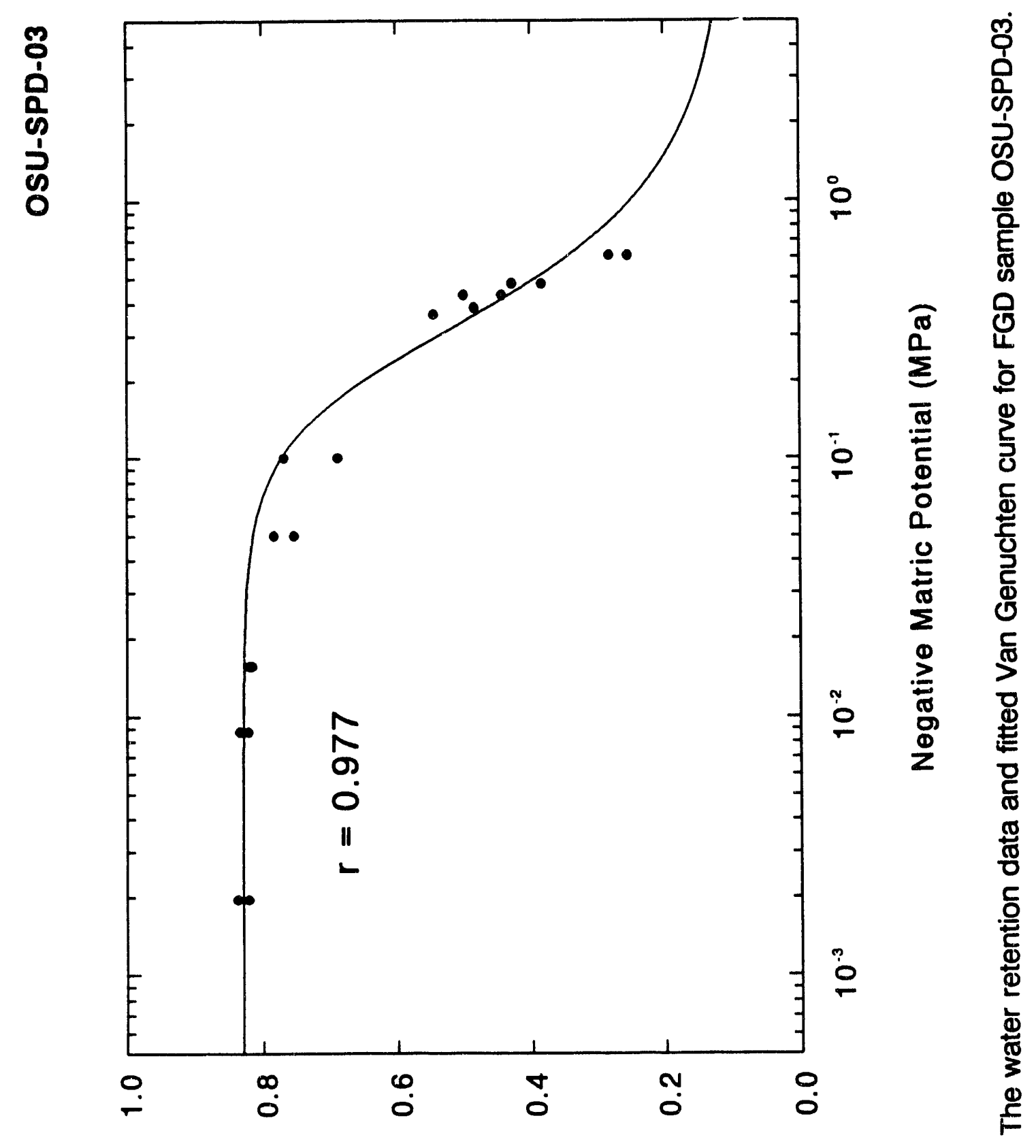

(w/w) juөןuos JөjeM

o

운 


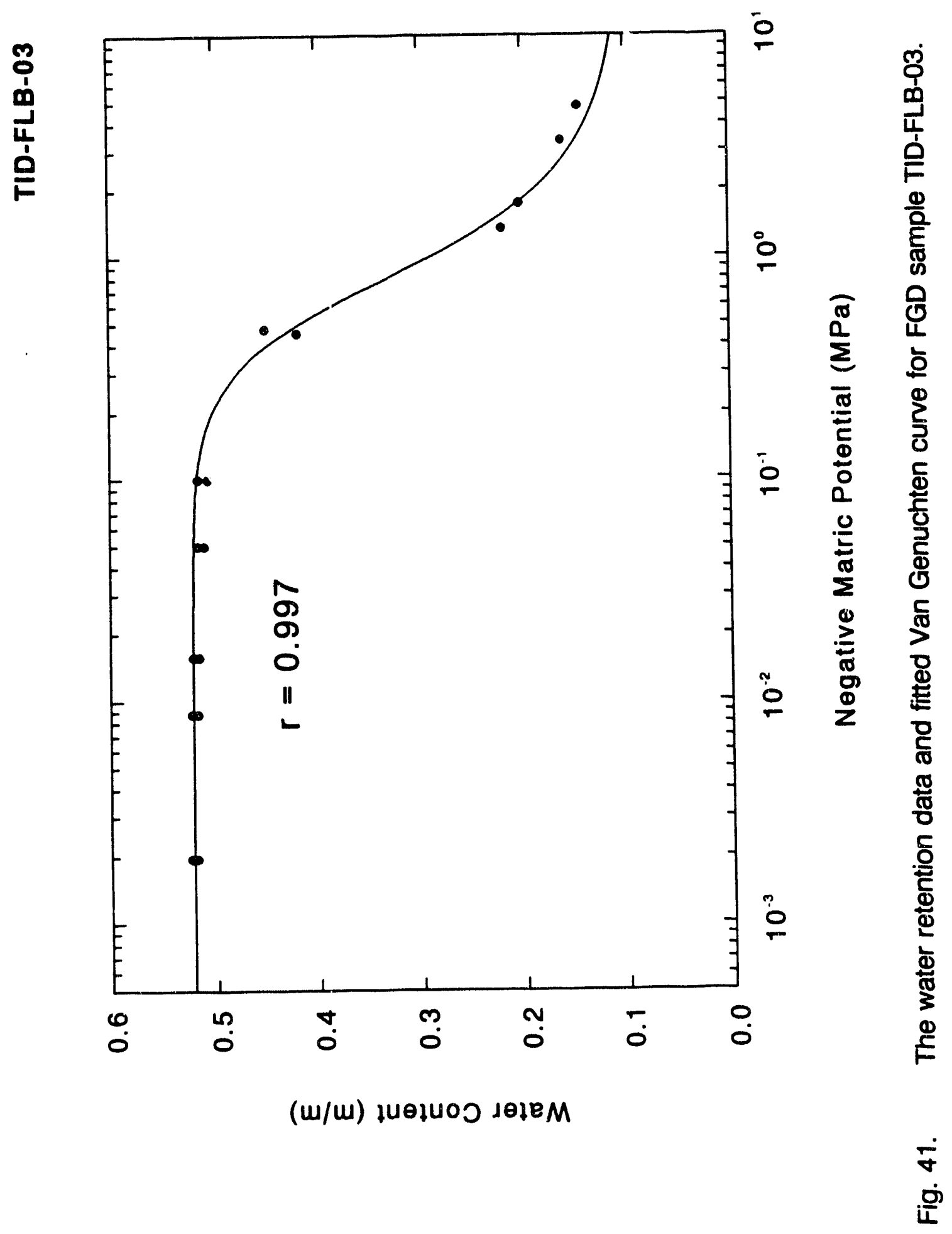




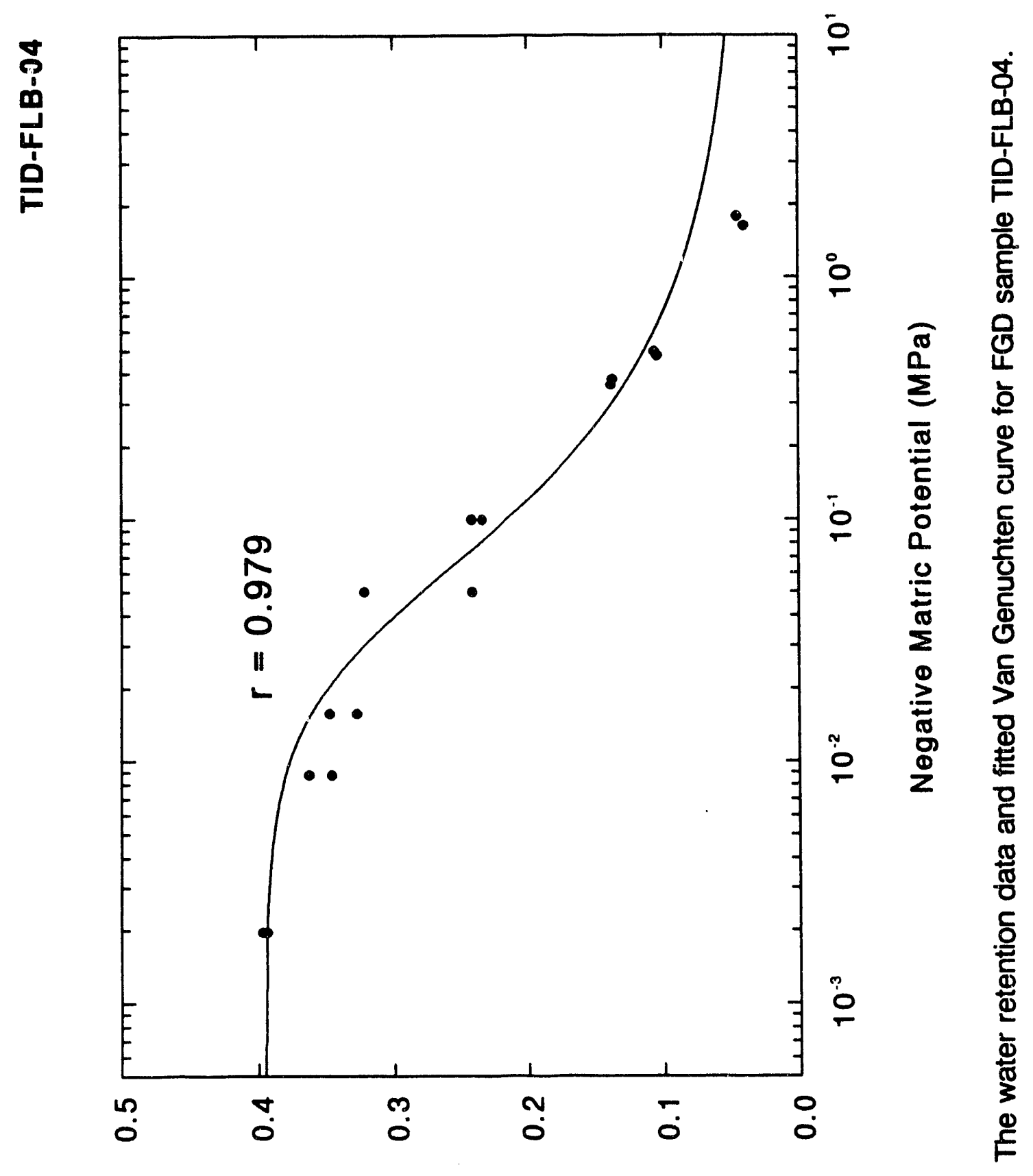

(w/w) fuөןuoj seleM

ஸे
iำ 


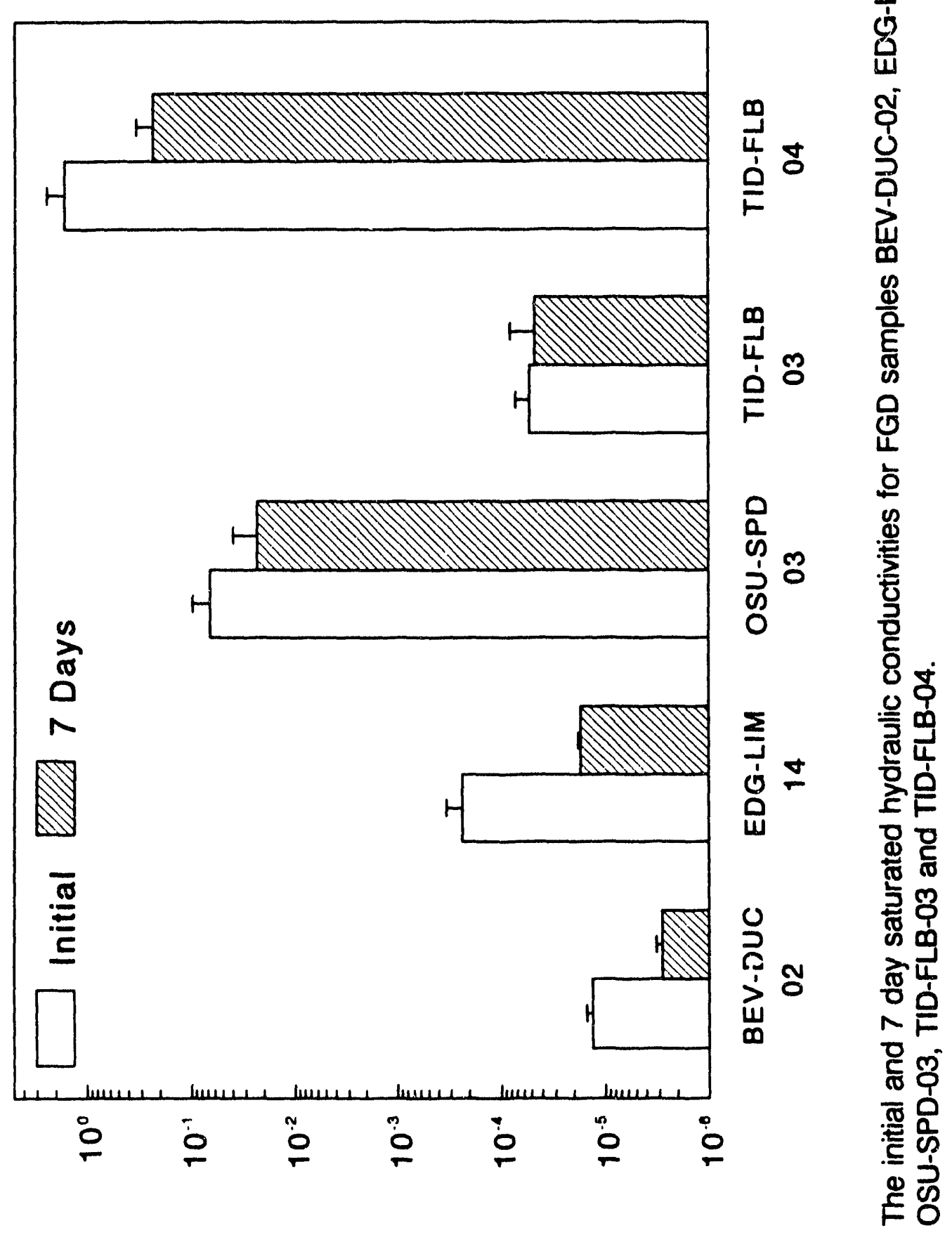

(s/uo) K!!n!!onpuoว ग!!nedp $K_{H}$

ซุ

문 
Phase 1 Report

\subsubsection{Engineering Characterization}

\subsection{Optimum Moisture Content and Density}

The compaction of each FGD sample was performed by applying a specified amount of energy to specified volume of material at a known initial moisture content. The compaction was conducted at several init'al moisture contents for each FGD sample and the final sample density was recorded as a function of moisture content. Moisture content is defined as the ratio of the weight of the water to the weight of the solio's. Figures 44 to 46 show the range of moisture-density curves obtained using the Standard Proctor compaction method. Note that for each material tested, a unique maximum density was identified. This maximum density and the moisture content at which it was achieved are defined as the optimum density and moisture (water) content.

For all FGD samples the moisture-density curve slopes are small (Fig. 44 to 46, Table 29) indicating that the range of moistures over which optimum density can be obtained is fairly broad. Thus the maximum density is not particularly sensitive to slight variations in the water content in the vicinity of optimum. With the exception of TID-FLB samples, all the FGD by-products would be considered light weight materials, i.e. compacted densities lower than those of a typical natural soil. Both these observations have some impact on the suitability of an FGD by-product as a replacement for natural soil in an embankment. The fact that compaction near the optimum can still result in in-place densities close to the maximum value mear.s that taking special care to achieve precisely optimum conditions in the field is probably not necessary. Light weight fills impose smaller loads on the natural soils upon which they are placed, resulting in less settlement in the underlying soils and less likelihood that the loaded soils will fail. 


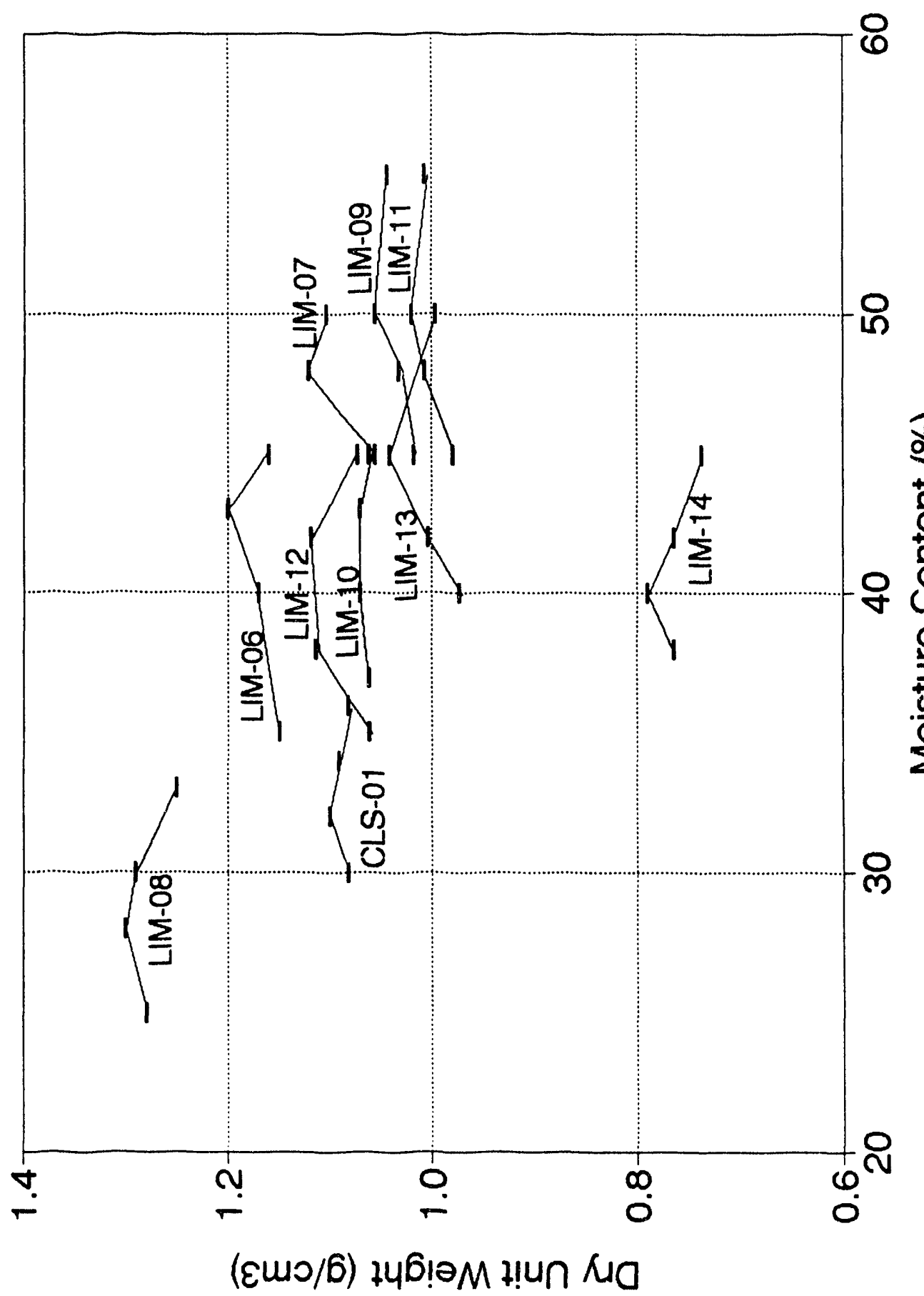

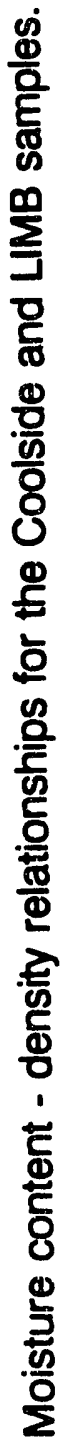

j

한 


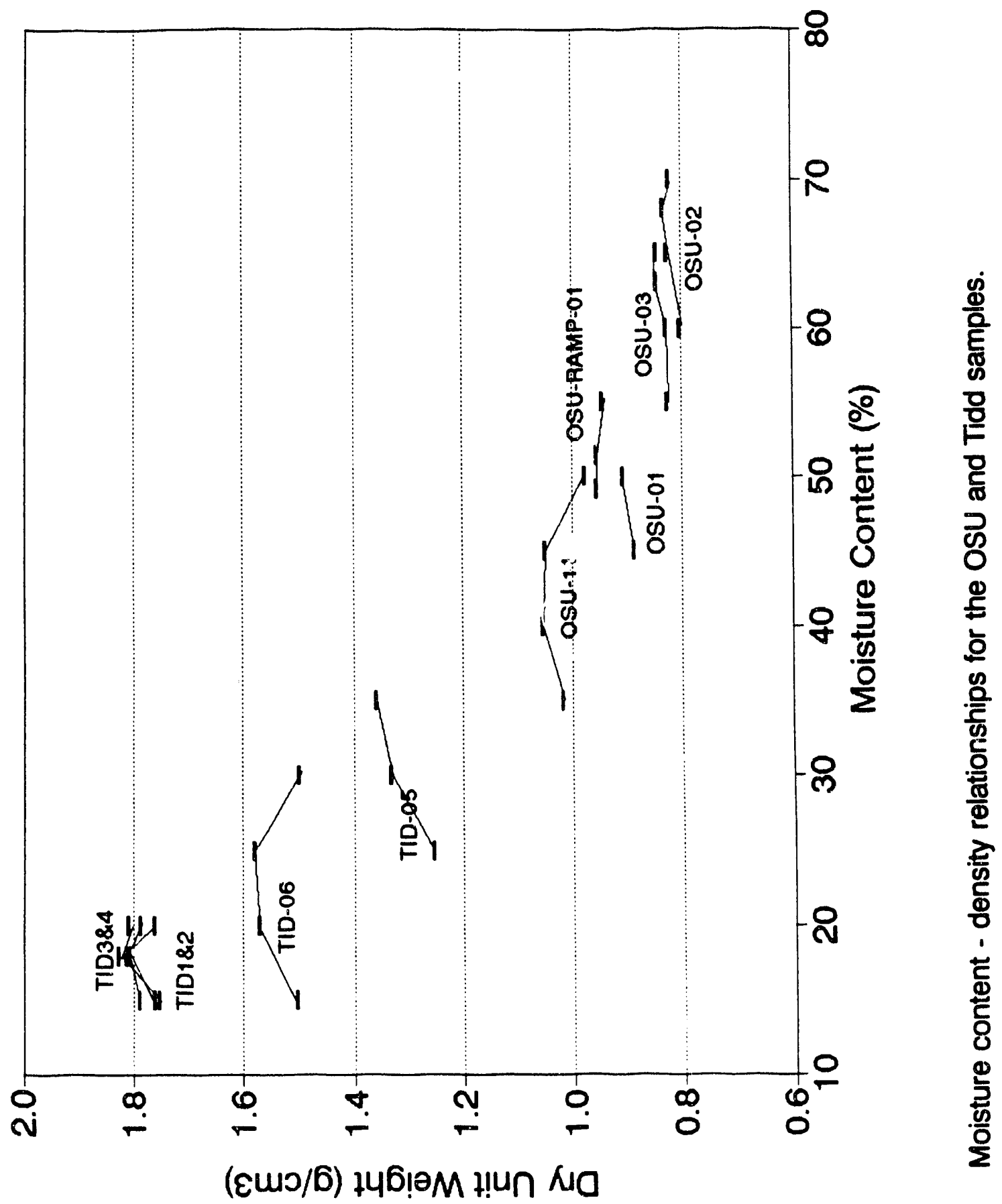

\%

인 


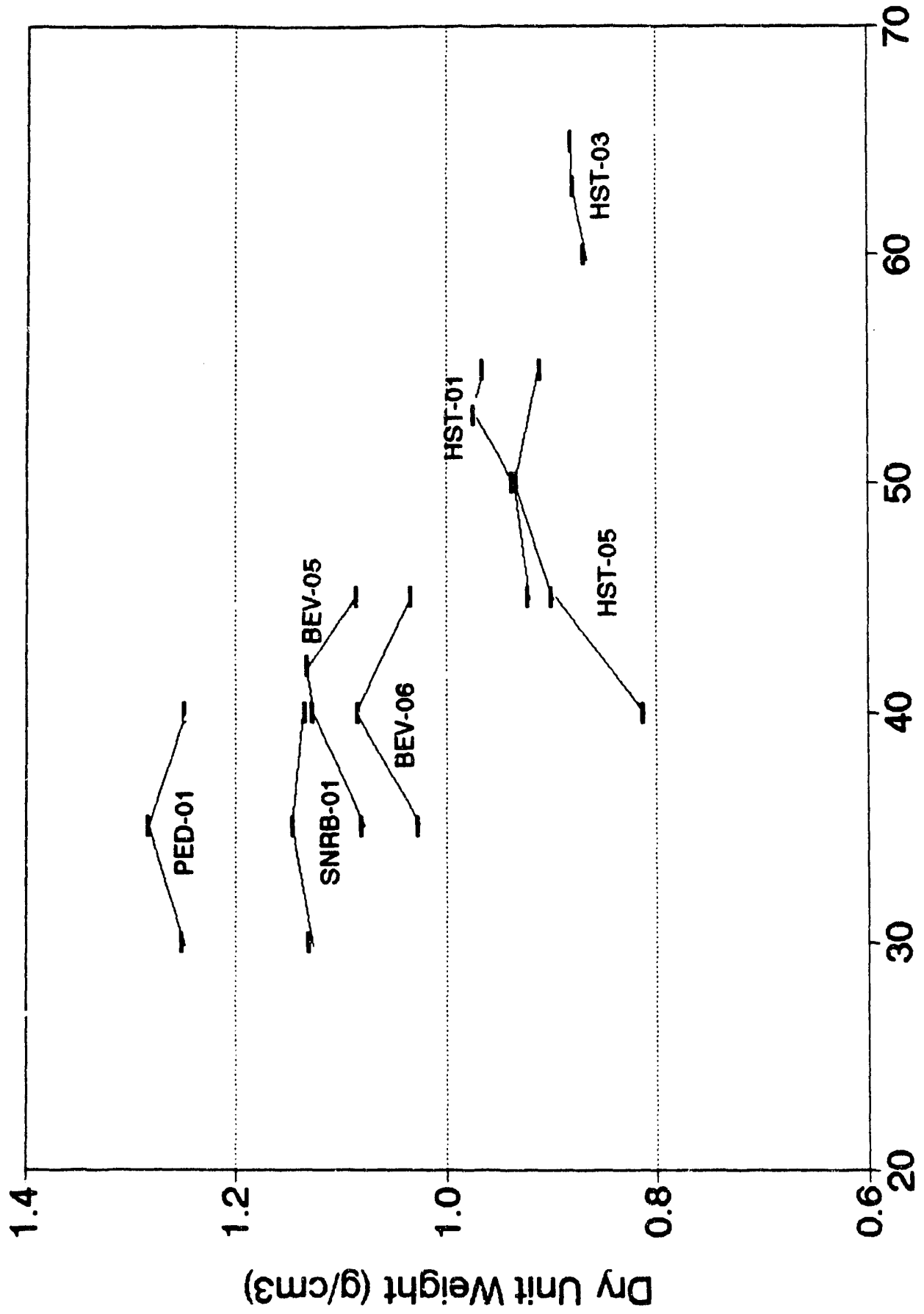

帟

도

R

交

8

8

20 $\frac{5}{5}$

토

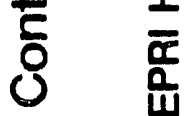

产

호

层

क

옹

क

롱

造

\%

i் 
Table 29. Optimum moisture content and density for FGD samples.

\begin{tabular}{|c|c|c|}
\hline Sample ID & Optimum Density & $\begin{array}{c}\text { Optimum Moisture } \\
\text { Content }\end{array}$ \\
\hline & $\mathrm{g} \mathrm{cm}^{-3}$ & $\%$ \\
\hline CLS-01 & 1.100 & 32 \\
\hline LIM-06 & 1.200 & 43 \\
\hline LIM-07 & 1.120 & 48 \\
\hline LIM-08 & 1.300 & 28 \\
\hline LIM-09 & 1.055 & 50 \\
\hline LIM-10 & 1.069 & 43 \\
\hline LIM-11 & 1.019 & 50 \\
\hline LIM-12 & 1.118 & 42 \\
\hline LIM-13 & 1.042 & 45 \\
\hline 니느-14 & $\underline{0.789}$ & 40 \\
\hline OSU-01 & 0.909 & 50 \\
\hline OSU-02 & 0.833 & 68 \\
\hline OSU-03 & 0.845 & 63 \\
\hline OSU-11 & 1.056 & 40 \\
\hline HST-01 & 0.974 & 53 \\
\hline HST-03 & 0.881 & 65 \\
\hline HST-05 & 0.933 & 50. \\
\hline BEV-05 & 1.132 & 42 \\
\hline BEV-06 & 1.084 & 40 \\
\hline $\begin{array}{c}\text { TID-1/2 } \\
60 \% / 40 \%\end{array}$ & $1.80 \%$ & 18 \\
\hline $\begin{array}{c}\text { TID-1/2 } \\
50 \% / 50 \%\end{array}$ & 1.815 & 18 \\
\hline $\begin{array}{c}\text { TID-3/4 } \\
40 \% / 60 \%\end{array}$ & 1.830 & 18 \\
\hline TID-05 & 1.359 & 35 \\
\hline TID-06 & 1.582 & 25 \\
\hline
\end{tabular}


Table 29. continued

\begin{tabular}{ccc}
\hline Sample ID & Optimum Density & $\begin{array}{c}\text { Optimum Moisture } \\
\text { Content }\end{array}$ \\
\hline & $\mathrm{g} \mathrm{cm}^{-3}$ & $\%$ \\
PED-01 & 1.272 & 35 \\
SNRB-01 & 1.146 & 35 \\
\hline
\end{tabular}




\subsection{Strength and Compressibility}

The engineering properties of a geotechnical material are strongly influenced by the density of the tested sample. Therefore, it is oftentimes convenient to record these properties as a function of the material density. Although any consistently reproducible density could be chosen for the design density, we chose the Standard Proctor as defined in ASTM Standard D-698 (Table 5) as our reference condition. Therefore, all our laboratory tests on FGD samples were compacted at (or in some particular cases near) the optimum moisture content and density. The specification of the Standard Proctor optimum moisture content and density was made because it is the most common way to relate the laboratory densities to field conditions, and this density can be readily achieved in the field by virtually all construction contractors using conventional highway equipment.

Sample strength (unconfined compressive strength) corresponds to the largest stress measurement recorded during the test. In most tests this value occurred when the sample failed rapidly (fractured). Some samples, usually those that had not been cured, did not fracture. In these cases, strength was taken to be the value of stress recorded over an extended stress range (typically $0.02 \%$ ).

Sample stiffness is determined by recording the rate of stress increase as a function of axial strain (the slope of the stress-strain curve). Figures 47 through 50 illustrate the experimental procedure by presenting the results of four tests performed on four different FGD materials. The sample identified as TID $3 / 4$ (a mixture of $40 \%$ bottom ash and $60 \%$ cyclone ash) demonstrated high strength values, reaching an average unconfined compressive strength of approximately $1300 \mathrm{lb} / \mathrm{in}^{2}$, which is approaching half the strength of conventional concrete. The values for the other three FGD materials shown are substantially lower, ranging between $50 \mathrm{lb} / \mathrm{in}^{2}$ and 240 $\mathrm{lb} / \mathrm{in}^{2}$. Figures 51 through 55 present in graphical form the results of all unconfined compression tests we performed in this phase of the project. As can be seen in these figures, the strengths of all the FGD samples were higher after 28 days than immediately after being compacted. As a class, FGD materials possessed high strengths when compared with the clay sample (Fig. 55), although some variability in the strength is apparent, particularly in the 7 and 28 day strengths. Table 30 summarizes the strength and stiffness measurements and the densities of the tested samples. Clearly the FGD materials as a class possess strengths considerably in excess of what would be required in a structural fill. 

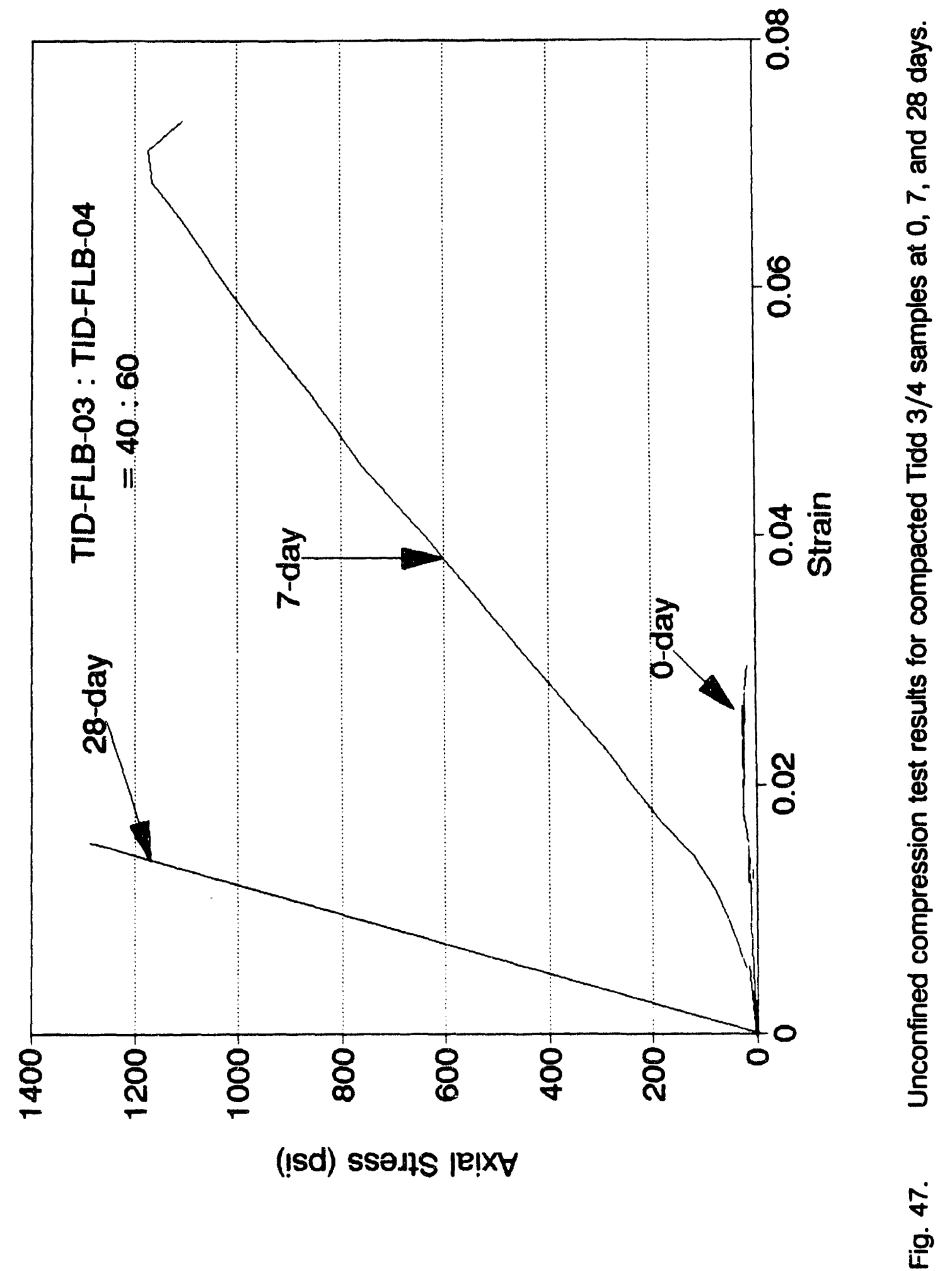


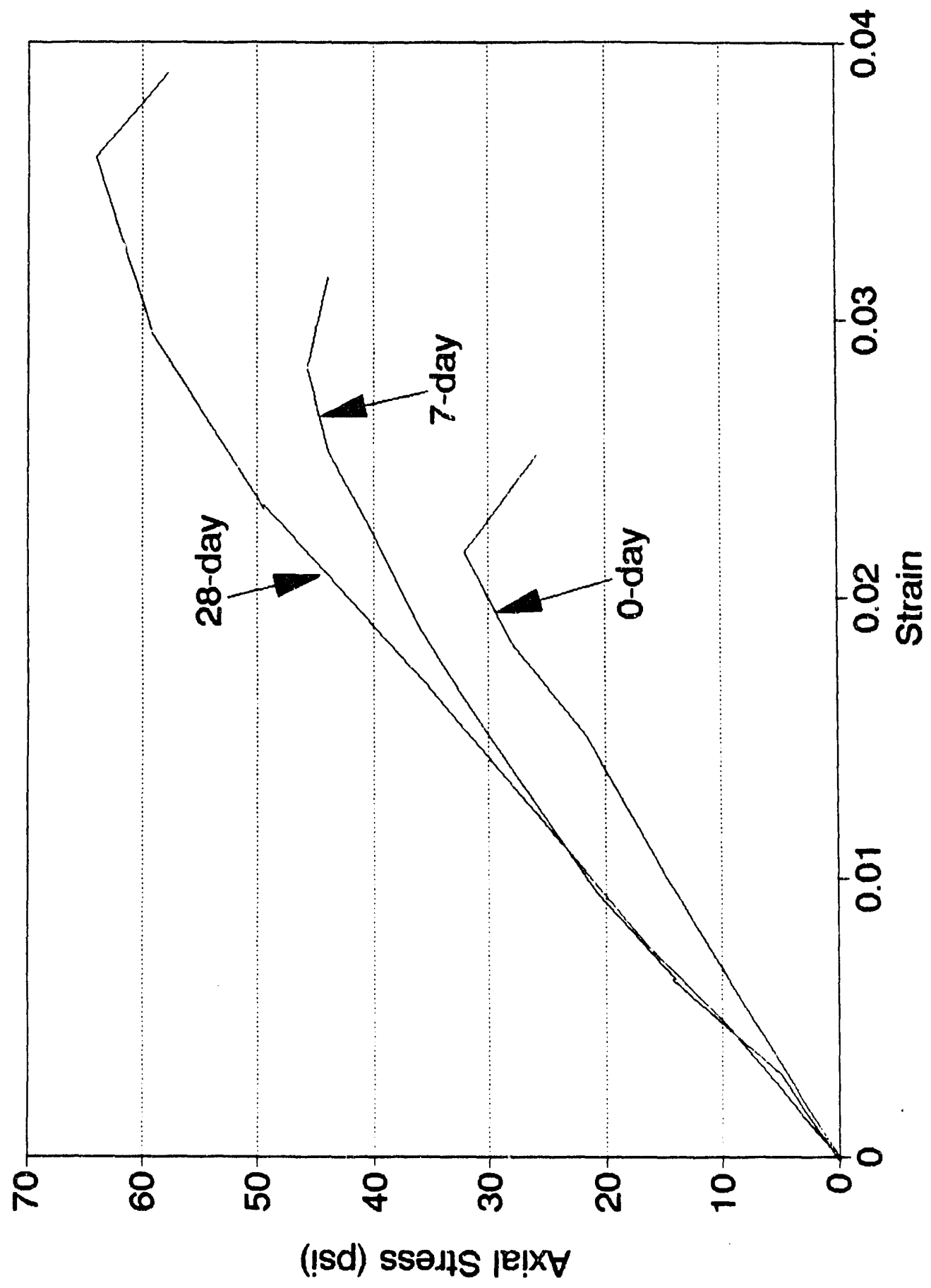

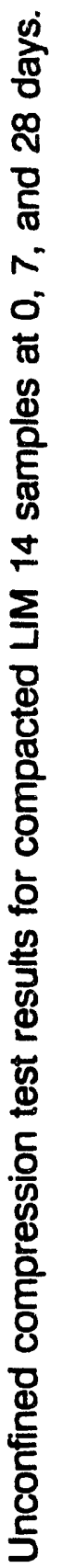

ơ

ํํㄴ 


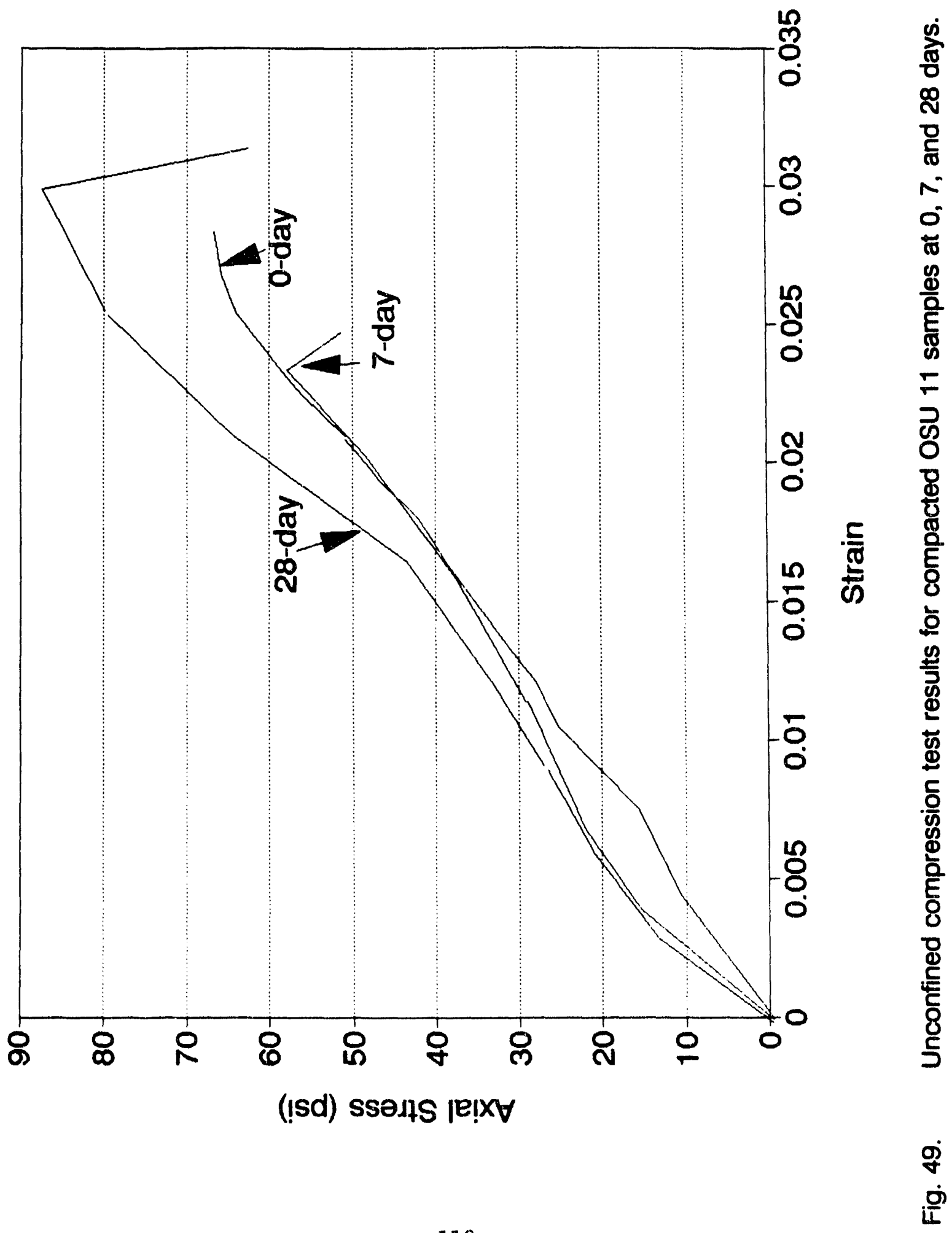




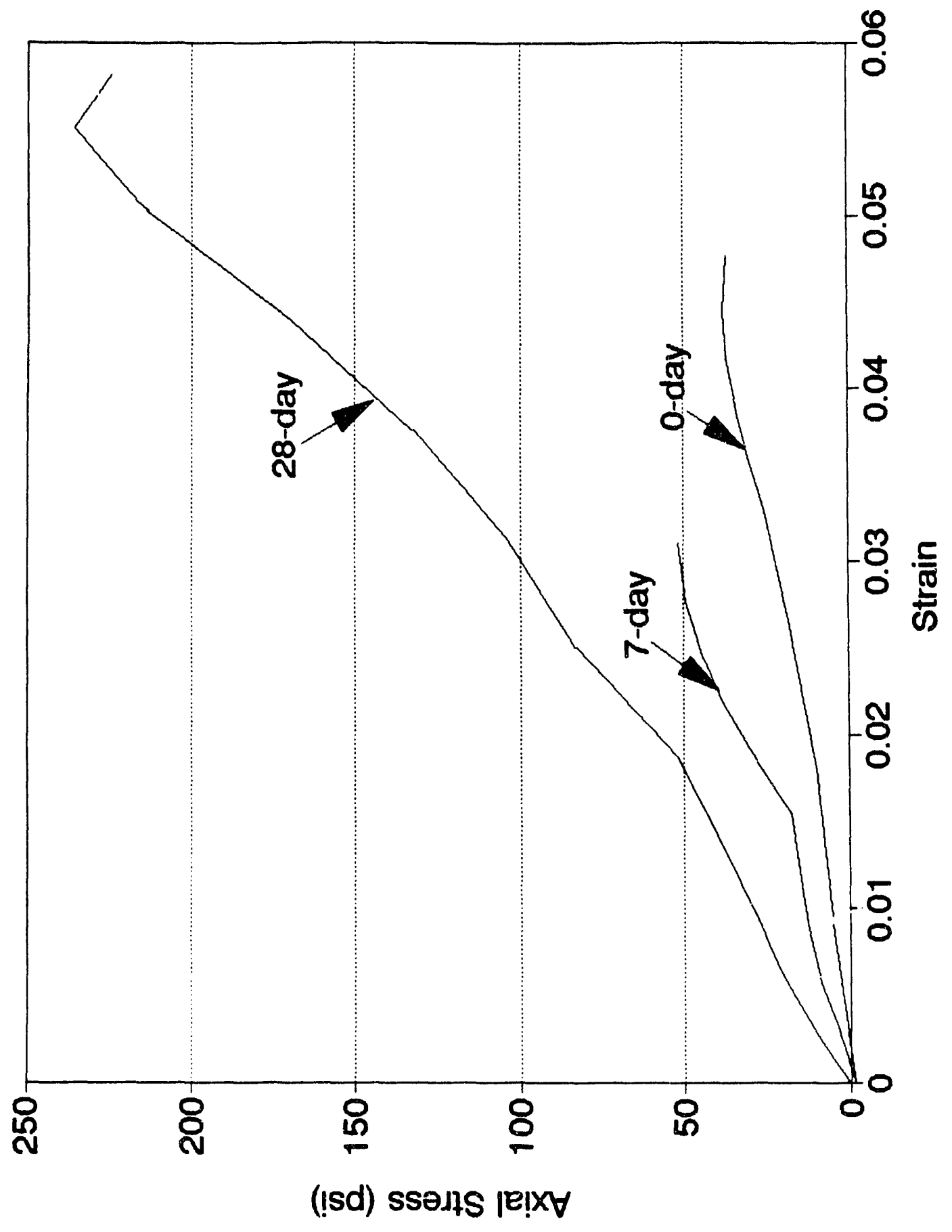

宛

$\stackrel{\infty}{\text { บ }}$

은

N

完

\&

틍

눙

II

崩

임 


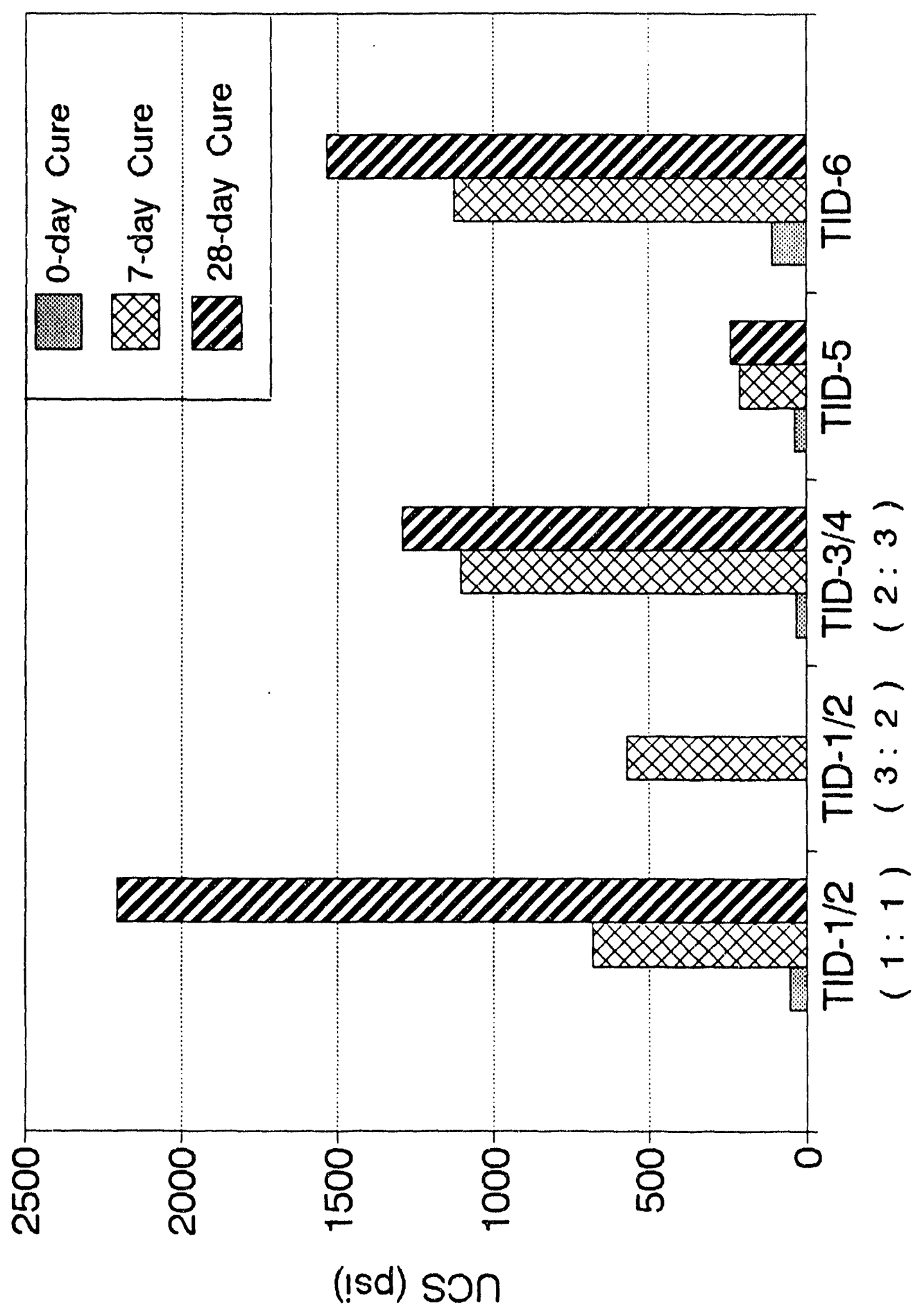

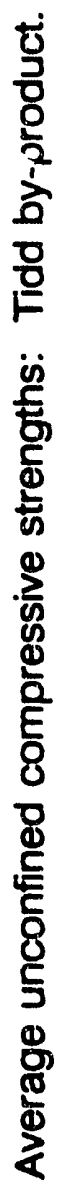

in ํํㄴ 


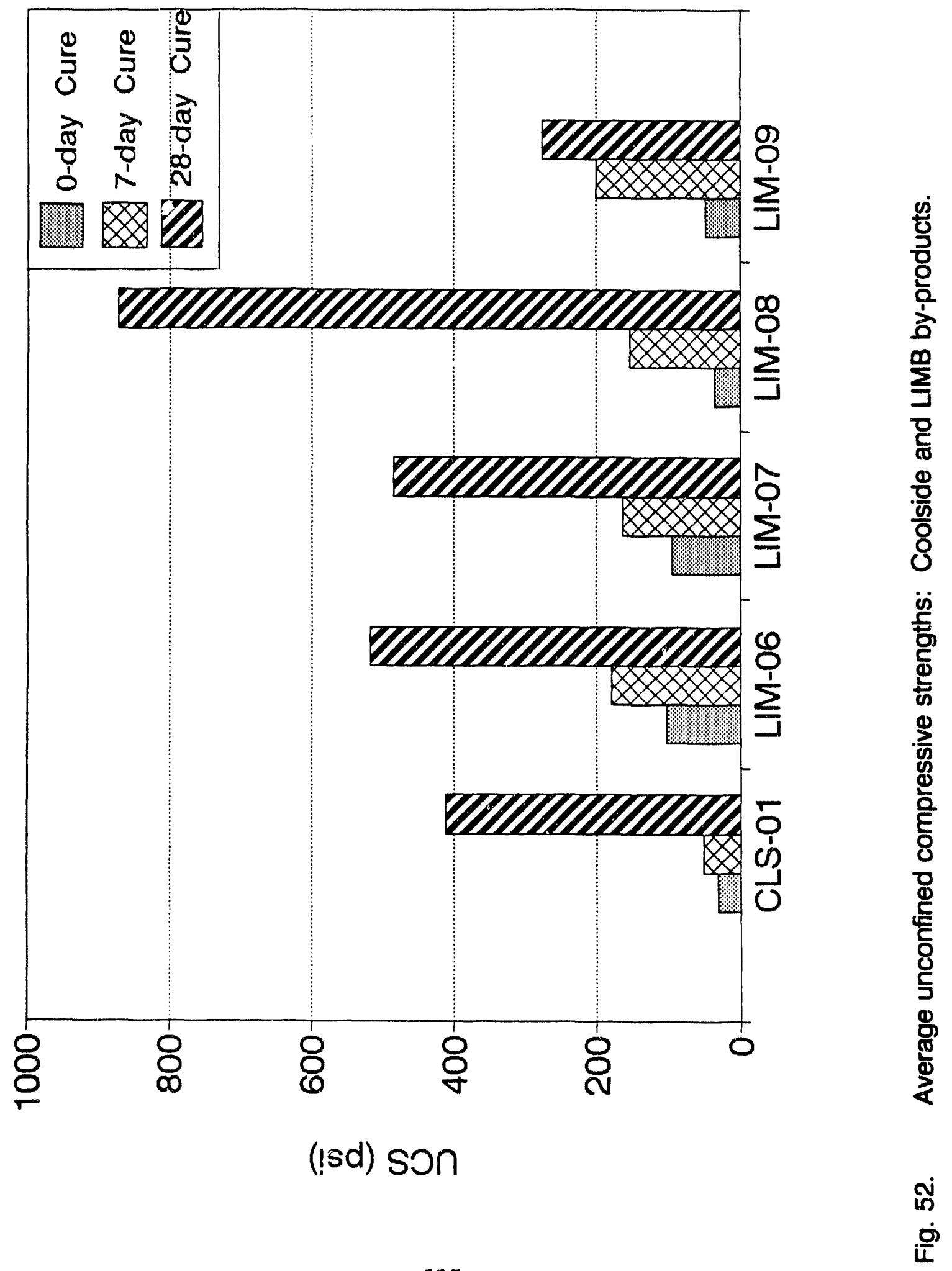




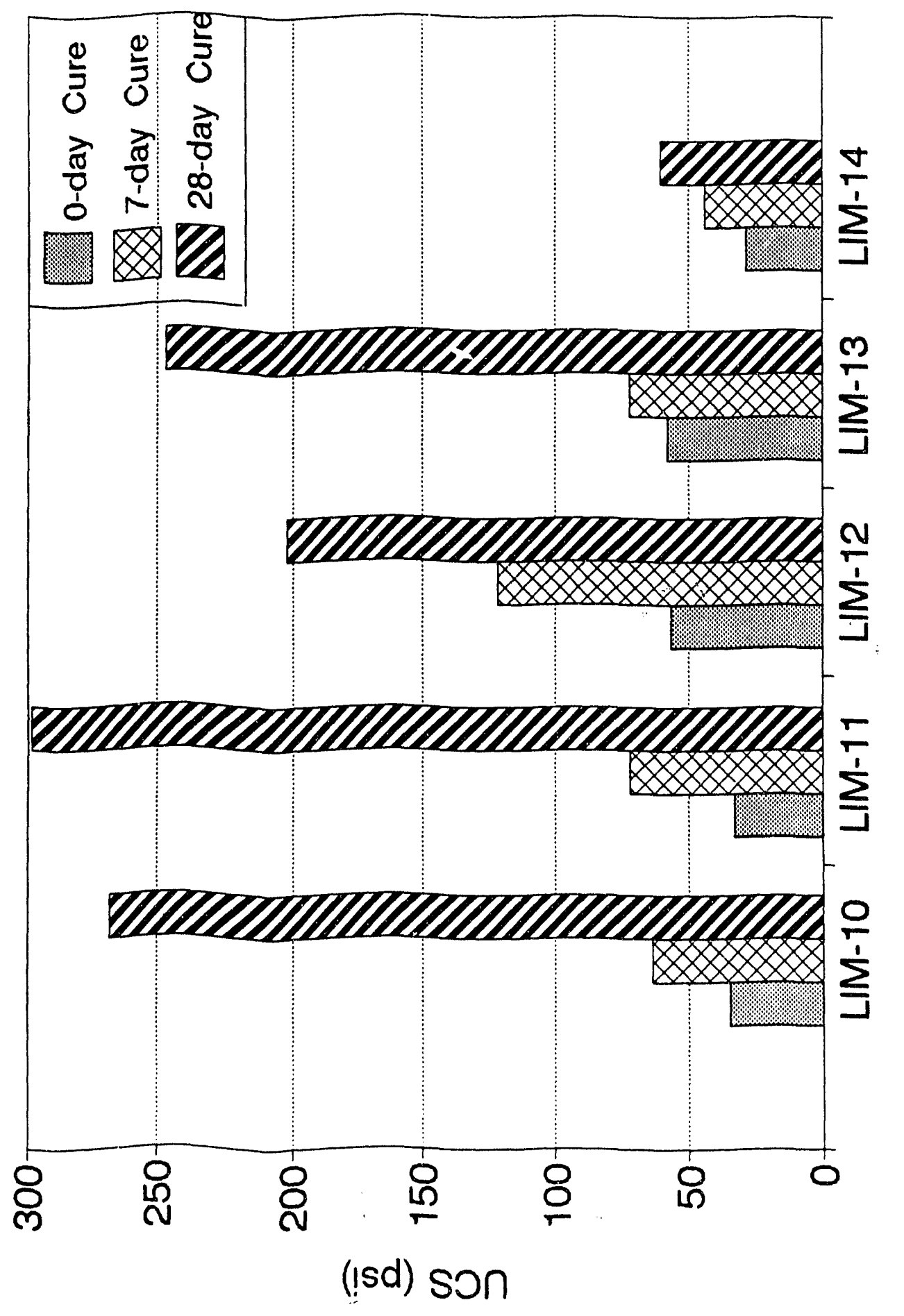

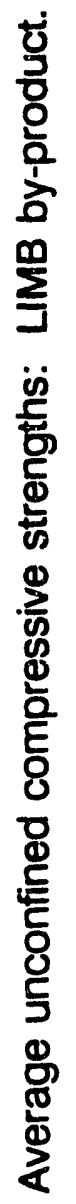

๓ึ क्षे 


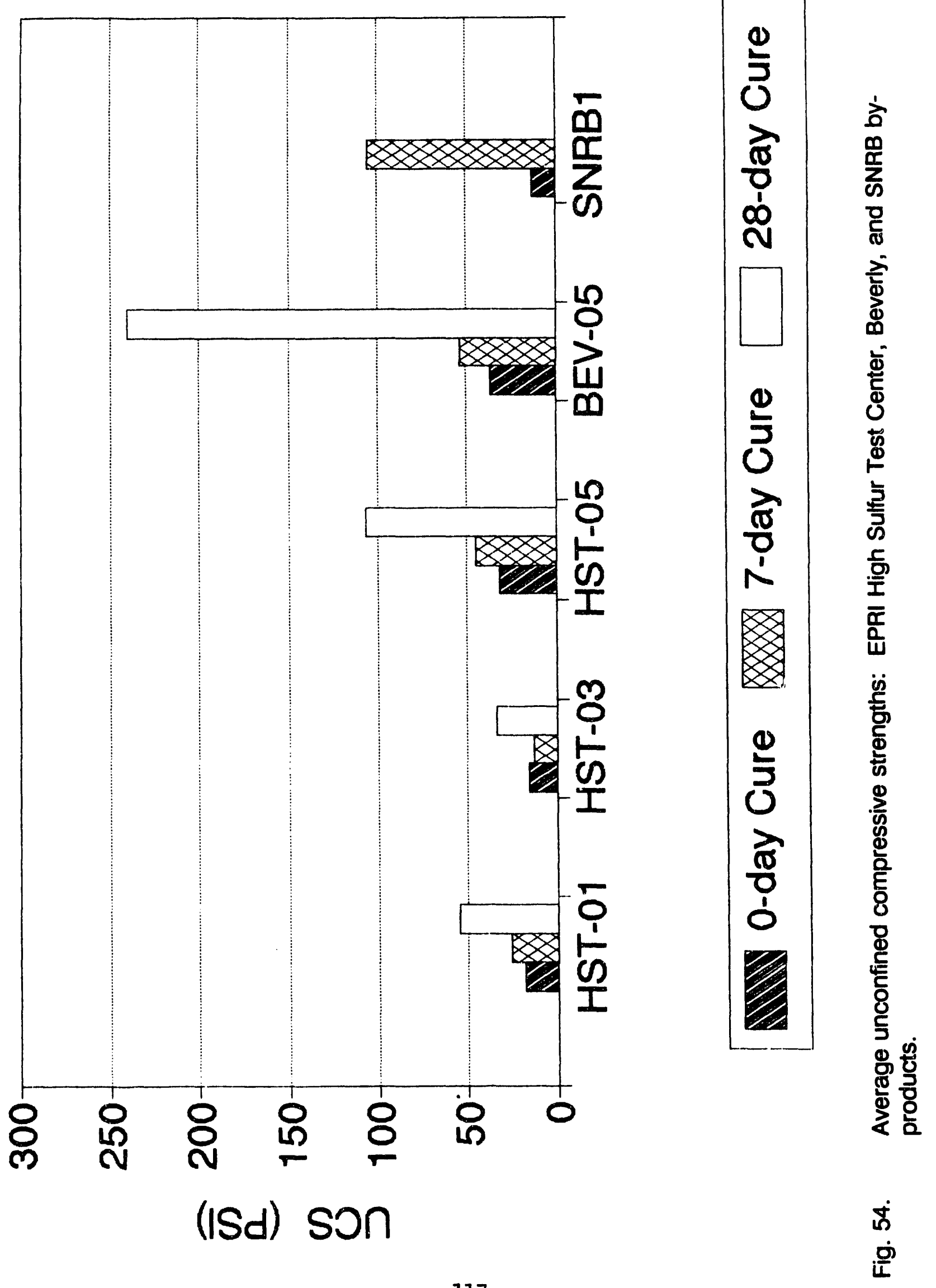




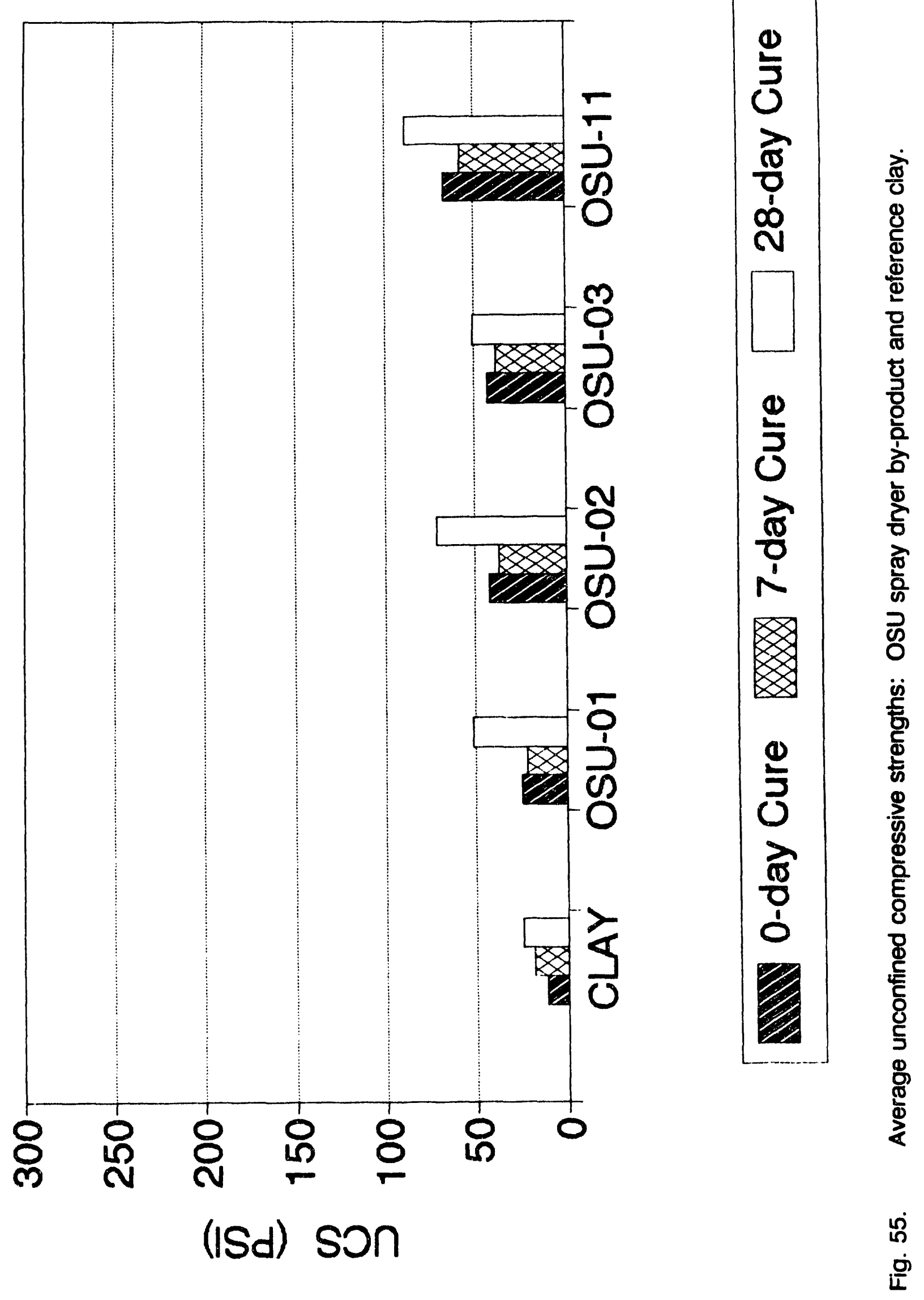


Table 30. Unconfined compressive strength for FGD samples.

\begin{tabular}{|c|c|c|c|c|}
\hline \multirow[t]{2}{*}{ Sample ID } & \multirow{2}{*}{$\begin{array}{c}\text { Optimum Density } \\
\mathrm{g} \mathrm{cm}^{-3} \\
\end{array}$} & \multicolumn{3}{|c|}{ Unconfined Compressive Strength (psi) } \\
\hline & & 0 & 7 & 28 \\
\hline CLS-01 & 1.100 & 28.7 & 50.3 & 410.0 \\
\hline LIM-06 & 1.200 & 103.0 & 179.0 & 518.0 \\
\hline ㄴIM-07 & 1.120 & 95.0 & 163.5 & 485.0 \\
\hline LIM-08 & 1.300 & 33.4 & 154.0 & 872.0 \\
\hline LIM-09 & 1.055 & 47.1 & 200.0 & 267.0 \\
\hline LIM-10 & 1.069 & 34.3 & 63.6 & 268.0 \\
\hline LIM-11 & 1.019 & 33.0 & 72.4 & 298.0 \\
\hline LIM-12 & 1.118 & 56.8 & 122.0 & 202.0 \\
\hline LIM-13 & 1.042 & 58.1 & 72.4 & 246.0 \\
\hline 니M-14 & $\underline{0.789}$ & 28.4 & 44.3 & 60.8 \\
\hline OSU-01 & 0.909 & 24.6 & 22.0 & 52.1 \\
\hline OSU-02 & 0.833 & 42.4 & 37.4 & 71.2 \\
\hline OSU-03 & 0.845 & 43.5 & 38.0 & 51.0 \\
\hline OSU-11 & 1.056 & 66.7 & 57.9 & 87.8 \\
\hline HST-01 & 0.974 & 18.3 & 25.4 & 54.8 \\
\hline HST-03 & 0.881 & 15.8 & 12.7 & 34.0 \\
\hline HST-05 & 0.933 & 31.9 & 45.0 & 107.0 \\
\hline BEV-05 & 1.132 & 36.3 & 53.8 & 240 \\
\hline BEV-06 & 1.084 & 38.0 & 63.0 & 111 \\
\hline $\begin{array}{l}\text { TID-1/2 } \\
60 \% / 40 \%\end{array}$ & 1.807 & ND & 568 & ND \\
\hline $\begin{array}{l}\text { TID-1/2 } \\
50 \% / 50 \%\end{array}$ & 1.815 & 52.7 & 680 & 2202 \\
\hline $\begin{array}{l}\text { TID-3/4 } \\
40 \% / 60 \%\end{array}$ & 1.830 & 28.4 & 1103 & 1290 \\
\hline TID-05 & 1.359 & 31.8 & 206 & 238 \\
\hline TID-06 & 1.582 & 104.5 & 1129 & 1532 \\
\hline PED-01 & 1.272 & 77.1 & 1148 & 1294 \\
\hline SNRB-01 & 1.146 & 12.8 & 104.7 & 72.9 \\
\hline
\end{tabular}

ND not determined 
A limited number of one-dimensional compressibility tests were conducted according to ASTM D2435 (Table 5) on samples of selected FGD by-product. This test was performed to provide the design engineer with the material parameters necessary to make estimates of the ar iount of settlement that could take place within the embankment when the FGD was l saded. A load settlement curve obtained for an Edgewater LIMB sample (Fig. 56) shows the decrease in pore volume (void ratio) as a function of applied load. Although the vcid ratio (i.e. volume of void space divided by the volume occupied by the solid portion) was high, which was typical of most of the FGD materials studied, the amount of compression during loading was small. A onedimensional test conducted on a compacted Tidd sample (ig. 57) indicates the initial void ratio was much lower than in the LIMB samples, and the compressibility, as measured by the slope of the stress vs. void ratio curve, was observed to be less than that measured in the EDG-LIM-06 sample. The above results were obtained for samples immediately after compaction. The results of compressibility tests performed on three Edgewater LIMB samples that had been allowed to cure for more than 400 days (Fig. 58 to 59) show that the void ratio vs. applied stress curve is similar to that seen in Figure 55 for the previously tested LIMB sample. However, the compressibility is less indicating an increase in stiffness accompanies curing (aging). A summary of these results compared to typical values of the same compressibility parameters for a soft and a stiff clay (Table 31) clearly suggests that the FGD materials are much less compressible than typical natural materials that might be used for embankment fill. 
Phase 1 Report

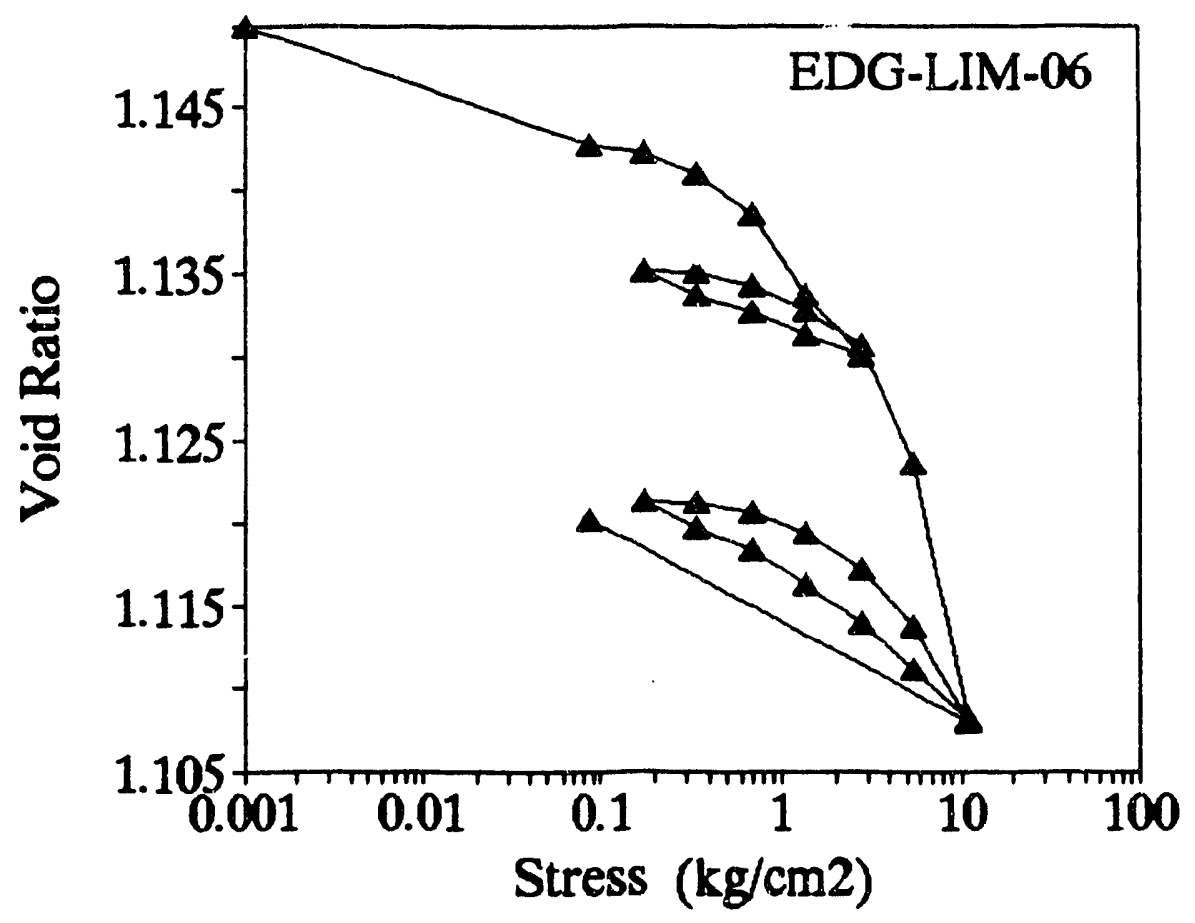

Fig. 56. One dimensional compression of a compacted LIMB sample 0 days after compaction.

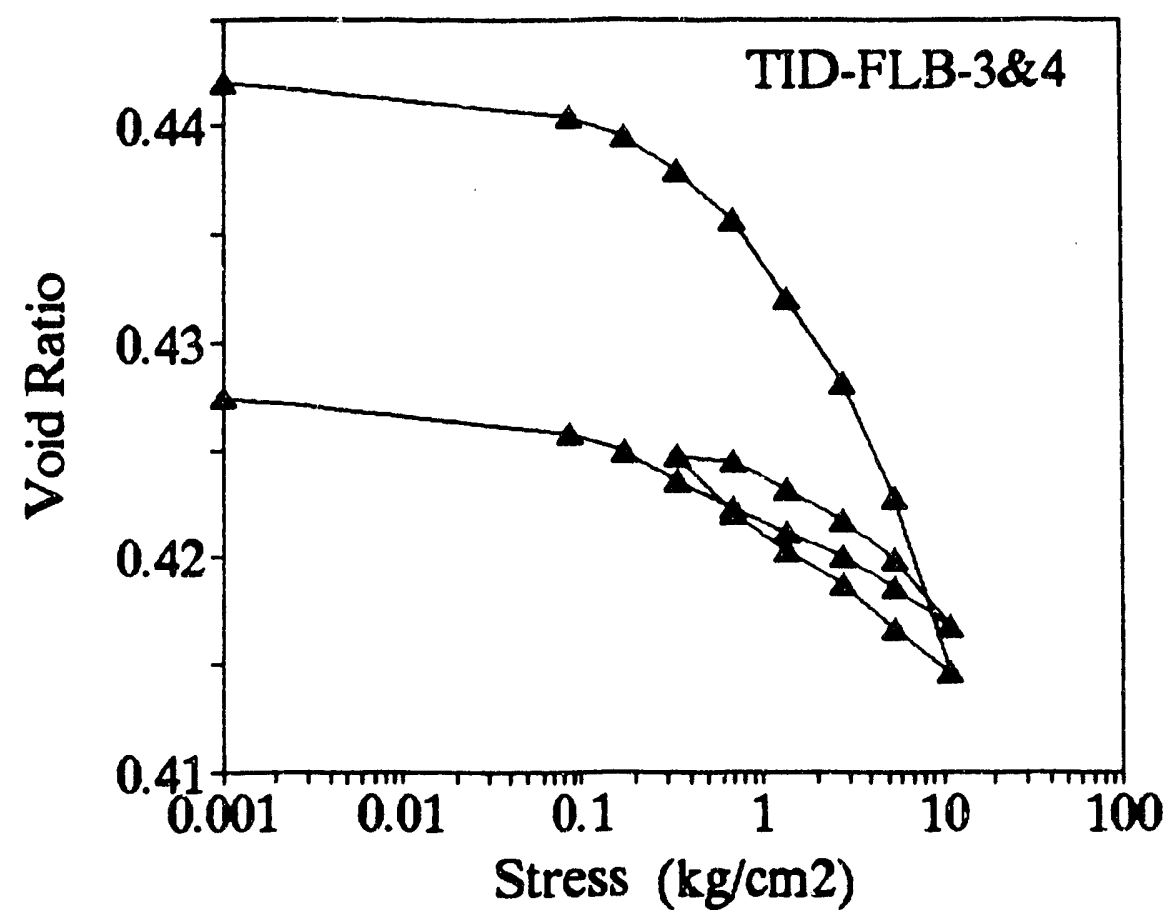

Fig. 57. One dimensional compression of a compacted Tidd sample 0 days after compaction. 


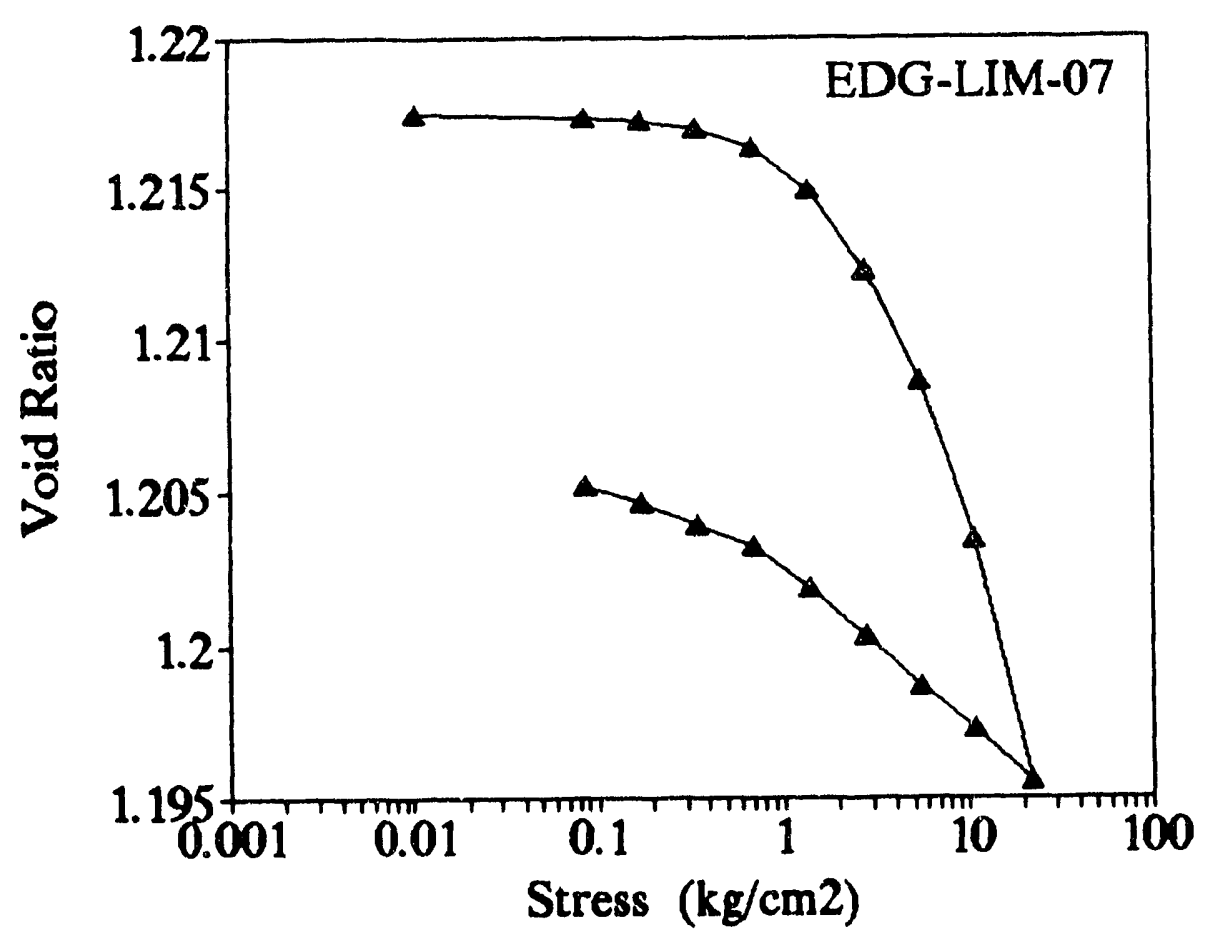

Fig. 58. One dimensional compression of a compacted LIMR sample 425 days after compaction.

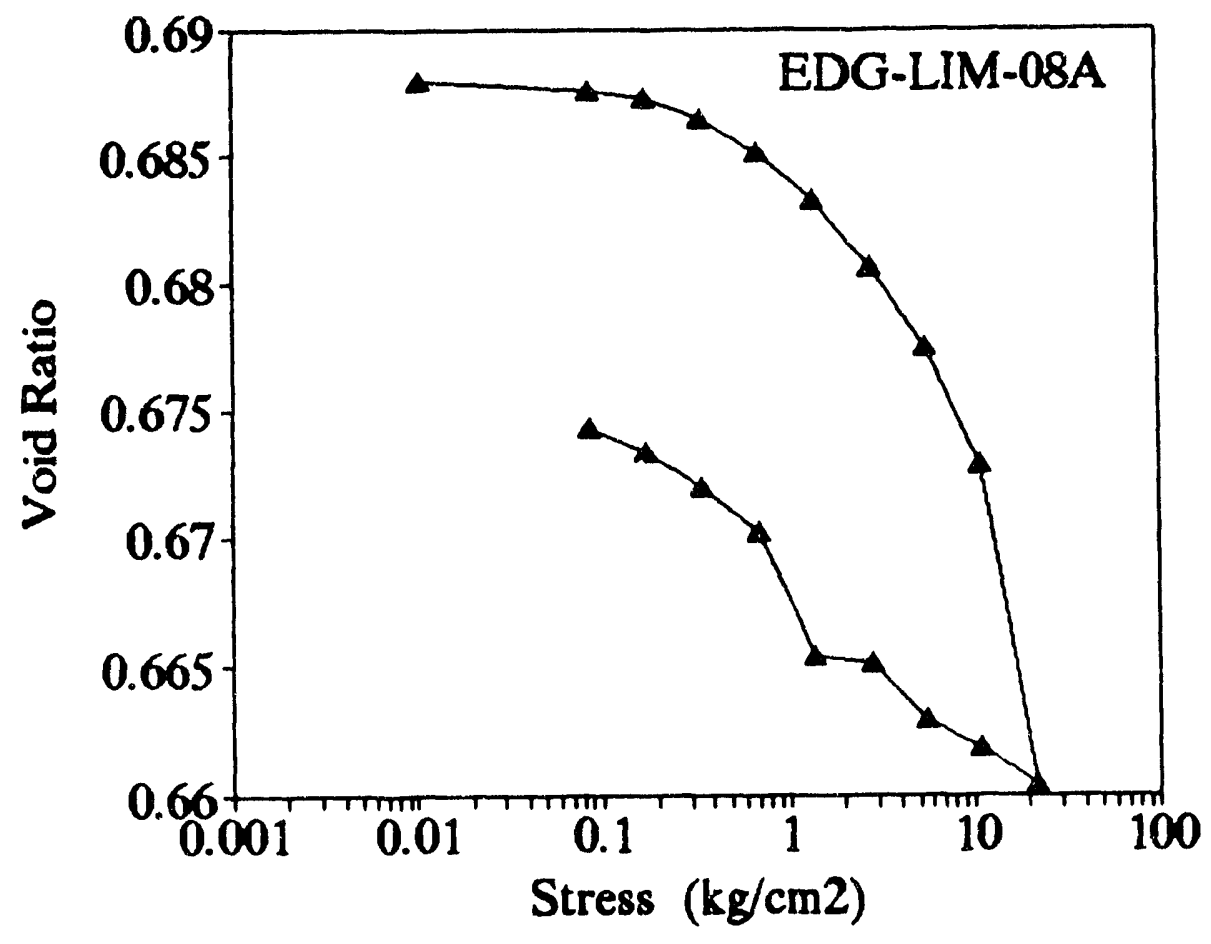

Fig. 59. One dimensional compression of a compacted LIMB sample 425 days after compaction. 


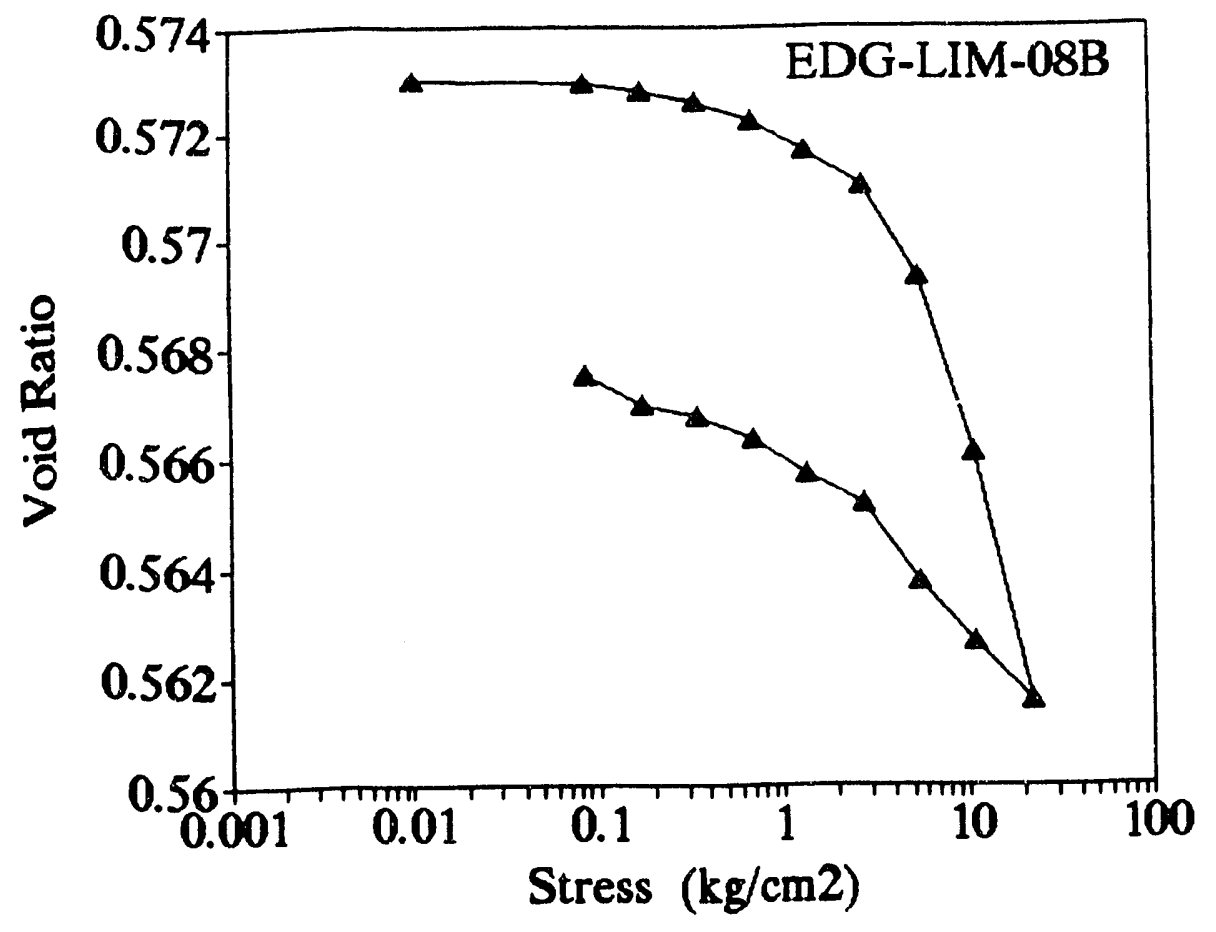

Fig. 60. One dimensional compression of a compacted LIMB sample 404 days after compaction. 
Table 31. One dimensional compression tests on FGD samples.

\begin{tabular}{|c|c|c|c|c|}
\hline \multirow[t]{2}{*}{ Sample ID } & \multirow{2}{*}{$\frac{\text { Initial Density }}{\left(\mathrm{g} \mathrm{cm}^{-3}\right)}$} & \multirow{2}{*}{$\frac{\text { Elapsed Time to Test }}{\text { (days) }}$} & \multicolumn{2}{|c|}{ Coefficient of Compression } \\
\hline & & & Initial $\left(C_{c}\right)$ & Reload $\left(C_{r}\right)$ \\
\hline LIM-06 & 1.200 & 0 & 0.051 & 0.004 \\
\hline TID-3/4 & 1.830 & 0 & 0.011 & 0.005 \\
\hline LIM-07 & +120 & 425 & 0.026 & 0.002 \\
\hline LIM-08A & 1.300 & 425 & 0.042 & 0.004 \\
\hline LIM-08B & 1.055 & 404 & 0.015 & 0.002 \\
\hline Soft Clay ${ }^{1}$ & & & 0.200 & \\
\hline Stiff Clay ${ }^{1}$ & & & 0.300 & \\
\hline
\end{tabular}

${ }^{1}$ Soil Mechanics 2nd Edition, by T.H. Wu, 1981, p.10 


\subsection{Permeability}

Since the strength and compressibility tests previously described have clearly shown that the scope of potential applications of the compacted FGD by-product could be quite broad, other properties that may ultimately determine the actual range of engineering uses for this material were explored. For this reason, a program of laboratory permeability tests was initiated. Results indicated that permeability is indeed an important parameter since, for the range of samples and conditions tested, the coefficient of permeability varies by a factor of more than 16,000 .

The measured coefficients of permeability for each type of by-product tested, as a function of the amount of time elapsed from sample preparation to the measurement, revealed a general trend toward lower permeabilities with increasing time (Fig. 61 to 65). The FGD process used to generate the FGD materials, however, has a more important role in the determination of actual permeability than does the curing time. As a class of materials, the spray dryer samples had the highest permeabilities with values ranging from $3.6 \times 10^{-5} \mathrm{~cm} / \mathrm{sec}$ (OSU-01 at 0 days) to $1.5 \times 10^{-6}$ $\mathrm{cm} / \mathrm{sec}$ (OSU-SPD-03 at 28 days). The Tidd samples (pressurized fluidized bed combustion) had permeabilities ranging between $1.7 \times 10^{-5} \mathrm{~cm} / \mathrm{sec}$ (TID-FLB-06 at 0 days) to $9.1 \times 10^{-10} \mathrm{~cm} / \mathrm{sec}$ (TID-FLB-3/4 at 28 days) and were the least permeable. Table 32 lists all of the permeability tests performed and the measured permeability coefficient for each sample. 


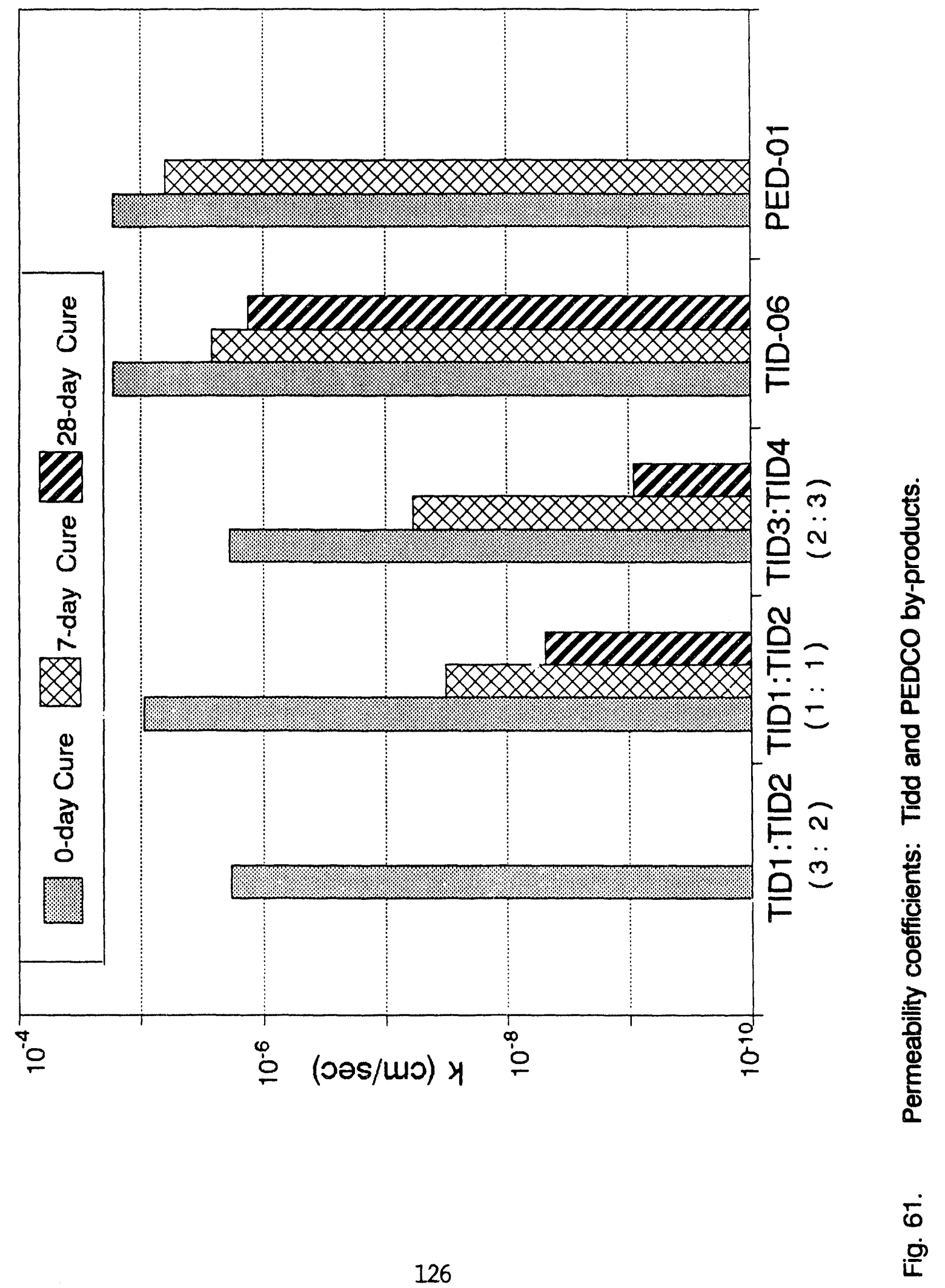




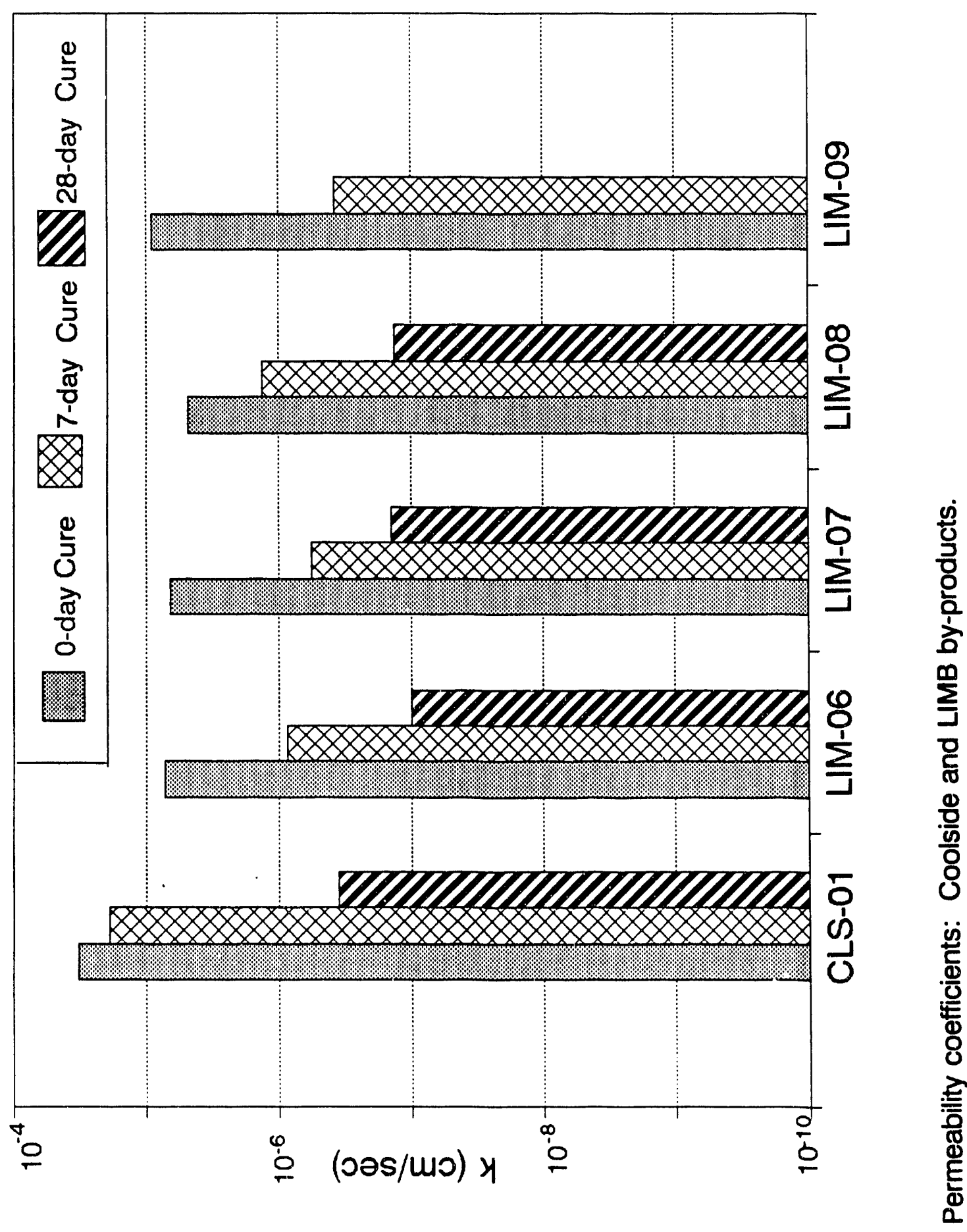

ช่

운 


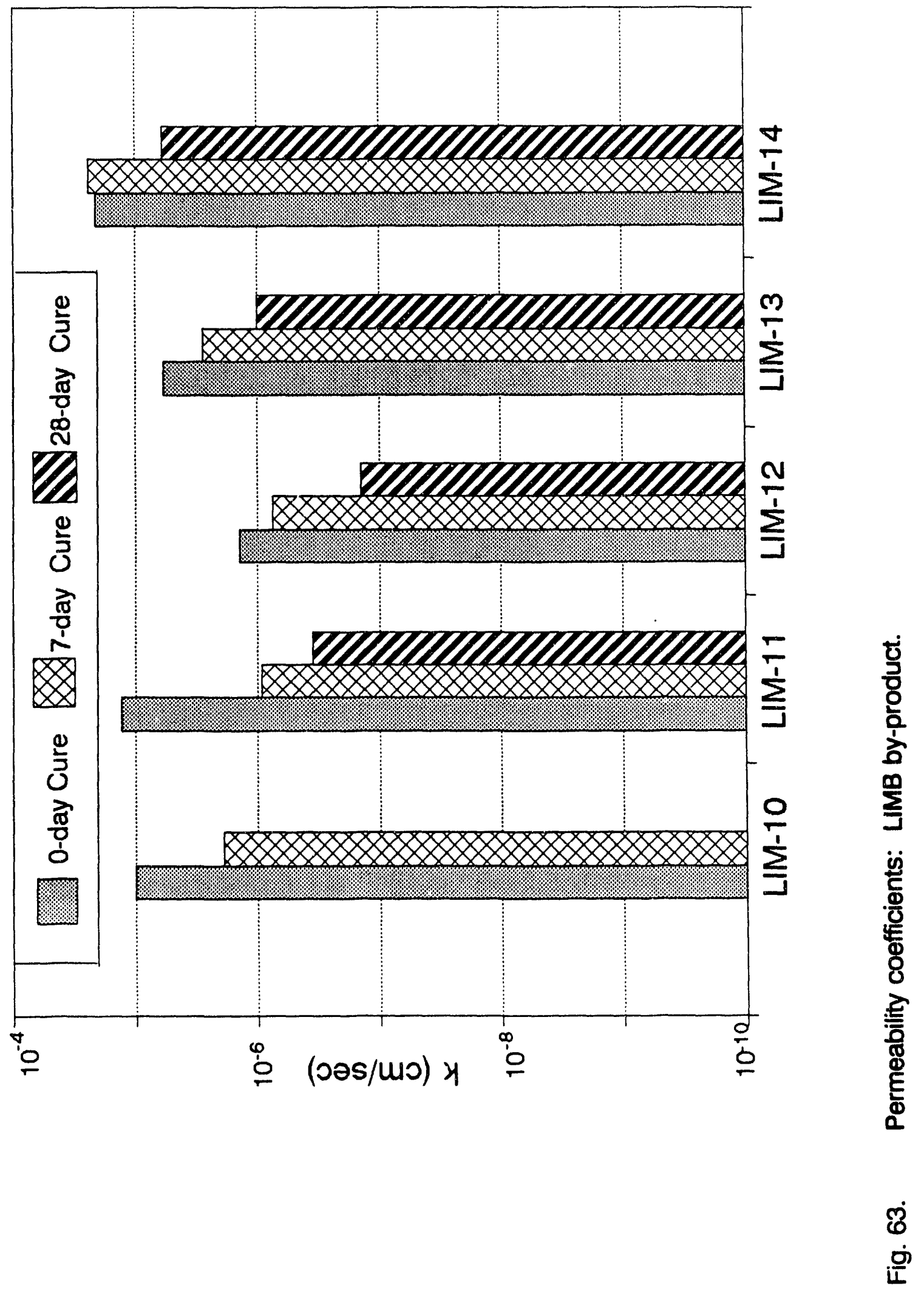




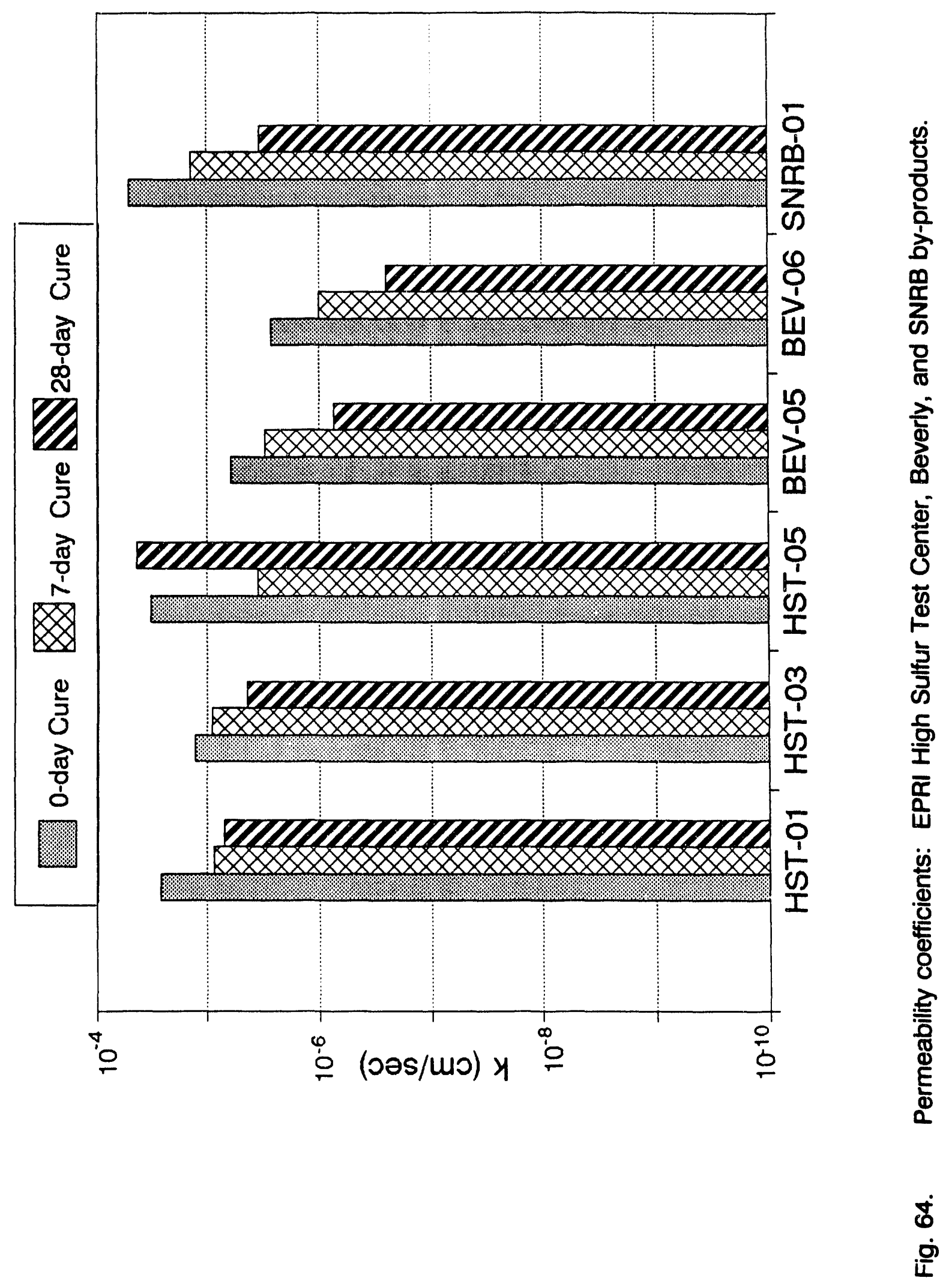




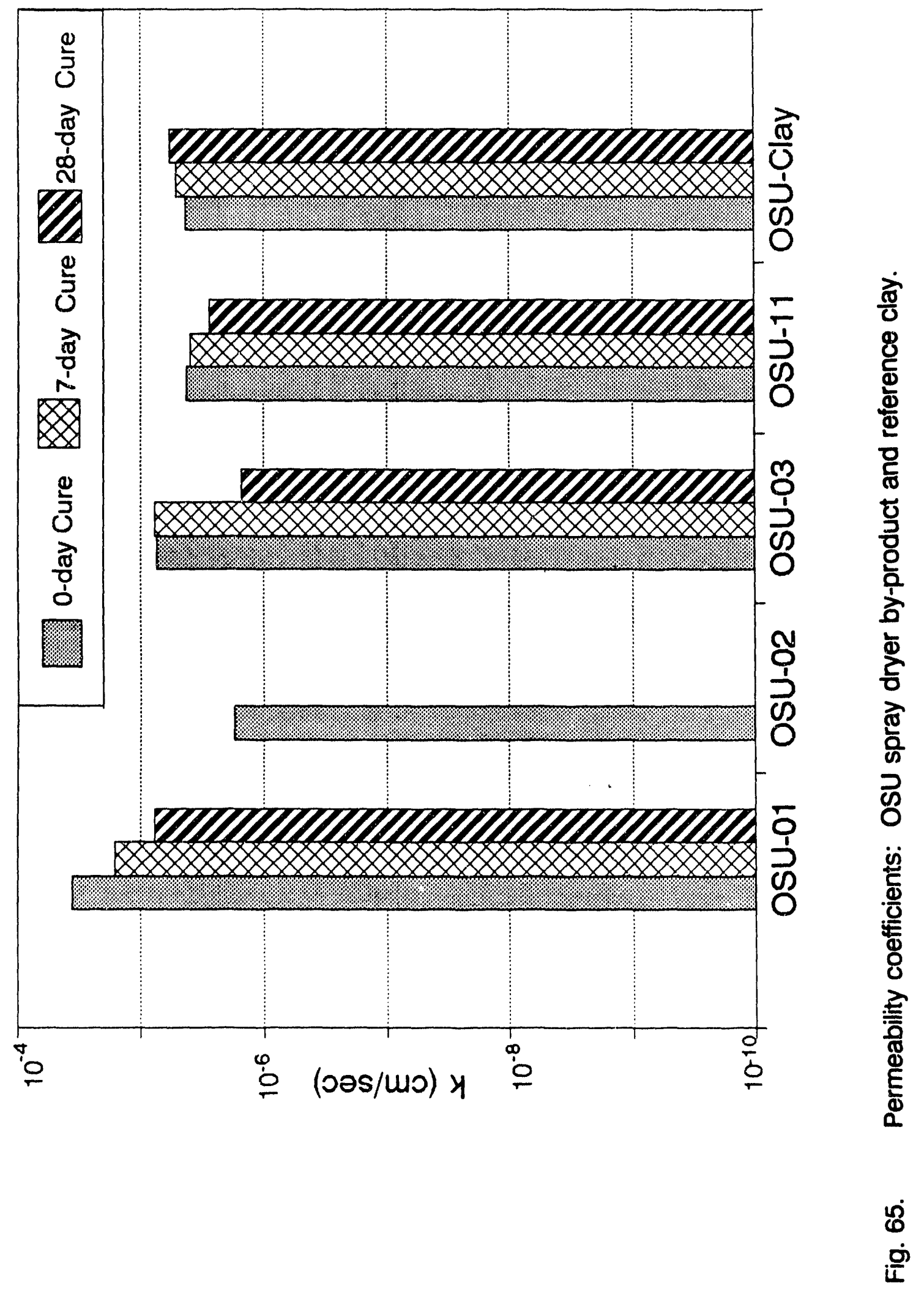


Table 32. Coefficient of permeability for FGD samples.

\begin{tabular}{|c|c|c|c|c|}
\hline \multirow[t]{2}{*}{ Sample ID } & \multirow{2}{*}{$\frac{\text { Optimum Density }}{9 \mathrm{~cm}^{-3}}$} & \multicolumn{3}{|c|}{$\begin{array}{l}\text { Permeability Coefficient }\left(\mathrm{cm} \mathrm{s}^{-1}\right) \text { at } \\
\text { curing time (days) }\end{array}$} \\
\hline & & 0 & 7 & 28 \\
\hline EDG-CLS-01 & 1.100 & $3.2 \times 10^{-5}$ & $1.9 \times 10^{-5}$ & $3.5 \times 10^{-7}$ \\
\hline EDG-LIM-06 & 1.200 & $7.2 \times 10^{-6}$ & $8.4 \times 10^{-7}$ & $9.8 \times 10^{-8}$ \\
\hline EDG-LIM-07 & 1.120 & $6.6 \times 10^{-6}$ & $5.6 \times 10^{-7}$ & $1.4 \times 10^{-7}$ \\
\hline EDG-LIM-08 & 1.300 & $4.8 \times 10^{-6}$ & $1.3 \times 10^{-6}$ & $1.3 \times 10^{-7}$ \\
\hline EDG-LIM-09 & 1.055 & $9.0 \times 10^{-6}$ & $3.7 \times 10^{-7}$ & * \\
\hline EDG-LIM-10 & 1.069 & $1.0 \times 10^{-5}$ & $1.9 \times 10^{-6}$ & * \\
\hline EDG-LIM-11 & 1.019 & $1.3 \times 10^{-6}$ & $9.0 \times 10^{-7}$ & $3.5 \times 10^{-7}$ \\
\hline EDG-LIM-12 & 1.118 & $1.4 \times 10^{-6}$ & $7.4 \times 10^{-7}$ & $1.4 \times 10^{-7}$ \\
\hline EDG-LIM-13 & $1.0 ั+2$ & $5.8 \times 10^{-6}$ & $2.8 \times 10^{-6}$ & $9.9 \times 10^{-7}$ \\
\hline EDG-LIM-14 & 0.789 & $2.1 \times 10^{-5}$ & $2.4 \times 10^{-5}$ & $5.9 \times 10^{-6}$ \\
\hline OSU-SPD-01 & 0.909 & $3.6 \times 10^{-5}$ & $1.6 \times 10^{-5}$ & $7.6 \times 10^{-6}$ \\
\hline OSU-SPD-02 & 0.833 & $1.7 \times 10^{-6}$ & ND & ND \\
\hline OSU-SPD-03 & 0.845 & $7.4 \times 10^{-6}$ & $7.7 \times 10^{-6}$ & $1.5 \times 10^{-6}$ \\
\hline OSU-SPD-11 & 1.056 & $4.2 \times 10^{-6}$ & $3.9 \times 10^{-6}$ & $2.7 \times 10^{-6}$ \\
\hline HST-SPD-01 & 0.974 & $2.6 \times 10^{-5}$ & $8.6 \times 10^{-6}$ & $7.1 \times 10^{-6}$ \\
\hline HST-SPD-03 & 0.881 & $1.3 \times 10^{-5}$ & $9.2 \times 10^{-6}$ & $4.5 \times 10^{-6}$ \\
\hline HST-SPD-05 & 0.933 & $3.2 \times 10^{-5}$ & $3.6 \times 10^{-6}$ & $4.3 \times 10^{-6}$ \\
\hline BEV-DUC-05 & 1.132 & $6.2 \times 10^{-6}$ & $3.1 \times 10^{-6}$ & $7.2 \times 10^{-7}$ \\
\hline BEV-DUC-06 & 1.084 & $2.7 \times 10^{-6}$ & $1.0 \times 10^{-6}$ & $2.5 \times 10^{-7}$ \\
\hline $\begin{array}{l}\text { TID-FLB-1/2 } \\
60 \% / 40 \%\end{array}$ & 1.807 & $1.8 \times 10^{-6}$ & * & * \\
\hline $\begin{array}{l}\text { TID-FLB-1/2 } \\
50 \% / 50 \%\end{array}$ & 1.815 & $9.4 \times 10^{-6}$ & $3.2 \times 10^{-8}$ & $4.7 \times 10^{-9}$ \\
\hline $\begin{array}{l}\text { TID-FLB-3/4 } \\
40 \% / 60 \%\end{array}$ & 1.830 & $1.9 \times 10^{-6}$ & $5.8 \times 10^{-8}$ & $9.1 \times 10^{-10}$ \\
\hline TID-FLB-05 & 1.359 & ND & ND & ND \\
\hline TID-FLB-06 & 1.582 & $1.7 \times 10^{-5}$ & $2.6 \times 10^{-6}$ & $1.3 \times 10^{-6}$ \\
\hline
\end{tabular}


Table 32. continued

\begin{tabular}{lcccc}
\hline Sample ID & Optimum Density & \multicolumn{3}{c}{$\begin{array}{c}\text { Permeability Coefficient (cm s } \\
\text { curing time (days) }\end{array}$} \\
\hline & $\mathrm{g} \mathrm{cm}^{-3}$ & 0 & 7 & 28 \\
PED-RCB-01 & 1.272 & $1.7 \times 10^{-5}$ & $6.3 \times 10^{-6}$ & $*$ \\
BUR-SNR-01 & 1.146 & $5.1 \times 10^{-5}$ & $1.4 \times 10^{-5}$ & $3.4 \times 10^{-6}$ \\
\hline No sample cracked during curing & & & \\
not determined & & &
\end{tabular}


Phase 1 Report

\subsection{Swelling}

Long term laboratory swell tests were conducted on 16 samples taken from four different power plants (Table 33). The materials included in the swell tests are illustrative of the range of by-products studied in the other portions of the laboratory program.

Figures 66 through 69 show the change in volume as a function of time for four specimens, one from each of the FGD processes investigated. Note that in each specimen, two distinct swelling episodes are apparent. The first episode occurred almost immediately after the water was supplied to the specimen. This corresponds to the time period during which naturally occurring soils typically experience the greatest volume increase. In natural soils, swelling is a result of hydration reactions and it is likely that the volume increases observed during the first days in the FGD by-product can be explained in a similar fashion, e.g. the hydration of lime $(\mathrm{CaO})$ to portlandite $\left(\mathrm{Ca}(\mathrm{OH})_{2}\right)$, and anhydrite $\left(\mathrm{CaSO}_{4}\right)$ to hemihydrate $\left(\mathrm{CaSO}_{4} \cdot 1 / 2 \mathrm{H}_{2} \mathrm{O}\right)$. The second episode of swelling usually began after ten or more days had elapsed.

Table 34 lists the swelling tests completed to date and the number of days each sample has been observed. Because the possibility of swelling would have such a profound effect on the choice of FGD for use in an embankment, we are continuing to study the swelling phenomenon in the laboratory in Phase 2 and are attempting to associate the occurrence of swell with evidence of mineralogical changes in the samples.

Table 33. Swelling test samples.

Sample Power Plant Process Replicates

\begin{tabular}{llll}
\hline CLS-01 & Edgewater & Coolside & A, B, C* \\
LIM-06 & Edgewater & LIMB & \\
LIM-07 & Edgewater & LIMB & \\
LIM-08 & Edgewater & LIMB & A, B* \\
LIM-10 & Edgewater & LIMB & A, B \\
LIM-14 & Edgewater & LIMB & A, B \\
OSU-03 & OSU & Spray Dryer & A, B, C \\
HST-05 & EPRI High S & Spray & \\
& Test Center & Dryer & \\
TID-3/4 & TIDD & PFBC & \\
& &
\end{tabular}


Table 34. Summary of swelling test results.

\begin{tabular}{lcc}
\hline Sample & Duration of Swell Test & Swell \\
\cline { 1 - 2 } & days & $\%$ \\
CLS-01A & 543 & 13.2 \\
CLS-01B & 169 & 11.1 \\
CLS-01C & 64 & 0.12 \\
LIM-06 & 544 & 1.02 \\
LIM-07 & 425 & 2.46 \\
LIM-03A & 425 & 9.60 \\
LIM-08B & 404 & 1.31 \\
LIM-10A & 423 & 5.90 \\
LIM-10R & 184 & 3.20 \\
LIM-14A & 246 & 69.3 \\
LIM-14B & 184 & 12.0 \\
OSU-03A & 423 & 1.97 \\
OSU-03B & 272 & 2.56 \\
OSU-03C & 82 & 1.60 \\
HST-05 & 243 & 0.58 \\
TID-3/4 & 267 & 0.87 \\
& & \\
\hline
\end{tabular}


Phase 1 Report

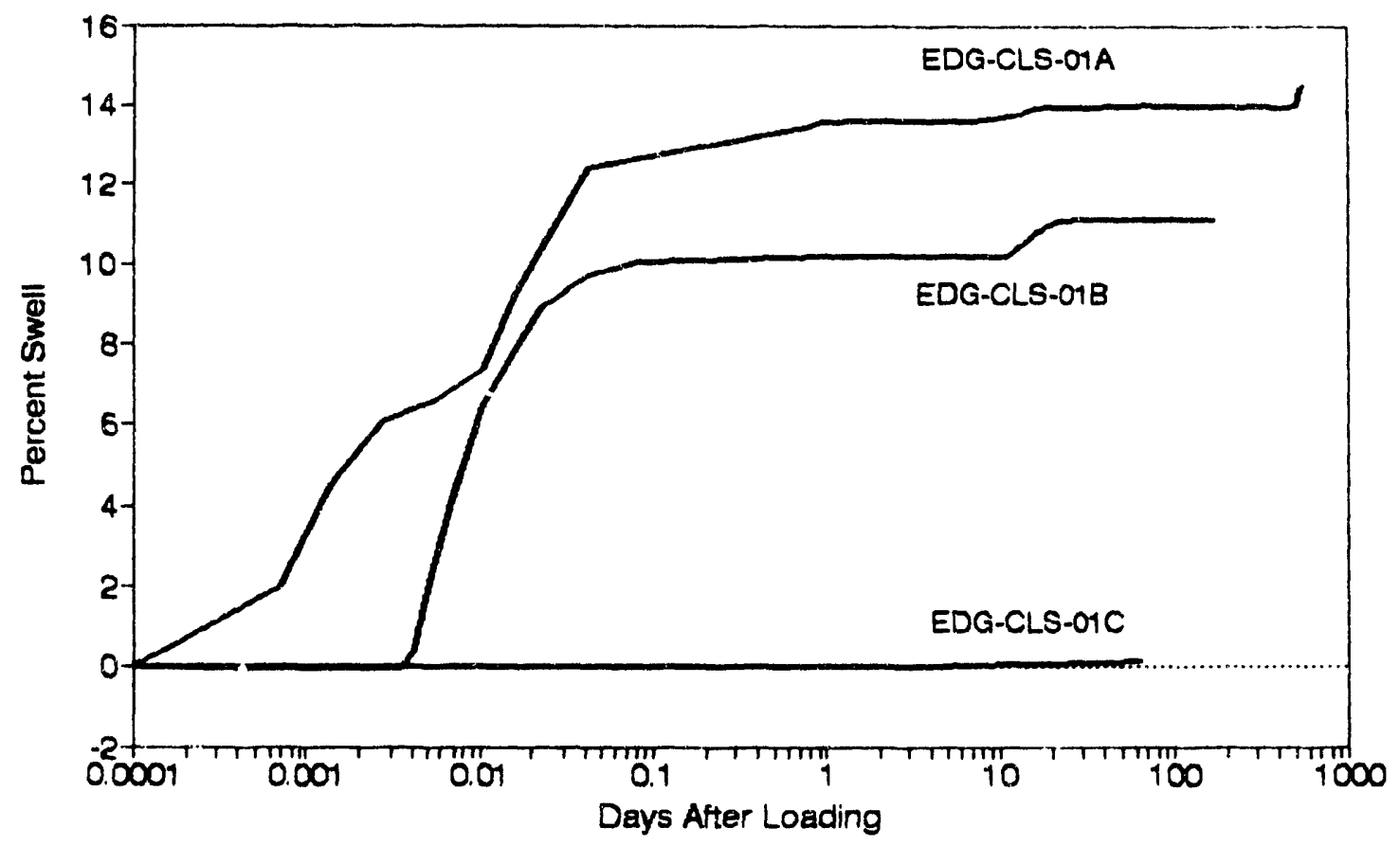

Fig. 66. Swelling vs. time: Coolside by-product.

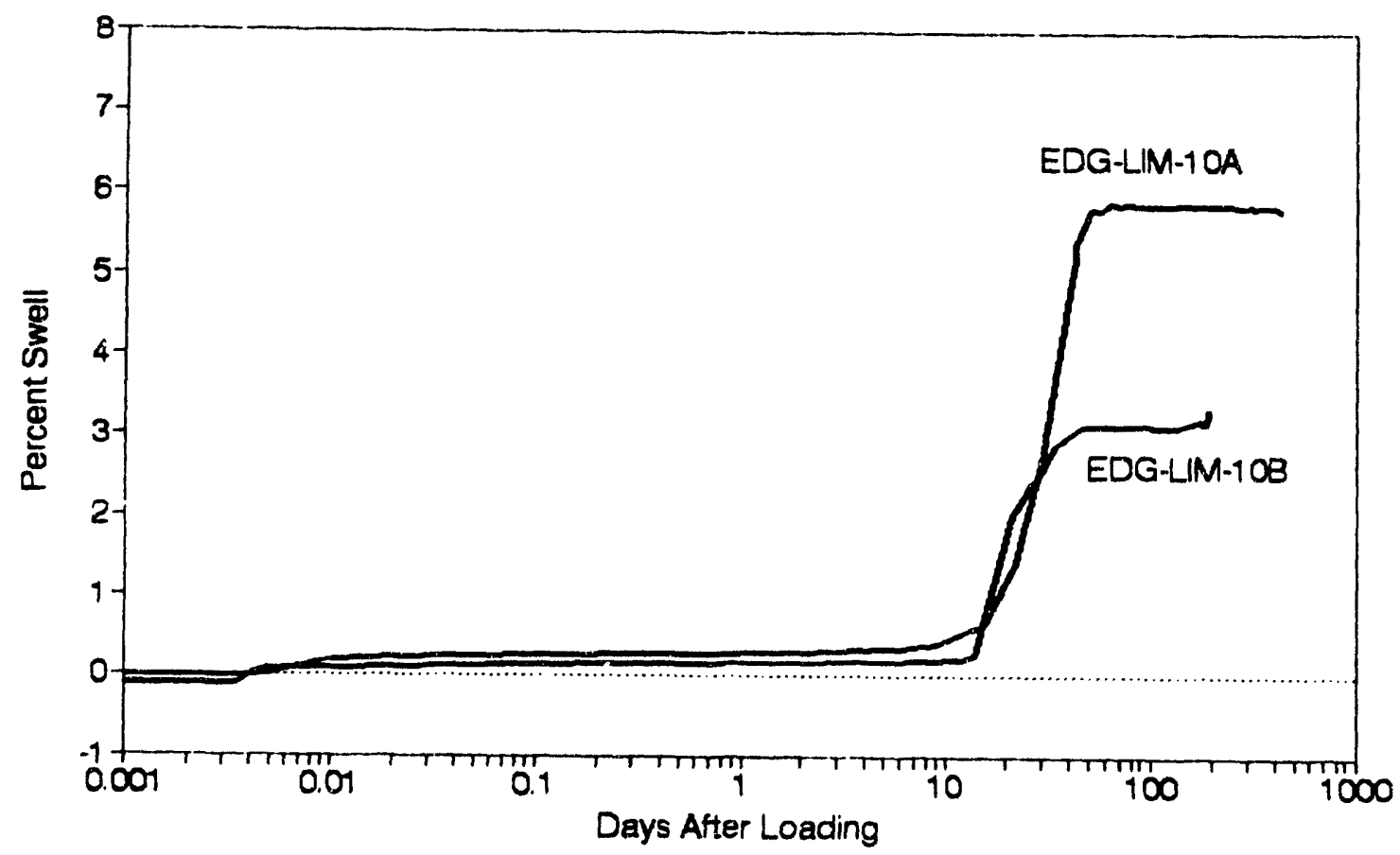

Fig. 67. Swelling vs. time: LIMB by-product. 


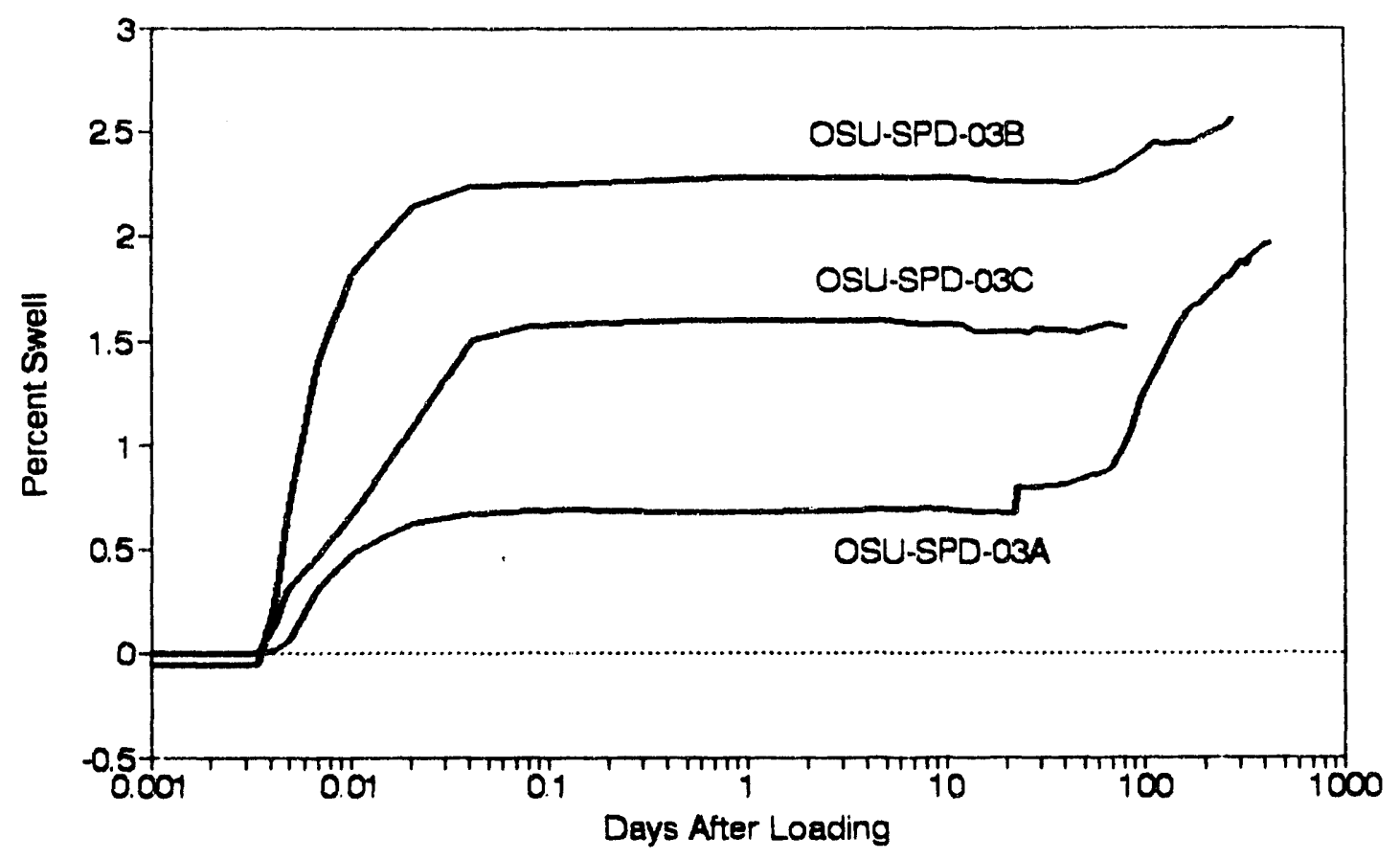

Fig. 68. Swelling vs. time: OSU spray dryer by-product.

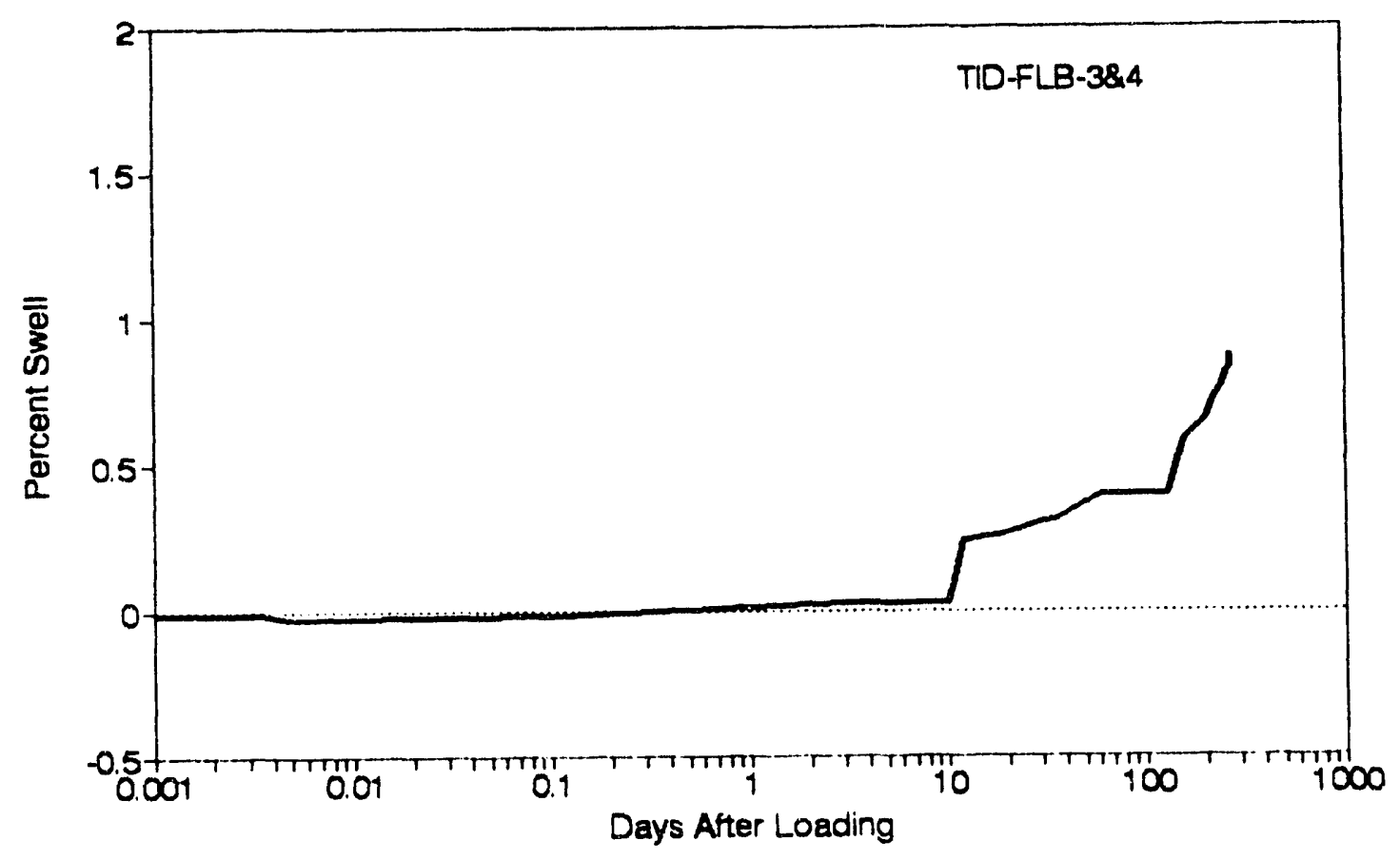

Fig. 69. Swelling vs. time: Tidd by-product. 
Phase 1 Report

\subsection{Economic Analyses}

\subsubsection{Overview}

The primary objectives of Phase 1 economic analyses have been (1) to develop the basic methodological framework for estimation of the financial and economic or social benefits and costs for FGD by-product recycling or disposal, and (2) to gather data not forthcoming from the technical tasks of the project so that preliminary runs can be made of our economic models. An extensive literature review, site visits and interviews, and considerable interaction with professional peers resulted in some refinements of the original objectives, major development of appropriate conceptual models and some preliminary data collection and model estimation.

\subsubsection{Materials Balance}

Flue gas desulfurization (FGD) by-products are one of the many residuals of production and consumption activities prevalent in a contemporary society. Specifically, FGD by-products result from the post-combustion "scrubbing" of flue gases in coal burning facilities. As the gross national product (GNP) or value of goods and services of a society grows so does the variety and volume of FGD and other residuals.

Raw materials are extracted from the environment, are processed in the production sector (that is, converted into consumer goods), and then--at least in part--are passed on to the household sector. The materials returning to the environment from the household sector are wastes or residuals. They are the unwanted by-products of the consumption activities of households. Similarly, not all of the material inputs that enter the production sector are passed on to the household sector. These are the wastes or residuals from production. Thus, there is a flow of residuals from both the production and consumption sectors back to the environment.

If the environment's capacity to absorb or assimilate wastes or residuals were unlimited, there would be no poilution problem and waste management would be a non-issue. However, the assimilative capacity of the environment is limited. One such limit results from the conflict or competition with other services provided by the environment such as human habitat, amenities, and materials inputs to the economic system. Many of these services provide significant economic benefits even though they may not be currently or directly priced in markets.

The materials balance model and the notion of a service-producing environment provide critical insights for the proper management of wastes or residuals. Examples suggested by Freeman et al. (1973) include (1) identification of the full range of technical options, (2) recognition of the interdependency among the various kinds of residual flows, (3) illumination of the relationships among population growth, economic growth and pollution, and (4) emphasis in public environmental institutions on broad jurisdiction over air, water, and land pollution, and over major physical systems such as river basins.

With increasing evidence of wastes or residuals exceeding the assimilative capacity of various environmental "sinks", it is important to first identify the major technical 
alternatives for either reducing wastes or altering assimilative capacity. Examples include the following:

1. Reducing the rate of throughput of materials and energy by reducing production, increasing the efficiency of production, converting residuals to new products or recycling them as inputs, or by changing the composition of economic activities so that lesser amounts of residuals are produced. The three alternative uses proposed for FGD by-products all involve recycling or conversion to new products.

2. Biologically, chemically, or mechanically treating or changing the residual to a more benign form for discharge to the environment.

3. Altering the time and place of residuals discharge.

4. Man-made investments to increase the residual assimilative capacity of the environment such as dams to store water for dispensing heavy waste loads and paddle wheels to augment the natural supplies of dissolved oxygen.

\subsubsection{Social Costs and Benefits}

Social costs and benefits -- or gains and losses -- from an economic perspective refer to the aggregation of individual producer and consumer measures of full willingness to accept or pay compensation. Individual preferences count in the determination of social benefits and costs and are weighted by income or, more narrowly, by market power. Since most policy changes involve economic gainers and losers, economists have developed the concept of potential Pareto improvement (PPI) to add up gains and losses to get net benefits. Simply stated, the concept holds that any policy change is a PPI or an increase in economic efficiency if at least one individual is better off after all losers are compensated to their original (or before the policy change) income positions. The compensation need not actually occur but must be possible (Dasgupta and Pearce, 1978).

These measures of social costs and benefits are not fully reflected in current market prices (thus the "social" terminology), such as the price of electricity resulting from coal-fired power generation, for several reasons. First, there are consumers willing to pay more and producers willing to sell for less than prevailing market or regulated prices. They receive what economists call consumer and producer surpluses. Second, technological externalities in coal-fired electric power generation exist to the extent that, external to the production and consumption of the resulting electricity, individuals experience uncompensated real economic losses or gains. Examples include air and water pollution, lake acidification from the combustion of coal, and adjacent property value losses from strip mining of coal. Finally, there may be willingness to pay to keep future economic options such as sport and commercial fishing open or to maintain plant or animal species threatened by water or air pollution. These externalities are not reflected in the market price of electricity.

Figure 70 illustrates both the concepts of economic surplus and technological externalities. One might think of $P$ as the market price for a kilowatt of electricity based on the intersection of marginal private cost (from the power plants perspective or accounting stance) of coal-fired production with demand. Thus, for example, at 


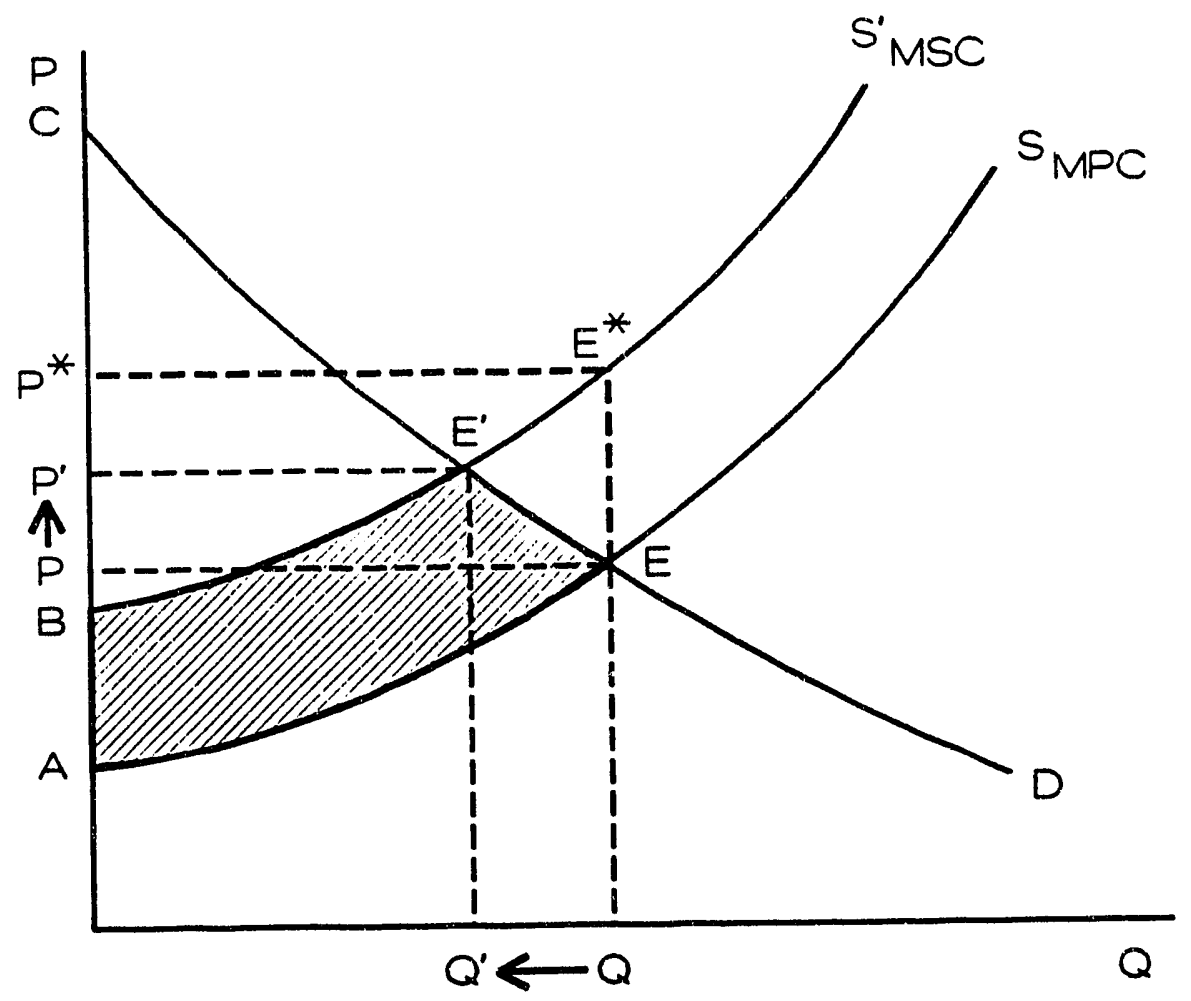

Technological Externality Defined (Dasgupta \& Pearce 1978)

1. Necessary Condition

Physical interdependence of production

and/or utility functions

2. Sufficient Condition

Not fully priced or compensated

$S=$ marginal private (e.g. power plant) cost function

$S^{\prime}=$ marginal social (e.g. air shed) cost function

$D=$ demand or marginal benefit function

$Q=$ output quantity

$P=$ price unit of output

Fig. 70. Concepts of economic surplus and techınological externalities. 
market price $P$ consumer surplus is equal to area PEC and producer surplus is equal to area PEA.

The fact that sulfur emissions from coal burning electric power plants appear to cause aquatic and forestry economic losses, the fact that strip mining of coal can lead to health and safety hazards as well as destruction of habitat and lower surrounding property values, and the possible global warming implications of $\mathrm{CO}_{2}$ emissions from coal combustion for electric power all suggest the presence of uncompensated technological externalities. Stated another way, output $Q$ exceeds the assimilative capacity of the environment. These external or social costs are internalized into the cost of producing coal-fired electricity and are represented by S' (i.e. the marginal social cost function). Price $P^{\prime}$ represents the price per kilowatt that would prevail if these external costs were included at output Q'. Price $P \star$ represents the marginal social cost at output $Q$. The shaded area BE'EA represents the net loss in producer and consumer surpluses from the presence of these uncompensated externalities.

The foregoing is a static analysis and does not show the adjustments that might occur over time due to, for example, a tax on or a subsidy for electricity equal to the distance between $P$ and $P *$. The willingness to pay to keep future options open or to maintain plant or animal species is also not shown in Figure 70 . However, if a proposed stripmine site impacts an endangered species for which considerable willingness to pay exists, it could result in the development of a higher cost alternative site which in turn would further increase the marginal social cost function in Figure 70.

A rapidly growing empirical economic literature (see, for example, Hufschmidt et al., 1983, Pearce and Turner, 1990, and V. Kerry Smith, 1993) has evolved from the foregoing conceptual concerns. The following major subsets are relevant to coal-fired electricity production:

1. Market values in related external markets. These values may be reflected in agricultural or forest crops damaged from air pollution, reduced maintenance and private re-routing costs from highway embankment stabilization, replacement costs such as electricity generation from biomass or natural gas, restoration or clean-up costs such as the liming of acidified lakes to return pH to normal levels, and monitoring and treatment costs of contaminated groundwater. For example, analysis by Hitzhusen and Nyamaah (1984) of private rerouting costs from the closure or weight limit posting of bridges in rural Ohio found that a repaired bridge resulted in much larger private savings than the public cost relative to public repair costs. This would suggest the possibility of relatively large economic benefits from the stabilization of highway embankments using FGD by-products. As a second example, sweden (as well as several northeastern states in the U.S.) is spending several million dollars per year on a very modest program to apply lime to a few of many acidified lakes. This is an attempt to reintroduce fish and other aquatic life presumably lost when coal combustion produced acid rain. The Swedes claim acid rain originates primarily from their European neighbors to the south, an example of a transnational externality.

2. Surrogate market measures. These include willingness to incur travel costs to use or avoid a particular natural resource or environmental service, impacts 
Phase 1 Report

(hedonic) on property values from the decrease or increase in the quality of a particular environmental service, reduction of landscape utility from strip mining, and wage differentials reflecting desirable or undesirable environmental attributes of a particular location impacted by water, air or visual pollution. For example, a travel cost analysis was done by Mullen and Menz (1985) on the economic effect of acidification damage in the Adirondack fishery to fisherman from New York State. The financial loss due to reduced travel and expenditures by fishermen to the Adirondack lakes for fishing exceeded \$1 million per year in 1976 values.

3. Direct surveys. These include surveys of willingness to pay for gain, or willingness to avoid loss of goods and services such as loss of visibility from air pollution or loss of sport fishing and related industries due to the impact of acid rain. Originally called hypothetical evaluation, this methodology is now known as contingent valuation and includes much concern for various forms of strategic behavior of respondents. Bidding and trade-off games are used to elicit the responses of willingness to accept and willingness to pay compensation. For example, Brookshire et al. (1976) used pictures of three alternative levels of visibility related to smokestacks and emissions from a proposed coal fired power plant in Lake Powell, Arizona. To elicit willingness to pay measures from respondents for these aesthetic damages or losses, an entrance fee to Lake Powell was used as the instrument to collect bids. The estimated aggregate bids ranged from $\$ 400,000$ to $\$ 700,000$ per year, not a trivial sum.

For a more detailed development of these concepts, see the attached paper by Hitzhusen presented at the ENVIROTECH conference in Vienna, Austria, April 23, 1992 (Appendix E) and the earlier mentioned publications by Hufschmidt et al., Pearce and Turner, and Smith.

\subsubsection{Analysis of Agricultural Lime Demand and Supply Relationships}

Limestone has a long history of use in agriculture. Agricultural lime, commonly termed aglime, is usually in the form of ground or crushed limestone. Its importance to agriculture is recognized by its being considered as a fertilizer, a soil conditioner, and as a soil amendment for correcting soil acidity and improving productivity.

There is a great disparity between the need for and actual use of agricultural lime even though there are proven benefits associated with its application. The returns on investment in agricultural limestone are very high if properly used at its recommended rates. Even though lime efficiency has been proven, U.S. farmers have decreased their use of lime. Factors contributing to a drop in aglime usage include government policy changes (decrease in government cost share for the purchase of lime used), and changes in farmers' cropping systems (shift away from crop rotations that include a legume forage). The supply of agricultural lime also has been affected by low profit margins for agricultural lime producers, seasonal demand for agricultural lime, the difficulties in its storage by producers, and the additional costs incurred from crushing operations to produce a very fine agricultural lime material. 


\subsubsection{Research Objective}

Our objective was to estimate demand and supply relationships that can best explain the observed variation in the usage of agricultural limestone in Ohio. The purpose of the demand equation is to quantify the sensitivity of farmers' demand for agricultural lime with respect to alternative factors such as prices of farm products, agricultural lime, and other inputs. The supply equation is used to estimate the effect of agricultural lime price, prices of key inputs such as transportation and fuel, and prices of non agricultural lime products on agricultural lime supplies.

\subsubsection{Data Collection}

This study concentrates on the demand and supply sides of agricultural lime in the State of Ohio. The data and the sources of data collected for the purpose of the present study consist of the following:

- The quantity of agricultural lime sales in short tons: Annual Report on Ohio Mineral Industries, Ohio Division of Geological Survey, Ohio Department of Natural Resources, 1955-1989. The assumption made here is that the quantity of agricultural lime sold by Ohio producers is the same as the quantity used in agriculture by Ohio farmers.

- The price of ground limestone in Ohio in dollars per ton: Annual Summary of Agricultural Prices, U.S. Department of Agriculture, 1960-1989 and the part from 1955-1960 was obtained from the archives of price paid by farmers from the Ohio Historical Library.

- The price of industrial lime: series LIME, the U.S. Department of the Interior, Bureau of Mines 1963-1990.

- Ohio riet farm income (in millions of dollar): Ohio Farm Income Series, Ohio Agricultural Research and Development Center, Wooster, Ohio, 1955-1960. The part of the data from 1955 to 1960 was also obtained from the Ohio Historical Library.

- The index of prices received by farmers for all crops, and index of prices paid by farmers for fertilizer: the Economic Report of the President, Council of Economic Advisors, 1990.

- The index of prices paid by farmers on items used for production: Annual Summary of Agricultural Prices, publication from the U.S. Department of Agriculture, 1990.

All prices are expressed in real terms, deflated by the producer price index for intermediate goods with 1982 as the base year. Ohio net farm income is deflated by the gross national product implicit price deflator (base year =1982). The data used to estimate the demand equation for agricultural lime are from 1955 to 1989. Data to estimate supply are from 1963 to 1989 because of the unavailability of data on industrial lime production from 1955 to 1962. 
Phase 1 Report

\subsection{Industry Structure in the United States}

The agricultural lime industry is a subsector of a larger lime industry and the crushed stone industry. The United States is the largest producer of crushed stone among the market economy countries. In 1989, total production of crushed stone reached 1.2 billion short tons of which $75 \%$ was limestone and dolomite. Agricultural lime accounted for $2 \%$ of total limestone production and $6 \%$ of total dolomite production. Of the 1989 total U.S crushed stone production, $74 \%$ was obtained from two major geographic areas, the south and the middle west. In the United States, limestone is produced in all states except Delaware, Louisiana, New Hampshire, and North Dakota.

The 1989 crushed dolomite output was reported in 27 states by 92 companies at 136 quarries. Of the 49 million tons of crushed dolomite consumed, $6 \%$ was used as agricultural lime.

The United States is self sufficient in crushed stone of which agricultural lime is a part. Production of limestone meets all domestic demand.

\subsection{Market Structure of Agricultural Limestone}

The agricultural lime industry is characterized by its low unit value. Agricultural limestone is a material of low price at the point of production. Transportation costs, however, substantially increase price at the point of delivery. Consequently, agricultural lime generally is produced near its marketable area and points of use, and the industry is mostly concentrated in high demand areas.

The limestone industry is highly competitive and characteristically serves local or regional markets as a result of an abundance of mineral deposits. Factors affecting production are mainly labor, equipment, energy, water, and compliance with environmental and safety regulations. These factors affect the cost of production which can vary with the natural formation of deposits, their geographic locations, and the quality and kind of product. The closer the markets are to the supply areas, the more significant the advantage to producers. Therefore, local production even though impure or of lower grade is more economical to farmers than purchasing higher quality material from distant markets at a higher cost. Most producers of agricultural lime are relatively small and face competition from large companies producing agricultural lime as a joint product of limestone or industrial lime production.

Limestone and dolomite were produced or sold by 80 companies at 122 operations in 54 Ohio counties during 1990. Total sales of limestone and dolomite were 52.7 million short tons from which $37.2 \%$ was the contribution of 5 counties (Erie, Franklin, Wyandot, Ottawa, and Sandusky). The 1990 reported sales of agricultural crushed and broken limestone accounted for $3 \%$ of total limestone sales in the state (Ohio Department of Natural Resources). 
Agricultural limestone producers, which are mainly crushed stone producers, face some problems related to environmental regulations, transportation costs, and marketing programs. Location of firms and processing quarries near suburban areas make air pollution from the crushing operation a major problem in the crushed stone industry. On the marketing side, in addition to the competition of the fertilizer industry, little effort has been made to promote the sale of agricultural limestone.

\subsection{Method of Estimation}

A simultaneous system of equations, estimated by a two-stage regression technique, was used to estimate factors influencing demand and supply of agricultural lime. Because demand and supply are believed to be determined simultaneously, the two stage least squares estimation technique was applied. This is to avoid the bias and inconsistency associated with ordinary least squares estimators. Indeed, ordinary least squares estimation is inappropriate when there is joint determination between two or more dependent variables. The following assumptions were made:

- demand and supply (quantity and price) of agricultural lime are simultaneously determined and the use of agricultural lime can be affected by economic factors that affect the supply as well as the demand side.

- the price of agricultural lime is determined with regard to economic phenomena related to its manufacturing, processing, and marketing situations. Price is considered as an endogenous variable.

\subsubsection{Results}

Two functional forms were used to estimate the model. One form involved the use of linear equations and the other form used was a logarithmic transform of these linear equations and is called a double-log linear regression model. The model that offers the better explanation of the demand and supply of agricultural lime is the double-log linear regression model and only results from this model are presented. The equations from the two stage least squares estimation process are as follows:

\subsection{Demand and Supply Estimates}

Demand Equation

$$
\begin{aligned}
& \log (\mathrm{QAL})=-1.9417-0.101 \log (\mathrm{PAL})+1.176 \log (\mathrm{IPP})+ \\
& (-1.639)(-0.271) \quad(4.764) \\
& 0.118 \log (\mathrm{NFI})-0.677 \log (\mathrm{IIP})+0.539 \mathrm{D} \\
& \text { (1.992) (-3.730) } \\
& R^{2}=0.77, \text { adjusted } R^{2}=0.73
\end{aligned}
$$


Phase 1 Report

Supply Equation

$$
\begin{aligned}
& \log (Q A L)=0.1468+0.646 \log (P A L)-0.014 \log (P I L)- \\
& \text { (0.063) (1.557) (-0.025) } \\
& 2.234 \log (\text { ITR })-0.349 \log (\text { IFU) }+2.264 \log (\text { IME) } \\
& (-2.932) \quad(-1.179) \quad \text { (2.712) } \\
& R^{2}=0.58, \text { adjusted } R^{2}=0.48
\end{aligned}
$$

wherein

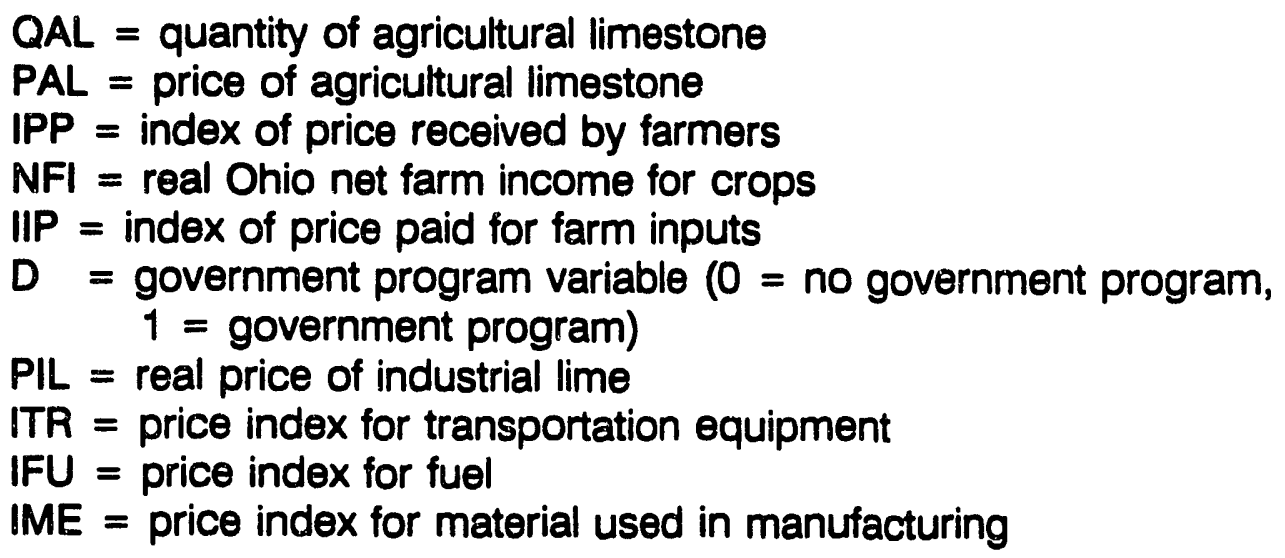

The number in parenthesis is the t-statistic. The use of the t-statistic is very common in the case of Ordinary Least Squares estimators and Two Stages Least Squares Estimators. It is a computed number for each parameter estimate in the regression. The most common use of the t-statistic is in testing hypotheses and creating interval estimates, and to infer the level of significance of the parameters of the estimated regression, e.g., each number in parenthesis indicates how the parameter in question is significantly different from zero.

Considering the demand side, in terms of explanatory power, the squared coefficient of determination $\left(R^{2}\right)$ is very high $(0.77)$ indicating that $77 \%$ of the variation in demand for agricultural lime is explained by the model. Also, the coefficient of determination $\left(R^{2}\right)$ in the supply estimation is 0.58 and indicates that the model has an appreciable explanatory power.

The estimated demand and supply relationships identify the contribution of individual factors (say price of agricultural lime) in explaining the variations in the quantity of agricultural lime demanded or supplied, holding all other variables constant.

The demand price of agricultural lime is inelastic $(-0.101)$. In this case, inelasticity implies that demand is relatively insensitive to price changes. There is a negative association between the price of agricultural lime and its purchase by farmers. As 
agricultural lime price increases by $1 \%$, quantity demanded by farmers decreases by $0.101 \%$. Lime usage proves to be income inelastic $(0.118)$ but highly elastic with respect to crop prices paid to farmers (1.176). That is, a $1 \%$ increase in net farm income increases quantity demanded by $0.118 \%$, while a $1 \%$ increase in crop prices increases quantity demanded of agricultural lime by $1.176 \%$. On the other hand, lime application in agriculture is inversely related to prices of other farm production inputs, and a $1 \%$ increase in the price of items used for production (IIP) decreases the demand for agricultural lime by $0.68 \%$. Last, on the demand side, cost share conservation programs have had a significant positive effect on agricultural lime usage.

The supply price of agricultural limestone is also considered inelastic (0.646). That is, agricultural lime producers respond to a $1 \%$ increase in agricultural lime price by increasing agricultural lime production by only $0.646 \%$. An inverse relationship between prices of industrial lime and the supply of agricultural lime is noted. That is, increasing industrial lime prices result in slightly lower agricultural lime supplies. One $\%$ increase in prices of transportation equipment and fuel leads respectively to a drop of 2.23 and $0.34 \%$ in lime supply. However, $1 \%$ increase in material handling equipment price increases agricultural lime supply by $2.264 \%$.

From the results of this econometric model of agricultural lime supply and demand relationships, the price elasticity of demand is 0.10 , and a rise in the price of agricultural lime, holding everything constant, has only a small direct effect on its use. However, the use of agricultural lime is affected by prices of other farm inputs, by net farm income, and by crop prices. An elasticity of supply of 0.64 roughly means that a $10 \%$ increase in price of agricultural lime would lead producers to increase supply by $6 \%$.

The industry appears to be capable of readily increasing supply in response to agricultural lime price increases. This analysis supports the comment by William L. Carter, NCSA's President, who mentioned at the 1980 National Limestone Conference that the crushed stone industry is able to meet the demand side for agricultural lime in a range between 30 million tons and 90 million tons, which are respectively the historic annual use of agricultural lime and the estimated annual need for lime in agriculture.

\subsubsection{Summary and Implications}

Agricultural lime is a product of both the crushed stone industry and lime industry. It is a material of low price per ton at point of production. However, due to its bulk, transportation costs constitute a considerable part of its price at points of delivery. Because of high transportation costs and the abundance of limestone deposits in the United States, agricultural limestone is marketed within small geographic areas and not transported large distances.

Agricultural limestone has experienced a declining market in agriculture even though the benefits from its application are well documented. A two stage model was used to analyze the demand and supply forces of this input market. A double-log 
linear regression model was used to estimate these relationships. This model shows that the demand for lime is inelastic with respect to its price. Its use also is affected by the prices of other agricultural inputs used in production. The quantity of agricultural lime supplied is also inelastic with respect to its price. It is affected by various factors of production such as transportation and fuel costs, which have an inverse relationship with respect to lime supply.

FGD by-product promises to be an effective substitute for agricultural lime, and characteristics of the agricultural lime market will affect FGD by-product use. This new product will be entering a highly competitive market. If it is to be used in agriculture, it will have to replace agricultural lime. Agricultural limestone producers stand to lose market opportunities with the introduction of FGD by-products, even though limestone producers would probably gain an even bigger market if coal burners are retrofitted with scrubbers. However, the agricultural lime market constitutes a relatively small share of total sales in the limestone industry. 
Table 35. Price paid by farmers tior ground limestone in dollars per ton.

\begin{tabular}{|c|c|c|}
\hline Year & Actual Price & $\begin{array}{c}\text { Real Price } \\
1982=100\end{array}$ \\
\hline $\begin{array}{l}1955 \\
1956 \\
1957 \\
1958 \\
1959\end{array}$ & $\begin{array}{l}4.20 \\
4.34 \\
4.46 \\
4.57 \\
4.62\end{array}$ & $\begin{array}{l}14.70 \\
14.65 \\
14.71 \\
15.03 \\
15.00\end{array}$ \\
\hline $\begin{array}{l}1960 \\
1961 \\
1962 \\
1963 \\
1964\end{array}$ & $\begin{array}{l}4.66 \\
1.67 \\
4.75 \\
4.74 \\
4.76\end{array}$ & $\begin{array}{l}15.12 \\
15.25 \\
15.52 \\
15.43 \\
15.45\end{array}$ \\
\hline $\begin{array}{l}1965 \\
1966 \\
1967 \\
1968 \\
1969\end{array}$ & $\begin{array}{l}4.60 \\
4.65 \\
4.50 \\
4.60 \\
4.60\end{array}$ & $\begin{array}{l}14.74 \\
14.53 \\
13.91 \\
13.93 \\
13.48\end{array}$ \\
\hline $\begin{array}{l}1970 \\
1971 \\
1972 \\
1973 \\
1974\end{array}$ & $\begin{array}{l}4.90 \\
4.50 \\
4.20 \\
4.50 \\
5.70\end{array}$ & $\begin{array}{l}13.84 \\
12.23 \\
10.90 \\
10.61 \\
10.85\end{array}$ \\
\hline $\begin{array}{l}1975 \\
1976 \\
1977 \\
1978 \\
1979\end{array}$ & $\begin{array}{l}6.40 \\
5.00 \\
7.64 \\
8.30 \\
8.90\end{array}$ & $\begin{array}{r}10.03 \\
8.21 \\
11.72 \\
11.94 \\
11.35\end{array}$ \\
\hline $\begin{array}{l}1980 \\
1981 \\
1982 \\
1983 \\
1984\end{array}$ & $\begin{array}{r}9.67 \\
10.50 \\
10.90 \\
10.30 \\
10.60\end{array}$ & $\begin{array}{l}10.70 \\
10.64 \\
10.90 \\
10.23 \\
10.24\end{array}$ \\
\hline $\begin{array}{l}1985 \\
1986 \\
1987 \\
1988 \\
1989\end{array}$ & $\begin{array}{l}12.10 \\
12.60 \\
12.70 \\
12.90 \\
12.70\end{array}$ & $\begin{array}{l}11.75 \\
12.71 \\
12.51 \\
12.04 \\
11.33\end{array}$ \\
\hline
\end{tabular}

Source: USDA, Series of Annual Summary Agricultural Prices. 
Table 36. Agricultural limestone sales report of crushed and broken limestone in Ohio.

\begin{tabular}{|c|c|}
\hline Year & $\begin{array}{c}\text { Total Quantity } \\
\text { (Million Short Tons) }\end{array}$ \\
\hline $\begin{array}{l}1955 \\
1956 \\
1957 \\
1958 \\
1959\end{array}$ & $\begin{array}{l}2.2743 \\
2.2457 \\
2.3517 \\
1.8303 \\
1.9289\end{array}$ \\
\hline $\begin{array}{l}1960 \\
1961 \\
1962 \\
1963 \\
1964\end{array}$ & $\begin{array}{l}2.1023 \\
2.0835 \\
1.9514 \\
2.1918 \\
2.1534\end{array}$ \\
\hline $\begin{array}{l}1965 \\
1966 \\
1967 \\
1968 \\
1969\end{array}$ & $\begin{array}{l}1.9355 \\
2.1328 \\
2.0458 \\
1.8775 \\
1.5918\end{array}$ \\
\hline $\begin{array}{l}1970 \\
1971 \\
1972 \\
1973 \\
1974\end{array}$ & $\begin{array}{l}1.5082 \\
1.6251 \\
1.1956 \\
1.5852 \\
1.7353\end{array}$ \\
\hline $\begin{array}{l}1975 \\
1976 \\
1977 \\
1978 \\
1979\end{array}$ & $\begin{array}{l}1.8918 \\
2.1893 \\
1.4211 \\
1.4293 \\
1.3039\end{array}$ \\
\hline $\begin{array}{l}1980 \\
1981 \\
1982 \\
1983 \\
1984\end{array}$ & $\begin{array}{l}1.7585 \\
1.3928 \\
1.2034 \\
1.1183 \\
1.6756\end{array}$ \\
\hline $\begin{array}{l}1985 \\
1986 \\
1987 \\
1988 \\
1989\end{array}$ & $\begin{array}{l}1.2342 \\
1.0787 \\
1.3070 \\
1.4923 \\
1.5621\end{array}$ \\
\hline
\end{tabular}

Source: Ohio Division of Geological Survey, ODNR, series: Annual Report on Ohio Mir eral Industries. 
Table 37. Ohio farm income.

\begin{tabular}{|c|c|c|}
\hline Year & $\begin{array}{c}\text { Actual } \\
\text { Total Net } \\
\text { Farm Income } \\
\text { (Million \$) }\end{array}$ & $\begin{array}{l}\text { Deflated } \\
\text { Total Net } \\
\text { Farm Income } \\
\text { (Million \$) }\end{array}$ \\
\hline $\begin{array}{l}1955 \\
1956 \\
1957 \\
1958 \\
1959\end{array}$ & $\begin{array}{l}368.50 \\
369.30 \\
309.00 \\
375.20 \\
374.70\end{array}$ & $\begin{array}{l}1352 \\
1314 \\
1062 \\
1263 \\
1232\end{array}$ \\
\hline $\begin{array}{l}1960 \\
1961 \\
1962 \\
1963 \\
1964\end{array}$ & $\begin{array}{l}326.70 \\
369.60 \\
333.40 \\
323.30 \\
322.80\end{array}$ & $\begin{array}{r}1057 \\
1185 \\
1045 \\
998 \\
981\end{array}$ \\
\hline $\begin{array}{l}1965 \\
1966 \\
1967 \\
1968 \\
1969\end{array}$ & $\begin{array}{l}397.10 \\
552.30 \\
385.90 \\
422.80 \\
411.90\end{array}$ & $\begin{array}{l}1174 \\
1578 \\
1074 \\
1121 \\
1035\end{array}$ \\
\hline $\begin{array}{l}1970 \\
1971 \\
1972 \\
1973 \\
1974\end{array}$ & $\begin{array}{l}404.50 \\
418.90 \\
564.80 \\
778.20 \\
727.30\end{array}$ & $\begin{array}{r}963 \\
943 \\
1215 \\
1572 \\
1347\end{array}$ \\
\hline $\begin{array}{l}1975 \\
1976 \\
1977 \\
1978 \\
1979\end{array}$ & $\begin{array}{l}711.90 \\
644.00 \\
640.00 \\
655.40 \\
886.80\end{array}$ & $\begin{array}{r}1200 \\
1021 \\
951 \\
908 \\
1128\end{array}$ \\
\hline $\begin{array}{l}1980 \\
1981 \\
1982 \\
1983 \\
1984\end{array}$ & $\begin{array}{l}611.90 \\
310.40 \\
476.40 \\
120.50 \\
915.90\end{array}$ & $\begin{array}{l}714 \\
330 \\
476 \\
116 \\
850\end{array}$ \\
\hline $\begin{array}{l}1985 \\
1986 \\
1987 \\
1988 \\
1989\end{array}$ & $\begin{array}{l}867.00 \\
819.00 \\
956.20 \\
766.60 \\
823.30\end{array}$ & $\begin{array}{l}782 \\
720 \\
814 \\
632 \\
652\end{array}$ \\
\hline
\end{tabular}

Source: OARDC, Wooster, Ohio, Ohio Farm Income Series. 
Table 38. Price indices: I.

\begin{tabular}{|c|c|c|c|c|c|}
\hline Year & $\begin{array}{c}\text { Trans- } \\
\text { portation }\end{array}$ & $\begin{array}{l}\text { Processed } \\
\text { Fuel }\end{array}$ & $\begin{array}{c}\text { Capital } \\
\text { Equipment }\end{array}$ & $\begin{array}{l}\text { Material and } \\
\text { Components for } \\
\text { Manufacturing }\end{array}$ & $\begin{array}{c}\text { Unit Labor } \\
\text { Cost }\end{array}$ \\
\hline $\begin{array}{l}1955 \\
1956 \\
1957 \\
1958 \\
1959\end{array}$ & $\begin{array}{l}34.30 \\
36.30 \\
37.90 \\
39.00 \\
39.90\end{array}$ & $\begin{array}{l}15.80 \\
16.30 \\
17.20 \\
16.20 \\
16.20\end{array}$ & $\begin{array}{l}27.40 \\
29.50 \\
31.30 \\
32.10 \\
32.70\end{array}$ & $\begin{array}{l}30.50 \\
32.00 \\
32.70 \\
32.80 \\
33.30\end{array}$ & $\begin{array}{l}27.40 \\
28.90 \\
30.00 \\
30.60 \\
30.80\end{array}$ \\
\hline $\begin{array}{l}1960 \\
1961 \\
1962 \\
1963 \\
1964\end{array}$ & $\begin{array}{l}39.30 \\
39.20 \\
39.20 \\
38.90 \\
39.10\end{array}$ & $\begin{array}{l}16.60 \\
16.80 \\
16.70 \\
16.60 \\
16.20\end{array}$ & $\begin{array}{l}32.80 \\
32.90 \\
33.00 \\
33.10 \\
33.40\end{array}$ & $\begin{array}{l}33.30 \\
32.90 \\
32.70 \\
32.70 \\
33.10\end{array}$ & $\begin{array}{l}31.80 \\
31.90 \\
32.20 \\
32.10 \\
32.40\end{array}$ \\
\hline $\begin{array}{l}1965 \\
1966 \\
1967 \\
1968 \\
1969\end{array}$ & $\begin{array}{l}39.20 \\
39.20 \\
39.80 \\
40.90 \\
41.70\end{array}$ & $\begin{array}{l}16.50 \\
16.80 \\
16.90 \\
16.50 \\
16.60\end{array}$ & $\begin{array}{l}33.80 \\
34.60 \\
35.80 \\
37.00 \\
38.30\end{array}$ & $\begin{array}{l}33.60 \\
34.30 \\
34.50 \\
35.30 \\
36.50\end{array}$ & $\begin{array}{l}32.60 \\
33.80 \\
34.80 \\
36.50 \\
39.10\end{array}$ \\
\hline $\begin{array}{l}1970 \\
1971 \\
1972 \\
1973 \\
1974\end{array}$ & $\begin{array}{l}43.30 \\
45.70 \\
47.00 \\
47.40 \\
51.40\end{array}$ & $\begin{array}{l}17.70 \\
19.50 \\
20.10 \\
22.20 \\
33.60\end{array}$ & $\begin{array}{l}40.10 \\
41.70 \\
42.80 \\
44.20 \\
50.50\end{array}$ & $\begin{array}{l}38.00 \\
38.90 \\
40.40 \\
44.10 \\
56.00\end{array}$ & $\begin{array}{l}41.80 \\
43.20 \\
44.60 \\
47.30 \\
52.90\end{array}$ \\
\hline $\begin{array}{l}1975 \\
1976 \\
1977 \\
1978 \\
1979\end{array}$ & $\begin{array}{l}57.60 \\
61.20 \\
65.20 \\
70.00 \\
75.80\end{array}$ & $\begin{array}{l}39.40 \\
42.30 \\
47.70 \\
49.90 \\
61.60\end{array}$ & $\begin{array}{l}58.20 \\
62.10 \\
66.10 \\
71.30 \\
77.50\end{array}$ & $\begin{array}{l}61.70 \\
64.00 \\
67.40 \\
72.00 \\
80.90\end{array}$ & $\begin{array}{l}57.10 \\
60.30 \\
64.10 \\
68.90 \\
76.70\end{array}$ \\
\hline $\begin{array}{l}1980 \\
1981 \\
1982 \\
1983 \\
1984\end{array}$ & $\begin{array}{r}83.10 \\
94.60 \\
100.00 \\
102.20 \\
104.10\end{array}$ & $\begin{array}{r}85.00 \\
100.60 \\
100.00 \\
95.40 \\
95.70\end{array}$ & $\begin{array}{r}85.80 \\
94.60 \\
100.00 \\
102.80 \\
105.20\end{array}$ & $\begin{array}{r}91.70 \\
98.70 \\
100.00 \\
101.20 \\
104.10\end{array}$ & $\begin{array}{r}85.10 \\
92.20 \\
100.00 \\
100.90 \\
102.80\end{array}$ \\
\hline $\begin{array}{l}1985 \\
1986 \\
1987 \\
1988 \\
1989\end{array}$ & $\begin{array}{l}106.40 \\
109.10 \\
111.70 \\
113.10 \\
116.10\end{array}$ & $\begin{array}{l}92.80 \\
72.70 \\
73.30 \\
71.20 \\
76.50\end{array}$ & $\begin{array}{l}107.50 \\
109.70 \\
111.70 \\
114.30 \\
118.70\end{array}$ & $\begin{array}{l}103.30 \\
102.20 \\
105.30 \\
113.20 \\
118.20\end{array}$ & $\begin{array}{l}105.60 \\
108.80 \\
111.60 \\
114.50 \\
119.00\end{array}$ \\
\hline
\end{tabular}

Source: The Economic Report of the President, Council of Economic Advisors, 1990. 
Table 39. Price indices: II.

\begin{tabular}{|c|c|c|c|}
\hline Year & $\begin{array}{l}\text { Items Used } \\
\quad \text { for } \\
\text { Production }\end{array}$ & $\begin{array}{c}\text { Fertilizer } \\
\text { Price } \\
\text { Index }\end{array}$ & $\begin{array}{l}\text { Prices } \\
\text { Paid to } \\
\text { Farmers }\end{array}$ \\
\hline $\begin{array}{l}1955 \\
1956 \\
1957 \\
1958 \\
1959\end{array}$ & $\begin{array}{l}28.30 \\
28.20 \\
29.00 \\
29.80 \\
30.00\end{array}$ & $\begin{array}{l}40.00 \\
39.00 \\
40.00 \\
40.00 \\
39.00\end{array}$ & $\begin{array}{l}53.00 \\
54.00 \\
52.00 \\
52.00 \\
51.00\end{array}$ \\
\hline $\begin{array}{l}1960 \\
1961 \\
1962 \\
1963 \\
1964\end{array}$ & $\begin{array}{l}29.90 \\
30.00 \\
30.50 \\
30.80 \\
30.50\end{array}$ & $\begin{array}{l}39.00 \\
40.00 \\
40.00 \\
39.00 \\
39.00\end{array}$ & $\begin{array}{l}51.00 \\
52.00 \\
54.00 \\
55.00 \\
55.00\end{array}$ \\
\hline $\begin{array}{l}1965 \\
1966 \\
1967 \\
1968 \\
1969\end{array}$ & $\begin{array}{l}31.20 \\
32.20 \\
32.40 \\
32.90 \\
34.30\end{array}$ & $\begin{array}{l}39.00 \\
39.00 \\
38.00 \\
36.00 \\
33.00\end{array}$ & $\begin{array}{l}53.00 \\
55.00 \\
52.00 \\
52.00 \\
50.00\end{array}$ \\
\hline $\begin{array}{l}1970 \\
1971 \\
1972 \\
1973 \\
1974\end{array}$ & $\begin{array}{l}35.40 \\
37.40 \\
39.50 \\
47.80 \\
54.30\end{array}$ & $\begin{array}{l}33.00 \\
35.00 \\
36.00 \\
39.00 \\
64.00\end{array}$ & $\begin{array}{r}52.00 \\
56.00 \\
60.00 \\
91.00 \\
117.00\end{array}$ \\
\hline $\begin{array}{l}1975 \\
1976 \\
1977 \\
1978 \\
1979\end{array}$ & $\begin{array}{l}59.60 \\
63.10 \\
65.30 \\
70.90 \\
81.10\end{array}$ & $\begin{array}{l}83.00 \\
71.00 \\
69.00 \\
69.00 \\
75.00\end{array}$ & $\begin{array}{l}105.00 \\
102.00 \\
100.00 \\
105.00 \\
116.00\end{array}$ \\
\hline $\begin{array}{l}1980 \\
1981 \\
1982 \\
1983 \\
1984\end{array}$ & $\begin{array}{r}90.20 \\
96.40 \\
100.00 \\
99.70 \\
101.60\end{array}$ & $\begin{array}{r}93.00 \\
100.00 \\
100.00 \\
95.00 \\
99.00\end{array}$ & $\begin{array}{l}125.00 \\
134.00 \\
121.00 \\
128.00 \\
138.00\end{array}$ \\
\hline $\begin{array}{l}1985 \\
1986 \\
1987 \\
1988 \\
1989\end{array}$ & $\begin{array}{r}98.60 \\
94.20 \\
96.40 \\
102.80 \\
108.10\end{array}$ & $\begin{array}{l}94.00 \\
86.00 \\
82.00 \\
90.00 \\
95.00\end{array}$ & $\begin{array}{l}120.00 \\
107.00 \\
106.00 \\
124.00 \\
134.00\end{array}$ \\
\hline
\end{tabular}

Source: USDA, Annual Summary Agricultural Prices, 1990; and The Council of Economic Advisors, 1990. 


\subsubsection{Representative Farm Preliminary Analysis of FGD as Agronomic Lime Substitute}

This section reports on a preliminary analysis of FGD by-product as an agricultural lime substitute. This required making a farm level comparison of current agricultural liming practices with those of the proposed substitute. In order to make this comparison, representative farms were depicted and alternative liming practices were developed for these farms. A typical farm was constructed for each of two geographic regions, the northwest and northeast quadrants of the state (Figure 71).

The northeast and northwest regions account for $60 \%$ of the agricultural lime usage in Ohio: $34 \%$ of Ohio lime is used in the northwestern region, and $26 \%$ in the northeastern region. These regions also represent extremes in market conditions for agricultural lime and FGD by-product. In contrast to the northeast region, the northwest region tends to have higher soil pH, lower agricultural lime application rates, closer distances to limestone quarries, and farther distances to potential FGD sources. Given these characteristics, the northwest region would appear to present weaker market opportunities for the FGD by-product than would the northeastern region. Farm types in the northwestern region of Ohio generalize to the southwestern region, and in the northeastern region to the southeastern region, reasonably well.

\subsubsection{Farm Selection}

Using the Ohio Farm Household Longitudinal Study (1990), a representative farm for each geographic region was constructed. The Ohio Farm Household Longitudinal Survey is a stratified sample, which is representative of Ohio farm households. Thus, mean farm size and agricultural practices for farms in the sample should be representative of average farming practices within these regions.

The boundaries for each region are shown in Figure 71. As illustrated by the crops grown on these representative farms, land use differs between these two regions (Figures 72 and 73 ). In the northwest, corn and soybeans are grown on almost 80 percent of the cropland, compared to about 60 percent in the northeast. Hay is an important crop in the northeast, but it is grown on a relatively small proportion of the cropland in the northwest.

\subsubsection{Agricultural Lime Use}

Agricultural lime application rates are estimated using the average soil $\mathrm{pH}$ and average lime test indexes (LTI) for each region (OARDC). From this information, suggested lime application rates are estimated assuming a pH of 7.0 is desired (Table 40). These suggested or recommended rates of application for the representative farms are lower than farmers actually apply. For example, from 1986-91, farmers annually spent about $\$ 0.07$ per acre on agricultural lime in the northwest and about $\$ 0.18$ per acre in the northeast, which is in sharp contrast to the $\$ 6$ to $\$ 12$ per acre agricultural lime costs projected in these budgets. However, application rates used in 


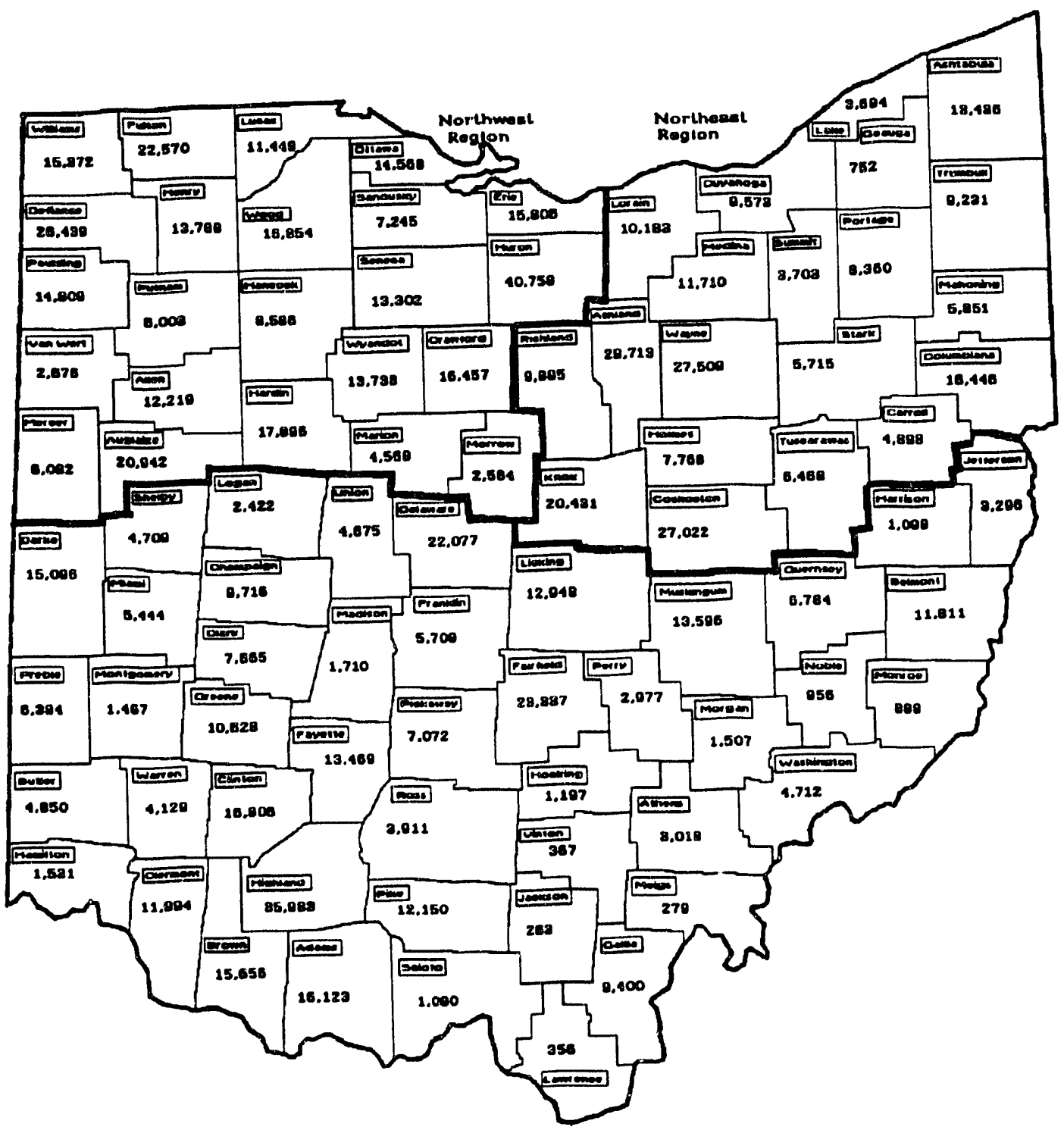

Fig. 71. Map of Ohio depicting quadrants used in liming study. The number in each count is the average annual sale of agricultural lime for that county. 


\section{Composition of Avg. Farm Northeast Region-- 246 total ac.}

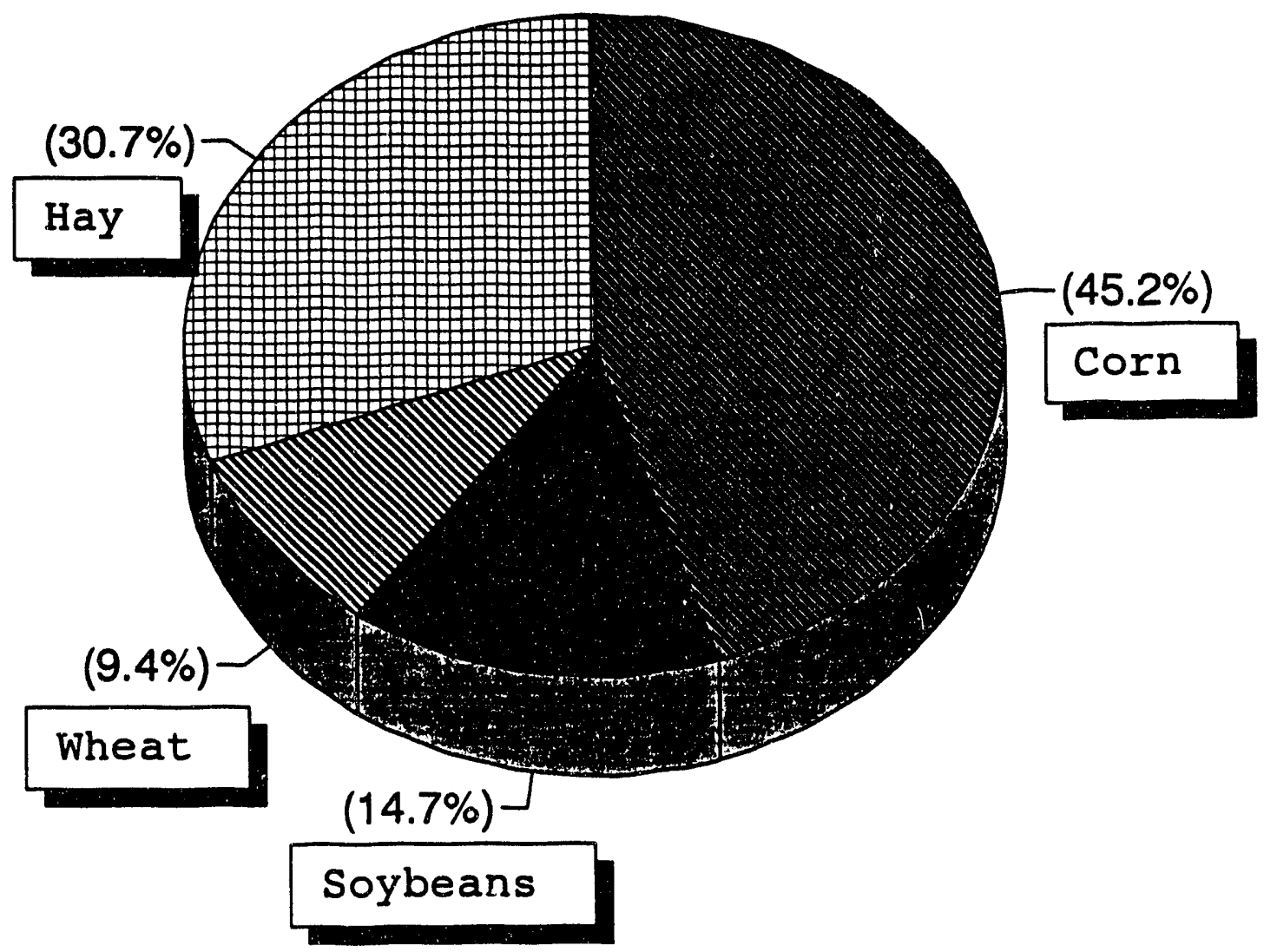

Fig. 72. Composition of an average farm in the Northeast Region of Ohio (total area $=246$ acres). 


\section{Composition of Avg. Farm Northwest Region-- 471 total ac.}

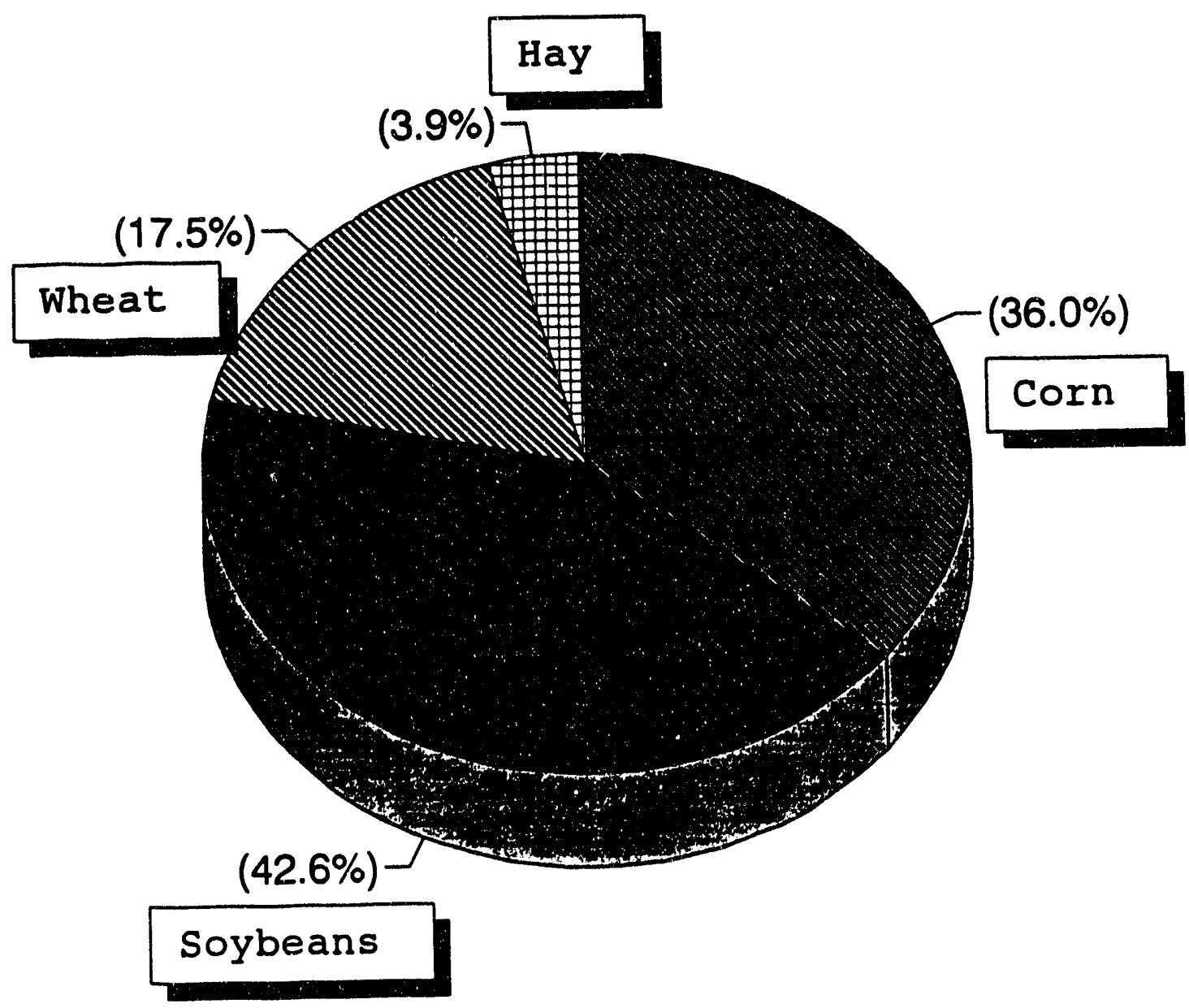

Fig. 73. Composition of an average farm in the Northwest Region of Ohio (total area $=471$ acres). 


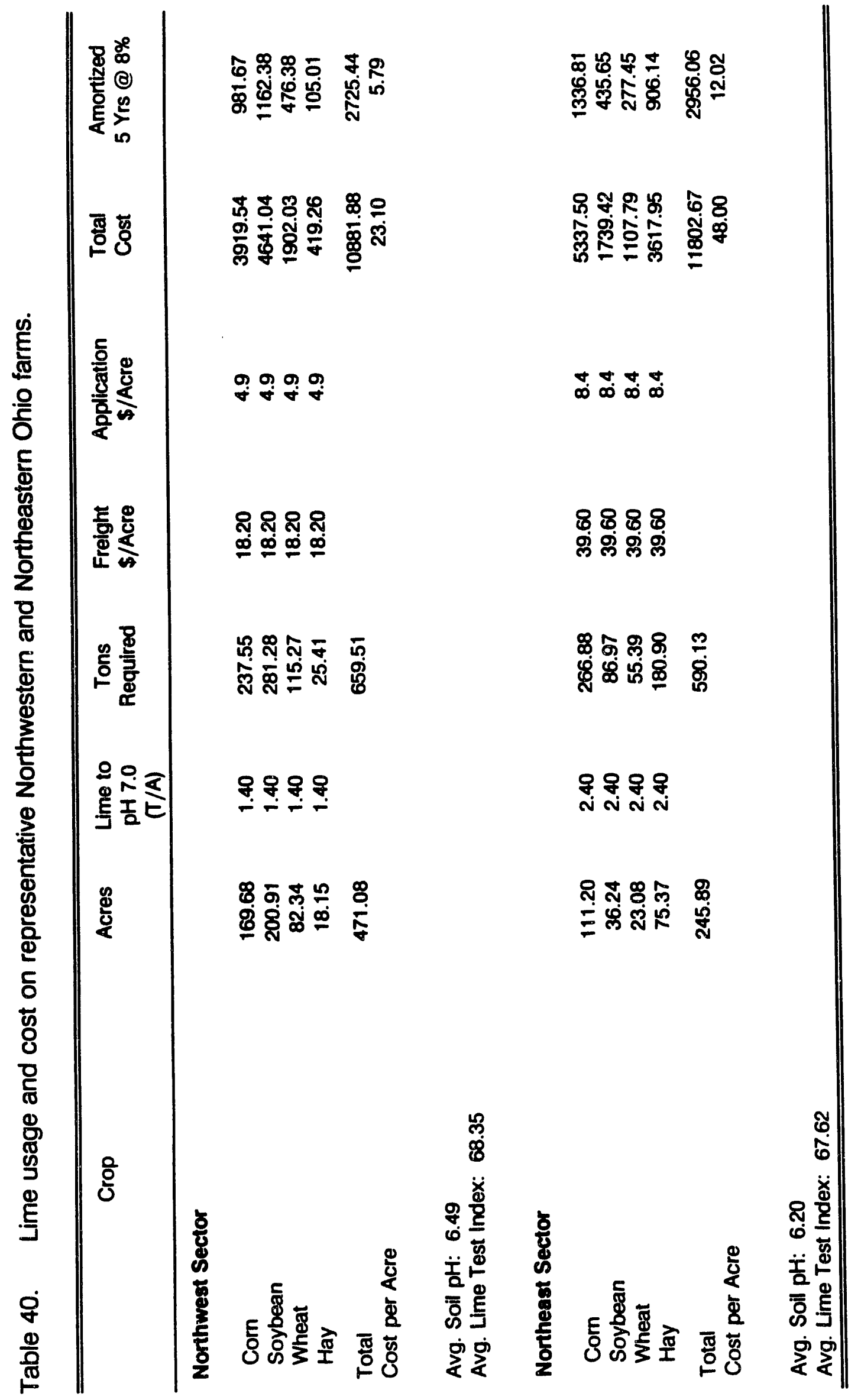


this analysis reflect the maximum economic potential for agricultural lime and FGD byproduct.

For eacin representative farm, agricultural lime costs were estimated from telephone conversations with individuals who provide liming services. Estimates quoted for wholesale lime are about $\$ 5.00$ per ton for both regions. Lower transportation costs of agricultural lime to the northwest reflects the fact that northwest Ohio farms are in closer proximity to limestone quarries than are farms in the northeastern part of the state. Transportation costs are $\$ 8$ per ton for the northwest region and $\$ 11.50$ per ton for the northeast region. Spreading costs are expected to be the same for both regions and are estimated at $\$ 3.50$ per ton. Again, the source of these cost estimates is agricultural lime dealers. It is assumed that liming occurs on average every five years, thus total lime costs have been amortized over their expected life at an 8 percent interest rate.

Due to higher soil $\mathrm{pH}$ in the northwestern region, lime application rates are lower for the representative farm in the northwest than for the one in the northeast (Table 40). The amortized lime cost per acre also is lower on the northwest farm (\$5.79 per acre) than on the northeast farm $(\$ 12.02)$, due to these lower application rates and to the lower costs of transporting agricultural lime from quarries to farms.

The results of the agricultural lime budget suggest that although the two regions differ with respect to lime cost per ton, farm size, and composition of crops grown, the total costs associated with liming on the two farms are not substantially different. Total agricultural liming cost for the typical farm in the northwest is estimated to be $\$ 10,882$ and the northeast to be $\$ 10,671$. Amortizing these costs over a five year life expectancy yields an annual cost of about $\$ 2,725$ and $\$ 2,956$ for the northwest and northeast regions, respectively.

\subsubsection{FGD By-Product Use}

The use of FGD by-product as a substitute for agricultural lime is estimated in the same manner, with the only differences being the cost of the product and the quantity applied. For this preliminary analysis, we have assumed there is no charge for FGD by-product material at its source. The only costs incurred by users are associated with transportation of the product to the application site and its application. It is also assumed that the by-product is $60 \%$ as effective as agricultural lime in total neutralizing power (TNP) and has physical properties similar to agricultural lime. If actual field testing during Phase 2 of this project finds otherwise, these preliminary estimates will be revised. With these assumptions more product must be applied to achieve desired results. Specialized equipment may also be required for transportation and application, but per ton transportation and application costs are assumed to be similar for the FGD by-product and lime.

Transportation costs are estimated to be $\$ 0.10$ per ton per mile. It is estimated that 100 miles are traveled from the FGD source to the representative farm in this region at an average cost of about $\$ 10$ per ton. The northeast region tends to be closer to the source of the by-product, and a 30 mile distance is used to estimate the 
average cost of transportation in this region, or about $\$ 3$ per ton. Application cost per ton is expected to be the same for the FGD by-product as for agricultural lime, and a $\$ 3.50$ per ton application cost is assumed.

The results of our estimates show that the total cost of using FGD by-product as a lime substitute for the northwestern farm are $\$ 14,838$ and for the northeastern farm is $\$ 6,393$ (Table 41). Amortizing these costs over a five year period at 8 percent interest provides an estimated annual cost of $\$ 3,716$ and $\$ 1,601$ for the northwestern and northeastern farms, respectively. Total costs associated with the by-product as an agricultural lime substitute are substantially less for the northeast region and substantially higher for the northwest region, relative to agricultural lime (Figures 74 and 75). This cost difference is primarily a function of the reduced costs associated with transporting the by-product shorter distances in the northeast region.

\subsubsection{Implications for FGD By-Product Use}

This preliminary comparison of representative farms illustrates potential problems in marketing FGD by-product in agricultural markets. First, the potential market for FGD by-product in agriculture is limited since it is to serve as a substitute for agricultural lime. While agricultural lime is used widely, demand for the product is unlikely to grow dramatically in the future. Second, both agricultural lime and FGD byproduct are bulky materials, and transportation is the most important component of their total cost. Since total neutralizing power of FGD by-product is less than that of agricultural lime, use of FGD by-product requires relatively more bulk to be hauled and spread. Third, FGD by-product's use on agricultural land may be feasib!e on cropland near its source (electric power plants); however, it may not be economically competitive with agricultural lime on cropland distant from its source.

Electric utilities might find it feasible to subsidize FGD by-product use in agriculture to avoid incurring landfilling costs. If the power plant were to bear all or a major part of the transportation costs, FGD by-product might be competitive with agricultural lime over most of Ohio.

Analysis of the southeastern and southwestern regions of Ohio is needed and more precise estimates for all regions of Ohio will be possible when actual field data are available in Phase 2. 


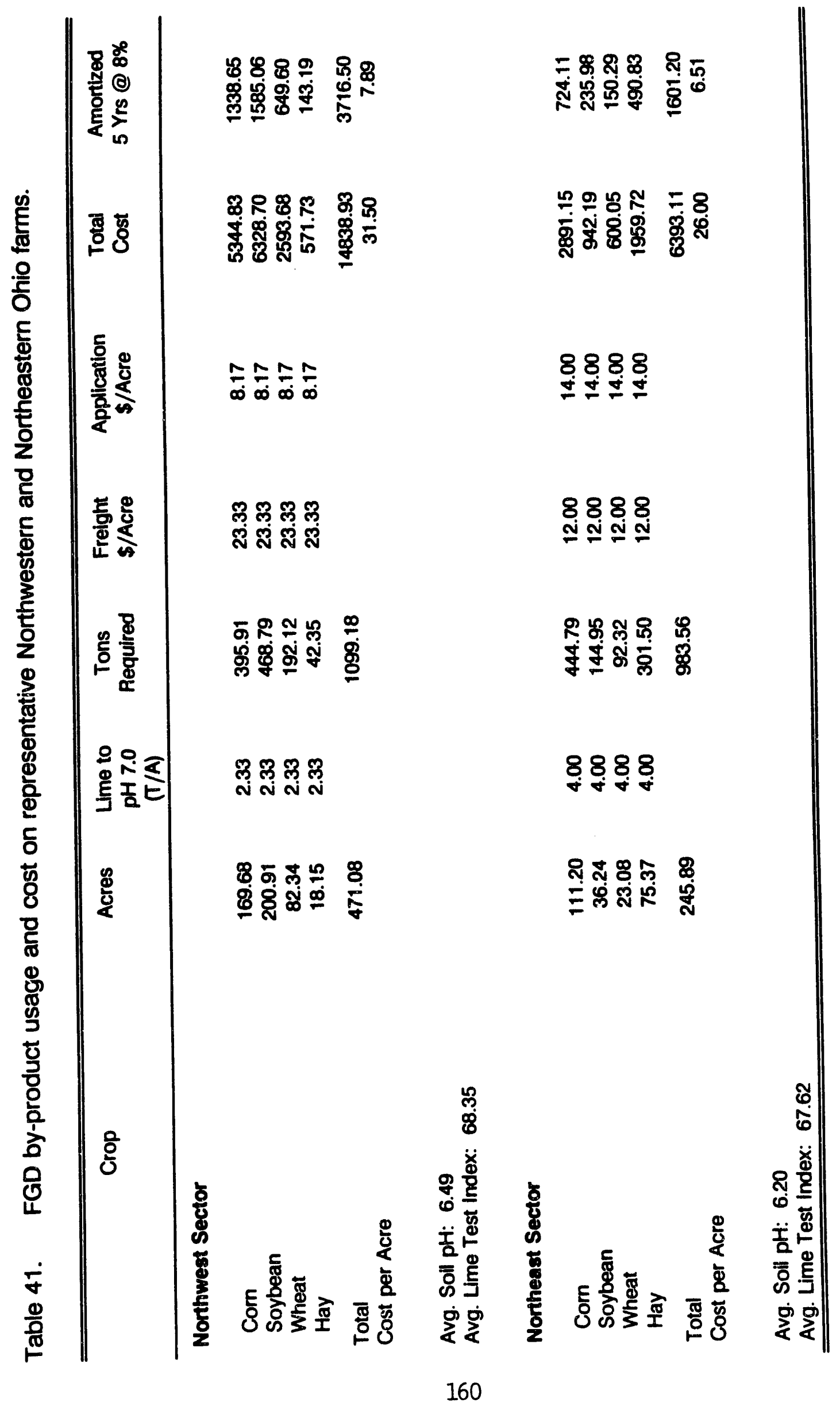




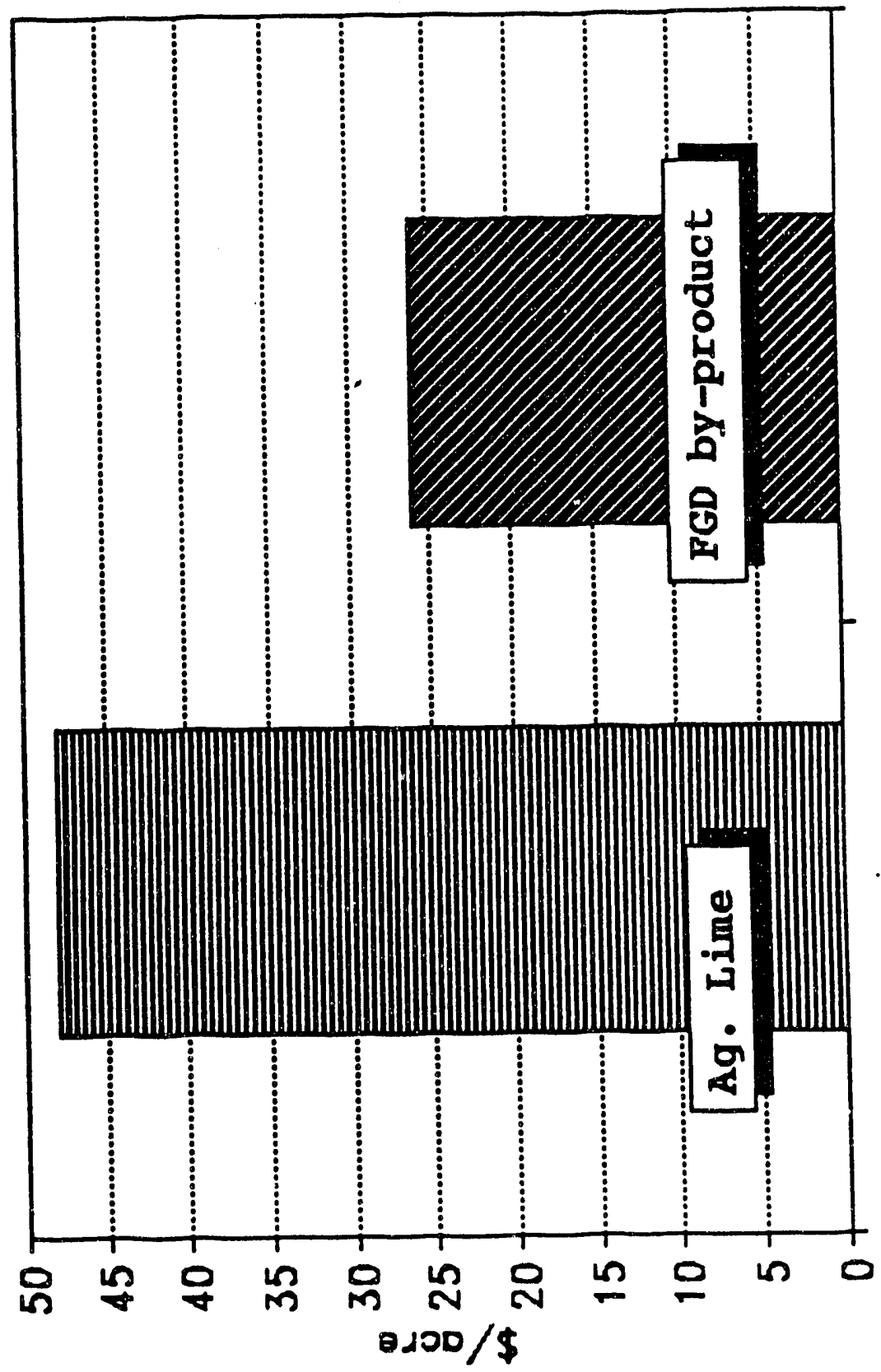

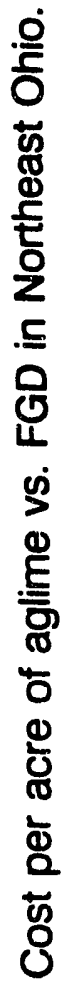

문 


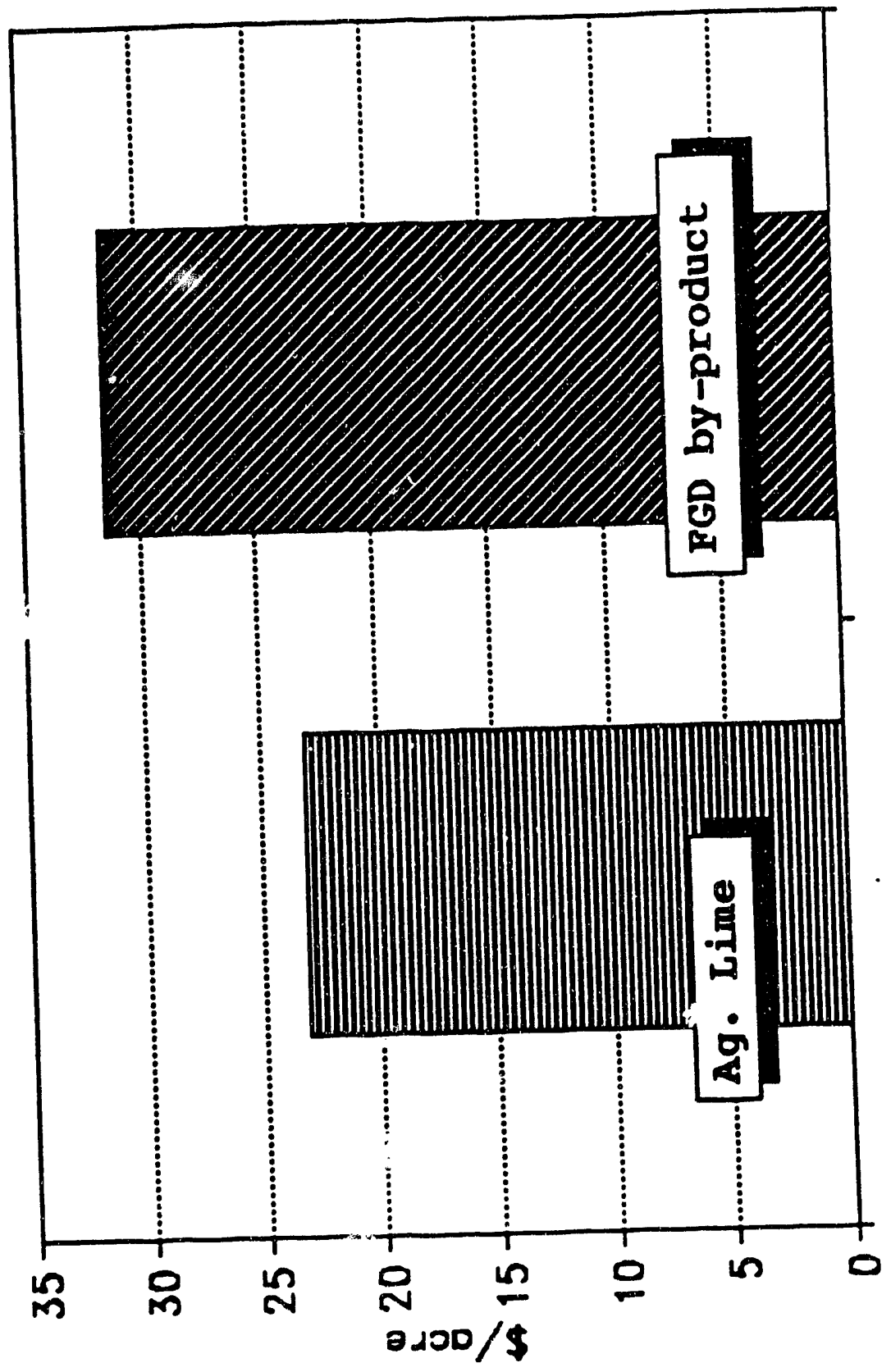

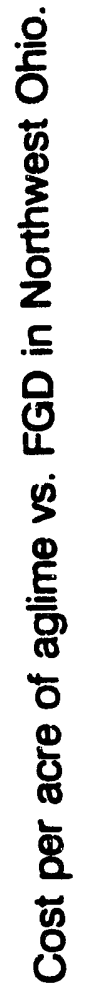

ñ

인 


\subsubsection{Property Value Impacts from Landrigling and Stripmine Reclamation}

During Phase 1 of this project two preliminary hedonic pricing models have been identified as appropriate for estimating extra-market effects as inputs in the economic optimization models. The hedonic pricing model is a well-established statistical technique which is used not only in environmental economic analysis but has also been widely adopted in the fields of urban and regional planning and real estate analysis. Because of the wide acceptance of the methodology, we have chosen the hedonic pricing model as one of our primary tools for estimating the social costs and benefits associated with use of FGD by-products.

First, a model which quantifies willingness to pay by individuals for mitigation of an environmental disamenity, as in the case of landfilling, will be specified. This model is based on landfill operations within Franklin County, and a significant amount of data have been collected thus far. Second, a model which estimates adjacent property value and downstream sediment impacts on areas in which many abandoned stripmines now exist will be specified.

The need for two models arises from the particular problem which FGD byproduct presents. At present it is difficult to estimate the capacity and feasibility of existing abandoned and active surface coal mines needing reclamation to assimilate FGD by-product. This lack of reliable information necessitates estimation of not only the positive impact of reclamation of mines, but also of the disamenity effect of landfilling FGD waste. In addition, further implications specific to the rural mine reclamation study may exist with respect to sedimentation and acid mine drainage.

The theoretical tasis of the hedonic model is to calculate "consumers' surplus", or economic benefit. Consumers' surplus is simply the amount which consumers are willing to pay above the market price for a good which was illustrated earlier in Figure 70. Although consumers' surplus is an abstract notion, it is possible to estimate a demand curve for a commodity econometrically and calculate consumers' surplus as the total area under the demand curve. In the case of a landfill or strip mine, we use the amount that an individual is willing to pay to be located away from a landfill. This is done by observing market prices of real estate transactions in areas around landfills and stripmines while statistically controlling confounding factors such as individual income, presence of additional neighborhood amenities and disamenities, as well as the characteristics of the property itself. In short, economic theory suggests that we should observe lower real estate transaction prices closer to landfills or stripmines, once confounding factors have been controlled for in the model.

Statistically rigorous estimation of the demand equation is essential in establishing willingness to pay. It is from the demand equation that consumers' surplus calculations will be made which in turn will become inputs into the optimization model. Estimation of the demand equation will be made simultaneously with the supply equation using a generalized linear regression model. The precise functional forms of the demand and supply equations will be established by rigorous statistical tests. The 
supply equation is made up of many of the same variables as the demand equation, and the only difference is in the factors which influence shifts in supply and demand.

\subsubsection{Model 1}

During Phase 1, significant progress was made in preliminary specification of a conceptual model of demand and supply for a study area in Franklin County which includes four landfill sites. Refinement and actual estimation of the model will take place in Phase 2. The Franklin County landfill sites were chosen for the model prototype in order to minimize costs associated with data collection and to expedite estimation. In addition, Franklin County landfills are located in marginal urban areas, i.e. areas where farms, and industrial and residential uses are adjacent to one another and involve disposal of municipal as well as demolition and construction wastes.

\subsection{Demand equation estimation}

The model specifies a demand equation as follows:

$$
f(p)=g(x, y, z, d)+e
$$

where $f(p)$ is a function (usually logarithmic) of the real (adjusted for infiation) price of housing, $x$ represents a vector of housing and property characteristics, $y$ represents a vector of neighborhood demographic characteristics, and $z$ is likewise a vector of neighborhood amenities and disamenities. The variable, $d$, is a set of parameters which shift demand for residential housing and is determined outside of the system, and $\theta$ is a statistical error term.

In our model, housing and property characteristics are comprised of such items as number of rooms, square footage of the structure, number of bathrooms, presence of air-conditioning, fireplaces and garages, lot size, number of outbuildings, and age of structure. Neighborhood demographics include average age, racial composition and average annual income. Another common measure of neighborhood quality is the quality of local school systems. Neighborhood amenities can generally be found in parks and shopping centers, and commuting distance is also often included in models of this nature. Factors which can degrade neighborhood quality are the presence of high air pollution, airports, freeways, industry, and high crime rates.

We have identified two major variables associated with landfills which we will investigate in our model: distance from landfills, and life expectancy of landfills. The landfill life expectancy variable attempts to capture the effect which "distance in time" plays in affecting willingness to pay. It is expected that distance from a landfill, both spatially and temporally will be inversely related to real estate prices. Finally, the vector $d$ of housing demand shift variables is generated by population changes, mortgage interest rates, real personal income and tax benefits.

The supply equation included in the system is differentiated from the demand 
equation by the variables which shift housing supply. In the housing market there are two distinctly different types of suppliers: 1) sellers of existing housing (homeowners), and 2) producers of new housing (construction firms). In the market of existing housing, supply is shifted by vacancy rates, and in the new housing market, supply is additionally affected by factor prices such as the cost of money, the cost and availability of land, and the cost of construction materials.

\subsection{Data}

Data has been collected via three major electronic databases: 1990 census block data, 1990 census block group data, and 1990 real estate transaction data. These databases provide us with the necessary data for calculating specific variables necessary for the estimation process. Variables which are in the process of being created from both the electronic databases and other sources are described briefly below.

Landfills: We have been informed by interviews with the Central District Office of the Ohio EPA that landfill operations in Central Ohio fall into three major categories: 1) toxic waste landfills, 2) sanitary landfills which are a source of methane emission, and 3) demolition dumps which accept the relatively more benign materials which are the by-product of construction.

The four study areas in Franklin County initially will include 3 mile radii around 4 landfill sites: Gahanna, a sanitary landfill with a life expectancy of 1 year; Grove City, a sanitary landfill with a life expectancy of 10 years; Alum Creek, an area with a combination of sanitary landfills and demolition dumps which have been closed for 14 years (life expectancy, -14 years); and Obetz, a demolition dump site closed for 6 years (life expectancy, -6 years). Our assumption at present is that demolition dumps approximate the profile of an FGD landfill site, although we have also initially included sanitary sites in our study until the FGD sites can be more thoroughly characterized. The purpose of including closed landfills in the study is to try to capture the full impact of the presence of a landfill throughout time.

Housing Price and Property Characteristics: We have obtained an electronic database of 1990 residential real estate transactions from the City of Columbus Development Department, Planning Division. The purpose of choosing 1990 data is that it can be matched with the most recent Census data which will be used to control for demographic and other factors. Included with each transaction are variables that describe the transaction price, size of the structure, lot size, presence of air conditioning, garages and fireplaces, age of structure, number of rooms and bathrooms and census identification and school district data. Since sales of housing take place in all 12 months of 1990, transaction prices will be "deflated" by the monthly Consumer Price Index for Urban Dwellers (Standard \& Poor's Corp, 1992). Each residence is then identified on a map, and its study area identified. Finally, the distance from the landfill is measured and entered as 
a variable on the database.

Neighborhood Demographics: Variables on average age and income within a census block group as well as racial distribution at census block level have been calculated from raw data available from an electronic version of 1990 Census micro data.

Dummy variables for the different school districts in the sample are used to capture school quality and differential taxation effects on housing prices. Crime statistics are being collected from the various municipalities involved and will be used at community level as a measure of neighborhood quality.

Housing Demand Shift Variables: A monthly index of average effective mortgage rates for the period under study will be used (US Dept. of Commerce, 1990). The loan rate is an average of all conventional mortgage loans based on an annual effective rate. Population growth variables of changes in census tract population from the 1980 to 1990 census will be used to proxy demand shifts caused by population growth (City of Columbus, $\mathrm{OH}$, Department of Development).

Real income growth and tax benefit variables at the local Columbus SMSA level are still being sought for inclusion in the estimation.

Housing Supply Shift Variables: Building permit data (US Dept. of Commerce, 1990 ) at the Columbus SMSA level have been obtained. Assuming that the average time to construct a new residence is six months, the data will be used at six month lags.

Cost of raw materials will be proxied by a national composite construction price index, the Construction Cost Index (US Dept. of Commerce, 1990). The raw materials index will be used monthly with a six month lag period.

Land availability has been collected as raw data on land and water acreage at the census block level. The land and water acreage variables will be combined with real estate data to create a measure of land available for new construction. Housing unit vacancy rates are also part of the census block data set and will be used as shift variables for the supply of existing housing.

\subsection{Analysis}

A system of simultaneous regression models will be estimated using the SAS statistical programming language Model procedure. (SAS Institute, Inc., 1988) Once the demand equation has been satisfactorily determined, we will calculate consumer surplus for various distance increments from the landfill sites. Consumer surplus related to landfill life expectancy will also be calculated. The consumer surplus estimates will then be used as inputs to the linear programming economic optimization model. 
Phase 1 Report

\subsubsection{Model 2}

Work on our second model, although begun during Phase 1, will be done primarily in Phase 2. We plan to include rural study sites which will be adjacent to abandoned surface mines in eastern Ohio. We feel a more pervasive environmental disamenity may exist in the case of a strip mine than is the case with a landfill, due to such problems as sedimentation and acid rumoff. In contrast, landfills are probably more contained in their effects. Thus, each rural study area will likely cover a larger geographic area than the study areas for Model 1. Our study sites will be located within the Muskingum Watershed Conservancy District, and will consist of at least four lakes; two of the lakes will be in an area where adjacent abandoned mines have a negative environmental impact. We hypothesize that real estate prices (and possibly recreation values) within a wide area will be depressed not only by the more immediate impact of an abandoned mine's presence but by the cumulative effects of sedimentation downstream from the mine as well.

\subsection{Data}

Housing Price and Property Characteristics: Unlike the urban data already collected, rural data are not available in any known electronic format. As a result, data collection from county auditors' records will be necessary, requiring travel to the county seats of the study areas. In addition, all data collected will require hand input into a database. A second problem associated with the rural data is the infrequency of transactions, plus the additional factor of differential land use (i.e., villages vs. farms).

Demographic Variables: Statewide 1990 Census tract data may be used to estimate these important variables. Other sources are under investigation. Property Demand and Supply Shift Variables: These variables will be similar to those used in Model 1, but data sources have not yet been identified.

\subsubsection{Summary}

Consumer surplus estimations are to be made from two different study areas comprising four landfills in Franklin County, and at least four lakes in a watershed in eastern Ohio which is impacted by abandoned strip mines. Based on future estimates of assimilative capacity of strip mines, land use applications, and highway embankment stabilization, weights will be developed for the hedonic price estimates. The weights, once established, will allocate net benefits derived from the different schemes for recycling FGD by-product, and will then be used as inputs into the economic optimization models discussed in the next section. 
Phase 1 Report

\subsubsection{Financial and Economic Optimization Models of Options}

The models being developed present a means of determining the most appropriate use of the FGD by-product under normal conditions. Given the objective of minimizing costs, the models determine the optimal use of the FGD by-products produced in Ohio from both the power plant (financial) and societal (economic) perspectives.

The alternative options (destinations) for the FGD by-product are assumed to be agricultural use as a lime substitute on cropland, coal surface reclarnation use as a topsoil amendment, landfill disposal, and other unspecified uses (e.g., highway embankment stabilizing material). Sources of the :jy-product are the power plants that are likely to be considering dry scrubbing processes for controlling sulfur emissions. The models assume that all quantities of FGD by-product produced by the power plants must be used in one of these options.

\subsubsection{Transportation Problem}

Transportation costs will be determined using a transportation model that has its origin in industrial logistics. A product is to be distributed from sources, which in this case are the power plants, to destinations, which are the alternative use locations. The total number of tons of FGD by-product material produced at each plant and the capacity of each destination to receive the material are assumed to be known. The objective is to distribute the material at the least cost.

To formulate the problem mathematically, the following terms are defined:

$a_{i}=$ number of tons available at source (power plant) $i, i=1,2, \ldots, m$;

$b_{j}=$ maximum number of tons required at each destination $j$ (use location), $j=$ $1,2, \ldots, n$;

$c_{i j}=$ unit processing, transportation, and application cost from source $i$ to destination $j(j=1,2, \ldots, m$ and $j=1,2, \ldots, n)$.

It is assumed that the sum of total production available is equal to the sum of total product use at all locations; that is,

$$
\Sigma a_{i}=\Sigma b_{j} .
$$

The amounts shipped from each source (power plant) to each destination (use location) are the decision variables or

$x_{i j}=$ number of tons annually shipped from source $i$ to destination $j$.

The transportation problem is formulated as follows:

minimize $z=\Sigma \Sigma c_{i j} x_{i j}$

subject to:

$\Sigma x_{i j}=a_{i}(i=1,2, \ldots, m)$,

$\Sigma x_{i j} \leq b_{j}(j=1,2, \ldots, n)$,

$x_{i j} \geq O(i=1,2, \ldots, m ; j=1,2, \ldots n)$

Expression (1) represents the minimization of total distribution cost, assuming a linear cost structure for shipping, processing, and applying the FGD by-product. Equation 
(2) states that the amount being shipped from source $i$ to all possible destinations should be equal to the total availability, $a_{i}$, at that source. Equation (3) indicates that the amounts being shipped to destination $\mathrm{j}$ from all possible sources should be less than or equal to some maximum usage, $b_{j}$, at that destination. Equation (4) specifies that each decision variable, $x_{i j}$, must be greater than or equal to zero.

\subsubsection{Example}

A simple example helps illustrate the problem. Assume there are two power plants producing FGD by-product: Shadyside and Marietta, Ohio. Annual production of FGD by-product is assumed to be 436,000 tons from Shadyside and 233,000 tons from Marietta. Alternative destinations for the by-product include its use as an agricultural lime substitute in Belmont, Monroe, Noble, and Washington Counties, where maximum annual demand is projected at 4,900,370,398, and 1,963 tons, respectively. Alternatively, the by-product could be used as a soil amendment in surface mine reclamation in Belmont, Noble, and Washington Count 35 , the maximum annual use is projected to be $267,000,332,000$, and 6,000 tons, res pectively. If not shipped to these locations for use as an agricultural lime substitute on cropland or as a soil amendment for reclamation (or embankment stabilizer for highways), then the material is to be landfilled.

The unit distribution costs from each plant to each destination, the quantities of material available at the two sources, and the potential demand in each county for agricultural and reclamation use (Table 42) serve as inputs into a standard computer algorithm ("Lindo"). The algorithm then determines the optimum distribution of FGD by-products from our two example sources to the final destinations (Fig. 76). The minimum distribution costs for the two plants total $\$ 4,464,100$. Shadyside distributes $4,900,400$, and 400 tons in Belmont, Monroe, and Noble Counties, respectively, on cropland. For reclamation of surface mines, 267,000 tons are distributed in Belmont County and 100,000 tons in Noble County. Also, Shadyside landfills 67,300 tons.

Marietta distributes 2,000 tons in Washington County on cropland, and the remainder is used in reclamation, 232,000 in Noble County and 6,000 in Washington County. Nothing is landfilled from Marietta.

This example illustrates trade-offs in an optimal distribution network of FGD byproduct among all power plants. Each power plant distributess the by-product to relatively low-cost and abundant surface mine reclamation land that is nearby. Then nearby agricultural land receives the by-product, rather than the more distant surface mines to be reclaimed. Finally, the high cost option, landfilling, is used as a last resort. Another use, such as using the dry FGD by-product for stabilizing road embankments, would be economical at each power plant if it costs less than $\$ 27.50$ per ton, the estimated cost of landfilling. 
Table 42. Unit production and shipping costs (example).

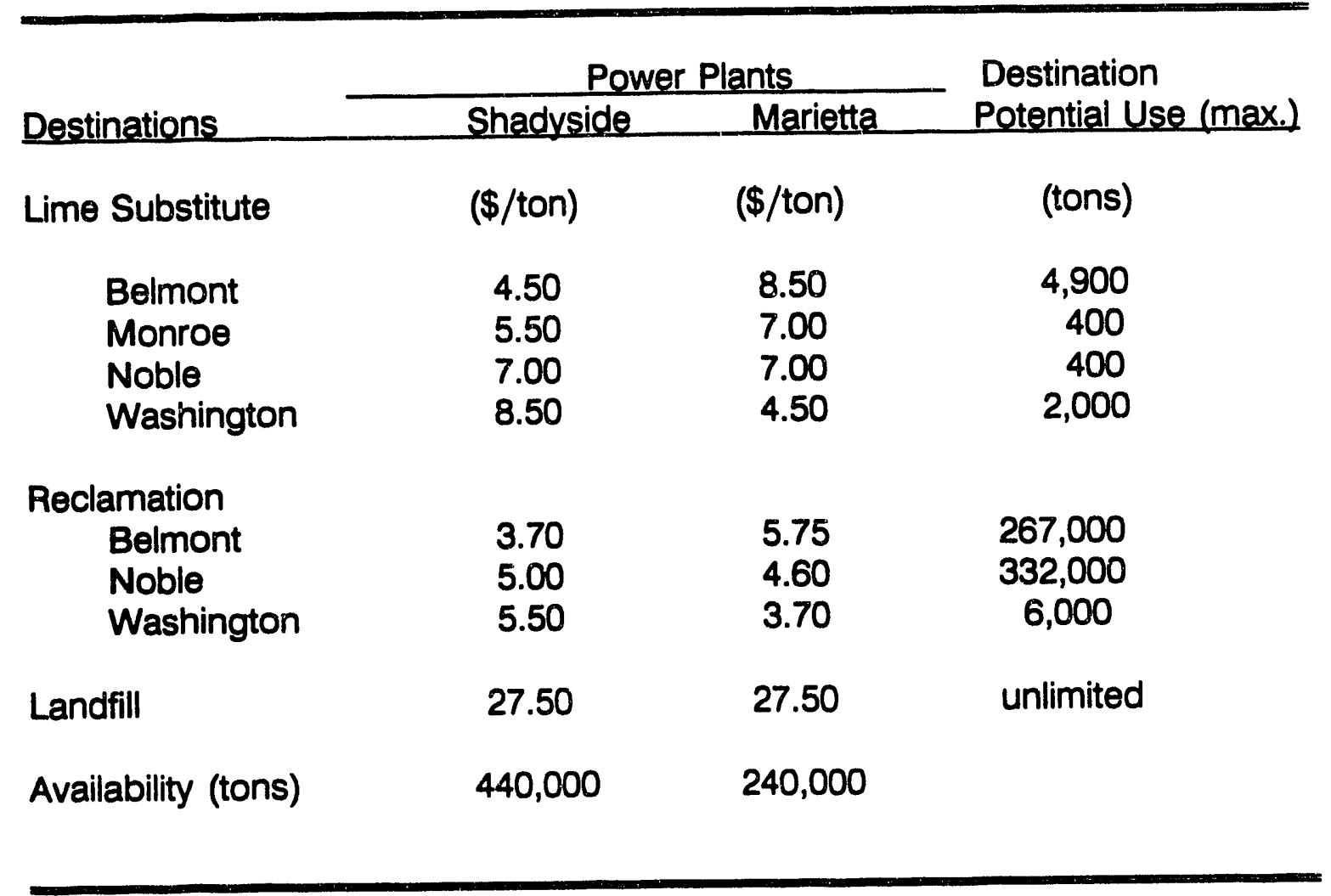




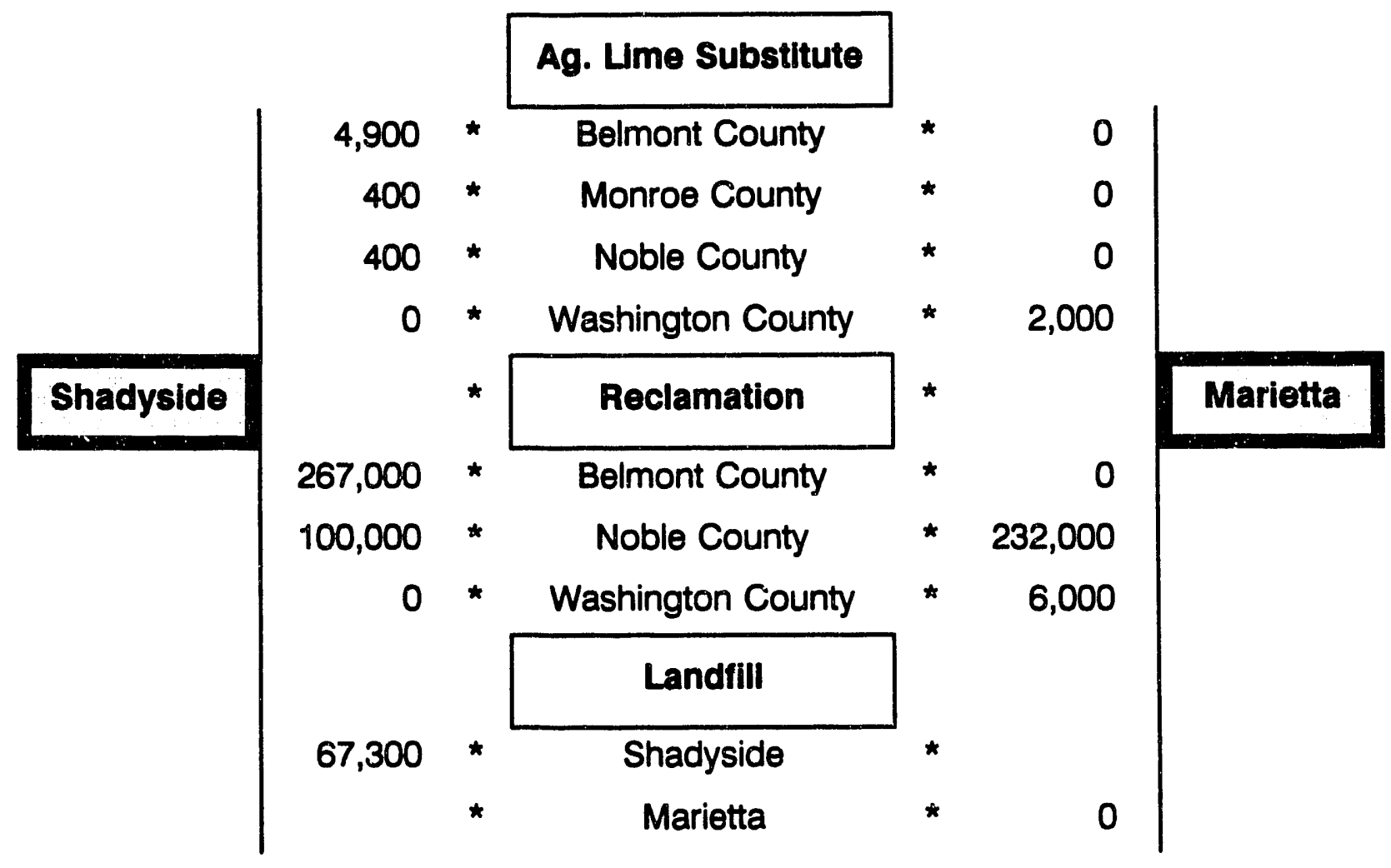

Fig. 76. Optimal distribution network for example problem. Numbers in the above example are the tons of FGD by-product that enter each route. 


\subsubsection{Model Development}

In reality the FGD by-product disposal problem is made more complicated by the number of power plants that serve as sources and the number of potential destinations for the by-product. Twenty-three Ohio power plants have beer identified as currently producing bottom and fly ash (Table 43). Many of these will not use the dry scrubber technology and will not be sources of dry FGD by-product. The model incorporates only those plants that might produce dry FGD by-product. In estimating the potential quantities of the by-product, it is assumed that FGD by-product is 60 percent as effective in total neutralizing power (TNP) as agricultural lime, thus 1.67 tons of FGD by-product is needed to substitute for one ton of agricultural lime. The substitutability of FGD by-product for agricultural lime will need to be altered as agronomic research results clarify the effectiveness of the FGD by-product and its handling costs.

All Ohio counties may be potential destinations for FGD by-product as it substitutes for agricultural lime. Recent agricultural lime use in each county provides as estimate of the potential market for FGD by-product in agriculture (Table 44). It is unrealistic to assume that FGD by-product would substitute completely for agricultural lime. This initial run of the model is being developed under the assumption that up to one-fourth of the agricultural lime could be replaced by FGD by-product in each county.

Ohio counties where surface mine reclamation activities occur would be potential destinations for dry FGD by-products used as alkaline amendments in reclamation. Recent reclamation activity provides an estimate of the area where the by-product might be used (Table 45), but current reclamation represents a small percent of total unreclaimed stripmine land. It is assumed that relatively high application rates, 240 tons per acre, would be used. Agronomic research results might alter this rate of application. Also, adjustments may be made in the model to reflect the fact that application rates for surface mine reclamation would vary.

Estimated costs of alternative FGD by-product use are shown in Table 46. These are distribution costs to be borne by the power plant. The minimum cost distribution system from the private financial perspective of the power plant will be estimated using a linear programming algorithm, like that used for the previous illustrative example.

In addition to these private distribution costs, there are other costs, called "externalities," that could be added to some disposal options. For example, landfill operation may cause costs to be imposed on others due to road congestion, road maintenance, loss of property, aesthetic values, etc. These externalities might be captured by a reduction in property values in nearby residences and commercial properties. Theoretically, the amount of the externality could be determined from property value loss estimates. These property value loss estimates are being approximated with hedonic pricing models discussed in the previous section and will be used to refine the costs used in this analysis of distribution costs.

The externality costs could be added to the private distribution costs to estimate the cost borne by society, or social cost, of landfilling. By the end of the project, the 
intention is to estimate the optimum distribution system from two perspectives, the perspective of the power plants (termed "financial analysis") and the perspective of society as a whole (labeled "economic analysis").

Table 43. Current ash production and estimated potential FGD by-product, by source.

\begin{tabular}{lcc}
\hline \hline Power Plants & $\begin{array}{c}\text { Current } \\
\text { Bottom + Fly Ash } \\
\text { (tons/year) }\end{array}$ & $\begin{array}{c}\text { Potential } \\
\text { FGD By-Product } \\
\text { (tons/year) }\end{array}$ \\
\hline Bay Shore Station & 95,000 & 316,670 \\
ACME Plant & 13,000 & 43,350 \\
Ashtabula Plant & 108,000 & 360,000 \\
Avon Lake Plant & 131,000 & 436,670 \\
Eastlake Plant & 200,000 & 666,670 \\
Lakeshore Plant & 17,000 & 56,670 \\
Toronto Plant & 39,000 & 130,000 \\
W. H. Sammis Plant & 520,000 & $1,733,330$ \\
Niles Plant & 14,000 & 46,670 \\
Gorge Plant & 10,000 & 33,330 \\
Edgewater & 21,000 & 70,000 \\
R. E. Burger Plant & 131,000 & 436,670 \\
Gorsuch Station & 70,000 & 233,330 \\
Cardinal Plant & 531,000 & $1,770,000$ \\
Gavin Plant & 689,000 & $2,296,670$ \\
Muskingum River & 282,000 & 940,000 \\
Kyger Creek Plant & 135,000 & 450,000 \\
W. C. Beckjord Station & 115,000 & 383,330 \\
Miami Fort Station & 300,000 & $1,000,000$ \\
Conesville & 120,000 & 400,000 \\
Picway Plant & 20,000 & 66,670 \\
J. M. Stuart Plant & 780,000 & $2,600,000$ \\
Mead Paper Co. & 47,000 & 156,670 \\
Total & & $14,626,670$ \\
\hline \hline
\end{tabular}

'Source: American Coal Ash Association, 1989.

${ }^{b}$ Current bottom and fly ash production $=10 \%$ of coal burned. Potential FGD byproduct $=33 \%$ of coal burned. 
Table 44. Potential FGD by-product use as an agricultural lime substitute, by county (tons per year) ${ }^{a}$.

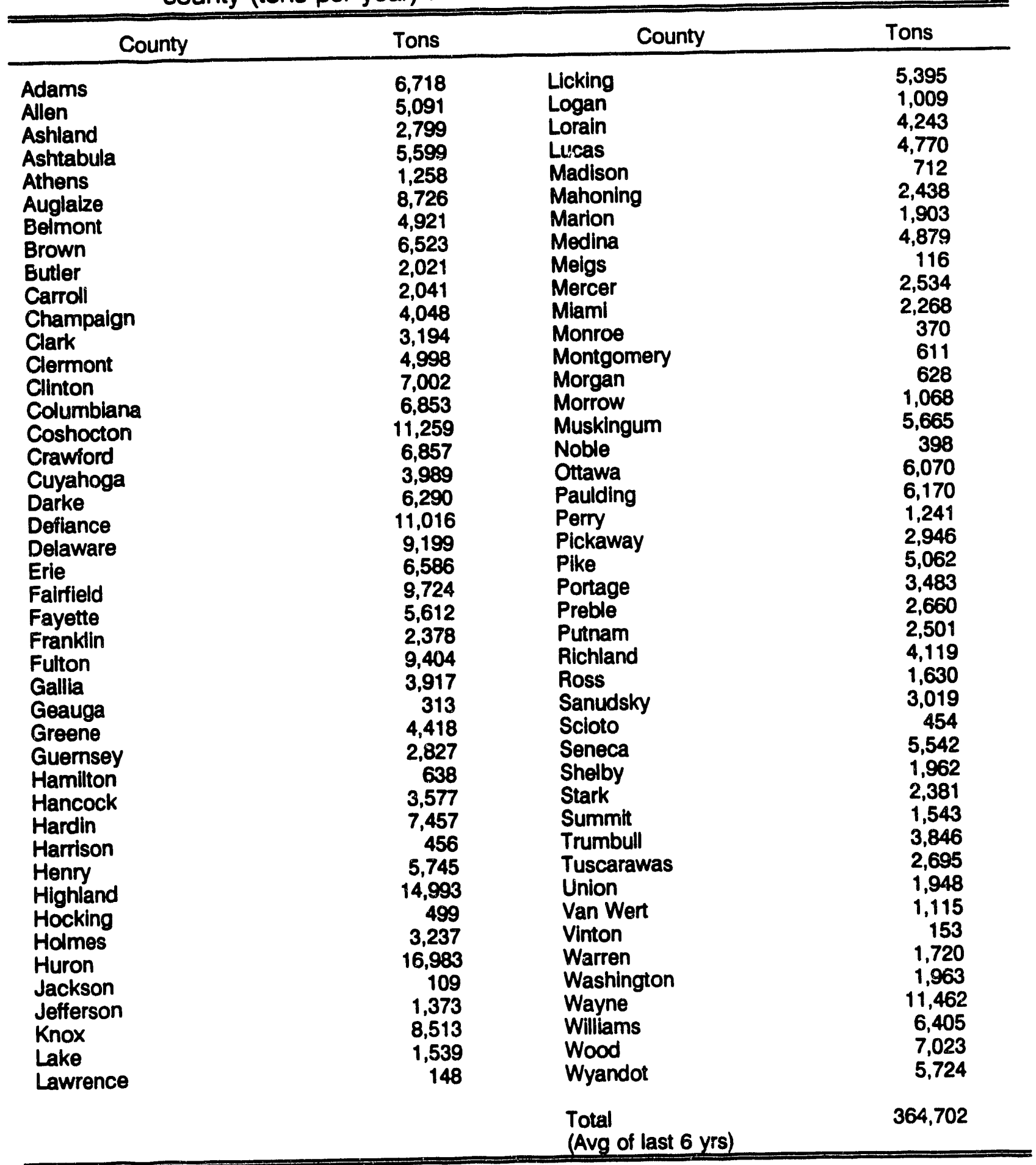

Assumptions: 1 ton of ag-lime $=1.667$ tons of FGD by-product. Maximum estimated amounts of FGD by-product potentially used is 25 percent of average ag-lime useci in each county each year from 1986 to 1991. 
Table 45. Potential use of FGD by-product in surface mine reclamacion

\begin{tabular}{lc}
\hline \multicolumn{1}{c}{$\begin{array}{c}\text { Location of Surface Mines } \\
\text { (County) }\end{array}$} & $\begin{array}{c}\text { Potential } \\
\text { FGD By-Product Use } \\
\text { (tons/year) }\end{array}$ \\
\hline Athens & 14,960 \\
Belmont & 267,140 \\
Carroll & 78,560 \\
Columbiana & 60,870 \\
Guernsey & 13,770 \\
Harrison & 204,560 \\
Hocking & 12,580 \\
Holmes & 44,810 \\
Jackson & 98,340 \\
Jefferson & 189,780 \\
Lawrence & 2,630 \\
Mahoning & 19,630 \\
Muskingum & 89,180 \\
Noble & 332,022 \\
Perry & 40,369 \\
Stark & 19,390 \\
Tuscarawas & 208,460 \\
Vinton & 146,270 \\
Washington & 6,480 \\
Wayne & 3,160 \\
\hline \hline
\end{tabular}

assumes that FGD by-product is applied to all mine reclamation permit area at 240 tons per acre.

Table 46. Cost estimates used in analysis of optimum FGD by-product distribution.

\begin{tabular}{cc}
\hline Item & Cost per ton \\
\hline Landfilling & $\$ 27.50$ \\
Ag. Lime Substitute & \\
Application & 3.50 \\
Transportation & 0.10 per mile \\
Reclamation Soil Amendment & \\
Application & \\
Transportation & 3.50 \\
& 0.10 per mile \\
\hline
\end{tabular}


Phase 1 Report

\subsection{Selection of Sites for Field Studies}

\subsubsection{Active Mine Site}

The first step taken in the site-selection process was to review the goals of the research project and prepare a list of site-selection criteria. The following criteria were considered during the site-selection process: (1) timing and extent of mining and reclamation, (2) cooperation from the land owner(s) and mining company, (3) requirement of alkaline amendments to ameliorate predicted acid-mine drainage, (4) acquisition of a representative site based on hydrogeology and soils (thereby increasing the transferability of results to similar sites in the region), (5) drainage-basin morphology and site accessibility, (6) premining land use, (7) distance to FGD byproduct source, (8) availability and turn-around time for revision of permits from the Ohio Department of Natural Resources (ODNR) and the Ohio Environmental Protection Agency (OEPA), (9) local cooperation, and (10) cooperating-agency site-selection criteria.

To assess the available sites in Ohio, a list of all actively permitted coal-mining sites obtained from the ODNR, Division of Reclamation, was screened to eliminate subsurface sites and surface sites smaller than 200 acres. Because the project requires four 5- to 10-acre test plots, permit areas smaller than 200 acres would not allow as much flexibility with respect to timing of mining and reclamation. This constraint narrowed the list of potential sites to 180. More than half of these sites are in Belmont, Carroll, Columbiana, Coshocton, Guernsey, Harrison, Jefferson, Monroe, Muskingum, and Tuscarawas Counties. These counties are primarily underlain by the Monongahela and Allegheny Formations of Pennsylvanian age.

The stratigraphy of the coal-bearing strata of eastern Ohio was then investigated to evaluate the need for addition of alkaline amendments for acidic spoils and (or) soils because the stratigraphy of a mined sequence of rocks can directly influence the potential for production of acid-mine drainage. Coal is mined in eastern Ohio from Pennsylvanian rock that was deposited as sediments that were deposited in a deltaic, near-shore environment approximately 286 to 320 million years ago. Some parts of the Ohio coal section are relatively deficient in carbonate minerals, which may neutralize the production of acidic water. Data obtained from ODNR mining inspectors and mining permits indicate that marine shales associated with the number 5 and 6 coals (Lower and Middle Kittanning coals, respectively) of the Allegheny Group are most likely to produce acidic discharge after mining and reclamation. These shales are typically enriched in iron sulfide $\left(\mathrm{FeS}_{2}\right)$ that, because of mining, exposure to air, and hacterial action, oxidizes to form sulfate, which can hydrolyze to form sulfuric acid in water.

In eastern Ohio, the number 5 and 6 coals outcrop in a northeast-southwest trending line that extends from Columbiana County in the northeast, southwestward through Coshocton County and then southward to Lawrence County. Active mining sites south of Coshocton County were generally excluded from this search because 
many underground mines that exist in the area could interfere with interpretations of water-quality data at the test sites. Approximately 45 sites met this criterion.

The 45 remaining sites were investigated individually. Field reconnaissance was conducted to evaluate the sites in additional detail. Each site was critically evaluated with respect to the site-selection criteria, and seven potential sites were selected as finalists (Table 47). All candidate sites were considered acceptable for use in the study, however four sites were evaluated in greatest detail (Table 48). These four sites are within 20 miles of one another, therefore the distance to the FGD by-product source (the location of which remains undecided) did not affect the site selection. 
Table 47. List of potential study sites for the active mine study within Ohio.

\begin{tabular}{|c|c|c|c|c|}
\hline Owner & $\begin{array}{l}\text { ODNR } \\
\text { Mining } \\
\text { Permit } \\
\text { Number }\end{array}$ & $\begin{array}{l}\text { Location of } \\
\text { Permit Area }\end{array}$ & $\begin{array}{l}\text { Size of } \\
\text { Permit } \\
\text { Area } \\
\text { (Acres) }\end{array}$ & $\begin{array}{l}\text { Coal } \\
\text { Seam(s) } \\
\text { Mined }\end{array}$ \\
\hline $\begin{array}{l}\text { Empire Coal Company } \\
\text { PO Box } 729 \\
\text { Gnaddenhutten, OH } 44629 \\
\text { Contact: Tom McCartney }\end{array}$ & D-533 & $\begin{array}{l}\text { Warwick Township, } \\
\text { Tuscarawas County }\end{array}$ & 372 & 5,6 \\
\hline $\begin{array}{l}\text { Holmes Limestone Co. } \\
\text { PO Box } 295 \\
\text { Berlin, OH } 44610 \\
\text { Contact: Ralph King }\end{array}$ & $\begin{array}{l}D-796 \\
D-796-1\end{array}$ & $\begin{array}{l}\text { Jefferson Township, } \\
\text { Tuscarawas County }\end{array}$ & $\begin{array}{l}106 \\
314\end{array}$ & 5,6 \\
\hline $\begin{array}{l}\text { Kimble Clay \& Limestone Co. } \\
\text { Rt. 1, Box } 386 \\
\text { Dover, OH } 44622 \\
\text { Contact: Floyd Kimble }\end{array}$ & $D-852$ & $\begin{array}{l}\text { Auburn \& York } \\
\text { Townships, } \\
\text { Tuscarawas County }\end{array}$ & $\$ 74$ & $\begin{array}{l}3 A, 4,5 \\
6,7\end{array}$ \\
\hline $\begin{array}{l}\text { Oxford Mining Co., Inc. } \\
\text { PO Box } 427 \\
\text { Coshocton, OH } 43812\end{array}$ & D-870 & $\begin{array}{l}\text { Franklin Township, } \\
\text { Coshocton County }\end{array}$ & 264 & 6 \\
\hline $\begin{array}{l}\text { R\&F Coal Company } \\
538 \text { North Main Street } \\
\text { Cadiz, OH } 44621 \\
\text { Contact: Brent Havin }\end{array}$ & $\begin{array}{l}\text { D-689 } \\
\text { PA-1096 }\end{array}$ & $\begin{array}{l}\text { Oxford Township } \\
\text { Coshocton County } \\
\text { Rush Township, } \\
\text { Tuscarawas County }\end{array}$ & $\begin{array}{l}541 \\
489\end{array}$ & 5,6 \\
\hline $\begin{array}{l}\text { Valley Mining, Inc. } \\
\text { PO Box } 148 \\
\text { Dennison, OH } 44621 \\
\text { Contact: Jim Klingler }\end{array}$ & $\begin{array}{l}\text { D-516, } \\
\text { PA-516-2 }\end{array}$ & $\begin{array}{l}\text { Salem Township, } \\
\text { Tuscarawas County }\end{array}$ & $\begin{array}{l}334 \\
231\end{array}$ & 6 \\
\hline $\begin{array}{l}\text { Miller Mining Co., Inc. } \\
\text { State Route } 93 \mathrm{~N} \\
\text { PO Box } 525 \\
\text { Sugar Creek, OH } 44681 \\
\text { Contact: Olen Miller }\end{array}$ & D-0967 & Tuscarawas County & & 5,6 \\
\hline
\end{tabular}


Table 48. Summary of site selection data and evaluation of four finalist candidate sites.

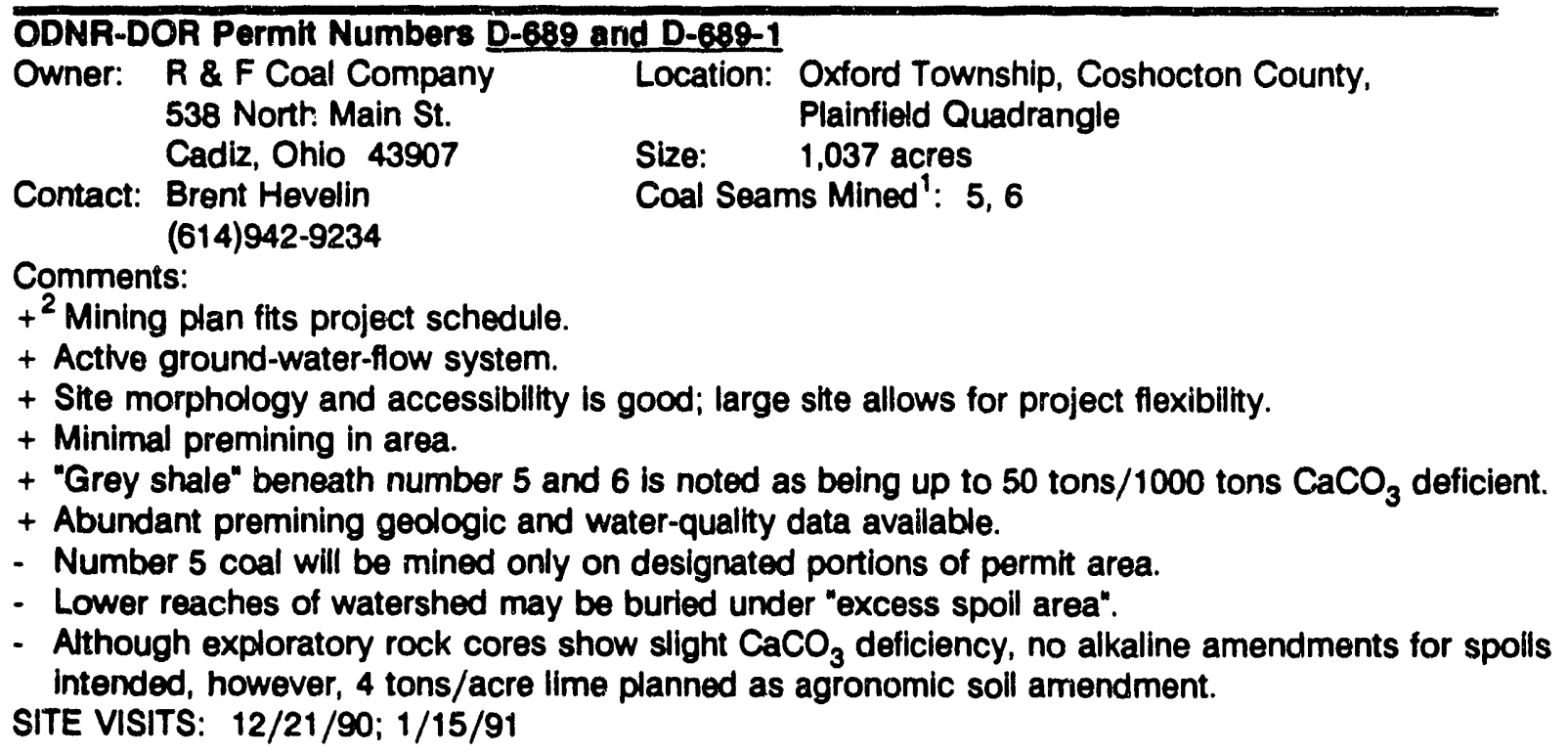

\section{ODNR-DOR Permit Number D-796-1}

Owner: Holmes Limestone Company Location: Jefferson Township, Tuscarawas

Berlin, Ohio

Contact: Ralph King

Comments:

(216)893-2721

Size: $3: 4$ acres
Coal Seams Mined': 5,6

+ Site has been deforested, with mining to begin soon.

+ Liming intended for soil pending results of soil tests.

+ Active ground-water-flow system.

+ Minimal premining in area.

+ Special handling of toxic spoils noted in permit.

- Permit still in application process.

- Although cores show slight $\mathrm{CaCO}_{3}$ deficiency, no alkaline amendments for spoils intended.

SITE VISIT: $1 / 31 / 91$

1 Coal Seam Names in Eastern Ohio: 7, Upper Freeport; 6, Middle Kittanning; 5, Lower Kittanning; 4, Brookville; 3A, Upper Mercer.

2 A plus $(+)$ indicates that this comment is a positive aspect with regards to performing the study at this site, that is it helps the site meet the site-selection criteria; a minus $(-)$ indicates that this comment is a negative aspect. 
Table 48. continued.

ODNR-DOR Permit Number p-582

Owner: Kimble Clay and Limestone RD:1, P.O. Box 386

Contact: Keith Kimble (216)339-5111
Location: Auburn and York Townships, Tuscarawas County, Stone Creek Quadrangle Size: $\quad 974$ acres Coal Seams Mined": $3 A, 4,5,6, \& 7$

\section{Comments:}

$+{ }^{2}$ Mining just begun on eastern end of permit area, and progressing rapidly westward.

+ Premining land use primarily forested.

+ Liming intended for solls pending results of soil tests.

+320 feet local relief, but permit area large enough to allow project flexibility and site accessibility good.

+ Abundant premining geologic and water-quality data avallable.

- Although cores show slight $\mathrm{CaCO}_{3}$ deficlency, no alkaline amendments for spolls intended.

- Three small "avoidance areas" may cause difficulty with subsite selection.

- Augering of coal along highwall.

- Lower reaches of watershed may be buried under "excess spoil area".

SITE VISIT: $1 / 31 / 91$

ODNR-DOR Permit Number D-870

Owner: Oxford Mining Co., Inc.

P.O. Box 427

Coshocton, Ohio 43812

(614)622-6302
Location: Franklin and Jackson Townships,

Coshocton County, Conesville Quadrangle

Size: $\quad 264$ acres

Coal Seam Mined': 6

Comments:

+ Approximately $20 \%$ of site has already been mined, but mining progressing slowly.

+ Active ground-water flow system.

- Timing may be questionable (projected mining until 1994).

- Athough cores show slight $\mathrm{CaCO}_{3}$ deficiency, no alkaline ameridments for spoils or solls intended.

- Abundant premining and gob plles west of permit area may cause problems with water-quality investigation.

- Limited access through haul road (which may vary as mining continues).

SITE VISIT: $1 / 31 / 91$

1 Coal Seam Names in Eastern Ohio: 7, Upper Freeport; 6, Middle Kittanning; 5, Lower Kittanning; 4. Brookville; 3A, Upper Mercer.

2 A plus $(+)$ indicates that this comment is a positive aspect with ragards to performing the study at this site, that is it helps the site meet the ste-selection criteria; a minus $(-)$ indicates that this comment is a negative aspect. 
Phase 1 Report

\subsubsection{Abandoned Mined Site}

The initial step in selecting a field site for beneficial reuse of dry FGD by-product materials for reclamation of abandoned mined lands was to develop a set of selection criteria. These criteria were:

1) a site that represents the major mine spoil types and that requires the addition of lime (i.e. it should have a lime test index of 66 or less),

2) access to the site for collection of the data after reclamation has been completed,

3) size of the area to be reclaimed must be sufficiently large to allow for creation of buffer space between treatments,

4) timing of the reclamation plans must fit with our research plans,

5) distance to the FGD by-product source and from Wooster,

6) protection of the area from vandals and/or livestock, and

7) cooperation of local and state agencies in preparation of reclamation plans and the implementation of those plans.

After formulating the selection criteria, a meeting was held with the Ohio Department of Natural Resources, Division of Reclamation - Abandoned Mined Lands. Seven candidate sites, in various stages of reclamation planning, were submitted by the Division of Reclamation. These sites were prioritized in order of preference for use in this project based upon the selection criteria.

After comparing the locations, conducting on-site inspections, and considering the relative merits of the different sites, the Fleming site was selected as our number one choice as a site for testing the beneficial reuse of dry FGD by-product materials for reclamation and revegetation purposes. The Fleming site is located in Sections 11 and 12, Franklin Township, Tuscarawas County, Ohio. Project coordinates are $40^{\circ}$ $33^{\prime} 19^{\prime \prime}$ north latitude and $81^{\circ} 31^{\prime \prime} 13^{\prime \prime}$ west longitude.

This site consists of approximately 25 acres of exposed, highly erodible underclay bordered on two sides with about 45 acres of unreclaimed spoil and 5 acres of refuse. The site is causing sedimentation problems and flooding for landowners below the hillside and is estimated to affect 75 offsite acres. The underclay is scarred with rills and gullies up to 10 feet in depth and is completely devoid of vegetation. Based on a 2-year, 24 hour storm, the soil loss from the site averages 450 tons/acre/year. The estimated average soil loss for vegetated sites in Tuscarawas County is 2.8 tons/acre/year. Water quality has been severely impacted with $\mathrm{pH}$ values being measured as low as 2.9. The Fleming site has been assigned a priority 2 rating by the Division of Reclamation due to its effect on the health, safety, and general welfare of the public. This site has also been included in the National Abandoned Mined Lands Inventory (OH-994).

\subsubsection{Agronomic Liming Sites}

The branch farms of The Ohio State University were evaluated as possible sites to test the beneficial reuse of the FGD by-product materials as an agricultural lime 
substitute. Several criteria were considered in selecting these field sites: 1) the soil must be deficient in exchangeable bases, i.e. it must have a low pH and a calcium carbonate deficiency, 2) more than one soil type must be included in the test so that the results can be applied to other areas of the state, 3 ) the soil types must exhibit a range in soil properties, especially in respect to soil $\mathrm{pH}$ and total cation exchange capacity, 4) the land must be located on Ohio State University property, and 5) we must know the history of plot use prior to the addition of the FGD by-product material.

Three field sites were chosen, after applying these criteria, and these sites are located at The Ohio Agricultural Research and Development Center (Wooster, $\mathrm{OH}$ ), the Mahoning Experimental and Educational Farm (Canfield, $\mathrm{OH}$ ), and the USDA-ARS North Appalachian Experimental Watershed (Coshocton, $\mathrm{OH}$ ). The soils at the three sites are a Wooster silt loam (pH 4.6), a Canfield silt loam (pH 5.9) and a Coshocton silt loam (pH 4.8), respectively. The highest amount of lime required, as determined by the Ohio State University's soil testing laboratory in Wooster, is 9.6 tons/acre (21.5 $\mathrm{Mg} / \mathrm{ha}$ ) of calcium carbonate equivalency for the Wooste" silt loam. This amount of lime would be sufficient to raise the pH of the Wooster s jil from 4.6 to 7 . 


\subsection{Embankment Design}

The results of the laboratory tests which have been presented in Section 2.1.3.4 clearly indicate that, although the physical properties of the FGD product are highly variable, all the materials tested to date would be suitable as fill in a properly engineered embankment.

The design of an engineered embankment consists of 1) specifying a design geometry, 2) determining the appropriate engineering properties for the proposed fill material, 3) evaluating the stability of the structure designed in step 1 using the engineering properties obtained for the material in step 2,4) revising the design as necessary until an adequate degree of safety or minimum acceptable performance is achieved, 5) monitoring the activities of the construction crews during construction, and 6) observing the long term behavior of the embankment after the construction is completed. Table 49 lists in general terms the requirements to be addressed when designing a highway embankment including the slopes, shoulders and the structural backfill placed around a buried culvert.

Table 49. Summary of properties and performance.

\begin{tabular}{|c|c|c|c|c|}
\hline & \multicolumn{4}{|c|}{ Structural Component } \\
\hline & $\begin{array}{c}\text { Embankment } \\
\text { (1) }\end{array}$ & $\begin{array}{l}\text { Slope } \\
\text { (2) }\end{array}$ & $\begin{array}{l}\text { Shoulder } \\
\text { (3) }\end{array}$ & $\begin{array}{l}\text { Backfill } \\
\text { (4) }\end{array}$ \\
\hline Properties & $\begin{array}{l}\text { static-stress- } \\
\text { strain-strength }\end{array}$ & same as (1) & $\begin{array}{l}\text { static and } \\
\text { dynamic stress- } \\
\text { strain-strength }\end{array}$ & same as (1) \\
\hline Laboratory Tests & $\begin{array}{l}\text { unconfined } \\
\text { compression, } \\
\text { direct shear, } \\
\text { triaxial }\end{array}$ & same as (1) & $\begin{array}{l}\text { same as (1), } \\
\text { freeze-thaw }\end{array}$ & same as (1) \\
\hline $\begin{array}{l}\text { Performance } \\
\text { Criterion }\end{array}$ & settlements & deformations & $\begin{array}{l}\text { deformations, } \\
\text { including rutting }\end{array}$ & $\begin{array}{l}\text { culvert } \\
\text { deformations }\end{array}$ \\
\hline $\begin{array}{l}\text { In-situ } \\
\text { Measurements }\end{array}$ & $\begin{array}{l}\text { slope indicator } \\
\text { tubes plus } \\
\text { magnetic collar } \\
\text { water quality }\end{array}$ & same as (1) & $\begin{array}{l}\text { dynaflect and/or } \\
\text { falling weight } \\
\text { deflectometer }\end{array}$ & \\
\hline Analytical Model & $\begin{array}{l}\text { finite element } \\
\text { models }\end{array}$ & $\begin{array}{l}\text { finite element } \\
\text { models } \\
\text { non-finite element } \\
\text { models }\end{array}$ & $\begin{array}{l}\text { paviament } \\
\text { equations }\end{array}$ & $\begin{array}{l}\text { finite element } \\
\text { models }\end{array}$ \\
\hline
\end{tabular}




\subsubsection{Evaluating Embankment Performance}

With the design of the embankment specifying the use of FGD materials completed and construction started, monitoring the construction to assure compliance with material placement specifications is critical. Since this can be more easily done if the FGD material can be treated by both the inspectors and the contractors as a familiar, rather than an exotic material, the results of the laboratory characterization program described in Section 2.1.3.4 were presented with the goal of describing the FGD as a natural soil. Such an approach should make it possible to have field inspectors capable of monitoring construction without special training or experience in FGD by-products. Of the several different dry FGD materials tested in the laboratory program, only the PFBC ash from the Tidd plant might require special handling since the very high early strengths observed in the laboratory indicate that placing a conditioned (water added) material could be difficult if the work cannot be completed in a timely fashion. Studies to be conducted on FGD/soil mixes during Phase 2 will increase our knowledge of the most appropriate dry FGD material and procedures to use for embankment construction.

To assess the performance of the FGD by-product in the engineered fill, two general areas will be studied. In the first, the physical behavior (i.e. stability and deformations) of the embankment will be recorded. In the second, the quality and quantity of water in the embankment and moving through it will be determined.

\subsubsection{Embankment stability}

Satisfactory performance of the embankment requires that the side slopes remain stable and that the material doesn't compress under allowable service loads. For both of these potential problems, the strengths of the FGD and the underlying natural materials are the critical parameters. The actual performance of the demonstration highway section will be most readily monitored by the installation of vertical settlement and horizontal displacement devices in the embankment, slope and shoulder.

The measurement of vertical movement will be done by installirig a settlement platform. This platform consists of a square plate placed on or in the natural soil prior to the construction of the embankment. As construction proceeds vertical pipe sections are attached to the platform. After completion of the embankment the elevation of a mark on the pipe is determined by surveying the embankment thereby providing a record of the settlement with time. However, since a single settlement platform can give only a single point measurement, a number of platforms will be installed. Such a procedure allows for time dependent settlement profiles to be constructed. An effective way to obtain additional settlement information is through the use of a probe extensometer. A probe extensometer is a device that measures the distance between two or more points along a common axis. During construction of the embankment, stainless steel wire rings will be attached to a rigid vertical tube at different elevations. A readout probe with an induction coil transducer is lowered into the tube and the depth at which the coil is aligned with the ring can be noted. 
Changes in the distance between marked locations over time will give estimates of the compression of each stratum of the embankment.

The measurement of horizontal motion is also an important part of the determination of the stability of the embankment slopes. The most common device for measuring horizontal movement is an inclinometer. The inclinometer measures the deformation normal to the axis of an embedded tube. In the embankment, the tube is installed vertically and any change in the orientation will be measured using an accelerometer built into a probe that fits into the tube.

Additional information regarding the suitability of the FGD as a base course can be obtained using in-situ tests such as the Dynaflect or Falling Weight Deflectometer. These tests will be performed to measure deflections of the pavement and shoulder.

\subsubsection{Monitoring water content and quality}

In both the FGD and the underlying soils, the water content and the location of the phreatic surface (from which effective intergranular stresses are calculated) are the two most important time dependent field variables, and so the measurement of these values must be included in a post-construction monitoring program. Water quality and content will be monitored in the embankment (1) so that estimates of solute mobility can be made, and (2) because the strength of the FGD material as well as the underlying soil is influenced by increasing or decreasing water content. At a minimum, the pressure in the pore water must be determined in order to calculate the effective stresses. The effective stresses must be known in order to make strength determinations.

Piezometers are typically used to measure pore water pressure at a specific depth below the embankment surface. Many types of piezometers are available and the final choice of a particular device usually depends on a variety of circumstances. However, since we have already recommended using a hollow tube for the inclinometers, it would seem reasonable to investigate ways to use the same tube as an observation well to monitor ground water. These open tube piezometers will be augmented with electronic piezometers, primarily to take advantage of the increased sensitivity this type of device offers.

The piezometers will provide the necessary field data for saturated materials. The FGD by-product, however, will be compacted at the optimum moisture content and is not saturated. Therefore, for at least some period of time after construction, the embankment, and most likely the underlying soil, will be only partially saturated. In unsaturated soil, negative (with respect to the atmosphere) pore pressure exists. Negative pressure in the pore water develops due to capillarity and adsorptive forces within the material matrix. Since water content has a significant effect on the strength of the material, the degree of saturation is an important design parameter. Tensiometers can be used to measure the value of negative pressure (or water tension) in the pore water. A tensiometer is typically comprised of a rigid plastic tube with a porous ceramic tip. The pore sizes in the tip are designed to allow movement of air across the tip while restricting water flow. The tube is filled with water and 
sealed. The measurement of negative pressure can be made using either a vacuum gauge or a transducer. As with the piezometer, the tensiometer is a one location sensor, so to obtain the data at more than one location as well as at different elevations, several tensiometers will be needed.

In order to monitor the migration and concentration of potential pollutants within and around the embankment, the results of a water sampling program will be included in an evaluation of the project. Fortunately, the slope indicator tubes will be suitable for the collection of water samples from within the embankment. Water samples will be collected from outside of the area impacted by the embankment and the quality compared with that measured in samples collected from within the embankment.

\subsubsection{Summary}

Instrumentation required for monitoring embankment performance and environmental impact in summarized in Table 50. In addition to the field instrumentation, samples from the completed demonstration section will be collected and returned to the laboratory for testing. To establish the acceptability of the dry FGD material, the measured behavior of the embankment will be compared with the accepted performance of highway components constructed with conventional materials. Analytical models will be used to predict the performance of the demonstration section and these predictions will be checked against the measured performance. 
Table 50. Proposed field instrumentation program.

\begin{tabular}{|c|c|c|}
\hline Instrument & Property Monitored & $\begin{array}{l}\text { Frequency of } \\
\text { Measurement }\end{array}$ \\
\hline 1) Optical survey & overall displacements & bi-weekly (4 months) \\
\hline 2) Settlement platform & vertical displacements & $\begin{array}{l}\text { bi-weekly (4 months) } \\
\text { monthly }\end{array}$ \\
\hline 3) Extensometer & vertical displacements & $\begin{array}{l}\text { bi-weekly ( } 4 \text { months) } \\
\text { monthly }\end{array}$ \\
\hline 4) Inclinometer & horizontal displacements & $\begin{array}{l}\text { weakly (4 months) } \\
\text { monthly }\end{array}$ \\
\hline $\begin{array}{l}\text { 5) Open standpipe } \\
\text { piezometer }\end{array}$ & $\begin{array}{l}\text { porewater pressure } \\
\text { water quality }\end{array}$ & $\begin{array}{l}\text { weekly(4 months) } \\
\text { monthly }\end{array}$ \\
\hline 6) Tensiometer & negative pore pressure & $\begin{array}{l}\text { weekly (4 months) } \\
\text { monthly }\end{array}$ \\
\hline
\end{tabular}




\subsection{LIMB Stockpile}

The use of an FGD by-product in a highway embankment such as described in section 2.5 will require large volumes of material be delivered to the construction site over a short period of time. In order to insure a timely delivery of material to the construction site, it is likely that the FGD material will have to be stockpiled. In order to study the effects of aging on the chemical, physical and engineering properties of an FGD by-product, a 1500 ton temporary pile using the LIMB by-product, was constructed in July, 1991, on the property of the Central Fuel Company in New Philadelphia, Ohio. Details of the design and construction of the stockpile are presented in Appendix F. Measured properties of the LIMB material used to construct the pile are presented in Table 51.

Table 51. Summary of measured properties of LIMB by-product placed in storage pile.

\begin{tabular}{|c|c|c|c|c|c|c|c|}
\hline & $\begin{array}{l}\text { Water } \\
\text { Added }\end{array}$ & $\begin{array}{c}\text { Moisture } \\
\text { Content }\end{array}$ & $\begin{array}{c}\text { Slaking } \\
\text { Temperature }\end{array}$ & $\begin{array}{l}\text { Free } \\
\text { CaO }\end{array}$ & $\begin{array}{l}\text { Particle } \\
\text { Density }\end{array}$ & $\begin{array}{l}\text { Blaine } \\
\text { Fineness }\end{array}$ & $\begin{array}{c}\text { Bulk } \\
\text { Denulty }\end{array}$ \\
\hline & (\%) & $(\%)$ & $\left(C^{\circ} 15 \mathrm{~min}^{-1}\right)$ & $(\%)$ & $\left(\mathrm{g} \mathrm{cm}^{-3}\right)$ & $\left(\mathrm{cm}^{2} \mathrm{~g}^{-1}\right)$ & $\left(\mathrm{g} \mathrm{cm}^{-3}\right)$ \\
\hline Mean & 43.5 & 17.5 & 8.2 & 21.4 & 2.84 & 10030 & 45.1 \\
\hline $\begin{array}{l}\text { Number of } \\
\text { Samples }\end{array}$ & 22 & 8 & 16 & 24 & 5 & 5 & 3 \\
\hline Range & $\begin{array}{l}31.0- \\
53.5\end{array}$ & $7.5-35.2$ & $6.5-13.7$ & $\begin{array}{l}11.4- \\
25.5\end{array}$ & $2.83-2.87$ & $\begin{array}{l}9790- \\
10460\end{array}$ & $44.5-45.5$ \\
\hline
\end{tabular}


Phase 1 Report

\section{PROBLEMS ENCOUNTERED IN COMPLETING PHASE 1 TASKS}

\subsection{Problems Encountered in Completing Characterization Tasks}

The two major problems which slowed progress in the characterization tasks were the unavailability of representative FGD by-product samples, and the unreliable performance of the inductively coupled plasma spectrophotometer instrument.

Because of the experimental nature of most dry FGD installations, units tended to go off-line frequently. Also there were frequent changes in operating parameters, making it difficult to obtain representative samples. Delays in the start-up of the Tidd PFBC unit delayed getting samples from this very important source.

The inductively coupled plasma spectrophotometer is the most important piece of analytical equipment for the overall chemical characterization of dry FGD by-product samples. Although purchased specifically for support of this project, we encountered numerous hardware problems with the instrument. This resulted in frequent down-time for the instrument, delaying data output. It also, in several instances, necessitated repeating sample preparation. Also, due to the nature of the dry FGD samples (mainly the high-salt sample matrix), analytical difficulties were encnuntered, particularly with respect to sample digestion and sample induction. This necessitated the testing of several different methodologies to find one which would produce high quality data.

\subsection{Problems Encountered in Field Site Selection}

The site-selection process revealed some interesting trends in surface mining in Ohio. New techniques for selective handling of "toxic" spoil materials can greatly reduce the threat of acid-mine drainage. Many mining companies selectively take spoils that are designated as "acid-producing" and bury them within carbonate-rock enclosures in the center of the spoil pile, thereby helping to neutralize reactions that may otherwise produce acidic water. Mining companies are also avoiding regions where potentially toxic spoils exist, which helps to minimize expenditures related to ameliorating acid-mine drainage. One question consistently raised by mine operators was how the FGD by-product would be stored, handled, and applied to the mine site. It is important that the research be conducted in a technically sound fashion but, at the same time, not disrupt the operations of the mining company. The logistics involved with material handling and application may ultimately decide the fate of using FGD by-products in active mine settings.

An unrelated, but perhaps more significant problem to site selection in regards to acid-mine drainage in Ohio appears to be abandoned-mine lands that were not reclaimed or were reclaimed using out-dated technology. These sites may require very large amounts of alkaline material to neutralize acid-mine drainage. FGD byproducts may also find a use in reclamation practices that require large amounts of "fill" to return the mined land to the original contour.

With respect to acid mine drainage in Ohio, a more significant problem than active-mine sites seems to be abandoned mine lands that were not reclaimed at all or 
were reclaimed using dated technology. The Fleming site is our candidate site to test the use of dry FGD by-product for reclamation of toxic spoil. This study will not only evaluate the beneficial reuse of dry FGD by-product as a reclamation amendment, but will also help eliminate acid mine drainage and sedimentation from a site in Ohio that has been documented as creating adverse environmental impacts. 


\section{SUMMARY AND CONCLUSIONS OF PHASE 1 TASKS}

\subsection{Characterization}

\subsubsection{Chemical Properties}

The chemical composition of the FGD by-products is dominated by $\mathrm{Ca}, \mathrm{S}, \mathrm{Al}$ and $\mathrm{Si}$, although the specific composition varies from sample to sample. Variation in concentration was particularly evident for the trace elements. These wide variations in concentrations seemed more likely to be due to variations in the original coal composition and sorbents used than in the specific clean coal technology employed at each coal-fired facility.

Arsenic appears to be the only regulated element present in the FGD byproducts at concentrations that are in excess of proposed standards for land-applied sewage sludge. The actual consequences of these concentrations are not known at this time. However, As appears to reside primarily in the fly-ash fraction, as do most of the trace elements in the FGD by-products. Thus, it is suggested that FGD technologies "improve" the environmental impact that coal ash will have when land applied or used in mine reclamation. Trace element contents in the FGD by-products could fall under the same regulatory restrictions as trace elements in fly ash from coal burning sources.

The long-term solıbility studies indicated that incubations in alkaline conditions led to production of gypsum, followed by ettringite. It is likely gypsum would still form in neutral pH regimes, but precipitation of ettringite should be inhibited.

\subsubsection{Mineralogical Properties}

The dry FGD by-products produced using duct injection, spray dryer, and coolside technologies were very similar in mineralogical composition. The primary constituents were portlandite, calcium sulfite-hemihydrate, calcite and fly ash. Duct injection samples produced using recycle contained more fly ash, more calcium sulfite, and less portlandite than those produced without recycle. Under field conditions, the portlandite component could be expected to dissolve and/or convert to calcite through reaction with atmospheric $\mathrm{CO}_{2}$.

Calcium sulfite, in contrast to calcium sulfate, is relatively insoluble and mobilization probably requires oxidation to calcium sulfate. Oxygen consumption by calcium sulfite might be of interest in mine reclamation if the initial oxidation of pyritic materials could be retarded by blending with calcium sulfite. From an agronomic perspective, the effects of sulfitic materials on plant metabolism are unclear and should be studied in greater depth. The relatively low strength, low swell characteristics of the spray dryer and duct injection materials described in this report are probably also related to their sulfitic mineralogy. Ettringite, a hydrated calcium aluminum sulfate, is widely recognized as a potential agent for expansion of cementitious materials. The 
presence of calcium sulfite in the spray dryer and duct injection materials would likely retard formation of ettringite.

The LIMB and pressurizec.fluidized bed combustion by-products generally contained small amounts (< $10 w t \%$ ) of portlandite, 5 to $20 w t \%$ lime, 10 to $20 w t \%$ calcite, and 15 to 50 wt\% anhydrite. When dolomite was employed as the sorbent, periclase and unreacted dolomite were also present. Coal ash contents were highly variable in the LIMB by-products and PFBC cyclone materials (30 to $80 \mathrm{wt} \%$ ) but were consistently low in the PFBC bed materials (10 to 20 wt\%). High heats of hydration associated with the conversion of lime to portlandite, periclase to brucite, and anhydrite to gypsum make handling a problem. Sufficient gypsum forms in the PFBC bed materials to cause cementation and high unconfined strengths. With time, the gypsum in all these by-products may serve as a feed material for the formation of ettringite and the onset of undesirable expansion characteristics.

\subsubsection{Physical Properties}

The most interesting physical feature of the FGD by-product material results from relations between particle size, water retention characteristics, saturated hydraulic conductivity and bulk density; particularly as compared with these relations for soii materials. The duct injection, spray dryer, and lime injection samples contained essentially silt sized particles. In the compressed state (25 psi), however, these materials held water tenaciously, more so than even a fine clay soil. Yet these same materials, also in a compressed state, had saturated hydraulic conductivities ranging from medium to low and corresponded to that obseived for fine sand and sandy clay soils, respectively. The explanation for this inconsistent behavior may result from the relatively low bulk densities, and correspondingly high total porosities, of these materials such that they conducted water more readily than their particle sizes or water retention characteristics would suggest. Also, since these materials remain saturated at relatively high suctions, they would retain their high conductivities over a wide range of soil suction values.

The fluidized bed fly ash was somewhat coarser as compared with materials from other processes and contained a comparatively wide range of particle sizes. This wide range of particle sizes is likely the principal reason why this material had a higher compressed bulk density, a relatively low saturated hydraulic conductivity and high water retention properties. The bed ash from the fluidized bed process contained particle sizes ranging from coarse sand to fine gravel. Its bulk density, conductivity and water retention characteristics were typical for a coarse textured soil material.

\subsubsection{Summary of engineering properties}

The objective of the Phase 1 Engineering tests was to generate sufficient laboratory data to demonstrate that FGD by-products could, if properly compacted, be a suitable material for use in a field demonstration project (e.g. in highway construction 
and repair). This objective was accomplished by conducting a comprehensive test program in the laboratory on samples obtained from a number of different dry FGD technologies. Of particular interest was a determination of compressive strength, compressibility, permeability and swell potential since, with these parameters, an engineer could properly design a highway embankment or other earth structure using the FGD by-product.

Included in the laboratory program were tests to evaluate the optimum moisture content and density of each material received in a manner consistent with widely accepted field compaction procedures. We observed that very good compaction could be achieved over a fairly broad range of moisture contents. This is an important observation since it means that a contractor who is placing an FGD byproduct material probably will not have to take special care to achieve precisely the design water content in crder to get specified densities. We also observed that the compacted densities of most of the FGD samples tested were well below typical compacted soil densities. Therefore an FGD embankment would be lighter than a comparable soil structure. Since a lighter FGD structure would impose a smaller load on the natural foundation soils than a conventional soil fill, the designrr could expect less settlement in the underlying soils and a smaller likelihood that the loaded soils would fail.

Samples made from the compacted FGD material were found to have generally higher strengths and lower compressibilities than the natural soils that would typically be used in an embankment. High strength means that the threat of a slope failure is less for the FGD by-product material than for natural soils. Alternatively, increased stability means that designs calling for steeper slopes could be considered thereby possibly reducing significantly the amount of right-of-way that must be obtained for such projects.

Permeability tests were performed on a large number of compacted FGD samples. The coefficient of permeability was measured at 0,7 and 28 days for most of these materials and correlations between the curing time and permeability were inferred. In spite of considerable range in the measured permeabilities, the test program clearly showed that all the FGD samples tested would be considered to be low permeability materials, with typical values in the range expected for clay.

All samples tested experienced two distinct swelling phases. In the first phase, sample hydration was accompanied by an increase in sample volume ranging between $0.1 \%$ and $12 \%$. The second episode of swelling, which began after ten or more days had elapsed, typically ranged between $0 \%$ to $7 \%$ volume increase. The swell tests conducted on the dry FGD by-product samples indicated that the amount of volume change experienced is related to the process used to generate the FGD by-product. Care must be taken by the design engineer to correctly identify the swelling tendency of a specific FGD material since the results obtained in this laboratory program indicate the potential for volume change can be quite high.

All the tests were performed in accordance with industry accepted standards. This report should, therefore, provide much of the information state and county 
Phase 1 Report

highway engineers would require if they are to consider using dry FGD by-products in embankment and highway design.

\subsection{Economics}

Analysis of agricultural lime supply and demand relationships was considered and provides a rigorous basis for determining the potential of FGD by-products as an agronomic lime substitute. The FGD by-product is entering a very competitive market if it is to displace agricultural lime even though agricultural lime is a relatively small share of total sales of limestone.

Preliminary analysis of representative farms in northwest and northeast, Ohio was used to approximate the financial feasibility of using dry FGD by-product materials as an agricultural lime substitute. as expected, the results are very sensitive to transport distances due to the bulky nature of the product. More precise results will be possible when the agricultural land application field trials are completed.

To approximate the impacts of stripmines and landfills on adjacent property values, two types of hedonic pricing models have been developed. Primary data collection on the landfill related model is well underway. Site selection for the stripmine related model is being done to facilitate the use of results from other ongoing research at The Ohio State University which has focused on the downstream impacts of sediments on boating and property values at Ohio state park lakes.

Basic economic optimization models have been developed to summarize all of the foregoing elements from both a power plant and a societal standpoint. Initial runs of the financial model (i.e., from the power plant perspective) have been done utilizing a limited number of source points and preliminary assumptions about costs and technical parameters. These results are useful to illustrate general patterns and to further assist in model refinement prior to the final runs to be conducted at the end of this project.

\subsection{Field Site Selection}

Of seven abandoned mine sites submitted by the Division of Reclamation Abandoned Mine Land Program (Ohio Department of Natural Resources) for project consideration, the Fleming site in Tuscarawas County was selected. This site consists of approximately 25 acres of exposed, highly erodible underclay bordered on two sides with about 45 acres of unreclaimed spoil and 5 acres of refuse. The site is causing sedimentation problems and flooding for landowners below the hillside and is estimated to affect 75 offsite acres. Because of the acidity levels and lack of vegetation, this site offers great potential to demonstrate the ability of dry FGD byproduct materials to be used beneficially as a reclamation amendment.

Three sites at three different locations (Wooster, Canfield, and Coshocton) were selected for conducting our field studies for the evaluation of using dry FGD byproduct materials as a substitute for agricultural lime. These sites are all located on property owned by The Ohio State University and have acidic soils that limit their 
productivity. Treating these soils with dry FGD by-product material containing neutralization potential of approximately $50 \%$ should provide a potential benefit in terms related to improved agronomic crop growth as well as providing a controlled experimental setting for evaluating plant uptake and water quality impacts of using dry FGD by-product materials as an agricultural lime substitute.

Phase I resulted in an extensive literature review, development of criteria and a strategy for site selection, and selection of seven potential active mine sites from an initial list of 45. 


\section{REFERENCES}

Allison, J.D., D.S. Brown, and K.J. Novo-Gradac. 1990. MINTEQA2/PRODEFA2, A geochemical assessment model for environmental systems. Environmental Research Laboratory, Office of Research and Development, U.S. EPA, Athens, Georgia.

American Public Health Association. 1985. "Conductivity." In Standard Methods for the Examination of Water and Wastewater, pp. 76-80. Washington: American Public Health Association.

American Public Health Association. 1985. "Determination of Anions by Ion

Chromatography With Conductivity Measurement." In Standard Methods for the Examination of Water and Wastewater, pp. 483-488. Washington: American Public Health Association.

American Society for Testing and Materials (ASTM). 1991. " Standard Methods for pH of Water." In Annual Book of ASTM Standards, Vol. 11.01, pp. 266-274. Philadelphia: American Society for Testing and Materials.

American Society for Testing and Materials (ASTM). 1991. " Standard Practice for Oxidation-Reduction Potential of Water." In Annual Book of ASTM Standards, Vol. 11.01, pp. 261-265. Philadelphia: American Society for Testing and Materials.

American Society for Testing and Materials. 1990. Annual Book of ASTM Standards 4.08, 1990.

Annual Report on Ohio Mineral Industries. (selected years) Ohio Department of Natural Resources.

Annual Summary of Agricultural Prices. (selected years) U.S. Department of Agriculture. National Agricultural Statistics Service.

Barber, Stanley A. 1984. Liming materials and practices. pp.171-205. In Fred Adams (ed). Soil acidity and liming. Agronomy Monograph 12, ASA, Madison, WI.

Batelle. 1989. Technical support for the Ohio Clean Coal Technology Program, Volume II. Baseline knowledge concerning process modification opportunities, research needs, by-product market potential, and regulatory requirements. Final Report. Ohio Coal Development Office, Columbus, $\mathrm{OH}$.

Bernas, B. 1968. "A New Method for Decomposition and Comprehensive Analysis of Silicates by Atomic Absorption Spectrometry." Anal. Chem. 40:1682-1686. 
Bradford J.M. and S.C. Gupta. 1986. Compressibility. pp. 479-492. In: A. Klute (ed.) Methods of Soil Analysis, Part 1, Physical and Mineralogical Methods. 2nd Ed. Agronomy 9, ASA, Madison WI.

Brookshire, D.S., B.C. Ives, and W.D. Schultze. 1976. "The valuation of aesthetic preferences," Journal of Environmental Economics and Management, 4: 325-46.

Claussen, Eileen. 1991. Acid rain: the strategy. EPA Journal 17(1). Office of Communication and Public Affairs, Washington, DC.

Council of Economic Advisers. 1990. Economic Report of the President, pp. 298-369.

Dasgupta, Ajit K. and D.W. Pearce. 1978. Cost-Benefit Analysis: Theory and Practice. The MacMillan Press, Ltd. London, England.

Department of Agricultural Economics and Rural Sociology. 1990. The Ohio farm household longitudinal survey. The Ohio State University, Columbus, $\mathrm{OH}$.

Dreimanis, A. 1962 Quantitative gasometric determination of calcite and dolomite by using the Chittick apparatus. J. Sed. Pet. 32:520-529.

Dunnicliff, J. 1988. Geotechnical Instrumentation for Monitoring Field Performance, John Wiley and Sons, New York, 1988.

Earnest, C.M. 1988. The modern thermogravimetric approach to the compositional analysis of materials. In Compositional Analysis by Thermogravimetry, ASTM STP 997, pp. 1-18. C.M. Earnest, Ed. American Society for Testing and Materials, Philadelphia.

EPA Journal. 1986. Acid rain an EPA journal special supplement. 12(5). Office of Public Affairs, Washington, DC.

Edwards, W.F., Green, R.L., Gilford, J.C. 1989. Implementation of a Dynamic Deflection Test for. Rigid and Flexible Pavements in Ohio, Report No. FHWA/OH-89/020, Ohio Dept. of Transportation, Columbus, 1989.

Electric Power Research Institute. 1986. Fly Ash Design Manual for Road and Site Applications, Volume 1: Dry or Conditioned Placement, EPRI Report No. CS4419, February, 1986.

Electric Power Research Institute. 1987. Management of Solid By-Products from Advanced $\mathrm{SO}_{2}$ Control Systems, EPRI Report No. CS-5076, April, 1987. 
Electric Power Research Institute. 1987. Utilization Potential of Advanced $\mathrm{SO}_{2}$ Control By-products, EPRI Report No. CS-5269, June, 1987.

Fawcett Center for Tomorrow. 1974. Ohio fertilizer and lime conference. pp. 1-55. The Ohio State University, Columbus, OH, November 21-22. 1974.

Freeman, A. Myrick III, Robert H. Haveman and Allen Kneese. 1973. The Economics of Environmental Policy. John Wiley and Sons, Inc., New York.

Gee, G.W. and J.W. Bauder. 1986. Particle-size analysis. pp. 383-412. In: A. Klute (ed.) Methods of Soil Analysis, Part i, Prijsical and Mineralogical Methods. 2nd Ed. Agronomy 9, ASA, Madison WI.

Helme, Ned and Chris Neme. 1991. Acid rain: the problem. EPA Journal 17(1). Office of Communication and Public Affairs, Washington, DC.

Hitzhusen, F.J. and K. Nyamaah. 1984. "A Circuity Cost Model for rehabilitation/closure of rural bridges: A Wayne County, Ohio application." Research Bulletin 1156, Ohio Agricultural Research and Development Center, Wooster.

Hufschmidt, Maynard M., David E. James, Anton D. Meister, Blair T. Bower and John A. Dixon. 1983. Environment, Natural Systems and Development: An Economic Valuation Guide, The Johns Hopkins University Press, Baltimore.

Huhtra, R. S. 1981. MSHA, aglime operations day highlights NLI meeting, Rock Products. March 1981. pp. 97-89.

Kennedy, Ralph. 1990. Moving rock by rail, Rock Products, Sept. 1990, pp. 2.2-24.

Klute, A. 1986. Water retention: laboratory methods. pp. 635-662. In: A. Klute (ed.) Methods of Soil Analysis, Part 1, Physical and Mineralogical Methods. 2nd Ed. Agronomy 9, ASA, Madison WI.

Klute, A. and C. Dirksen. 1986. Hydraulic conductivity and diffusivity: laboratory methods. pp. 687-734. In: A. Klute (ed.) Methods of Soil Analysis, Part 1, Physical and Mineralogical Methods. 2nd Ed. Agronomy 9, ASA, Madison WI.

Lindsay, W.L. 1979. "Chemical equilibria in soils" John Wiley \& Sons, New York, 449 p.

McLean, E. O. and J. R. Brown. 1984. Crop response to lime in the midwestern United States. pp. 277-303. In Fred Adams (ed.) Soil acidity and liming. 2nd edition. ASA, Madison, WI. 
Mullen, John K. and Fredrick Menz. 1985. "The effect of acidification damages on the economic value of the Adirondack Fishery to New York anglers," AJAE, 67:112119.

National Fertilizer Development Center. 1980. Conference on Agricultural Limestone. NFDC, Muscle Shoals, AL, pp. 1-80.

Ohio Agricultural Research and Development Center. Selected yuars. In Ohio farm income series.

Ohio Agriculture Statistics Service. 1988. Estimated lime usage. Fertilizer and Lime Division, Columbus, $\mathrm{OH}$.

Ohio Department of Natural Resources. Selected years. In report on Ohio mineral industries series.

Ohio Electric Institute. 1986. Ohio electric utility rate effects of HR4567, "The Acid Deposition Control Act of 1986". Prepared by Temple, Barker and Slcine, Inc., Lexington MA for the Ohio Electric Utility Institute, Columbus, $\mathrm{OH}$.

Ohio Farm Household Longitudinal Study. 1990. Department of Agricultural Economics and Rural Sociology, The Ohio State University.

Pearce, David W. and R. Kerry Turner. 1990. Economics of natural resources and the environment, The Johns Hopkins University Press, Baltimore.

Rawlins, S.L. and G.S. Campbell. 1986. Water potential: thermocouple psychrometer. pp. 597-618. In: A. Klute (ed.) Methods of Soil Analysis, Part 1, Physical and Mineralogical Methods. 2nd Ed. Agronomy 9, ASA, Madison WI.

Rukavina, Mitchell. 1990. Crushed stone: top crushed stone plants. Rock Products, May 1990, pp. 44-51.

SAS Institute, Inc. 1988. SA.S/ETS User's Guide, Version 6, 1st Edition. Ch. 13, p. 315-397.

Schultz, G. A. 1981. Economics of producing aglime. Rock Products, Oct. 1981, pp. 46-51 and 104

Smith, V. Kerry. 1993. "Nonmarket Valuation of Environmental Resources: An Interpretive Appraisal," Land Economics, Vol. 69, No. 1, February 1993, pp. 1 26. 
Sposito, G. and J. Coves. 1988. "Soilchem: A computer program for calculation of chemical speciation in soils. "The Kearney Foundation of Soil Science. University of California.

Sposito, G. and S. Traina. 1987. An ion-association model for highly saline, sodium chloride-dominated waters. J. Environ. Qual. 16:80-85.

Standard and Poor's Corporation. 1992. Standard and Poor's Statistical Service, Current Statistics, April 1992, New York, NY.

Tepordei, Valentin V. 1989. Crushed stone. pp.1-13 and 25-27. In Minerals yearbook 1989, Bureau of Mines.

U.S. Department of Agriculture. Selected years. Annual summary of agricultural prices. NASS. U.S. Gov. Print. Office, Washington DC.

U.S. Department of Commerce International Trade Administration. 1990. Construction Review Bi-Monthly Report, Sept.-Oct. 1990, pp. 13, 37, 44, Washington, D.C.

Van Genuchten, M.Th. 1980. A closed-form equation for predicting the hydraulic conductivity of unsaturated soils. Soil Sci. Soc. Am. J. 44:892-898.

White, J. W. 1917. The relative value of lime of different degrees of fineness for soil improvement. The Penn. State College. Agr. Exper. Station, Bulletin No. 149, Oct. 1917, pp. 3-23.

Whitson, A.R. and W. W. Weir. Soil Acidity and Liming, pp. 8-27.

Wu, T.H. 1987. Long-term Strength of Embankment Materials: Shale and Colluvium, Report FHWA/OH-87-008, Civil Engineering Dept., Ohio State Univ., Columbus, 1987.

Wu, T.H. 1981. Soil Mechanics, 2nd Edition, publ. T.H. Wu, Worthington, Ohio, 1981. 


\section{GLOSSARY}

Abandoned mined land. An area of land that was mined for the extraction of a specific mineral resource prior to the passage of the Surface Mining Control and Reclamation Act of 1977 and not returned to an environmentally acceptable state.

Acid insoluble residue. A solid residue composed primarily of fly ash that is froduced by the dissolution of ary FGD by-product with a weakly acidic buffer solution (pH 5.0) prepared by mixing sodium acetate, acetic acid, and water.

Agricultural lime. A soil amendment containing calcium carbonate, magnesium carbonate, and other material, used to neutralize soil acidity and furnish calcium and magnesium for plant growth. Classification including calcium carbonate equivalent and limits in lime particle size is usually prescribed by law or regulation.

Alkaline amendment. Any material applied to a soil or spoil to raise the $\mathrm{pH}$.

Anhydrite. The mineral name for anhydrous calcium sulfate, $\mathrm{CaSO}_{4}$.

Approach to saturation. A measurement of the moisture content of flue gasses, in terms of the number of degrees the gas temperature is above the temperature at which the gas would be saturated (100\% relative humidity) with water at its current moisture content.

ASTM leachate. The aqueous extract produced by the American Society for Iesting and Materials standard test method for shake extraction of solid waste with water (ASTM D 3987-85).

Available lime index. A method for measuring the amount of calcium oxide $(\mathrm{CaO})$ in a material (ASTM C 25).

Baghouse. A particulate emission control device which utilizes fabric filters in the shape of elongated bags to remove particulate matter from flue gasses.

Base saturation. The extent to which the adsorption complex of a soil is saturated with alkali or alkaline earth cations expressed as a percentage of the cation exchange capacity measured at pH 7.0, which may include acidic cations such as $\mathrm{H}^{+}$and $\mathrm{Al}^{3+}$.

Bed (or bottom) ash. Non-combusted particulate material which accumulates on furnace beds during combustion of coal. 
Beneficial reuse. Use of an industrial by-product in a manner which provides an economic and/or environmental benefit as an alternative to disposal.

Benefit-cost analysis. A procedure for evaluating decisions, or projects, in terms of their full economic consequences (i.e., social bei lefits and costs).

Eulk density. The ratio of the dry mass of a material to its bulk volume.

Calcine. To remove all volatile components through heating. In this report the term is used to refer more specifically to the conversion of a carbonate mineral to its corresponding oxide by the removal of $\mathrm{CO}_{2}$.

Calcite. The mineral name for calcium carbonate, $\mathrm{CaCO}_{3}$

Calcium carbonate equivalency. The quantity of acid-neutralizing substances in a material expressed relative to the acid-neutralizing capacity of $\mathrm{CaCO}_{3}$.

Cation exchange capacity. The sum of exchangeable cations that a soil, soil constituent, or other material can adsorb at a specific pH. It is usually expressed in centimoles of charge per kilogram of exchanger $\left(\mathrm{cmol}_{c} \mathrm{~kg}^{-1}\right)$

Coefficient of determination. The ration of explained variation to total variation in multiple regression statistical analysis.

Compression index (strengths). A ratio of stress to strain used to characterize a soil subjected to orie-dimensional strain.

Darcy's Law. A law describing the rate of flow of water through porous media. As formulated by Darcy the law is

$$
Q=K S(H+\theta) / \theta
$$

where $Q$ is the volume of water passed in unit time, $S$ is the area of the ved, $\theta$ is the thickness of the bed, $H$ is the depth of water on top of the bed aid $F$ is a coefficient dependent on the nature of the porous media (the hydraulic conductivity of the media).

Detection limit. The limit of an analytical technique to detect the presence of an analyte. Specificelly the conceritration of an analyte which produces a signal equal to twice the standard deviation of th's background signal fluctuations.

Dolomite. The mineral name for calcium magnesium carbonate, $\mathrm{CaMg}\left(\mathrm{CO}_{3}\right)_{2}$

Dry scrubber. Any of several technoiogies for removing $\mathrm{SO}_{2}$ from flue gasses in which the reaction product :s collected in a dry state in the particulate emission control devices (c.f. wet scrubber). 
Duct injection. A dry scrubber technology in which the sorbent is injected into the ductwork downstream from the boiler air pre-heaters in the lower flue gas temperature regions.

Economic analysis. In contrast to financial analysis, economic analysis takes into account net economic returns to the whole society which frequently involves shadow prices to adjust for market or administered price imperfections.

Elasticity (economic).

a) price elasticity of supply (demand): the ratio of the percentage change in the quantity of a commodity supplied (demanded) per unit of time to the percentage change in the price of that commodity. If the elasticity is denoted $e$ then:

$$
\begin{array}{ll}
e>1 & \text { elastic demand/supply, } \\
e<1 & \text { inelastic demand/supply, and } \\
e=1 & \text { unitary elastic demand/supply. }
\end{array}
$$

b) income elasticity $\left(e_{m}\right)$ : The ratio of the percentage change in the amount of a commodity purchased per unir time to the percentage change in the buyer's income. If

$$
\begin{array}{ll}
e_{m}>0 & \text { the commodity is normal, } \\
e_{m}<0 & \text { the commodity is inferior, } \\
e_{m}=1 & \text { the commodity is a luxury, and } \\
0<e_{m}<1 & \text { the commodity is a necessity. }
\end{array}
$$

Electrical conductivity. The ability of a solution to allow the passage of an electrical current, generally expressed in units of $\mu \mathrm{mho} \mathrm{cm}^{-1}$.

Electrostatic precipitator. A particulate emission control device in which flue gasses are passed through a charged field and particulate matter is removed due to electrostatic attraction to charged plates.

Environmental disamenity. Any environmental intrusion, such as a landfill or air pollution which is unpleasant or even dangerous.

Ettringite. A hydrated calcium-aluminum hydroxysulfate mineral, $\mathrm{Ca}_{6} \mathrm{Al}_{2}\left(\mathrm{SO}_{4}\right)_{3}(\mathrm{OH})_{12} \cdot 26 \mathrm{H}_{2} \mathrm{O}$.

Externalities. Incidental, third party or external effects from economic producers or consumption activity which is not accounted for by market prices.

Financial analysis. Refers to net returns to private equity capital based on market or administereci prices. 
Flue gas desulfurization (FGD). The removal of sulfur dioxide from the combustion gasses of fossil fuel- (coal-) fired boilers.

Flue gas. Gasses resulting from the combustion of fossil fuels (coal).

Fluidized bed combustion. A coal combustion process in which a bed of mixed pulverized coal and sorbent (generally limestone) is fluidized by jets of air blowing up from the furnace floor.

Fly ash. The glassy inorganic particulate residue suspended in the flue gasses resulting from combustion of fossil fuel (coal).

Geochemical speciation. The equilibrium distribution of cationic, anionic, and neutral dissolved species in a solution expressed as the activity of the species.

Gypsum. The mineral name for hydrated calcium sulfate, $\mathrm{CaSO}_{4} \cdot 2 \mathrm{H}_{2} \mathrm{O}$.

Hedonic prices. The implicit prices of attributes revealed to economic agents from the observed prices of differentiated goods and the specific amounts of characteristics associated with them.

Hedonic impacts. Impacts on the implicit prices of characteristics of differentiated goods.

Hematite. The mineral name for an iron oxide with the formula $\mathrm{Fe}_{2} \mathrm{O}_{3}$.

Hydrated lime. Portlandite, $\mathrm{Ca}(\mathrm{OH})_{2}$, formed by the reaction of lime $(\mathrm{CaO})$ with water or steam.

Hydraulic conductivity. The rate of flow of pure water through a cross sectional area under a unit hydraulic gradient at the prevailing temperature. Synonymous with permeability coefficient, $K$.

Hydraulic gradient. The change in water level over a given distance, be it horizontal, vertical or somewhere in between. Defined as $\Delta h / \Delta l$ where $\Delta h$ is the change in head or water level, and $\Delta l$ is the change in distance or elevation.

ICP. Inductively Coupled Plasma atomic emission spectrophotometer.

Inclinometer. An instrument capable, when placed in an embankment, of measuring movement of a soil mass. 
Instrument calibration and standardization. The optimization of an analytical instrument so as to provide specific output from analytical standards of known composition.

LIMB process. Lime Injection Multistage Burners. A dry scrubber technology in which the sorbent is injected into the furnace above the combustion zone

Lime test index. An index value generated by reaction of a soil with an alkaline buffer and used to determine the amount of agricultural lime required to raise the $\mathrm{pH}$ of the soil to a specified level.

Lime. The mineral name for calcium oxide, CaO.

Limestone. A rock of marine origin that is typically composed of calcite $\left(\mathrm{CaCO}_{3}\right)$.

Magnetite. The mineral name for a magnetic iron oxide with the formula $\mathrm{Fe}_{3} \mathrm{O}_{4}$.

NIST. National Institute of Standards and Iechnology.

Optimum density. The maximum density achievable with a standard compaction effort.

Optimum moisture content. The moisture content at which the optimum density is achieved.

Overburden. In surface mining practices, there is usually some quantity of rock or soil that overlies the mineral resource. This material is known as overburden and must be removed during surface mining to expose the mineral.

Oxidation-reduction potential (Eh). A measurement (expressed in $\mathrm{mV}$ ) of the tendency of a system to oxidize (accept electrons from) or reduce (donate electrons to) chemical species introduced into the system.

Particle size distribution. The fractions of the various soil separates in a soil sample, often expressed as mass percentages.

Periclase. The mineral name for magnesium oxide, MgO.

Permeability. A measure of the relative ease of fluid flow under unequal pressure.

Piezometer. A device for measuring the water pressure at a specific elevation in a soil mass.

Portlandite. The mineral name for calcium hydroxide, $\mathrm{Ca}(\mathrm{OH})_{2}$. 
Potential pareto improvement. An improvement in social welfare in which those who gain from the improvement could potentially compensate the perceived losses of the losers and still be no worse off.

Pressurized fluidized bed combustion. A fluidized bed combustion technology modified such that the boiler is pressurized and the pressurized flue gas is used to turn a gas turbine for production of electricity in addition to steam generation to turn steam turbines.

Quality assurance. Refers to a program of activities organized to insure that a laboratory produces data of adequate quality for its intended end use. To meet this data quality goal, an overall quality assurance program comprises numerous quality control activities.

Quality control. Activities which address day-to-day analyses, as well as laboratory management, and are designed to insure that the data produced by a specific analytical procedure is of adequate quality for its intended end use.

Residuals. The amount of a resource which is left over after a material has been transformed from one state to another in a economic production or consumption process, e.g., fly ash is a residual of the process of transforming coal to electric energy.

Saturation index (SI). A measurement of the degree to which a chemical system is under- or oversaturated with respect to a particular solid phase mineral. When $\mathrm{SI}$ is greater than 0 , the system is oversaturated and the mineral will tend to precipitate; when $\mathrm{SI}$ is less than $\mathrm{O}$, the system is undersaturated and the mineral will tend to dissolve.

Shift variable. In a supply and demand system, a shift variable is one which is exogenous, or outside, of the system. It effectively causes exogenous changes in supply and/or demand.

Soil stabilization. The application of physical or chemical additives to a soil mass for the purpose of improving soil strength.

Specific surface area. The surface area per unit weight of a material, generally expressed in units of $\mathrm{m}^{2} \mathrm{~g}^{-1}$.

Spoil. Typically a mixture of overburden and uneconomic mineral deposits that are the result of mining operations. 
Spray dryer. A dry scrubber technology in which the sorbent is injected into a dry scrubber vessel located downstream from the boiler air preheater in the lower flue gas temperature region. The scrubber vessel allows for increased flue gas residence time and therefore increased time for the sorbent to react with $\mathrm{SO}_{2}$

Stiffness (soil). The ratio of applied stress to induced strain i.e. $\sigma / \epsilon$.

Strength (soil). The maximum imposed stress a soil can withstand without failing.

TCLP leachate. The extract produced by the US EPA Method 1311 Ioxicity Characteristic Leaching Procedure which is designed to determine the mobility of both organic and inorganic analytes present in liquid, solid, and multiphasic wastes.

Tensiometer. A device for measuring soil water tension.

Thermal reactivity. The amount of heat generated by a material upon addition of water. Generally expressed as the increase in temperature in a specified time period from the addition of a specified amount of water to specified amount of the material.

Thermal gravimetric analysis. An analytical method for the quantification of mineral components in a sample by measuring the weight loss induced by heating over a specified temperature range.

Tipping fee. The amount charged by a facility accepting waste materials for the disposal of a given weight or volume of a specified waste.

Total neutralizing potential. The total amount of alkalinity in a material, determined by causing a complete reaction of a specified amount of the material with a specified amount of a standard acid.

Wet scrubber. A process for removing $\mathrm{SO}_{2}$ from flue gasses in which the sorbent is injected downstream from the particulate emission control system, and the reaction product is collected in the form of a slurry consisting primarily of gypsum (c.f. dry scrubber).

Willingness to accept. This is the supply curve of an economic agent; it is the price at which the agent is willing to engage in trade with a demander of a good.

Willingness to pay. The demand curve of an economic agent. The price at which the agent is willing to purchase a good from a supplier. 
Phase 1 Report

$x$-ray diffraction. An analytical technique for the qualitative identification of crystalline mineral components by measuiting the scattering of $X$-rays by the atoms of $a$ crystal in definite directions away from the crystal (diffraction pattern). 
Phase 1 Report

7 APPENDICES 


\section{APPENDIX A \\ Steering Committee}

Baker, Bob

Ohio Dept. of Natural Resources

1855 Fountain Square Court

Columbus, $\mathrm{OH} 43224$

614-265-6633

Bedick, Robert C.

U.S. Department of Energy

Morgantown Energy Technology Center

P.O. Box 880

Collins Ferry Rd.

Morgantown, WV 26505

304-291-4505

Beeghly, Joel

Dravo Lime Co.

Research Center

3600 Neville Rd.

Pittsburgh, PA 15225

412-777-0711

Bigham, Jerry

The Ohio State University

420A Kottman Hall

2021 Coffey Rd.

Columbus, $\mathrm{OH} 43210$

614-292-9066

Bird, Jacqueline

Ohio Coal Development Office

77 S. High Street

P.O Box 1001

Columbus, $\mathrm{OH}$ 43266-0101

614-466-3465

Brdicka, Ed

Ohio Env. Prot. Agency

Division of Solid Waste Managment

P.O. Box 1049

1800 Water Mark Drive

Columbus, $\mathrm{OH}$ 43266-1049

614-644-3181
Cook, Adrian

Ohio Edison Co.

76 South Main St.

Akron, $\mathrm{OH} 44308$

216-384-4550

Dick, Warren

The Ohio State University

109A Williams Hall

OARDC/OSU

Wooster, OH 44691-4096

216-263-3877

Forsythe, Russ

Dravo Lime Company

3600 One Oliver Plaza

Pittsburgh, PA 15222-2682

412-566-5553

Haefner, Ralph

USGS Water Resources Division

975 West Third Ave.

Columbus, $\mathrm{OH} 43212-3192$

614-469-5553 (FTS 943 5553)

Harness, Jerry

U.S. Department of Energy

Morgantown Energy Technology

Center

P.O. Box 880

Collins Ferry Road

Morgantown, WV 26505

304-291-4835

Hopkins, Ed

Ohio Citizens Action

17 Brickel Street

Columbus, $\mathrm{OH} 43215$

614-224-4111 
Hyman, David

U.S. Bureau of Mines

Cochran Mill Road

P.O. Box 18070

Pittsburgh, PA 15236

412-892-6572

Johnson, Howard

Ohio Coal Development Office

77 S. High Street

P.O Box 1001

Columbus, $\mathrm{OH}$ 43266-0101

614-466-3465

Keenan, Gregory

AEP Service Corporation

1 Riverside Plaza

Columbus, $\mathrm{OH} 43215$

614-223-1388

MacDonald, R. Jeffrey

ODNR Div of Reclamation AML

1855 Fountain Square Ct.

Columbus, $\mathrm{OH} 43224$

614-265-1016

Militaru, Calin

AEP Service Corporation

1 Riverside Plaza

Columbus, $\mathrm{OH} 43215$

614-223-1384

Murarka, Ishwar P.

Electric Power Research Institute

3412 Hillview Avenue

P.O. Box 10412

Palo Alto, CA 94303

415-855-2150

Rotering, Ernest

Ohio EPA, Div. Solid Waste

Management

P.O. Box 1049

1800 Water Mark Drive

Columbus, OH 43266-1049

614-644-3020
Seibel, Rick

Office of Surface Mining

U.S. Department of Interior

Ohio Section

2242 S. Hamilton

Columbus, $\mathrm{OH} 43232$

614-866-0578

Showman, Ray

AEP Service Corporation

1 Riverside Plaza

Columbus, $\mathrm{OH} 43215$

614-223-1000

Shupert, John

Ohio Mining \& Reclamation Association

129 N Tenth Street

Cambridge, OH 43725

614-432-5645

Skiles, Mervin S.

USDA- Soil Conservation Service

200 N. High Street

Columbus, $\mathrm{OH} 43215$

614-469-6980

Stehouwer, Rick

The Ohio State University

110A Williams Hall

OARDC/OSU

Wooster, OH 44691-4096

216-263-3655

Theodore, Frank W. Consolidation Coal Co.

4000 Brownsville Road

Library, PA 15129

412-854-6663

Tostenson, Neal

Ohio Mining \& Reclamation Association

$50 \mathrm{~S}$. Young

Columbus, $\mathrm{OH} 43215$

614-228-6336 
Phase 1 Report

Appendix B

\section{APPENDIX B}

Following are two bibliographies of litererature related to FGD production, characterization, and environmental impacts of land application and disposal. The first was compiled by the USGS, Water Resources Division, and the second was compliled by the Ohio State University, Department of Agronomy. There are several entries which appear in both bibliographies.

\section{USGS Bibliography}

Adams, L.M., Capp, J.P., and Gillmore, D.W., 1972, Coal mine spoil and refuse bank reclamation with powerplant fly ash: Compost Science, v. 13, no. 6, p. 20-26.

Aller, Linda, Bennett, T.W., Hackett, Glen, Petty, R.J., Lehr, J.H., Sedoris, Helen, Nielsen, D.M., and Denne, J.E., 1989, Handbook of Suggested Practices for the Design and Installation of Ground- Water Monitoring Wells: National Water Well Association, publ., Dublin, $\mathrm{OH}, 398 \mathrm{p}$.

Ammons, J.T., Coburn, C.B. Jr., and Shelton, P.A., 1990, An application of acid-base accounting for highway construction in east Tennessee, in Skousen, J., Sencindiver, J. and Samuel, D., eds., Proceedings of the 1990 Mining and Reclamation Conference and Exhibition: 2 vols., West Virginia University, Morgantown, WV, p. 265-269.

Anderson, M.A., Bertsch, P.M., Feldman, S.B., and Zelazny, L.W., 1991, Interaction of acidic metal-rich coal pile runoff with a subsoil: Environmental Science and Technology, v. 25, p. 2038-2046.

Anderson, M.A., and Woessner, W.W., 1992, Applied Groundwater Modeling, Simulation of Flow and Advective Transport: Academic Press Inc., publ., San Diego, CA, 92101, $381 \mathrm{p}$.

Arbogast, B.F., ed., 1990, Quality assurance manual for the Branch of Geochemistry, U.S. Geological Survey: U.S. Geological Survey Open-File Report 90-668, 184 p.

Bair, E.S., Sheets, R.A., and Eberts, S.M., 1990, Particle-tracking analysis of flow paths and traveltimes from hypothetical spill sites within the capture area of a wellfield: Ground Water, v. 28, no. 6, p. 884-892.

Ball, J.W., and Nordstrom, D.K., 1991, User's manual for WATEQ4F, thermodynamic data base and test cases for calculating speciation of major, trace, and redox elements in natural waters: U.S. Geological Survey Open-File Report 91-183, $189 \mathrm{p}$. 
Ball, J.W., Nordstrom, D.K., and Zachman, D.W., 1987, WATEQ4F-- a personal computer FORTRAN translation of the geochemical model WATEQ2 with revised data base: U.S. Geological Survey Open-File Report 87-50, 108 p.

Bullukraya, P.N. and Sharma, K.K., 1991, Estimation of storativity from recovery data: Ground Water, v. 29, no. 4, p. 495-498

Bass Becking, L.G.M., and Moore, D., 1961, Biogenic sulfides: Economic Geology, v. 56, p. 259-272. Bassett, R.L., and Davidson, G.R., 1990, 11B/10B isotopic ratio for environmental, geochemical, and hydrologic application [abs.]: EOS Transactions, American Geophysical Union, v. 71, no. 28, p. 877.

Bell, J.F., and Reeves, M.J., 1982, MINES: a model to forecast mine wastewater quality, international Journal of Environmental Studies, v. 20, p. 47-52.

Bennett, G.D., 1976, Introduction to ground-water hydraulics, a programed text for self-instruction: Techniques of Water- Resources Investigations of the U.S. Geological Survey, Chapter B2, Book 3, 172 p.

Bennett, O.L., Hern, J.L., Perry, H.D., Reid, R.L., Stout, W.L., Edwards, J.H., and Smedley, K.O., 1985, Agricultural uses of atmospheric fluidized bed combustion residue (AFBCR) - a seven year study: Second Annual Pittsburgh Coal Conference Proceedings, Paper no. 30, $20 \mathrm{p}$.

Berndtsson, Ronny, 1990, Transport and sedimentation of pollutants in a river reach: a chemical mass balance approach: Water Resources Research, v. 26, no. 7, p. 1549-1558.

Bhumbla, D.K., Singh, R.N., and Keefer, R.F., 1990, Retardation of pyrite oxidation by massive fly ash application to mine spoils: [abs.], in Skousen, J., Sencindiver, J., and Samuel, D., eds., Proceedings of the 1990 Mining and Reclamation Conference and Exhibition: 2 vols., West Virginia University, Morgantown, WV, p. 469.

Botoman, George, and Stith, D.A., 1988, Analyses of Ohio Coals, 1982- 1984: Ohio Department of Natural Resources, Division of Geological Survey, Information Circular No. 55, 17 p., 4 plates.

Botoman, George, and Stith, D.A., 1986, Analyses of Ohio Coals, 1979-1980: Ohio Department of Natural Resources, Division of Geological Survey, Information Circular No. 52, 26 p., 4 plates.

Botoman, George, and Stith, D.A., 1981, Analyses of Ohio Coals, 1977-1978: Ohio Department of Natural Resources, Division of Geological Survey, Information Circular No. 50,54 p., 4 plates. 
Botoman, George, and Stith, D.A., 1987, Analyses of Ohio Coals: Ohio Department of Natural Resources, Division of Geological Survey Information Circular 47, 148 p., 5 plates.

Bradham, W.S., and Caruccio, F.T., 1990, A comparative study of tailings analysis using acid/base accounting, cells, columns, and soxhlets, in Skousen, J., Sencindiver, J., and Samuel, D., eds., Proceedings of the 1990 Mining and Reclamation Conference and Exhibition: 2 vols., West Virginia University, Morgantown, WV, p. 19-25.

Brady, K.B., and Cravotta, C.A., 1992, Acid-base accounting: an improved method of interpreting overburden chemistry to predict quality of coal-mine drainage, in Proceedings of the West Virginia Surface Mine Drainage Task Force Symposium, April 8-9, 1992: Morgantown, WV, 9 p.

Brady, K.B.C., and Hornberger, R.J., 1990, The prediction of mine drainage quality in Pennsylvania: Water Pollution Control Association of Pennsylvania Magazine, September-October, 1990, p. 8-15.

Brady, K.B.C., Shaulis, J.R., and Skema, V.W., 1988, A study of mine drainage quality and prediction using overburden analysis and paleoenvironmental reconstructions, Fayette County, Pennsylvania, in Proceedings Mine Drainage and Surface Mine Reclamation, v. 1, Mine Water and Mine Waste: U.S. Department of the Interior, Bureau of Mines Information CIrcular 9183, p. 33-43.

Brady, K.B.C., and Smith, M.W., 1990, Pyritic sulfur analyses for coal overburden: differences between laboratories, in Proceedings 1990 National Symposium on Mining: University of Kentucky, Lexington, KY, p. 53-58.

Brady, K.B.C., Smith, M.W., Beam, R.L., and Cravotta, C.A. III, 1990, Effectiveness of the addition of alkaline materials at surface coal mines in preventing or abating acid mine drainage: Part 2. Mine site case studies, in Skousen, J., Sencindiver, J., and Samuel, D., eds., Proceedings of the 1990 Mining and Reclamation Conference and Exhibition: 2 vols., West Virginia University, Morgantown, WV, p. 227-241.

Buck, J.K., Houston, R.J., and Beimborn, W.A., 1990, Direct seeding of anthracite refuse using coal fly ash as a major soil amendment: [abstr.], in Skousen, J., Sencindiver, J., and Samuel, D., eds., Proceedings of the 1990 Mining and Reclamation Conference and Exhibition: 2 vols., West Virginia University, Morgantown, WV, p. 603. 
Busby, J.F., Plummer, L.N., Lee, R.W., and Hanshaw, B.B., 1991, Geochemical evolution of water in the Madison Aquifer in parts of Montana, South Dakota, and Wyoming: U.S. Geological Survey Professional Paper 1273-F, 89 p. Capp, J.P., 1978, Power plant fly ash utilization for land reclamation in the eastern United States, in Schaller, F.W., and Sutton, Paul, eds., Reclamation of Drastically Disturbed Lands: American Society of Agronomy, Inc.; Crop Science Society of America, Inc., and; Soil Science Society of America, Inc. Publishers, Chapter 19, p. 339-353.

Caruccio, F.T., , Trace element distribution in reactive and inert pyrite: (unknown source), p. 48-53.

Caruccio, F.T., Ferm, J.C., Horne, John, Geidel, Gwendelyn, and Boganz, Bruce, 1977, Paleoenvironment of coal and its relation to drainage quality: Industrial Environmental Research Laboratory, Office of Research and Development, U.S. Environmental Protection Agency, Cincinnati, OH, 45268, EPA-600/7-77-067, $118 \mathrm{p}$.

Caruccio, F.T., and Geidel, Gwendelyn, 1978, Geochemical factors affecting coal mine drainage quality, in Schaller, F.W., and Sutton, Paul, eds., Reclamation of Drastically Disturbed Lands: American Society of Agronomy, Inc.; Crop Science Society of America, Inc, and; Soil Science Society of America, Ir.s. Publishers, Madison, WI, Chapter 8, p. 129-148.

Chao, T.T., 1984, Use of partial dissolution techniques in geochemical exploration: Journal of Geochemical Exploration, v. 20, p. 101-135.

Chao, T.T., and Sanzolone, R.F., 1989, Fractionation of soil selenium by sequential partial dissolution: Soil Science Society of America Journal, v. 53, no. 2, p. 385-392.

Chapman, B.M., Jones, D.R., and Jung, R.F., 1983, Processes controlling metal ion attenuation in acid mine drainage streams: Geochimica et Cosmochimica Acta, v. 47, p. $1957-1973$.

Cherkauer, D.S., 1980, The effect of fly ash disposal on a shallow ground-water system: Ground Water, v. 18, no. 6, p. 544-550.

Christophersen, Nils, and Hooper, R.P., 1992, Multivariate analysis of stream water chemical data: the use of principal components analysis for the end-member mixing problem: Water Resources Research, v. 28, No. 1, p. 99-107.

Chung, S.O., Ward, A.D., Schalk, C.W., 1992, Evaluation of the hydrologic component of the ADAPT water table management model: American Society of Agricultural Engineers, v. 35, no. 2, p. 571-579. 
Churey, D.J., Gutenmann, W.H., Kabata-Pendias, Alina, and Lisk, D.J., 1979, Element concentrations in aqueous equilitriates of coal and lignite fly ashes: Journal of Agricultural Food Chemistry, v. 2"', no. 4, p. 910-911.

Claassen, H.C., 1982, Guidelines and teshniques for obtaining water samples that accurately represent the water chemistry of an aquifer: U.S. Geological Survey Open-File Report 82-1024, 49 p.

Cleaves, E.T., Godfrey, A.E., and Bricker, O.P., 1970, Geochemical balance of a small watershed and its geomorphic implications: Geological Society of America Bulletin, v. 81, p. 3015-3032.

Collier, C.R., and others, 1964, Influences of strip mining in the hydrologic environment of parts of Beaver Creek Basin, Kentucky, 1955-1959: U.S. Geolugical Survey Professional Paper 427-B, 85 p.

Collier, C.R., Pickering, R.J., and Musser, J.J., 1970, Influences of strip mining on the hydrologic environment of parts of Beaver Creek Basin, Kentucky, 1955-1966: U.S. Geological Survey Professional Paper 427-C, 80 p.

Collins, H.R., 1979, The Mississippian and Pennsylvanian (Carboniferous) Systems in the United Sta. 's- Ohio: U.S. Geological Survey Professional Paper 1110-E, 26 p.

Cooper, L.W., Olsen, C.R., Solomon, D.K., Larsen, I.L., Cook, R.B., and Grebmeier, J.M., 1991, Stable isotopes of oxygen and natural and fallout radionuclides used for tracing runoff during snowmelt in an Arctic watershed: Water Resources Research, v. 27, no. \&, p. 2171-2179.

Corbett, D.M., 1968, Ground-water hydrology per_aining to surface mining for coal-southwestern Indiana: Seconc Symposium on Coal Mine Drainage Research, Coal Industry Advisory Committee to the Ohio River Valley Water Sanitation Commission, publishers, p. 164-189.

Cox, J.A., Lundquist, G.L., Przyjazny, A. and Schmulbach, C.D., 1978, Leaching of boron from coal ash: Environmental Science and Technology, v. 12, no. 6, p. $722-723$.

Cravotta, C.A., 1992, Effect of sewage sludge on formation of acidic water at reclaimed coal mines in western Pennsylvania: Geological Society of America, Northeastern Section 1992 Meeting, Abstracts with programs, v. 24, no. 3, p. 14. 
Cravotta, C.A., 1991, Geochemical evolution of acidic tround water at a reclaimed surface coal mine in western Pennsylvania, in Oaks, W.R., and Bowden, J., eds., Proceedings of the 1991 National Meeting of the American Society for Surface Mining and Reclamation:American Society for Surface Mining and Reclamation, Princeton, WV, p. 43-68.

Cravotta, C.A. III, 1989, Geochemical evolution of ground water at a surface coal mine reclaimed with urban sewage sludge in western Pennsylvania, [abs.], in Pederson, G.L., and Smith, M.M., compilers, U.S. Geological Survey Second National Symposium on Water Quality: Abstracts of the Technical Sessions: Orlando, FL, November 12-17, 1989: U.S. Geological Survey Open-File Report 89- 409, p. 13.

Cravotta, C.A. III, Brady, K.B.C., Smith, M.W., and Beam, R.L., 1990, Effectiveness of the addition of alkaline materials at surface coal mines in preventing or abating acid mine drainage: Part 1. Geochemical considerations, in Skousen J., Sencindiver, J. and Samuel, D., eds., Proceedings of the 1990 Mining and Reclamation Conference and Exhibitic r: 2 vols., West Virginia University, Morgantown, WV, p. 221-225.

Crouch, T.M., Collins, H.R., and Helgesen, J.O., 1980, Abandoned subsurface coal mines as a source of water for coal conversion in eastern Ohio: Ohio Dapartment of Natural Resources, Division of Geological Survey, Report of Investigations No. 118, 25 p.

Cunningham, W.L. and Jones, R.L., 1990, Long-term effects of surface coal mining on ground-water levels and quality in two small watersheds in eastern Ohio: U.S. Geological Survey Water- Resources Investigations Report 90-4136, 74 p.

Curry, R.R., 1975, Biogeochemical limitations on western reclamation, in Wali, M.K., ed., Practices and Problems of Land Reclamation in Western North America: The University of North Dakota Press, Grand Forks, ND, 196 p.

Curtis, W.R., 1973, Effects of strip mining on the hydrology of small mountain watersheds in Appalachia, in Hutnick, R.J., and Davis, Grant, eds., Ecology and Revlamation of Devastated Land: Gordan and Breach Scientific Publishers, Inc., NY, p. 145-157.

Daniels, W.L., and Haering, Kathryn, 1990, The feasibility of large- scale sewage sludge/compost utilization on central Appalachian surface mined lands, in Skousen, J., Sencindiver, J., and Samuel, D., eds., Proceedings of the 1990 Mining and Reclamation Conference and Exhibition: 2 vols., West Virginia University, Morgantown, WV, p. 165-170. 
Davidson, G.R., and Bassett, R.L., 1993, Application of boron isotopes for identifying contaminants such as fly ash leachate on groundwater: Environ. Sci. Technol., v. 27 , no. 1, p. $172-176$.

Davison, R.L., Natusch, D.F.S., Wallace, J.R., and Evans, C.A. Jr., 1974, Trace elements in fly ash- dependence of concentration on particle size: Environmental Science \& Technology, v. 8, no. 13, p. 1107-1113.

Destouni, Georgia, 1992, Prediction uncertainty in solute flux through heterogeneous soil: Water Resources Research, v. 28, no. 3, p. 793-801.

Dick, W.A., Bonta, J.V., Haghiri, F., and Page, J.R., 1983, Stream water quality of two small watersheds as affected by surface coal mining: Journal of Environmental Quality, v. 12, no. 3, p. 351-358.

Dickens, P.S., Minear, R.A., and Tschantz, B.A., 1989, Hydrologic alteration of mountain watersheds from surface mining: Journal of the Water Pollution Control Federation, v. 61, no. 7, p. 1249-1260.

Dinger, J.S., Wunsch, D.R., and Kemp J.E., 1990, Occurrence of ground water in mine spoil, a renewable resource: Star Fire Tract, eastern Kentucky, in Skousen, J., Sencindiver, J., and Samuel, D., eds., Proceedings of the 1990 Mining and Reclamation Sonference and Exhibition: 2 vols., West Virginia University, Morgantown, WW, p. 171-179.

Diodato, D.M., 1989, Quantitative characterization of unsaturated fluid flow behavior in disturbed mine spoil: twe nuclear methodologies: unpublished Master's Thesis, The Pennsylvania State University Department of Geosciences, State College, PA, 247 p.

diPretoro, R.S., 1986, Premining prediction of acid drainage potential from surface coal mines in northern West Virginia: unpublished Master's Thesis, West Virginia University, Morgantown, $W V, 217 \mathrm{p}$.

difretoro, R.S., and Rauch, 1988, Use of acid-base accounts in premining prediction of acid drainage potential: A new approach from northern West Virginia, in Mine Drainage and Surface Mine Reclamation: Bureau of Mines Information Circular 9183, p. 2-10.

Driscoll, F.G., 1986, Groundwater and Wells: Johnson Division, publ., St. Paul, MN, 55112,1089 p.

Duda, A.M., and Penrose, D.L., 1980, Impact of mining activities on water quality in western North Carolina: Water Resources Bulletin of the American Water Resources Association, v. 16, no. 6, p. 1034-1040. 
Dudas, M.J., 1981, Long-term leachability of selected elements from fly ash: Environmental Science \& Technology, v. 15, no. 7, p. 840-843.

Eberle, Michael, and Razem, A.C., 1985, Effects of surface coal mining and reclamation on ground water in small watersheds in the Allegheny Plateau, Ohio: U.S. Geological Survey Water- Resources Investigations Report 85-4205, $13 \mathrm{p}$.

Ebraheem, A.M., Hamburger, M.W., Bayless, E.R., and Krothe, N.C., 1990, A study of acid mine drainage using earth resistivity measurements: Ground Water, v. 28, no. 3, p. 361-368.

Edwards, K.B., 1991, Estimating aquifer parameters from a horizontal well pumping test in an unconfined aquifer: Water Resources Bulletin, American Water Resources Association, Paper No. 91115, v. 27, no. 5, p. 831-839.

Engelke, M.J., Roth, D.K., and others, 1981, Hydrology of area 7, eastern coal province, Ohio: U.S. Geological Survey Water- Resources Investigations Report 81-815, $60 \mathrm{p}$.

Electric Power Research Institute, 1992, Strategies for field calibration and validation of groundwater models: EPRI Report TR-101063, Project 2485-09, Interim Report, $40 \mathrm{p}$.

Electric Power Research Institute, 1992, Comanagement of coal combustion by-products and low-volume wastes, a midwestern site: EPRI Report TR 100955 Project 2485-09.

Electric Power Research Institute, 1990, Short- and long-term leaching dynamics: field and laboratory study of a wet fly ash disposal facility: Land and Water Quality News, v. 5, no. 3, p. 4-6.

Electric Power Research Institute, 1989, FASTCHEM package, volume 1: Overview and application to a chemical transport problem: EPRI Report EA-5870, Volume 1, Project 2485-2.

Electric Power Research Institute, 1989, MYGRT Code version 2.0: an IBM code for simulating migration of organic and inorganic chemicals in groundwater: EPRI Report EN-6531, Project 2879-2.

Electric Power Research Institute, 1989, Measuring hydraulic conductivity with the borehole flowmeter: EPRI Report EN-6511, Project 2485-5.

Electric Power Research Institute, 1989, Field investigation of a flue gas desulfurization (FGD) sludge disposal site: EPRI Report EA-5923, Project 2485-8. 
Electric Power Research Institute, 1988, FASTCHEM package, volume 4: User's guide to the ECHEM equilibrium geoche nistry code: EPRI Report EA-5870-CCM, Volume 4, Project 2485-2.

Electric Power Research Institute, 1988, FASTCHEM package, volume 3: user's guide to the ETUBE pathline and streamtube database code: EPRI Report EA-5870-CCM, Project 2485-2.

Electric Power Research Institute, 1988, FASTCHEM package, volume 2: user's guide to the EFLOW 91- idwater flow code: EPRI Report EA-5870-CCM, Project 2484-2.

Electric Power Research Institute, 1987, Chemical form and leachability of inorganic trace elements in coal ash: EPRI Report EA-5115, Project 1371-1.

Electric Power Research Institute, 1986, Geochemical behavior of chromium species: EPRI Report EA-1544, Research Project 2485-3, 198 p.

Electric Power Research Institute, 1986, Geohydrochemical models for solute migration, volume 3: evaluation of selected computer codes: EPRI Report EA-3417, Project 2485-2.

Electric Power Research Institute, 1985, Field measurement methods for hydrogeologic investigations: a critical review of the literature: EPRI Report EA-4301, Project 2485-7, 328 p.

Electric Power Research Institute, 1984, Groundwater model parameter estimation using a stochastic-convective approach: EPRI Report CS-3629, Project 1406-1, $68 \mathrm{p}$.

Electric Power Research Institute, 1984, Chemical attenuation rates, coefficients, and constants in leachate migration, volume 2: an annotated bibliography: EPRI Report EA-3356, Project 2189-1, 178 p.

Electric Power Research Institute, 1984, Chemical attenuation rates, coefficients, and constants in leachate migration, volume 1: a critical review: EPRI Report EA-3356, Project 2198-1, 302 p.

Electric Power Research Institute, 1983, Pilot study of time variability of elemental concentrations in power plant ash: EPRI Report EA-2959, Project 1620, 180 p.

Electric Power Research Institute, 1983, A statistical comparison of two studies on trace element composition of coal ash leachates: EPRI Report EA-3181, Project $1487,92 \mathrm{p}$. 
Electric Power Research Institute, 1982, Monitoring the fixed FGD sludge landfill, Conesville, Ohio, phase II, second interim: EPRI Report CS-2498, Research Project 1406-2, $118 \mathrm{p}$.

Electric Power Research Institute, 1981, Monitoring the fixed FGD sludge landfill, Conesville, Ohio, phase II: EPRI Report CS- 1984, Research Project 1406-2, 150 p.

Electric Power Research Institute, 1981, Trace element and phase relations in fly ash: EPRI Report EA-1822, Project 1061, 78 p.

Electric Power Research Institute, 1980, Coal mine disposal of flue gas cleaning wastes: EPRI Report CS-1376, Research Project 1260-14, 138 p.

Erickson, P.M., and Hedin, R.S., 1988, Evaluation of overburden analytical methods as a means to predict post-mining coal mine drainage quality, in Mine Drainage and Surface Mine Reclamation: Bureau of Mines Information Circular 9183, p. 11-19.

Ericzon, Christina, Pettersson, Jean, Andersson, Marit, and Olin, Ake, 1989, Determination and speciation of selenium in end products from a garbage incinerator: Environmental Science Technology, v. 23, no. 12, p. 1524-1528.

Ferguson, K.D., and Morin, K.A., 1991, The prediction of acid rock drainage-lessons form the database: Proceedings from the Second International Conference on the Abatement of Acidic Drainage, Montreal, Canada, p. 85-106.

Fetter, C.W., 1988, Applied Hydrogeology: Macmillan Publishing Company, New York, NY, 10022, $592 \mathrm{p}$.

Ficken, J.H., 1989, Advances in instrumentation for automatically monitoring water quality [abs.], in Pederson, G.L., and Smith, M.M., compilers, U.S. Geological Survey Second National Symposium on Water Quality: Abstracts of the Technical Sessions: Orlando, Florida, November 12-17, 1989: U.S. Geological Survey Open-File Report 89-409, p. 24.

Fillipek, L.H., Nordstrom, D.K., and Ficklin, W.H., 1987, Interaction of acid mine drainage with waters and sediment of West Squaw Creek in the West Shasta Mining District, California: Environmental Science and Technology, v. 21, p. 388-396.

Finkleman, R.B., 1989, What we don't know about the occurrence and distribution of the trace elements in coal: Journal of Coal Quality, v. 8, nos. 3-4, p. 63-66. 
Finklemian, R., 1988, Coal geochemistry: practical applications, in Bryers, R., and Vorres, K., eds., Mineral Matter and Ash Deposition from Coal: Proceedings of the Engineering Foundation Conference: 1988, Santa Barbara, CA, p. 1-12.

Finkleman, R.B., and Giffen, D.E., 1986, Hydrogen peroxide oxidation: an improved method for rapidly assessing the acid-generating potential of sediments and sedimentary rocks: Reclamation and Revegetation Research, v. 5, p. 521-534.

Finkleman, R.B., Palmer, C.A., Krasnow, M.R., Aruscavage, P.J., Sellers, G.A., and Dulong, F.T., 1990, Combustion and leaching behavior of elements in the Argonne premium coal samples: Energy and Fuels, v. 4, p. 755-766.

Fishman, M.J., and Friedman, L.C., eds., 1989, Methods for determination of inorganic substances in water and fluvial sediments: Techniques of Water-Resources Investigations of the U.S. Geological Survey, Chapter A1, Book 5, 545 p.

Franke, O.L., Reilly, T.E., and Bennett, G.D., Definition of boundary and initial conditions in the analysis of saturated ground-water flow systems- an introduction: Techniques of Water-Resources Investigations of the U.S. Geological Survey, Chapter B5, Book 3, 15 p.

Franke, O.L., and Reilly, T.E., 1987, The effects of boundary conditions on the steady-state response of three hypothetical ground-water systems- results and implications of numerical experiments: U.S. Geological Survey Water-Supply Paper 2315, $19 \mathrm{p}$.

Freeze, R.A., and Cherry, J.A., 1979, Groundwater: Prentice-Hall, publ., Englewood Cliffs, NJ, 07632, $604 \mathrm{p}$.

Friedman, L.C., and Erdmann, D.E., 1982, Quality assurance practices for the chemical and biological analyses of water and fluvial sediments: Techniques of Water Resources Investigations of the U.S. Geological Survey, Chapter A6, Book 5, $181 \mathrm{p}$.

Fruchter, J.S., Rai, Dhanpat, and Zachara, J.M., 1990, Identification of solubility controlling solid phases in a large fly ash field lysimeter: Environ. Sci. Technol., v. 24, no. 8 , p. 1173-1179.

Gardner, H.R., and Woolhiser, D.A., 1978, Hydrologic and climatic factors, in Schaller, F.W., and Sutton, Paul, editors, Reclamation of Drastically Disturbed Lands: American Society of Agronomy, Inc.; Crop Science Society of America, Inc., and; Soil Science Society of America, Inc. Publishers, Madison, WI, Chapter 10, p. 173-191.

Geidel, Gwendelyn, 1979, Alkaline and acid production p.tentials of overburden material: the rate of release: Reclamation Review, v. 2, p. 101-107. 
Phase 1 Report

Appendix B

Geidel, Gwendelyn, and Caruccio, F.T., 1977, Time as a factor in acid mine drainage pollution: Proceedings of the Seventh Symposium on Coal Mine Drainage Research, Louisville, KY, p. 41-50.

Germani, M.S., and Zoller, W.H., 1988, Vapor-phase concentrations of arsenic, selenium, bromine, iodine, and mercury in the stack of a coal-fired power plant: Environmental Science Technology, v. 22, no. 9, p. 1079-1085.

Gerritse, R.G., and Adeney, J.A., 1985, Rapid determination in water of chloride, sulphate, sulphite, selenite, selenate and arsenate among other inorganic and organic solutes by ion chromatography with UV detection below $195 \mathrm{~nm}$ : Journal of Chromatography, v. 347, p. 419-428.

Goodale, D.M., Bruetsch, T.F., and Kowal, John, 1990, Using N-VIRO soil as a soil amendment: (unknown source), $11 \mathrm{p}$.

Goodrich, D.C., Woolhiser, D.A., and Keefer, T.O., 1991, Kinematic routing using finite elements on a triangular irregular network: Water Resources Research, v. 27, no. 6, p. 995-1003.

Grisafe, D.A., Angino, E.E., and Smith, S.M., 1988, Leaching characteristics of a high-calcium fly ash as a function of $\mathrm{pH}$ : a potential source of selenium toxicity: Applied Geochemistry, v. 3, p. 601-608.

Grube, W.E., Smith, R.M., Singh, R.N., and Sobek, A.A., 1973 Characterization of coal overburden materials and minesoils in advance of surface mining: in Research and Applied Technology Symposium on Mined-Land Reclamation, Pittsburgh, PA, p. 144-145.

Guthrie, R.K., and Cherry, D.S., 1979, Trophic level accumulation of heavy metals in a coal ash basin drainage system: Water Resources Bulletin, v. 15, no. 1, p. 244-248. Hach Corporation, 1989, Hach water analysis handbook: Hach Corporation, Loveland, Colorado, $690 \mathrm{p}$.

Hackbarth, D.A., 1979, The effects of surface mining of coal on water quality near Grande Cache, Alberta: Canadian Journal of Earth Science, v. 16, p. 1242-1253.

Hale, A.M., 1982, Little Kyger Creek demonstration plot program: Proceedings of the Abandoned Mine Reclamation Symposium, p. 6-1 through 6-24.

Hall, D.C., and Davis, R.E., 1986, Ground-water moverient and effects of coal strip mining on water quality of high-wall lakes and aquifers in the Macon-Huntsville area, north-central Missouri: U.S. Geological Survey Water-Resources Investigations Report 85-4102, 102 p. 
Phase 1 Report

Appendix B

Harbaugh, A.W., A generalized finite-difference formulation for the U.S. Geological Survey modular three-dimensional finite- difference ground-water flow model: U.S. Geological Survey Water Resources-Investigations Open File Report 91-494, $60 \mathrm{p}$.

Hardy, M.A., 1981, Effects of coal fly-ash disposal on water quality in and around the Indiana Dunes National Lakeshore, Indiana: U.S. Geological Survey Water-Resources Investigations 81-16, 64 p.

Hardy, M.A., Leahy, P.P., Alley, W.M., 1989, Well installation and documentation, and ground-water sampling protocols for the pilot National Water-Quality Assessment Program: U.S. Geological Survey Open-File Report 89-396, 36 p.

Hassett, D.J., Pflughoeft-Hassett, D.F., and McCarthy, G.J., 1991, Ettringite formation in coal ash as a mechanism for stabilization of hazardous trace elements, in American Coal Ash Association proceedings from the 9th International Coal Ash Symposium: p. 31-1 through 31-17.

Hedin, R.S., and Erickson, P.M., 1988, Relationships between the initial geochemistry and leachate chemistry of weathering overburden samples, in Mine Drainage and Surface Mine Reclamation: U.S. Bureau of Mines Circular 9183, p. 21-28.

Hedrick, N.W., Meiser, E.W., Jr., and Hershey, R.M., 1984, Backfilling techniques and alkaline addition to control acid mine drainage, in Innovative Means of Dealing with Potential Sources of Ground Water Contamination, Proceedings from the Seventh National Ground-water Quality Symposium: September 26- 28, 1984, Las Vegas, NV: National Well Water Association, p. 209-223. Helgeson, J.O., Larson, S.P., and Razem, A.C., 1982, Model modification for simulation of flow through stratified rocks in eastern Ohio: U.S. Geological Survey Water-Resources Investigations Report 82-4019, 109 p.

Helsel, D.R., 1990, Less than obvious, statistical treatment of data below the detection limit: Environ. Sci. Technol., v. 24, no. 12, p. 1767-1774.

Hem, J.D., 1989, Study and interpretation of the chemical characteristics of natural water: U.S. Geological Survey Water- Supply Paper 2254, 263 p.

Henzel, D.S., and Ellison, W., 1990, Commercial utilization of SO2 removal wastes in the application of new advanced control technology, in Proceedings of the 1990 SO2 Control Symposium: May 8-11, 1990, sponsored by the Electric Power Research Institute and the U.S. Environmental Protection Agency, New Orleans, LA, $20 \mathrm{p}$.

Herlihy, A.T., Mills, A.L., and Herman, J.S., 1988, Distribution of reduced inorganic sulfur compounds in lake sediments receiving acid mine drainage: Applied Geochemistry, v. 3, p. 333-344. 
Phase 1 Report

Appendix B

Herring, William C., 1977, Groundwater re-establishment in cast overburden: Seventh Symposium Coal Mine Drainage Research, National Coal Association and Bituminous Coal Research Inc., Louisville, KY, p. 71-87.

Hill, M.C., 1990, Preconditioned conjugate gradient 2 (PCG2), a computer program for solving ground-water flow equations: U.S. Geological Survey Water Resources Investigations Report 90-4048, 43 p.

Hindall, S.M., 1984, Effects of surface coal-mine reclamation on stream quality in a small watershed near Nelsonville, southeastern Ohio: U.S. Geological Survey Water-Resources Investigations Report 84-4179, 28 p.

Hirsch, R.M., Alexander, R.B., and Smith, R.A., 1991, Selection of methods for determination and estimation of trends in water quality: Water Resources Research, v. 27, no. 5, p. 803-813.

Hobba, W.A. Jr., 1991, Relation of fracture system to transmissivity of coal and overburden aquifers in Preston County, West Virginia: U.S. Geological Survey Water-Resources Investigations Report 89-4137, 24 p.

Hodder, R.L., 1978, Potentials and predictions concerning reclamation of semiarid mined lands, in Wright, R.A., ed., The Reclamation of Disturbed Arid Lands: University of New Mexico Press, Albuquerque, NM, Chapter 7, p. 149-154.

Hodges, R.E., and Teasdale, W.E., 1991, Considerations related to drilling methods in planning and performing borehole-geophysical logging for ground-water studies: U.S. Geological Survey Water- Resources Investigations Report 91-4090, 16 p.

Hoffman, R.V., Eiceman, G.A., Long, Yao-Ting, Collins, M.C., and Lu, Mao-Qin, 1990, Mechanism of chlorination of aromatic compounds adsorbed on the surface of fly ash from municipal incinerators: Environ. Sci. Technol., v. 24, no. 11, p. 1635-1641.

Horton, R.E., 1940, An approach toward a physical interpretation of infiltration-capacity: Soil Science Proceedings 1940, p. 399-417.

Hren, Janet, 1986, Changes in ground-water quality resulting from surface coal mining of a small watershed in Jefferson County, Ohio: U.S. Geological Survey Water-Resources Investigations Report 86-4108, 38 p.

Hren, Janet, Wilson, K.S., and Helsel, D.R., 1984, A statistical approach to evaluate the relation of coal mining, land reclamation, and surface-water quality in Ohio: U.S. Geological Survey Water Resources Investigations Report 84-4117, 325 p. 
Phase 1 Report Appendix B

Hurlbut, C.S., and Klein, Cornelius, 1977, Manual of Mineralogy (after James D. Dana), 19th ed.: John Wiley \& Sons, publ., New York, NY, 532 p.

Hustwit, C.C., Ackman, T.E., and Erickson, P.E., 1992, The role of oxygen transfer in acid mine drainage (AMD) treatment: Water Environment Research, v. 64, no. 6, p. 817-823.

International Atomic Energy Agency, 1983, Guidebook on Nuclear Techniques in Hydrology: IAEA, publ., Vienna, Austria, (UNIPUB, dist., New York, NY), Technical Report Series No. 91, 439 p.

Iwanski, M.L., and Browman, M.G., 1989, Power industry wastes: Journal of the Water Pollution Control Federation, v. 61, no. 6, p. 887-897.

Janzer, V.J., 1985, The use of natural waters as U.S. Geological Survey reference waters: American Society for Testing and Materials, Special Technical Testing Publication 867, p. 319-333.

Jones, B.E., 1987, Quality control manual of the U.S. Geological Survey's National Water Quality Laboratory: U.S. Geological Survey Open-File Report 97-457, 17 p.

Jorgensen, D.G., 1991, Estimating geohydrologic properties from borehole-geophysical logs: Ground-Water Monitoring Review, Summer, 1991, p. 123-129.

Karathanasis, A.D., Evangelou, V.P., and Thompson, Y.L., 1988, Aluminum and iron equilibria in soil solutions and surface waters of acid mine watersheds: $J$. Environ. Qual., v. 17, no. 4, p. 534-543.

Kauppinen, E.I., and Pakkanen, T.A., 1990, Coal combustion aerosols: a field study: Environ. Sci. Technol., v. 24, no. 12, p. 1811-1818.

Kenoyer, G.L., and Bowser, C.J., 1992, Groundwater chemical evolution in a sandy silicate aquifer in northern Wisconsin, 1. patterns and rates of change: Water Resources Research, v. 28, no. 2, p. 579-589.

Kenoyer, G.J., and Bowser, C.J., 1992, Groundwater chemical evolution in a sandy silicate aquifer in northern Wisconsin, 2. Reaction Modeling: Water Resources Research, v. 28, no. 2, p. 591-600.

Keys, W.S., 1990, Borehole geophysics applied to ground-water investigations: U.S. Geological Survey Techniques of Water Resources Investigations, Chapter E2, Book 2, 150 p. 
Kilgour, C.L., 1990, Utilization and disposal of fly ash, in Proceedings of the NSA SO2 Emission Control Conference: Sept. 10, 1990, Pittsburgh PA, 16 p.

Kleinmann, R.L.P., Crerar, D.A., and Pacelli, R.R., 1981, Biogeochemistry of acid mine drainage and a method to control acid formation: Mining Engineering, v. 33. $p$. 300-305.

Kondolf, G.M., and Matthews, W.V. Graham, 1991, Unmeasured residuals in sediment budgets: a cautionary note: Water Resources Research, v. 27, no. 9, p. 2483-2486.

Kopsick, D.A., and Angino, E.E., 1981, Effect of leachate solutions from fly and bottom ash on groundwater quality, in Back, W., and Letolle, R., eds., Symposium on Geochemistry of Groundwater-26th International Geological Congress: Journal of Hydrology, v. 54, p. 341-356.

Krabbenhoft, D.P., Bowser, C.J., Anderson, M.P., Valley, J.W., 1990, Estimating groundwater exchange with lakes 1 . the stable isotope mass balance method: Water Resources Research, v. 26, no. 10, p. 2445-2453.

Krapac, I.G., Smyth, C.A., and Griffin, R.A., Collection of representative coal refuse samples for leachate generation studies: Illinois Department of Energy and Natural Resources State Geological Survey Division, Environmental Geology Notes 106, $68 \mathrm{p}$.

Kurtz, L.T., and Melsted, S.W., 1973, Movement of chemicals in soils by water: Soil Science, v. 115, no. 3, p. 231-239.

LaFevers, J.R., Economics of mined land reclamation and land-use planning in western states, in Wright, R.A., ed., The Reclamation of Disturbed Arid Lands: University of New Mexico Press, Albuquerque, NM, Chapter 5, p. 68-71.

Lamborn, R.E., 1954, Geology of Coshocton County: Ohio Department of Natural Resources, Division of Geological Survey, Bulletin 53, 245 p., 1 plate.

Larsen, G.E., 1991, Pennsylvanian nomenclature of Ohio: The Ohio Journal of Science, v. 91 , no. 1, p. 69-76.

La Venue, A.M., and Pickens, J.F., 1992, Application of a coupled adjoint sensitivity and kriging approach to calibrate a groundwater flow model: Water Resources Research, v. 28, no. 6, p. 1543-1569.

Lieberman, J.A., and Hoover, M.D., 1951, Stream-flow frequency changes on Coweeta experimental watersheds: Transactions, American Geophysical Union, v. 32, no. 1, p. 73-76. 
Lindahl, P.C., and Finkleman, R.B., 1986, Factors influencing major, minor, and trace element concentrations in U.S. coal, in Vorres, K.S., ed., Mineral Matter and Ash in Coal: American Chemical Society Symposium Series No. 301, p. 62-69.

Loague, Keith, 1992, Using soil texture to estimate saturated hydraulic conductivity and the impact of rainfall-runoff simulations: Water Resources Bulletin of the American Water Resources Association Paper No. 92032, v. 28, no. 4, p. 687-693.

Logan, T.J., , Potential Markets for N-VIRO Soil, (unknown source), 11 p.

Loper, W.C., Behrendt, T.E., and Schaffstall, W.P., 1989, Water resources data for Pennsylvania, water year 1987, Volume 2, Susquehanna and Potomac River Basins: U.S. Geological Survey HD-89/214, 330 p.

Maas, C., 1992, Groundwater withdrawal from a hill with uniformly sloped seepage faces: Water Resources Research, v. 28, no. 2, p. 365-371.

Martens, D.C., and Plank, C.O., Basic soil benefits from ash utilization, in Third International Ash Utilization Symposium: Pittsburgh, PA, March 13-14, 1973, U.S. Bureau of Mines Inf. Circular 8640., U.S. Government Printing Office, Washington D.C., p. 269-279.

Martin, J.D., Crawford, C.G., Duwelius, R.F., and Renn, D.E., 1987, Description of the physical environment and coal-mining history of West-central Indiana, with emphasis on six small watersheds: U.S. Geological Survey Water-Supply Paper 2368, Chapter A, 38 p.

Martin, J.D., Duwelius, R.F., and Crawford, C.G., 1990, Effects of surface coal mining and reclamation on the geohydrology of six small watersheds in west-central Indiana: U.S. Geological Survey Water-Supply Paper 2368, Chapter B, 71 p.

Martinez, M.J., Dykhuizen, R.C., and Eaton, R.R., 1992, The apparent conductivity for steady unsaturated flow in periodically fractured porous media: Water Resources Research, v. 28, no. 11, p. 2879-2887.

Massey, H.F., and Barnhisel, R.I., 1972, Copper, nickel, and zinc released from acid coal mine spoil materials of eastern Kentucky: Soil Science, v. 113, no. 3, p. 207-212.

Mattigod, S.V., Rai, Dhanpat, Eary, L.E., and Ainsworth, C.C., 1990, Geochemical factors controlling the mobilization of inorganic constituents from fossil fuel combustion residues: I. review of the major elements: J. Environ. Qual., v. 19, pp 188-201. 
Phase 1 Report Appendix B

Mayo, A.L., Nielsen, P.J., Loucks, Mark, and Brimhall, W.H., 1992, The use of soiute and isotopic chemistry to identify flow patterns and factors which limit acid mine drainage in the Wasatch Range, Utah: Ground Water, v. 30, no. 2, p. 243-249.

McDonald, M.G., and Harbaugh, A.W., 1988, A modular three-dimensional finite-difference ground-water flow model: Techniques of Water- Resources Investigations of the U.S. Geological Survey, Chapter A1, Book 6, 586 p.

McDonald, M.G., Harbaugh, A.W., Orr B.R., and Ackerman, D.J., 1991, A method of converting no-flow cells to variable-head cells for the U.S. Geological Survey Water Resources Investigation Open- File Report 91-536, 99 p.

McDonnell, J.J., Stewart, M.K., and Owens, I.F., 1991, Effect of catchment-scale subsurface mixing on stream isotopic response: Water Resources Research, v. 27 , no. 12 , p. 3065-3073.

Meinzer, O.E., 1960, Outline of ground-water hydrology with definitions: U.S. Geological Survey Water-Supply Paper 494 (original printing 1923), 71 p.

Mercer, J.W., and Faust, C.R., 1986, Ground-Water Modeling: National Well Water Association, publ., Dublin, $\mathrm{OH}, 60 \mathrm{p}$.

Merkel, R.H., 1972, The use of resistivity techniques to delineate acid mine drainage in ground water: Ground Water, v. 10, no. 5, p. 38-42.

Minear, R.A., and Tschantz, B.A., 1976, The effect of coal surface mining on the water quality of mountain drainage basin streams: Journal WPCF, v. 48, no. 11, p. 2549-2569.

Mitchell, R.L., 1972, Trace elements in soils and factors that affect their availability: Geological Society of America Bulletin, v. 83, p. 1069-1076.

Morrison, J.L., Atkinson, S.D., Davis, Alan, and Scheetz, B.E., 1990, The use of CO2 coulometry in differentiating and quantifying the carbonate phases in the coal-bearing strata of western Pennsylvania: its applicability in interpretation and modifying neutralizing potential: in Skousen, J., Sencindiver, J., and Samuel, D., eds., Proceedings of the 1990 Mining and Reclamation Conference and Exhibition: 2 vols., West Virginia University, Morgantown, WV, p. 243-248.

Morrison, J.L., Atkinson, S.D., Scheetz, B.E., 1990, Delineation of potential manganese sources in the coal overburdens of western Pennsylvania, in Skousen, J., Sencindiver, J.,and Samuel, D., eds., Proceedings of the 1990 Mining and Reclamation Conference and Exhibition: 2 vols., West Virginia University, Morgantown, WV, p. 249-256. 
Moses, C.O., Nordstrom, D.K., Herman, J.S., Mills, A.L., 1987, Aqueous pyrite oxidation by dissolved oxygen and by ferric iron: Geochimica et Cosmochimica Acta, v. 51 , p. $1561-1571$.

Musser, J.u., 1963, Description of physical environment and of strip- mining operations in parts of Beaver Creek Basin, Kentucky: U.S. Geological Survey Professional Paper 427-A, 25 p.

Nichols, V.E., 1985, Evaluation of the effects of coal-mine reclamation on water quality in Big Four Hollow near Lake Hope, so!ntheastern Ohio: U.S. Geological Survey Water-Resources Investigations Report \&5-4197, 215 p.

Nimnı, J.R., and Mello, K.A., 1991, Centrifugal techniques for measuring saturated hydraulic conductivity: Water Resources Research, v. 27, no. 6, p. 1263-1269.

Nordq. ist, A.W., Tsang, Y.W., Tsang, C.F., Dverstorp, Bjorn, and Andersson, Johan, 1992. A variable aperture fracture network model for flow and transport in fractured rocks: Water Resources Research, v. 28, no. 6, p. 1703-1713.

Nordstrom, D.K., 1982, Aqueous pyrite oxidation and the consequent formation of secondary iron minerals, in Acid Sulfate Weathering: Soil Science of America Special Publication, v. 10, p. 37-56.

Nordstrom, D.K., Jeanne, E.A., and Ball, J.W., 1979, Redox equilibria in acid mine waters, in Jeanne, E.A., ed., Chemical Modeling in Aqueous Systems: American Chemical Society Symposium Series, v. 93, p. 51-79.

Norris, S.E., 1969, Water budget in Ohio: Ground Water, v. 7, no. 5, p. 25-33.

O'Hagan, M., and Caruccio, F.T., 1986, The effect of admixed limestone on rates of pyrite oxidation in low, medium, and high sulfur rocks, in National Symposium on Mining, Hydrology, Sedimentology, and Reclamation, 1986: Lexington, KY.

Oblinger Childress, C.J., 1985, Clelssification of stream basins in southeastern Ohio according to extent of surface coal mining: U.S. Geological Survey Water-Resources Investigations Report 84-4212, $83 \mathrm{p}$.

Ohio Department of Natural Resources, 1990, 1988 Report on Ohio Mineral Industries with directories of reporting coal and industrial mine operators: Lopez, S.W., compiler, Division of Geological Survey, 4383 Fountain Square Drive, Columbus, Ohio, 118 p., 1 plate.

Olem, Harvey, 1989, Coal and coal mine drainage: journal of the Water Pollution Control Federation, v. 61, no. 6, p. 879-882. 
Paces, Tomas, 1983, Rate constants of dissolution derived from the measurements of mass balance in hydrological catchments: Geochimica et Cosmochimica Acta, v. 47 , p. $1855-1863$.

Paces, Tomas, 1973, Steady-state kinetics and equilibrium between ground water and granitic rock: Geochimica et Cosmochimica Acta, v. 37, p. 2641-2663.

Paillet, F.L., and Kapucu, Kemal, 1989, Fracture characterization and fracture-permeability estimates from geophysical logs in the Mirror Lake Watershed, New Hampshire: U.S. Geological Survey Water Resources Investigations Report 89-4058, 49 p.

Papp, C.S., Filipek, L.H., and Smith, K.H., 1991, Selectivity and effectiveness of extractants used to release metals associated with organic matter: Applied Geochemistry, v. 6, p. 349-353.

Parker, L. V., Hewitt, A.D., and Jenkins, T.F., 1990, Influence of casing materials on trace-level chemicals in well water: Ground Water Monitoring Review, v. 10, no. 2, p. 146-156.

Parkhurst. D.L., Thorstenson, D.C., and Plummer, N.L., 1980, PHREEQE- - A computer program for geochemical calculations: U.S. Geological Survey Water-Resources Investigations Report 80-96, $210 \mathrm{p}$.

Peffer, J.R., 1982, Fly ash disposal in a limestone quarry: Ground Water, v. 20, no. 3 , p. 267-273.

Perry, E., 1985, Overburden analysis: an evaluation of methods, in Proceedings of the Symposium on Surface Mining, Hydrology, Sedimentology, and Reclamation: University of Kentucky, p. 365-375.

Pfaff, C.L., Heisel, D.R., Johnson, D.P., and Angelo, C.G., 1981, Assessment of water quality in streams draining coal-producing areas in Ohio: U.S. Geological Survey Water-Resources Investigations Open-File Report 81-409, 98 p.

Phung, H.T., Lund, L.J., Page, A.L., and Bradford, G.R., 1979, Trace elements in fly ash and their release in water and treated soils: J. Environ. Qual., v. 8, no. 2, F. 171-175.

Pietz, R.I., Peterson, J.R., and Lue-Hing, C., 1974, Ground-water quality at a strip-mine reclamation area in west central Illinois, in Second Res. Appl. Technol.

Symposium, Mined Land Reclamation: National Coal Association, Louisville, KY, p. 124-144.

Pionke, H.B., Rogowski, A.S., and Montgomery, C.A., 1980, Percolate quality of strip mine spoil: Trans. Am. Soc. Agric. Eng., v. 23, p. 621-628. 
Plummer, L.N., Prestemon, E.C., and Parkhurst, D.L., 1991, An interactive code (NETPATH) for modeling mass transfer reactions along a flow path: U.S. Geological Survey Water Resources Investigations Report 91-4078, 227 p.

Pollman, C.D., Lee, T.M., Andrews, W.J., Sacks, L.A., Gherini, S.A., and Munson, R.K., 1991, Preliminary analysis of the hydrologic and geochemical controls on acid-neutralizing capacity of two acidic seepage lakes in Florida: Water Resources Research, v. 27, no. 9, p. 2321-2336.

Pollock, D.W., 1989, Documentation of computer programs to compute and display pathlines from the U.S. Geological Survey modular three-dimensional finite-difference ground-water flow model: U.S. Geological Survey Water-Resources Investigations Open File Report 89-381, 188 p.

Power, J.F., Sandoval, F.M., and Ries, R.E., 1978, Restoration of productivity to disturbed land in the northern Great Plains, in Wright, R.A., ed., The Reclamation of Disturbed Arid Lands: University of New Mexico Press, Albuquerque, NM, Chapter 3, p. 33-49.

Prudic, D.E., 1989, Documentation of a computer program to simulate stream-aquifer relations using a modular, finite-difference, ground-water flow model: U.S. Geological Survey Water-Resources Investigations Open-File Report 88-729, 113 p.

Razem, A.C., 1984, Ground-water hydrology and quality before and after strip mining of a small watershed in Jefferson County, Ohio: U.S. Geological Survey Water Resources Investigations Report 83-4215, 39 p.

Razem, A.C., 1983, Ground-water hydrology before, during, and after coal strip mining of a small watershed in Coshocton County, Ohio: U.S. Geological Survey Water-Resources Investigations Report 83-4155, $36 \mathrm{p}$.

Razem, A.C., Sedam, A.C., 1985, Ground-water quality and geochemistry of aquifers associated with coal in the Allegheny and Monongahela Formations, southeastern Ohio: U.S. Geological Survey Water-Resources Investigations Report 85-4034, 39 p.

Rehm, B.W., Groenewold, G.H., and Morin, K.A., 1980, Hydraulic properties of coal and related materials, Northern Great Plains: Ground Water, v. 18, no. 6, p. 551-561. Reilly, T.E., Franke, O.L., and Bennett, G.D., 1987, The principle of superposition and its application to ground-water hydraulics: Techniques of Water-Resources Investigations of the U.S. Geological Survey, Chapter B6, Book 3, 28 p.

Rich, D.H., and Hutchison, K.R., 1990, Neutralization and stabilization of combined refuse using lime kiln dust at High Power Mountain, in Skousen, J., Sencindiver, 
Phase 1 Report

Appendix B

J., and Samuel, D., eds., Proceedings of the 1990 Mining and Reclamation Conference and Exhibition: 2 vols., West Virginia University, Morgantown, WV, p. 55-60.

Rich, D.H., and Hutchison, K.R., 1990, Neutralization and stabilization of combined refuse using lime kiln dust at High Power Mountain, in Skousen, J., Sencindiver, J., and Samuel, D., eds., Proceedings of the 1990 Mining and Reclamation Conference and Exhibition: 2 vols., West Virginia University, Morgantown, WV, p. 55-59.

Rogowski, A.S., 1977, Acid generation within a spoil profile: preliminary experimental results, in Proceedings of the Seventh Symposium on Coal Mine Drainage Research, NCA/BCR Coal Conference and Expo IV: Louisville, KY, October 18-20, 1977, p. 25-40.

Rogowski, A.S., 1973, Water regime in strip mine spoil, in Sammuel, D.E., ed., Surface Mining and Fish and Wildlife Needs in Eastern United States: West Virginia University and U.S. Fish and Wildlife Service, p. 137-145.

Rophe, B., Berkowitz, B., Magaritz, M., and Ronen, D., 1992, Analysis of subsurface flow and formation anisotropy in a fractured aquitard using transient water level data: Water Resources Research, v. 28, no. 1, p. 199-207.

Rose, A.W., Williams, E.G., and Parizek, R.R., 1983, Predicting potential for acid drainage from coal mines: University Park, Pennsylvania, The Pennsylvania State University, Earth and Mineral Sciences, v. 52, no. 4, p. 37-41.

Roy, W.R., Griffin, R.A., Dickerson, D.R., and Schuller, R.M., 1984, Illinois Basin coal fly ashes. 1. Chemical characterization and solubility: Environ. Sci. Technol., v. 18, no. 10, p. $734-739$.

Saad, D.A., and Cravotta, C.A., 1991, Modeling of ground-water flow along a cross section through a reclaimed surface coal mine in western Pennsylvania:

Proceedings of the National Meeting of the American Society for Surface Mining and Reclamation, Durango, Colorado, p. 43-68.

Sakata, Masahiro, 1987, Movement and neutralization of alkaline leachate at coal ash disposal sites: Environmental Science Technology, v. 21, no. 8, p. 771-777.

Schroeder, S.A., and Bauer, A., 1984, Soil water variation in spoil and undisturbed sites in North Dakota: Soil Sci. Soc. Am. J., v. 48, p. 656-659.

Schwartz, Franklin, and Crowe, A.S., 1987, Model study of some factors influencing the resaturation of spoil following mining and reclamation: Journal of Hydrology, v. 92, p. 121-147. 
Scott, J.C., 1991, Computer software for converting ground-water and water-quality data from the National Water Information System for use in a Geographic Information System: U.S. Geological Survey Water-Resources Investigations Report 90-4200, 55 p.

Scott, J.C., 1990, A statistical processor for analyzing simulations made using the modular finite-difference ground-water flow model: U.S. Geological Survey Water Resources Investigations Report 89-4159, 218 p.

Sedam, A.C., 1991, Geologic setting and water quality of selected basins in the active coal-mining areas of Ohio, 1987-88: U.S. Geological Survey Water-Resources Investigations Report 90-4109, 97 p.

Sen, Zekai, 1992, Unsteady ground-water flow toward extended wells: Ground Water, v. 30 , no. 1 , p. $61-67$.

Severson, R.C., and Shacklette, H.T., 1988, Essential elements and soil amendments for plants: sources and use for agriculture: U.S. Geological Survey Circular 1017, $48 \mathrm{p}$.

Shamsai, Abolfazl, and Sitar, Nicholas, 1991, Method for determination of hydraulic conductivity in unsaturated porous media: Journal of Irrigation and Drainage Engineering, v. 117, no. 1, p. 64-78.

Shanley, J.B., Peters, N.E., and Hooper, R.P., 1989, Factors controlling aqueous sulfate concentrations at Panola Mountain, Georgia [abs.], in Pederson, G.L., and Smith, M.M., compilers, U.S. Geological Survey Second National Symposium on Water Quality: Abstracts of the Technical Sessions: Orlando, Florida, November 12-17, 1989: U.S. Geological Survey Open-File Report 89-409, p. 88.

Shih, S.F., and Cheng, K.S., 1991, Evapotranspiration estimation for data-short environment: Journal of Irrigation and Drainage Engineering, v. 117, no. 1, p. 107-122. Shuter, Eugene, and Teasdale, W.E., 1989, Application of drilling, coring, and sampling techniques to test holes and wells: Techniques of Water Resource Investigations of the U.S. Geological Survey, Chapter F1, Book 2, 97 p.

Sidle, R.C., Stout, W.L., Hern, J.L., and Bennett, O.L., 1979, Solute movement from fluidized bed combustion waste in acid soil and mine spoil columns: J. Environ. Qual. v. 8, no. 2, p. 236-241.

Simpson, H.J., and Herczeg, A.L., 1991, Stable isotopes as an indicator of evaporation in the River Murray, Australia: Water Resources Research, v. 27, no. 8, p. 1925-1935. 
Skousen, J.G., 1988, Chemicals for treating acid mine drainage: Green Lands, v. 18. no. 3, p. $36-40$.

Skousen, J., Politan, K., Hilton, T., and Meek, A., 1990, Acid mine drainage treatment systems: chemicals and costs: Green Lands, v. 20, no. 4, p. 31-37.

Skousen, J.G., Sencindiver, J., and Samuel, D., (eds.), 1990, Proceedings of the 1990 Mining and Reclamation Conference and Exhibition: Morgantown, WW, West Virginia University, 2 Volumes, $615 \mathrm{p}$.

Skousen, J.G., Sencindiver, J.C., and Smith, R.M., 1987, A review of procedures for surface mining and reclamation in areas with acid- producing materials: West Virginia University Energy and Water Research Center, Publication No. EWRC871, Morgantown, WV.

Skousen, J.G., Smith, R.M., and Sencindiver, J., 1990, The development of the acid-base account: Green Lands, v. 20, no. 1, p. 32-37.

Skousen, Jeff, and Larew, Glenn, 1992, Alkaline addition to prevent acid mine drainage: a field example: Green Lands, v. 22, no. 3, p. 32-35.

Smith, C.L., 1987, Eleven million tons of fly ash yearly in FGD sludge fixation: (1987 EPRI; 8th Proceedings), p. 7-1 through 7-7.

Smith, M.W., and Brady, K.B., 1990, Evaluation of acid-base accounting data using computer spreadsheets, in Skousen, J., Sencindiver, J., and Samuel, D., eds., Proceedings of the 1990 Mining and Reclamation Conference and Exhibition: 2 vols., West Virginia University, Morgantown, WV, p. 213-220.

Smith, R.M., Grube, W.E., Arkle, T.A., and Sobek, A.A., 1974, Mine spoil potentials for soil and water quality: Environmental Protection Agency Report 600/2-74-070.

Smith, R.M., Sobek, A.A., Arkle, T.A., Sencindiver, J.C., and Freeman, J.R., 1976, Extensive overburden potentials for soil and water quality: Environmental Protection Agency Report 600/1-76-184.

Smith, R.E., and Woolhiser, D.A., 1978, Some applications of hydrologic simulation models for design of surface mine topography, in Wright, R.A., ed., The Reclamation of Disturbed Arid Lands: University of New Mexico Press, Albuquerque, NM, Chapter 11, p. 189-196.

Smith, M.W., and Brady, K.B.C., 1990, Evaluation of acid base accounting data using computer spreadsheets, in Skousen, J., Sencindiver, J., and Samuel, D., eds., Proceedings of the 1990 Mining and Reclamation Conference and Exhibition: 2 vols., West Virginia University, Morgantown, WV, p. 213-220. 
Smith, E.E., and Shumate, K.S., 1970, Sulfide to sulfate reaction mechanism: Ohio State Research Foundation, publ., Columbus, Ohio, for the Federal Water Pollution Control Administration, FWPCA Grant Number 14010 FPS, 115 p.

Smith, R.M., and Sobek, A.A., 1978, Physical and chemical properties of overburdens, spoils, wastes, and new spoils, in Schaller, F.W., and Sutton, Paul, eds., Reclamation of Drastically Disturbed Lands: American Society of Agronomy, Inc.; Crop Science Society of America, Inc.; and, Soil Science Society of America, Inc. Publishers, Madison, WI, Chapter 9, p. 149-172.

Sobek, A.A., Schuller, W.A., Freeman, J.R., and Smith, R.M., 1978, Field and laboratory methods applicable to overburdens and minesoils: Environmental Protection Agency Report 600/2-78-054, 203 p.

Solomon, D.K., and Sudicky, E.A., 1991, Tritium and helium 3 ratios for direct estimation of spatial variations in groundwater recharge: Water Resources Research, v. 27, no. 9, p. 2309-2319.

Stam, A.C., Mitchell, M.J., Krouse, H.R., and Kahl, J.S., 1992, Stable sulfur isotopes of sulfate in precipitation and stream solutions in a northern hardwood watershed: Water Resources Research, v. 28, no. 1, p. 231-236.

Stipp, S.L., 1990, Speciation in the $\mathrm{Fe}$ (II)-Fe(III)-SO4-H2O system at $25 \mathrm{C}$ and low pH: sensitivity of an equilibrium model to uncertainties: Environ. Sci. Technol., v. 24, no. 5, p. 699-706. Stout, W.L., Hern, J.L., Korcak, R.F., and Carlson, C.W., 1988, Manual for applying fluidized bed combustion residue to agricultural lands: U.S. Department of Agriculture, Agricultural Research Service, ARS-74, $15 \mathrm{p}$.

Sudicky, E.A., and McLaren, R.G., 1992, The LaPlace transform Galerkin technique for large-scale simulation of mass transport in discretely fractured porous formations: Water Resources Research, v. 28, no. 2, p. 499-514.

Sukhija, B.S., Reddy, D.V., and Bhattacharya, S.K., 1987, Source of seepage in the Sudamdih Mine area using environmental isotopes, Bihar, India: Journal of Hydrology, v. 93, p. 191-197.

Taft, A.G., 1988, A geotechnical evaluation of ash residue from solid waste incineration: Unpublished Master's Thesis, Kent State University Graduate College, Kent, OH, May 1988, 148 p. 
Phase 1 Report

Appendix B

Tai, D.Y., Jennings, M.E., White, K.D., and Garcia, L.A., 1989, Evaluation of a modified commercial automatic sampler for the collection of water samples containing trace organics [abs.], in Pederson, G.L., and Smith, M.M., compilers, U.S. Geological Survey Second National Symposium on Water Quality: Abstracts of the Technical Sessions: Orlando, Florida, November 12-17, 1989: U.S. Geolonical Survey Open-File Report 89-409, p. 99.

Taylor, B.E., Wheeler, M.C., and Nordstrom, D.K., 1984, Stable isotope geochemistry of acid mine drainage: Experimental oxidation of pyrite: Geochimica et Cosmochimica Acta, v. 48, p. 2669-2678.

Taylor, B.E., Wheeler, M.C., and Nordstrom, D.K., 1984, Isotope composition of sulphate in acid mine drainage as a measure of bacterial oxidation: Nature, $v$. 308, p. 538-541.

Thatcher, L.L., Janzer, V.J., and Edwards, K.W., 1977, Methods for determination of radioactive substances in water and fluvial sediments: Techniques of Water-Resources Investigations of the U.S. Geological Survey, Chapter A5, 95 p.

Theis, T.L., and Wirth, J.L., 1977, Sorptive behavior of trace metals on fly ash in aqueous systems: Environmental Science \& Technology, v. 11, no. 12, p. 1096-1100.

Todd, D.K., 1980, Groundwater Hydrology: 2nd ed., John Wiley \& Sons, publ., New York, NY, 535 p.

Truax, C.N., Jr., 1965, Water storage potential of surface mined coal lands: Mining Congress Journal, November, 1965, p. 40-46.

U.S. Department of Commerce, 1990, Surface coal mining effects on ground water recharge: National Academy Press, publ., Washington D.C., and National Technical Information Service, Springfield, VA, 159 p.

U.S. Environmental Protection Agency, 1983, Neutralization of Acid Mine Drainage, Design Manual: EPA 600/2-83-001.

U.S. Environmental Protection Agency, 1989, Stabilization/ Solidification of CERCLA and RCRA Wastes, Physical Tests, Chemical Testing Procedures, Technology, and Field Activities: EPA 625/6-89/022.

U.S. Environmental Protection Agency, 1983, Land Application of Municipal Sludge, Process Design Manual: EPA 625/1-83-016.

U.S. Environmental Protection Agency, 1982, Sulfur Oxides Control Technology Series: Flue Gas Desulfurization Spray Dryer Process: EPA 625/8-82-009, 26 p. 
U.S. Environmental Protection Agency, 1980, Disposal of Flue Gas Desulfurization Wastes Shawnee Field Evaluation, Capsule Report: EPA 625/2-80-028, 20 p.

U.S. Environmental Protection Agency, 1980, Sulfur Oxides Control Series: Flue Gas Desulfurization, Dual Alkali Process: EPA 625/8-80-004, 22 p.

U.S. Environmental Protection Agency, 1979, Bahco Flue Gas Desulfurization and Particulate Removal System, Capsule Report: EPA 625/2-79-022, 24 p.

U.S. Environmental Protection Agency, 1972, Environmental Protection Agency:A Progress Report, December 1970 - June 1972: U.S. Environmental Protection Agency, Washington, D. C., 20460, 177 p.

Vence, T.D., 1985, Potential of recycling ash from resource recovery facilities in California: Journal of Energy Resources Technology Transactions of the AS? 'E, v. 107, p. $152-162$.

Vimmerstedt, J.P., and Struthers, P.H., 1968, Influence of time and precipitation on chemical composition of spoil drainage: Preprints of papers from the Symposium on Coal Mine Drainage Research, 2nd ed., Mellon Institute, May 14-15, 1968, Coal Industry Advisory Committee p. 152-163.

Voelker, Richard, 1989, Power without acid: Civil Engineering, July, p. 45-47.

Vogel, W.G., 1981, A guide for revegetating coal minesoils in the eastern United States: United States Department of Agriculture, Forest Service, General Technical Report NE-68, $190 \mathrm{p}$.

Wallach, Rony, and Shabtai, Rina, 1992, Surface runoff contamination by soil chemicals: simulations for equilibrium and first-order kinetics: Water Resources Research, v. 28, no. 1, p. 167-173.

Walton, W.C., 1962, Selected analytical methods for well and aquifer evaluations: State of Illinois, Department of Registration and Education, Illinois State Water Survey, Bulletin 49, 81 p., 4 plates.

Wang, Herbert, and Anderson, M.P., 1982, Introduction to Groundwater Modeling: W.H. Freeman and Company, publ., San Francisco, CA, 237 p.

Ward, A.D., Wells, L.G., Day, G.B., and Phillips, R.E., 1981, Drainage and rainfall instrumented probe network-design University of Kentucky (DRIPIN-DUK): Proceedings from the American Society of Agricultural Engineers 1981 Summer Meeting, paper 81-2025, $25 \mathrm{p}$. 
Wells, L.G., Ward, A.D., Moore, I.D., Phillips, R.E., Comparison of four infiltration models in characterizing infiltration through surface mine profiles: American Society of Agricultural Engineers, v. 29, no. 3, p. 785-793.

Westover, Susan, and Eberle, Michael, 1987, Overview of surface-water quality in Ohio's coal regions: U.S. Geological Survey Water Resources Investigations Open-File Report 84-4061, 32 p.

Wilson, K.S., 1988, Chemical quality, benthic organisms, and sedimentation in streams draining coal-mined lands in Raccoon Creek Basin, Ohio, July 1984 through September 1986: U.S. Geological Survey Water Resources Investigations Report 88-4022, $80 \mathrm{p}$.

Wilson, K.S., 1985, Surface-water quality of coal-mine lands in Raccoon Creek Basin, Ohio: U.S. Geological Survey Water- Resources Investigations Report 85-4060, $61 \mathrm{p}$.

Wood, W.W., 1976, Guidelines for collection and field analysis of ground-water samples for selected unstable constituents: Techniques of Water-Resources Investigation of the U.S. Geological Survey, Book Chapter D2, 24 p.

Yang, I.C., Turner, A.K., Sayre, T.M., and Montazer, Parviz, 1988, Triaxial-compression extraction of port water from unsaturated tuff, Yucca Mountain, Nevada: U.S. Geological Survey Water- Resources Investigations Report 88-4189, 68 p.

Young, T.C., 1991, A method to assess lake responsiveness to future acid inputs using recent synoptic water column chemistry: Water Resources Research, v. 27, no. 3, p. 317-326.

Zarger, T.G., Scanlon, D.H., Nicholson, C.P., Brown, S.R., Starnes, L.B., and Harned, W.D., 1987, Ecological recovery after reclamation of toxic spoils left by coal surface mining: Phase II as assessment of environmental changes following intensive remedial treatments: Project Summary, EPA/600/S2-87/052, September 1987, 6 p.

Ziemkiewicz, P.F., and Skousen, J.G., 1991, Prevention of acid mine drainage by alkaline addition: Green Lands, v. 21, p. 42-51. 


\section{OSU Bibliography}

Ainsworth and Rai. 1987. Chemical characterization of fossil fuel combustion wastes. EPRI Report EA-5321. Research Project 2485-8. Final Report. Electric Power Research Institute, Palo Alto, CA.

Alva, A.K., M.E. Sumner, and W.P. Miller. 1990. Reactions of gypsum of phospogypsum in highly weathered acid subsoils. Soil Sci. Soc. Am. J. 54:993-998

American Society for Surface Mine Reclamation. 1988. Mine drainage and surface mine reclamation conference. American Society for Surface Mining and Reclamation and the U.S. Department of the Interior--Bureau of Mines and Office of Surface Mining Reclamation and Enforcement.

Ball, J. W.,D. K. Nordstrom, and D. W. Zachmann. 1984. WATEQ4F - A personal computer FORTRAN translation of the geochemical model WATEQ2 with revised data base. U.S. Geological Survey Open File Report 87-50, 108 p.

Bennett, O.L., J.L. Hern, H.D. Perry, R.L. Ried, W.L. Stout, J.H. Edwards, and K.O. Smedly. 1985. Agricultural uses of atmospheric fluidized bed combustion residue(AFBCR) - a seven year study. Second Annual Coal Conference, Sept 16-20, 1985, Pittsburgh, PA.

Brady, K.B.C. and R.J. Hornberger. 1989. Mine drainage prediction and overburden analysis in Pennsylvania. Ninth Annual West Virginia Surface Mine Drainage Task Force Symposium, April 25-26, 1989, Morgantown, WV.

Brady, K.B.C., M.W. Smith, R.L. Beem, and C.A. Cravotta III. 1990. Effectiveness of the addition of alkaline materials at surface coal mines in preventing or abating acid mine drainage: Part II. Mine site case studies. 1990 Mining Reclamation Conference and Exhibition, Charleston, WV. April 23-26, 1990.

Bryden, G.W., and L.R. Smith. 1989. Sampling for environmental analysis: Part 1. Planning and preparation. American Laboratory 21(7):30-39.

Bryden, G.W., and L.R. Smith. 1989. Sampling for environmental analysis. Part 2: Sampling methodology. American Laboratory 21(9):19-24.

Buchanan, D.B. 1984. The Ohio abandoned mined lands reclamation program. 1984 Report on Ohio Mineral Industries. 
Phase 1 Report

Appendix B

Burnham, J.C., N. Hatfield, G.F. Bennett, and T.J. Logan. 1990. Use of quicklime and cement or lime kiln dust for municipal sludge pasteurization and stabilization with the $\mathrm{N}$-viro soil process. ASTM Symposium on Innovation and Uses for Lime. San Francisco, CA. June 19, 1990.

Center for By-Products Utilization, EPRI, Canada Centre for Mineral and Energy Technology. 1991. Workshop on Coal Ash Utilization.

Claassen, H. C. 1982. Guidelines and techniques for obtaining water samples that accurately represent the waste chemistry of an aquifer. U.S. Geological Survey Open File Report 82-1024.

Collins, R.J. 1982. Aggregate-related applications for residues from fluidized bed combustion boilers. Extending Aggregate Resources, ASTM STP 774, American Society for Testing and Materials, 1982, pp. 3-30.

Consol. 1988. Part 2: Coolside waste management studies - Final report on the run-off simulation test. DOE report Sept. 1988.

Cravotta, C.A., III, K.B.C. Brady, M.W. Smith, and R.L. Beem. 1990. Effectiveness of the addition of alkaline materials at surface coal mines in preventing or abating acid mine drainage: Part I. Geochemical considerations. 1990 Mining Reclamation Conference and Exhibition, Charleston, WV. April 23-26, 1990.

Dahlin, R.S., C.L. Lishawa, C.C. Clark, P.S. Nolan, and N. Kaplan. 1987. Disposal, recycle, and utilization of modified fly ash from hydrated lime injection into coal-fired utility boilers. 80th Annual Meeting of the Air Pollution Control Association. New York, NY. June 21-26, 1987.

Dahlin, R.S., C.L. Lishawa, and N. Kaplan. 1986. Analysis of LIMB waste management options. 2nd Joint Symposium on Dry SO2 and Simultaneous SO2/NOx Control Technologies. June 2-6, 1986, Raleigh, North Carolina.

Dorsey, D.L., and B. Buecker. 1986. TGA identifies scrubber materials. Research and Development, May 1986 pp. 93.

Dravo Lime Company. 1989. Land application uses for FGD by-products: A pilot scale demonstration proposal to Ohio Coal Development Office, Vols 1 and 2.

Dudas, M.J., and C.J. Warren. 1987. Submicroscopic model of fly ash particles. Geoderma, 40:101-114.

Dugan, P.R, and W.A. Apel. 1983. Bacteria and acidic drainage from coal refuse: Inhibition by sodium lauryl sulfate and sodium benzoate. Applied and Environmental Microbiology 46:279-282. 
Eary, L.E., Dhanpat Rai, S.V. Mattigod and C.C. Ainsworth. 1990. Geochemical factors controlling the mobilization of inorganic constituents from fossil fuel combustion residues: II. Review of the minor elements. J. Environ. Qual. 19:188-201.

Electric Power Research Institute. 1980. Studies of long-term chemical and physical properties of mixtures of flue gas cleaning wastes. CS-1533. Palo Alto, CA.

Electric Power Research Institute. 1985. Leaching studies on utility solid wastes: Feasibility experiments. EA-4215. Palo Alto, CA.

Electric Power Research Institute. 1985. Field measurement methods for hydrologic investigations: A critical review of the literature. EA-4301. Palo Alto, CA.

Electric Power Research Institute. 1986. Advanced SO2 control solid-waste management planning study. CS-4402. Palo Alto, CA.

Electric Power Research Institute. 1986. Fly ash design manual for road and site applications: Volumes 1 and 2: Dry or conditioned placement, and wet or slurried placement, respectively. CS-4419. Palo Alto, CA.

Electric Power Research Institute. 1986. Mobilization and attenuation of trace elements in an artificially weathered fly ash. EA-4747. Palo Alio, CA.

Electric Power Research Institute. 1986. Round-robin evaluation of regulatory extraction methods for solid wastes. EA-4740. Palo Alto, CA.

Electric Power Research Institute. 1987. Sampling guidelines for groundwater quality. EA-4952. Palo Alto, CA.

Electric Power Research Institute. 1987. Utilization of advanced sulfur dioxide control by-products, interim report. CS-5269. Palo Alto, CA.

Electric Power Research Institute. 1987. Evaluation of the toxicity characteristic leaching procedure (TCLP) on utility wastes. CS-5355. Palo Alto, CA.

Electric Power Research Institute. 1987. Inorganic and organic constituents in fossil fuel combustion residues-Volume 1: A critical review. EA-5176 vol. 1. Palo Alto, CA.

Electric Power Research Institute. 1987. Inorganic and organic constituents in fossil fuel combustion residues-Vol. 2: An annotated bibliography. EA-5176 vol.2. Palo Alto, CA.

Electric Power Research Institute. 1987. Calcium spray dryer waste management design guide. CS-5312. Palo Alto, CA. 
Electric Power Research Institute. 1987. Proceedings of the 8th international ash utilization symposium. CS-5362 Vol. 1-2. Palo Alto, CA.

Electric Power Research Institute. 1987. Chemical characterization of fossil fuel combustion wastes. EA-5321. Palo Alto, CA.

Electric Power Research Institute. 1987. Solid-waste environmental studies (SWES): Description, status, and available results. EA-5322-SR. Palo Alto, CA.

Electric Power Research Institute. 1987. Field evaluation of instruments for the measurement of unsaturated hydraulic properties of fly ash. EA-5011. Palo Alto, CA.

Electric Power Research Institute. 1988. Sampling and analytical protocol for advanced sulfur dioxide control by-products. CS-5625. Palo Alto, CA.

Electric Power Research Institute. 1988. Laboratory characterization of advanced SO2 control by-products: Furnace sorbent injection wastes. CS-5783. Palo Alto, CA.

Electric Power Research Institute. 1988. Laboratory characterization of advanced SO2 control by-products: Spray dryer wastes. CS-5782. Palo Alto, CA.

Electric Power Research Institute. 1988. Advanced sulfur dioxide control by-product utilization, laboratory evaluation. CS-6044. Palo Alto, CA.

Electric Power Research Institute. 1988. The fossil fuel combustion waste leaching (FOWL(TM)) Code: Version 1 User's Manual. EA-5742-CCM. Palo Alto, CA.

Electric Power Research Institute. 1988. Boron uptake and accumulation by higher plants: A literature review. EA-5817. Palo Alto, CA.

Electric Power Research Institute. 1988. Overview of FASTCHEM(TM) Code package: Application to chemical transport problems. SA-5870-CCM vol. 1. Paio Alto, CA.

Electric Power Research Institute. 1988. FASTCHEM(TM) package: User's guide to EFLOW, the groundwater flow code. EA-5870-CCM vol. 2. Palo Alto, CA.

Electric Power Research Institute. 1988. FASTCHEM(TM) package: User's guide to ETUBE, the pathline and streamtube database code. EA-5870-CCM vol. 3. Palo Alto, CA.

Electric Power Research Institute. 1988. FASTCHEM(TM) Package: User's guide to ECHEM, the equilibrium geochemistry code. EA-5870-CCM vol. 4. Palo Alto, CA. 
Electric Power Research Institute. 1983. Thermochemical data used by the FASTCHEM(TM) package. EA-5872. Palo Alto, CA.

Electric Power Resear, i Institute. 1989. FASTCHEM(TM) Package: User's guide to EICM, the coupled geohydrochemical/transport code. EA-5870-CCM vol. 5. Palo Alto, CA.

Eiectric Power Research Institute. 1989. The FASTCHEM(TM) Package work-station: Integration on pre- and post-processing functions. EA-5871. Palo Alto, CA.

Electric Power Research Institute. 1989. User's manual for MYGRT-Version 2.0: An IBM,PC code for simulating migration of inorganics and organics in groundwater. EN-6531. Palo Alto, SA.

Electric Power Research Institute. 1989. MYGRT* Code Version 2.0: An IBM code for simulating migration of organic and inorganic chemicals in groundwater. EN-6531. Ilo Alto, CA.

Electric Powe: Research Institute. 1989. Laboratory characterization of advanced SO2 conirol by-products: Dry sodium and calcium in-duct injection wastes. GS-6622. Palo Altu, CA.

Electric Power Research Institute. 1989. Quality assurance and quality control for environmental laboratories: Design guidelines. GS-6258. Palo Alto, CA.

Electric Power Research Institute. 1990. Waste disposal and groundwater quality assessment methods. Southeastern Regional Technology Transfer Seminar, Atlan:a, Georgia, August 7-8, 1990.

Electic Power Research Institute. 1989. Progress in waste-use environmental effects study. Land and Water Quality News 4(2).

Electric Power Research Institute. January, 1990. EPRI Guide: Technical reports published Jan. 1987-Dec. 1989 MD-6801. Palo Alto, CA.

Erickson, P.M., and R.S. Hedin. 1988. Evaluation of overburden analytical methods as means to predict post-mining coal mine drainage quality. American Society for Surface Mining and Reclamation, April 17-22, 1988, Pittsburgh, PA.

Fishman, M.J. and L.C. Friedman (eds.). 1989. Methods for determination of inorganic substances in water and fluvial sediments. Techniques of water-resources investigations of the United States Geological Survey, Chapter A1, Book 5, Third Edition. 545 p. 
Forster, D., C. Bardos, and D. Southgate. 1987. Soil Erosion and water treatment costs. J. Soil Water Conserv. 42:349-351.

Foster, G. R., W. H.. Neibling, and R. A. Natterman. 1982. A programmable rainfall simulator. Paper No. 82-2570. Am. Soc. Agr. Eng., St. Joseph, MI.

Friedman, L.C. and D.E. Erdmann. 1982. Quality assurance practices for the chemical and biological analyses of water and fluvial sediments. Techniques of water-resources investigations of the United Sates Geoiogical Survey. Chapter A6, Book 5. $181 \mathrm{p}$.

Friedman, L.C., F.E. King, H.J. Miller, and L.J. Schroder. 1980. Procedures for quality assurance of polypropelene bottles and nitric acid ampoules used for trace-metal analyses of water-quality samples. U.S. Geological Survey Open-File Report 80-157. 19 p.

Fruchter, J.S., D. Rai, and J.M. Zachara. 1990. Identification of solubility-controlling solid phases in a large fly ash field lysimeter. Environ. Sci. Technol. 24:1173-1179.

Golden, D.M. 1988. Design and costs of waste management systems for advanced SO2 control technologies. Paper presented at Joint Power Generation Conference, September, 1988.

Golden, D.M. 1991. EPRI coal ash utilization research. Workshop on coal ash utilization. April 22-23, 1991.

Harness, J.L., Y.C. Chung, D.A. Mays. 1987. Shawnee AFBC demonstration project ash utilization program. Proc. 9th Int. Conf. on Fluidized Bed Combustion: Vol II.

Hassett, D.J., G.J. McCarthy, P. Kumarathasan, and D. Pflughoeft-Hassett. 1990. Synthesis and characterization of selenate and sulfate-selenate ettringite structure phases. Mat. Res. Bull. 25:1347-1354.

Henzel, D.S., and W. Ellison. 1990. Commercial utilization of SO2 removal wastes in the application of new advanced control technology. EPRI and EPA 1990 SO2 Control Symposium, May 8-11, 1990, New Orleans.

Holcombe, L., A. Weinberg, R. Butler, and J. Harness. 1990. Field study of wastes from a lime injection technology. FGD Symposium, New Orleans.

Hostetler, C. J., R. L. Erickson, and D. Rai. 1988. The Fossil Fuel Combustion Waste Leaching (FOWL) Code: Version 1, User's Manual. EPRI Report EA-5742-CCM, Electric Power Research Institute, Palo Alto, CA. 
Phase 1 Report

Appendix B

Idso, S.B. 1990. A role for soil microbes in moderating the carbon dioxide greenhouse effect? Soil Sci. 149:179-180.

Jones, B.E. 1987. Quality Control manual of the U.S. Geological Survey's National Water Quality Laboratory. U.S. Geological Survey Open-File Report 87-457. 17 p.

Keefer, R.F., R.N. Singh, H.E. Ghazi, and D.K. Bhumbla. 1989. Amelioration of acid soils with fly ash. Ninth Annual West Virginia Surface Mine Drainage Task Force Symposium, April 25-26, 1989, Morgantown, WV.

Kilgour, C.L. 1990. Utilization and disposal of fly ash and spent bed material from atmospheric fluidized bed combustion. NSA SO2. emission Control Conf., Sept 10, 1990, Pittsburgh, PA.

Manager, A.M. 1990. The future of fluidized bed combustion. The National Stone Association SO2 Emission Control Conference, September 10, 1990, Pittsburgh, PA.

Mattigod, S.V., Dhanpat Rai, L.E. Eary, and C.C. Ainsworth. 1990. Geochemical factors controlling the mobilization of inorganic constituents from fossil fuel combustion residues: I. Review of the major elements. J. Environ. Qual. 19:188-201.

Mays, D.A., and P.M. Giordano. 1987. Evaluation of fluidized bed combustion waste for agricultural use: 1986 results. Internal TVA Report.

McCullough, M., and F. Hitzhusen. 1981. A solid waste economic planning model for non-metropolitan counties: An Ohio simulation analysis. Research Bulletin 1128, O.A.R.D.C., Wooster, Ohio.

Murarka, I. 1989. Coal ash use sites, Environmental performance assessment. EPRI Journal, December 1989 pp. 52-56.

National Mine Land Reclamation Center Newsletter. Vol. 1., No. 1. 1989. Minelands National Mine Land Reclamation Center Newsletter.

Nolan, P.S., and N. Kaplan. 1987. Disposal, recycle, and utilization of modified fly ash from hydrated lime injection into coal-fired utility boilers. 80th Annual Meeting of the Air Pollution Control Association, New York, NY. June 21-26, 1987.

Otio EPA. 1988. Design criteria; Disposal of non-toxic fly ash, bottom ash, foundry sand, and other exempted solid wastes. Policy No. 4.07. 
Phase 1 Report

Appendix B

Olfenbuttel, R., et al. 1989. Technical support for the Ohio Clean Coal Technology Program: Vol I. Baseline of knowledge concerning by-product characteristics. Batelle report prepared for OCDO.

Olfenbuttel, R., et al. 1989. Technical support for the Ohio Clean Coal Technology Program: Vol II. Baseline of knowledge concerning process modification opportunities, research needs, by-product market potential, and regulatory requirements. Batelle report prepared for OCDO.

Paces, Tomas. 1983. Rate constants of dissolution derived from the measurements of mass balance in hydrological catchments. Geochimica et Cosmochimica Acta 47:1855-1863.

Parker, J. C., J. B. Kool, and M. Th. Van Genuchten. 1985. Determining soil hydraulic properties from one-step outtlow experiments by parameter estimation: II. Experimental studies. Soil Sci. Soc. Am. J. 49:1354-1359.

Parkhurst, D. L., D. C. Thorstenson, and L. N. Plummer. 1980. PHREEQE - A computer program for geochemical calculations. U.S. Geological Survey Water Resources Investigation Report 80-96. 210 p.

Prodan, P.F., L.M. Mele, and J.P. Schubert. 1982. Runoff water quality and hydrology at coal refuse disposal sites in Southern Illinois. 1982 Symposium on Surface Mining Hydrology, Sedimentlogy and Reclamation. Univ. Kentucky. Lexington, KY 40506-0046.

ProMac Systems. 1988. Abandoned mine reclamation at Dawmont, W. Virginia Land and Water, November/December 1988.

Rawlins, S. L., and G. S. Campbell. 1986. Water Potential: Thermocouple psychrometry. pp 597-618. In A. Klute (ed.), Methods of Soil Analysis, Part 1. Physical and Mineralogical Methods, 2nd Edition, American Society of Agronomy, Madison, WI.

Rich, D.H., and K.R. Hutchinson. 1990. Neutralization and stabilization of combined refuse using lime kiln dust at High Power Mountain. Mining and Reclamation Conference and Exhibition, April 23-26, 1990, Charleston, WW.

Ro, T. H., D. L. Forster, L. J. Hushak, and G. W. Moese. 1984. Environmental regulation and regional economic growth: An input-output analysis of the Ohio coal mining region. Research Bulletin, O.A.R.D.C., Wooster, OH.

Rose, J.G., A.E. Bland, and C.E. Jones. 1986. Production of concrete using fluidized bed combustion waste and power plant fly ash. Final Report. TVA Contract No TV-60443A. 
Schubert, J.P., and P.F. Prodan. 1981. Groundwater pollution resulting from disposal of pyritic coal wastes. Quality of Groundwater. Proceedings of an International Symposium. Noordwijkerhout, The Netherlands, 23-27 March, 1981. W. van Duijvenbooden, P. Glasbergen and H. van Lelyveld (Eds.). Studies in Environmental Science, Volume 17.

Schubert, J.P., and R. Michael Miller. 1982. Subsurface oxidation of pyritic coal-cleaning wastes by chemoautotrophic bacteria. 1982 Symposium on Surface Mining Hydrology, Sedimentology and Reclamation. Univ. Kentucky, Lexington, KY 40506-0046.

Sidle, R.C. W.L. Stout, J.L. Hern, and O.L. Bennett. 1979. Solute movement from fluidized bed combustion waste in acid soil and mine spoil columns. J. Environ. Qual. 8:236-241.

Skousen, J., J. Sencindiver, and D. Samuel. 1990. Proceedings of the 1990 mining and reclamation conference and exhibition: Volumes I and II. West Virginia University, Morgantown, April 23-26, 1990.

Skousen, J., K. Politan, T. Hilton, A. Meek. 1990. Acid mine drainage treatment systems: Chemicals and costs. Green Lands vol. 20, no. 4. p. 31-37.

Skousen, J.G., J.C. Sencindiver, and R.M. Smith. 1987. A review of procedures for surface mining and reclamation in areas with acid-producing materials. Division of Plant and Soil Sciences, College of Agriculture and Forestry, West Virginia University, Morgantown, West Virginia.

Sobek, A.A., W.A. Schuller, J.R. Freeman, and R.M. Smith. 1978. Field and laboratory methods applicable to overburden and mine soils. PB-280 495, EPA-600/2-78-054, March 1978.

Stout, W.L., J.L. hern, R.F. Korcak, and C.W. Carlson. 1988. Manual for applying fluidized bed combustion residue to agricultural lands. U.S. Dept. of Agric.,. Res. Service, ARS-74.

Tatro, M.E., V.M. Giampa, and R.J. Collins. Recent advances in the dissolution of zeolites and coal ash for flame AA and ICP analyses. Spectroscopy 4:18-22

Taylor, B. E., M. C. Wheeler, and D. K. Nordstrom. 1984. Oxygen and sulfur isotope compositions of oxygen and sulfate in acid mine drainage: Evidence for oxidation mechanisms. Nature 308:538-541.

Thatcher, L.L., V.J. Janzer, and K.W. Edwards. 1977. Methods for determination of radioactive substances in water and fluvial sediments. Techniques of water-resources investigations of the United States Geological Survey. Chapter A5, Book 5. 95 p. 
Phase 1 Report

Appendix B

USDA. 1979. Field manual for research in agricultural hydrology. Agr. Handbook No. 224. United States Department of Agriculture, U.S. Government Printing Office, Washington, D.C.

Wadell, R.K.Jr., R.R. Parizek, and D.R. Buss. 1980. The application of limestone and lime dust in the abatement of acidic drainage in Centre County, Pennsylvania: Executive Report FHWA/PA-80/011 Research Project 73-9 Final Report Executive Summary. Sponsored by Pennsylvania Dept. of Transportation

West Virginia University. 1990. Semi-annual progress report. National Mine Land Reclamation Center, West Virginia University.

Wolfe, W.E., and T.H. Wu. 1990. Clean coal by-product utilization in roadways, embankments and backfills - 1990-91 construction. EPRI RFP 3176-5.

Wu, M.M, R.C. Winschel, G.E. Wasson and T.C. Jageman. 1990. Properties of Solid wastes from the Edgewater Coolside and LIMB process demonstrations. 83rd annual meeting of the Air and Waste Management Association, Pittsburgh, PA June 24-29, 1990.

Wu, M.M., and R.A. Winschel. 1988. Coolside waste management studies: Final report. Consolidated Coal Co/DOE Cooperative Agreement No. DE-FC22-87PC79798.

Ziemkiewicz, P.F. 1990. Advances in the prediction and control of acid mine drainage. 1990 Mining and Reclamation Conference and Exhibition, Charleston, West Virginia, April 23-26, 1990. 


\section{Appendix C \\ Dry FGD by-Product Samples and Plant Operating Conditions}

Sample code
Date
Sampling point
Sampler
Comments
Cond. of op.
Sample code
Date
Sampling Point
Sampler
Comments
Cond. of op.
Sample code
Date
Sampling point
Sampler
Comments
Cond. of op.
Sample code
Date
Sampling point
Sampler
Comments
Cond. of op.
Com.

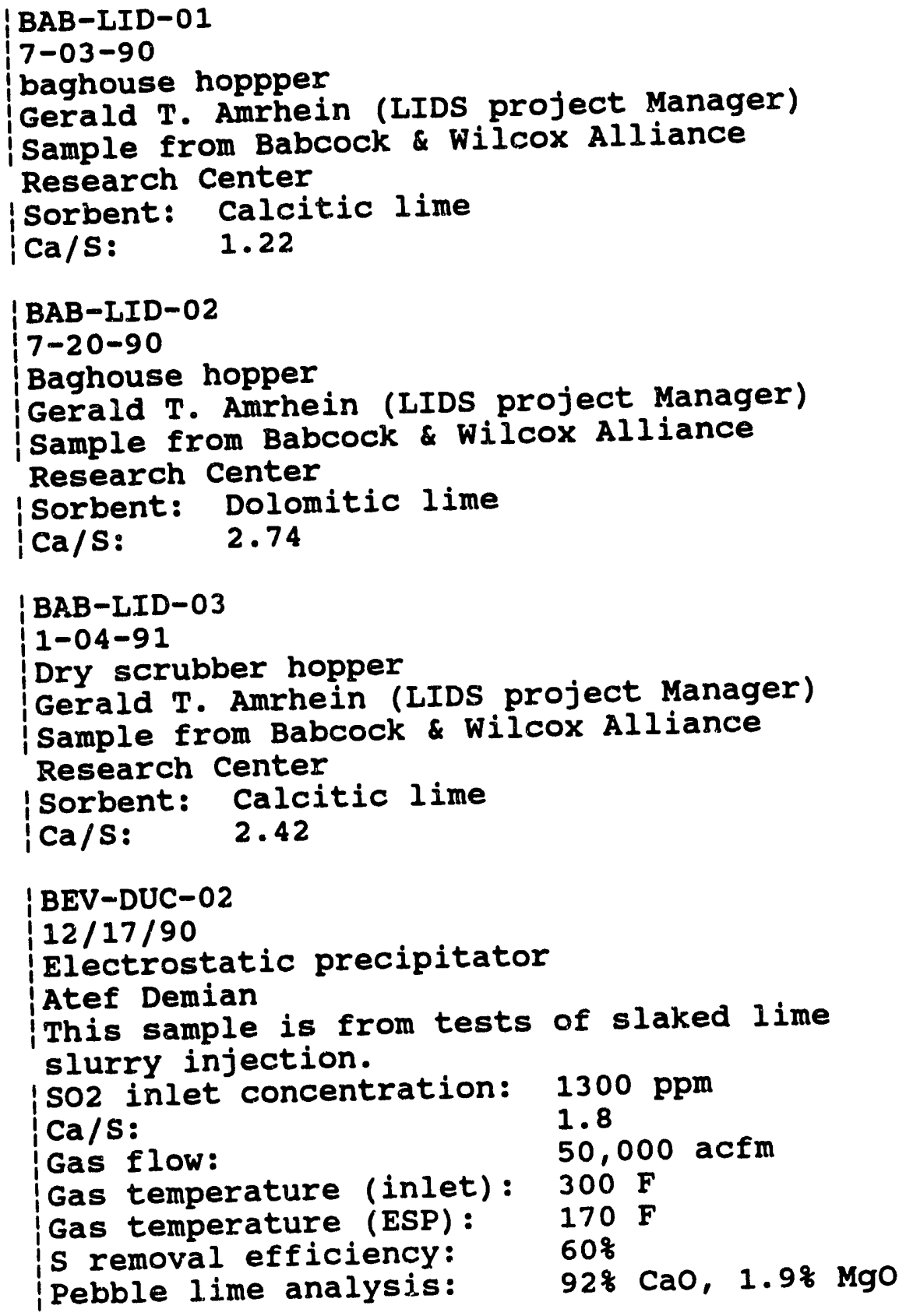


Sample code

Date

Time

Sampling Point

Sampler

cond. of op.

Sample code

Date

Time

Sampling Point

Sampler

Comments

Cond. of op.
BEV-DUC-03

$1-04-91$

1400

ESP Hopper

Atef Demian

SO2 inlet concentration: $1300 \mathrm{ppm}$

$\mathrm{Ca} / \mathrm{S}$ :

Gas flow:

Gas temperature (inlet): $300 \mathrm{~F}$

Gas temperature (ESP) $160 \mathrm{~F}$

Approach to sat.

S removal efficiency $75 \%$

Pebble lime analysis: $\quad 92 \% \mathrm{CaO}, 1.9 \% \mathrm{MgO}$

I BEV-DUC-05

$7-23-91$

1345

ESP hopper

Atef Demian

Slurry/Recycle system, ash recycled through injection system.

S02 inlet concentration: $2000 \mathrm{ppm}$

$\mathrm{Ca} / \mathrm{s}$ :

Gas flow:

1.5

Gas temperature (inlet): $300 \mathrm{~F}$

Gas temperature (ESP): $155 \mathrm{~F}$

Approach to sat.

25 degrees

Recycle ratio

3.3:1 (ash to

pebble lime)
Sample code

Date

Time

sampling point

Sampler

Comments

Cond. of op.

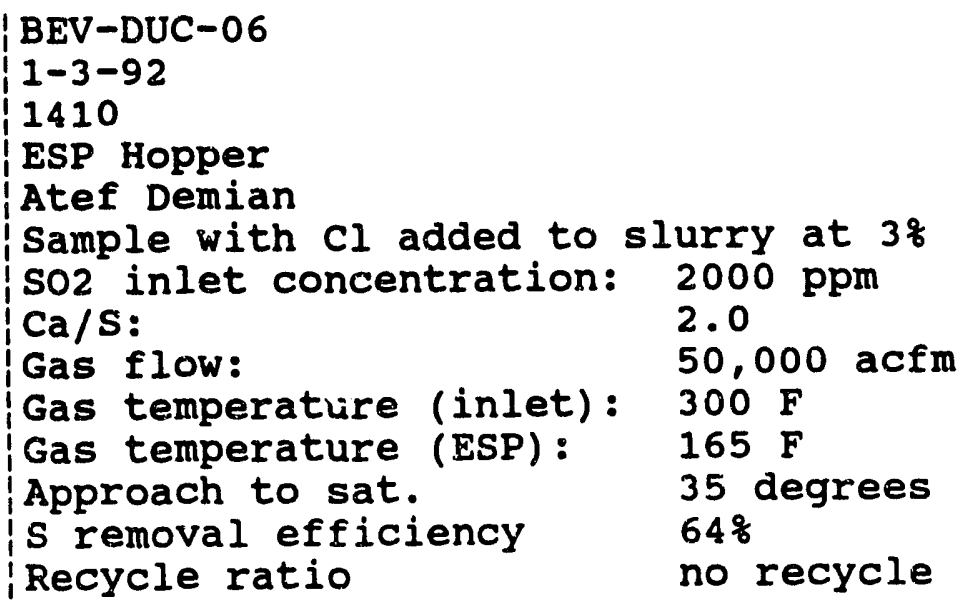


Sample code
Date
Time
Sampling Point
Sampler
Comments
Cond. of op.

Sample code

Date

Time

Sampling Point

Sampler

Comments

Cond. of op.

Sample code Date

Sampling Point Sampler

Cond. of op.

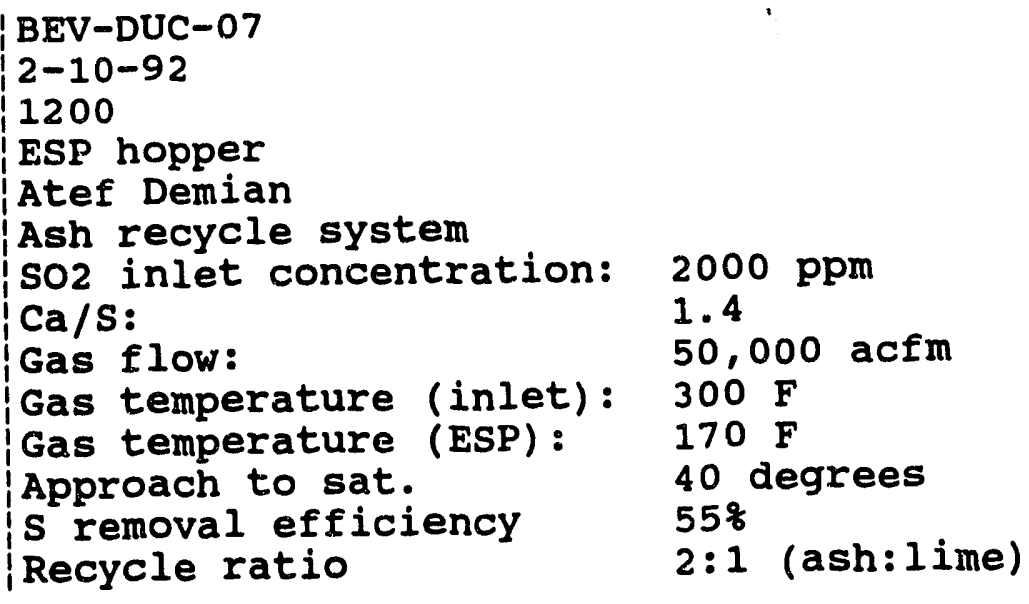


Phase 1 Report

Appendix C

Sample code Date Time

Sampling Point Sampler

Cond. of op.

Sample code

Date

Time

Sampling Point

Sampler

Comments

Cond. of op.

Sample code

Date

Time

Sampling Point

Sampler

Comments

Cond. of op.

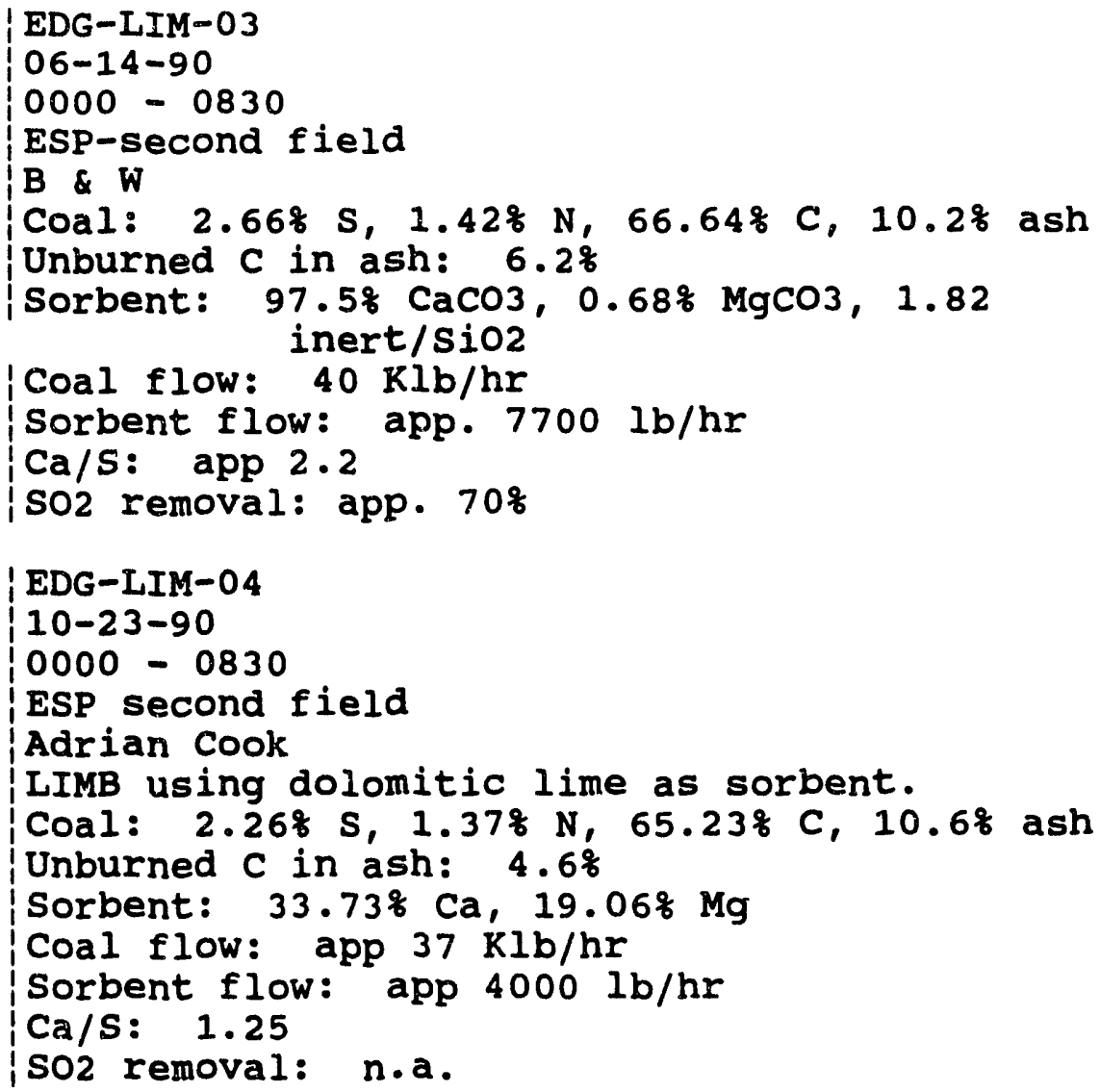


Sample code

Date

Time

Sampling Point

Sampler

Cond. of Op.

Sample code

Date

Time

Sampling point

Sampler

Cond. of op.

Sample code

Date

Time

Sampling Point

Sampler

Comments

Cond. of op.
Sample code

Date

Time

Sampling Point

Sampler

Comments

cond. of op.
EDG-LIM-06

$11 / 16 / 90$

1000

2nd field ESP

A. Cook

Sorbent: $33.858 \mathrm{Ca}, 19.428 \mathrm{Mg}$

Sorbent flow: app. $4000 \mathrm{lb} / \mathrm{hr}$

$\mathrm{Ca} / \mathrm{s}: 1.2$

SO2 removal: app. 258

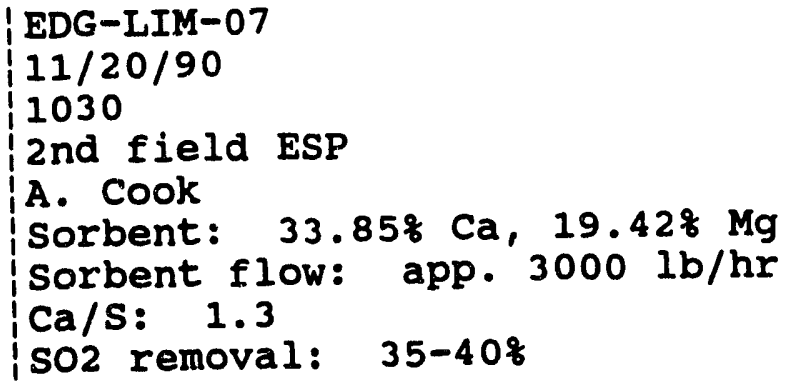

EDG-LIM-07

$11 / 20 / 90$

1030

2nd field ESP

A. Cook

Sorbent: $33.85 \% \mathrm{Ca}, 19.428 \mathrm{Mg}$

Sorbent flow: app. $3000 \mathrm{lb} / \mathrm{hr}$

$\mathrm{Ca} / \mathrm{S}$ : 1.3

so2 removal: 35-40\%

EDG-LIM-08

$1-25-91$

1300

ESP 2nd field

A. Cook

calcitic limestone sorbent

coal: $1.58 \% \mathrm{~S}, 1.37 \% \mathrm{~N}, 65.23 \% \mathrm{C}, 11.23 \mathrm{ash}$

Unburned $C$ in ash: 4.68

Sorbent: $33.73 \% \mathrm{CaCO}_{3}, 0.68 \% \mathrm{MgCO} 3$

Coal flow: app. $\mathrm{Klb} / \mathrm{hr}$

Sorbent flow: app. Ib/hr

$\mathrm{Ca} / \mathrm{S}$ : 2.00

so2 removal: 35

EDG-LIM-09

2-13-91

1130

ESP 2nd field

A. Cook

lime sorbent

Coal: $3.27 \%$ S, $1.37 \%$ N, $65.23 \%$ C, $9.59 \%$ ash

Unburned $C$ in ash: $4.6 \%$

Sorbent: $\quad 62.3 \% \mathrm{Ca}(\mathrm{OH}) 2,00 \% \mathrm{Mg}$

Coal flow: app $\mathrm{Klb} / \mathrm{hr}$

Sorbent flow: app $5000 \mathrm{lb} / \mathrm{hr}$

$\mathrm{Ca} / \mathrm{S}$ : 1.25

so2 removal: $30-35 \%$ 


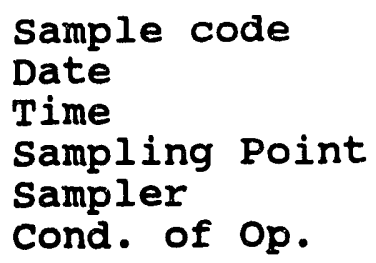

Sample code Date Time

Sampling Point Sampler

Sample code Date

Sampling Point Sampler

Cond. of op.
Cond. of op.

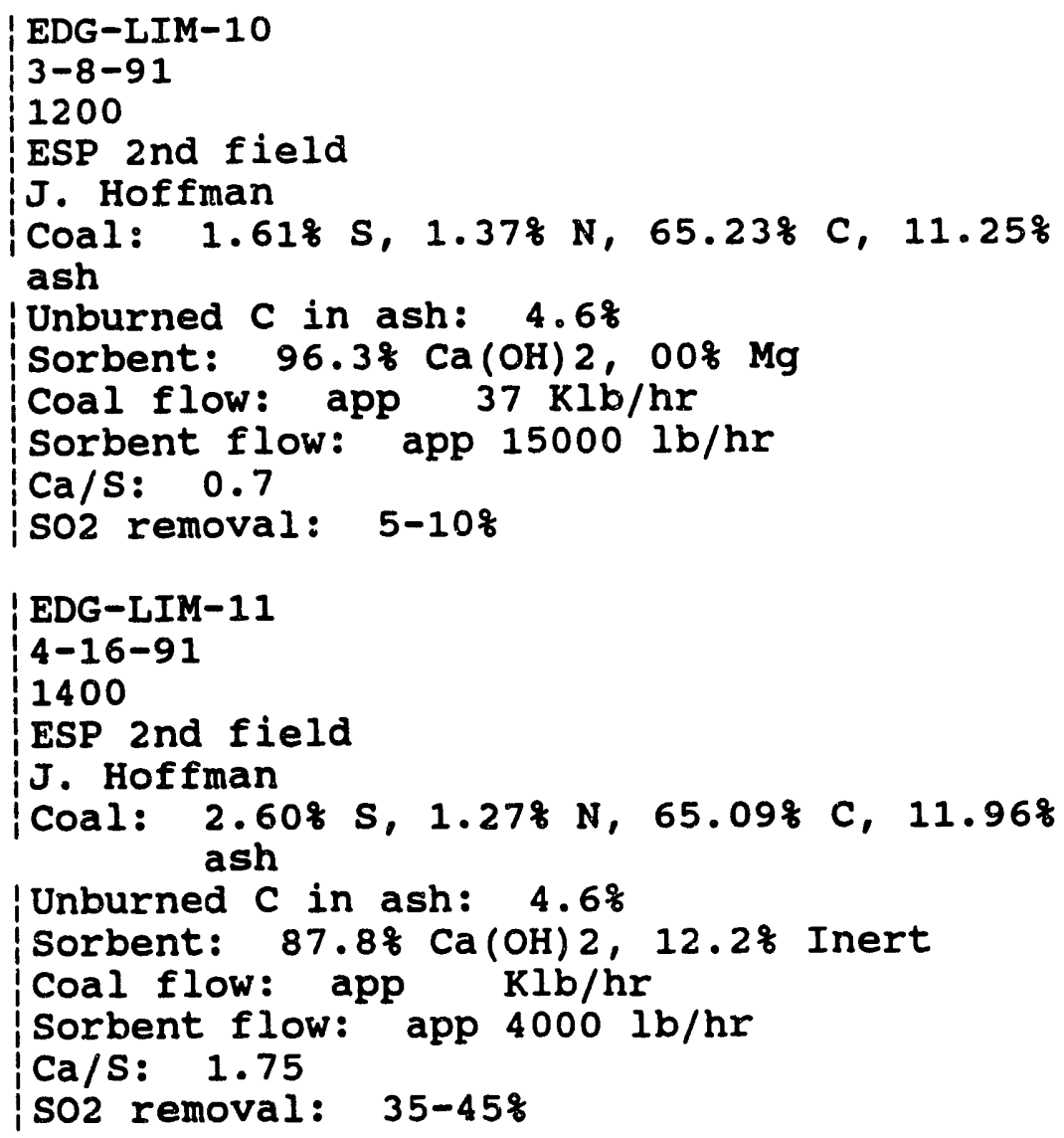

| EDG-IIM-12

5-24-91

ESP 2nd field

A. Cook

Coal: $1.75 \% \mathrm{~S}, 1.27 \% \mathrm{~N}, 65.09 \% \mathrm{C}, 12.81 \%$ ash

Unburned $C$ in ash: $4.6 \%$

Sorbent: $87.8 \% \mathrm{Ca}(\mathrm{OH}) 2,12.2 \%$ Inert

Coal flow: app $50 \mathrm{Klb} / \mathrm{hr}$

Sorbent flow: app $4000 \mathrm{lb} / \mathrm{hr}$

$\mathrm{Ca} / \mathrm{S}: 1.7$

SO2 removal: $55 \%$

Sample code

Date

Sampling Point Sampler

Cond. of op.

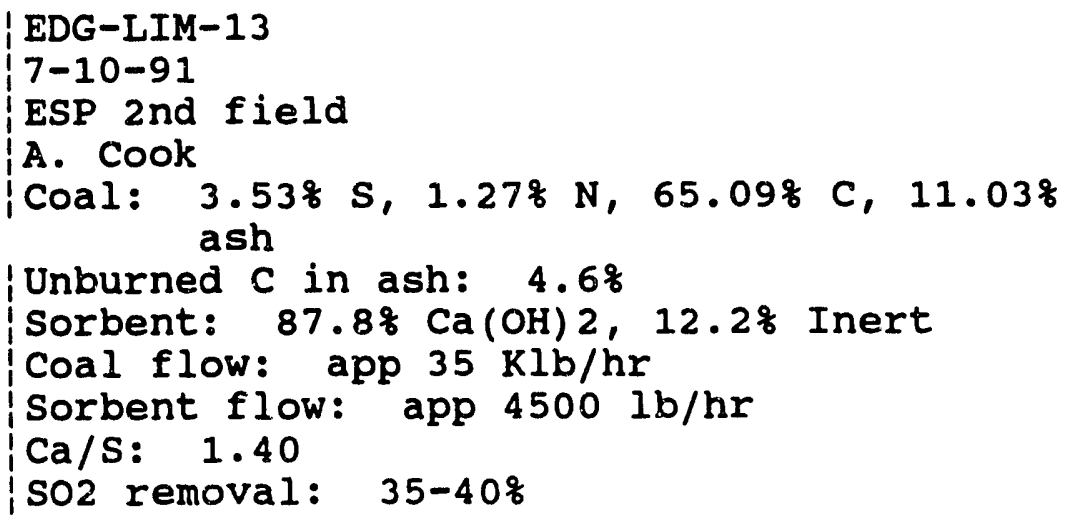


Phase 1 Report Appendix C

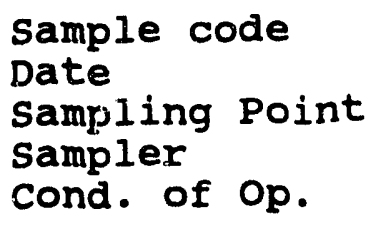

Sample code Date

Sampling Point Sampler

Sample code Date Sampling Point Sampler Comments

Cond. of Op.

Sample code Date Sampling Point Sampler Comments

Cond. of op.

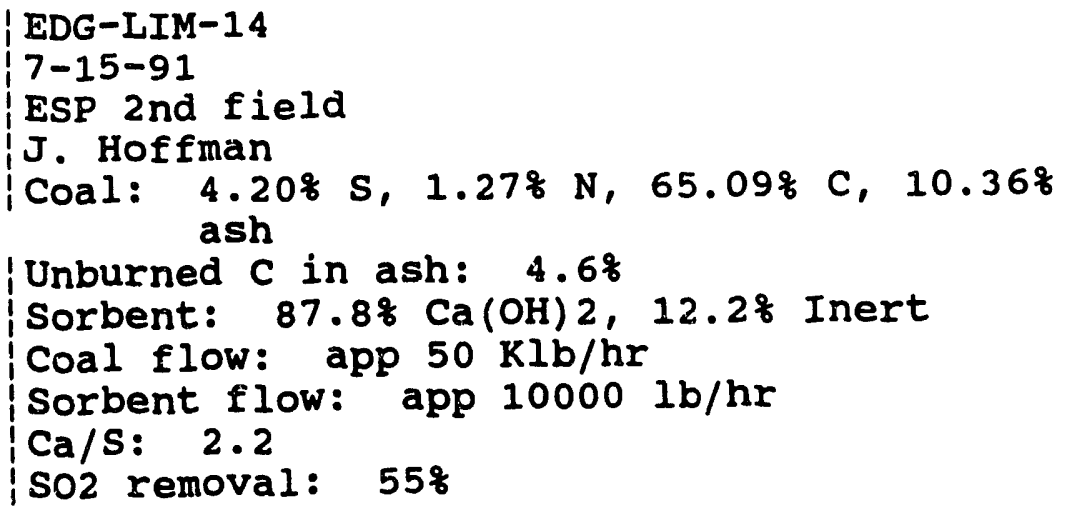




\author{
Sample code \\ Date \\ Sampling Point \\ sampler \\ cond. of op. \\ sample code \\ Date \\ Sampling Point \\ sampler \\ cond. of op.
}

Sample code Date

Sampling Point sampler

cond. of op.

Sample code

Date

Sampling Point sampler

cond. of $\mathrm{Op}$.

Sample code Date

Sampling Point

Sampler

comments

Sample code Date

Sampling Point

Sampler

Cond. of op.
| HST-SPD-01

3-20-91

baghouse fabric filter

Joe Peterson

Sorbent: Mississippi lime

Ca/S: 1.3

Spray dyer inlet so2 conc: 1500 ppm

HST-SPD-02

3-20-91

Spray dryer drop out solids

Joe Peterson

Sorbent: Mississippi lime

Ca/s: 1.3

Spray dyer inlet so2 conc: 1500 ppm

|HST-SPD-03

4-15-91

Baghouse fabric filter

Joe Peterson

Sorbent: Mississippi lime

$\mathrm{Ca} / \mathrm{s}: 1.6$

Spray dyer inlet so2 conc: 2500 ppm

HST-SPD-04

4-15-91

spray dryer drop out solids

Joe Peterson

Sorbent: Mississippi lime

Ca/s: 1.6

Spray dyer inlet so2 conc: 2500 ppm

HST-SPD-05

$10-03-91$

Mix of SPD dropout solids and baghouse ash

Joe Peterson, Joel Beeghly

This sample is a mix of two ash streams; spray dryer drop-out solids and pulse jet fabric filter ash. The previous samples are separate samples of these ash streams.

| NSP-SPD-01

$3-7-91$

baghouse

John Hietala

Sorbent: $90 \%$ CaO (slaked then fed as slurry)

Coal flow: $370-400$ tons $/ \mathrm{hr}$

Sorbent flow: app $39.5 \mathrm{Klb} / \mathrm{hr}$

Ca/s: 1.2

Spray dyer inlet so2 conc: 532 ppm

sO2 removal: $75.5 \%$ 
Sample code

Date

Sampling Point

Sampler

Sample code

Date

Time

Sampling Point

Sampler

Sample code

Date

Time

Sampling Point

Sampler

Sample code

Date

Time

Sampling Point

Sample code

Date

Time

Sampling point

Sampler

Sample ccde

Date

Time

Sampling point

sampler

Sample code

Date

Time

Sampling Point

Sampler

Comments

Sample code

Date

Time

Sampling Point

Sampler

Comments
NSP-SPD-02

February, 1992

baghouse

John Hietala

|OSU-SPD-01

1-11-91

1115

Baghouse

Don Smith

|OSU-SPD-02

2-22-91

10,0

Baghouse compartment A

Don Smith

| OSU-SPD-03

4-1-91

1305

Baghouse compartment B

|OSU-SPD-04

4-1-91

1236

Bottom Ash

John Harris

OSU-SPD-05

5-2.3-91

1300

Baghouse compartment $C$

Frank Paskievitch

|OSU-SPD-07

5-23-91

0930

North Eccnomizer hopper

Frank Paskio: „tch

economizer ash

|OSU-SPD-08
5-23-91
1040
Boiler bottom ash
Frank Paskievitch
Bottom Ash 


\author{
Sample code \\ Date \\ Time \\ Sampling Point \\ Sampler \\ Comments \\ Sample code \\ Date \\ Sampling Point \\ Sample code \\ Date \\ Sampling Point \\ Sampler \\ Comments \\ Sample code \\ Date \\ Sampling Point \\ Comments
}

Cond. of op.

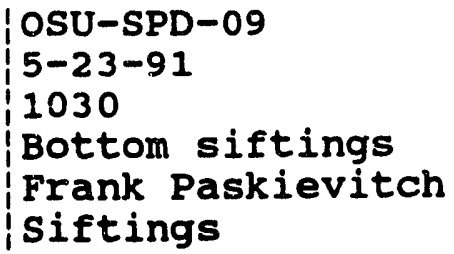

Sample code Date

Sampling Point Sampler Comments Cond. of op.
QST-FLB-01

$10-10-90$

economizer ash

Joel Beeghly

high coal content ash

Sorbent: limestone

Coal flow: $\quad 146$ Ton/day, 6.1 Ton/hr

Sorbent flow: app. 1.6 Ton $/ \mathrm{hr}$

Ca/S: 2.9 
Sample code Date

Sampling Point Sampler Comments cond. of op.

Sample code Date

Sampling Point Sampler

Cond. of op.

Sample code Date

Sampling Point Sampler

Cond. of op.

Sample code Date

Time

Sampling point Sampler

cond. of op.
QST-FLB-02

$10-10-90$

baghouse

Joel Beeghly

high coal content ash

Sorbent: limestone

Coal flow: $\quad 146$ Ton/day, 6.1 Ton $/ \mathrm{hr}$

Sorbent flow: app. 1.6 Ton $/ \mathrm{hr}$

$\mathrm{Ca} / \mathrm{s}$ :

2.9

QST-FLB-03
10-24-90
boiler bottom ash
Joel Beeghly
Sorbent:
$\begin{array}{ll}\text { Coal flow: } & 1 \text { imestone } \\ \text { Sorbent flow: } & \text { app. } 1.6 \text { Ton } / \mathrm{hr} \\ \text { Ca/S: } & 2.9\end{array}$

| STA-FLB-01

fly ash

J. Beeghly

Coal:

$2.8-3.0 \% \mathrm{~S}$

Sorbent: high Ca limestone

Coal flow: app 380,000 tons/yr

Ash production app 150,000 tons/yr

$\mathrm{Ca} / \mathrm{s}$ : $\quad 3.0$

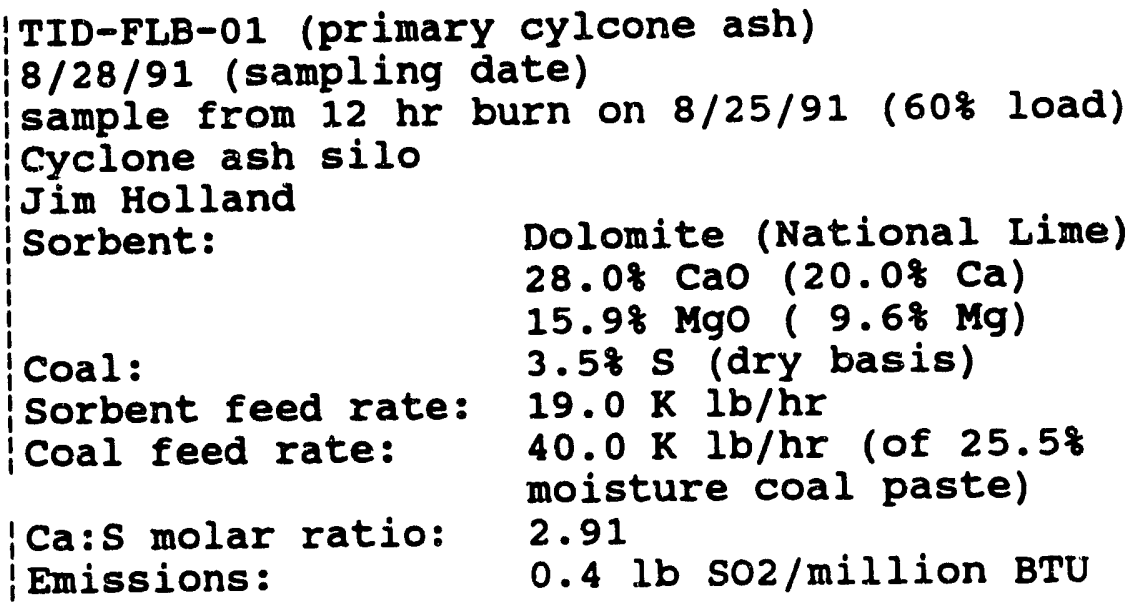


Phase 1 Report

Appendix C

Sample code
Date
Time
Sampling Point
Sampler
Cond. of op.

Sample code Date Time

Sampling Point Sampler Cond. of op.

Sample code

Date

Time

Sampling Point Sampler

Cond. of op.

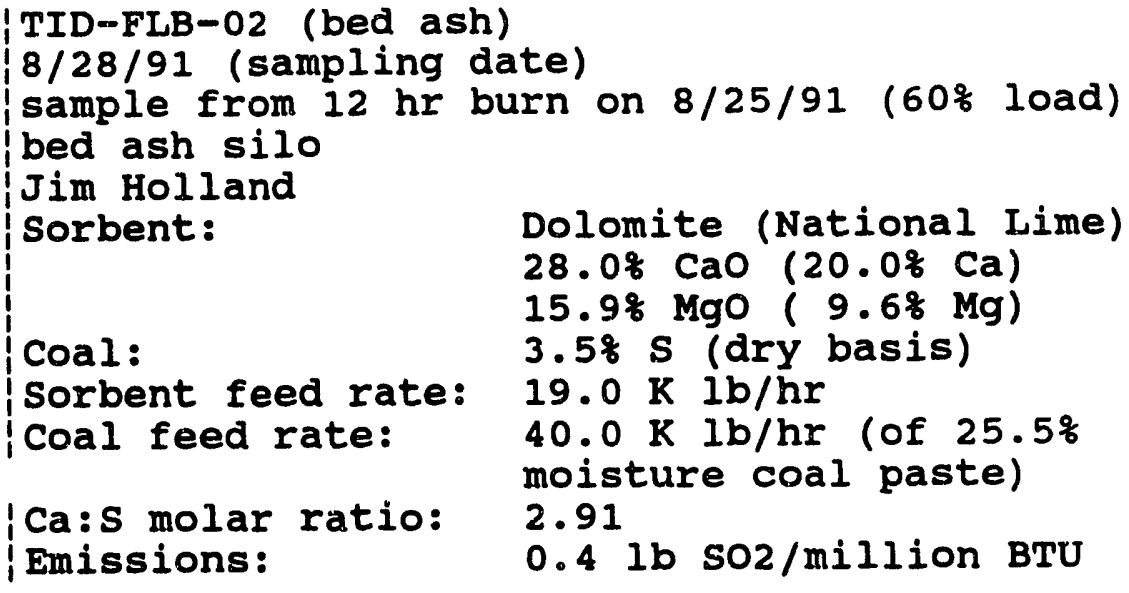




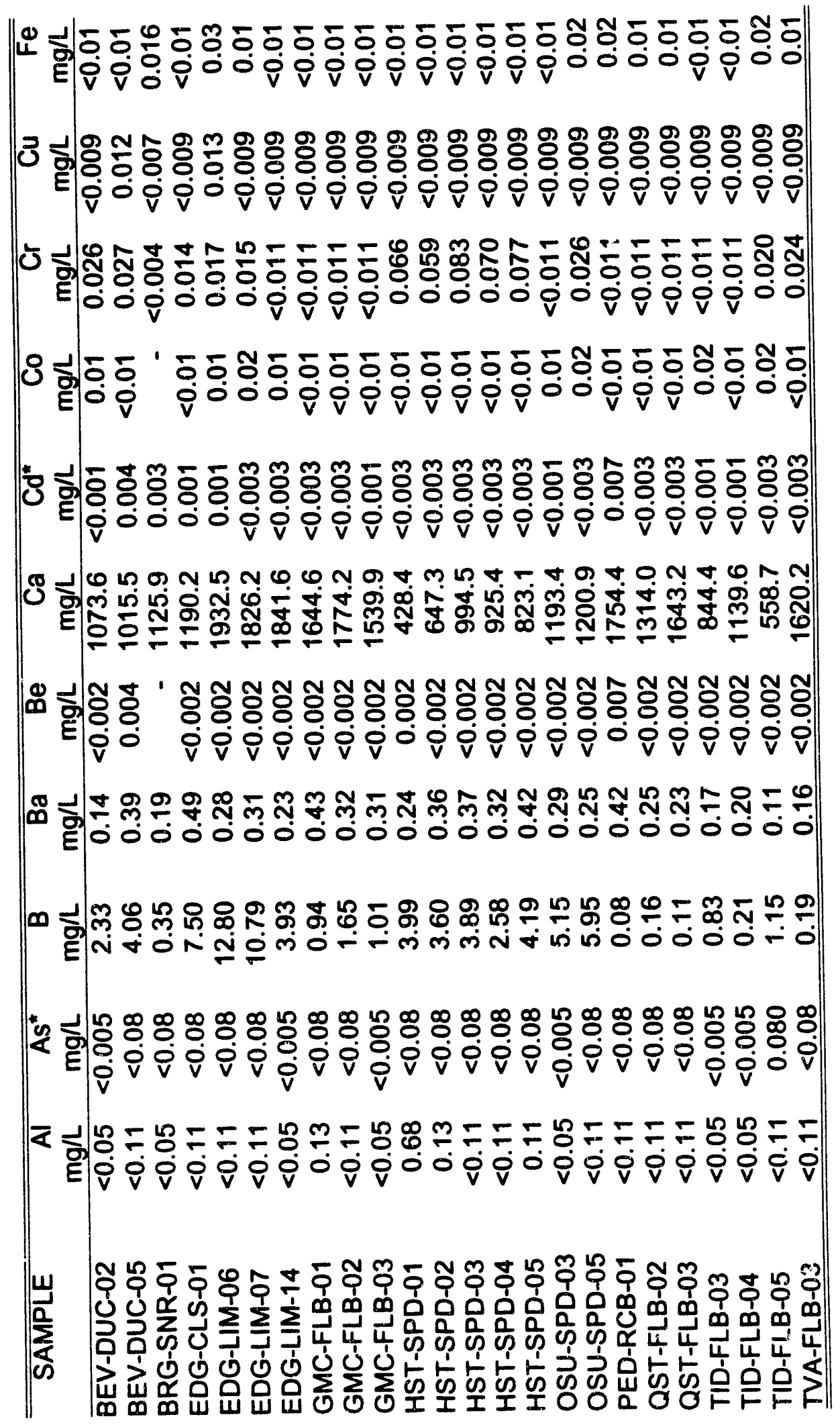


$\omega=$ ก

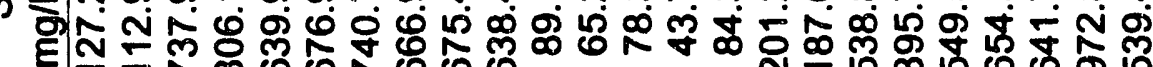

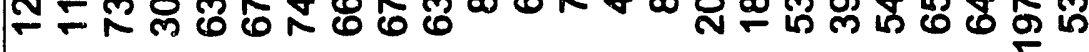

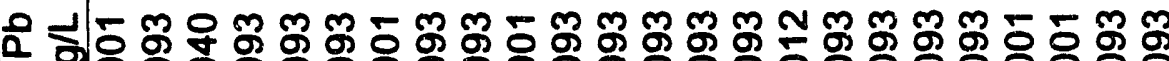

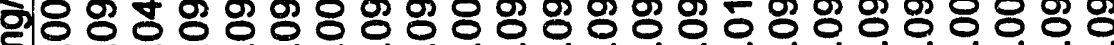

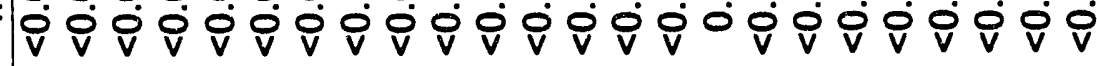

Q F FFFFFFFFFFFFЕFFF FFFFFFF

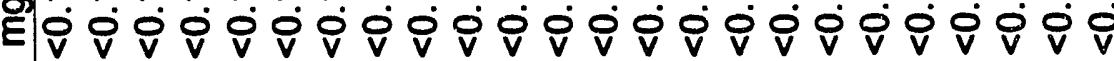

z Elo 0 V

胥

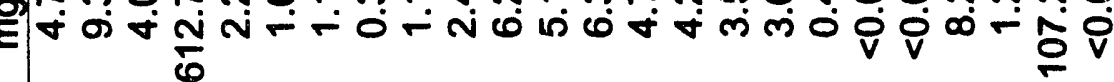

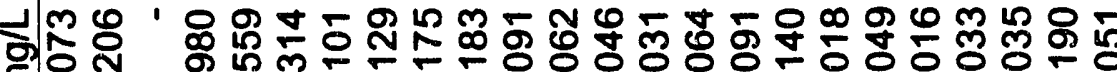

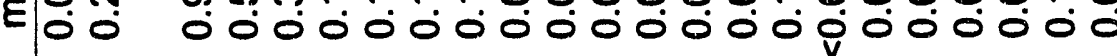

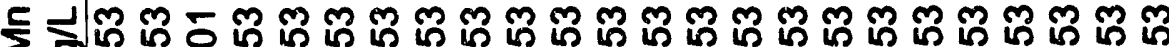
象定 i

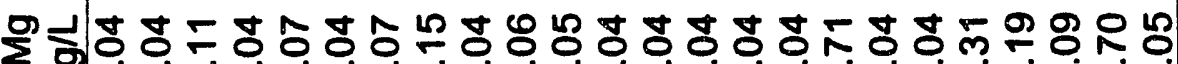

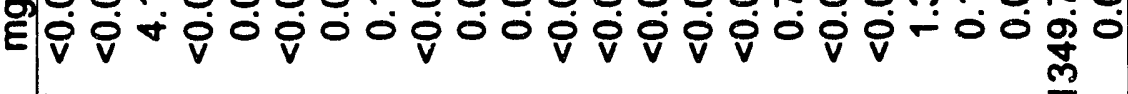

노ำ

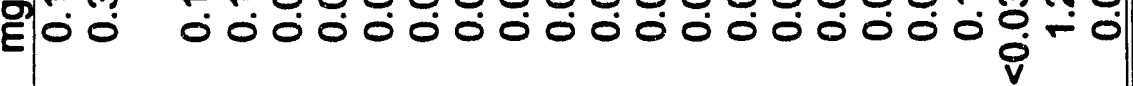

บ

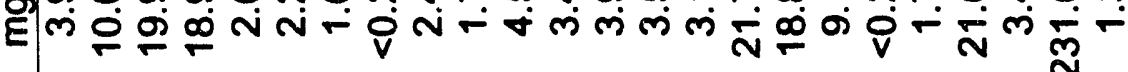

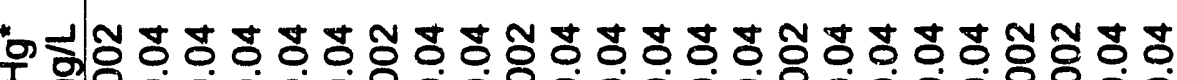
焉

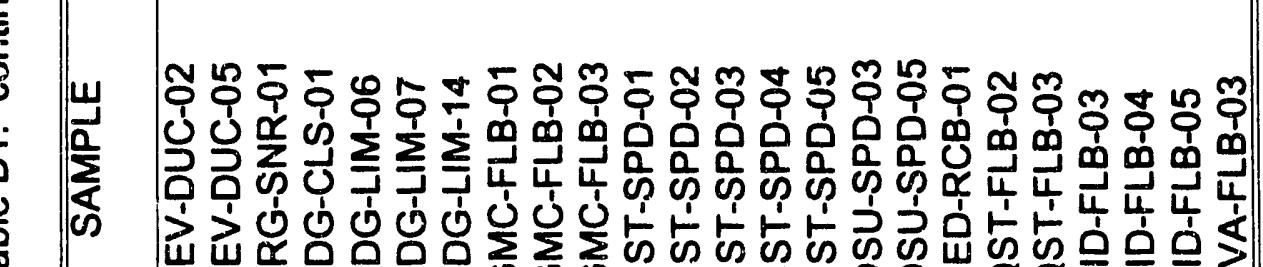




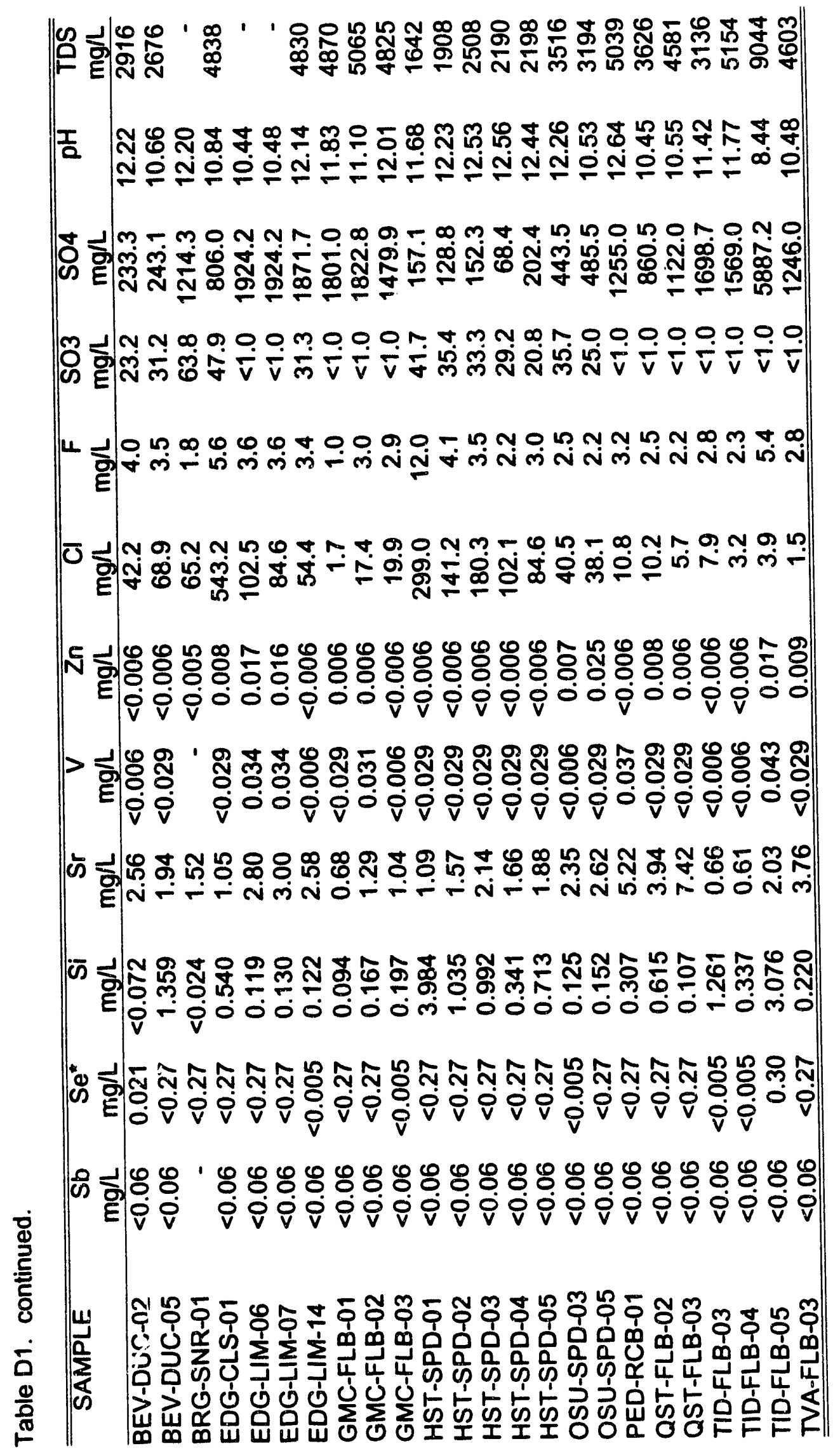




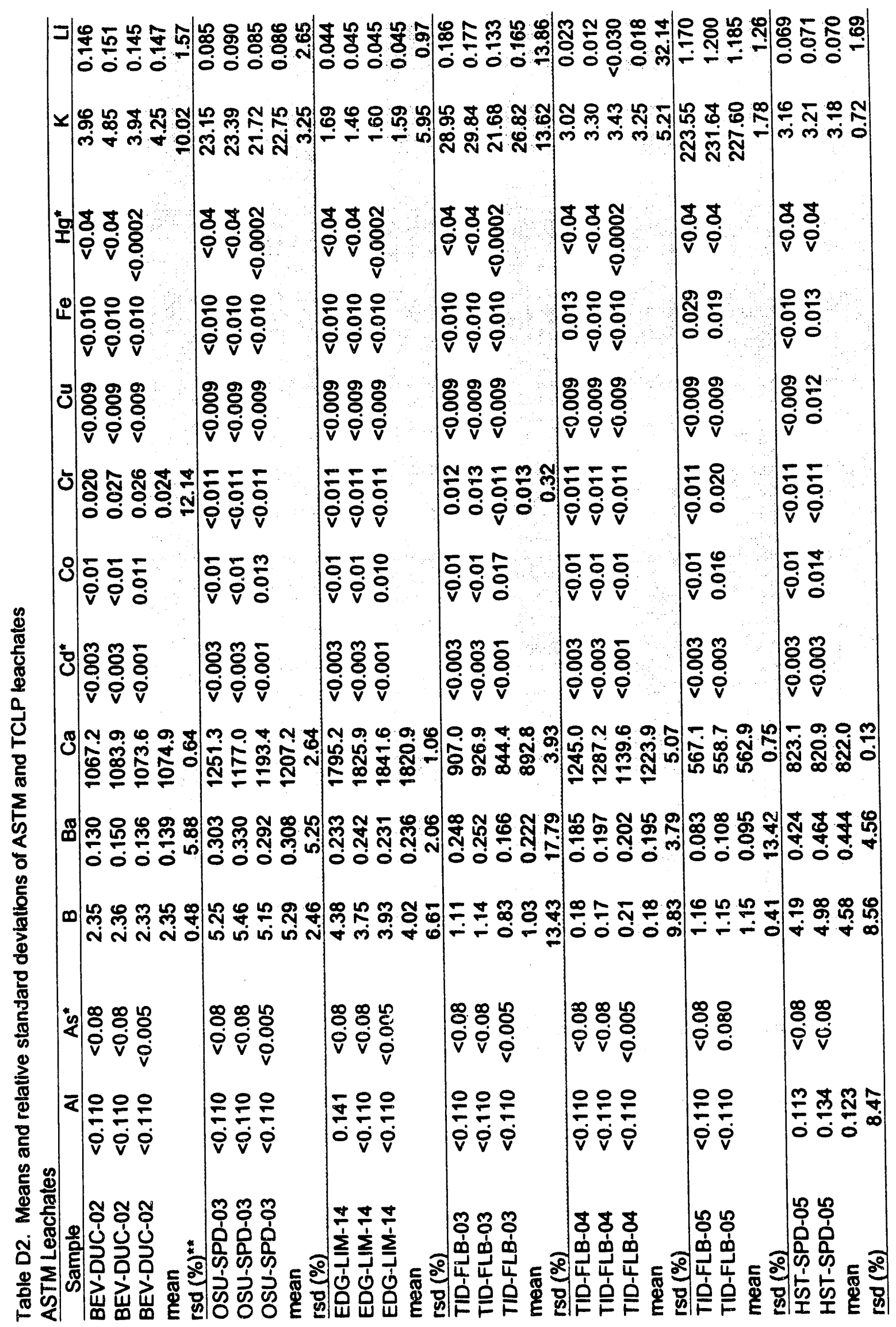




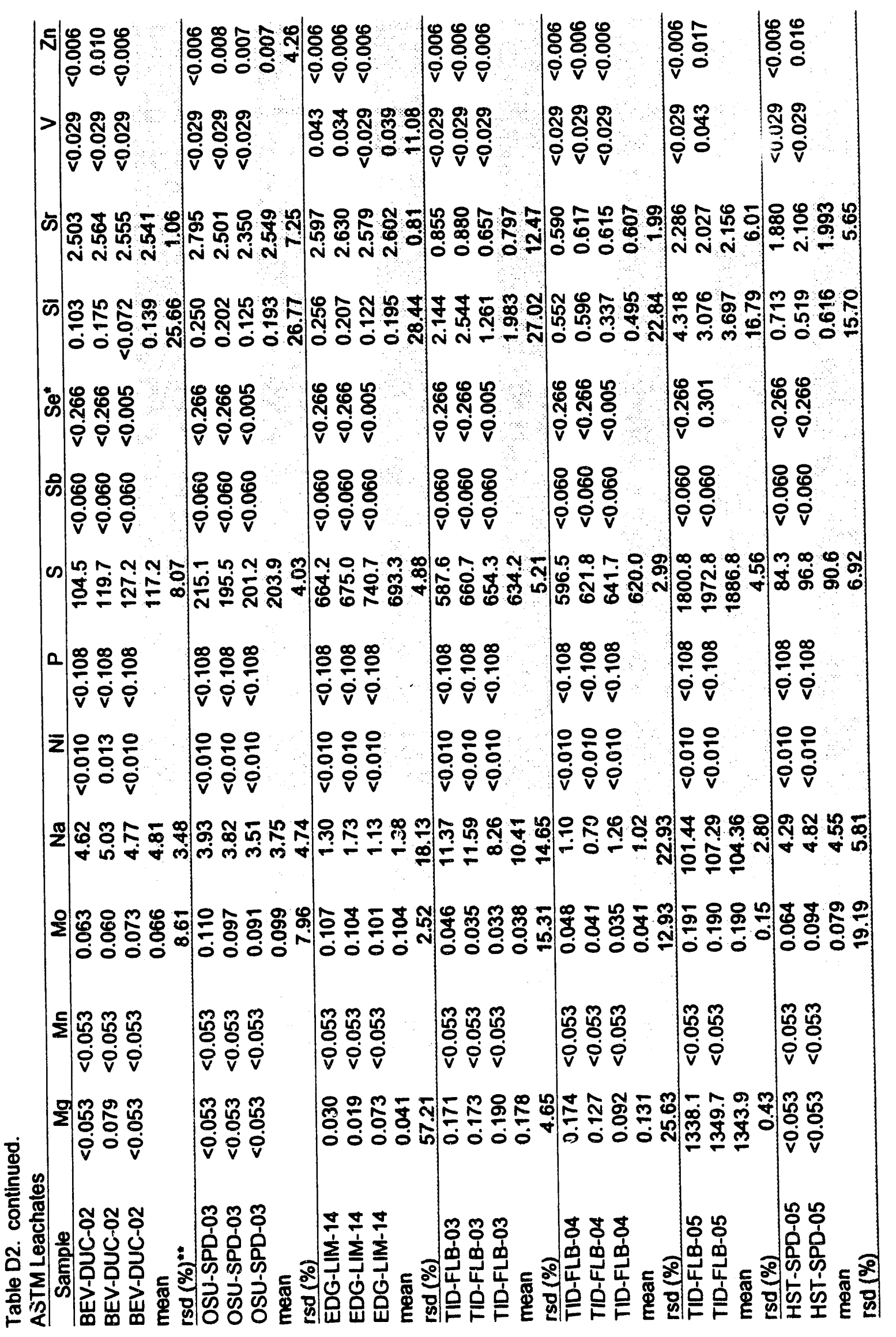



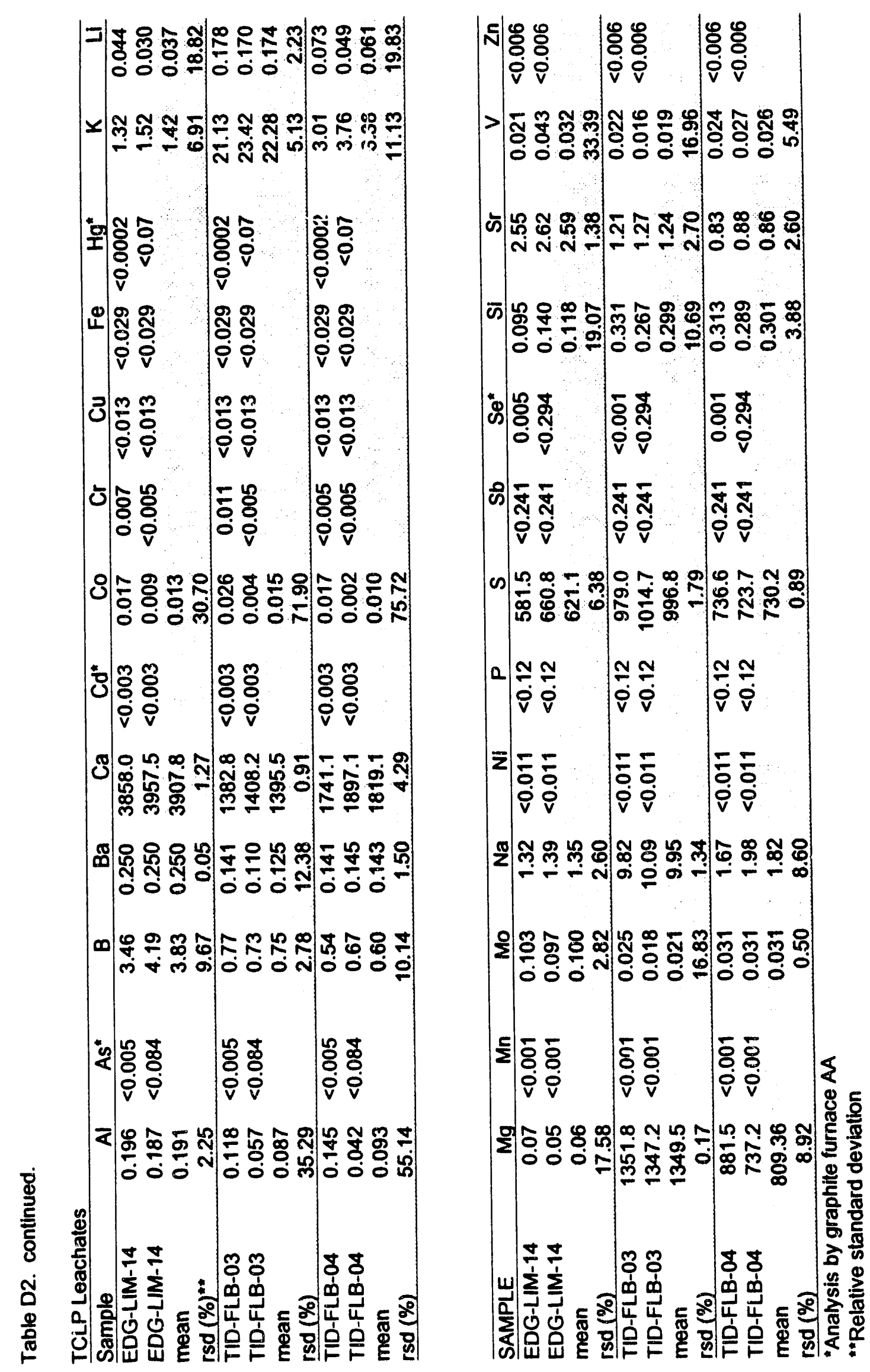


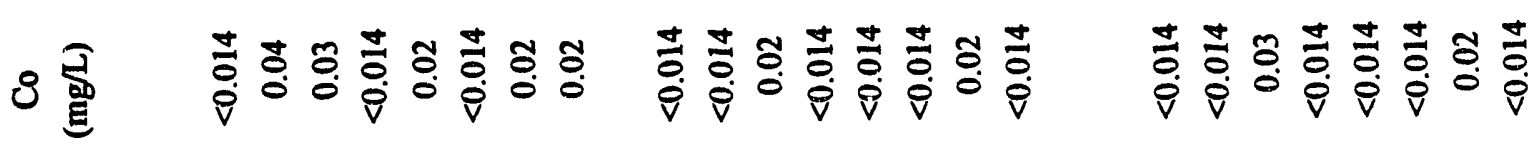

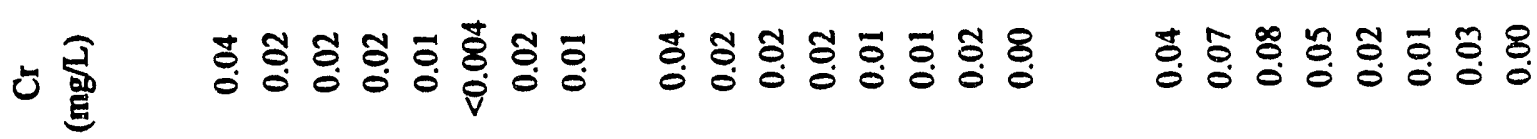

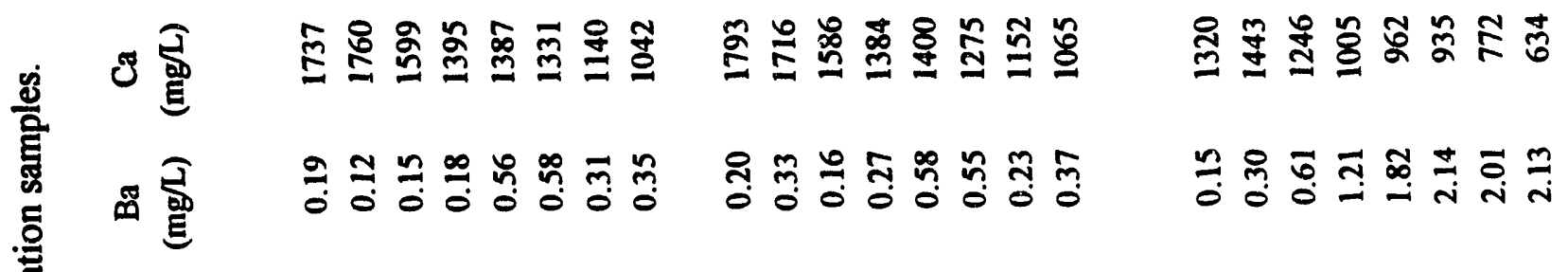

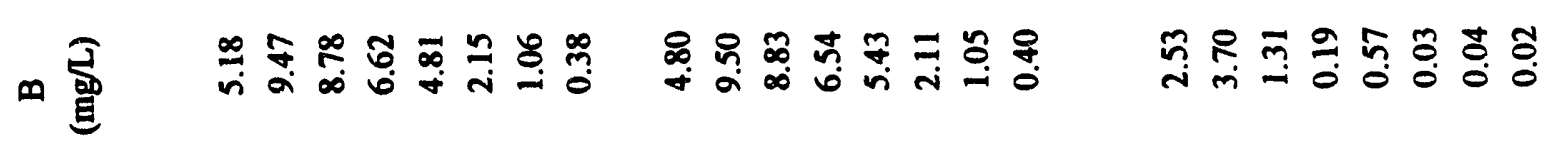

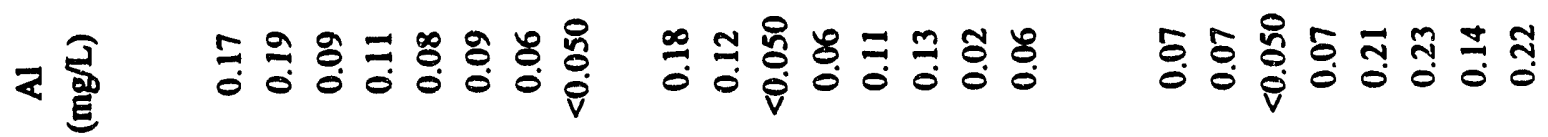

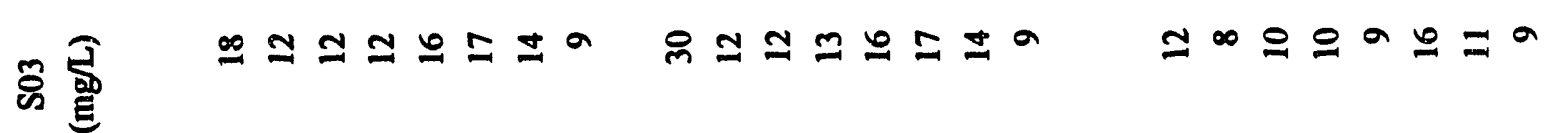

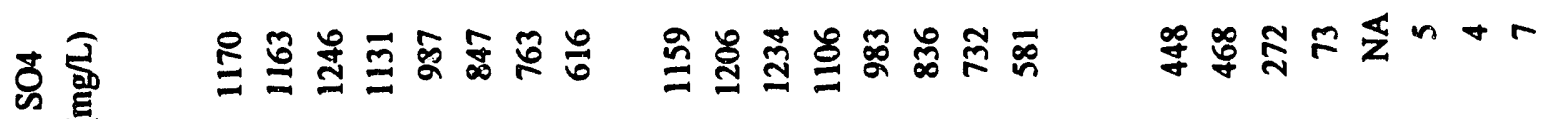
ร

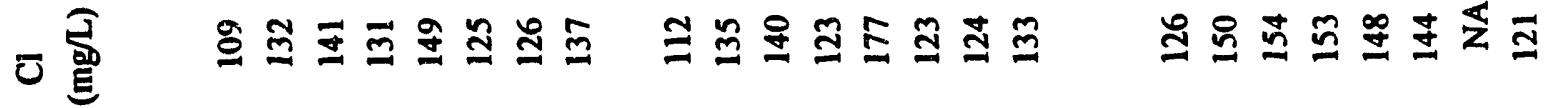
ธิ

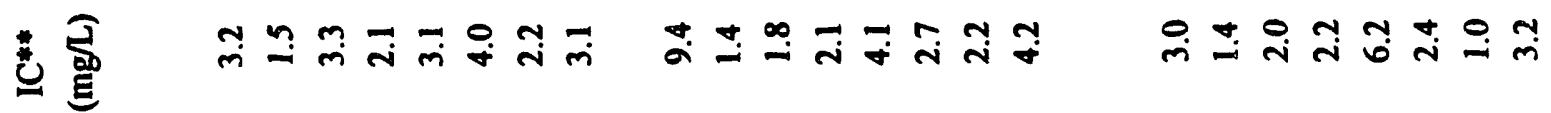

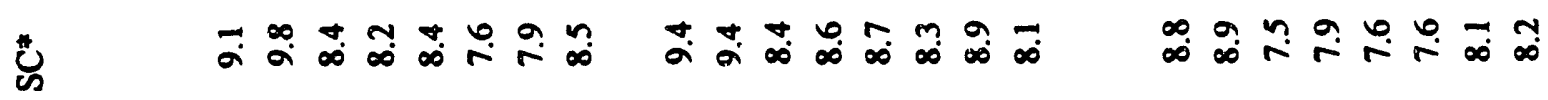

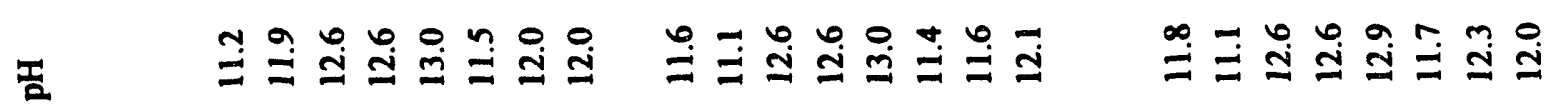

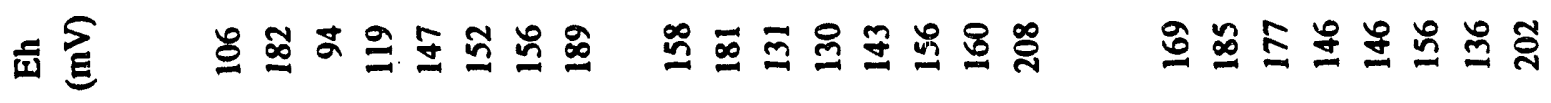

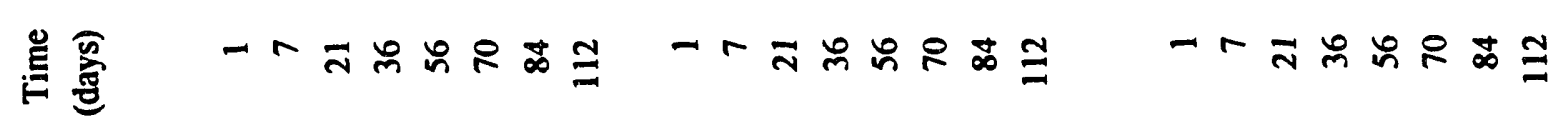

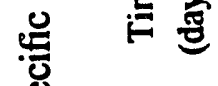

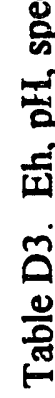




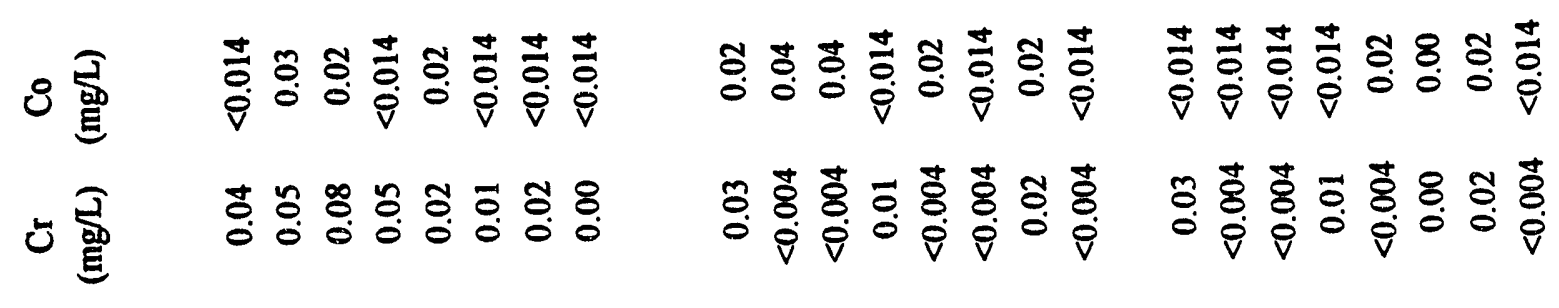

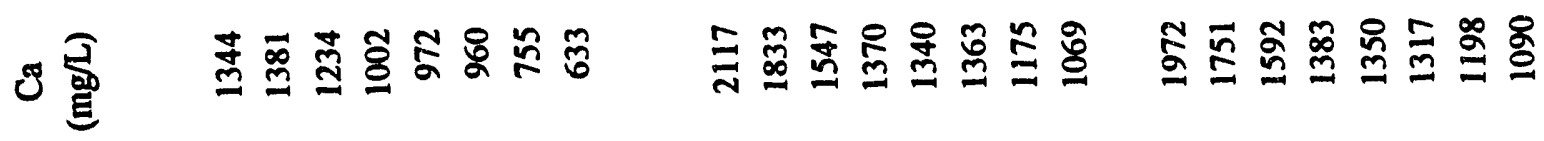

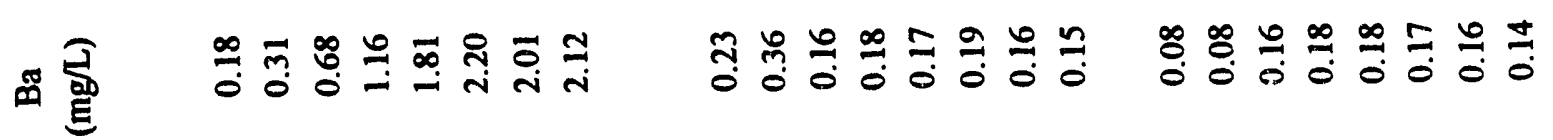

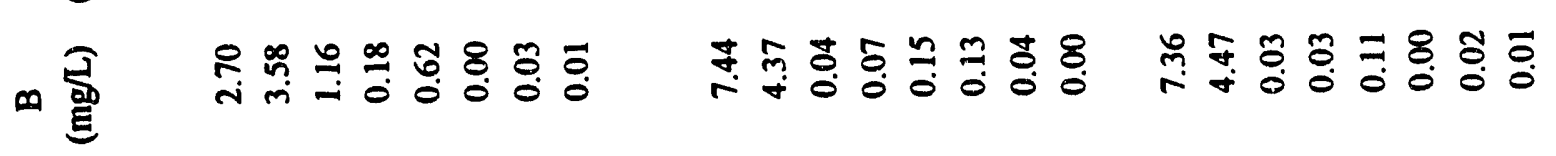

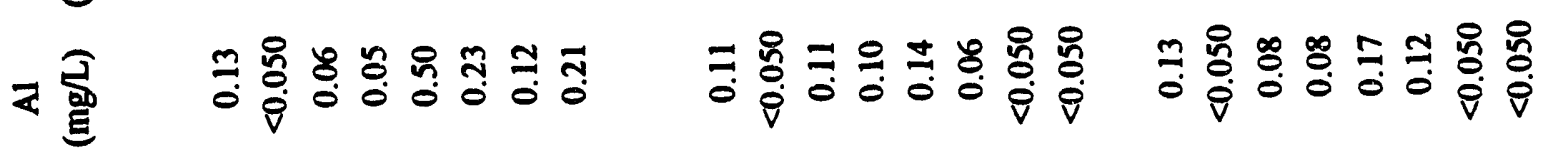

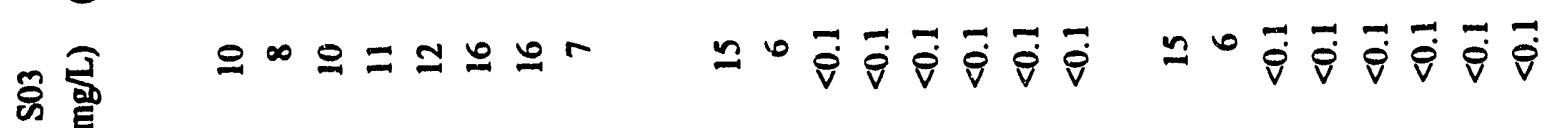

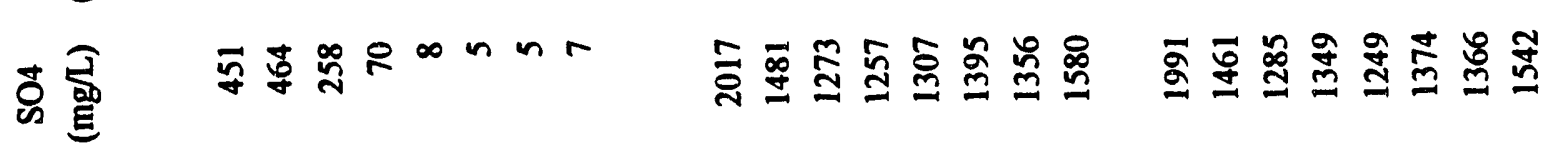

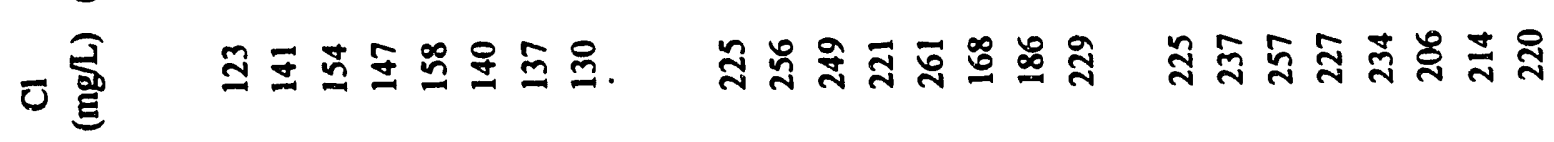
$\stackrel{\alpha}{a}$

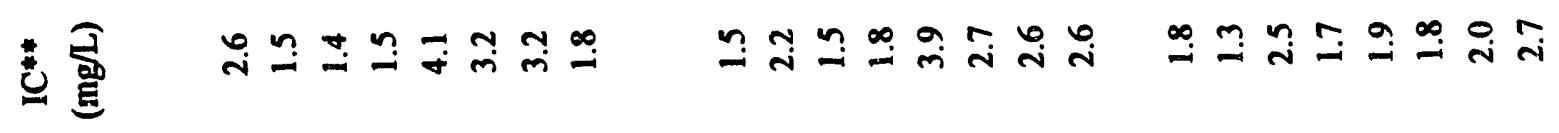
¿

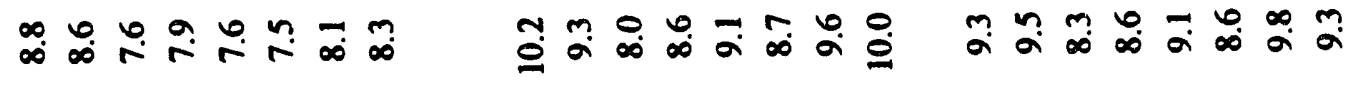

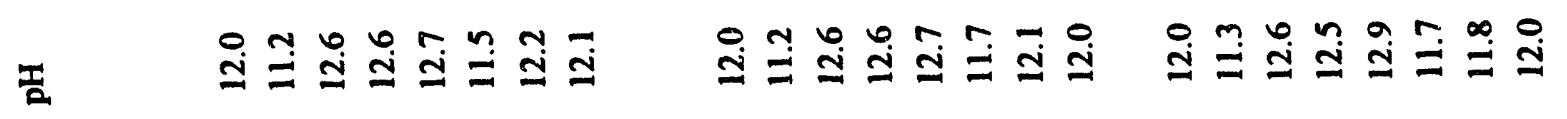

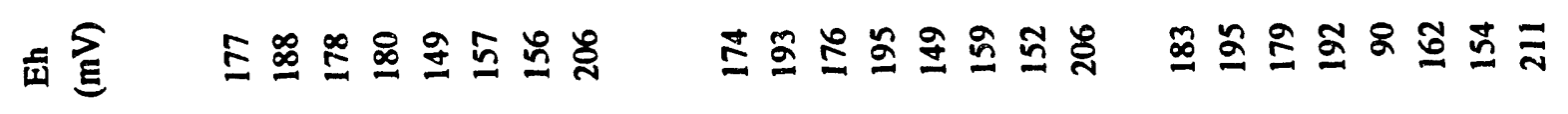

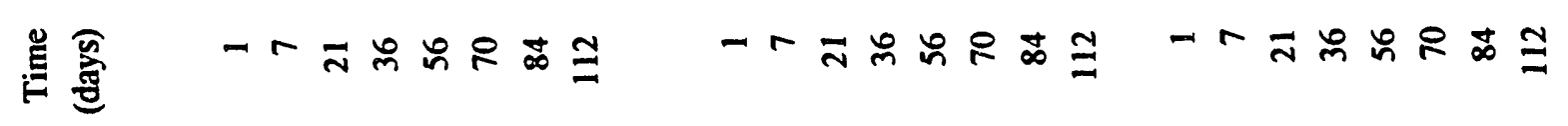




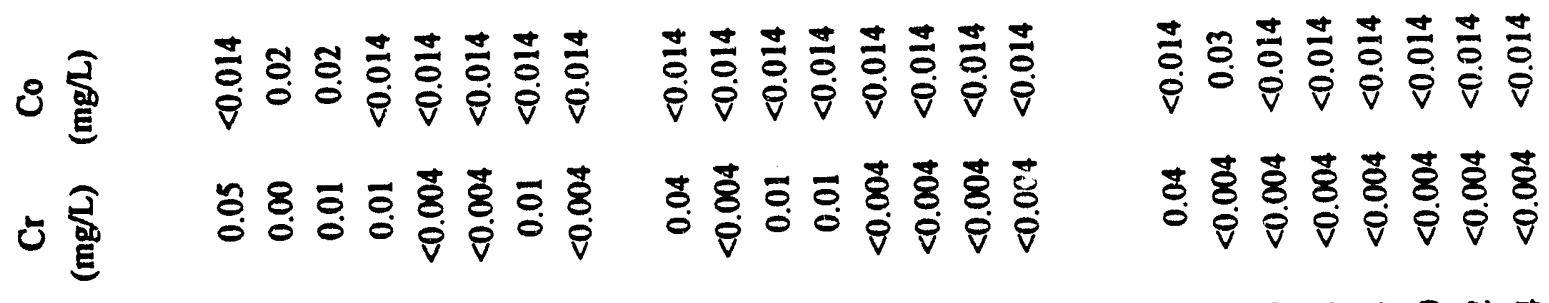

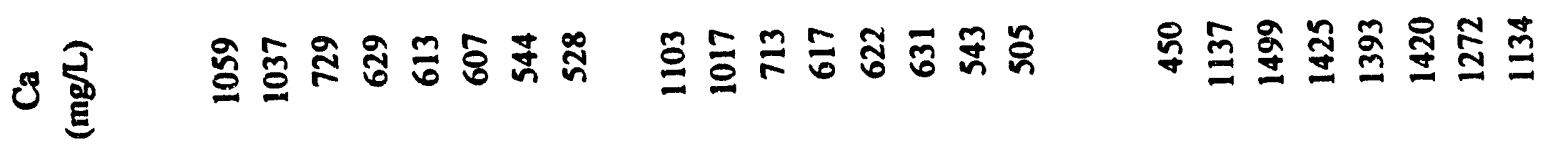

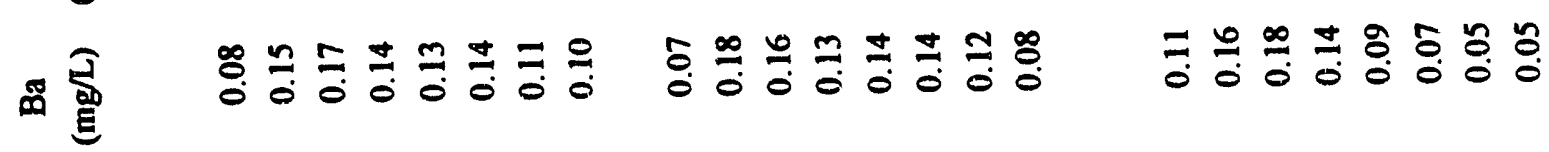

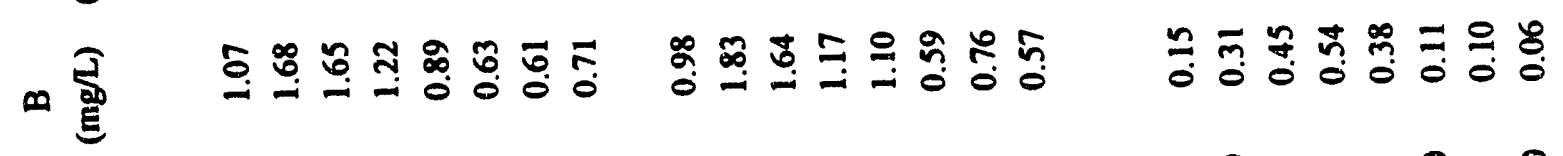

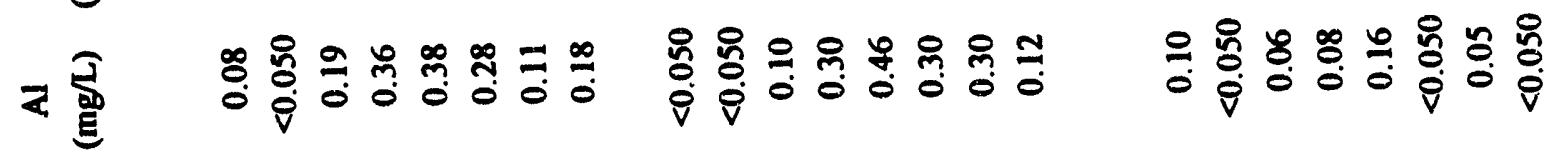

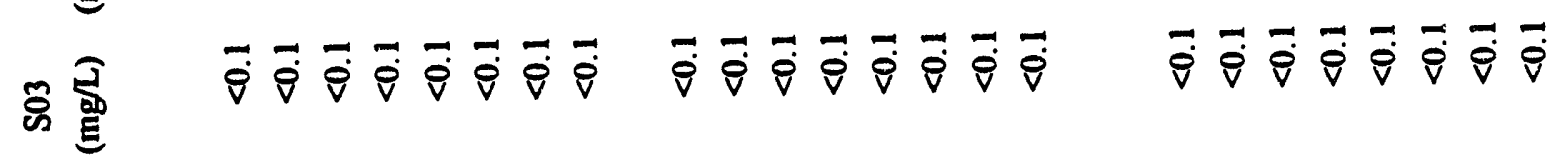

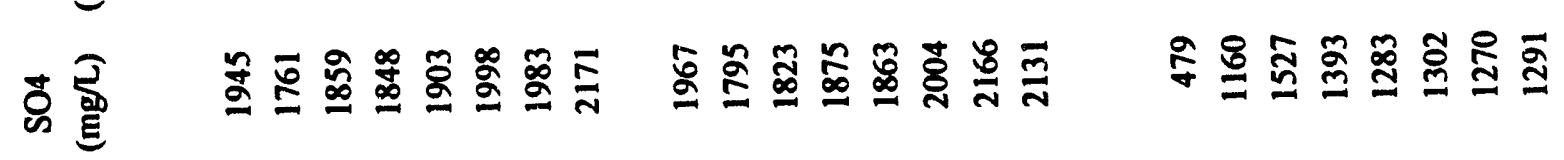

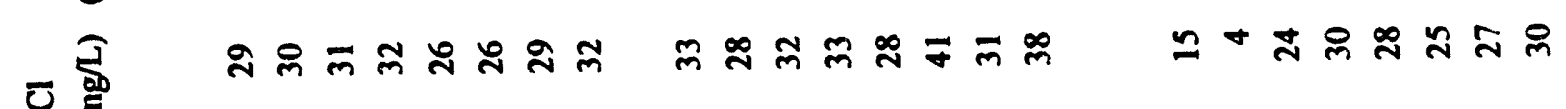

\begin{tabular}{|c|c|c|c|}
\hline 总 & 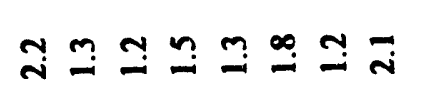 & 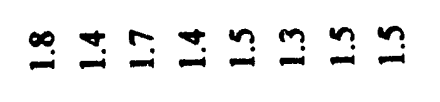 & 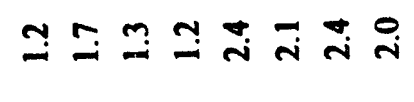 \\
\hline ¿ & 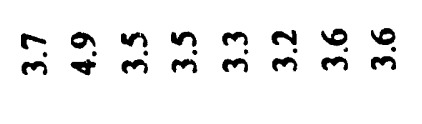 & 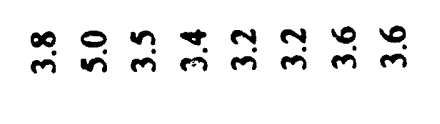 & 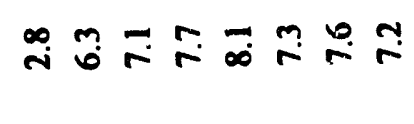 \\
\hline & 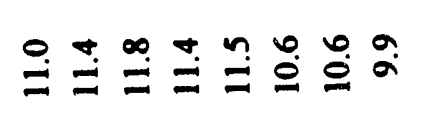 & 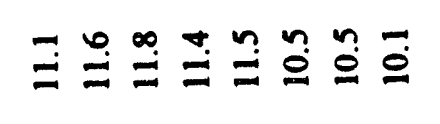 & 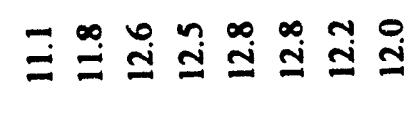 \\
\hline
\end{tabular}

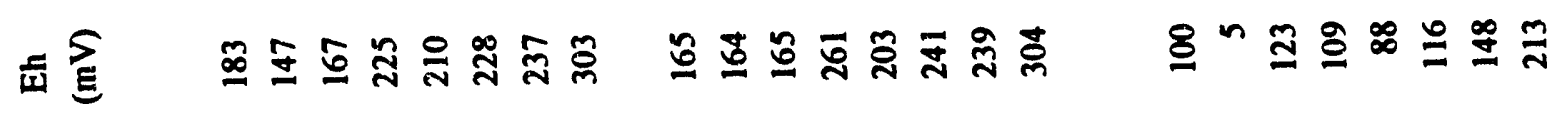

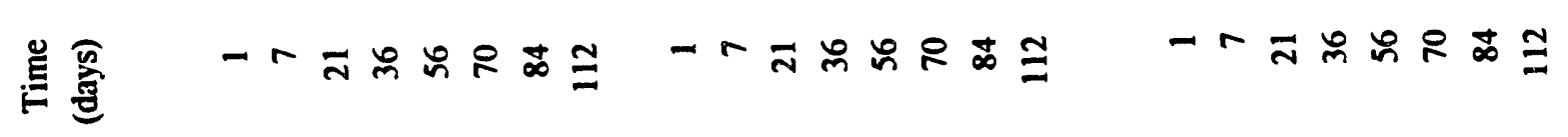




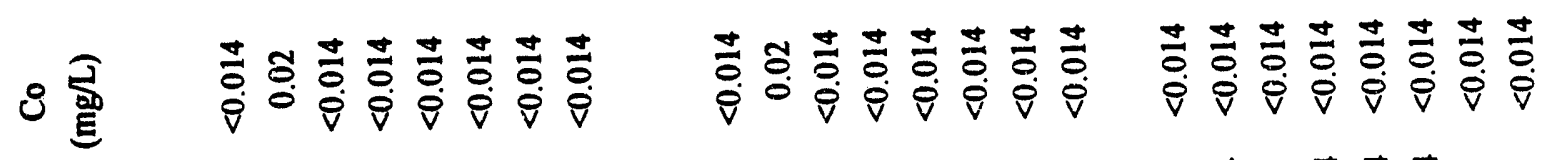

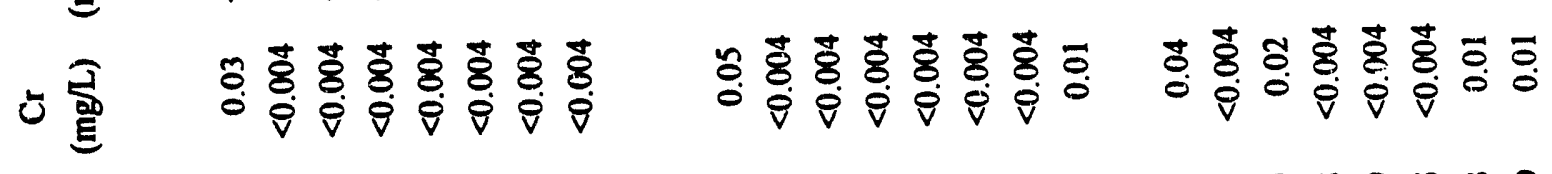

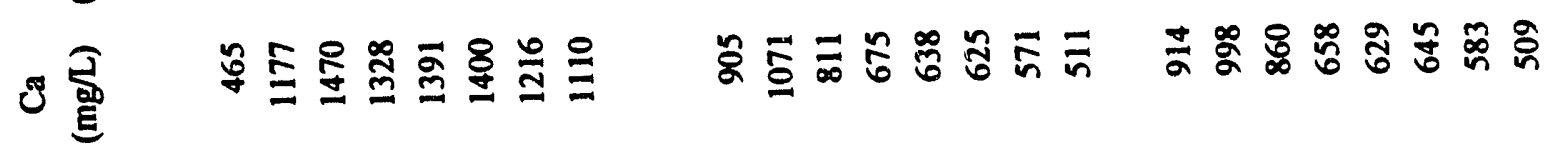
要需

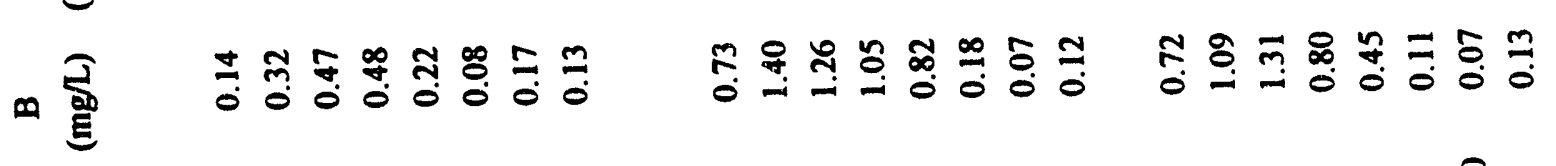

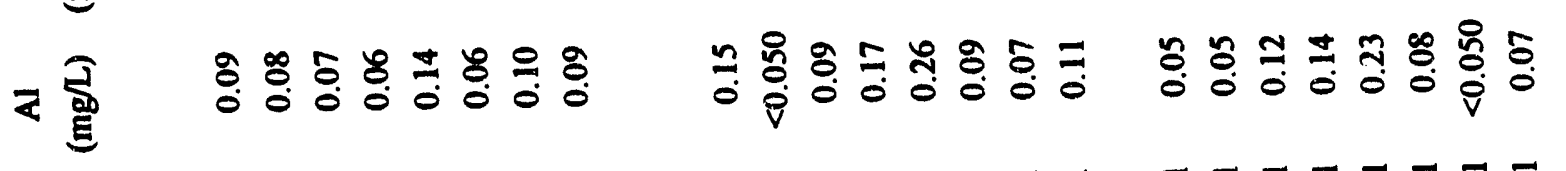

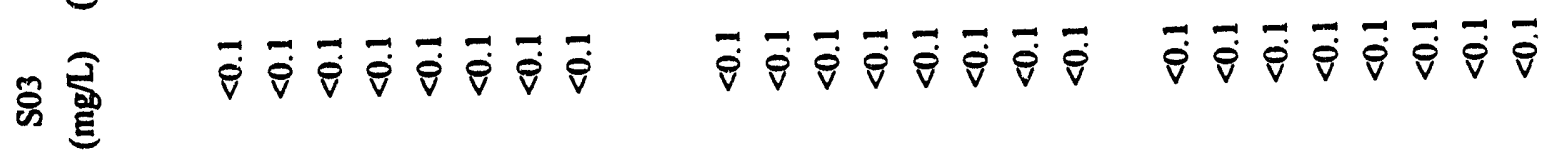

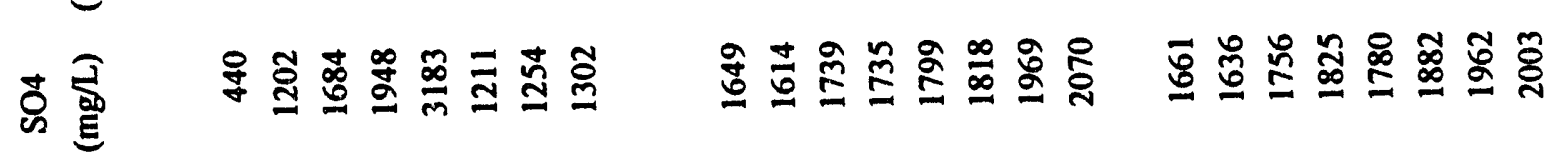

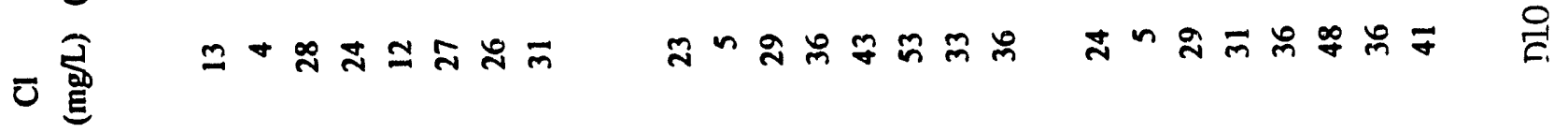

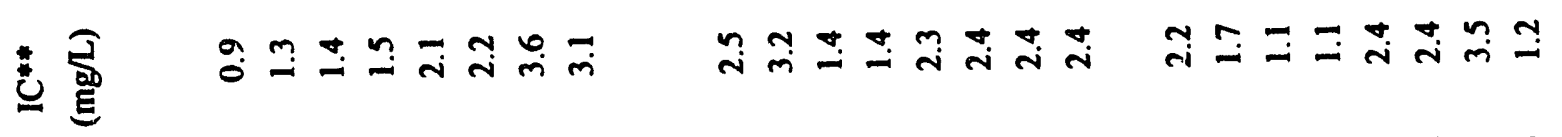

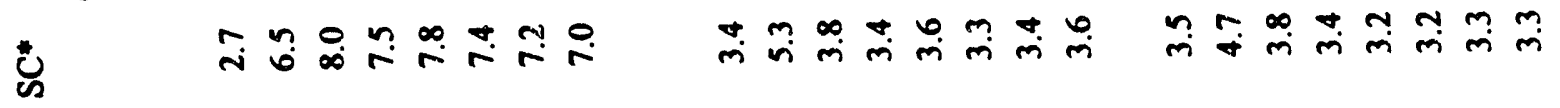

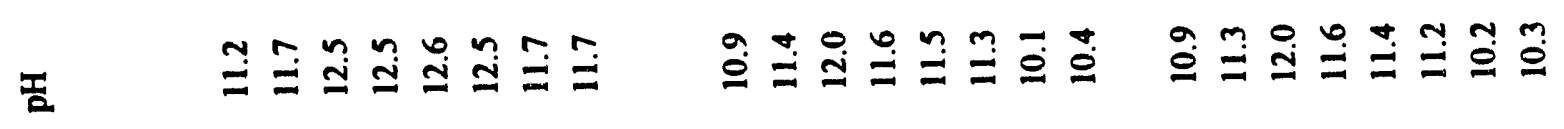
两目

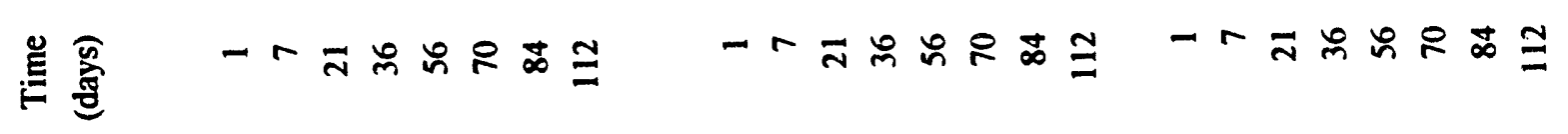




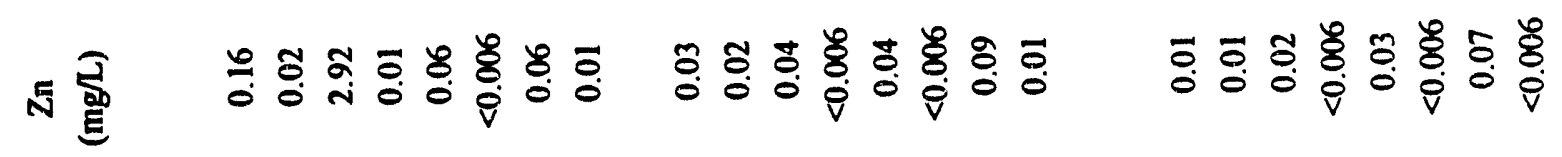

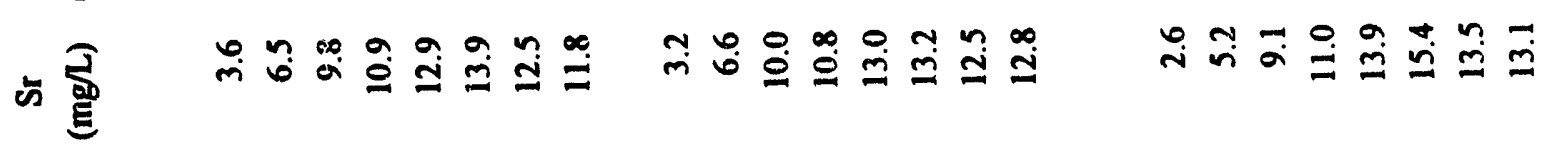

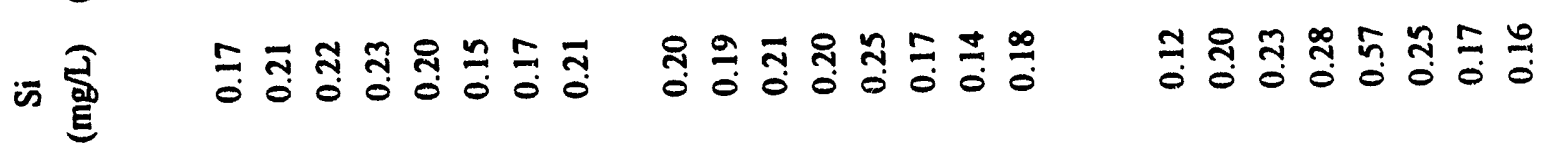

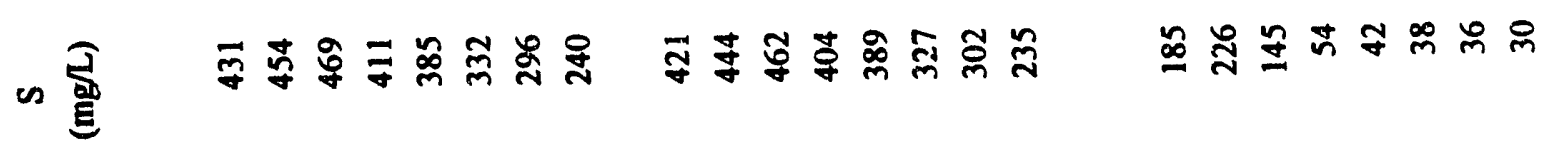

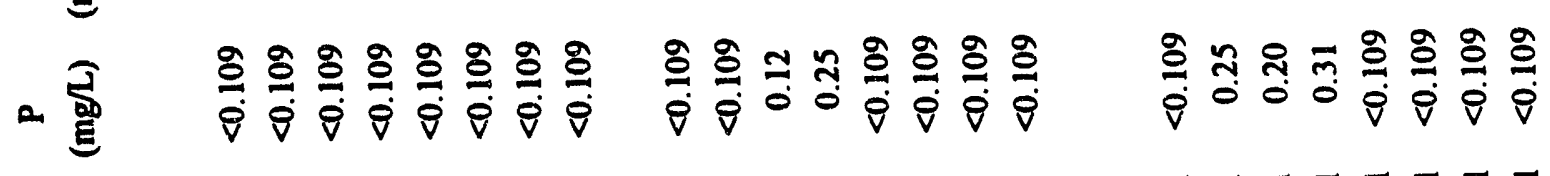

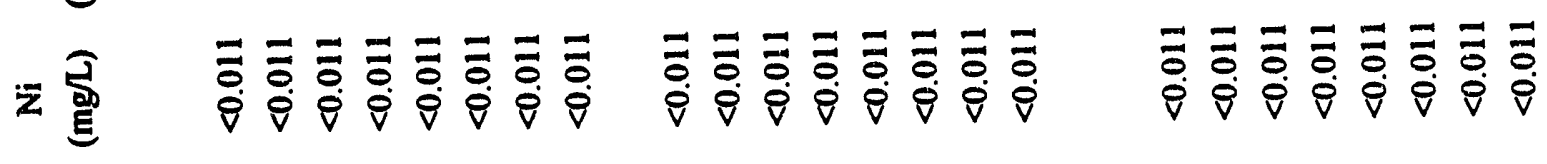

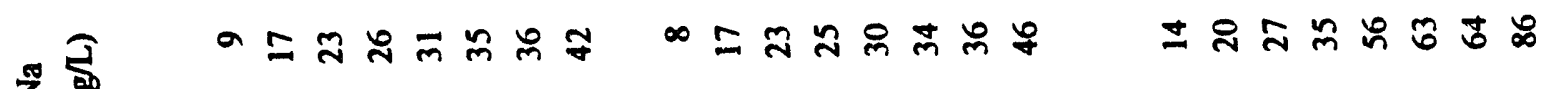
粃

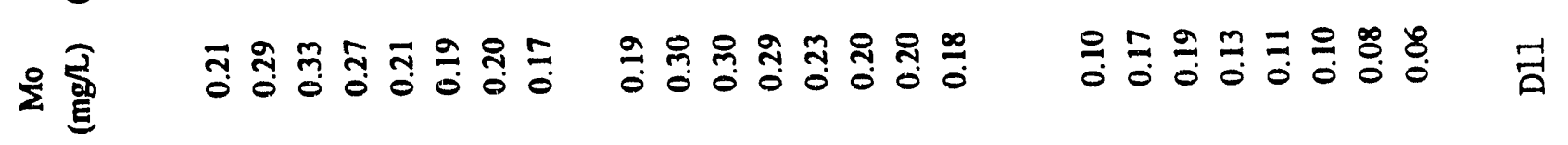

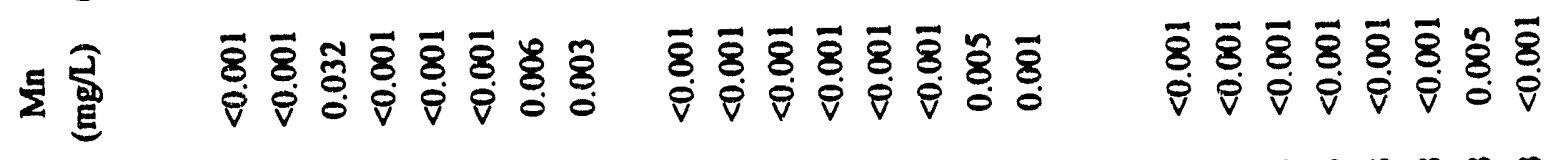

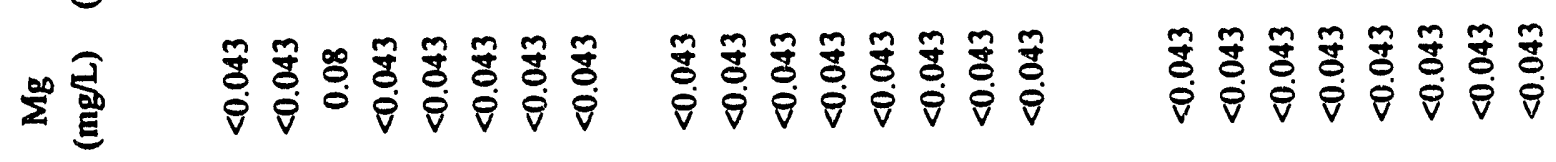

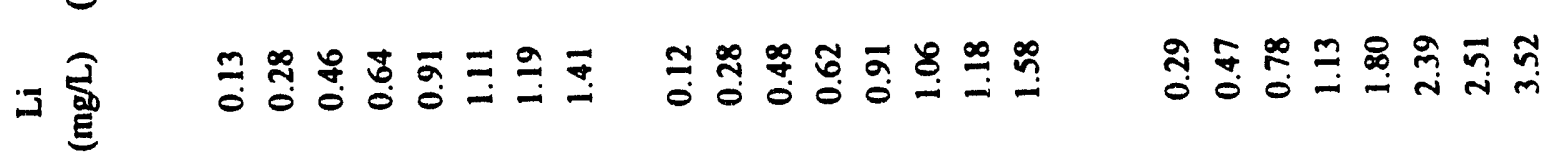

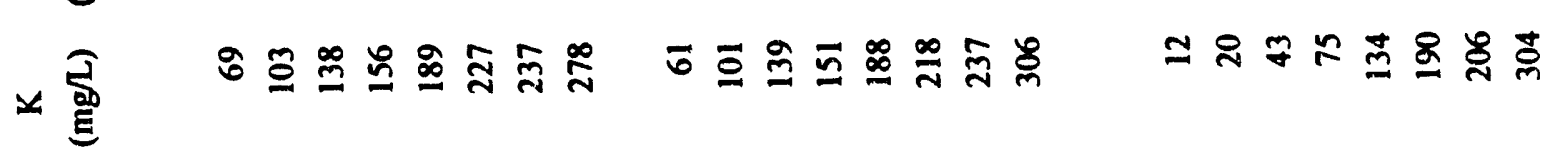

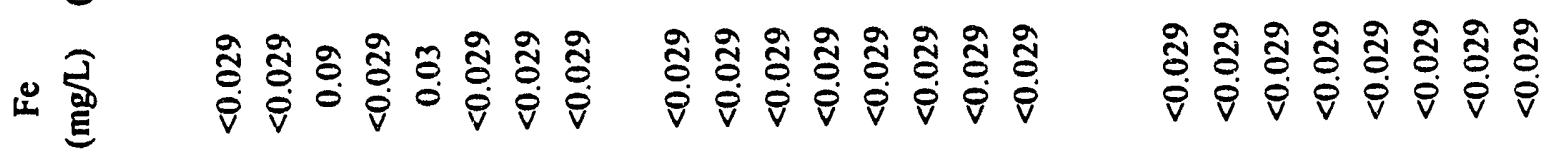

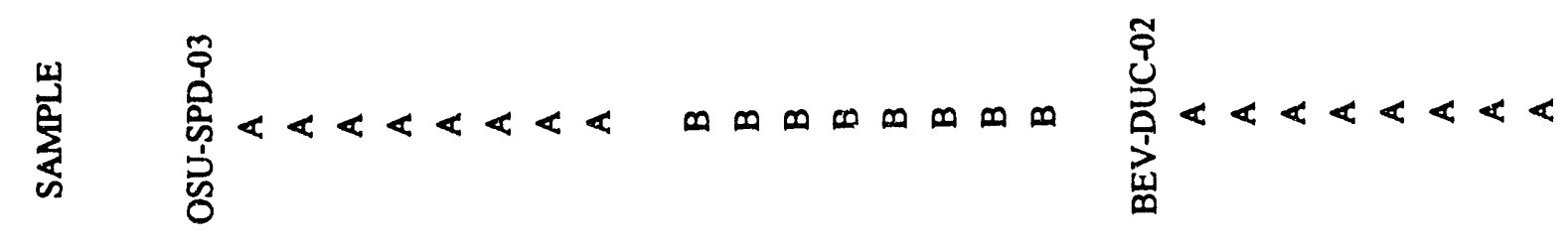




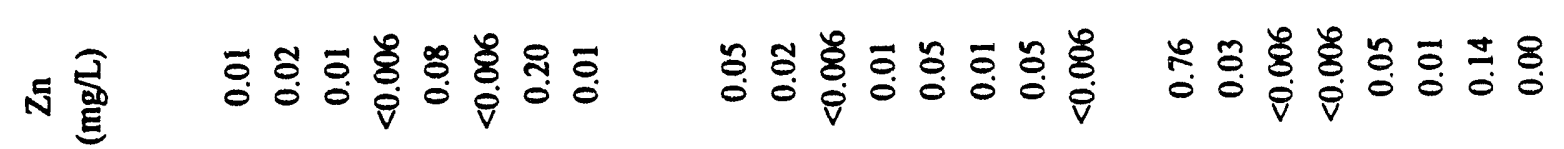

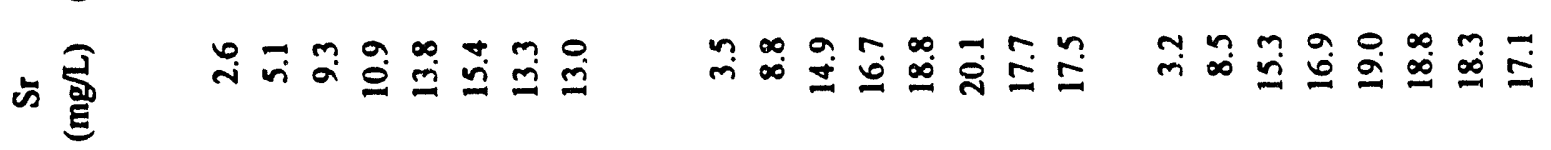

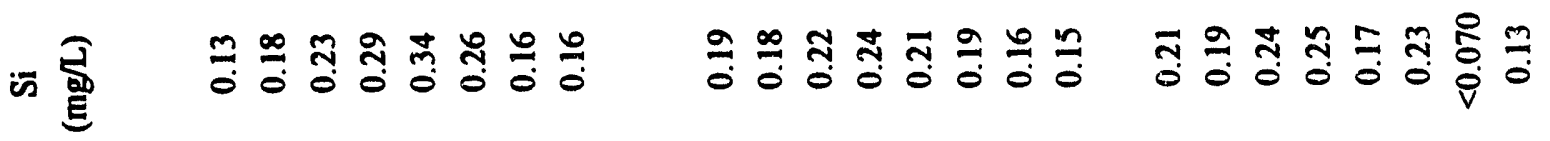

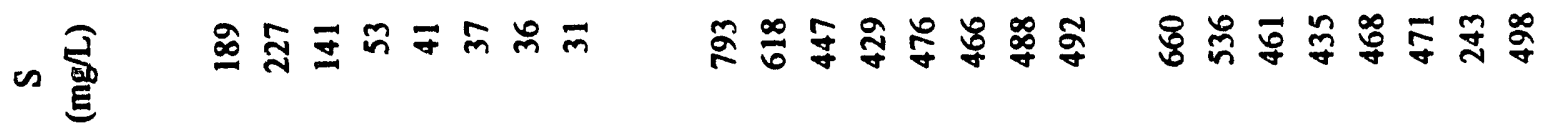

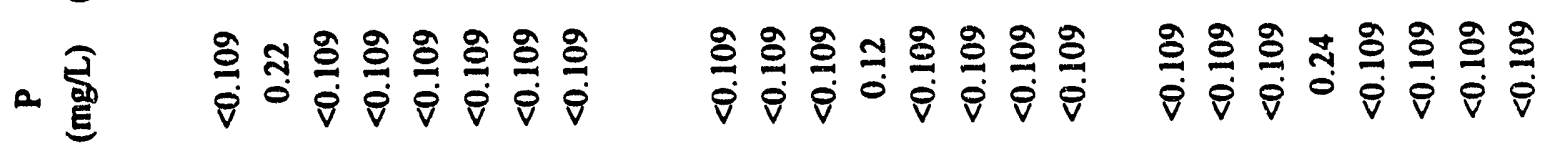

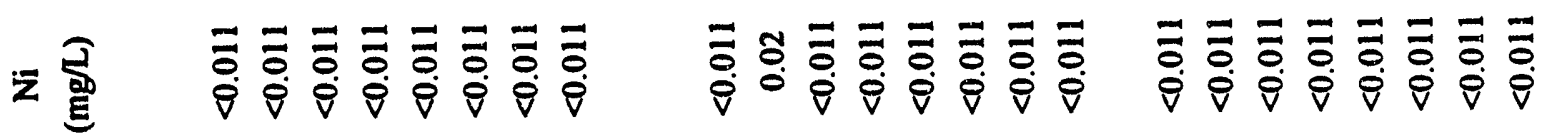

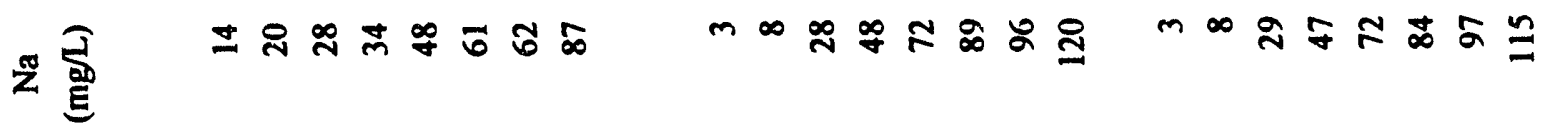

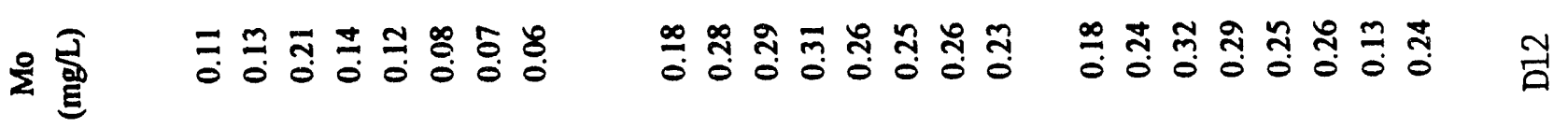

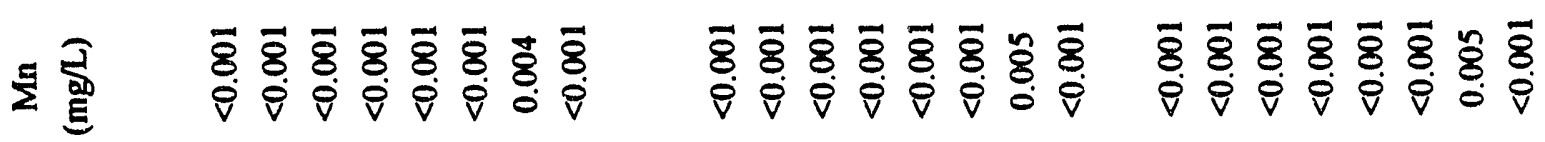

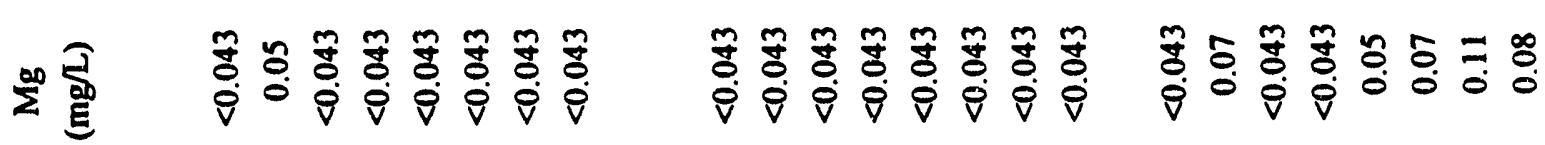

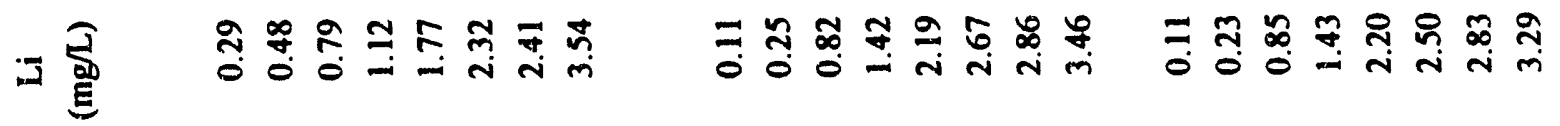
メ离

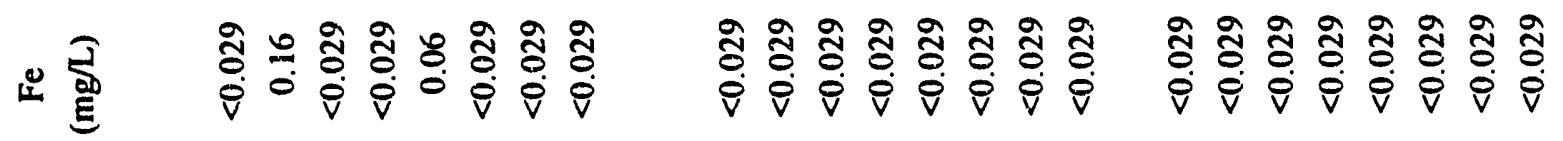




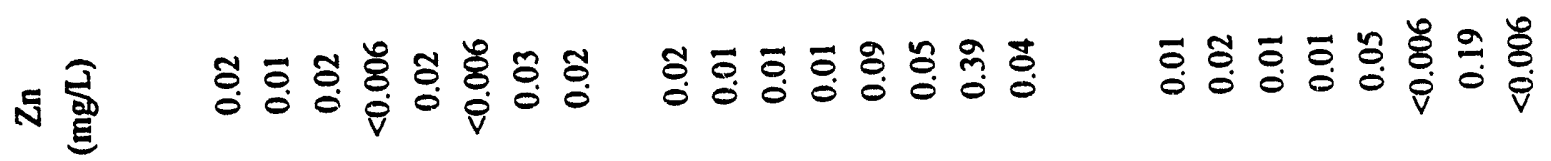

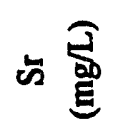

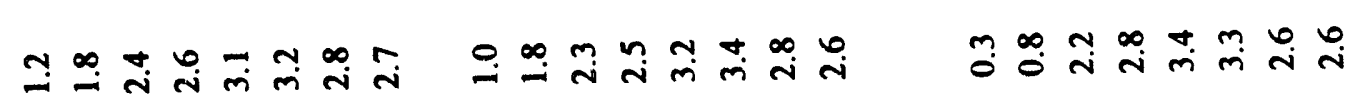

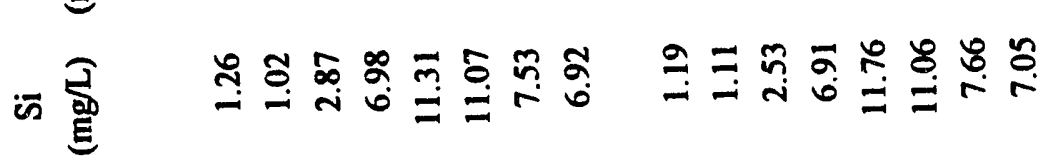

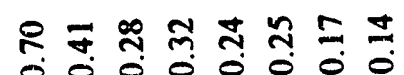
is $\stackrel{\widehat{D}}{\mathrm{E}}$

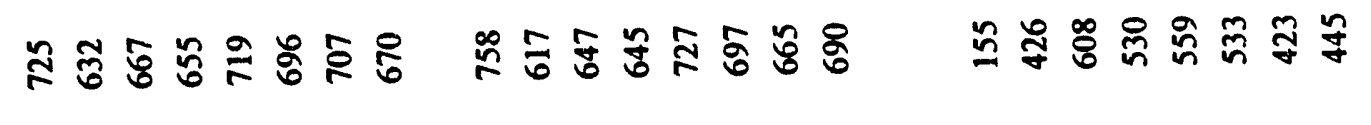

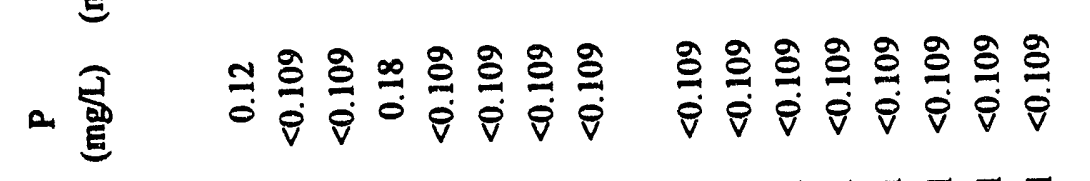

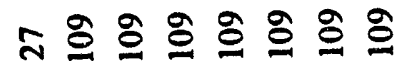

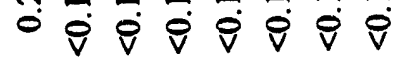

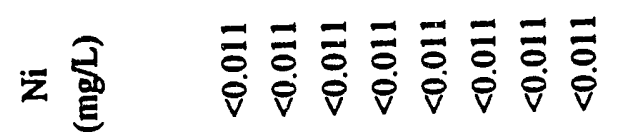

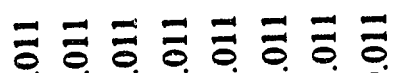

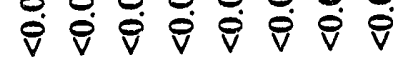
$\overline{\bar{\partial}} \overline{\bar{\partial}} \overline{\bar{\partial}} \overline{\overline{0}} \overline{\bar{\partial}} \bar{\partial}$

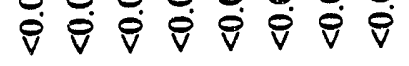
z窟

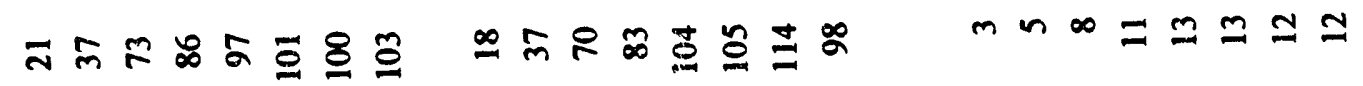

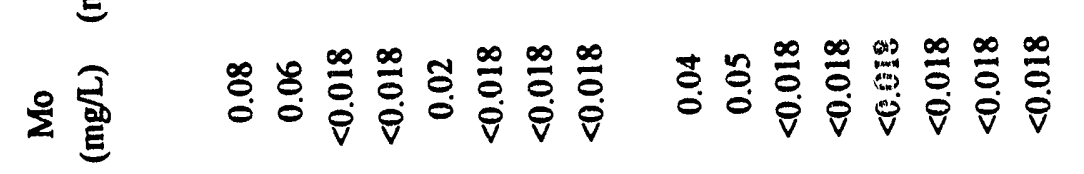

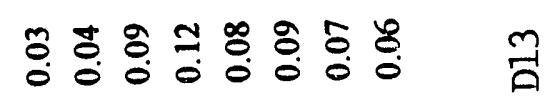
点量

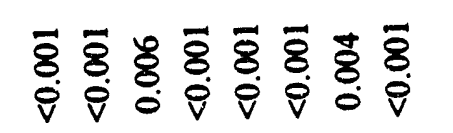

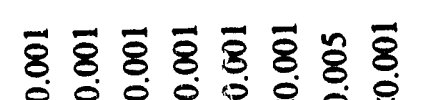
$\bar{\delta} \overline{8} \overline{8} \overline{8} \overline{8} \overline{8} \overline{8}$

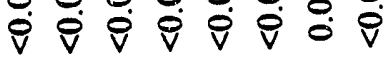
$\sum^{\infty} \stackrel{\text { 品 }}{\mathrm{E}}$

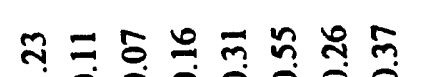

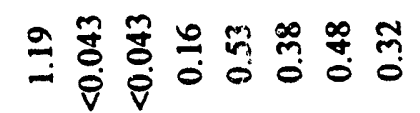
彳 $=\stackrel{?}{\stackrel{9}{\mathrm{~B}}}$

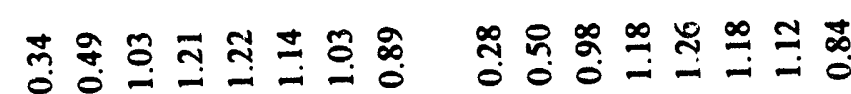

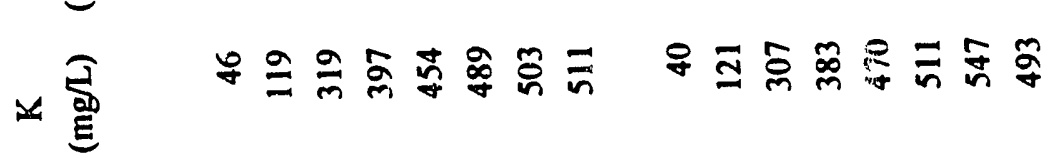

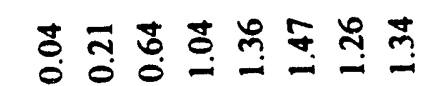

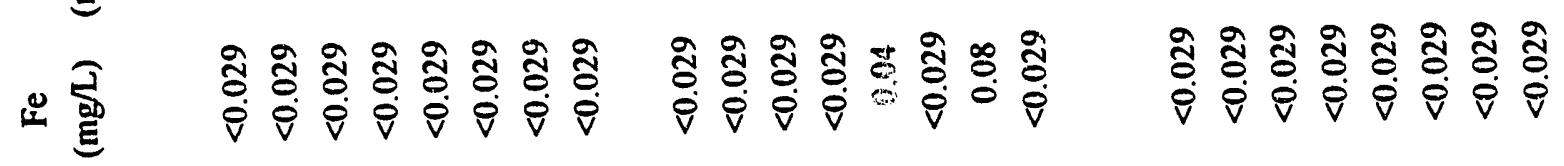




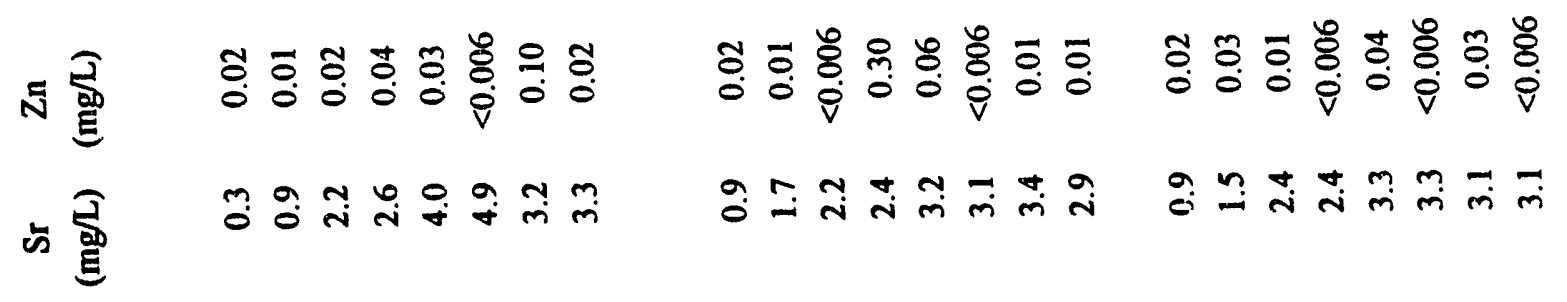

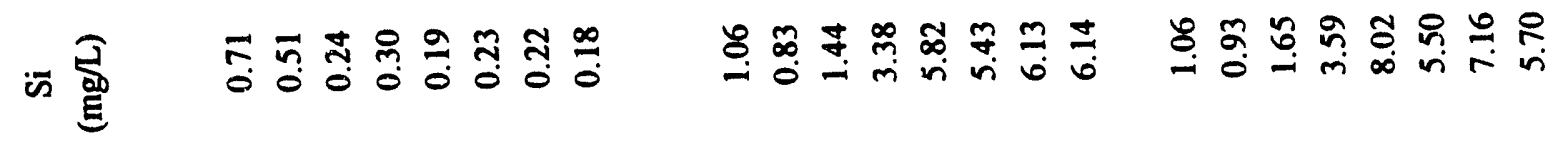

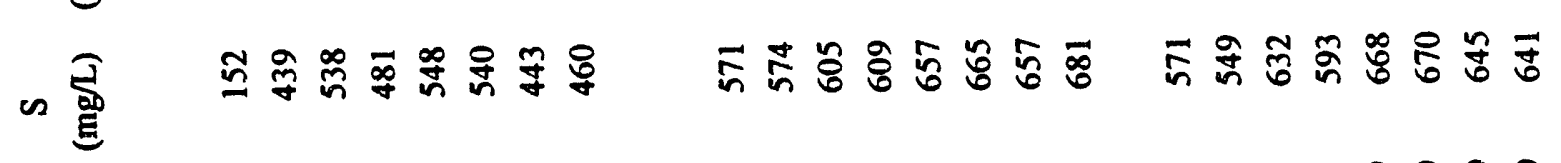

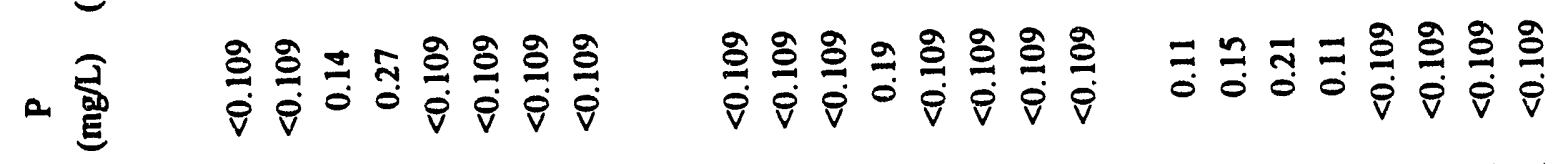

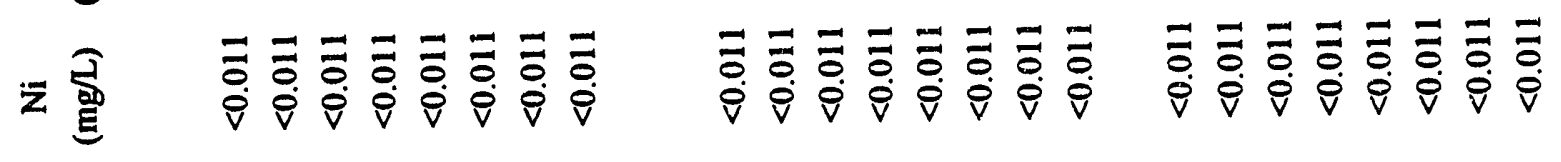

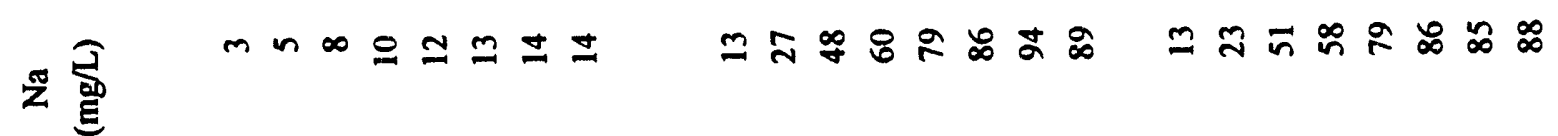

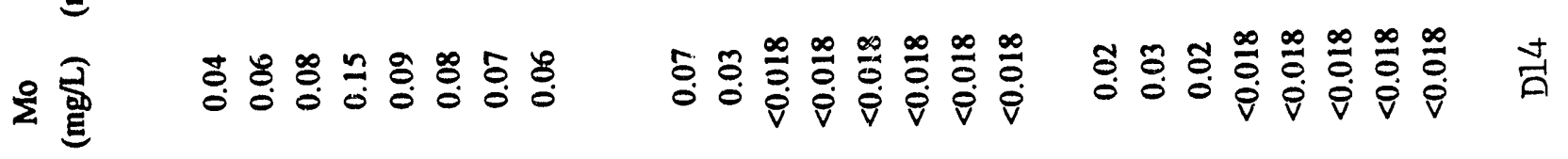

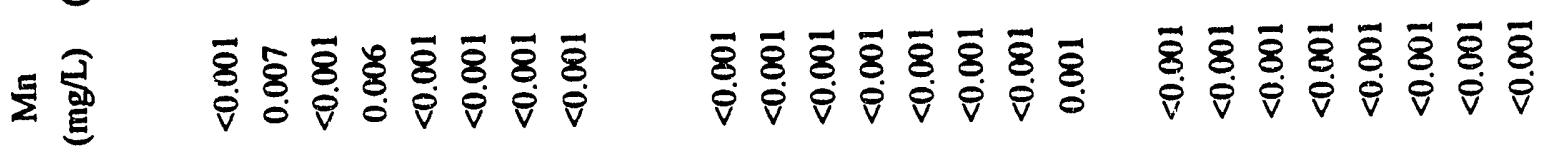

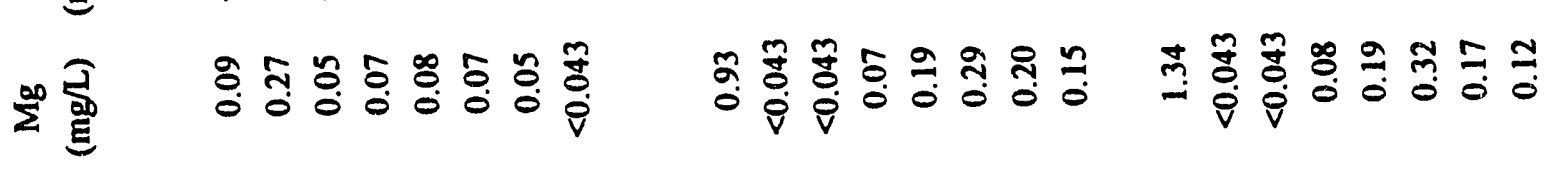

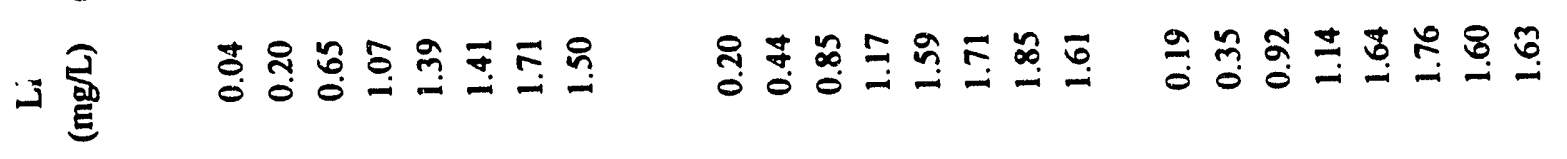

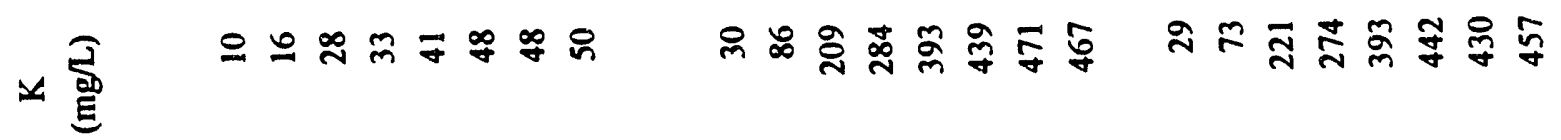

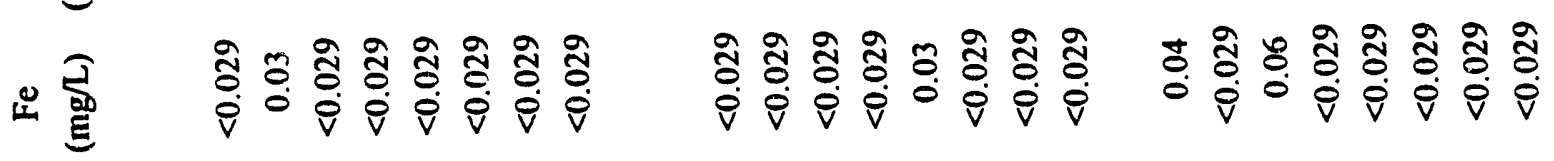


昌

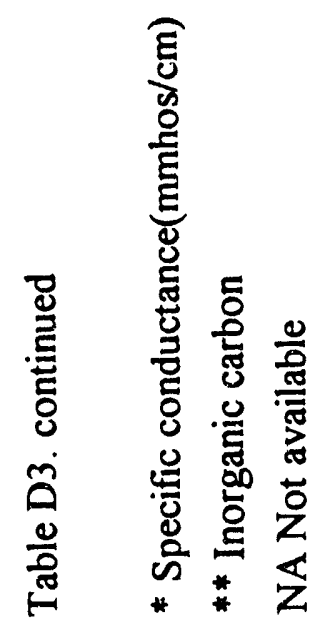


Phase 1 Report

Appendix D

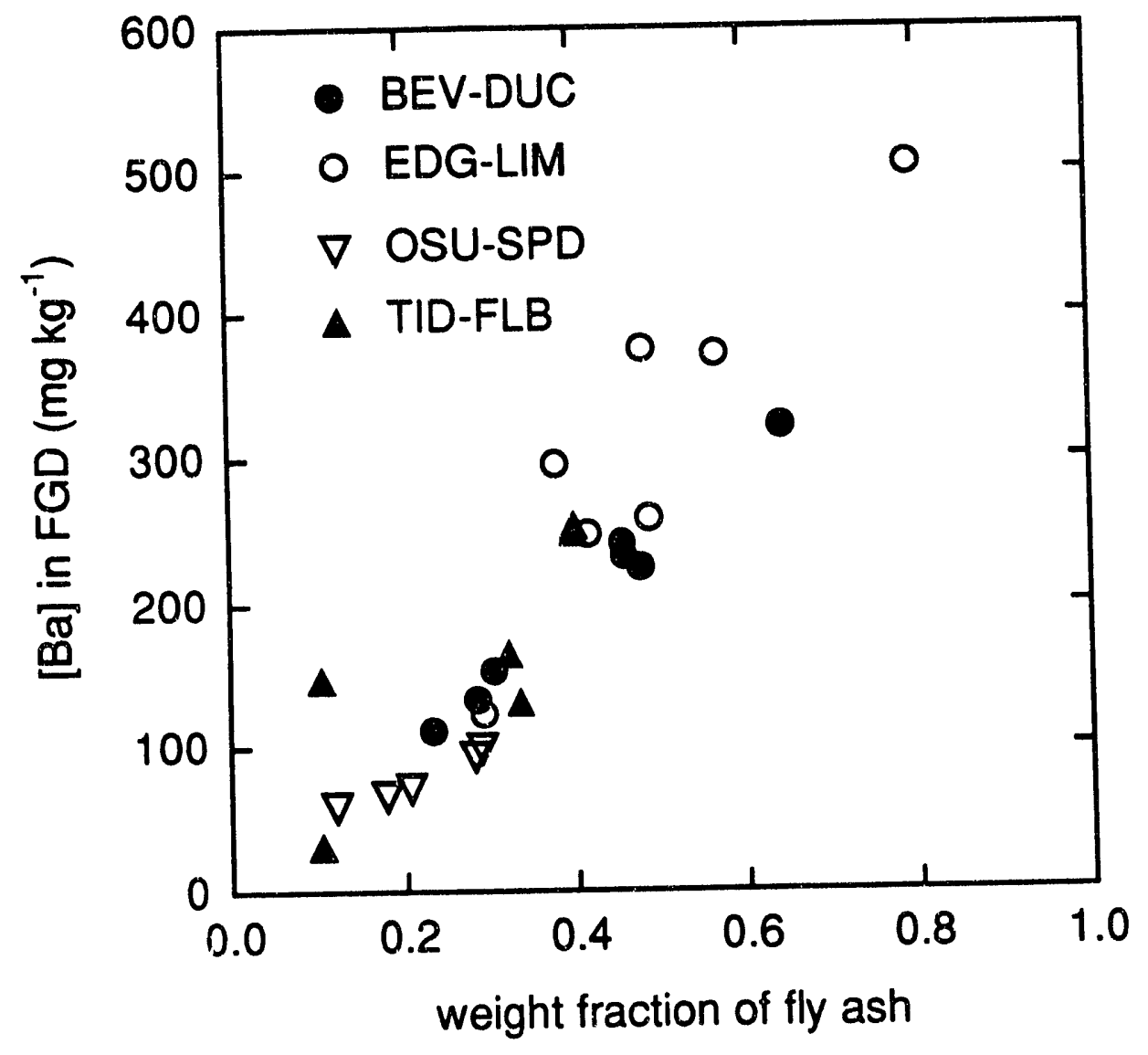

Fig. D1. Concentration of Ba versus the weight fraction of fly ash (acid insoluble residue) in FGD by-products. 


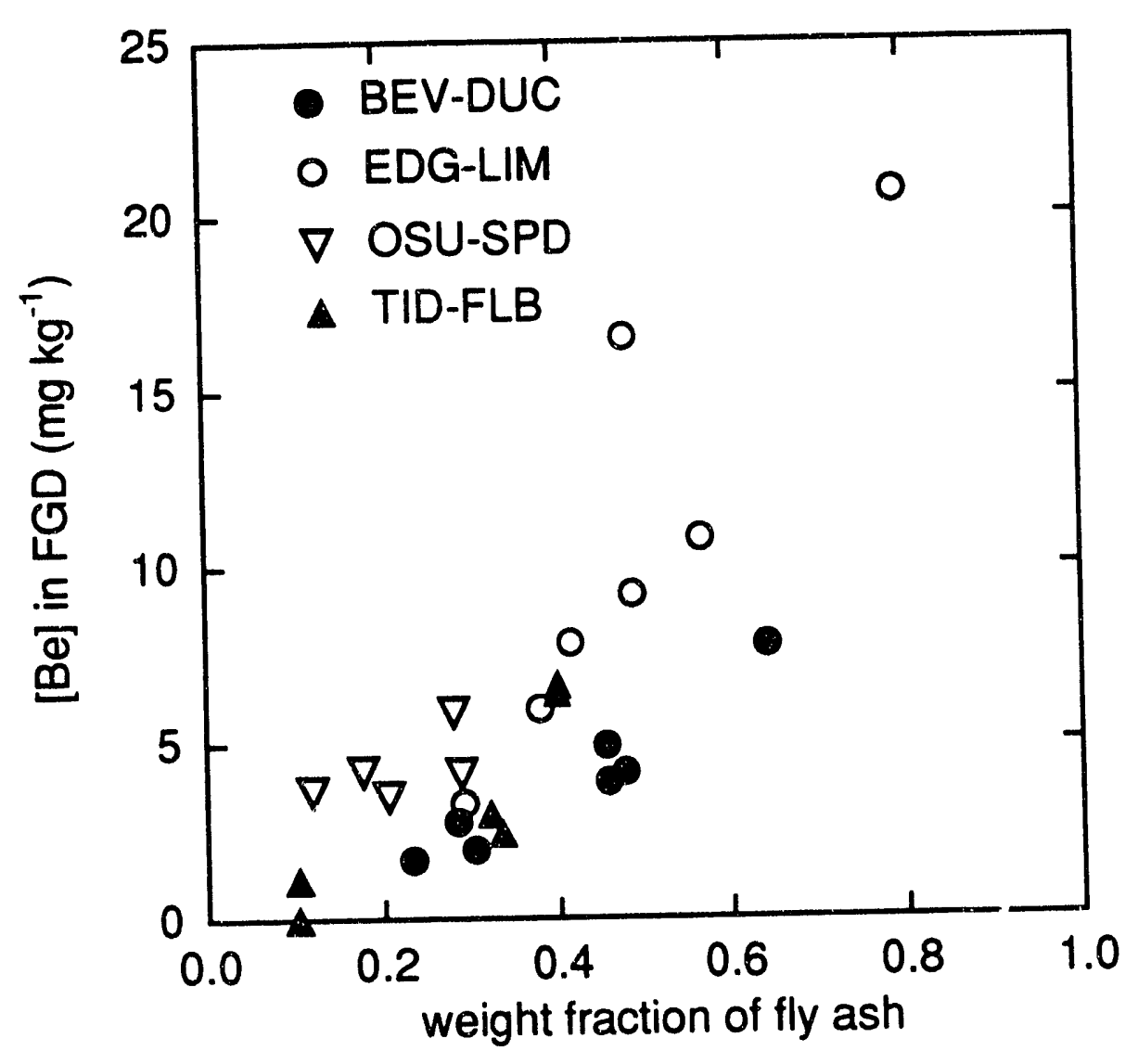

Fig. D2. Concentration of Be versus the weight fraction of fly ash (acid insoluble residue) in FGD by-products. 
Phase 1 Report

Appendix D

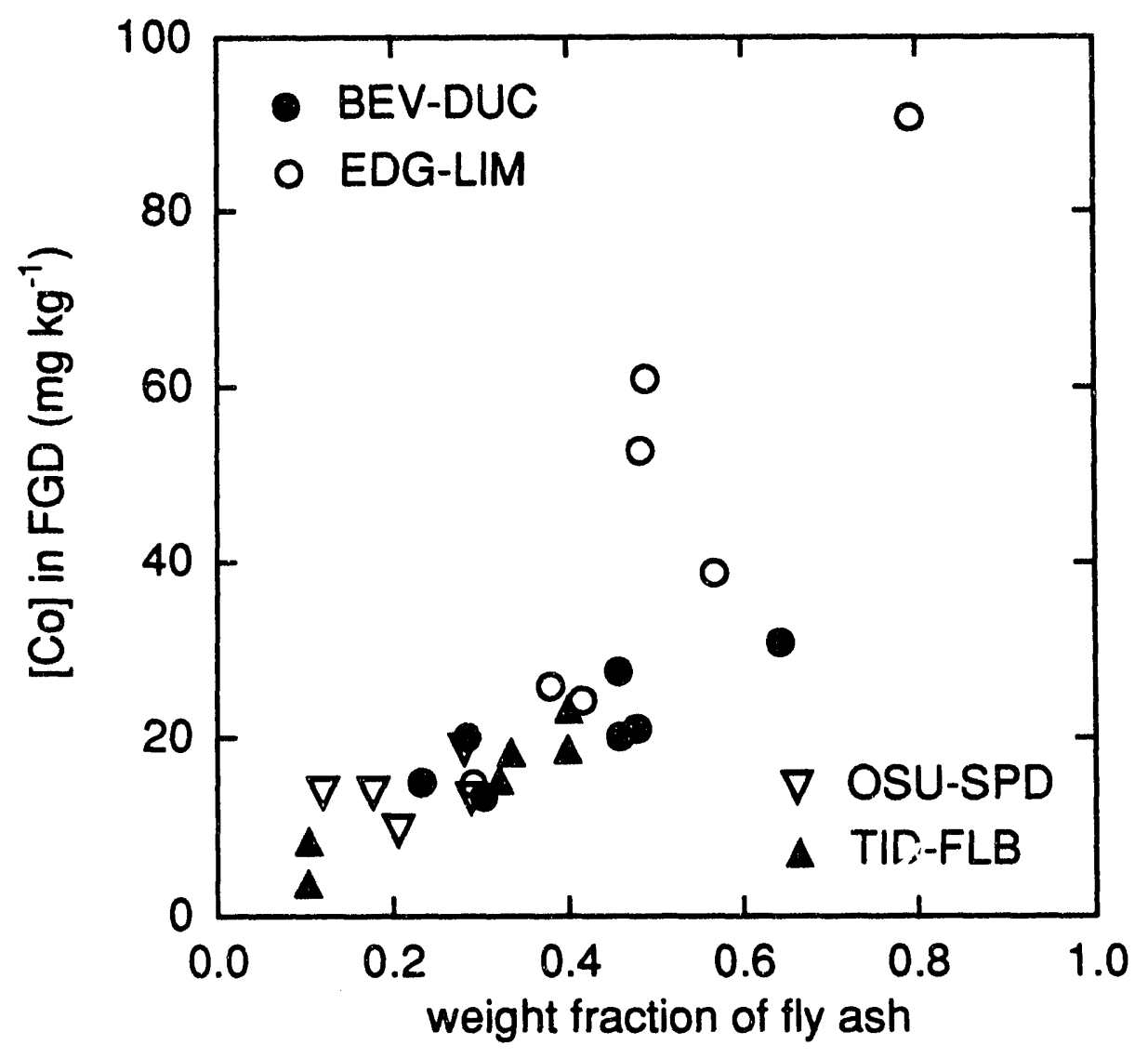

Fig. D3. Concentration of Co versus the weight fraction of fly ash (acid insoluble residue) in FGD by-products. 
Phase 1 Report

Appendix D

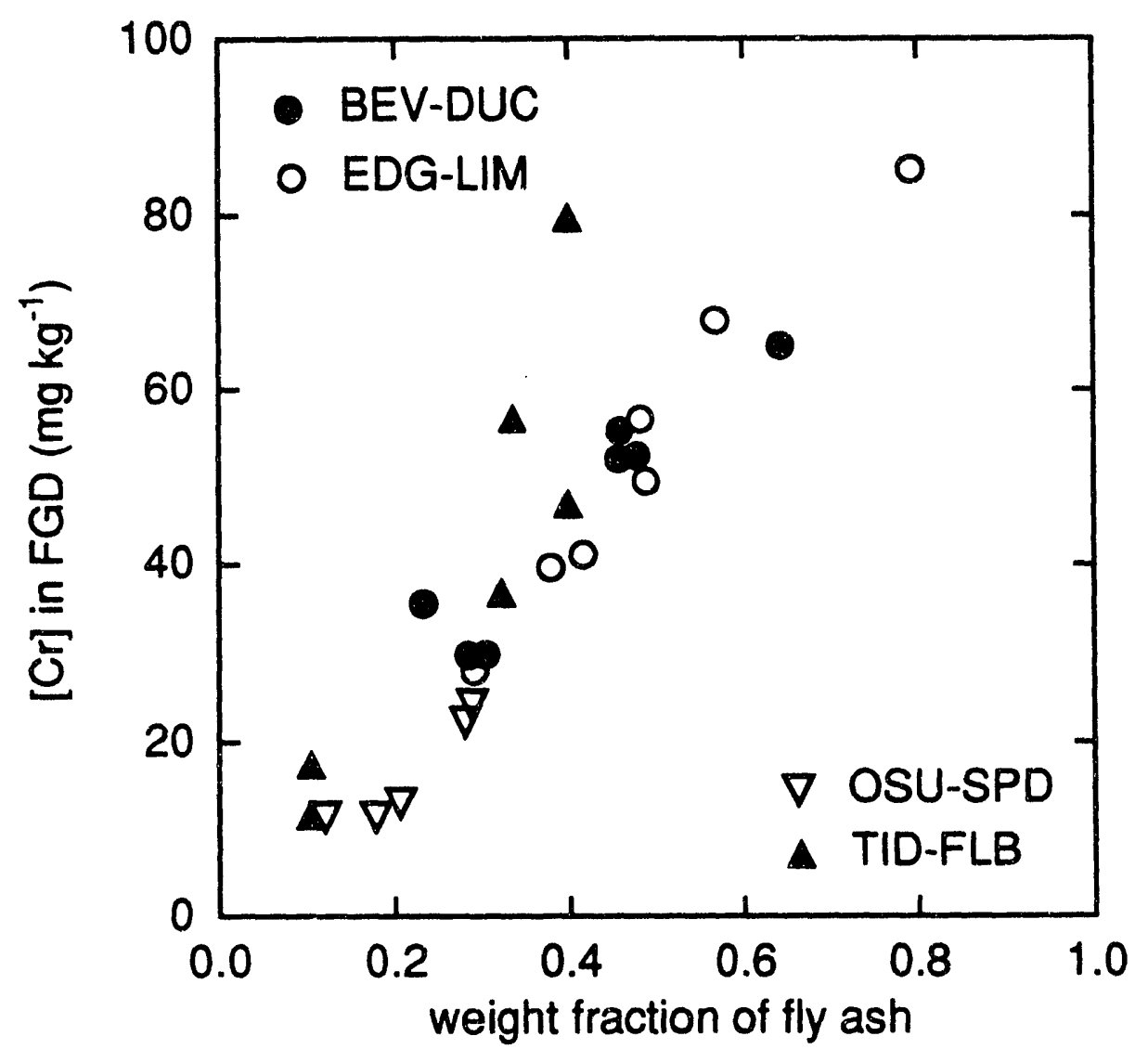

Fig. D4. Concentration of $\mathrm{Cr}$ versus the weight fraction of fly ash (acid insoluble residue) in FGD by-products. 
Phase 1 Report

Appendix D

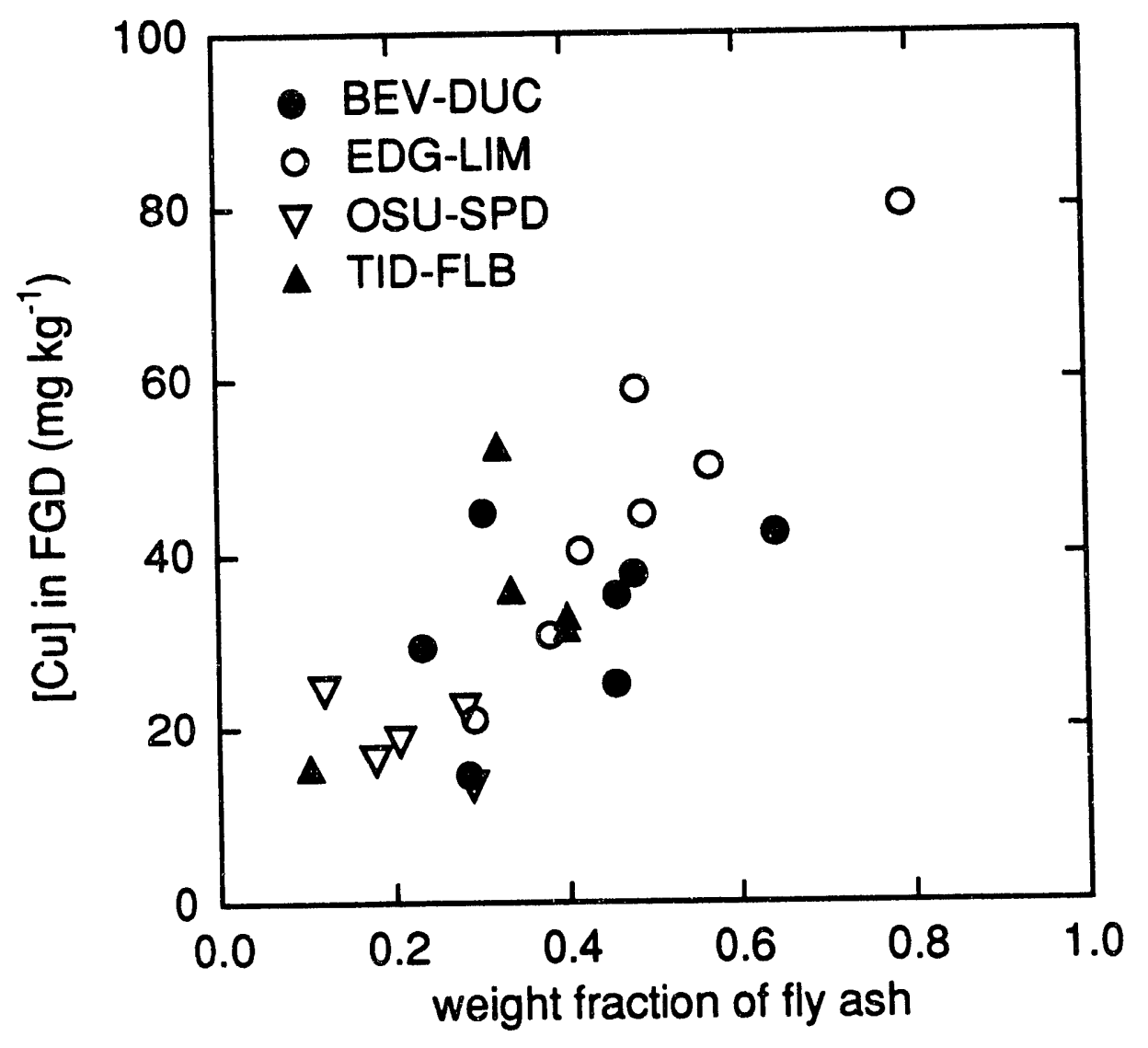

Fig. D5. Concentration of Cu versus the weight fraction of fly ash (acid insoluble residue) in FGD by-products. 


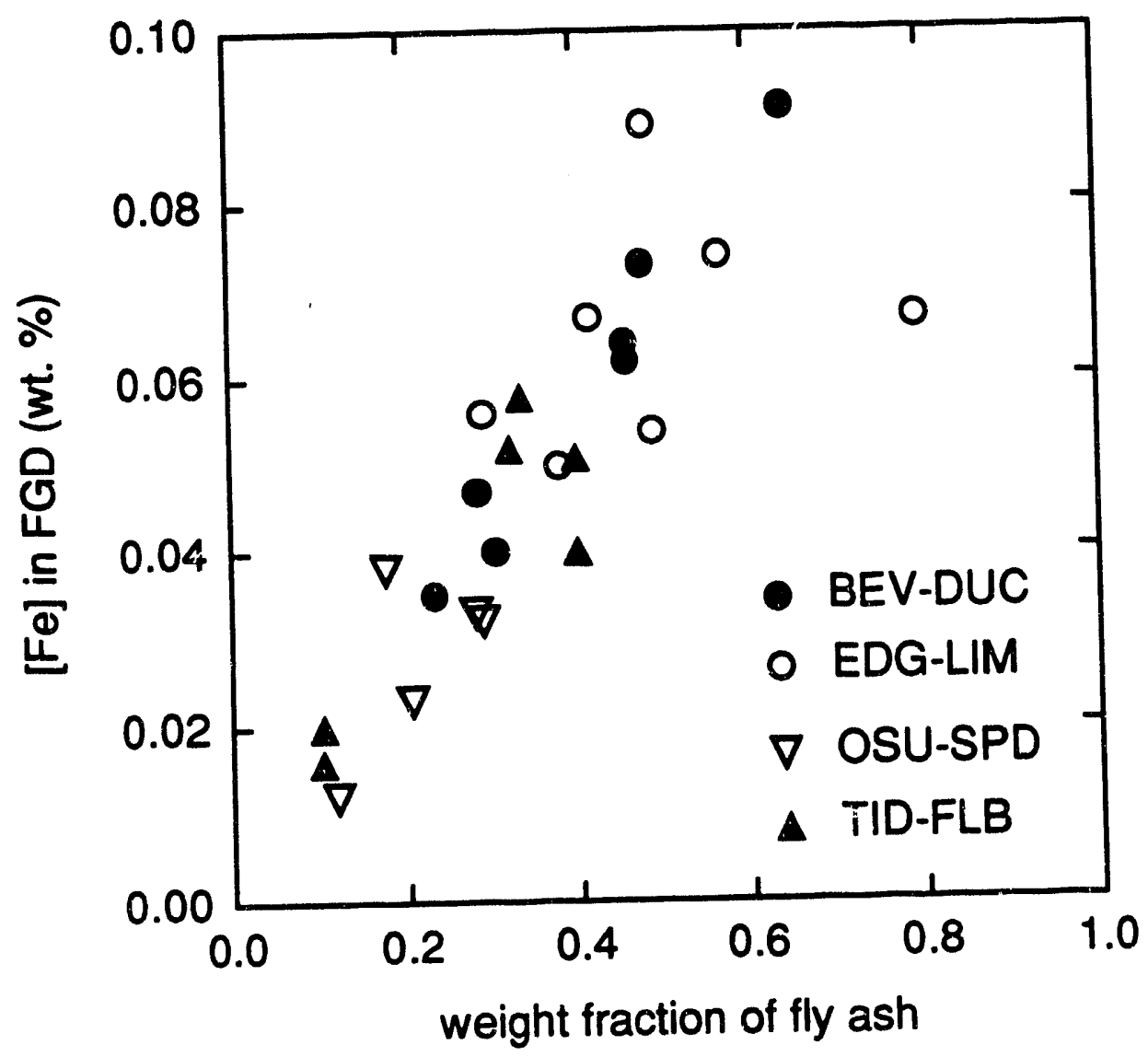

Fig. D6. Concentration of Fe versus the weight fraction of fly ash (acid insoluble residue) in FGD by-products. 
Phase 1 Report

Appendix D

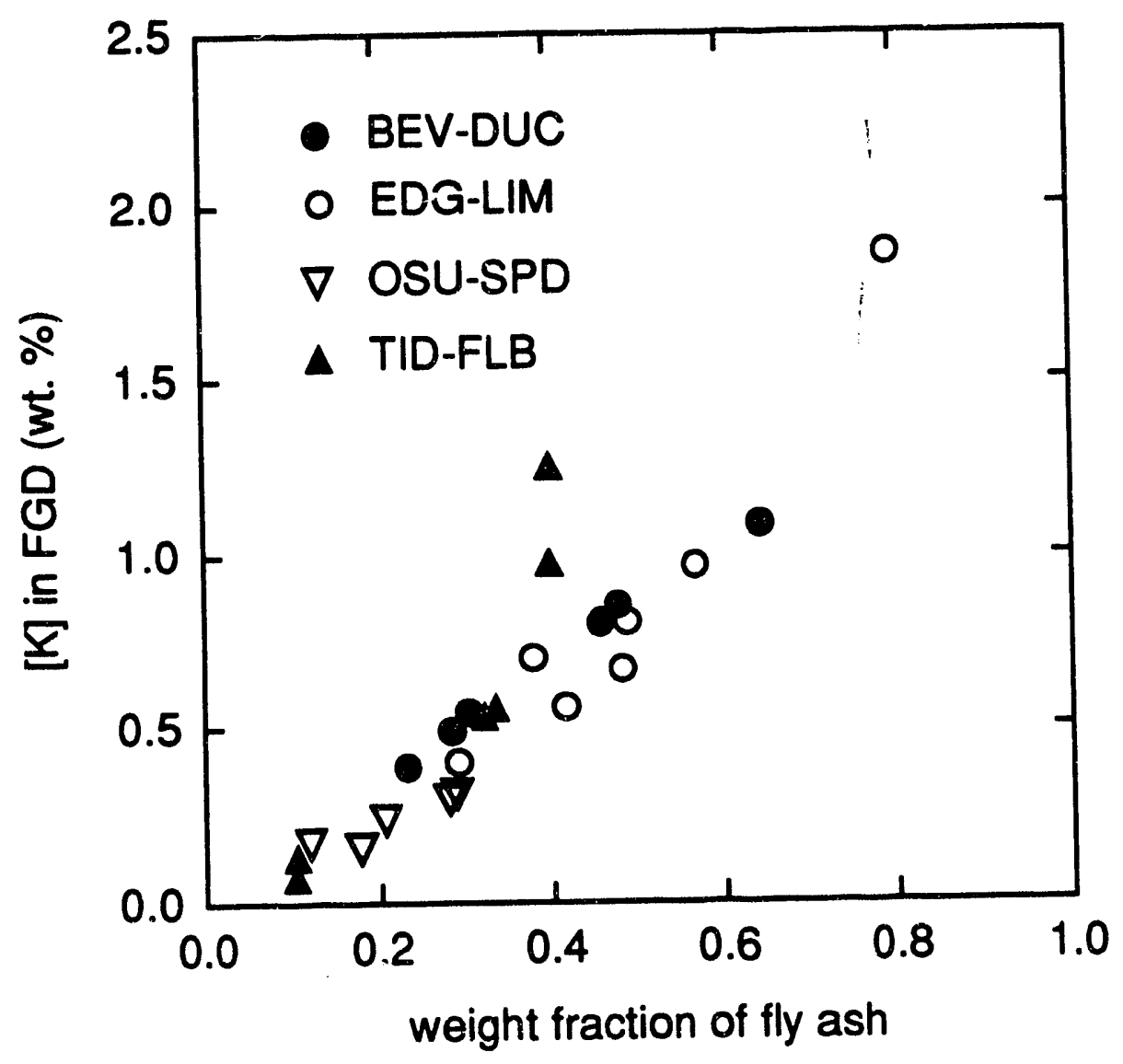

Fig. D7. Concentration of $\mathrm{K}$ versus the weight fraction of fly ash (acid insoluble residue) in FGD by-products. 
Phase 1 Rerort

Appendix D

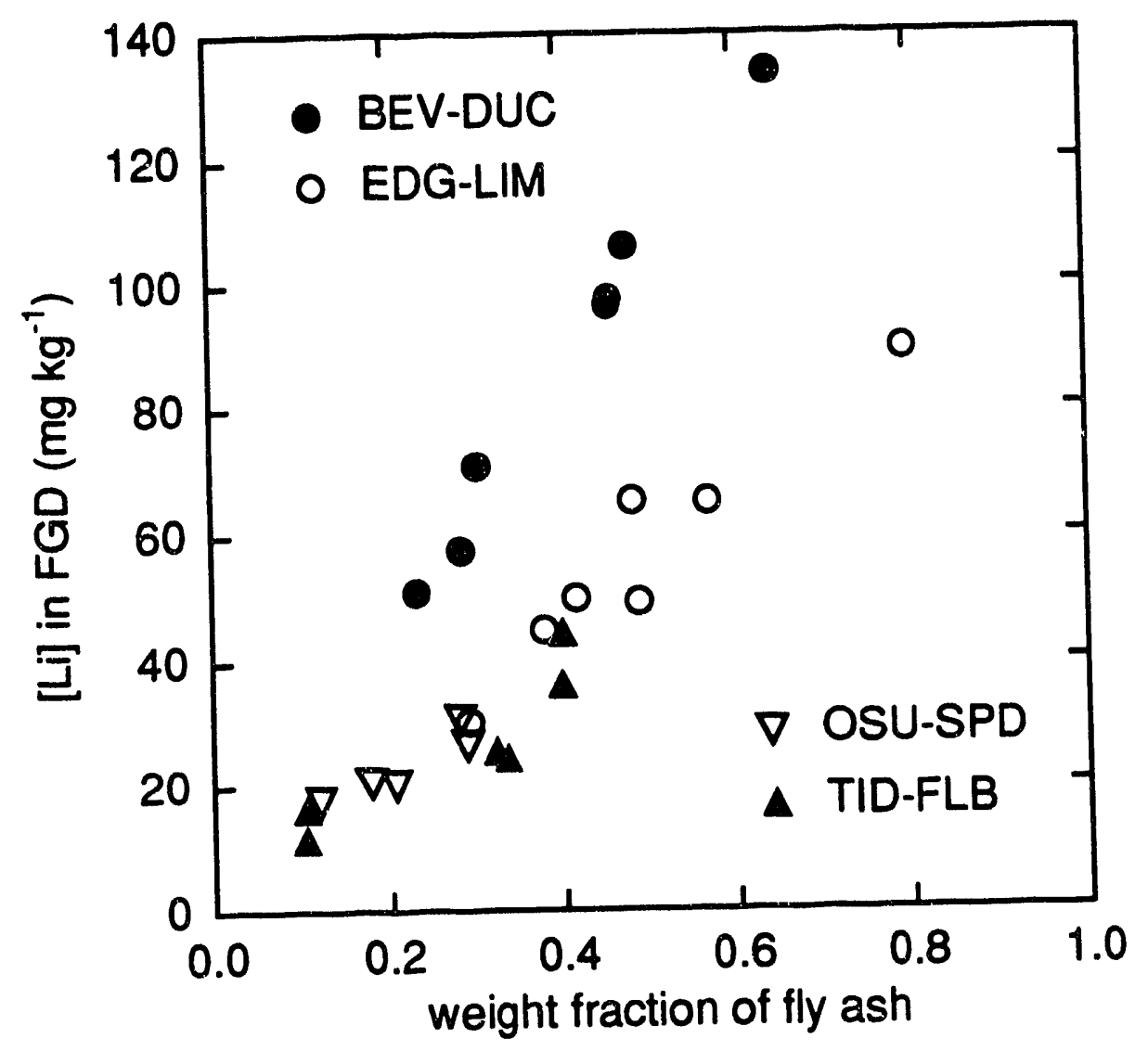

Fig. D8. Concentration of Li versus the weight fraction of fly ash (acid insoluble residue) in FGD by-products. 




Fig. D9. Concentration of Mn versus the weight fraction of fly ash (acid insoluble residue) in FGD by-products. 
Phase 1 Report

Appendix D

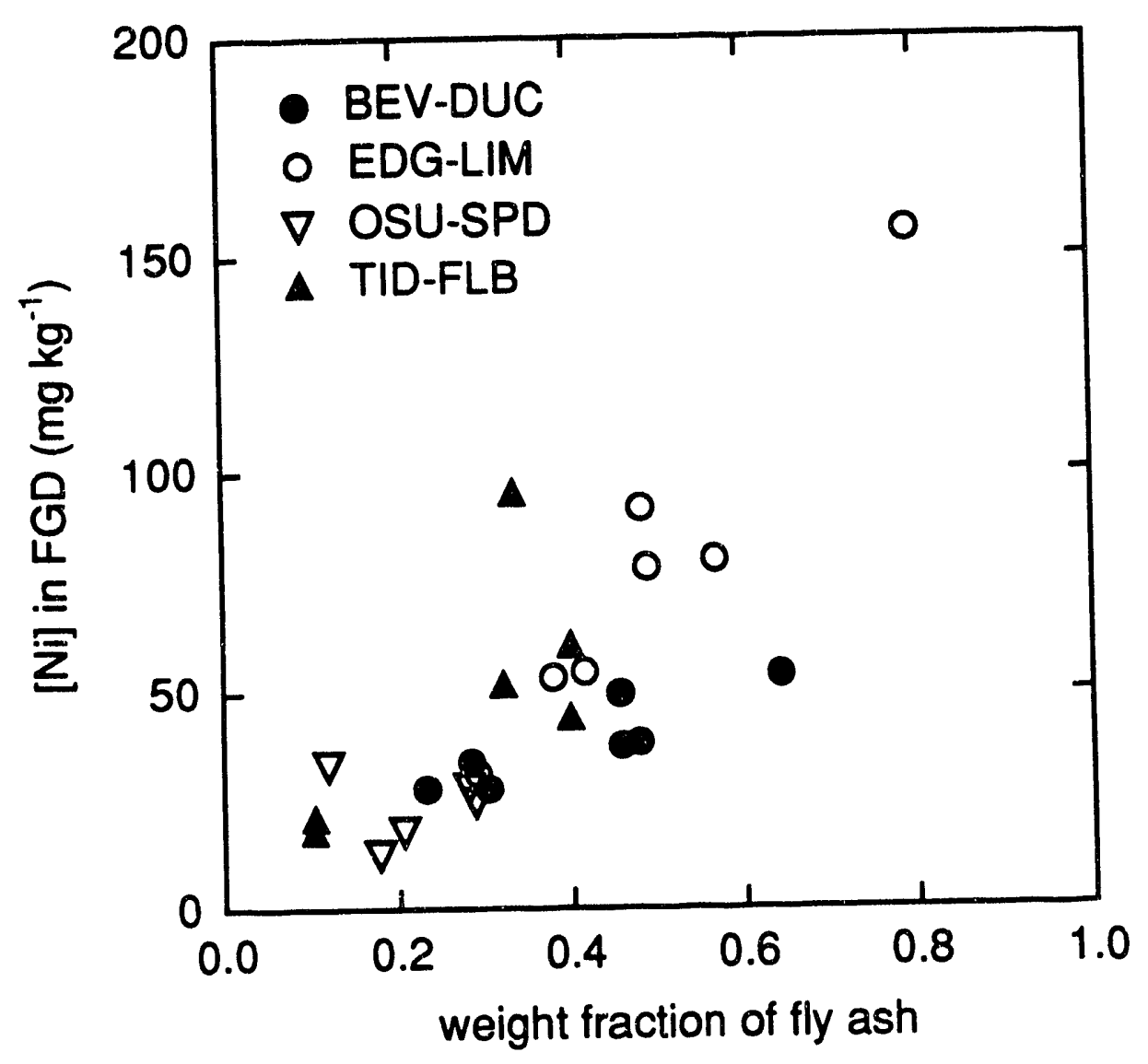

Fig. D10. Concentration of Ni versus the weight fraction of fly ash (acid insoluble residue) in FGD by-products. 


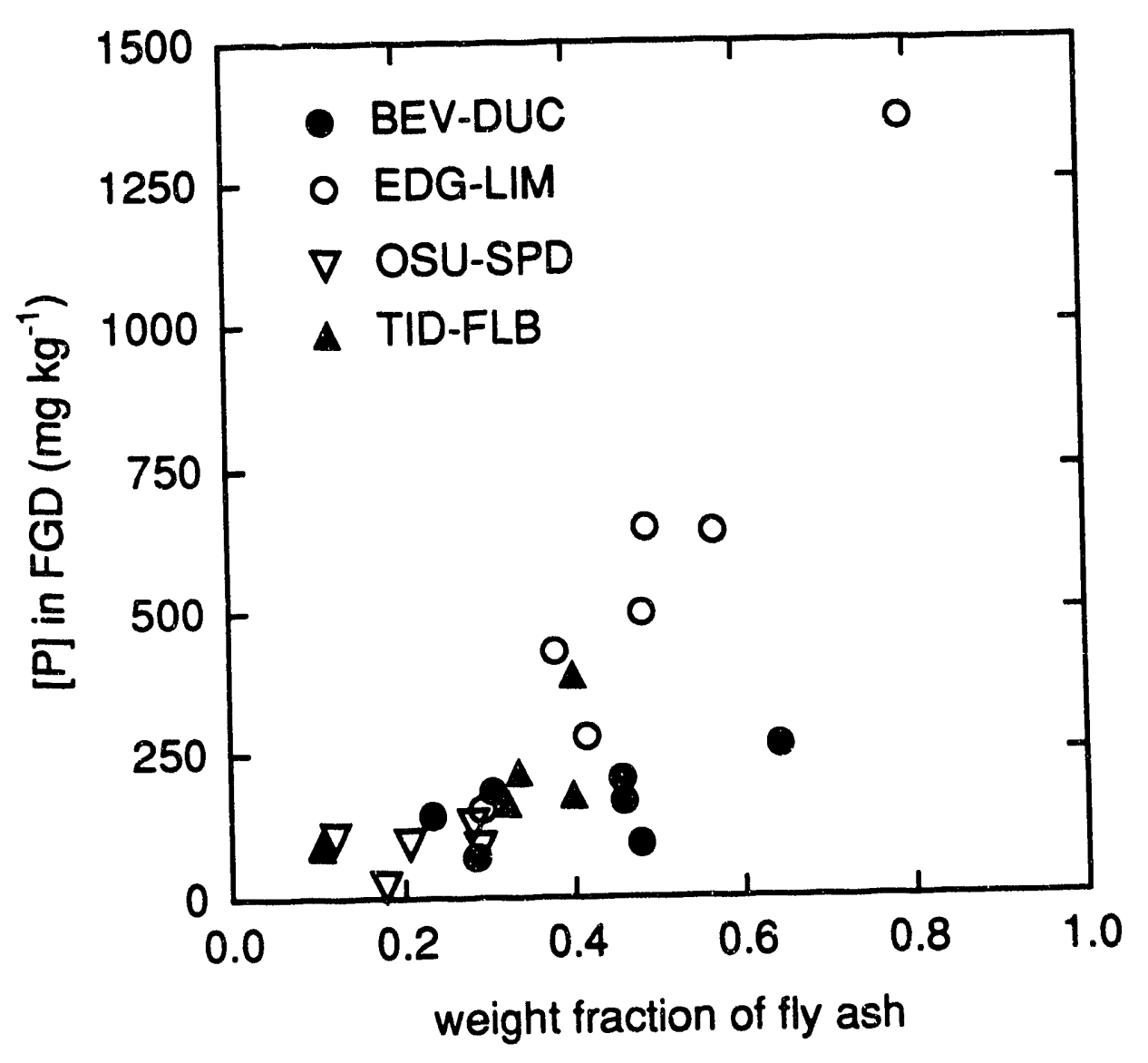

Fig. D11. Concentration of $P$ versus the weight fraction of fly ash (acid insoluble residue) in FGD by-products. 


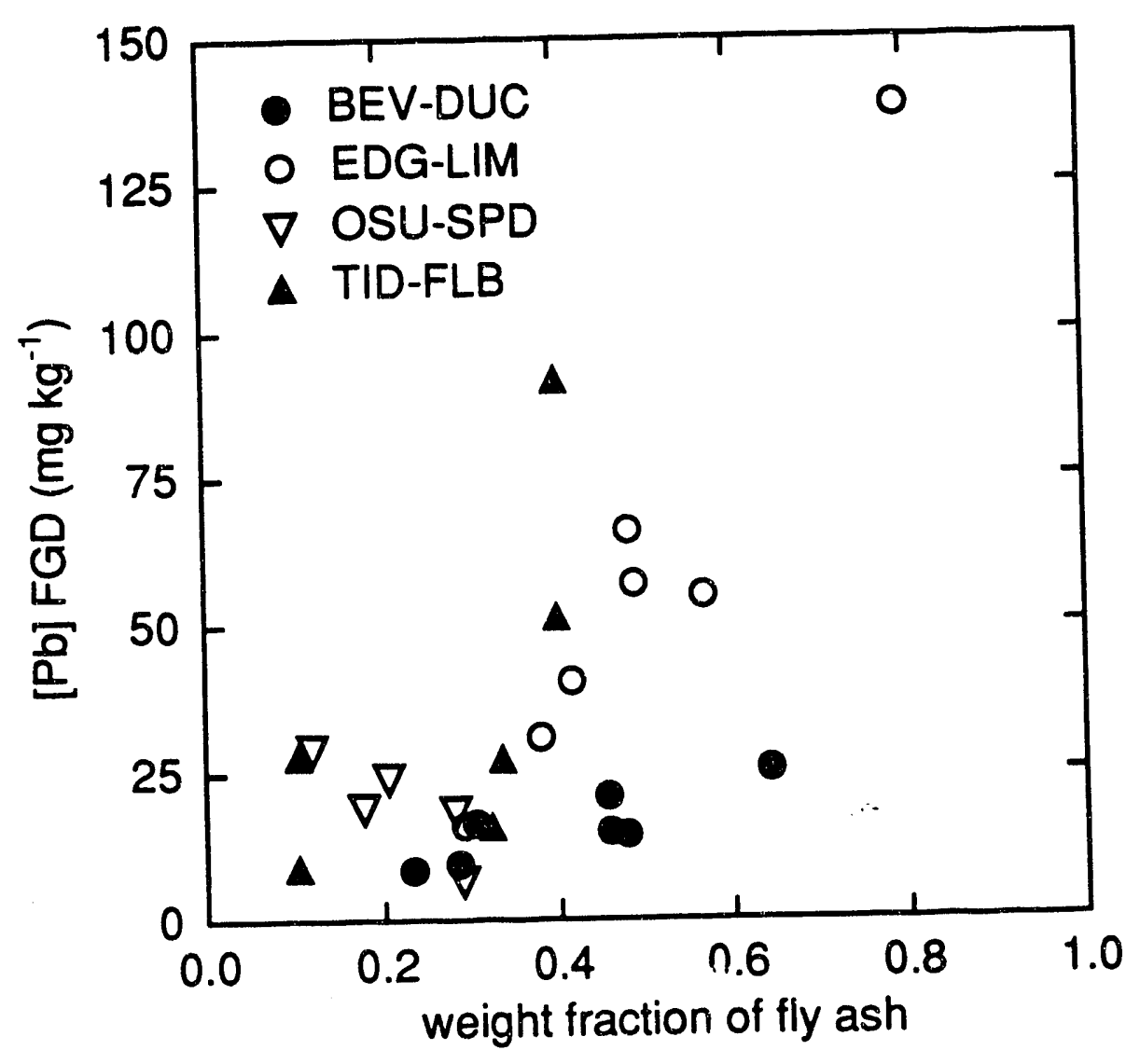

Fig. D12. Concentration of $\mathrm{Pb}$ versus the weight fraction of fly ash (acid insoluble residue) in FGD by-products. 


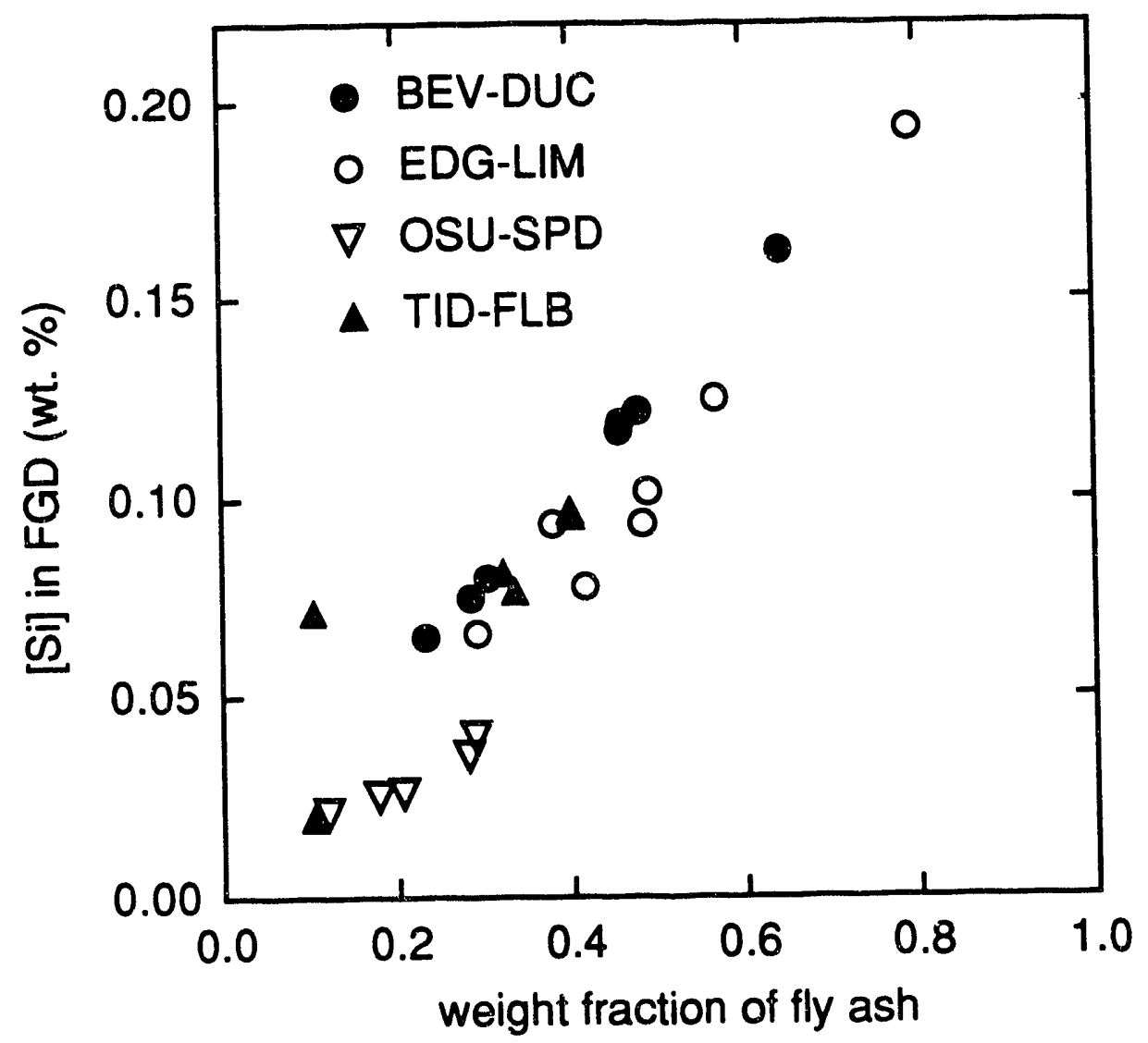

Fig. D13. Concentration of Si versus the weight fraction of fly ash (acid insoluble residue) in FGD by-products. 


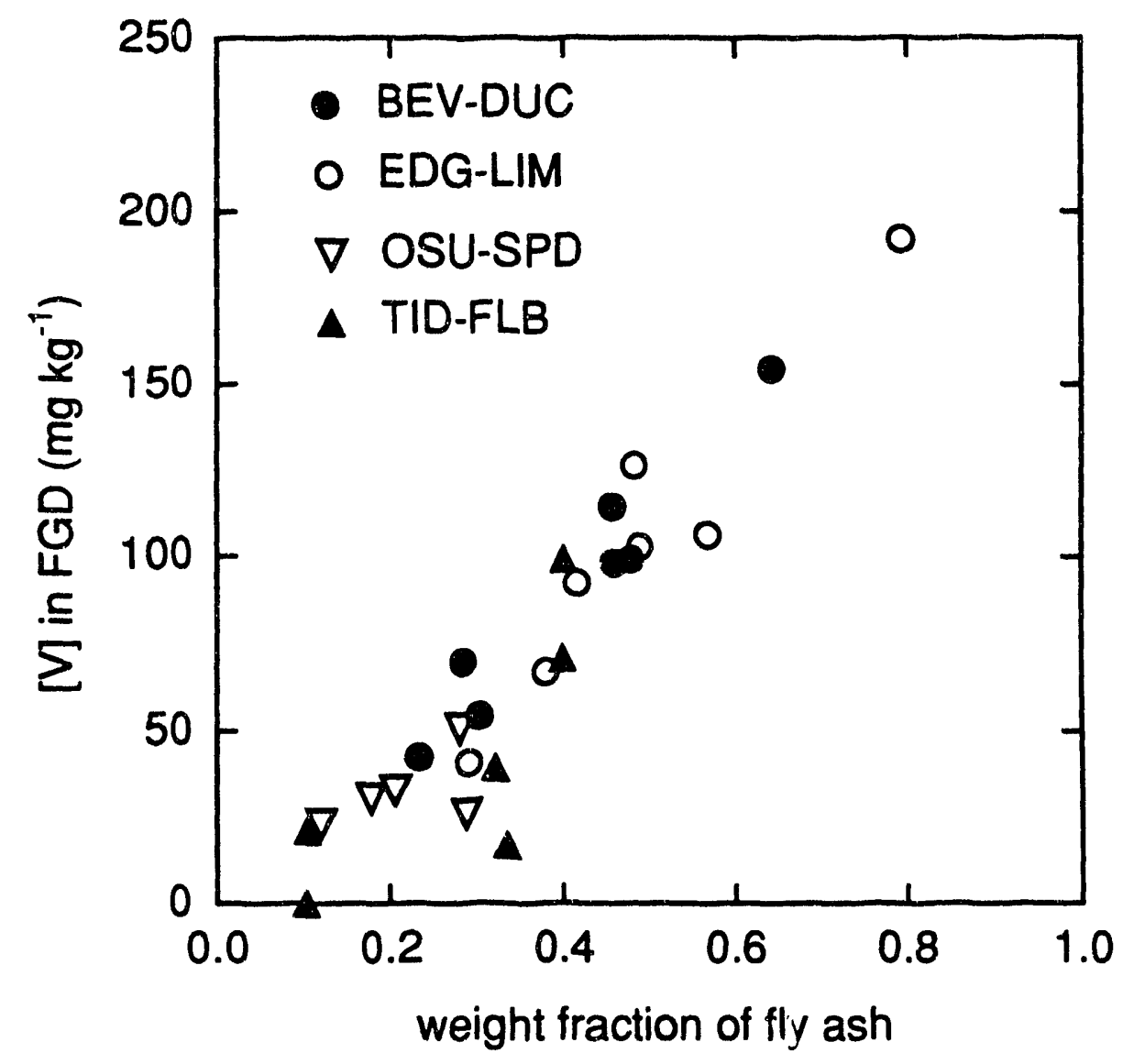

Fig. D14. Concentration of $\mathrm{V}$ versus the weight fraction of fly ash (acid insoluble residue) in FGD by-products. 


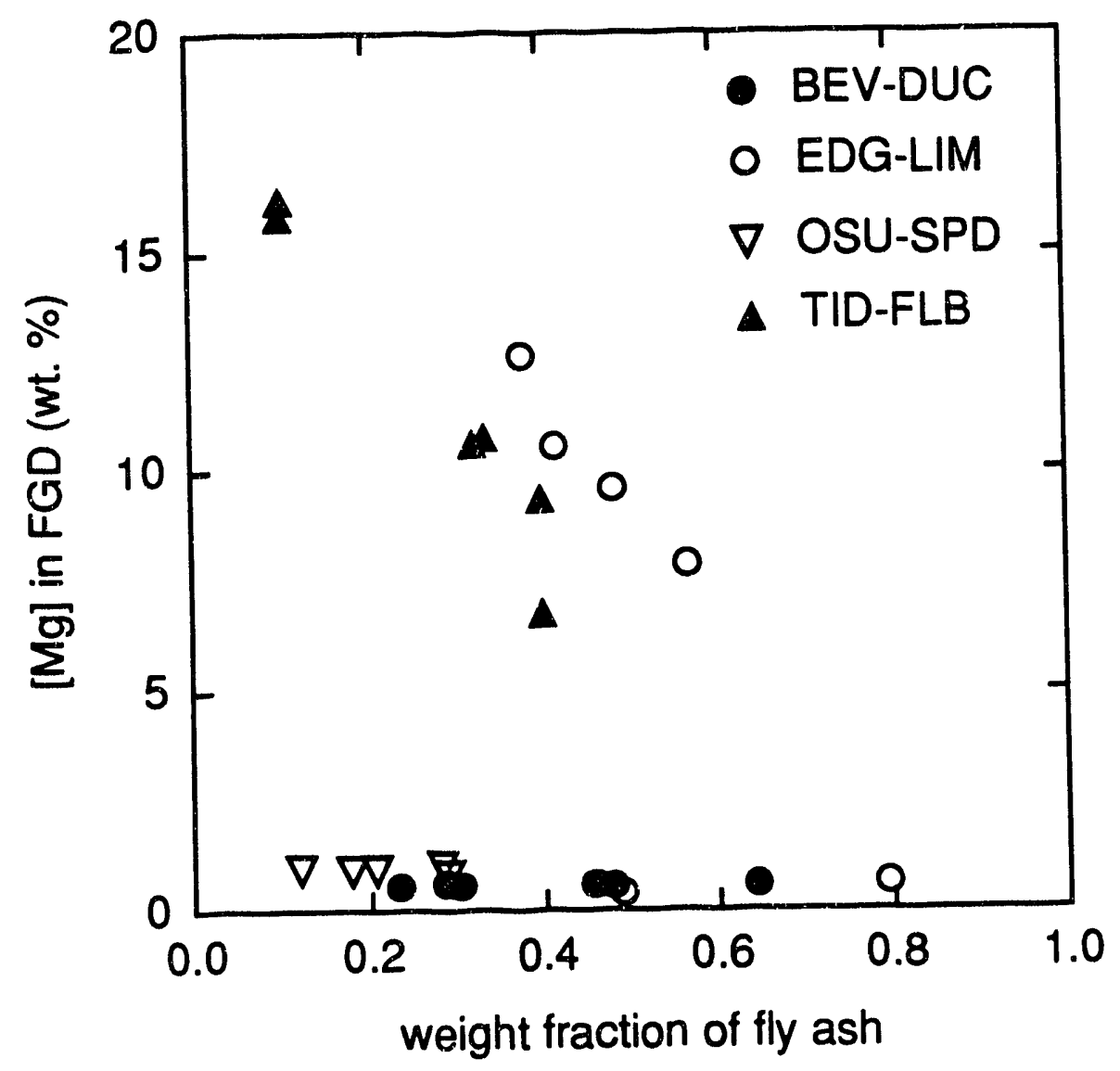

Fig. D15. Concentration of $\mathrm{Mg}$ versus the weight fraction of fly ash (acid insoluble residue) in FGD by-products. 


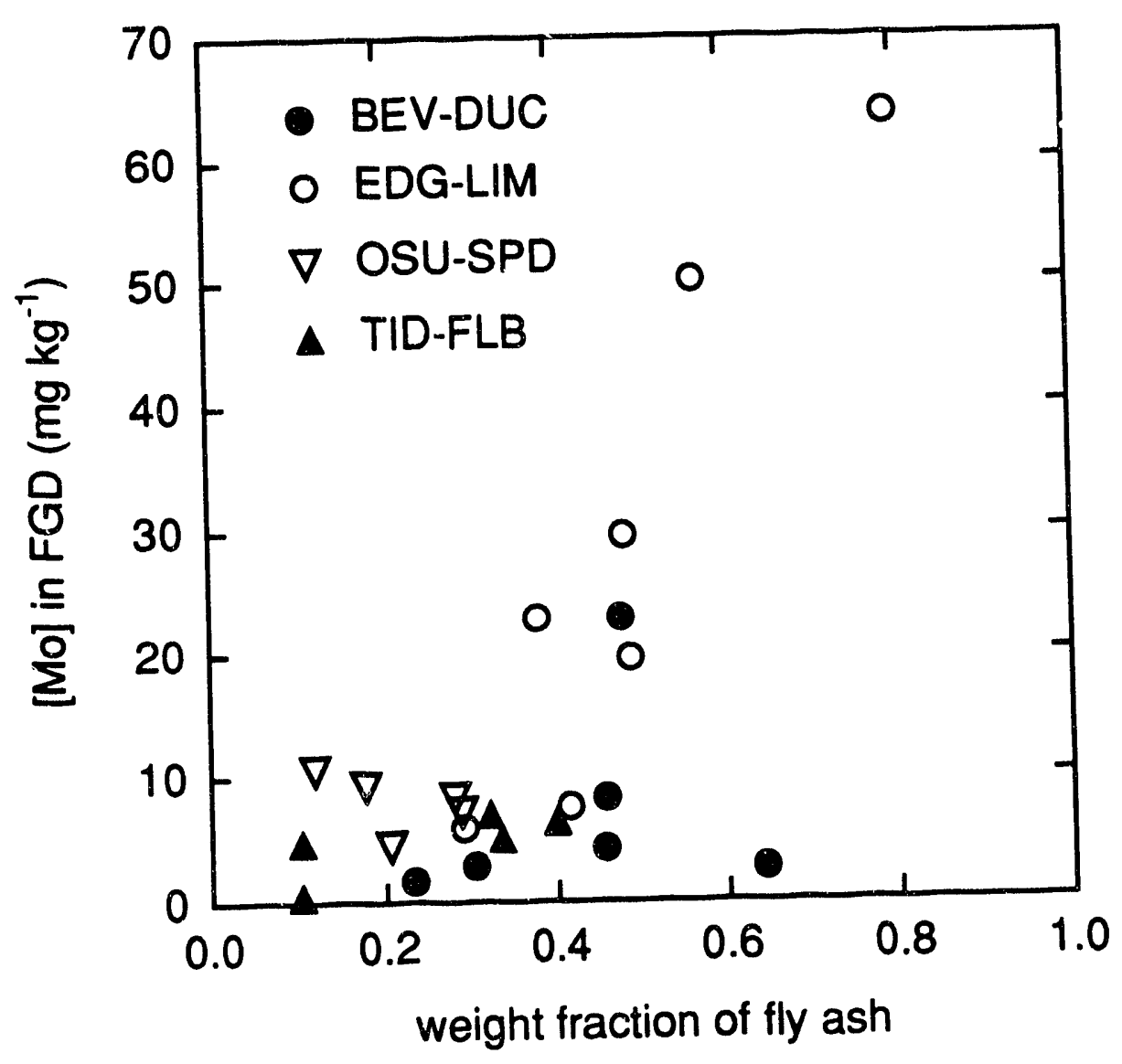

Fig. D16. Concentration of Mo versus the weight fraction of fly ash (acid insoluble residue) in FGD by-products. 
Phase 1 Report

Appendix D

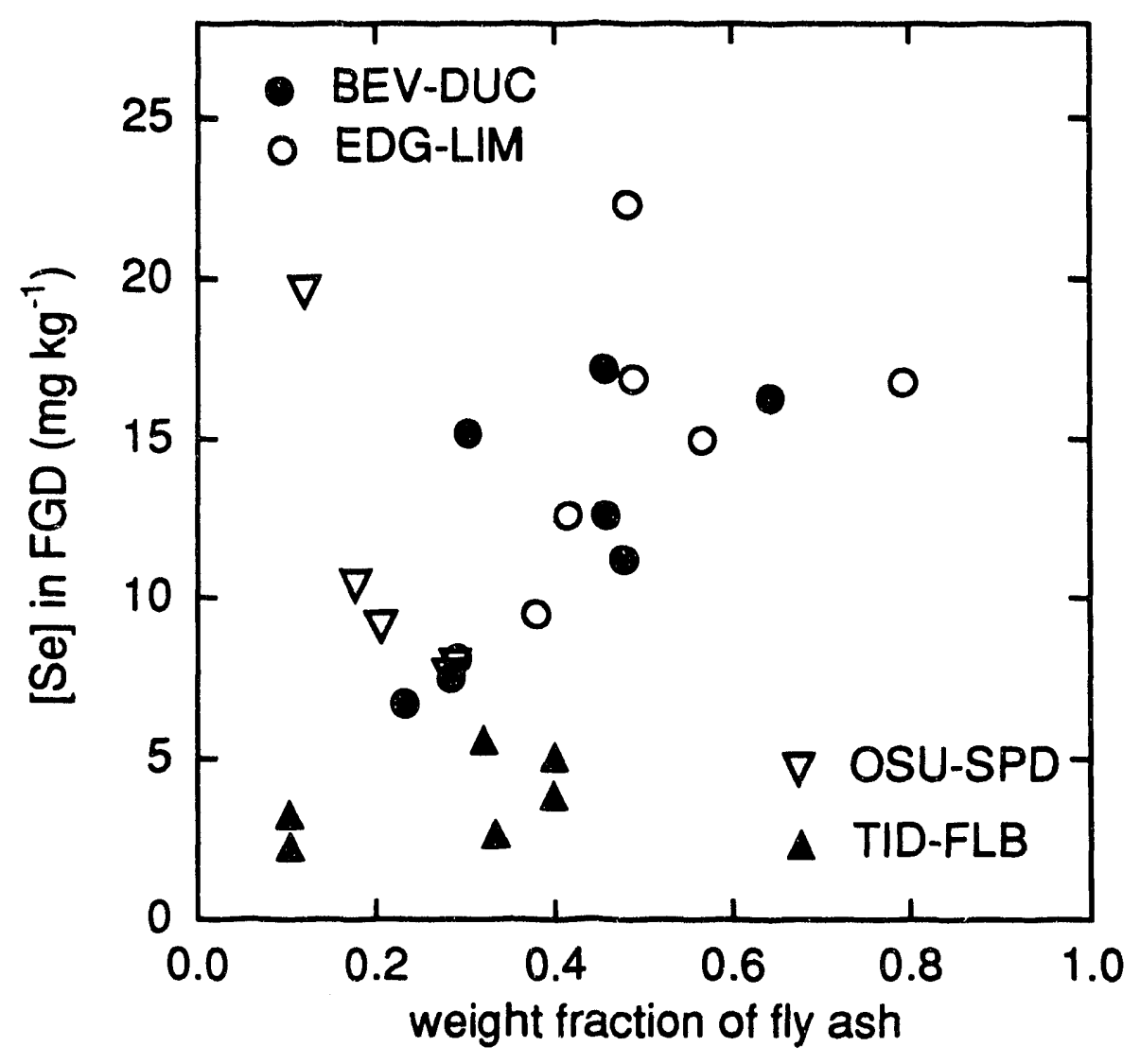

Fig. D17. Concentration of Se versus the weight fraction of fly ash (acid insoluble residue) in FGD by-products. 
Phase 1 Report

Appendix D

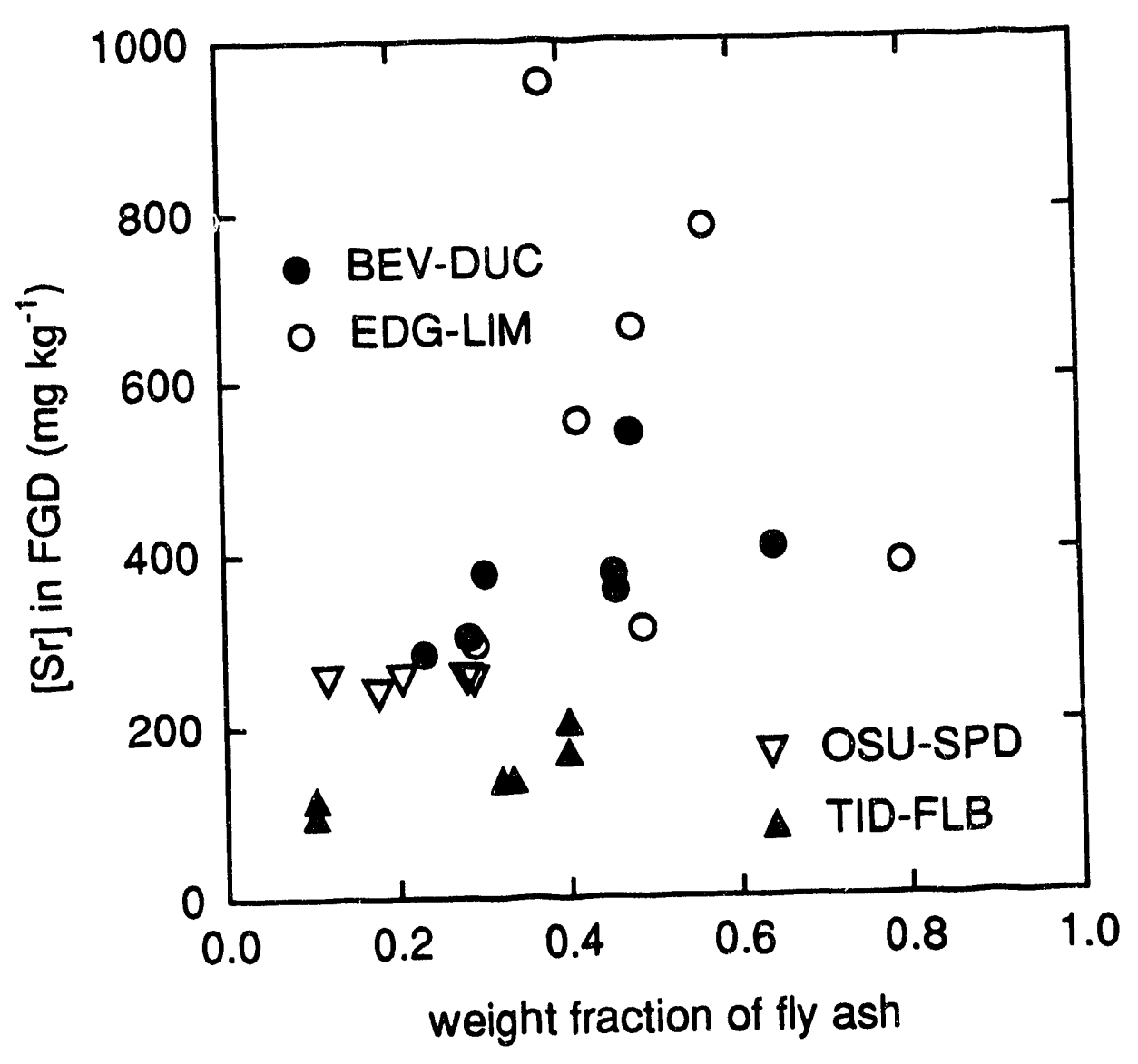

Fig. D18. Concentration of Sr versus the weight fraction of fly ash (acid insoluble residue) in FGD by-products. 


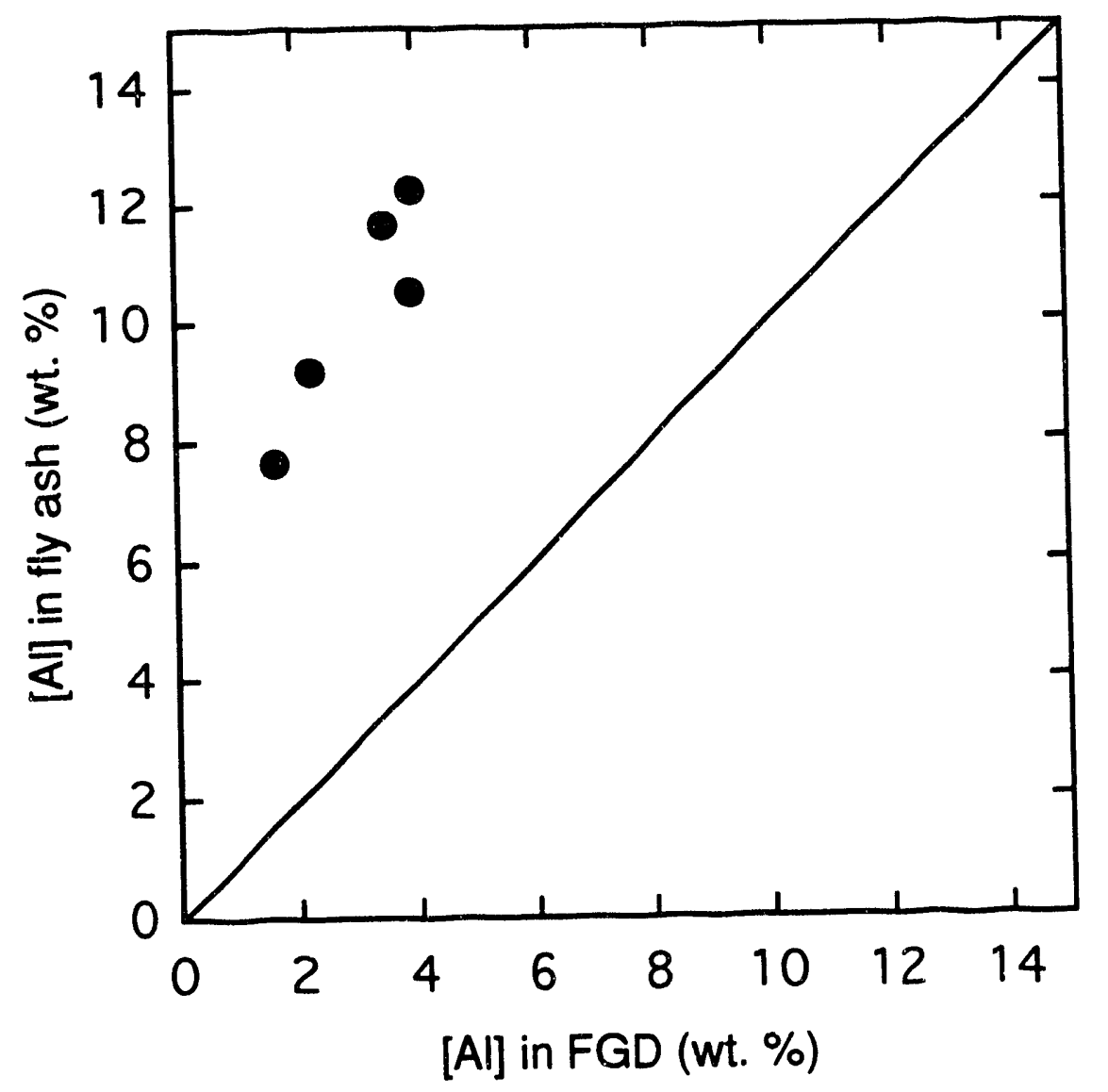

Fig. D19. Concentration of $A l$ in the fly ash fraction (acid insoluble residue) versus the concentration of $A$ I in whole FGD by-product. Data for samples: OSU-SPD-03, BEV-DUC-02, EDG-LIM-14, TID-FLB-03 and TID-FLB-04. 
Phase 1 Report

Appendix D

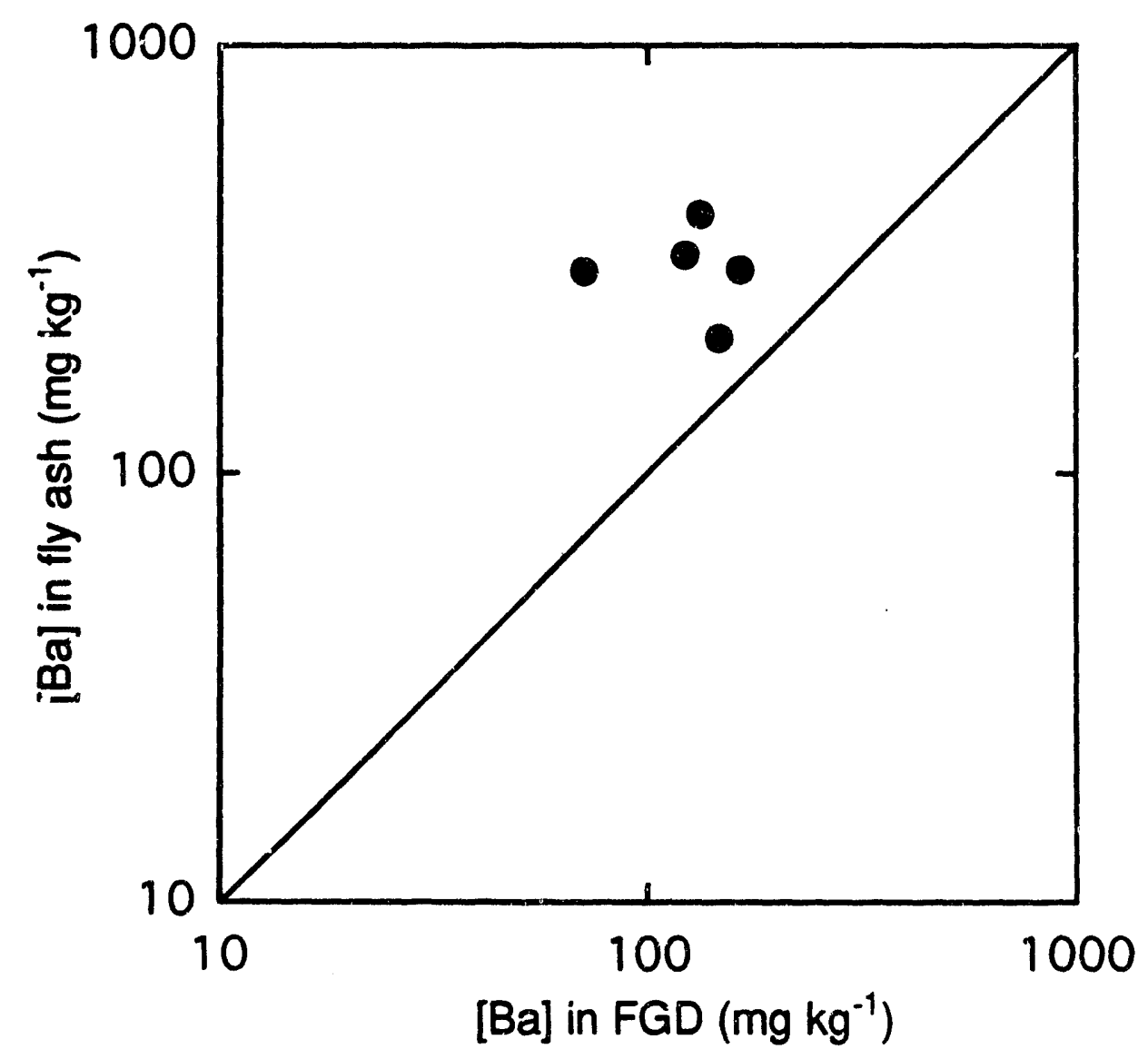

Fig. D20. Concentration of $\mathrm{Ba}$ in the fly ash fraction (acid insoluble residue) versus the concentration of $\mathrm{Ba}$ in whole FGD by-product. Data for samples: OSU-SPD-03, BEV-DUC-02, EDG-LIM-14, TID-FLB-03 and TID-FLB-04. 
Phase 1 Report

Appendix D

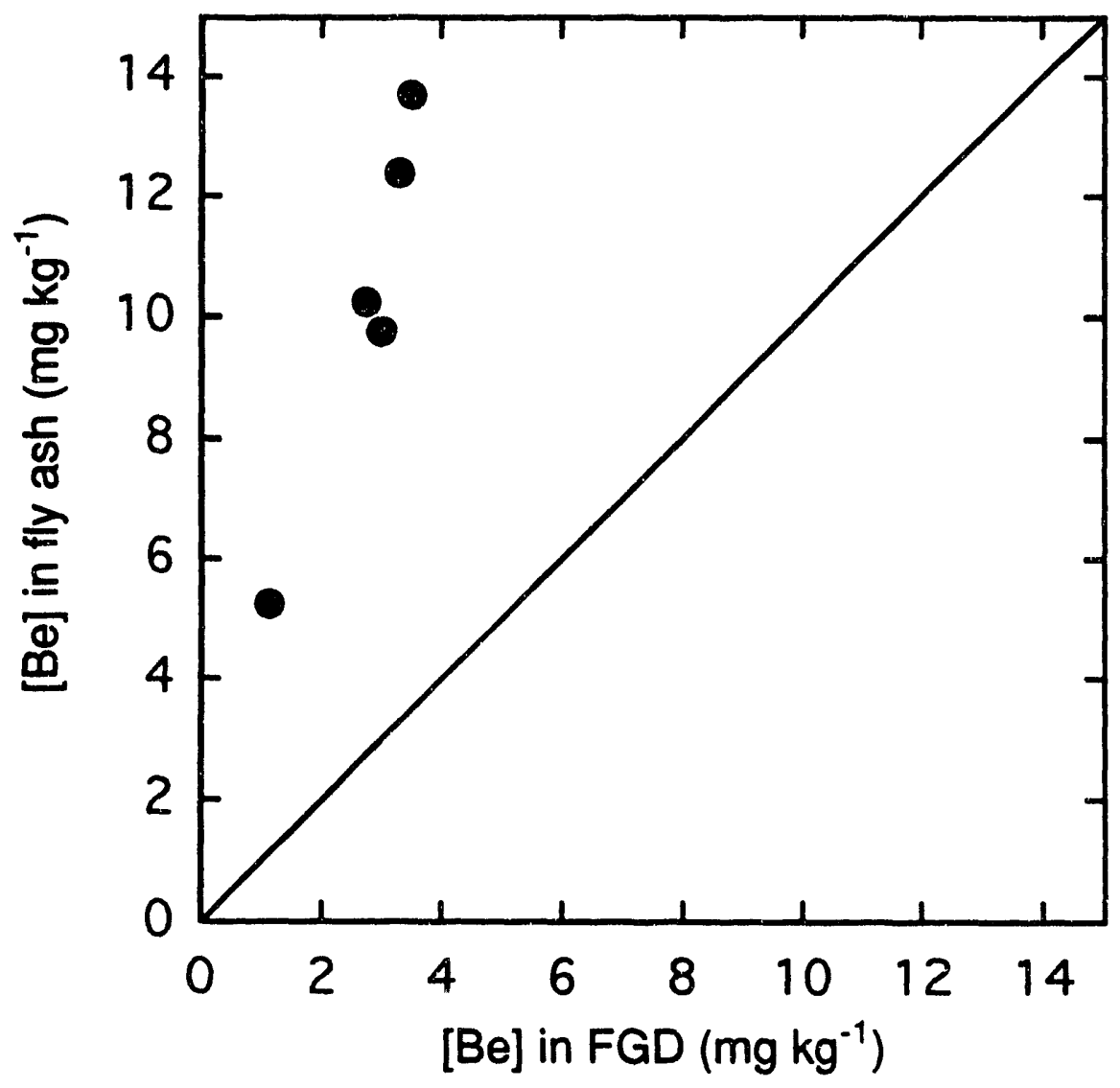

Fig. D21. Concentration of $\mathrm{Be}$ in the fly ash fiaction (acid insoluble residue) versus the concentration of $\mathrm{Be}$ in whole FGD by-product. Data for samples: OSU-SPD-03, BEV-DUC-02, EDG-LIM-14, TID-FLB-03 and TID-FLB-04. 
Phase 1 Report

Appendix $D$

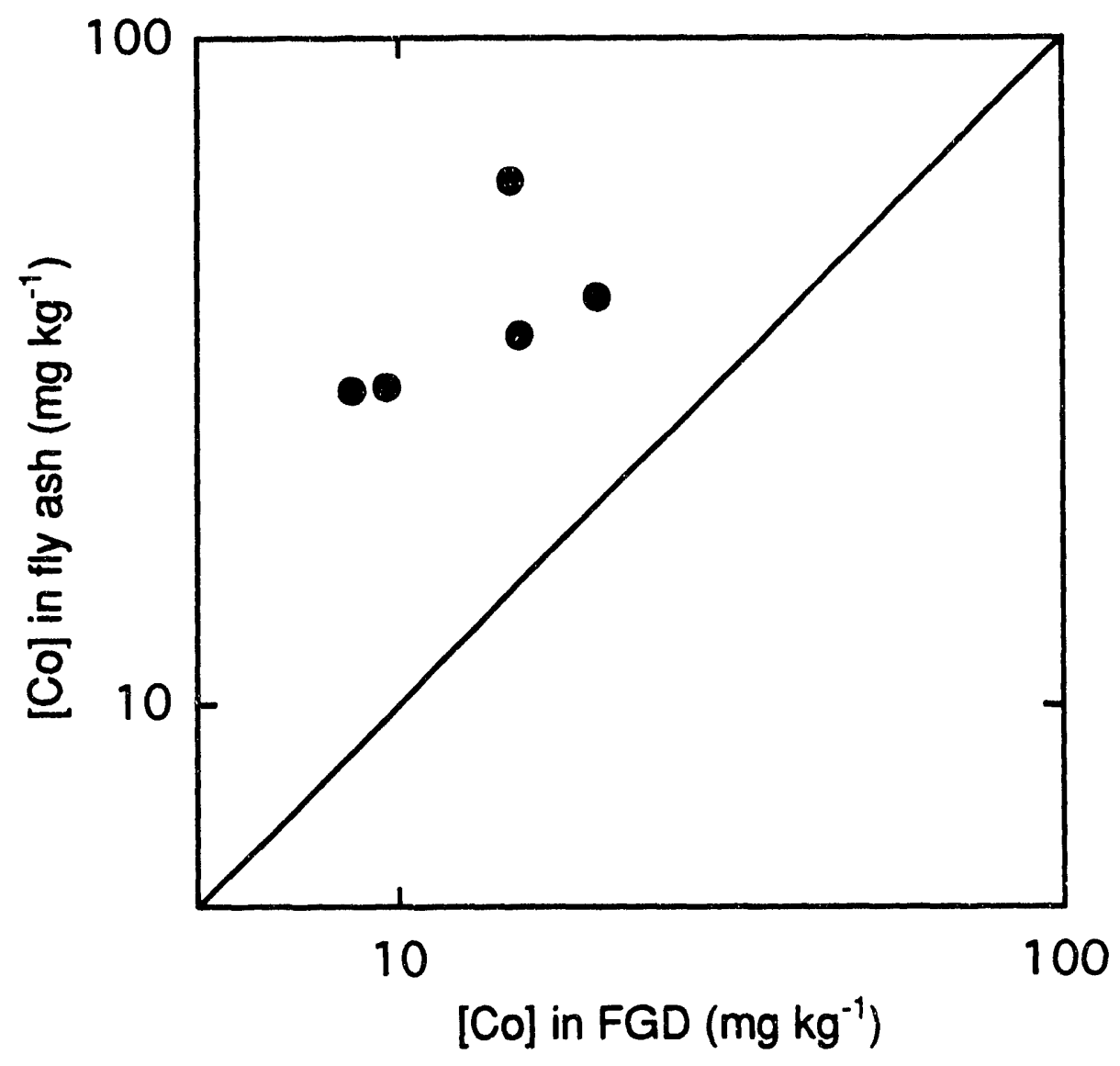

Fig. D22. Concentration of Co in the fly ash fraction (acid insoluble residue) versus the concentration of $\mathrm{Co}$ in whole FGD by-product. Data for samples: OSU-SPD-03, BEV-DUC-02, EDG-LIM-14, TID-FLB-03 and TID-FLB-04. 
Phase 1 Report

Appendix D

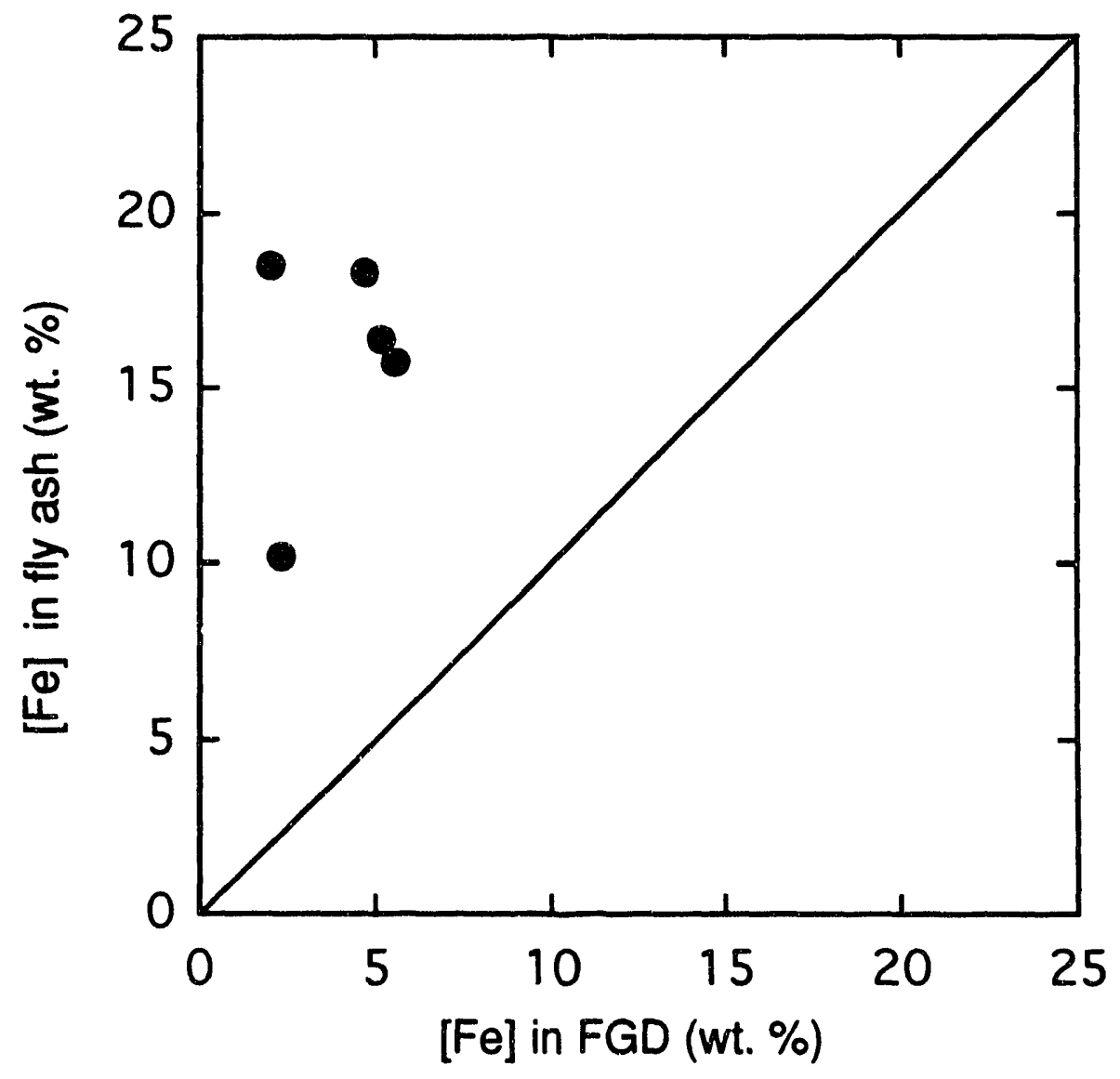

Fig. D23. Concentration of $\mathrm{Fe}$ in the fly ash fraction (acid insoluble residue) versus the concentration of $\mathrm{Fe}$ in whole FGD by-product. Data for samples: OSU-SPD-03, BEV-DUC-02, EDG-LIM-14, TID-FLB-03 and TID-FLB-04. 
Phase 1 Report Appendix D

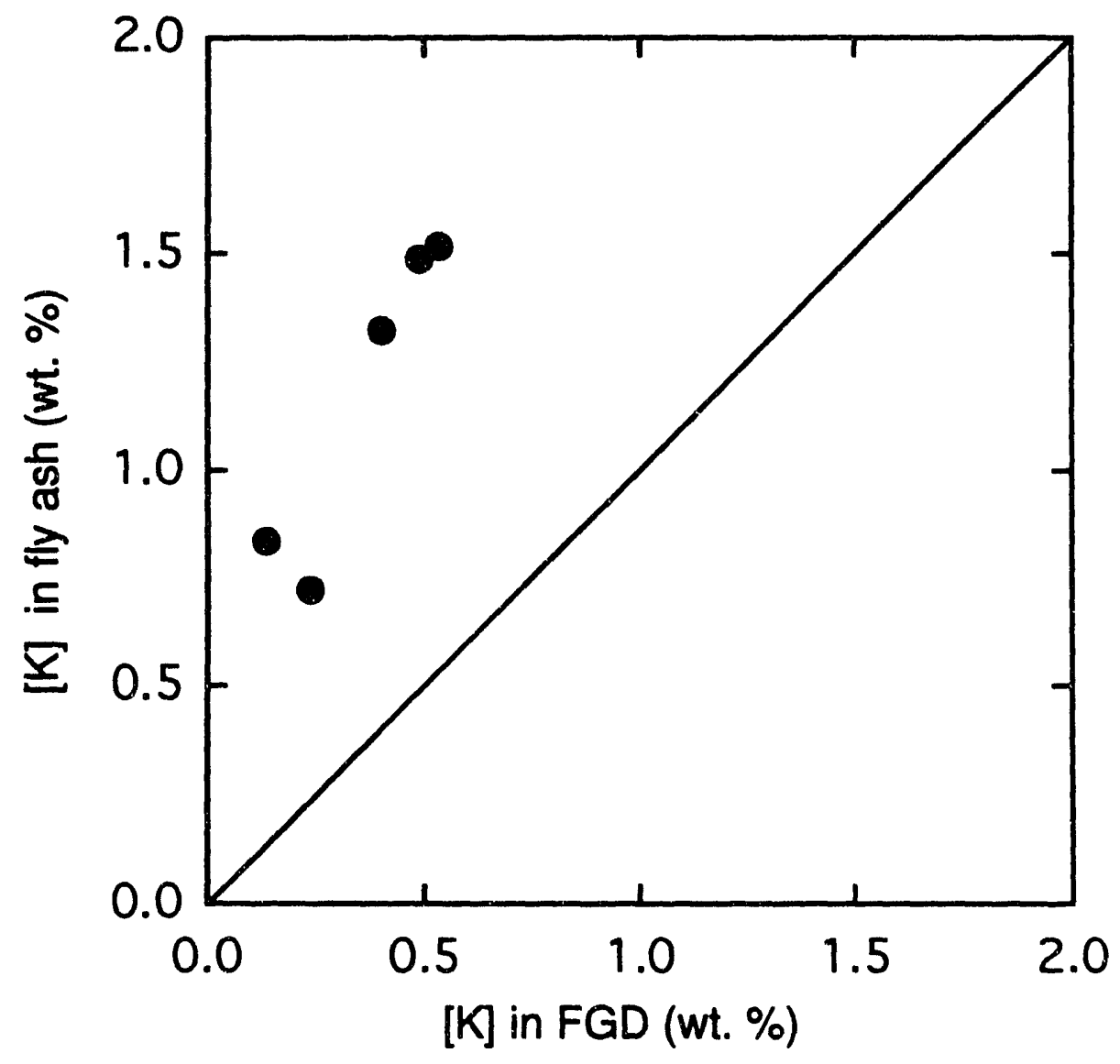

Fig. D24. Concentration of $K$ in the fly ash fraction (acid insoluble residue) versus the concentration of $K$ in whole FGD by-product. Data for samples: OSU-SPD-03, BEV-DUC-02, EDG-LIM-14, TID-FLB-03 and TID-FLB-04. 
Phase 1 Report

Appendix D

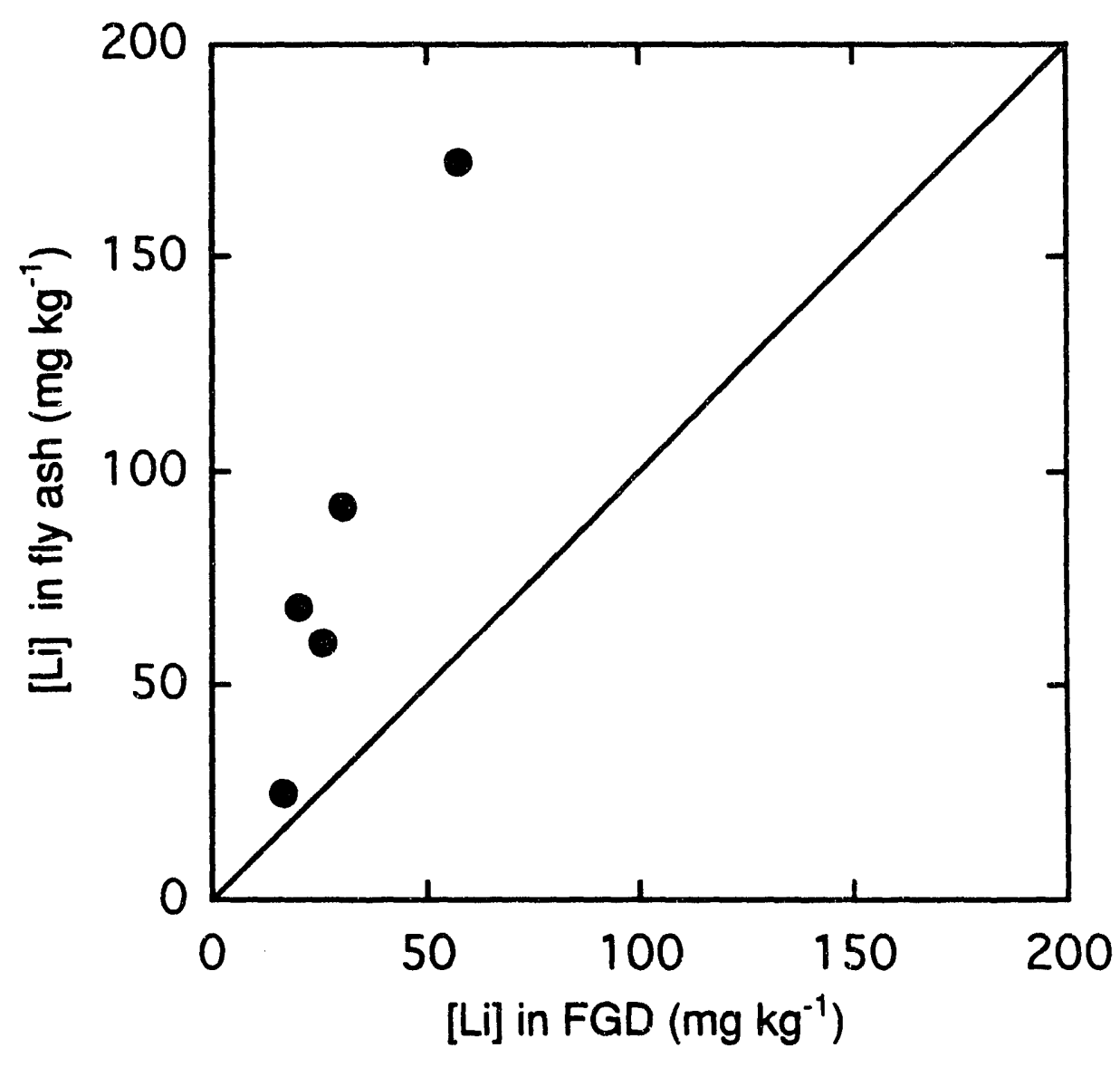

Fig. D25. Concentration of $\mathrm{Li}$ in the fly ash fraction (acid insoluble residue) versus the concentration of $L i$ in whole FGD by-product. Data for samples: OSU-SPD-03, BEV-DUC-02, EDG-LIM-14, TID-FLB-03 and TID-FLB-04. 
Phase 1 Report

Appendix D

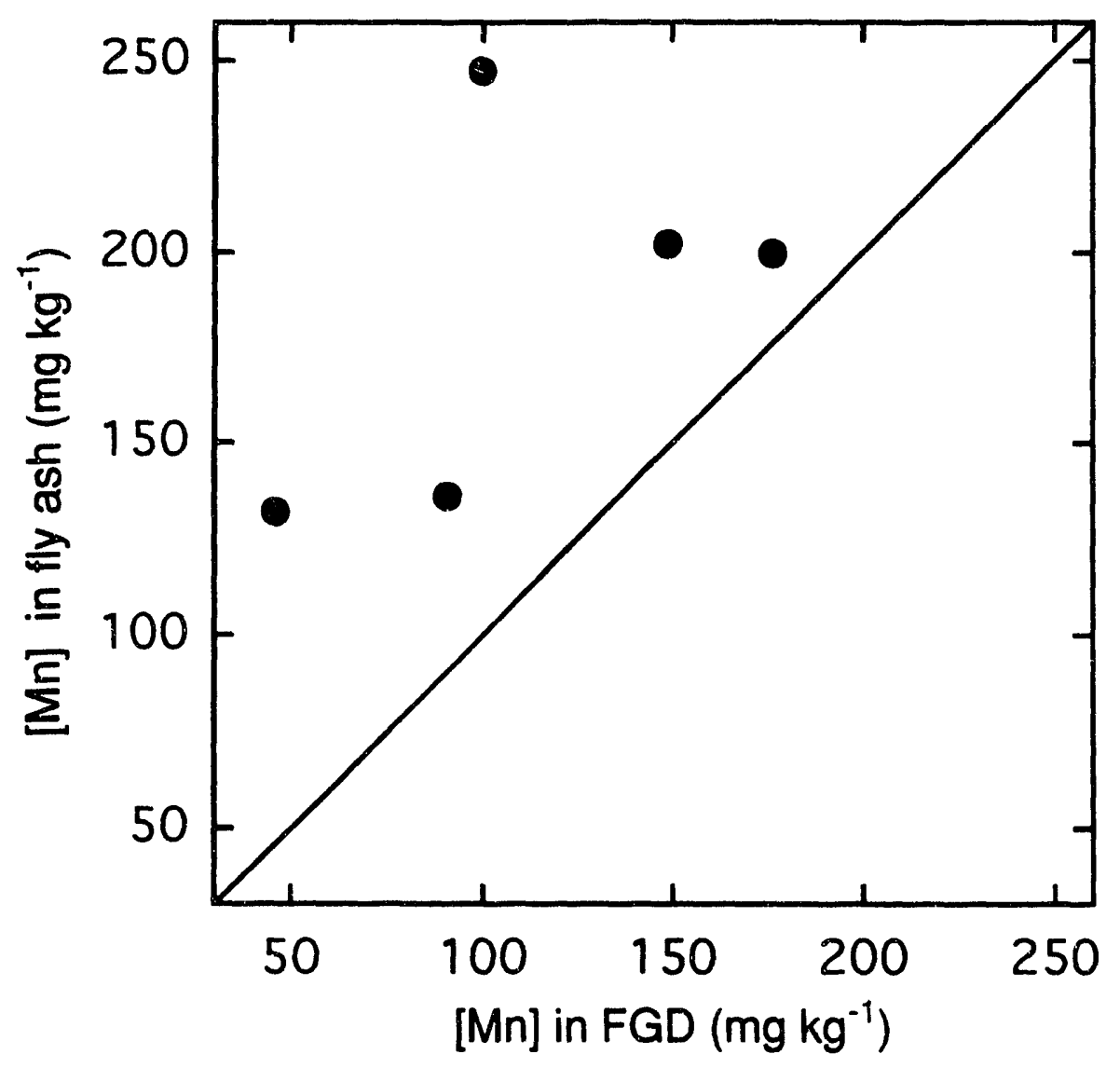

Fig. D26. Concentration of $\mathrm{Mn}$ in the fly ash fraction (acid insoluble residue) versus the concentration of $\mathrm{Mn}$ in whole FGD by-product. Data for samples: OSU-SPD-03, BEV-DUC-02, EDG-LIM-14, TID-FLB-03 and TID-FLB-04. 
Phase 1 Report

Appendix D

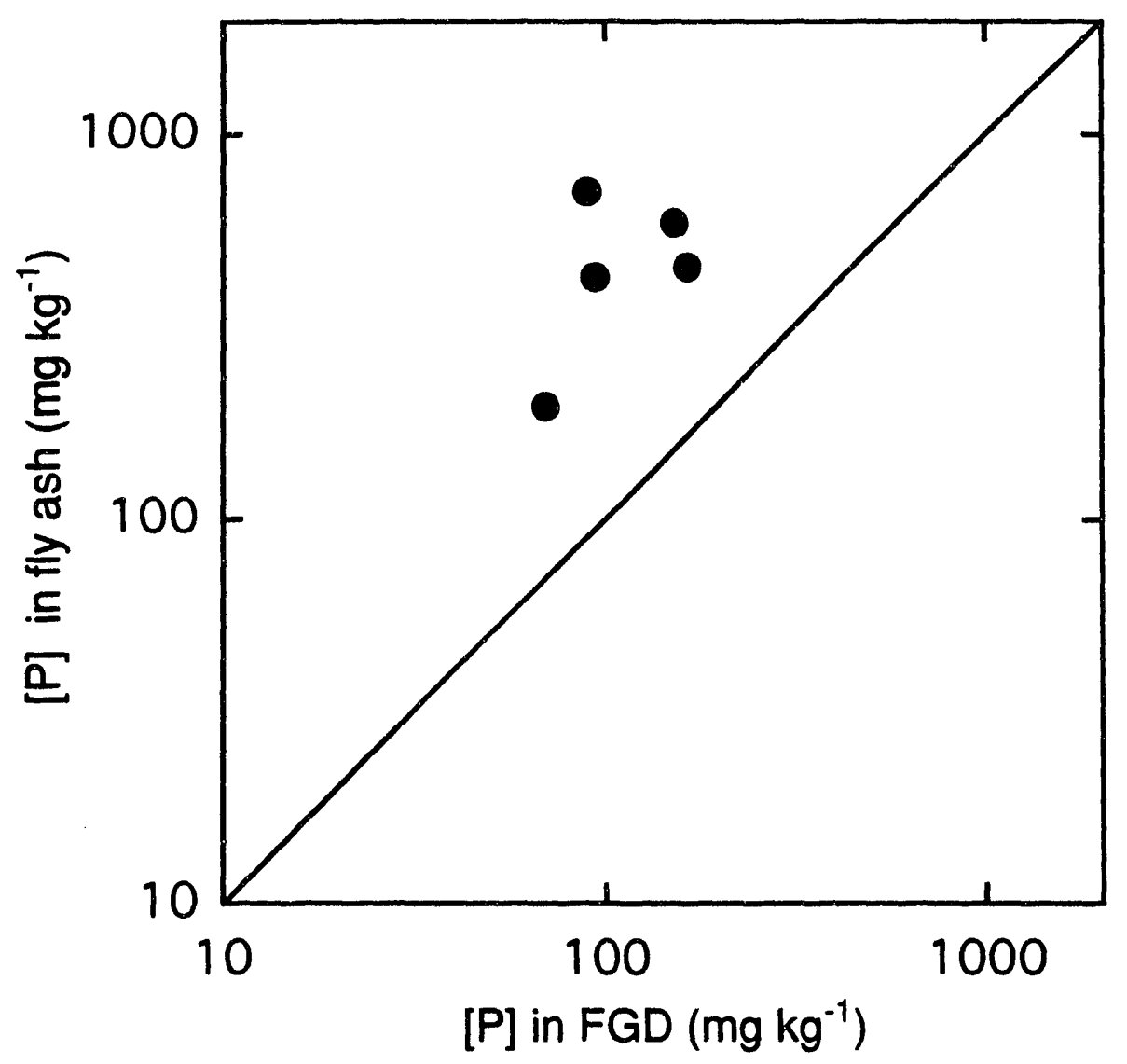

Fig. D27. Concentration of $P$ in the fly ash fraction (acid insoluble residue) versus the concentration of $P$ in whole FGD by-product. Data for samples:

OSU-SPD-03, BEV-DUC-02, EDG-LIM-14, TID-FLB-03 and TID-FLB-04. 
Phase 1 Report

Appendix D

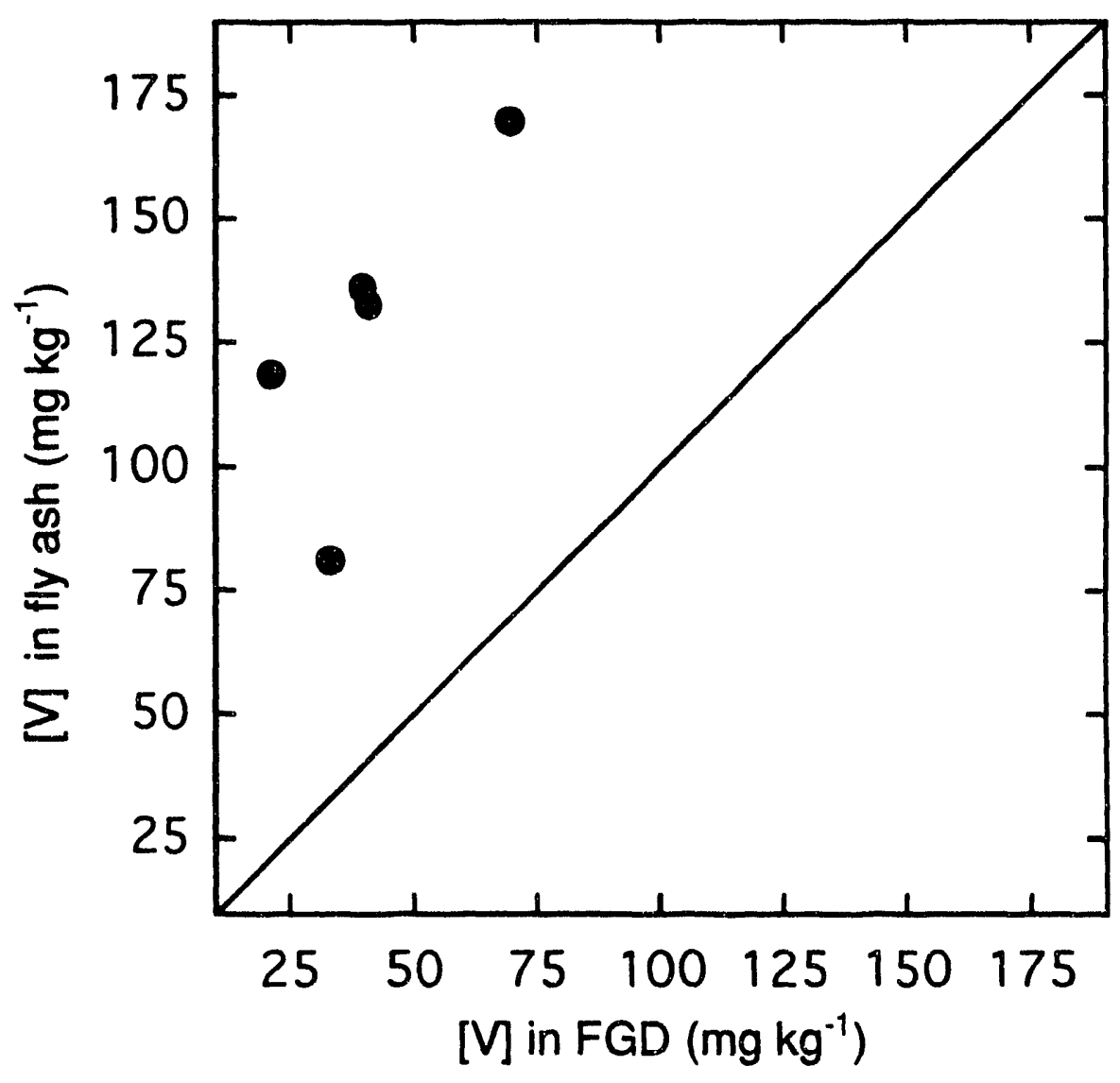

Fig. D28. Concentration of $V$ in the fly ash fraction (acid insoluble residue) versus the concentration of $V$ in whole FGD by-product. Data for samples: OSU-SPD-03, BEV-DUC-02, EDG-LIM-14, TID-FLB-03 and TID-FLB-04. 
Phase 1 Report Appendix D

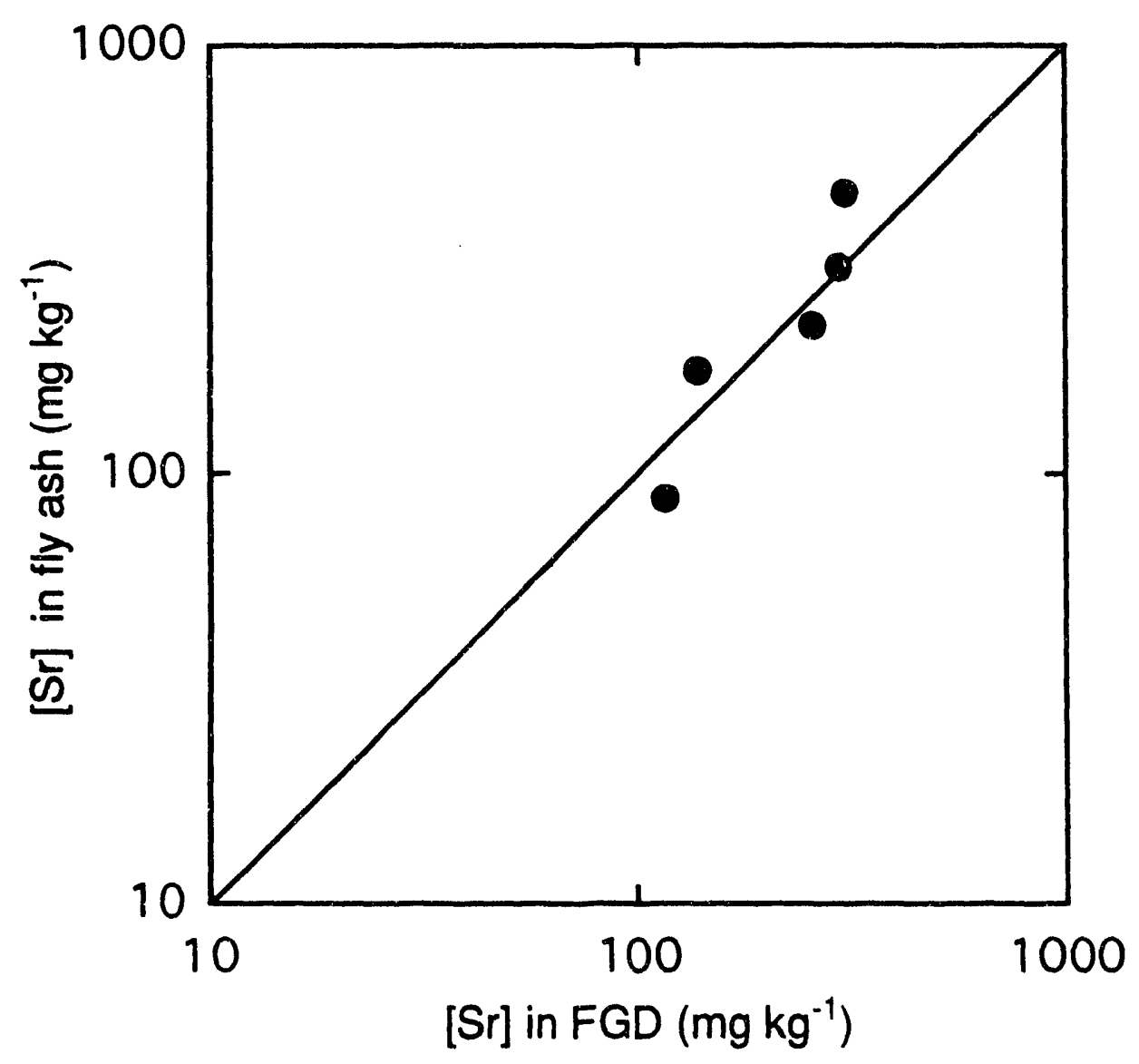

Fig. D29. Concentration of $\mathrm{Sr}$ in the fly ash fraction (acid insoluble residue) versus the concentration of $\mathrm{Sr}$ in whole FGD by-product. Data for samples: OSU-SPD-03, BEV-DUC-02, EDG-LIM-14, TID-FLB-03 and TID-FLB-04. 


\section{APPENDIX E \\ Social Costs and Benefits of \\ Recycling Coal Fired Electric Power Plant FGD By-Products}

Fredrick Hitzhusen*

\section{Summary}

Flue gas desulfurization (FGD) by-products from coal-fired electric power generation are increasing due to Clean Air Act legislation in the U.S. requiring removal of sulfur from coal. The FGD by-products are one of many waste products or residuals of economic production and consumption activities that may impose social costs when entering a natural environment with limits to its assimilative or "sink" capacity. The options for dealing with this problem include reducing levels of throughput, converting the residuals to new products or recycling them as inputs, changing the wastes to a more benign form, altering the time and place of residuals discharge and changing the assimilative capacity of the environment. This paper is part of a larger multidisciplinary research effort on FGD Recycling at The Ohio State University (see Dick et al., 1991) and focuses on developing a correct method for assessing the social or complete costs and benefits. It is oriented primarily to non-economists. The three options for converting FGD by-products to new products or recycling them as inputs include FGD by-products as an agronomic lime substitute, as an amendment on active and abandoned stripmine spoil, and as an embankment stabilizer for highway construction.

Social cost benefit analysis is concerned with estimating full willingness to pay and willingness to accept measures of economic value regardless of whether or not those values are currently reflected in market prices. It

\footnotetext{
* Professor of Resource Economics, The Ohio State University, 2120 Fyffe Road, Columbus, Ohio 43210 USA. This paper was presented at ENVIROTECH Conference, Vienna, Austria, Apri] 23, 1992. Helpful comments were received from OSU colleagues, Leroy Hushak, Joe Havlicek and Diane Hite.
} 
Phase 1 Report

Appendix $E$

recognizes that technological externalities or unpriced environmental services can result in large gaps between private and social costs and benefits. A rapidly growing methodological literature in environmental economics is drawn upon to demonstrate how several of these gaps can be given economic expression in the coal-fired electricity production case. Examples in the landfill disposal vs. recycling of FGD by-products include: (1) monitoring, testing and remediation costs of groundwater contamination, (2) reduced rerouting, highway repair and maintenance costs related to embankment stabilization from FGD by-products, and (3) property value impacts (hedonic pricing) and contingent evaluation of willingness to pay for changes in amenities from landfil? and stripmine reclamation activities. Finally, a hedonic pricing model is developed to illustrate how one might estimate the benefits of using FGD byproducts for stripmine reclamation.

\section{$\therefore$ Meterials Balance}

Flue gas desulfurization (FGD) by-products are one of the many residuals of production and consumption activities prevalent in a contemporary society. Specifically, FGD by-products result from the post-combustion "scrubbing" of flue gases in coal burning electric power plants by wet or dry lime processes. As the gross national product (GNP) or value of goods and services of a society grows so does the variety and volume of FGD and other residuals. In fact, it has been suggested that GNP might more appropriately refer to "gross national pollution." According to Boulding (1968), Georgesen-Roegen (1977) and others, the controversy over the foregoing residuals and the environment stems from the tendency to treat the environment as a free good or God given right rather than a source of raw materials and a waste disposal "sink" with limits. In the simplest materials balance model, Freeman et al. (1974) view 
Phase 1 Repor

Appendix E

the environment as a large shell surrounding the economic system. It has the same relationship to the economy as does a mother to an unborn child--it provides sustenance and carries away wastes.

Raw materials flow from the environment, are processed in the production sector (that is, converted into consumer goods), and then--at least in part-pass on to the household sector. The materials returning to the environment from the household sector are wastes or residuals. They are the unwanted byproducts of the consumption activities of households. Similarly, not all of the material inputs that enter the production sector are embodied in the consumption goods flowing on to the household sector. These are the wastes or residuals from production. Thus, there is a flow of residuals from both the production and consumption sectors back to the environment.

If the environment's capacity to absorb or assimilate wastes or residuals were unlimited, there would be no pollution problem and waste management would be a non-issue. However, the assimilative capacity of the environment is limited and in the case of some residuals like mercury it has no assimilative capacity. One of the limits of the environment's capacity to assimilate is the conflict or competition with other environmental services such as human hatitat, amenities and materials inputs to the economic system. Many of these environmental services provide significant economic benefits even though they may not be currently or directly priced in markets.

The materials balance model and the notion of a service producing environment provide critical insights for the proper management of wastes or residuals. Examples suggested by Freeman et al. (1973) include (1) identification of the full range of technical options, (2) recognition of the interdependency among the various kinds of residual flows, (3) illumination of the relationships among population growth, economic growth and pollution, and (4) 
Phase 1 Report

Appendix E

emphasis in public environmental institutions on broad jurisdiction over air, water and land pollution and over major physical systems such as river basins. With increasing evidence of wastes or residuals exceeding the assimilative capacity of various environmental "sinks", it is important to first identify the major technical alternatives for either reducing wastes or altering assimilative capacity. Examples include the following:

1. Reducing the rate of throughput of materials and energy by reducing production, increasing the efficiency of production, converting residuals to new products or recycling them as inputs, or by changing the composition of GNP to lower residual products. The three alternatives uses proposed for FGD by-products all involve recycling or conversion to new products.

2. Biologically, chemically or mechanically treating or changing the residual to a more benign form for discharge io the environment.

3. Altering the time and place of residuals discharge.

4. Man-made investments to increase the residual assimilative capacity of the environment such as dams to store water for dispensing heavy waste loads and paddle wheels to augment the natural supplies of dissolved oxygen.

\section{Social Costs and Benefits}

Social costs and benefits or gains and losses from an economic perspective refer to the aggregation of individual producer and consumer measures of full willingness to accept or pay compensation. Individual preferences count in the determination of social benefits and costs and are weighted by income or more narrowly market by power. Since most policy changes involve economic gainers and losers, economists have developed the concept of potential Pareto 
improvement (PPI) to add up ga ins and losses to get net benefits. Simply stated, the concept holds that any policy change is a PPI or an increase in economic efficiency if at least one individual is better off after all losers are compensated to their original or before ths policy change income positioris. The compensation need not actually occur but must be possible (Dasgupta and Pearce, 1978).

These measures of social costs and benefits are not fully reflected in current market prices (thus the "social" terminology) such as the price of electricity resulting from the coal-fired power generation for several reasons. First, because there are consumers willing to pay more and producers willing to sell for less than prevailing market or regulated prices, they receive what : :onomists call consumer and producer surpluses. Secondly, technological externalities in coal-fired electric power generation exist to the extent that external to the production and consumption of the resulting electricity, individuals experience uncompensated real economic losses or gains. Examples include water pollution or adjacent property value losses from strip mining of coal or air polluzion and lake acidification from the combustion of coal to produce electricity. Finally, there may be willingness to pay to keep future economic options such as sport and commercial fishing open or for existence value of plant or animal species threatened by water or air pollution which are not reflected in the market price of electricity.

Figure 1 illustrates both the concepts of economic surplus and technological externalities. For example, at market price $P$ consumer surplus is equal to area PEC and producer surplus is equal to area PEA. One might think of $P$ as the mark $t$ price for a kilowatt of electricity based on the intersec- 


\section{FIGURE 1}

\section{ACID RAIN AS AN EXTERNALITY}

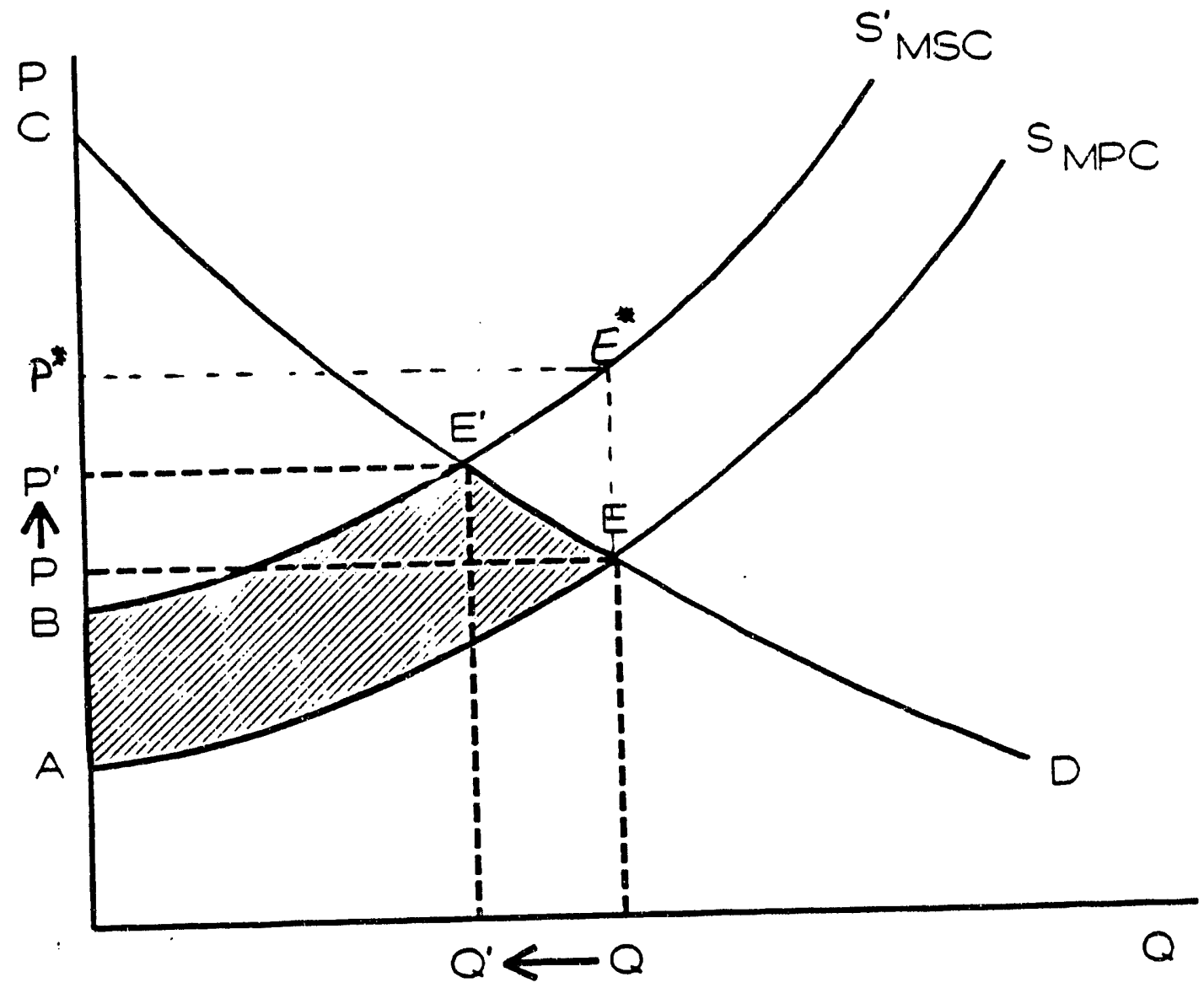

Technological Externality Defined (Dasgupta \& Pearce 1978)

1. Necessary Condition

Physical interdependence of production and/or utility functions

2. Sufficient Condition

Not fully priced or compensated

$S=$ ma:ginal private (power plant) cost function $S^{\prime}=$ marginal social (air shed) cost function 
Phase 1 Report

tion of marginal private cost (from the power plants perspective or accounting stance) of coal-fired production with demand.

The fact that some aquatic and forestry economic losses appear to be related to the sulfur emissions from coal burning electric power plants, the fact that strip mining of coal can lead to water contamination and lower surrounding property values and the possible global warming implications of $\mathrm{CO}_{2}$ emissions from coal combustion for electric power all suggest the presence of uncompensated technological externalities. Stated another way, output $Q$ exceeds the assimilative capacity of the environment. These external or social costs are internalized into the cost of producing coal-fired electricity in $S^{\prime}$ or the marginal social cost function and $\mathrm{P}^{\prime}$ represents the price per kilowatt that would prevail if these external costs were included. The shaded area $B E^{\prime} E A$ represents the net loss in producer and consumer surpluses from the presence of these uncompensated externalities.

The foregoing is a static analysis and does not show the adjustments that might occur over time due to, for example, a tax on or a subsidy for electricity equal to the distance between $P$ and $P^{*}$. The willingness to pay to keep future options open or for existence value of species is also not shown in Figure 1. However, if a proposed stripmine site impacts an endangered species for which considerable WTP exists, it could result in the development of a higher cost alternative site which in turn would further increase the MSC function in Figure 1.

A rapidly growing empirical economic literature (see, for example, Hufschmidt et all., 1983 and Pearce and Turner, 1990) has evolved from the foregoing conceptual concerns which has the following major subsets relevant to the coal fired electricity production case: 
1. Market values in related external markets such as agricultural or forest crops damaged from air pollution or reduced maintenance and private re-routing costs from highway embankment stabilization, replacement costs such as electricity generation from biomass or natural gas, and restoration or clean-up costs such as the liming of acidified lakes to return $\mathrm{pH}$ to normal levels or monitoring and treatment costs of contaminated groundwater. For example, analys is by Hitzhusen and Nyamaah (1984) of private re-routing costs from the closure or weight limit posting of bridges in rural ohio found very large private savings relative to public repair costs. This would suggest the possibility of relatively large economic benefits from the stabilization of highway embankments from FGD by-products. As a second example, Sweden is spending several million dollars per year on a very modest program to apply lime to a few of many acidified lakes. This is an attempt to reintroduce fish and other aquatic life lost from coal burning induced acid rain which the Swedes claim comes primarily from their European neighbors to the south, an example of a transnational externality.

2. Surrogate market measures such as willingness to incur travel costs to use or avoid a particular natural resource or environmental service, impacts (hedonic) on property values from the decrease or increase in the quality of a particular environmental service such as a stripmine reduction of a landscapes utility, and wage differentials reflecting desirable or undesirable environmental attributes of a particular location impacted by water, air or sight pollution. For example, a travel cost analysis was done by Mullen 
and Menz (1985) on ine economic effect of acidification damage in the Adirondack fishery to fisherman from New York State. The lost willingness to pay as expressed by the willingness of New York fishermen to travel to Adirondack lakes and make expenditures to fich exceeded $\$ 1$ million per year in 1976 values.

3. Direct surveys of WTP and WTA for gain or loss of goods and services such as loss of visibility from air pollution or loss of sport fishing from an acid rain impacted lake. Originally called hypothetical evaluation, this methodology now goes under the rubric of contingent valuation and includes much concern for various forms of strategic behavior of respondents. Bidding and trade-off games are used to elicit the responses on WTA and WTP. For example, Brookshire et al. (1976) used pictures of three alternative levels of visibility related to smokestacks and emissions from a proposed coal fired power plant in Lake Powell, Arizona. To elicit WTP measures from respondents for these aesthetic damages or losses, an entrance fee to Lake Powell was used as the instrument to collect bids. The estimated aggregate bids ranged from $\$ 400,000$ to $\$ 700,000$ per year, not a trivial sum.

\section{Hedonic Pricing Illustration}

One beneficial reuse or recycling option for FGD by-products is as a reclamation material for abandoned coal stripmines. While federal regulations in the U.S. require current mining activity to restore the mining area to its original environmental state, the legislation does not require abandoned stripmines to be reclaimed. If there are no substitute reclamation materials for the FGD by-products or no plan to reclaim the area, FGD-based reclamation 
will increase the income stream of the reclaimed land. In addition, it may increase surrounding property and land values and increase the life of existing landfills by diverting the FGD waste from landfills to reclamation of abandoned stripmines.

Hedonic pricing attempts to infer or derive a value for the pleasure lost or gained from environmental changes. The approach involves an attempt econometrically to capture differential prices for property (e.g., 1 and and housing) which can be attributed to variations in one or more environmental characteristics. The hedonic pricing model for land and housing valuts assumes a well-functioning housing/land market in equilibrium with the major environmental costs and benefits accruing to owners of 1 and and housing. It also assumes that buyers can perceive environmental impacts (e.g., stripmine reclamation) on land and housing values. The basic model can be stated as follows:

$S_{i}=f\left(P_{i}, N_{i}, Q_{1}\right)$

where

$S_{i} \quad=$ Sale price of property unit $i$

$P_{i}=$ Characteristics of property unit $i$

$N_{i} \quad=$ Characteristics of neighborhood for property unit $i$

$Q_{i} \quad=$ Environmental quality characteristic for property unit i.

The foregoing hedonic implicit price function model is sufficient for estimating the land and/or housing price impacts of marginal changes in $Q_{i}$. However, for non-marginal changes in $Q_{i}$ more complex procedures are required to "net out" an entire demand function from supply side factors. Figure 2 presents a schematic of the foregoing simple hedonic model showing housing, land use, community and environmental variables and data sources for applying 
Phase 1 Report

Appendix $E$

\section{FIGURE 2}

\section{A Schematic of the Hedonic Model}

Purchase Price of Home or Property

Dependent Variable

Characteristics

Housing

Land Use

Community

Environmental

Examples of Independent Variable Characteristics

* house size

* No. of bdrms

* No. of baths

* Air condit.

* Fireplace

* Patio
* homesite

* tillable

* pasture

* wasteland

* woodland

* R.0.H.
* quality of schools

* population density

* \% of unemployment
* area of reclamation

* distance from mining

* type of mining damage

Data Sources

Real Estate Records
Real Estate Records
Courity Census

Ohio Dept.

Natural

Resources

\section{Estimated Model}

$Y_{i}=\beta_{0}+\beta_{i}$ housing $+\beta_{j}$ landuse $+\beta_{k}$ community $+\beta_{i}$ environ $+u_{i}$ 
the model to the estimation of property value benefits from FGD based stripmine reclamation. Remaining conceptual and empirical issues include identifying correct time lags in realization of benefits, estimating the increased landfill capacity from diversion of FGD, and any potential impacts of $F G D$ chemical properties.

Earlier hedonic analysis by Havlicek et al. (1985) of adjacent residential property value impacts of a sanitary landfill in Fort Wayne, Indiana found significant statistical coefficients on both distance of the property from the landfill and the location (in absolute degrees) of the property away from being downwind (prevailing) from the landfill. Specifically, residential property values increased an average of $\$ 1.92$ per foot of additional distance from the landfill and an average of $\$ 32.96$ for each additional degree away from being directly in line and downwind from prevailing winds and the landfill.

Research by Ibrahim et al. (1982) using 1976 cross-sectional data studied the relationship between surface coal mining and reclamation activity, and property values in seven Ohio counties. Mining activity was found to have a positive relationship with residential property values and a negative relationship with agricultural and commercial property values. The opposite relationship is observed with surface mine reclamation. One explanation for the unexpected results on residential property is that surface mining reduces and reclamation increases supply of residential property sufficiently to impact price. Surface mine reclamation enforcement has also gotten more strict since 1976 which suggests the need to update this earlier analysis.

To the extent that stripmine reclamation reduces soil erosion from the mine site, related downstream sediment impacts may also decrease. Hedonic 
pricing was used by Hitzhusen et al. (1992) to estimate the downstream sediment impacts on residential property owners at four Ohio state park lakes. The statistical results are presented in Appendix $A$ and show that the set of varibles measuring housing, community and environmental characteristics explain from 67 to 75 percent of the variation in prices of lakeside residential properties. For each foot of lake depth lost to sedimentation, the average lakeside property price decrease was $\$ 1,875$.

The statistical estimation of the model in Figure 2 is underway but not complete. However, the earlier empirical results, preliminary hedonic results, and increasing public concern for environmental impacts of surface mining and coal combustion suggest that these externality values (as well as the earlier discussed existence values) will not be trivial and may be increasing over time. Economically efficient public policy requires that these "social" values be estimated and incorporated into the decision-making process. One need not necessarily appeal to non-economic motives or values to be more sustainable or environmentally correct in the analysis of FGD byproducts or other issues. 
Phase 1 Report

Appendix E 14

APPENDIX A

Table 1: Coefficient and Associated standard Errors for Alternative Property Price Modele.

\begin{tabular}{|c|c|c|c|c|c|c|}
\hline \multirow{2}{*}{$\begin{array}{l}\text { Vari- } \\
\text { able }\end{array}$} & \multicolumn{2}{|c|}{ Model I } & \multicolumn{2}{|c|}{ Model II } & \multicolumn{2}{|c|}{ Model III } \\
\hline & Coef. & std.Err & Coef & std.Err & Coef. & std.Err \\
\hline $\begin{array}{l}\text { CONST. } \\
\text { SIZE } \\
\text { DWELL } \\
\text { ROOM } \\
\text { AC } \\
\text { GR } \\
\text { DSTL } \\
\text { AGE } \\
\text { PCOM } \\
\text { DCTY } \\
\text { ADEP } \\
\text { STPS }\end{array}$ & $\begin{array}{l}3.006 \\
0.113 \\
0.654 \\
0.419 \\
0.012 \\
0.058 \\
0.237 \\
0.099\end{array}$ & $\begin{array}{l}0.3069 \star \star \star \\
0.0319 \star \star \star \\
0.1054 \star \star \\
0.1252 \star \star \star \\
0.0379 \\
0.0284 \star \\
0.0286 \star \star \\
0.0341 * \star\end{array}$ & $\begin{array}{r}0.718 \\
0.176 \\
0.664 \\
0.235 \\
0.021 \\
0.065 \\
-0.229 \\
-0.085 \\
0.648 \\
-0.042\end{array}$ & $\begin{array}{l}0.5273 \\
0.0331 \star \star \star \\
0.1041 * \star \star \\
0.1264 \star \\
0.0366 \\
0.0265 * \star \\
0.0275 * \star \star \\
0.0319 * \star \\
0.1146 * \star \\
0.1208\end{array}$ & $\begin{array}{c}2.679 \\
0.235 \\
0.554 \\
0.203 \\
0.072 \\
0.049 \\
-0.250 \\
-0.086 \\
0.405 \\
-0.329 \\
0.196 \\
-0.221\end{array}$ & $\begin{array}{l}0.8788 \star \star \star \\
0.0365 \star \star \star \\
0.1012^{\star} \star \star \\
0.12111^{\star} \\
0.0382 \star \\
0.0253 \star \\
0.0273 \star \star \star \\
0.0302 \star \star \star \\
0.1546 \star \star \star \\
0.1383 \star \star \\
0.0447 \star \star \star \\
0.0852 \star \star\end{array}$ \\
\hline $\begin{array}{l}R^{2} \\
A D J R^{2} \\
\text { Fvalue }\end{array}$ & $\begin{array}{l}0.685 \\
0.674 \\
64.885\end{array}$ & & $\begin{array}{c}0.729 \\
0.718 \\
62.009\end{array}$ & & $\begin{array}{r}0.762 \\
0.749 \\
59.529\end{array}$ & \\
\hline
\end{tabular}

** indicates the significant level at 0.01 percent for $t-t e s t$.

* indicates the significant level at 0.05 percent for $t-t e s t$.

* indicates the significant level at 0.10 percent for $t-t e a t$.

All * imply rejection of the null hypothesis which Ho: $a_{i}=0$.

Table 2: The Marginal Effects of Independent Variables on Property

value.

\begin{tabular}{|c|c|c|}
\hline Variable & \multicolumn{2}{|c|}{ Marginal Price } \\
\hline $\begin{array}{l}\text { SIZE } \\
\text { DWELL } \\
\text { ROOM } \\
\text { AC } \\
\text { GR } \\
\text { DSTL } \\
\text { AGE } \\
\text { PCOM } \\
\text { DCTY } \\
\text { ADEP } \\
\text { STPS }\end{array}$ & $\begin{array}{r}21437.45 \\
26.88 \\
1589.58 \\
35.57 \\
24.34 \\
19.43 \\
147.00 \\
2.96 \\
282.71 \\
1875.06 \\
879.74\end{array}$ & $\begin{array}{l}\text { \$/ac. } \\
\text { \$/gq.ft } \\
\text { S/room } \\
\text { S/AC } \\
\text { \$/GR } \\
\text { S/ft. } \\
\text { \$/yr. } \\
\text { \$/person } \\
\text { \$/mi. } \\
\text { \$/ft. } \\
\text { S/ton/ac. }\end{array}$ \\
\hline
\end{tabular}


Phase 1 Report

Appendix $\mathbf{E}$

\section{Bibliography}

Boulding, Kenneth, "The Economics of the Coming Spaceship Earth," Bevond Economics: Essays on Society, Religion, and Ethics. The University of Michigan Press, Ann Arbor, Michigan, 1968, pp. 275-287.

Brookshire, D.S., B.C. Ives, and W.D. Schultze. "The Valuation of Aesthetic Preferences," Journal of Environmental Economics and Management $4(1976): 325-46$

Dasgupta, Ajit K. and D.W. Pearce. Cost-Benefit Analysis: Theory and Practice. The MacMillan Press, Ltd. London, England, 1978.

Dick, W. A., J. Beeghly and R. Stehomwer. "Land Uses of Dry Scrubber ByProduct Materials: Agriculture, Highway Construction and Mine Reclamation," Department of Agronomy, The Ohio State University, Columbus, Ohio, June, 1991.

Freeman, A. Myrick, Robert Haveman and Allen Kneese. The Economics of Environmental Policy, John Wiley and Sons, Inc., New York, 1973. Georgescu-Roegen N., "Bioeconomics: A New Look at The Nature of Economic Activity," The Political Economy of Food and Eneray. The University of Michigan, 1977, pp. 105-129.

Havlicek, Joseph Jr., Robert Richardson, and Lloyd Davies, "Impacts of Solid Waste Disposal on Property Values," George S. Tolley, Joseph Havlicek Jr., and Robert Fabian, editors, Environmental Policy: Solid Waste, Vol. 4, Ballinger Publishing Co., Cambridge, Mass., 1985, pp. 157-167. Hemphill, R.C., G.W. Morse, and Fred Hitzhusen. "Acid Rain Abatement Policy and State Level Impacts: The Dilemma Facing Ohio," ESO 1737, Department of Agricultural Economics and Rural Sociology, The Ohio State University, July 1990 
Hitzhusen, Fred J. "Community Economics of Solid Waste Management," Invited paper presented at an International Conference on The University and Rural Resource Development: The Road Between Theory and Practice, held in Kristianstad, Sweden, June 23-30, 1981.

Hitzhusen, Fred. "Evaluation of Bio and Other Future Energy Projects: A Resource Economics Perspective," June 1984, Department of Agricultural Economics and Rural Sociology, The Ohio State University, Columbus, Ohio Hitzhusen, F.J. and M. Abdallah. "Economics of Electrical Energy from Crop Residue Combustion with High Sulfur Coal, " AJAE, 62:416-425, 1980. Hitzhusen, F.J. and M. Luttner. "Benefit-Cost Analysis of a Non-metropolitan Prototype for Solid Waste Resource Recovery," AJAE, 59(1977)691-8. Hitzhusen, F., R. Macgregor, S. Bejranonda and T. Lehman. "To Dredge or Not to Dredge: The Political Economy of Sedimentation in Ohio State Park Lakes," paper presented at Water Quantity/Quality Disputes Resolution Conference, Washingtor, D.C., May 2-3, 1992.

Hitzhusen, F.J. and K. Nyamaah. "A Circuity Cost Model for Rehabilitation/ Closure of Rural Bridges: A Wayne County, Ohio, Application. Research Bulletin 1156, Ohio Agricultural Research and. Development Center, Wooster, Ohio, 1984.

Hufschmidt, M. et al. Environment, Natural Systems and Development: An Economic Valuation Guide. The Johns Hopkins University Press, Baltimore, 1983.

Ibrahim, G., D.L. Forster, and L. Hushak. "Impact of Coal Surface Mine Reclamation on Land Prices," Department of Agricultural Economics and Rural Sociology, The Ohio State University, Columbus, Ohio. 
Mullen, John K. and Fredrick Menz. "The Effect of Acidification Damages on the Economic Value of the Adirondack Fishery to New York Anglers," AJAE, $67: 112-119,1985$.

Pearce, David W. and R. Kerry Turner. Economics of Natural Resources and the Environment, The Johns Hopkins University Press, Baltimore, 1990.

Ro, T.H., D.L. Forster, L.J. Hushak, and G.W. Morse. "Environmental Regutation and Regional Economic Growth: An Input-Output Analysis of the Ohio Coal Mining Region," Research Bulletin, Ohio Agricultural Research and Development Center, Wooster, Ohio, 1984. 


\section{APPENDIX F}

An Interim Report:

$$
5-14-92
$$

\section{IIMB Ash Stockpile Ervirormental Impact Study}

\section{J. Beeghly, Dravo Lime Company \\ R. Stehouwer, Dept. of Agronomy, The Ohio State University April, 1992}

A 1,500 ton "temporary" storage pile of ITMB ash by-product from the Ohio Edison Edgewater plant was constructed in July 1991 at the Central Fuel

Company, New Philadelphia, Ohio. Four envirormental operating permits required for construction of the storage pile were obtained; three from Ohio EPA (air, water and solid waste), and one fram the ODNR Division of Reclamation (revised permit). Costs of building the clay liner, berm, and drainage system required by these permits were donated by the central Fuel Co. (This LTMB ash is a type of dry FGD scrubber residual solid waste from the LIMB clean coal combustion technology as opposed to a wet FGD scrubber sludge solid waste.)

The purpose of this interim report is to review technical information on the stockpile material as it was placed and during 8 months of storage.

\section{Stockpile construction and Moisture}

The storage pile was constructed as proposed in our permit application except that a single pile was constructed with a resicual moisture content of approximately 17\%. The normal amount of water to control fugative dust was added in the ash conditioner at the power plant while being loaded into the 
Phase 1 Report

Appendix $F$

dump trucks. More water would have plugged the mixer conditioner. Our objective was to add enough water $t$, be close to the optimm moisture content (ONC) for optimm compacted density i.e., to construct a compacted fill or road base. It turned out that the amount of water they add normally in the conditioning process is close to the avc, which is about $40-50$ on a dry weight basis.

It is important to note that during construction of the pile, efforts were made to minimize compaction of the IIMB ash by avoiding driving over it with the dump trucks or front end loader. The pile was constructed by placement with a large front end loader. Sane campaction around the edges with the tires was unavoidable to stockpile the ash as high as possible.

Because of the chemical characteristics of the ITMB ash (i.e., contains free lime ( $\mathrm{CaO})$ and anhydrite $\left(\mathrm{CaSO}_{4}\right)$ ) it has a high demand for waters of hydration, also called combined water. An attempt was made to estimate the moisture content of LDMB by-product leaving the Lorain, Ohio Power Plant by measuring the total amount of water added and the wet ash weight of each truck load leaving the plant (Table 1). This amounted to an average of $43.5 \%$ water added (dry weight basis) and is based on 22 separate truckloads. This number is a good estimate but the measurements are not precise and an unknown fraction of added water was lost as steam vapor. In any case, about $43 \%$ of the 1,500 ton pile was water added at the power plant.

Free muisture was also determined on samples collexted on delivery of the conditioned ITMB by-product to the storage pile to determine the initial pile 
Phase 1 Report

Appendix F

moisture content (Table 1). This average value of $17.5 \%$ residual moisture is lower than the water added values of $43.5 \%$ due in part to the reasons given above as well as chemical reaction of added water with the by-product, and drying during transport and handling of the by-product.

A rain gauge has been installed at the storage pile site and a precipitation record is being kept (Table 2). Rainfall during the summer and fall of 1991 was below average. The pile has been monitored during all significant rainfall events since construction; however, there have been no runoff events or leachati fran the storage pile.

\section{Moisture After 3 and 6 Months}

The effects of weathering on chemical, physical and engineering properties of the storage pile material will be determined by analyses of samples collected after 3, 6, 9 and 12 months of storage. Results of the 3 and 6 month sampling period are given in Table 3. After 3 months the exposed pile had only a weak crust from cementation. After six months, the ash moisture content at the surface of the pile was about 70\% (dry weight basis) and under 6 inches was 43-49\%. The pile is very firm and easy to walk on because of the conditioning process. Water infiltration has apparently not been significantly decreased by the crust formation since the rainfall events (>1 inch) of 4 and 13 December resulted in no surface runoff from the pile. The increase in moisture content from 17 to $70 \%$ during 6 months of exposure demonstrates the high capacity of the LTMB ash to absorb water and prevent storm runoff and leaching. 
Physical \& Iime Neutralization Properties

Data on physical properties of the LTMB ash by-product in a dry condition are presented in Table 1: These include particle density, surface area, Blaine fineness, and bulk unit weight (lbs/cubic feet).

Available free lime content averaged about $21 \% \mathrm{CaO}$ as per ASTM method C-25. In terms of calcium carbonate equivalency ( $\mathrm{CCE}$ as\% $\mathrm{CaCO}_{3}$ ), the total neutralizing power was about $50 \%$ as per ASTM method C-602, based on 10 samples. Data on percent free lime and $C C E$ after 6 months is seen in Table 3.

Total Chemical \& Leachate Analysis

Leachate tests by both the ASTM 3987-85 water method (20:1, water:FGD) and the TCIP acetic acid extraction method \#1311 are shown in Table 4 as conducted on the original dry LMMB ash (Sample EDG-LMM-14) which represents the material shipped to the stockpile. The ASTM results and TCLP results (As, Hg, \& Se were not yet tested on TCIP leachate) were less than primary drinking water standards, which are far lower than levels required for classification as non-toxic fly ash by the Onio EPA Policy 4.07 .

The major ions in the leachate were calcium, sulfate and hydroxide. Long term equilibrium solubility leaching tests on this sample are not yet complete.

The total chemical analysis is also given in Table 4. 
Phase 1 Report

Appendix F

All the above data in Table 4 are very similar to that shown in the two articles on characterization of ITMB FED by-products included in the LTMB Stockpile application: Field Study of Wastes From a Lime Injection Technology by L. Holcombe, R. Butler, and J. Harness; and Properties of Solid Waste From the Edgewater Coolside and LTMB Process Demonstration by M. Wu, R. Winschel, G. Wasson and T. Jageman.

The data are also representative of reported values in the literature of stabilized/fixated forced oxidized FGD waste as shown in Table 5.

\section{Mineralogy}

The major mineral phases in ITMB ash are Lime (CaO), Portlandite $\left(\mathrm{Ca}(\mathrm{OH})_{2}\right.$, and Anhydrite $\left(\mathrm{CaSO}_{4}\right)$. Minor phases are quartz $\left(\mathrm{SiO}_{2}\right)$, Hematite $\left(\mathrm{Fe}_{2} \mathrm{O}_{3}\right)$, Magnetite $\left(\mathrm{Fe}_{3} \mathrm{O}_{4}\right)$, and Mullite $\left(\mathrm{Al}_{9} \mathrm{Si}_{2} \mathrm{O}_{13}\right)$. Upon aging other mineralogical forms will appear i.e., ettringitte. Ettringitte is a calcium sulfo-aluminate $\left(\mathrm{Ca}_{6} \mathrm{Al}_{2}\left(\mathrm{SO}_{4}\right)_{3}(\mathrm{OH})_{12} \cdot 2 \mathrm{GH}_{2} \mathrm{O}\right)$. Note the high degree of hydration which helps explain the water absorbing properties of ITMB ash in addition to that of free lime and anhydrite.

\section{IMMB Ash Test Cells}

To review, approximately 140 truckloads of LIMB ash were placed in two test cells in 1989 at the Ohio Edison Sheffield Township ash landfill under a 
Phase 1 Report

Appendix F

related US Dept. of Energy-sponso: :is .. . Data from their report when complete should be compared to these results. The background information on this test cell study was also presented in the proposal for this stockpile study.

Conclusion \& Summary

1) A description of the 1500T (wet weight) ITMB ash stockpile (storage pile) is presented herein in terms of water added, moiscure contents, physical, chemical, and leachate properties.

2) About $43 \%$ of the 1500 tons is water added in the conditioning process. Moisture gains (surface only) after six months of exposure to rain are also reported herein. On average the initial resicual moisture was $17 \%$ but the surface moisture level increased to $70 \%$ (dry weight basis or about $40 \%$ on wet weight basis). Below 6 inches the residual moisture increased to about 43-49\% (dry weight basis or about 29-34\% on wet weight basis).

3) The ASTM water and acid TCIP leachate laboratory procedure yielded metals concentrations less than drinking water standards for important water quality parameters. This is due to very low levels of these metals in the LTMB ash.

4) Same physical properties are listed in Table 1. Engineering properties of this aged material for use in fill or embankment construction will be shown in a future report. 
Phase 1 Report

Appendix F

5) Rainfall events during 8 months of observation have caused no surface runoff or leaching from the stockpile. The enclosed photographs show there is no sign of any discharge from the pipes which drain surface and leachate water. Thus, there is no data for the impact of the stockpile on water quality. 


\section{5}

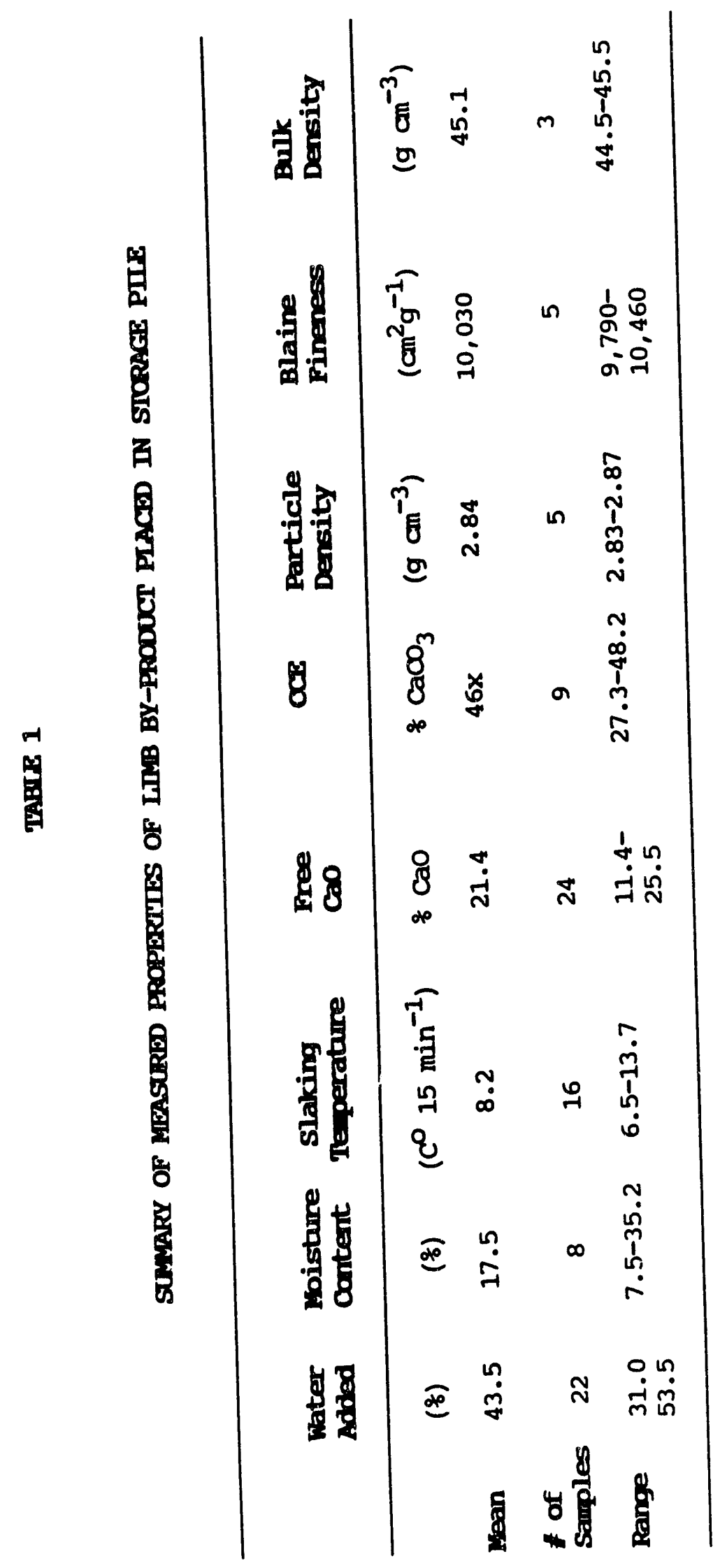


TABTE 4

IMB FED ASH IEACAATE AND TOIAL CHFIICAI, ARALYSIS
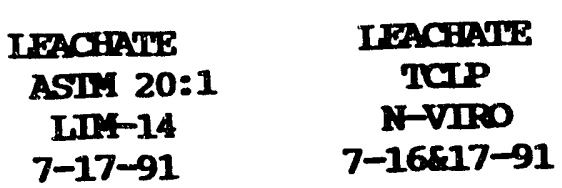

TOTAL CHFMCAL

ANALYSIS

III)-14

7-17-91

SAYPTE DATE

$\mathrm{mg} / \mathrm{L}$

Major Cations:

$\begin{array}{ll}\text { Al } & <0.11 \\ \mathrm{Ca} & 1,842 \\ \mathrm{Fe} & <0.01 \\ \mathrm{Mg} & 0.07 \\ \mathrm{Na} & 1.1 \\ \mathrm{~K} & 1.6 \\ \mathrm{Si} & 0.12 \\ \mathrm{Sr} & 2.58\end{array}$

Major Anions:

$\mathbf{F}$

$\mathrm{Cl}$

$\mathrm{SO}_{3}$

$\mathrm{SO}_{4}$

$\mathbf{S}$

3.4

54.4

31.3

1,872

740.7 $\underline{m g / L}$

0.15

3,670

$<0.01$

0.12

1.8

2.1

0.15

2.21

$$
\begin{array}{r}
64.8 \\
- \\
1,590 \\
605
\end{array}
$$

$$
\begin{array}{r}
3.60 \% \\
33.68 \% \\
5.32 \% \\
0.60 \% \\
0.08 \% \\
0.38 \% \\
5.74 \% \\
0.03 \%
\end{array}
$$

\begin{tabular}{|c|c|c|c|c|}
\hline $\mathrm{Sb}$ & $<0.06$ & $<0.060$ & & \\
\hline As & $<0.005$ & $\star$ & & \\
\hline $\mathrm{Ba}$ & 0.231 & 0.26 & 100 & $\operatorname{ug} / g$ \\
\hline Be & $<0.002$ & $<.002$ & 4 & $u g / g$ \\
\hline B & 3.93 & 5.78 & & \\
\hline cd & $<0.001$ & $<0.005$ & & \\
\hline cr & $<0.011$ & $<0.011$ & 33 & $u g / g$ \\
\hline$C o$ & 0.01 & $<0.01$ & 20 & $u g / g$ \\
\hline cu & $<0.009$ & 0.01 & 10 & $u g / g$ \\
\hline $\mathrm{Pb}$ & $<0.093$ & $<0.093$ & & \\
\hline
\end{tabular}

$5.77 \%$

$\left(17.3 \%\right.$ as $\left.\mathrm{SO}_{4}\right)$

ug/a

Trace Metals: 
TABIE 4

CON'D

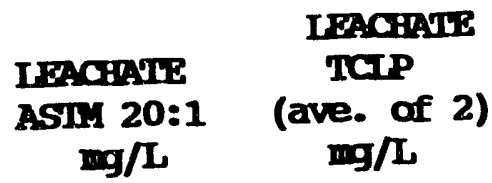

IEACAAITE

ve. of 2)

Total chemical Data

if or ug/g

Major Cations:

$\underline{\mathrm{mg} / \mathrm{L}} \underline{\mathrm{mg} / \mathrm{L}} \quad \underline{\mathrm{ug} / \mathrm{g}}$

$\begin{array}{llll}\text { ii } & 0.05 & 0.08 & 36 \\ \mathrm{Mn} & <0.053 & <0.01 & 182 \\ \mathrm{Hg} & <.0002 & \star & \\ \mathrm{Mo} & 0.101 & 0.15 & 10 \\ \mathrm{Ni} & <0.01 & <0.012 & 28 \\ \mathrm{P} & <0.108 & 0.054 & 300 \\ \mathrm{Se} & <0.005 & \star & \\ \mathrm{Ag} & - & - & \\ \mathrm{Sn} & - & - & 9 \\ \mathrm{~V} & <0.029 & 0.049 & 54 \\ \mathrm{Zn} & <0.006 & <0.006 & \end{array}$

pH $\quad 10.63$

TDS 4,815

(Total Dissolved solids)

* data reported later 
Phase 1 Report

Appendix F

Table 5

Literature Reported Values of Leachate From

Stabilized/Fixated Forced Oxidized FGD Waste (a)

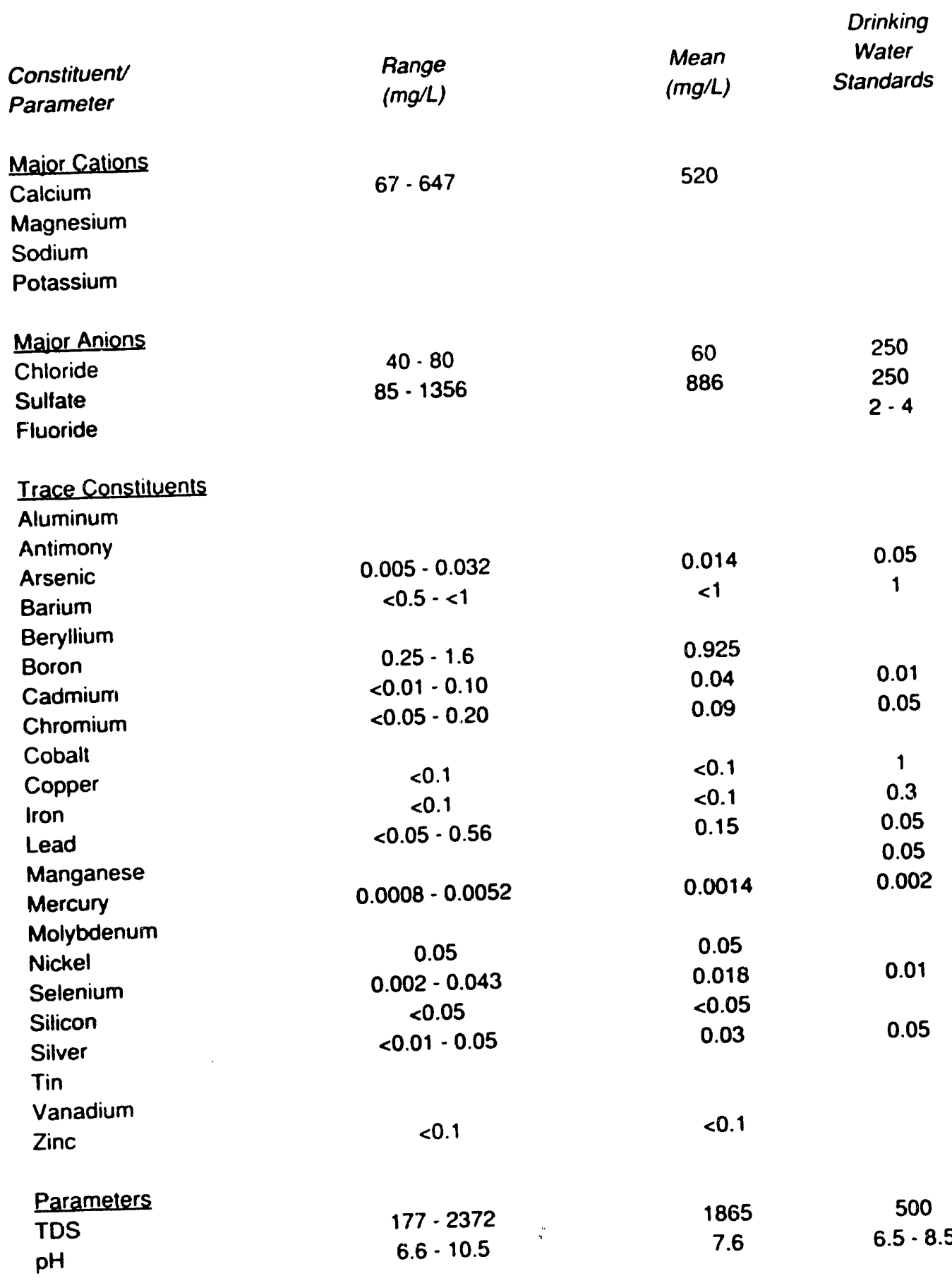

(a) Source: Conversion Systems, Inc.

Source: Golden, D.M. 1981. EPRI FGD Sludge Disposal Demonstration and Site Monitoring Projects; In Proceedings: Symposium on Flue Gas Desulfurization Houston, October 1980; Volume 2. EPA- 0600/9-81-09b. 

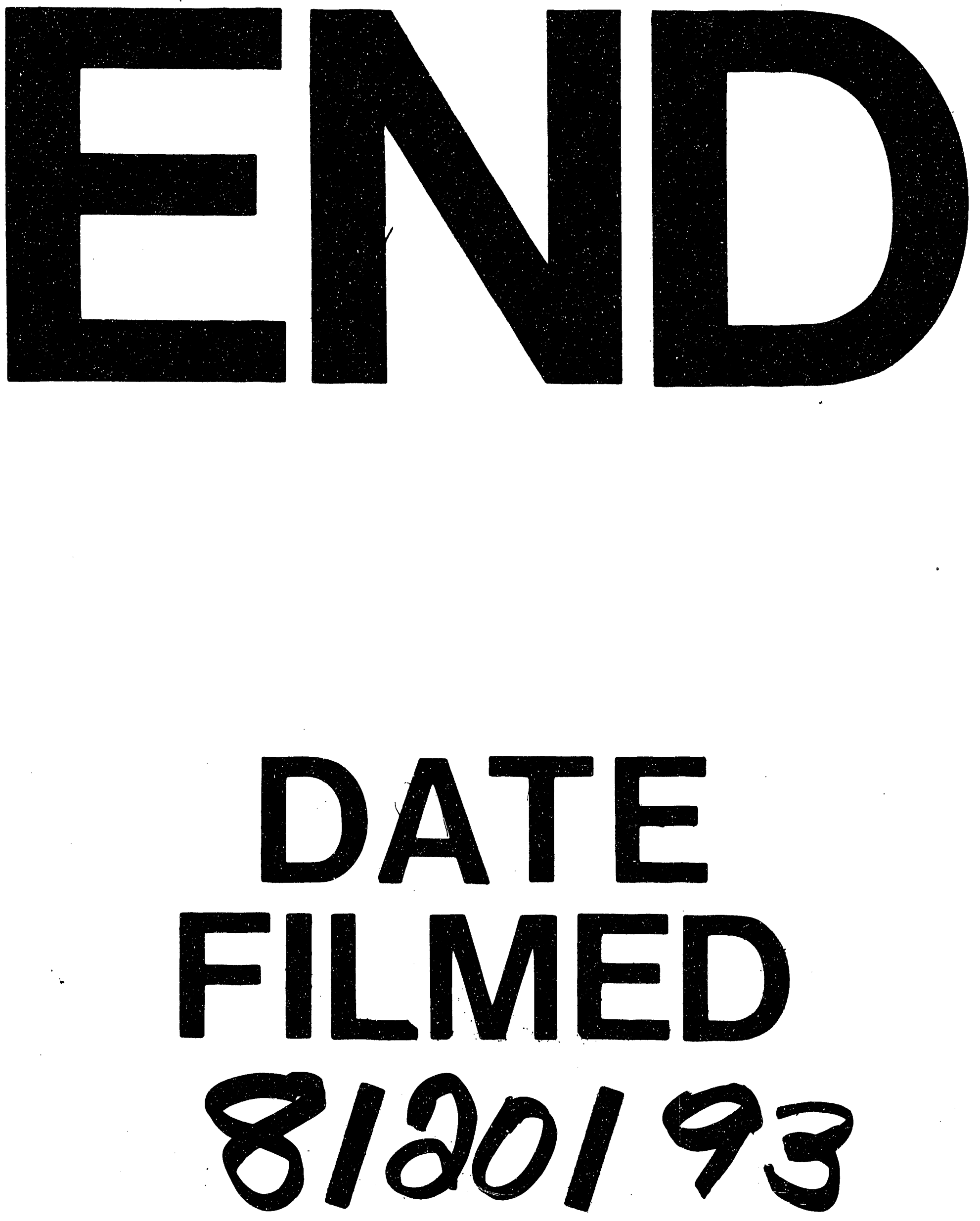
